DEPARTMENT OF ENERG DECLASSIFICATION REVIEW

1st review date Determination (circle numbers)

Authority. DC

DD 1. Classification retained

CLASSIBICATION CANCHITH

Nape: $N+4$

2. Classification changed to

2nd review date $6-4-12$

3. Contains no DOE classified info

Authority

4. Coordinate with

QD

5. Xlassification cancelled

- Name 6. Classified info bracketed

Title: os 1 Coes. Counther(specify)

Derived from: $C G-R P-1$ DOE OOssue date $8 / 2 / 97$

OR GHANCED TO-

BI AYTHORITY OD DOC

B* Placken Darele-21-7

\title{
TAGS-85/2N \\ RTG POWER FOR \\ VIKING LANDER CAPSULE
}

4

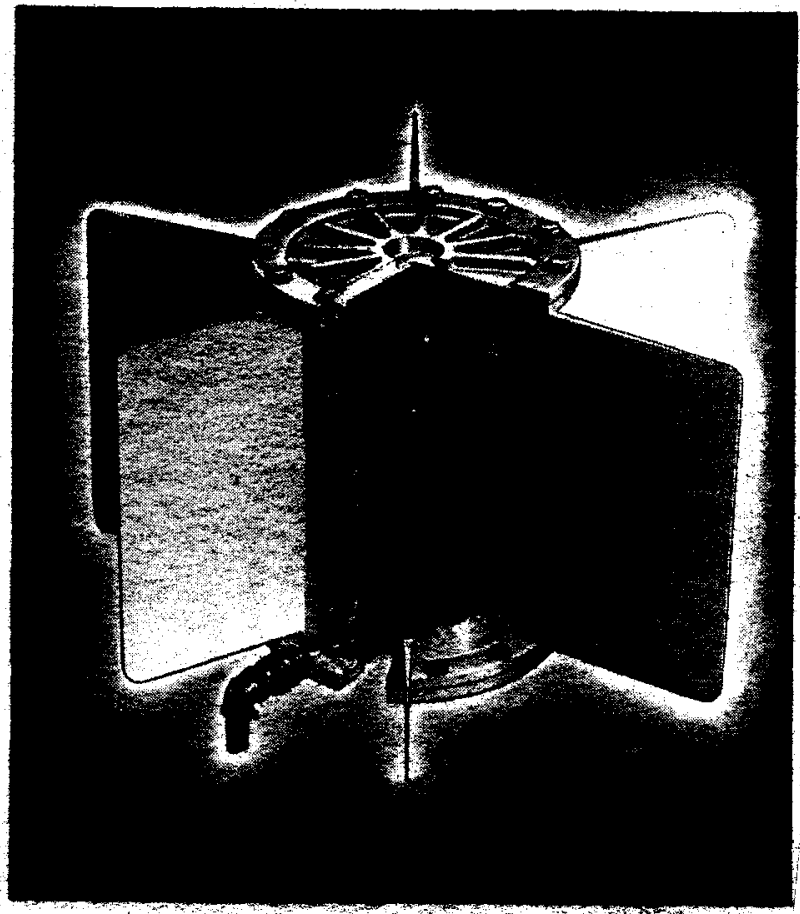

This report wa worice

uponsored by the Unitod States an account of work

Ened States nor the United Govemment. Nesither the

Energy, nor any of their employetes Department of

contractorn, aubcontracton, or their, nor any of their

any warranty, express or implied or amployses, makea

Hablity or responstibitity forplied, or amumes, makes

or userialnew of any inf for the accuracy, complogen

proces disclosed, or in mation, apparatus produenes

infringe privately oumed resents that its une woduct or

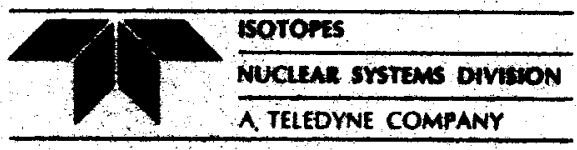

\section{RESTRICTED DAJA}

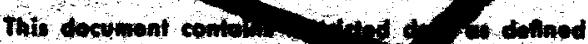

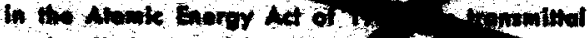
or the dhelowine of the comp" tory on unauthortsed ponger othor.
DISTRIBUTION OE THIS DOCUMENT IS UNLIMITED

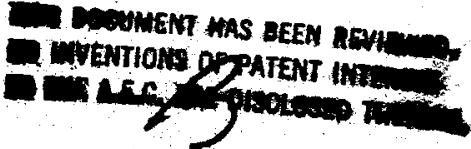


Report No. IIJSD - 2600-29

Report Date August 1069

Former Classification $\mathrm{C} / \mathrm{RD}$

Author (s)

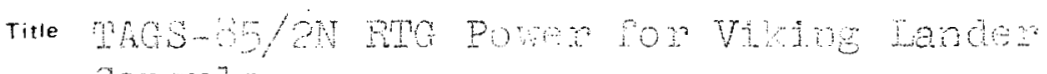
Census 19

Category $D / W(0)$ TD $D G$

Topic (s)

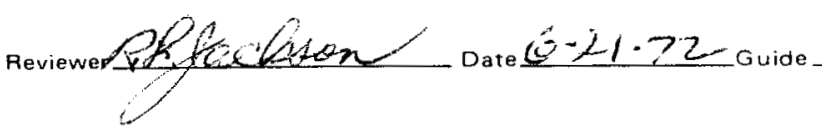

1
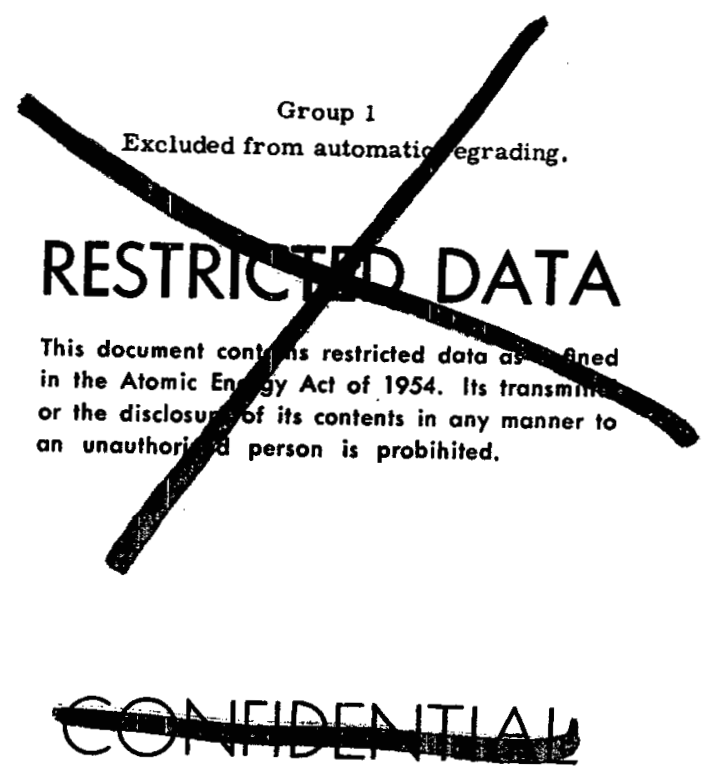


\section{DISCLAIMER}

This report was prepared as an account of work sponsored by an agency of the United States Government. Neither the United States Government nor any agency Thereof, nor any of their employees, makes any warranty, express or implied, or assumes any legal liability or responsibility for the accuracy, completeness, or usefulness of any information, apparatus, product, or process disclosed, or represents that its use would not infringe privately owned rights. Reference herein to any specific commercial product, process, or service by trade name, trademark, manufacturer, or otherwise does not necessarily constitute or imply its endorsement, recommendation, or favoring by the United States Government or any agency thereof. The views and opinions of authors expressed herein do not necessarily state or reflect those of the United States Government or any agency thereof. 


\section{DISCLAIMER}

Portions of this document may be illegible in electronic image products. Images are produced from the best available original document. 


\section{TAGS-85/2N RTG POWER FOR \\ VIKING IANDER CAPSULE}

DEPARTMENT OF ENERGY DECLASSIFICATION REVIEW

1 st review date

Authority: Determination (circle numbers)

$\triangle D C \quad D D$ 1. Classification retained

Name: 1 (COP) 2. Classification changed to

2nd review date $=4-124$ Coordinate with

Authority (5) Classification cancelled

Authority Name fual

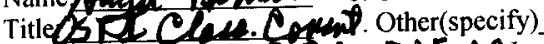

Derived from: $C G-A P L$ DOE OC Issue date $8 / 25 / 97$

INSD-2650-29

AUGUST 1969
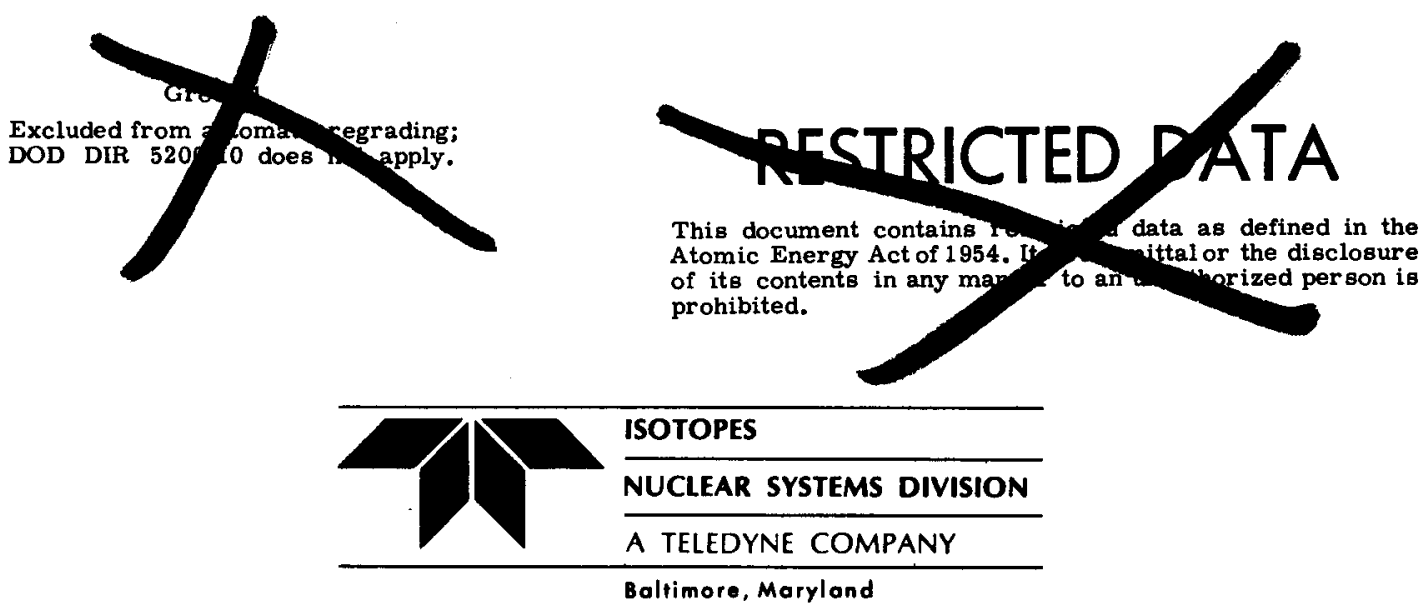

DISTRIBUTION OF. THIS DOCUMENT IS UNLIMITED

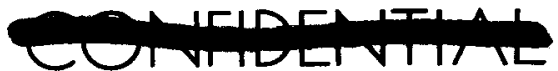

INSSD-2650-29 


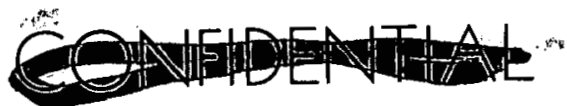

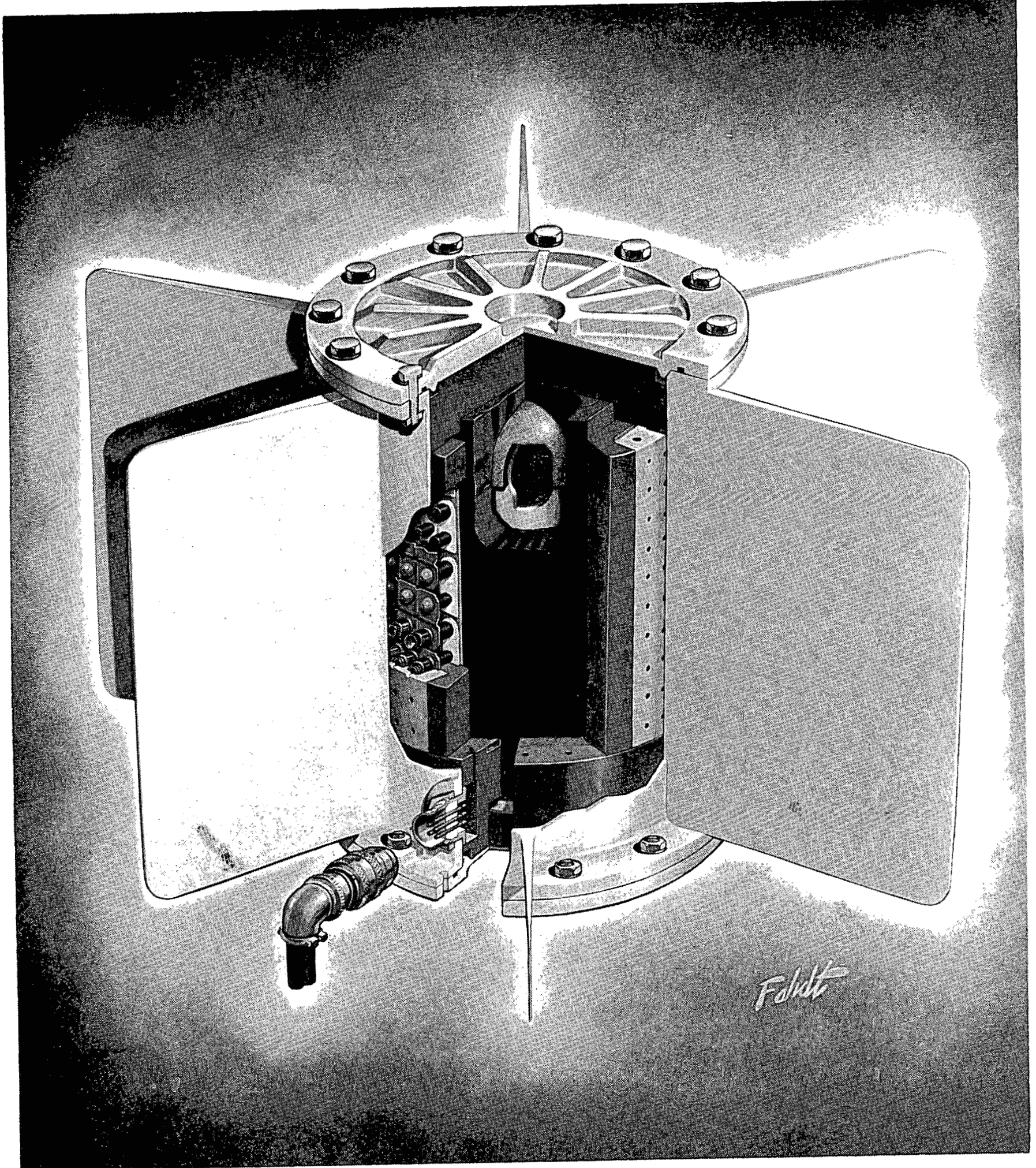

\&

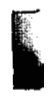

5

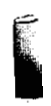

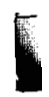

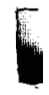

, 


\section{LEGAL NOTICE}

This report was prepared as an account of Government sponsored work. Neither the United States, nor the Commission, nor any person acting on behalf of the Commission:

A. Makes any warranty or representation, expressed or implied, with respect to the accuracy, completeness, or usefulness of the information contained in this report, or that the use of any information, apparatus, method, or process disclosed in this report may not infringe privately owned rights; or

B. Assumes any liabilities with respect to tie ise of, or for damages resulting from the use of any information, apparatus, method, or process disclosed in this report.

As used in the above, "person acting on behalf of the Commission" includes any employee or contractor of the Commission, or employee of such contractor, to the extent that such employee or contractor of the Commission, or employee of such contractor prepares, disseminates, or provides access to, any information pursuant to his employment or contract with the Commission, or employment with such contractor. 


\section{FOREWORD}

This report presents the results of studies performed by Isotopes, Inc., Nuclear Systems Division, to optimize and baseline a TAGS-85/2N RTG for the Viking Lander Capsule prime electrical power source. These studies generally encompassed identifying the Viking RTG mission profile and design requirements, and establishing a baseline RTG design consistent with these requirements. Ac..Ativities in this report were performed under AEC Contract AT(29-2)-2650. 
Page

Legal Notice . . . . . . . . . . . . . . . ii

Foreword . . . . . . . . . . . . . . . . iii

Contents . . . . . . . . . . . . . . . . iv

Summary . . . . . . . . . . . . . . . . . vii

I. Introduction .................... I-I

A. SNAP 19 Nimbus RTG Design . . . . . . . . . . . I-1

B. Guidelines for Viking RTG Study. . . . . . . . . I-5

C. Scope of Viking RTG Study. . . . . . . . . . . I-6

II. Viking RTG Options ................... II-I

A. TAGS-85/2N RTG ............... II-I

1. Design Description ............. II-1

2. Predicted Performance. . . . . . . . . . . II-IO

B. $3 \mathrm{P} / 2 \mathrm{~N}$ RTG .............. II-28

1. Design Description ............. II-28

2. Predicted Performance. . . . . . . . . II-34

III. Performance Studies................. III-I

A. RTG Optimization ................ III-1

1. Radiator Parameters............. III-I

2. TAGS-85/2N RTG ............ III-3

3. 3P/2N RTG . . . . . . . . . . . . . III-9

B. Thermoelectric Supporting Data........... III-I2

1. Property Data............... III-12

2. TAGS Performance Data ........... III-13

3. 3P/2N Performance Data........... . III-54

4. Mechanical Properties.............. III-64

5. Sublimation ............. III-75 
C. Fill Gas Management . . . . . . . . . . III-78

1. Analytical Model. . . . . . . . . . III-78

2. Results . . . . . . . . . . . . . III-83

3. Viton 0-Ring Summary........... III-104

IV. Heat Source Studies . . . . . . . . . . . . IV-I

A. General . . . . . . . . . . . . . . . . IV-I

B. Intact Impact Heat Source (IIHS) Design . . . . . IV-2

l. Capsule Design. . . . . . . . . . . . . IV-4

2. Heat Shield Design............. . IV-I4

3. Capsule Suitability to Solid Fuel Forms . . . . IV-I4

C. Steady State Temperature Profiles . . . . . . . . IV-16

D. Launch Pad Abort Study. . . . . . . . . . . . IV-20

1. Environment Characterization. . . . . . . . IV-2I

2. Heat Source Response.. . . . . . . . . . IV-29

3. Composite Launch Pad Abort Probabilities. . . . IV-44

E. Flight Abort Study............... IV-46

1. Flight Profile Analysis . . . . . . . . . . IV-46

2. Re-entry Trajectory Evaluation. . . . . . IV-5I

3. Heat Source Thermal Response. . . . . . . IV-58

4. Heat Shield Thermal Stresses . . . . . . . IV-66

5. Flight Abort Event Probabilities . . . . . . . IV-73

F. Impact and Post-Impact Study . . . . . . . . . . IV-78

1. Impact Containment. . . . . . . . . . . . IV-78

2. Post-Impact Containment . . . . . . . . . IV-79

G. Design Considerations . . . . . . . . . . . . IV-86

V. RTG/VLC Integration Considerations . . . . . . . . . . V-I

A. Mechanical ................... V V-I

1. Installation . . . . . . . . . . . . . . V-I

2. Dynamic Considerations . . . . . . . . . V-4

B. Thermal . . . . . . . . . . . . . . . . V-6

1. RTG Temperature Limitations . . . . . . . . V-6

2. Viking Study Resuzts... . . . . . . . . V-8

C. Electrical... . . . . . . . . . . . . . V-ll

1. Load Condition................ V-ll

2. Environmental Effects ........... . V-14

3. Related Equipment . . . . . . . . . . V-20

4. Instrumentation .............. V-28

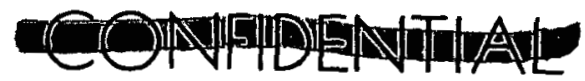


D. Nuclear Radiation . . . . . . . . . . . V-38

1. Unshielded Fluxes . . . . . . . . . . . V-38

2. Shield Attenuation and Weight Optimization . . . V-52

3. Total Flux Criterion . . . . . . . . V-58

4. Gamma FIux Criterion ............ V-60

5. Discussion of Results............ . V-60

6. Biological Dose Rates... . . . . . . . V-66

E. Magnetics . . . . . . . . . . . . . V-83

1. Units . . . . . . . . . . . . . . . V-83

2. Equivalent Circuit of RTG . . . . . . . . V-84

3. Evaluation of Experimental and Calculational . .

Results . . . . . . . . . . . . . V-90

4. Conclusions . . . . . . . . . . . V-93

F. Ground Handling . . . . . . . . . . . . . V-95

1. Ground Support Test Console. . . . . . . . . V-97

2. Power Supply Rack . . . . . . . . . . . . V-99

3. Fuel Capsule Shipping Cask . . . . . . . . V-99

4. Generator Subsystem Handling Adaptor . . . . . V-IOI

5. Mobile Carriage and Handling Sling . . . . . V-10I

6. RTG Subsystem Shipping Container . . . . . V-104

7. ETG Shipping Container . . . . . . . . . V-104

8. Portable Monitor Package .......... V-104

VI. Reliability . . . . . . . . . . . . . . . VI-I

A. Performance Criteria . . . . . . . . . . . . VI-I

1. Objective... . . . . . . . . . . . . VI-1

2. Criteria . . . . . . . . . . . . . . . VI-2

3. Approach . . . . . . . . . . . . . . VI-3

B. RTG Analysis and Prediction ........... VI-4

l. Thermal Reliability... . . . . . . . . VI-5

2. Mechanical Reliability . . . . . . . . VI-6

3. Electrical Reliability ........... VI-14

4. Generator Prediction ........... VI-23

C. Reliability-Power Distribution . . . . . . . . VI-24

1. Mathematical Model ............ VI-25

2. State Probability ... . . . . . . . . VI-25

3. Power Distribution ............ VI-26

4. Results................. VI-27

VII. References . . . . . . . . . . . . . . VII-I

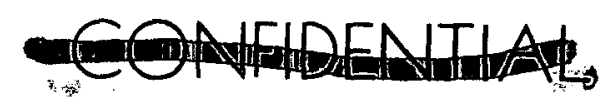

INSD-2650-29 


\section{SUMMARY}

The principal goal of the NASA Viking project is to send two instrumented spacecraft, each consisting of a Lander and orbiter, to Mars during the launch opportunity that occurs in the summer of 1973. Arrival at Mars will be early in 1974, at which time the Viking Lander Capsule (VLC) of each spacecraft will descend to the Martian surface for a 90 day minimum surface mission. The landed weight will be approximately 1100 pounds. The orbiter will remain in Mars orbit and provide data storage and communications support for the Lander as well as gather scientific data from orbit. The Titan III-C Centaur launch vehicle will be used for earth orbit insertion and subsequent insertion into the Mars interplanetary trajectory.

The prime power source for the VLC portion of the spacecraft will consist of multiple radioisotope thermolectric generator (RTG) units. The anticipated RTG electrical power requirement for the VLC is a minimum of 140 watts during the 90-day surface mission. This value is based on data currently being considered by the Viking integrator contractor, Martin Marietta Corporation-Denver Division.

The baseline RTG design selected for the Viking mission employs TAGS-85/2N thermoelectrics and an intact impact heat source (IIHS) containing a 675 thermal watt inventory of Pu-238 fuel. Each RTG weighs 28.2 pounds and produces a nominal 44.1 watts at 2.9 volts at beginning-of-life (BOL). At end-of-mission (EOM), conservatively assumed in this stidy as occurring one year after launch, the nominal

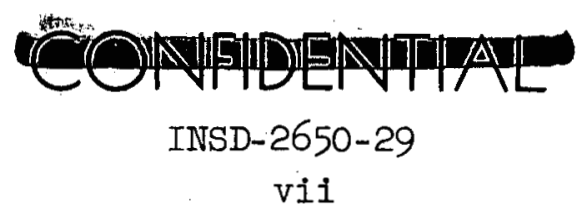


power output is 40.7 . With reliability considerations, the 40.7 watt nominal value yields 38.5 watts at a 0.99 reliability. Thus, four of the baseline RTG's make up the RTC complement for the VLC. The baseline TAGS-85/2N RTG configuration is similar to that of units presently on test at Isotopes (see frontispiece). At the writing of this report, three TAGS-85/2N engineering units, two of which have been hardmounted and vibrated to simulated Viking dynamic levels, have been fabricated and performance tested. Other units are scheduled for fabrication during this calendar year. TAGS-85/2N thermoelectric materials were selected for this mission because of their demonstrated stability and high conversion efficiency. The existing SNAP 19 configuration was retained to the fullest practical extent due to the demonstrated dynamic and performance capability on the Nimbus program. Table S-I summarizes the performance and configuration of the baseline design.

Each Viking RTG occupies an envelope 10.75 inches high by 24.4 inches across the fin tips. Ninety TAGS-85/2N thermoelectric couples convert the thermal energy from the heat source to electrical energy. In the current Nimbus design the couples are arranged in three seriesparallel strings (three couples in a branch, thirty branches in series), but it is anticipated that the arrangement will be modified for Viking to a two series-parallel arrangement (two couples in a branch, fortyfive branches in series) to increase the load voltage from 2.9 to 4.4 volts, thus enhancing converter reliability and joule efficiency.

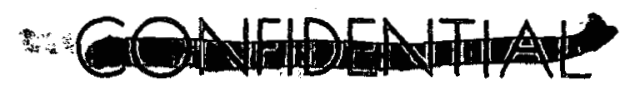

INSD-2650-29

viii 


\section{COAEHOEATHAL}

TABLE S-I

SUMMARY OF VIKING TAGS-85/2N RTG CONFIGURATION AND PERFORMANCE CHARACTERISTICS

RTG System

Number of RTG units

4

Power output at 2.9 volts (watts)

BOL (nominal) ( 1 )

EOM $(0.96$ reliability) (1)

EOM (0.99 reliability) (프)

176.4

156.8

154.0

Weight (pounds)

112.8

RTG Unit

Thermoelectric materials

$$
\begin{aligned}
& \text { N-leg } \\
& \text { P-leg }
\end{aligned}
$$

Heat Source

Type

Fuel

Thermal inventory (watts)

Dimensions

$$
\begin{aligned}
& \text { Height (in.) } \\
& \text { Diameter, across fin tips } \\
& \text { (in.) }
\end{aligned}
$$

Weight (pounds)

$3 M-T E G S-2 N(M)(2)$

Isotopes-TAGS-8 5 with 0.100

inch $\mathrm{SnTe}$ segment

Intact impact (IIHS)

$\mathrm{PuO}_{2}$ microspheres

675

10.75

24.4

28.2

Nominal Performance

Power output (watts)
BOL
EOM
Load voltage (volts)
44.1

40.7

$2.9(4.4)(\underline{3})$

(1) Assumes parallel electrical hookup of RTG's

(2) Supplied by $3 \mathrm{M}$ Company

(3) Value in parantheses is for RTG configuration with two series-parallel strings for the thermoelectric circuit.

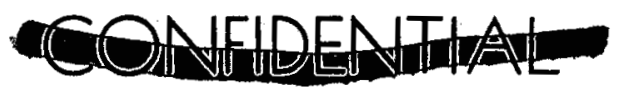

INSD-2650-29 
At fueling the RTG is sealed with approximately one atmosphere of argon internal pressure. With the passage of time, helium generated by fuel decay is released to the thermolectric converter through a filter vent in the fuel capsule. Simultaneously the argon and released helium permeate to space through the RTG Viton O-ring seals in a controlled manner. This behavior is well understood and has a predictable influence on electrical power output and generator internal pressure and gas composition.

The baseline intact impact heat source (IIHS) design for Viking is consistent with requirements for maximum enhancement of nuclear safety. Analyses herein permitted nuclear safety evaluation and decisions with regard to design selection. Component design criteria was provided by evaluation of three major postulated abort categories: launch pad, flight (orbital and superorbital) and impact/post-impact containment. In each case environments consequent to the malfunctions were considered as well as the response of each candidate configuration. The specific objective was to estimate the fuel release probabilities for each environment for the design. These release probabilities were combined with indices which are measures of the resultant nuclear safety and sumed for the candidate heat source designs. The outcome was the selection of the baseline IIHS design.

Integration studies performed included evaluation of mechanical, thermal, electrical, nuclear radiation and magnetic interfaces as well as associated ground handling equipment. These studies show the base- 


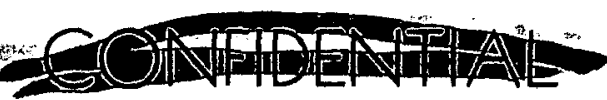

line RTG design is compatible with expected mission environments and will satisfy the Viking mission electrical power requirements. Analyses were performed for both single RTG units and stacked units; Martin Denver is presently evaluating both arrangements. 


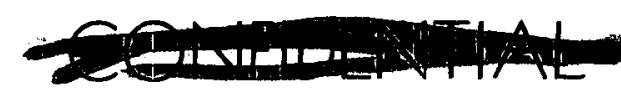

\section{INIRODUCTION}

\section{A. SNAP 19 NIMBUS RTG DESIGN}

The SNAP 19 radioisotope thermoelectric generator (RTG) was developed by Isotopes, Inc., under contract with the U.S. Atomic Energy Commission for use on the Nimbus weather satellite. RTG subsystem $S / N 9$, launched aboard the Nimbus III satellite in April 1969, is representative of the present operational configuration. The Nimbus III RTG subsystem, shown in Fig. I-I, consists of two electrically and mechanically independent RTG units bolted together at two end cover flanges in a stack configuration. The stacked RTG units are mounted on the Nimbus spacecraft sensory ring through a support base and standoff. All electronic equipment associated with the complete RTG power supply system (i.e., power and telemetry signal conditioners) is contained within modules in the spacecraft temperature-controlled sensory ring.

The SNAP 19 Nimbus III RTG power supply system is designed to provide approximately 50 watts $(e)$ of dc power at a spacecraft bus voltage of 24.5 VDC during orbital operation for a minimum period of one year. The RTG subsystem supplies approximately 57 watts of unconditioned power at 2.7 VDC. The electrical output is obtained by direct conversion of thermal energy, produced during the normal decay of the radioisotope fuel, to electrical energy in a thermoelectric converter consisting of lead telluride ( $\mathrm{PbTe}$ ) thermoelectric elements. Waste heat from the conversion process is rejected to the environment by the finned RTG unit housings.

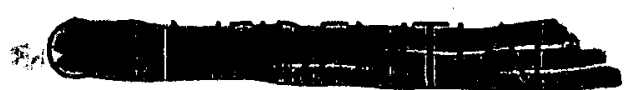

INSD-2650-29 


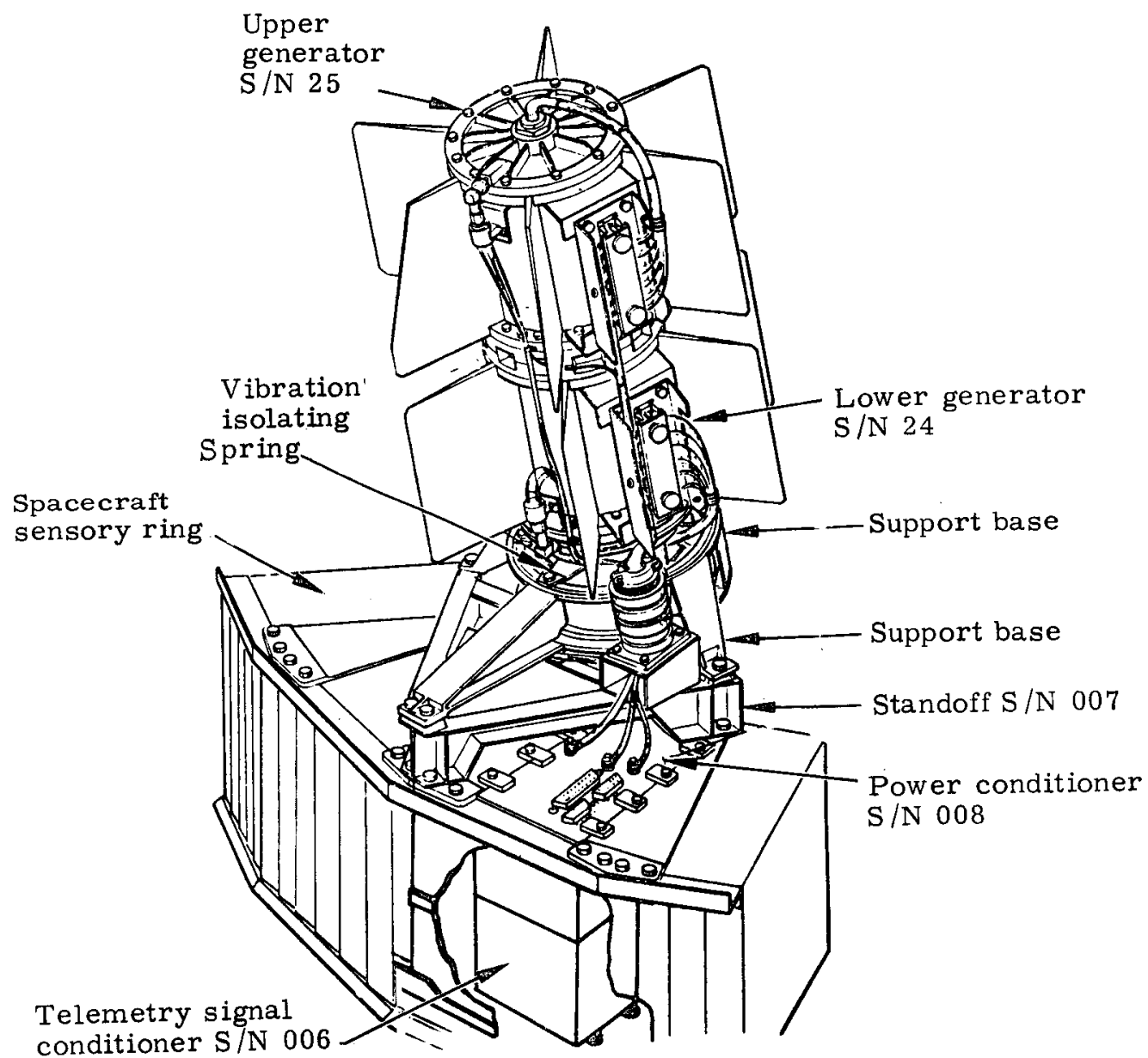

FIG. I-1. SNAP 19 NIMBUS IIIRTG POWER SUPPLY SYSTEM S/N 9 
Figure I-2 shows the configuration of the SNAP 19 Nimbus III RTG unit. Each unit contains a 625-watt thermal inventory derived from plutonium dioxide $\left(\mathrm{PuO}_{2}\right)$ microspheres. The $\mathrm{PuO}_{2}$ radioisotope fuel is contained within an intact re-entry heat source (IRHS) consisting of a superalloy fuel capsule and graphite re-entry body. The superalloy capsule assures containment of the radioisotope fuel by providing impact protection for inadvertent ground handling and launch pad accidents and low altitude launch aborts where the re-entry heating pulse is low. The graphite re-entry body provides for fuel containment during re-entry from high altitude launch aborts and orbital decay from short-lived, offoptimum orbits. The graphite housing remains intact for all credible re-entry heating conditions. to assure that the fuel is not dispersed in the upper atmosphere. For the high altitude abort and orbital decay re-entry modes, the superalloy fuel capsule in some cases may melt within the graphite housing during re-entry to form a solidified fuel/metal matrix prior to impact. After earth impact the fuel is jmmobilized in the matrix and confined to the point of impact.

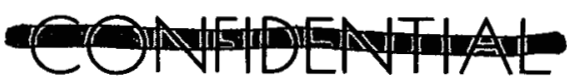

INSD-2650-29

$\mathrm{I}-3$ 
Fin tips

Housing height

$=22-1 / 2$ inches

Housing height

$=10$ inches

Housing diameter $=6-1 / 2$ inches
This half of the upper cover and the top insulation disc have been
Short fin (for

orientation only) $\longrightarrow$
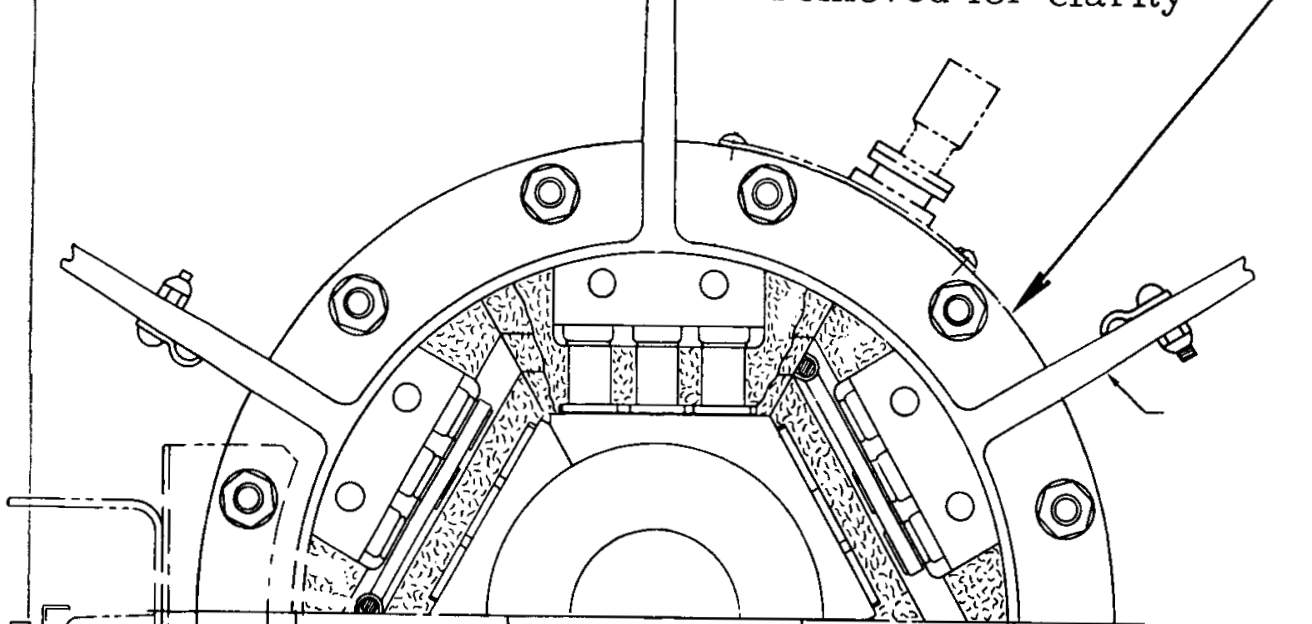

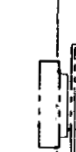

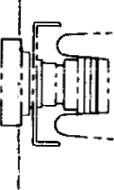

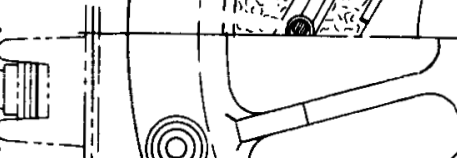

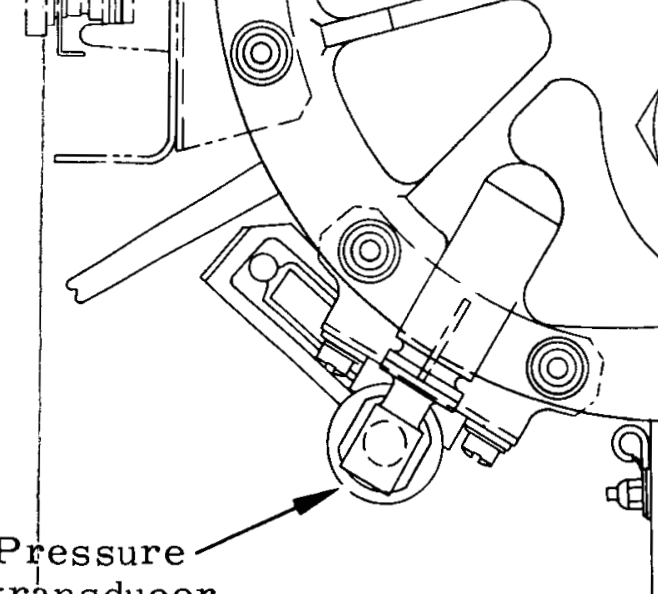

transducer

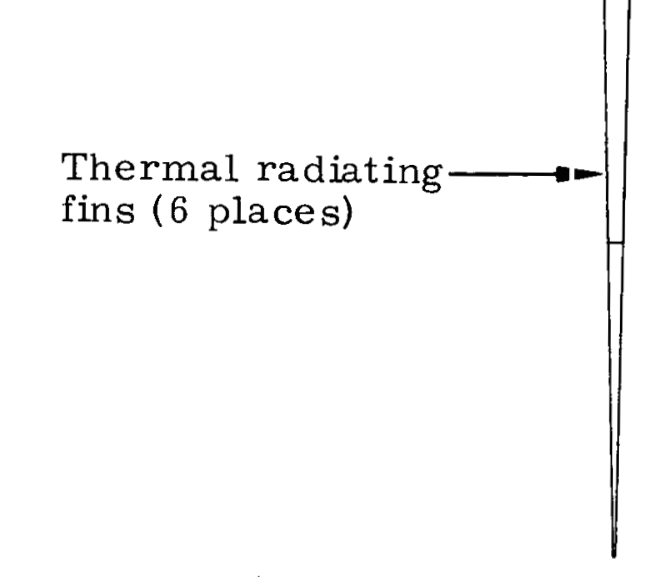

removed for clarity

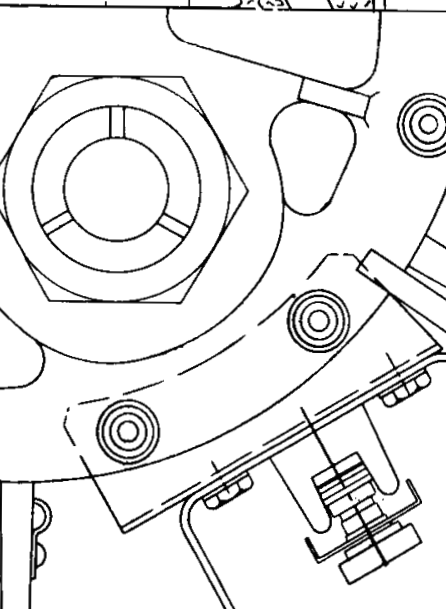

Electrical

connector

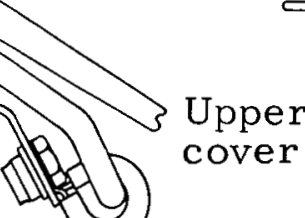

See

See Detail A for assembly hardw

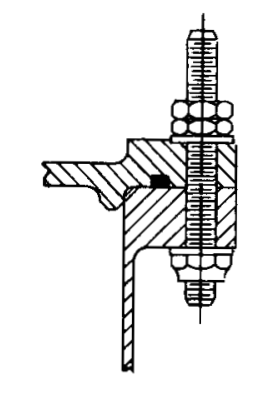

Detail A Lower generator assembly hardware

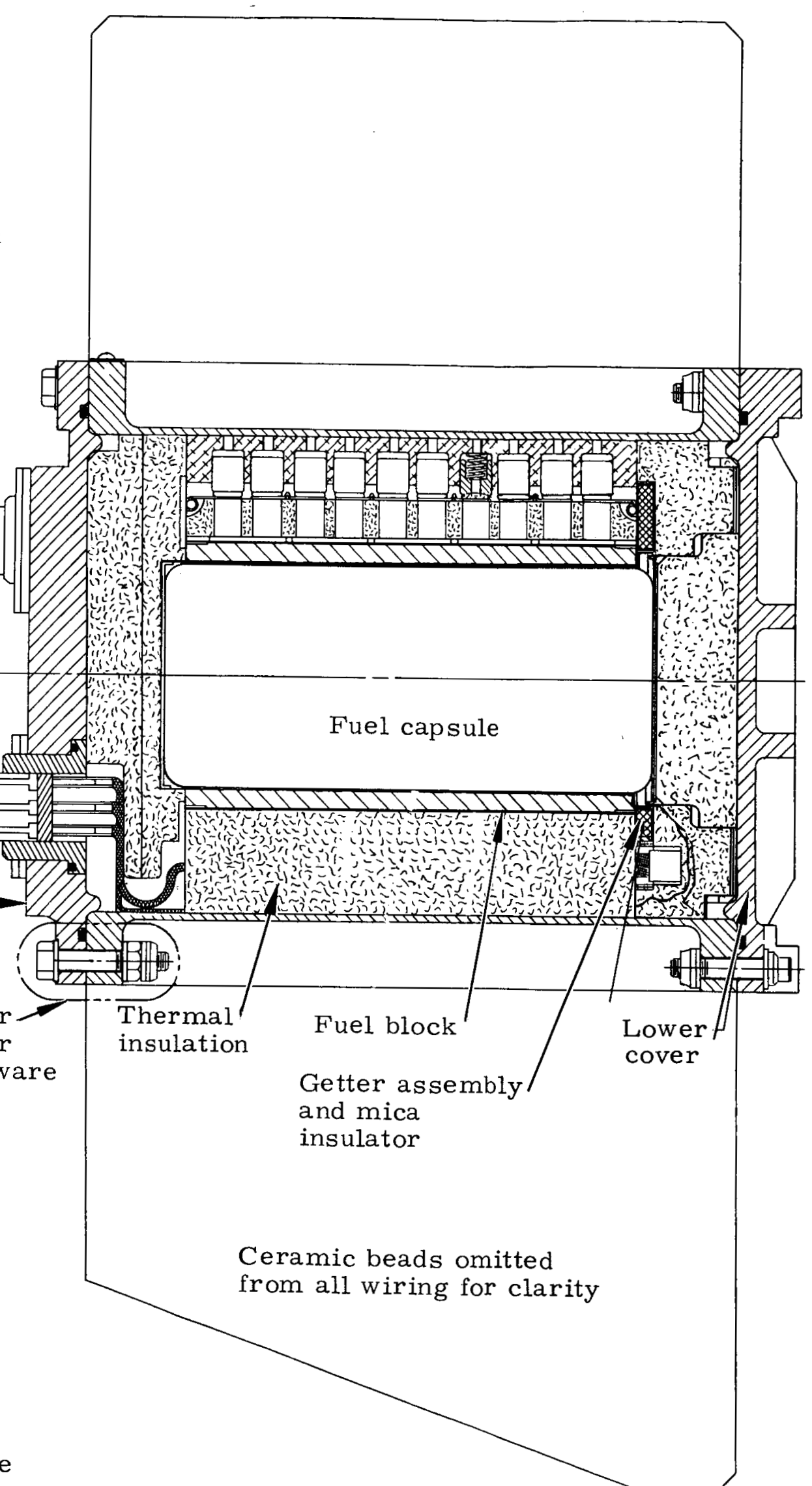

FIG. I-2. FUELED GENERATOR CONFIGURATION 


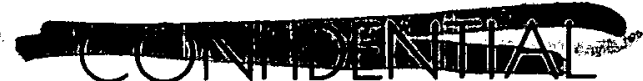

B. GUIDELINES FOR VIKING RTG STUDY

This study of the application of SNAP 19 RTG technology to the Mars Viking mission has been conducted by Isotopes in accordance with the applicable portions of AEC Contract AT(29-2)-2650. In directing the activities of this study, the following technical guidelines were established:

(1) The RTG/spacecraft electrical interface was assumed to be at the RTG electrical connector plug, and the mechanical interface to be at the RTG mounting flange.

(2) The TAGS-85/2N RTG units presently being fabricated and tested at Isotopes are the baseline Viking units. Performance parameters for the SNAP 19 3P/2N Nimbus III design are also presented.

(3) The baseline heat source provides intact-impact capability (IIHS), with the alternate being the present SNAP 19 intact re-entry heat source (IRHS).

(4) RTG system configurations considered include single generator units as well as the present SNAP 19 stacked, two-unit configuration to permit spacecraft integration flexibility.

(5) End-of-mission is considered to occur approximately one year after launch, however generator performance up to five years after launch is presented.

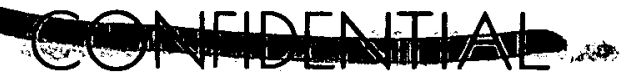

INSD-2650-29 


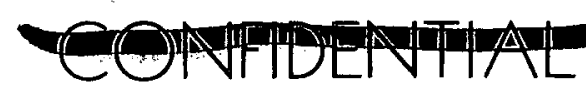

\section{SCOPE OF VIKING RTG STUDY}

The SNAP 19 Nimbus RTG system was developed and optimized for the Nimbus spacecraft and an Earth orbit operating environment. It has been the purpose of this study to identify and evaluate those modifications required and/or desirable for adaptation of the RTG to the Viking Lander Capsule (VLC). This work has been performed in conformance with the guidelines set forth in the preceding section and guidance obtained through discussions with AEC, Sandia, NASA Project and Viking Integrator Contractor personnel. The principal consideration which gave direction to the study was the requirement for from two to four RTG units to satisfy the VLC power profile for a minimum operational period of 90 days on the Martian surface. The number of units to be selected and power requirements depend on the results of studies now being performed by the Viking Integrator Contractor, Martin Marietta Corporation-Denver Division, which was awarded the Viking contract in May 1969. Martin Denver is currently evaluating an all-RTG power system in addition to the hybrid RTG/battery system presented in their Viking proposal. Present indications are that an RTG unit with a minimum power output of approximately 36 watts at end-of-mission is desirable for the all-nuclear, four RTG configuration, while a minimum output of approximately 25 watts per RTG is sufficient for the two-RTG, hybrid configuration. Current emphasis at Martin Denver and NASA is being placed on the four-RTG configuration, and thus has been given priority in this study.

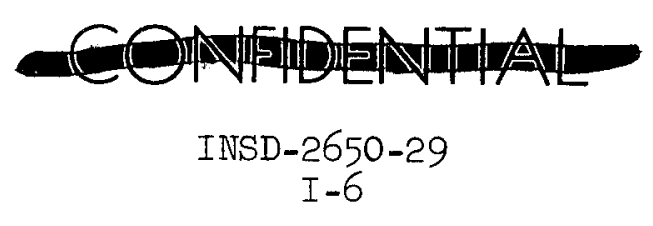


The Viking RTG study has been primarily concerned with the following areas:

(1) Thermoelectric converter design and performance

(2) Heat source design and re-entry performance

(3) Housing/radiator weight optimization

(4) RTG/spacecraft interface considerations.

A brief description of each area of study is presented below.

1. Thermoelectric Converter

The present SNAP 19 Nimbus III thermoelectric converter contains lead telluride $\mathrm{N}$ and P-type thermoelectric elements. Thermoelectric material designations are 3M-TEGS-3PB for the P-type material and 3MTEGS-2N(M) for the N-type.* These materials have demonstrated stable performance in long-term endurance testing of both fueled and electrically heated SNAP units on the SNAP 11,19 and 29 programs. Although the experience factor is an incentive for retaining these materials, a significant increase in system efficiency and specific power can be realized with a change in only the P-leg thermoelectric material. An Isotopes proprietary silver antimony telluride/germanium telluride P-type thermoelectric compound (designated TAGS-85) has demonstrated stable performance in life testing of couples, modules and commercial RTG units. This material has replaced the lead telluride P-leg previously used in the SNAP 29 based on module and couple testing performed on that program.

*These thermoelectric elements are supplied by 3M Company.

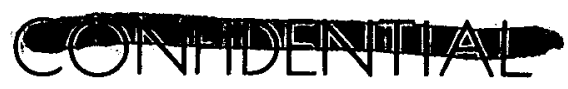




\section{COANFHOEATIAL:}

SNAP 29 RTG modules and couples are presently on test incorporating this material. Also, three engineering electrically heated test units of a Viking type RTG incorporating the TAGS-85 material in the P-leg of the thermoelectric couples have been fabricated at Isotopes, and initial electrical performance and dynamic testing performed. Additional Viking type units are scheduled for fabrication and testing during the current calendar year.

Power output from fueling of the RTG through five years after launch has been determined for both the TAGS-85/2N and 3P/2N thermoelectric configurations. Variations in RTG performance due to changes in fuel loading, selection of inert fill gas, and housing seal leakage have been conducted.

\section{Heat Source}

The baseline Viking RIG unit can be mated with either the existing intact re-entry heat source (IRHS) or the intact impact heat source (IIHS) which is currently being developed at Isotopes. The basic difference between the IRHS and IIHS is in the fuel capsule materials technology. The SNAP 19 IRHS utilizes a single-wall superalloy vented capsule, whereas a higher melting, double layer, vented capsule is required to achieve the Isotopes' IIHS concept of containment of the radioisotope fuel during re-entry and on Earth impact. The IIHS concept incorporates a hex-shaped graphite heat accumulator block as an integral part of the graphite heat shield. This modification enhances the success probability for intact re-entry from superorbial velocities by providing additional

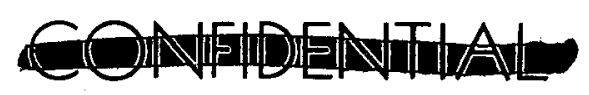

INSD-2650-29 


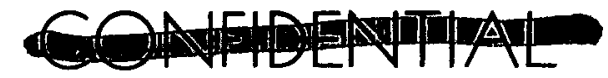

heat shield ablation/heat sink capability and for fuel containment on earth impact by lowering the impact velocity through increased drag. 3. Housing/Radiator Optimization

The SNAP 19 Nimbus III subsystem consists of two RTG units bolted end-to-end in a stack arrangement but otherwise mechanically and electrically independent. This study has considered optimization of the housing and fins for the Viking mission thermal and dynamic environments, and has considered both single RTG's and stacked configurations.

4. Spacecraft Integration

Use of RTG power for the Viking Lander Capsule requires an examination of the various technical interfaces between the spacecraft and RTG system. These interfaces can generally be categorized as either mechanical, thermal, electrical, magnetic, nuclear radiation or operational support in nature. During the study these interfaces were examined quantitatively where possible and qualitatively where specific definition was not available.

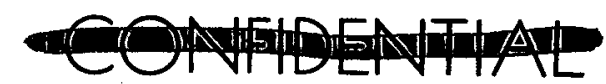

INSD-2650-29

I-9 


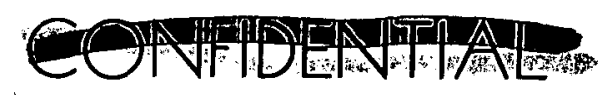

\section{VIKING RTG OPTIONS}

This chapter presents the results of performance studies performed for the Viking RTG options. The baseline RTG configuration is a TAGS$85 / 2 N$ unit employing a 675 thermal watt heat source. The 3P/2N RTG configuration is similar to the SNAP 19 Nimbus III units incorporating 625 thermal watts. Performance parameters are presented for both the baseline intact impact heat source (IIHS) and the alternate intact re-entry heat source (IRHS).

\section{A. TAGS $-85 / 2 N$ RTG}

The TAGS-85/2N RTG, considered as the baseline design for the Viking mission, is a modified SNAP 19 Nimbus RTG. Figure II-I depicts the modified design, and shows the internal details of a unit. Each RTG unit weighs 28.2 pounds and produces a nominal 44.1 watts at beginning-of-life, decreasing to 40.7 watts at end-of-mission, conservatively defined in this study as one year after launch. The baseline heat source design is a 675 thermal watt IIHS. An RTG unit occupies an envelope approximately 11 inches long by 24.4 inches across the fin tips. The internals of the generator are sealed by Viton 0-rings at each end of the finned magnesium thorium alloy cylindrical housing. The initial fill gas is argon at approximately 1 atmosphere absolute pressure. 1. Design Description

A detailed description of each major component in an RTG unit follows :

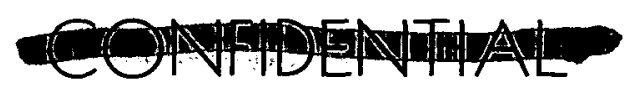

INSD-2650-29

II -I 


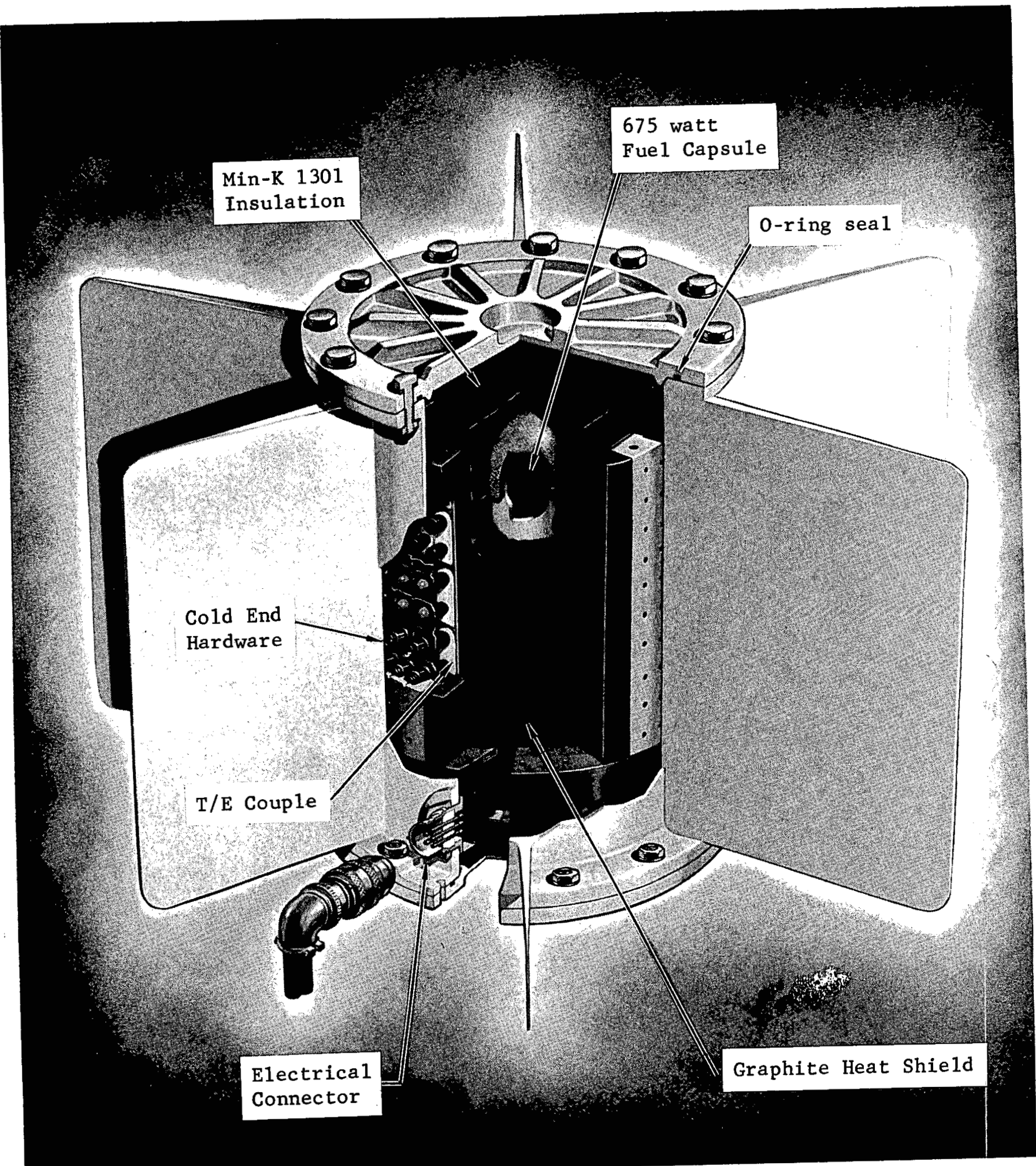

Q

(1)

B

B

\&

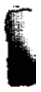

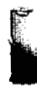

FIG. II-1. VIKING RTG CONFIGURATION

COAWHEATIALE

INSD $-2650-29$

II -2 


\section{a. Thermoelectric converter}

The thermoelectric converter consists of six thermoelectric modules containing a total of 90 thermoelectric couples connected electrically in three series-parallel strings. To enhance power conditioning equipment efficiency and to decrease joule losses, the 90 couples may be electrically connected in two series-parallel strings in future SNAP 19 units to increase the output voltage 50\%. Reliability analyses presented in Chapter VI show that virtually no reliability penalty is entailed with this circuit configuration modification.

The converter thermoelectric materials are Isotopes-TAGS-85 with a 0.1 in. thick SnTe segment at the hot end (P-leg) and 3M-TEGS-2N(M) (Nleg), selected because of their demonstrated high conversion efficiency and long-term stability in various SNAP-type devices and the Isotopes commercial RTG (Sentinel) line. The RTG designation TAGS-85/2N thus signifies the $N$ and $P$ leg materials. Figure II-2 is an exploded view of the baseline couple. This couple design is identical in materials and fabrication to that being used in the SNAP 29 RTG design and in three existing Viking type engineering RTG's (S/N 26, S/N 27, and $\mathrm{S} / \mathrm{N}$ 28) presently on test.

Figure II-3 shows a single thermoelectric module with 15 couples. Also shown in the figure is the module cold end hardware which consists of alignment buttons, springs, pistons and heat sink bars. This hardware provides compressive forces on the thermoelectric elements through alignment buttons adjacent to the copper connecting strap thermoelectric leg. One side of the button is flat to permit radial movement and the

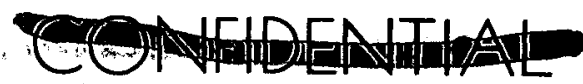



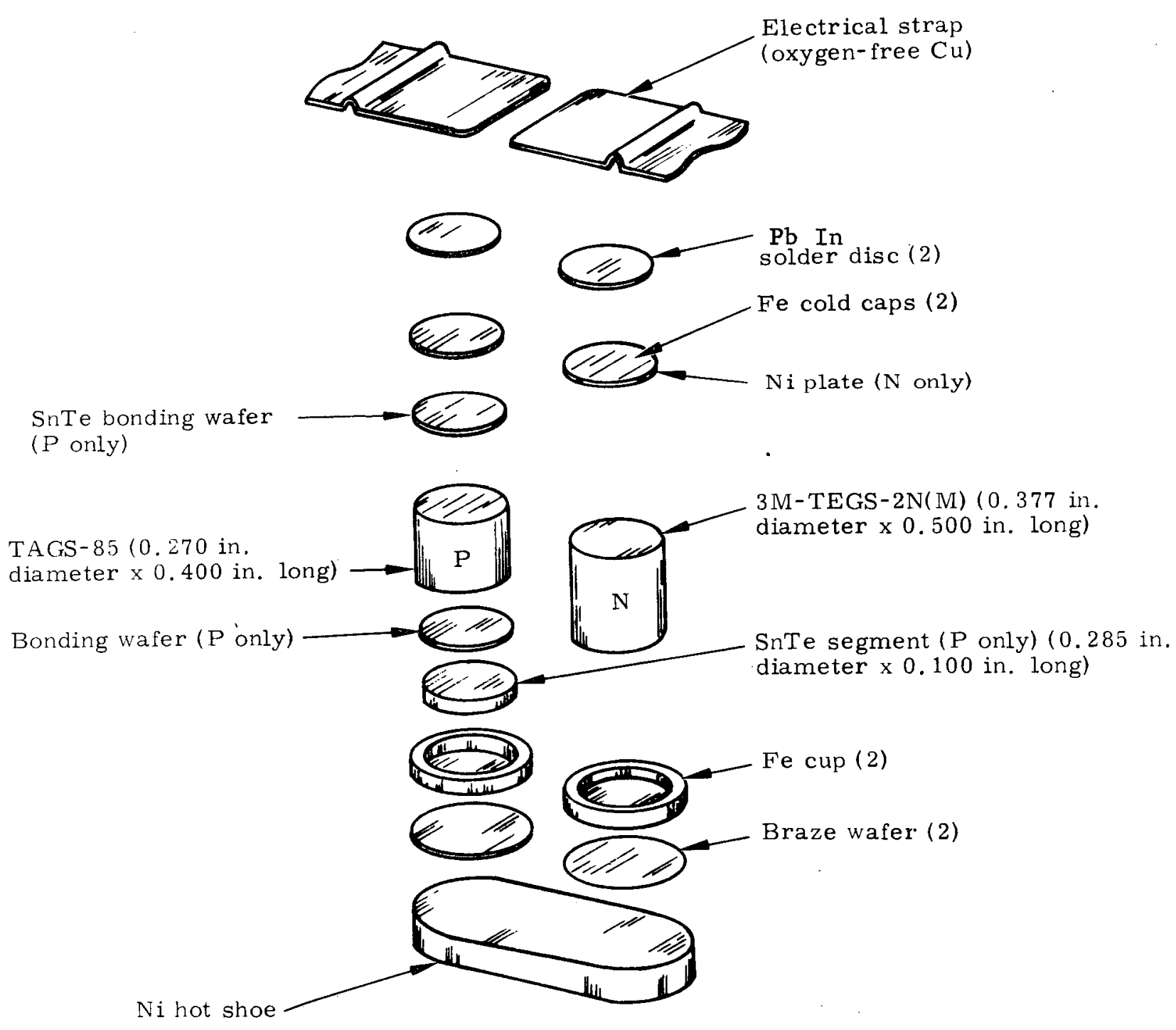

FIG. II-2. TAGS- $85 / 2 \mathrm{~N}$ COUPLE CONFIGURATION

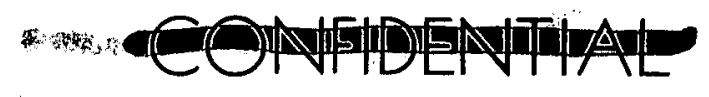

INSD $-2650-29$

II -4 

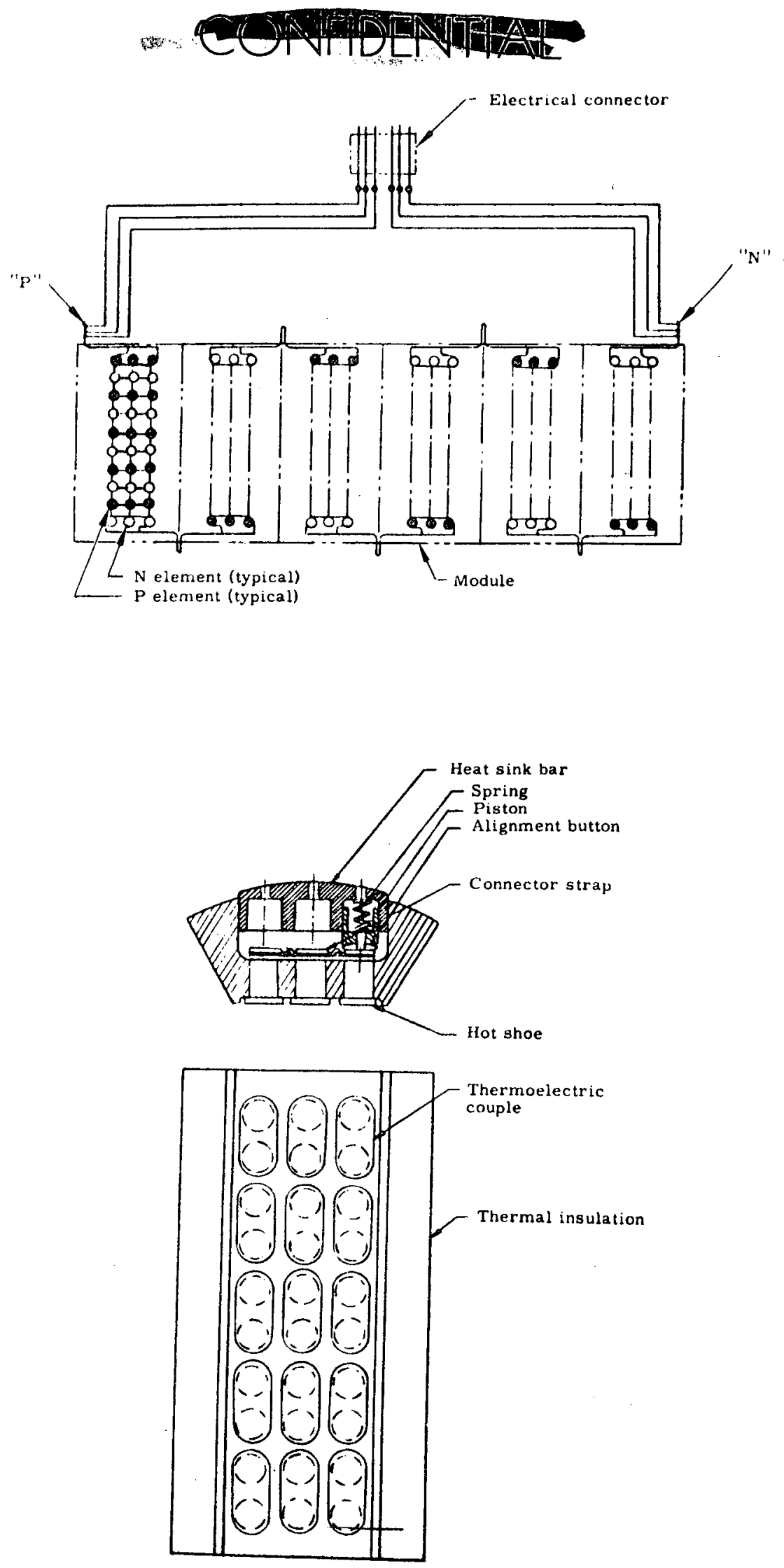

FIG. II-3. THERMOELECTRIC MODULE AND COLD END HARDWARE

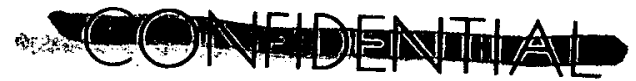

INSD - 2650-29

II -5 
other side is spherical to allow for angular misalignment. A springloaded piston with a concave surface bears on each alignment button to allow for axial movement and keeps the elements in compression. The springs and pistons are retained by a heat sink bar machined to match the generator housing inner diameter and to accept the pistons with minimal clearance to reduce the temperature drop across this interface. The buttons, pistons and heat sink bars are made of 6061-T6 aluminum alloy, selected for its high thermal conductivity and low density. Each cold end component (except the spring) is hardcoated (a process which results in a thin oxide coating on the surface of the treated parts) to provide multiple redundant electrical insulation barriers.

The six thermoelectric module assemblies are cositioned at. 60degree increments around the hex-shaped heat source. Flectrical insulation at the hot end of the thermoelectric modules is provided by a mica sheet. The thermoelectric couples within each module assembly are wired in 3 series-parallel strings, with the six modules connected in series.

Figure II-4 shows the alternate two series-parallel string electrical schematic for the thermoelectric circuit. Also included in the figure is the cold strap hardware configuration required to achieve this electrical arrangement.

Johns Manville Type 1301 Min-K thermal insulation is used for both the thermoelectric modules and at both ends of the heat source to minimize heat losses. The Min-K is cast into the required configurations at JohnsManville and trimmed upon final installation in the generator.

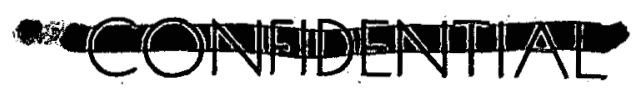



connector

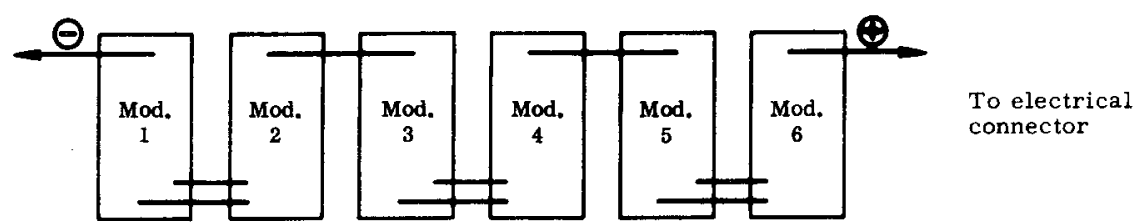

Module Interconnection (two parallel branch shown)
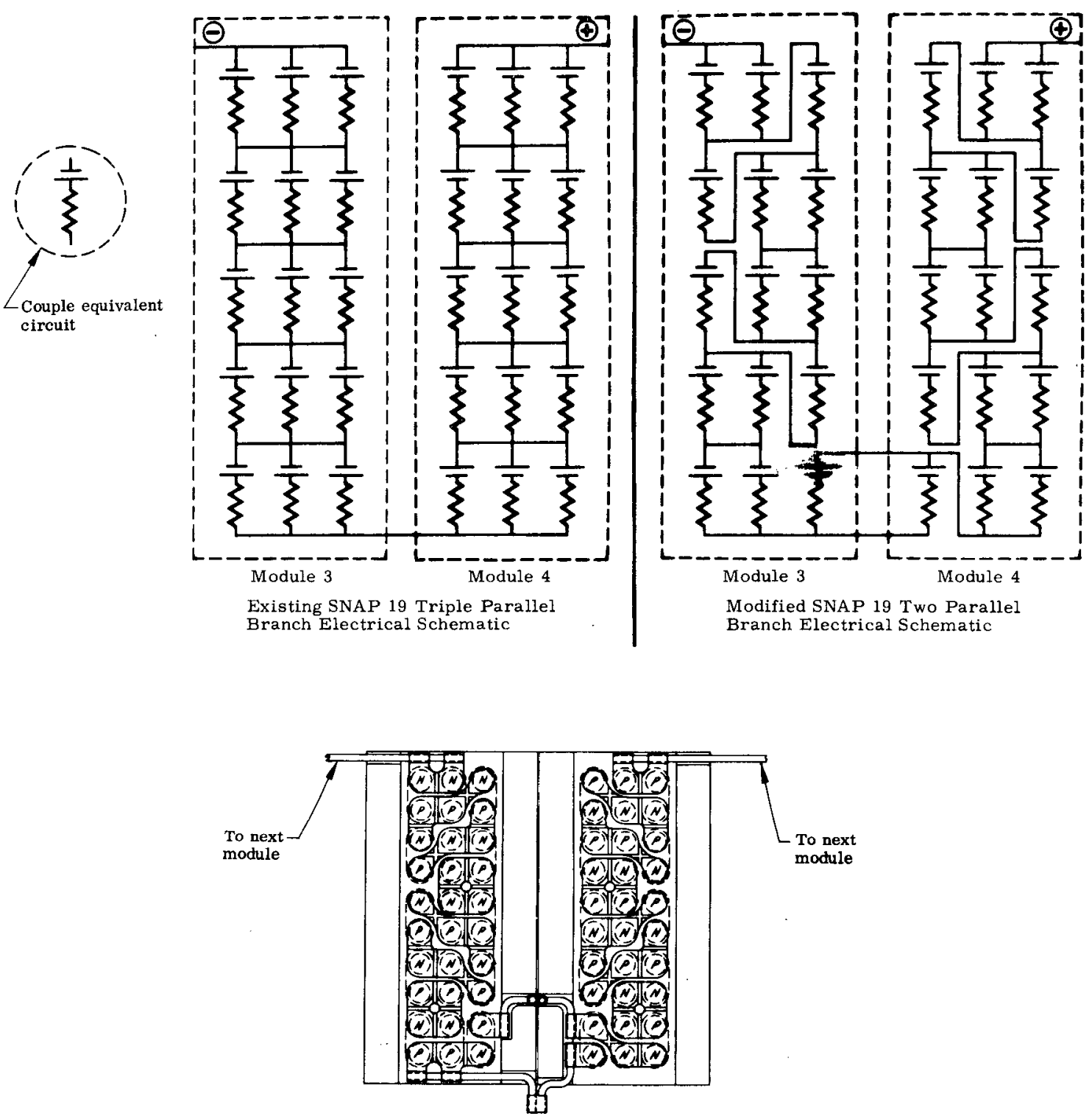

Couple Interconnection (two parallel branch)

FIG. II-4. ELECTRICAL SCHEMATICS OF T/E CONVERTER ASSEMBLY 
The thermoelectric converter (along with the rest of the internals of the generator) is initially sealed in argon. With the generation of helium associated with the radioisotope fuel decay and the subsequent release of this gas through the heat source filter, a helium/argon atmosphere is established in the RTG. (Additionally, some nitrogen and oxygen enter from the ambient air during storage with the oxygen being gettered by a zirconium sponge contained in an annular stainless steel cup next to the heat source.) The Viton o-rings in the housing permit a controlled release of these gases by permeation. The resultant equilibrium pressure in the generator is controlled by the leakage rate through the seals and the rate of helium release from the fuel.

b. Housing/radiator

The RTG housing (finned cylinder and end cover details) is fabricated from a magnesium-thorium alloy. The end covers are bolted to the cylinder top and bottom flanges with titanium bolts and nuts, and provide preload

for (1) the Viton O-ring seals installed at these joints and (2) the fuel block through predetermined compression of the Min-K thermal insulation. The electrical power outlet in each unit, also sealed with a Viton o-ring, is mounted in the side of the cylindrical housing section. Six fins are welded at 60-degree increments around the cylindrical housing to provide the required radiator area.

Mounting of the individual RTG units to the spacecract is provided by six holes equally spaced on a 7.5 inch diameter circle in the flanges of the RTG unit. This attachment arrangement may easily be modified if deemed necessary to satisfy a particular mounting requirement.

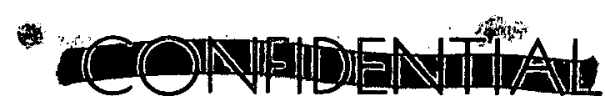


The housing/radiator design employs the same basic design features used on previously built and tested SNAP 19 units with some modifications to reduce weight. The cylindrical housing is the same diameter and wall thickness as previous units. The fins and end cover thickness have been weight optimized for the Viking mission environments.

All housing, fin and end cover (radiator) surfaces are coated with a zirconium oxide/sodium silicate mixture developed under the SINAP 9A. program and subsequently used on both the SNAP 11 and SNAP 19 RTG systems. The coating consists of finely milled zirconium oxide, which is bonded to the radiator substrate by a sodium silicate inorganic binder. This coating composition is attractive for space $\mathrm{RTG}$ radiators since it exhibits a high surface emissivity (0.83) in conjunction with a low solar absorptivity (0.2). SNAP 9A data have demonstrated the excellent stability of this coating in a space environment for a period now approaching six years.

c. Heat source

The proposed heat source for the Viking RTG is a hexagonal right prism in configuration and utilizes a helium-vented, two-layer capsule. The capsule inner liner is a molybdenum-50\% rhenium alloy to provide for fuel compatibility. The outer liner, which functions as the strength member, is constructed from TZM (titanium-zirconium-molybdenum) for protection against severe mechanical environments such as impact, blast and shrapnel. The capsule contains 675 thermal watts of $\mathrm{PuO}_{2}$ fuel. For re-entry protection, a graphite heat shield fabricated from Carb-I-Tex 
graphite is provided. The heat source is designed to provide for intactimpact re-entry of the heat source through re-entry heating and subsequent earth impact.

A summary of design characteristics for a TAGS-85/2N RTG unit is presented in Table II-1 and a weight summary is presented in Table II- 2 . 2. Predicted Performance

The performance of the Viking RTG depends primarily on the following parameters:

(1) thermoelectric stability,

(2) initial fill gas,

(3) percentage of fuel decay-generated helium released from the plutonium fuel,

(4) tightness of the RTG housing seals, and

(5) fuel decay.

Thermoelectric stability is discussed in Section III-B and parameters relating to the RTG fill gas are discussed in Section III-C. The nominal TAGS-85/2N RTG performance that results from variations on these parameters is presented in this section. For detailed reliability aspects of the RTG performance refer to Chapter VI.

\section{a. Initial argon fill}

Power and temperature profiles for generators filled with argon at the time of fueling are presented in Fig. II-5, II-6 and II-7 for helium release rates (from the fuel) of $100 \%, 50 \%$ and $25 \%$, respectively. Net power output and RTG temperatures are presented parametric in load voltage

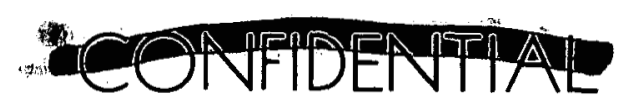


TABLE II-I

TAGS-85/2N RTG UNIT DESIGN CHARACTERISTICS FOR 675 WATT IIHS

T/E Converter

Conversion materials

TAGS $-85 / 2 N$

Hot shoe material

Nickel

Hot end cups for $\mathrm{T} / \mathrm{E}$

Ferro-Vac-E iron

Cold end caps for $\mathrm{T} / \mathrm{E}$

Ferro-Vac-E iron

Number of $\mathrm{T} / \mathrm{E}$ modules

6

Number of $T / E$ couples

90

$\mathrm{N}$-element dimensions

Diameter (in.)

0.377

wength (in.)

0.500

P-element dimensions

$$
\begin{aligned}
& \text { Diameter (in.) } \\
& \text { Length (in.) }
\end{aligned}
$$

Thermal insulation

Cold end electrical strap material

Number of parallel strings

Heat sink assembly

Number of assemblies

Pistons, hardcoated Al 6061-T6

Alignment buttons, hardcoated AL $6061-\mathrm{T} 6$

Springs, SS

Module bar, hardcoated A1 6061-T6
0.270

$0.100 \mathrm{SnTe}+0.400$ TAGS

Johns-Manville Type 1301

Oxygen-free Cu

3

6

180

180

180

6

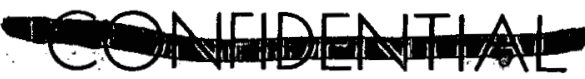

INSD-2650-29

$I I-I I$ 


\section{TABLE II-I (Continued)}

Heat Source

Radioisotopic fuel

$\mathrm{PuO}_{2}$ microspheres

Fuel power density (watts $/ \mathrm{cm}^{3}$ )

2.7

Materials

\section{Heat shield \\ Strength member \\ Inner liner \\ Compliant support pads \\ Compliant support cup}

Dimensions

$$
\begin{aligned}
& \text { Hex-shaped heat shield } \\
& \text { Across flats (in.) } \\
& \text { Length (in.) }
\end{aligned}
$$

3.500

6.750

Wall thickness (in.)

0.562

Capsule strength member

ID (in.)

Wall thickness (in.)

Capsule thermal inventory at BOL (watts)

2.030

0.060

675

Capsule inner liner

$$
\text { ID (in.) }
$$

Wall thickness (in.)

1. 970

0.020

Housing/Radiator

Housing material

MgTh (HM3IA-T5)

Fin and end cover material

MgTh (HM21A-T8)

Housing OD at flanges (in.)

8.15

Housing OD (in.)

6.45

Length, including end covers (in.)
10.75 


\section{TABIE II-1 (Continued)}

$\begin{array}{ll}\text { Overall diameter, including fins (in.) } & 24.4 \\ \text { End cover minimum wall thickness (in.) } & 0.156 \\ \text { Housing wall thickness (in.) } & 0.093 \\ \text { Assembly bolts and nuts } & \begin{array}{l}\text { No. } 10 \text { and } 1 / 4 \text { in. } \\ \text { diameter Ti alloy }\end{array} \\ \text { O-ring seals } & \text { Viton-A }\end{array}$

Fin dimensions

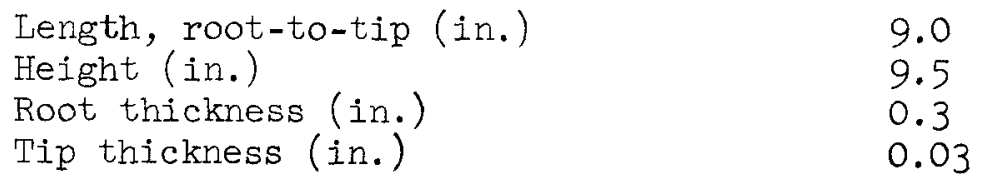


TABLE II-2

TAGS-85/2N RTG UNIT WEIGHT SUMMARY

Weight. (Ib)

$T / E$ Modules (6)

7.86

Couples, straps and wiring

3.22

Cold end hardware

3.91

Min-K insulation

0.73

Housing/Radiator

10.24

Housing and fins

7.66

End cover, fueling end

1.16

End cover, joined end

1.02

Retaining hardware and 0-rings

0.40

Heat Source (IIHS; 675 watts)

8.14

Fuel and $\mathrm{ZrO}_{2}$ filler

4.10

Capsule components

1.78

Heat shield components

2.26

Miscellaneous

Min-K at ends

0.84

Getter

0.75

Miscellaneous (shims, mica, plug)

0.35

Total

28.2

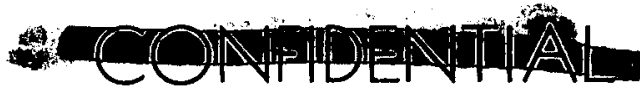

INSD-2650-29

II -14 

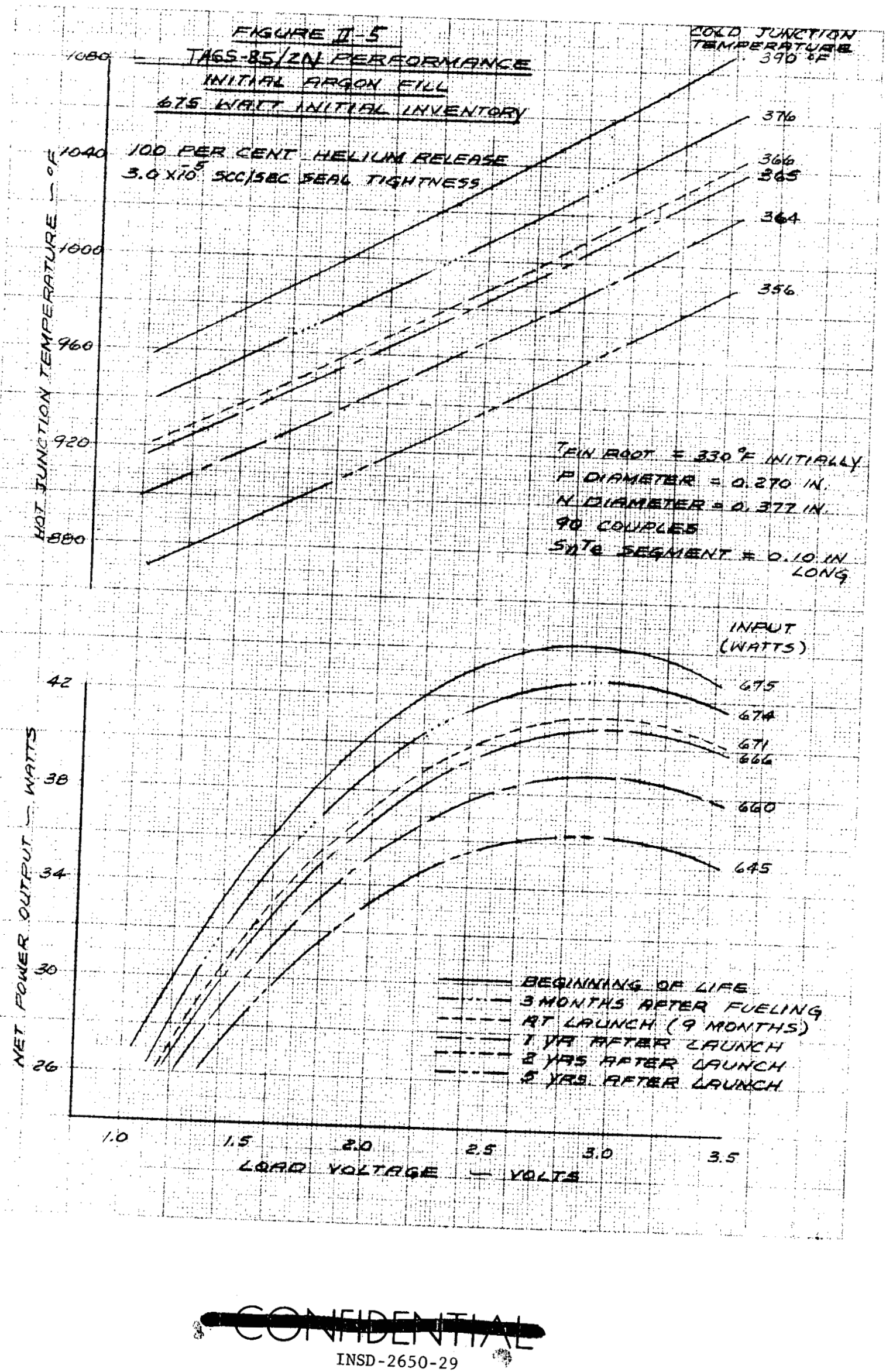

II -15 


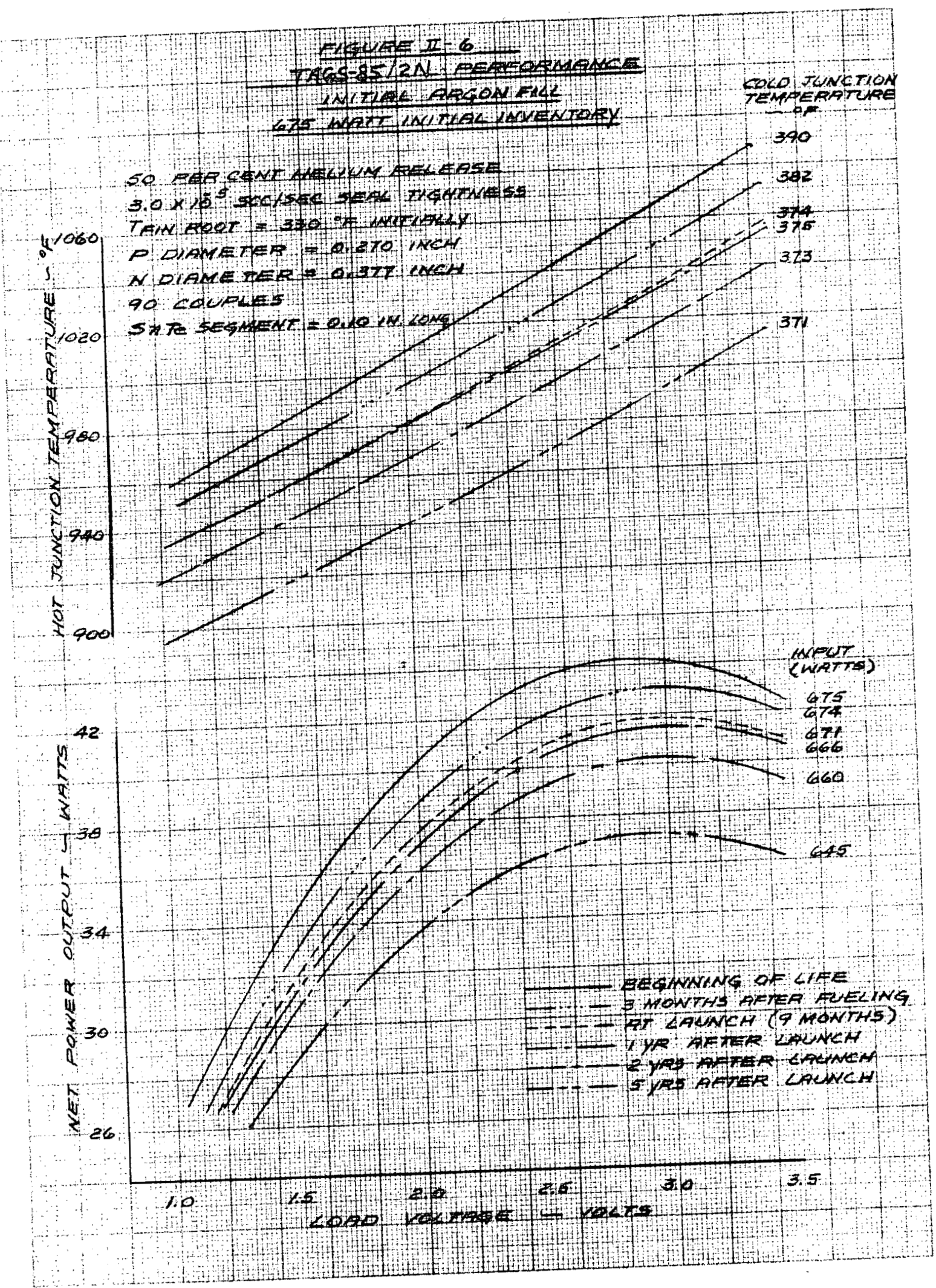


ty

COTriountiaz
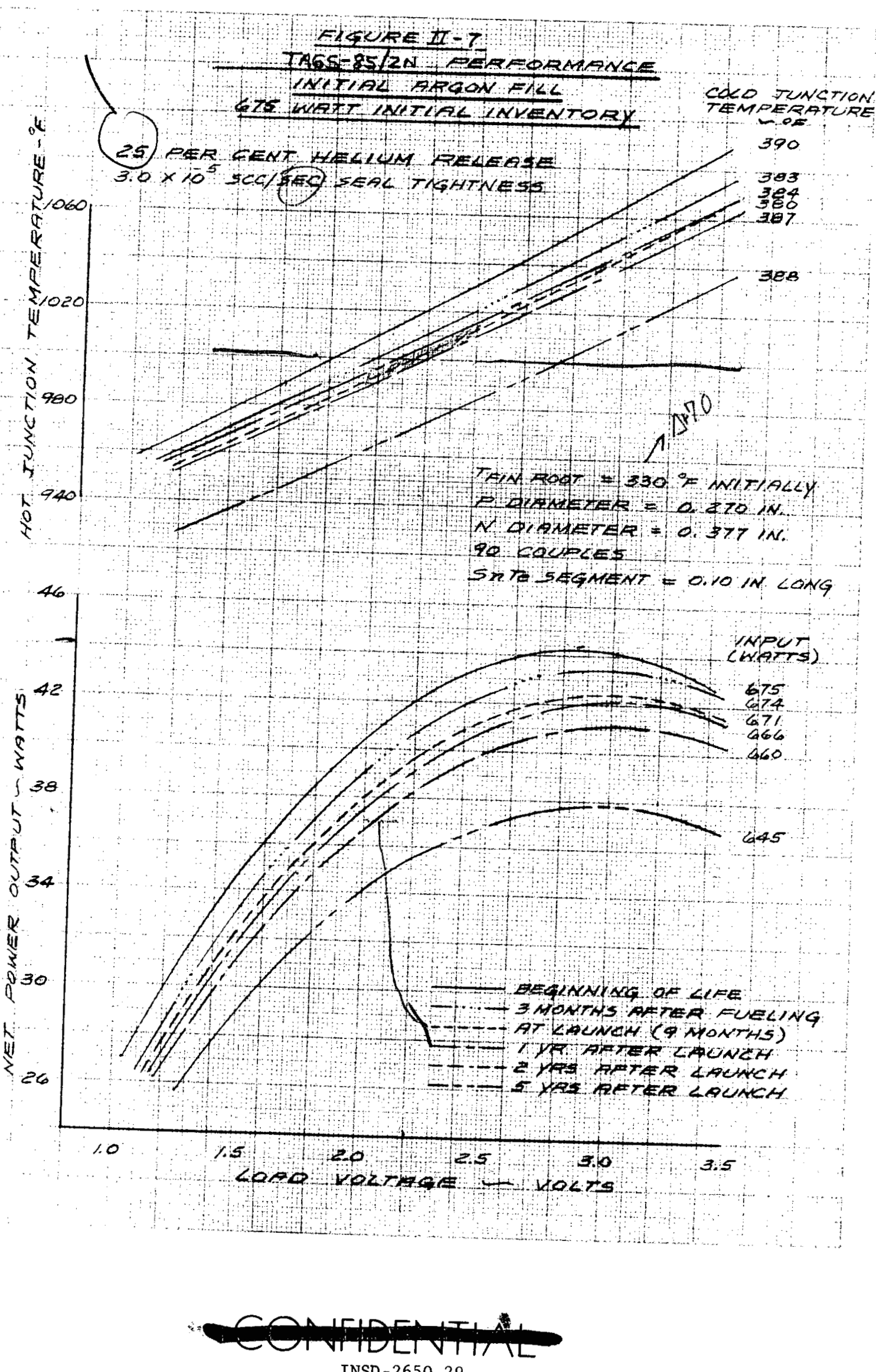

INSD - 2650-29

II -17 
for six mission times up to 5 years. The load voltages shown in the figures assume the present three series-parallel string electrical arrangement. For the two series-parallel string arrangement, the load voltage will be $50 \%$ higher with the power output virtually identical to that shown for three series-parallel strings. For all performance analyses in this report, the present three series-parallel arrangement is assumed except where noted otherwise.

Generator power is relatively flat between 2.6 and 3.2 volts, and peak power points occur between 2.8 and 3.0 volts during the 5 -year period analyzed and the range of helium release rates expected. Hot junction temperature varies approximately linearly with load voltage and generally decreases with time at any load voltage. A nominal seal tightness factor of $3 \times 10^{-5} \mathrm{scc} / \mathrm{sec}$, typical for SNAP 19 type generators, was assumed to construct the curves. Complete release (100\% rate) of all helium generated by fuel decay, which apparently has occurred on the Nimbus III generators $S / N 24$ and $S / N 25$ (see Section III-C), is conservative for power prediction analyses and was assumed herein in conjunction with the $3 \times 10^{-5} \mathrm{scc} / \mathrm{sec}$ seal tightness for nominal performance predictions.

The effect of seal tightness and helium release rate on power is minimal as shown in Fig. II-8. Power output at the end-of-mission (one year after launch) varies less than $4 \%$ about the nominal for the range of seal tightness and helium release rates expected. The maximum effect on reducing power from the nominal expected value at end-of-mission, 40.7 
FIGURE II- $\theta$

TAGS-85/2N POWER OUTPUT AT ONE YEAR AFTER LAUNCH NORMALIZED TO THE NOMINAL VALUE

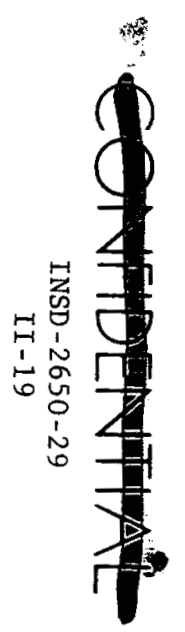

ANTRAL FUEL INURN TOE $4=675$ WAT IS EFFECTIVE $\$ N K$ TEMPERATURE $=100^{\circ} \mathrm{F}$ NOMINAL POWER AT ONE YEAR $=40.7$ WATTS

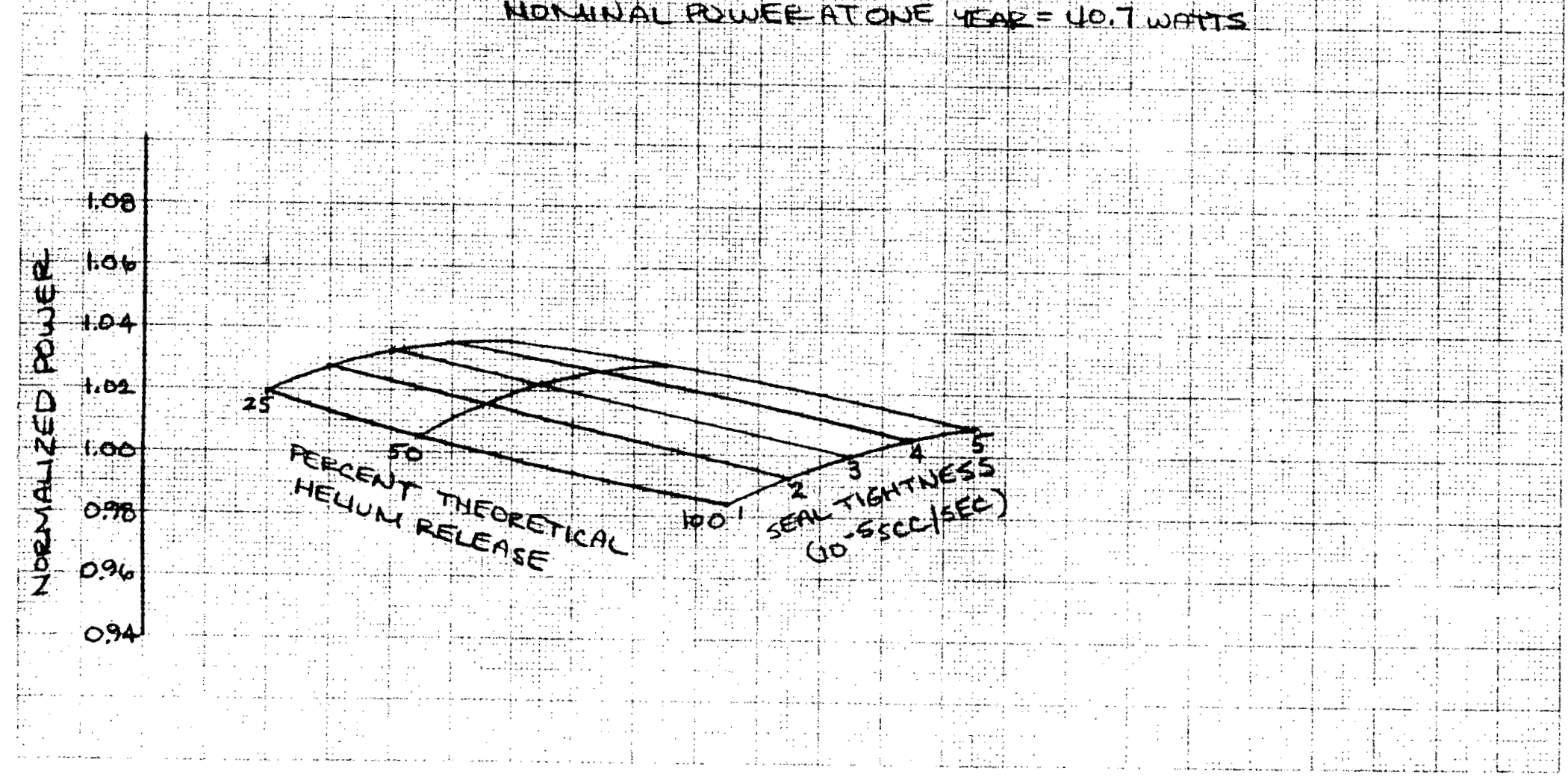


watts, is seen to be less than $2 \%$, and occurs for $100 \%$ helium release and the tightest seal, $1 \times 10^{-5} \mathrm{scc} / \mathrm{sec}$.

From Fig. II-9, the beginning-of-life design hot junction temperature is $1058^{\circ} \mathrm{F}$ at a cold junction temperature of $390^{\circ} \mathrm{F}$ and a fin root temperature of $330^{\circ} \mathrm{F}$. Assuming $100 \%$ helium release from the fuel and $3 \times 10^{-5} \mathrm{scc} / \mathrm{sec}$ tightness to be nominal values, the hot junction temperature decreases to $1009^{\circ} \mathrm{F}$ over the period from nine months preceding launch to one year after launch. During this same period, the nominal power changes from 44.1 watts per RTG to 40.7 watts at the 2.9 load voltage design point which results in maximum power at end-ofmission for the nominal design conditions.

For the Viking mission, electrical power may not be required at all times, such as during interplanetary cruise, and the RTG may be placed on short circuit if desired. Thus the power profile shown in Fig. II-9 may be considered as an "available" power curve. The primary effect on the temperature profiles of short circuiting the RTG will be to decrease the hot junction by approximately $100^{\circ} \mathrm{F}$ from the values shown assuming the fin root temperature does not vary appreciably from the $330^{\circ} \mathrm{F}$ design value ( $100^{\circ} \mathrm{F}$ effective environmental sink temperature).

Table II-3 summarizes the performance parameters for the Viking TAGS-85/2N RTG for beginning-of-life (BOL) and end-of-mission (EOM) conditions. As is shown in Chapter VI, a 40.7 watt EOM nominal power output per RTG results in a 0.99 probability of obtaining 154 watts from four such units connected in parallel (38.5 watts per RTG). Thus

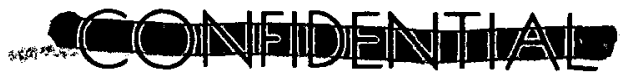


PERFORMANCE SUMMARY FOR TAGS-85/2N RTG DESTGN

(INITIAI ARGON FILI)

\begin{tabular}{|c|c|c|}
\hline & $\mathrm{BOL}^{1}$ & $\mathrm{EOM}^{2}$ \\
\hline Nominal input power (watts) & 675 & 666 \\
\hline Nominal output power (watts) & 44.1 & $40.7(38.5)^{3}$ \\
\hline RTG efficiency $(\%)$ & 6.53 & 6.11 \\
\hline RTG specific power (watts/1b) & 1.56 & 1.44 \\
\hline Load voltage (volts) 4 & $2.9(4.4)$ & $2.9(4.4)$ \\
\hline Load current (amps) ${ }^{4}$ & $15.2(10.0)$ & $14.0(9.2)$ \\
\hline Hot junction temperature $\left({ }^{\circ}\right)$ & 1058 & 1009 \\
\hline Cold junction temperature $\left({ }^{O} \mathrm{~F}\right)$ & 390 & 365 \\
\hline Fin root temperature $\left({ }^{O} F\right)$ & 330 & 327 \\
\hline Total internal pressure (psia) ${ }^{5}$ & 14.7 & $7 \cdot 3$ \\
\hline Helium concentration $(\%)^{5}$ & 0 & 59 \\
\hline
\end{tabular}

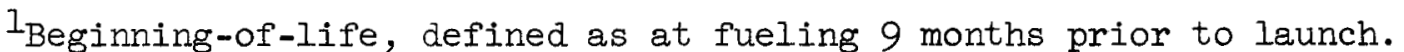

${ }^{2}$ End-of-mission, defined as one year after launch.

3output power at EOM for a 0.99 reliability shown in parentheses.

${ }^{4}$ Values in parentheses are for two series-parallel strings.

5 Based on $100 \%$ He release from capsule and $3 \times 10^{-5} \mathrm{scc} / \mathrm{sec}$ seal tightness (see Section III-C). 


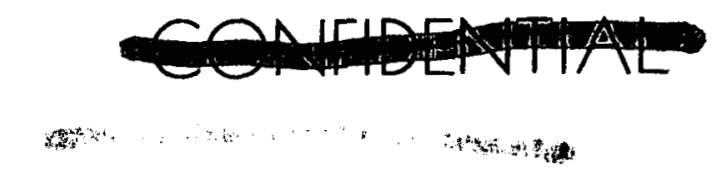

a 2.5 watt margin is provided over the 36 watt minimum RTG power requirement based on present Martin Denver studies for an all-RTG power system. As is shown in Section III-A, the nominal BOL performance of a TAGS-85/2N RTG with the alternate Nimbus III 625-thermal watt IRHS is 37.8 watts. End-of-mission nominal power is approximately 34.8 watts. No further performance increase with the present SNAP 19 IRHS can be realized, as 625 watts is its present capacity.

b. Initial helium fill RTG

The principal advantage of an initial helium fill in lieu of an argon fill is a somewhat flatter electrical power profile and lower hot junction operating temperatures as illustrated in Figs. II-IO, II-II, and II-12, at the expense of a lower output for mission periods of less than two years. The five-year power and temperature levels, however, are essentially equivalent to those for argon filled generators, since by that time the equilibrium gas compositions and pressures are nearly the same. Post fueling, BOL, power of the helium generator is 38.3 watts as compared to 44.1 watts for an argon filled unit. The temporary power and temperature jncreases of generators, shown in Fig. II-13, result from the pressure and helium concentration changes for a period after launch.

For the Viking mission, an initial argon fill offers a significant performance advantage at one-year after launch, 40.7 watts compared to 38.7 watts (at $100 \%$ release rate), and thus is the recommended fill gas approach. As an initial helium fill offers no performance advantage

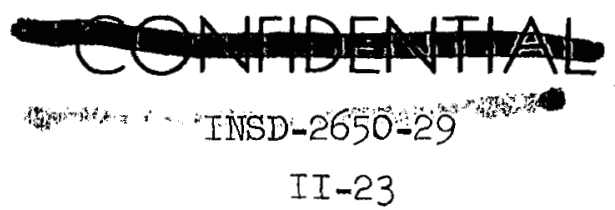




\section{(1)}
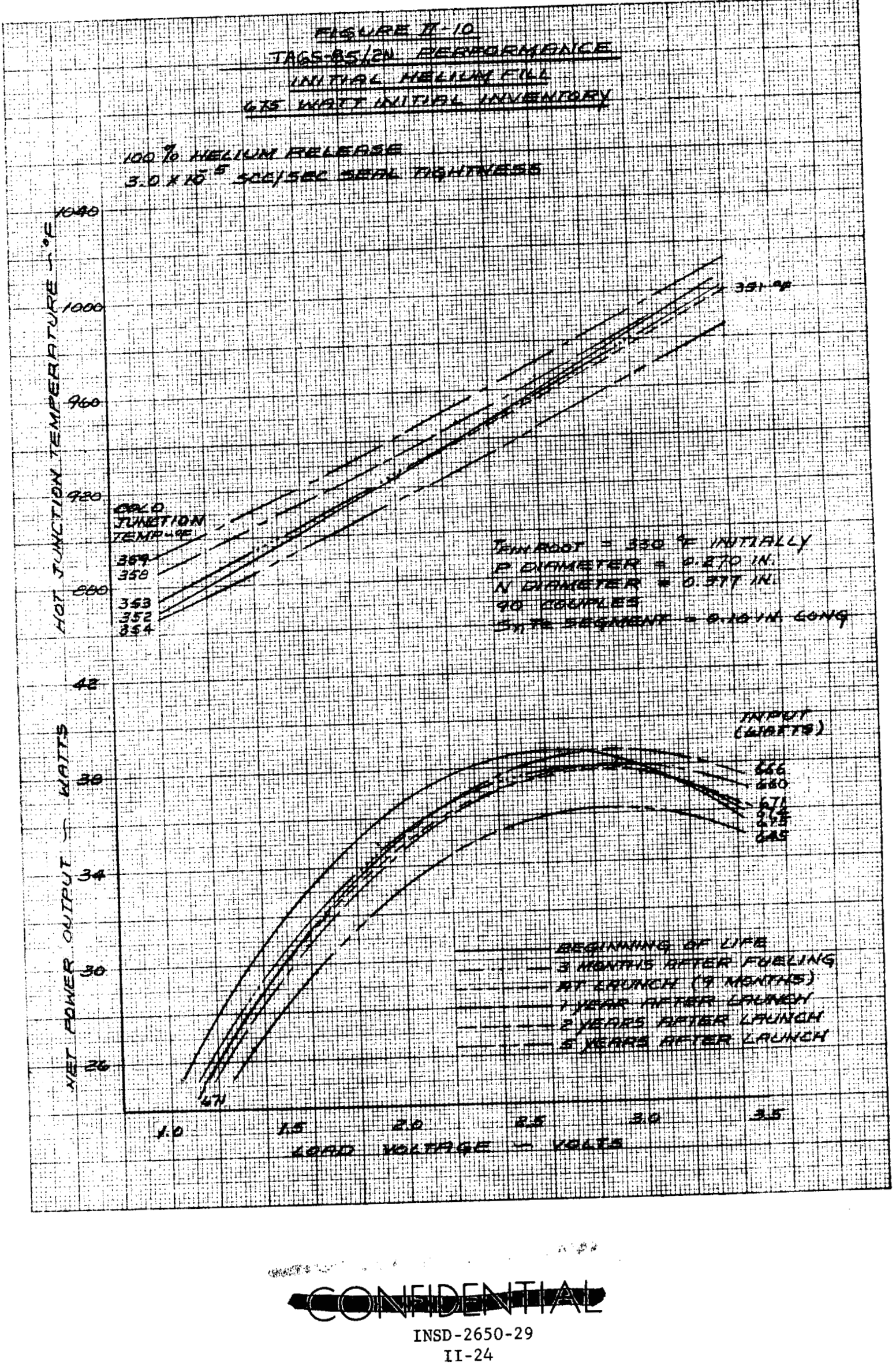
tow
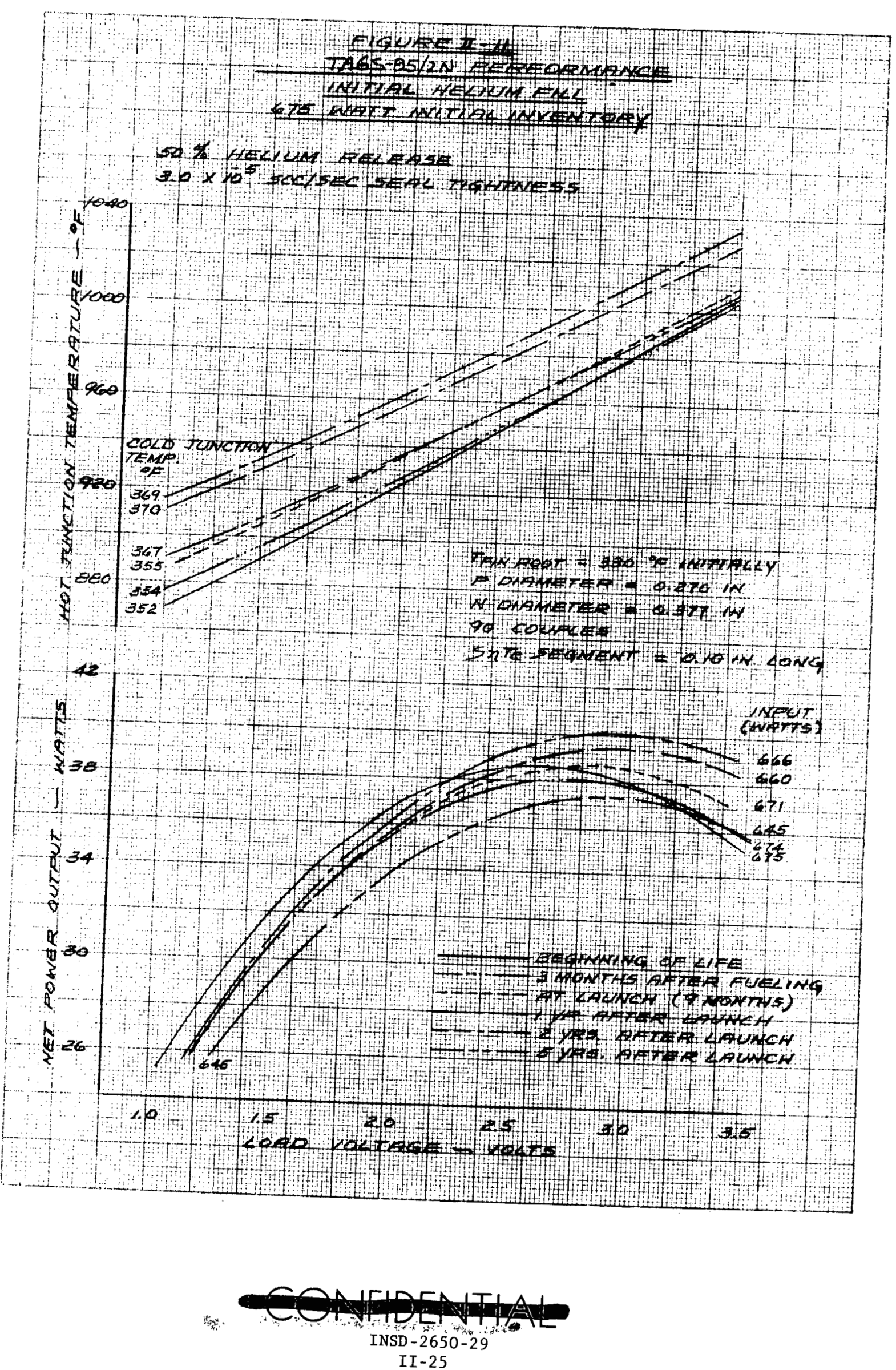

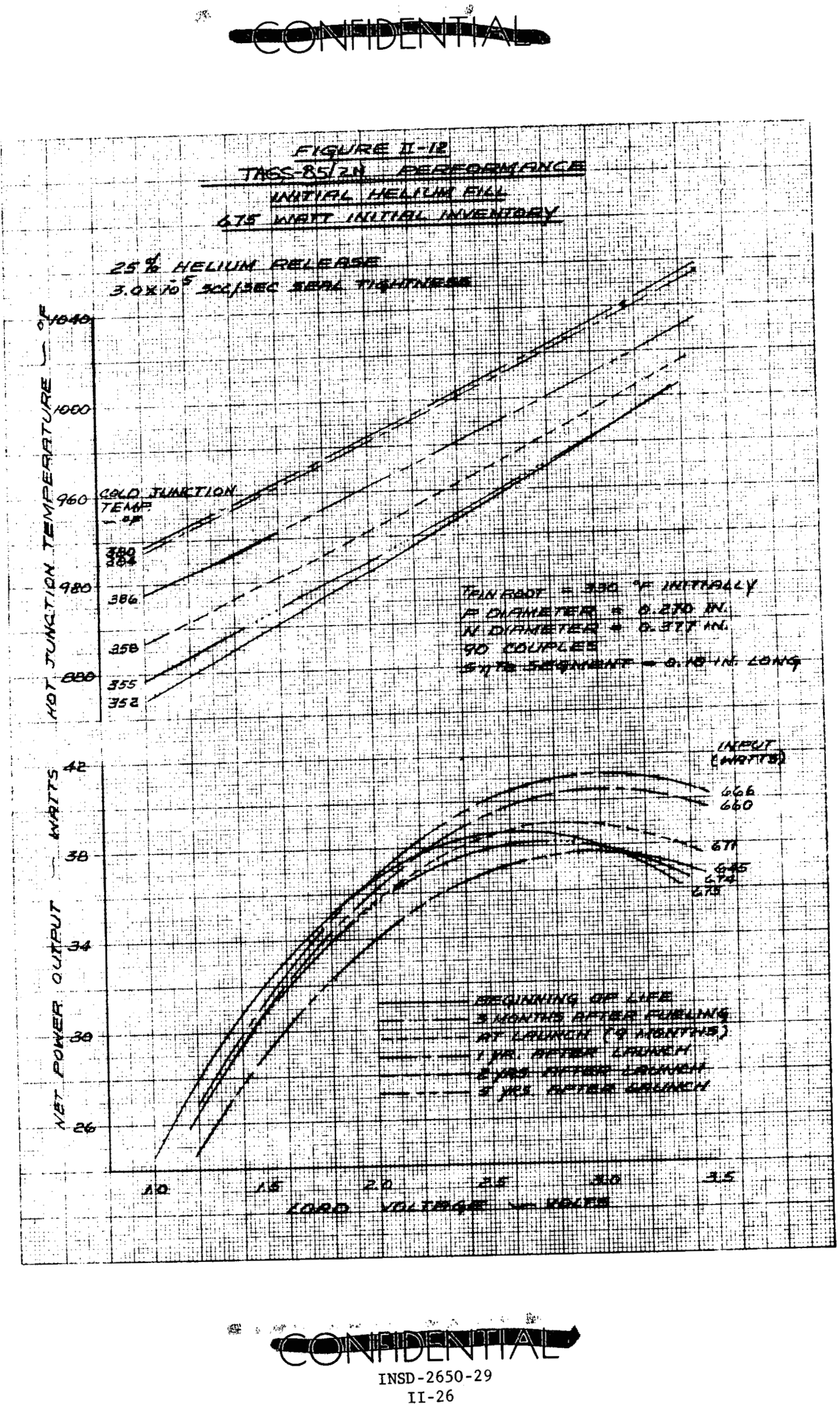
EIGUAE II-13

TAGS-85/2N HELYU FLLED RTG NOMINAC PERFOAMANKE PARANTETERS

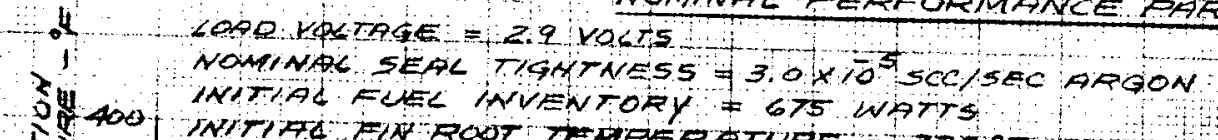

PER GENR HIEORETICAL

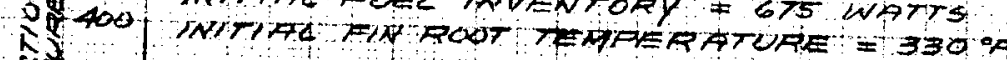

HEL OUY AELEASE

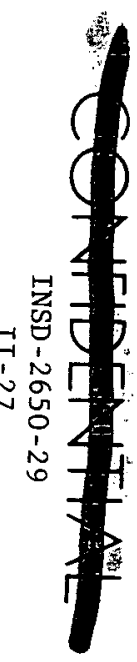

sit.

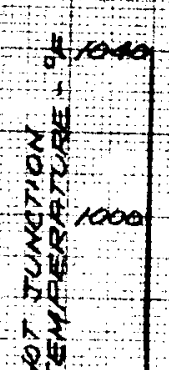

$\frac{1+2}{2+1}$
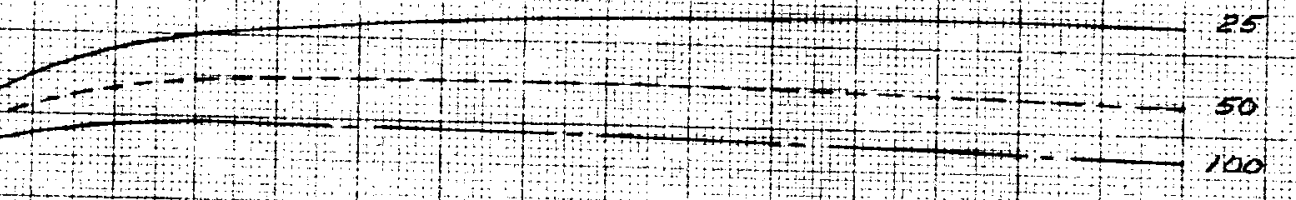

$1+9$

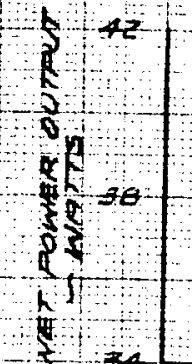
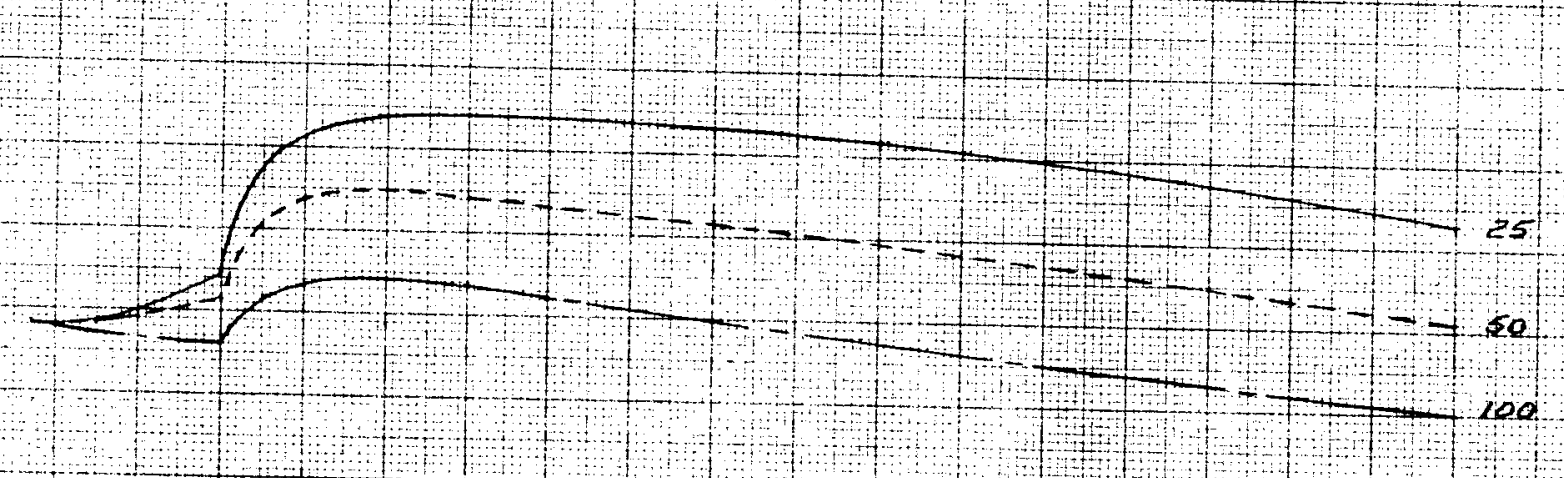

100

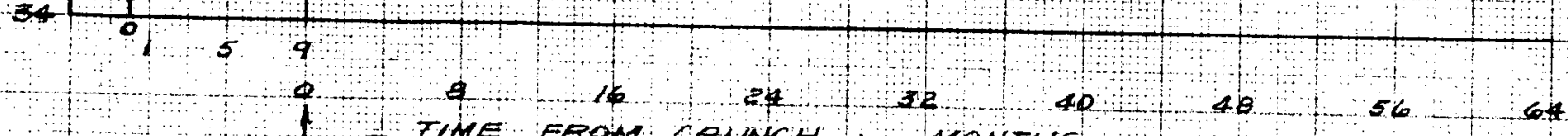

THE FAON GAUKA H MONTHS 
over an argon fill for the Viking mission, the former was not considered further in this study.

\section{B. $3 \mathrm{P} / 2 \mathrm{~N}$ RTG}

In this section the performance of a $3 \mathrm{P} / 2 \mathrm{~N}$ RTG is presented for the Viking mission. With the present Nimbus III 625 watt fuel inventory, the RTG weight is 26.7 pounds and the nominal power output is 26.6 watts at end-of-mission.

1. Design Description

The 3P/2N RTG unit design option evaluated for the Viking mission, is similar to that of the present SNAP 19 Nimbus III RTG with the following exceptions:

a. The fins and housing have been optimized for the Viking mission to the configuration shown in Fig. II-1.

b. A 625 watt intact-impact heat source (IIHS), identical to that for the TAGS-85/2N design except for fuel loading, has been substituted for the Nimbus III 625 watt intact re-entry heat source (IRHS) with the latter considered as an alternate.

With the exception of the thermoelectric converter P-leg and shoe materials (see Fig. II-14), the detailed description and construction materials are identical to those previously presented for the TAGS-85/ 2N RTG in section II-A.

A summary of design characteristics and weight parameters for a 3P/2N RTG unit is presented in Tables II-4 and II-5.

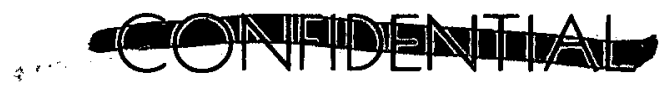

INSD-2650-29 


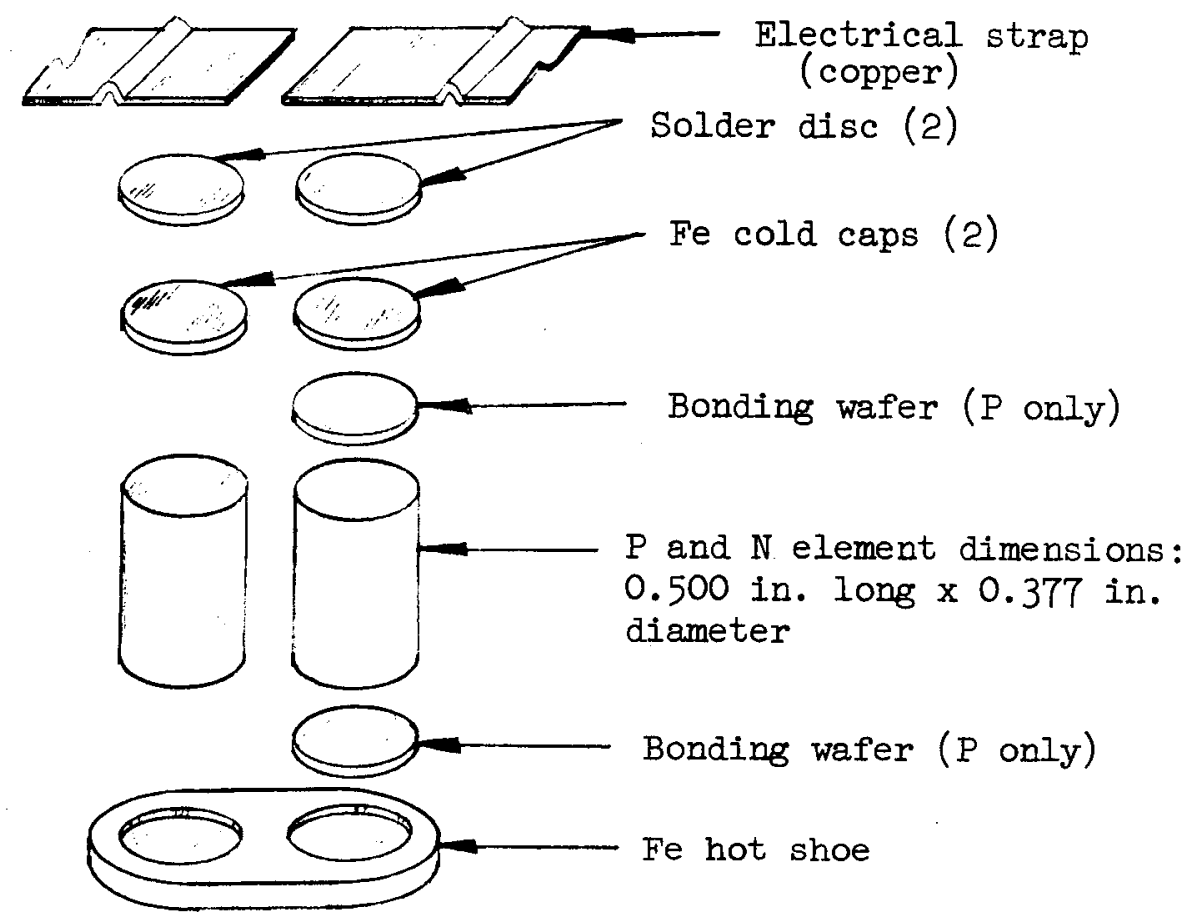

Fig. II-14. 3P/2N Couple Design 
$\underline{\text { TABLE II }-4}$

3P/2N RTG UNIT DESIGN CHARACTERISTICS FOR 625 WATT IIHS

\section{$\underline{T / E}$ Converter}

Conversion materials

Hot shoe material

Cold end caps for $T / E$

Number of $\mathrm{T} / \mathrm{E}$ modules

Number of $\mathrm{T} / \mathrm{E}$ couples

N-element dimensions

Diameter (in.)

Length (in.)

P-element dimensions

Diameter (in.)

Length (in.)

Thermal insulation

Cold-end electrical strap material

Number of parallel strings

Heat sink assembly

Number of assemblies

Pistons, hardcoated A1 6061-T6

Alignment buttons, hardcoated

A1 6061-T6

Springs, SS

Module bar, hardcoated Al 6061-T6

Heat Source

Radioisotopic fuel

Fuel power density (watts $/ \mathrm{cm}^{3}$ )

Materials

Heat shield

Strength member
$3 \mathrm{P} / 2 \mathrm{~N}$

Ferro-Vac-E iron

Ferro-Vac-E-iron

6

90

0.377

0.500

0.377

0.500

Johns-Manville Type 1301

Oxygen-free copper

3

6

180

180

180

6

$\mathrm{PuO}_{2}$ microspheres

2.7

Carb-I-Tex graphite TZM

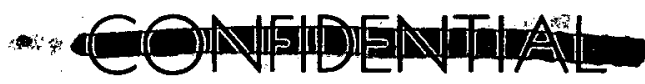

INSD-2650-29 
Inner liner

Compliant support pads

Compliant support cup
Mo-50\% Re

Ta felt

$\mathrm{Ta}$

Dimensions

Hex-shaped heat shield Across flats (in.)

Length (in.)

3.500

6.750

Wall thickness (in.)

0.562

Capsule inner liner

ID (in.)

Wall thickness (in.)

1.970

0.020

Capsule strength member

ID (in.)

Wall thickness (in.)

2.030

Capsule thermal inventory

at BOL (watts)

0.060

625

Housing/Radiator

Housing material

MgTh (HM3IA-T5)

Fin and end cover material

MgTh (HM21A-T8)

Housing OD at flanges (in.)

8.15

Housing OD (in.)

6.45

Length, including end covers (in.)

10.75

Overall diameter, including fins (in.)

18.0

End cover minimum wall thickness (in.)

0.156

Housing minimum wall thickness (in.)

0.093

Assembly bolts and nuts

No. 10 and $1 / 4$ in. diameter Ti alloy

o-ring seals

Viton-A

Fin dimensions

Length, root-to-tip (in.)

5.8

Height (in.)

9.5 


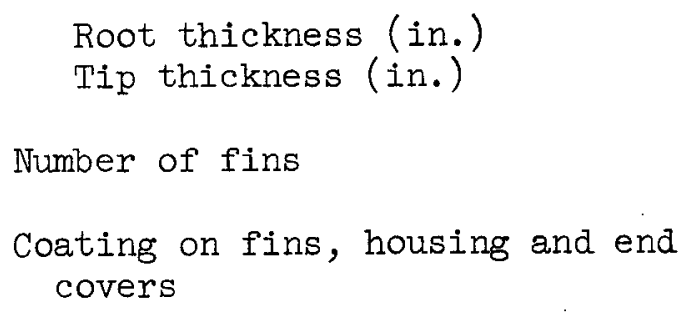

Miscellaneous

Hot end electrical insulation

Getter

Initial fill gas
0.30

0.03

6

Zirconia with sodium silicate binder

Ti

mica

Zirconium sponge in stainless steel container

Argon at approximately

1 atmosphere 
TABLE II - 5

3P/2N RTG UNIT WEIGHT SUMMARY

\begin{tabular}{|c|c|c|}
\hline Item & Weight & $(1 \mathrm{~b})$ \\
\hline T/E Modules (6) & & 8.35 \\
\hline Couples, straps and wiring & 3.71 & \\
\hline Cold end hardware & 3.91 & \\
\hline Min-K insulation & 0.73 & \\
\hline Housing/Radiator & & $8 \cdot 30$ \\
\hline Housing and fins & 5.72 & \\
\hline End cover, fueling end & 1.16 & \\
\hline End cover, joined end & 1.02 & \\
\hline Retaining hardware and 0 -rings & 0.40 & \\
\hline Heat Source (IIHS - 625 watts) & & 8.09 \\
\hline Fuel & 4.05 & \\
\hline Capsule components & 1.78 & \\
\hline Heat Shield components & 2.26 & \\
\hline Miscellaneous & & 1.94 \\
\hline Min-K at ends & 0.84 & \\
\hline Getter. & 0.75 & \\
\hline Miscellaneous (shims, mica, plug) & 0.35 & \\
\hline TOTAL & & 26.7 \\
\hline
\end{tabular}




\section{Predicted Performance}

The nominal performance of Nimbus III type 3P/2N RTG's employing a 625 watt IIHS (or IRHS) is shown in Fig. II-15 for various mission operating periods. The nominal power output at end-of-mission (one year after launch) is 26.6 watts at 2.4 volts. Hot and cold junction operating temperatures are $938^{\circ} \mathrm{F}$ and $390^{\circ} \mathrm{F}$, respectively, at end-of-mission, decreasing from initial $978^{\circ} \mathrm{F}$ and $415^{\circ} \mathrm{F}$ values at beginning-of-life. Figure II-16 shows the power and temperature profiles for the nominal helium release rate $(100 \%)$ and argon leak rate $\left(3 \times 10^{-5} \mathrm{scc} / \mathrm{sec}\right)$ values. The performance is essentially identical to that predicted for the SNAP 19 Nimbus III application where the RTG operates at a fin root temperature of $354^{\circ} \mathrm{F}$ with a 625 watt fuel inventory.

Table II-6 summarizes the nominal performance parameters for a $3 \mathrm{P} / 2 \mathrm{~N}$ RTG. As is evident, the 26.6 watts obtained at end-of-mission is significantly less than the 40.7 watts available from the TAGS-85/2N RTG previously discussed. However, as is shown in ChaptervI, approximately 50 watts at a 96\% reliability is available at end-of-mission from two $3 \mathrm{P} / 2 \mathrm{~N}$ RTG's connected in parallel. Thus, the $3 \mathrm{P} / 2 \mathrm{~N}$ units may be satisfactory for the RTG/battery hybrid power supply concept which requires approximately 25 watts from each of two RTG's.

Additional power may be obtained from a 3P/2N generator by increasing the fuel inventory and decreasing the operating fin root temperature by increasing the fin area. This evaluation, discussed in detail in Section III-A, shows that nominal beginning-of-life power outputs up to

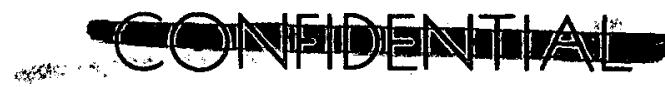




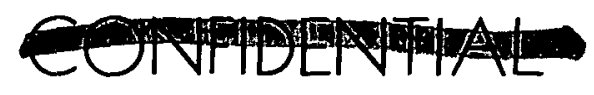

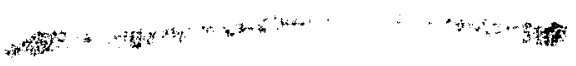

36 watts are feasible. Thus, a 3P/2N RTG cannot be satisfactorily

utilized for the present Martin Denver all-RTG system which requires

36 watts minimum per RTG at end-of-mission.

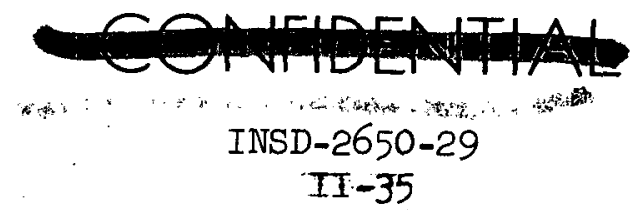



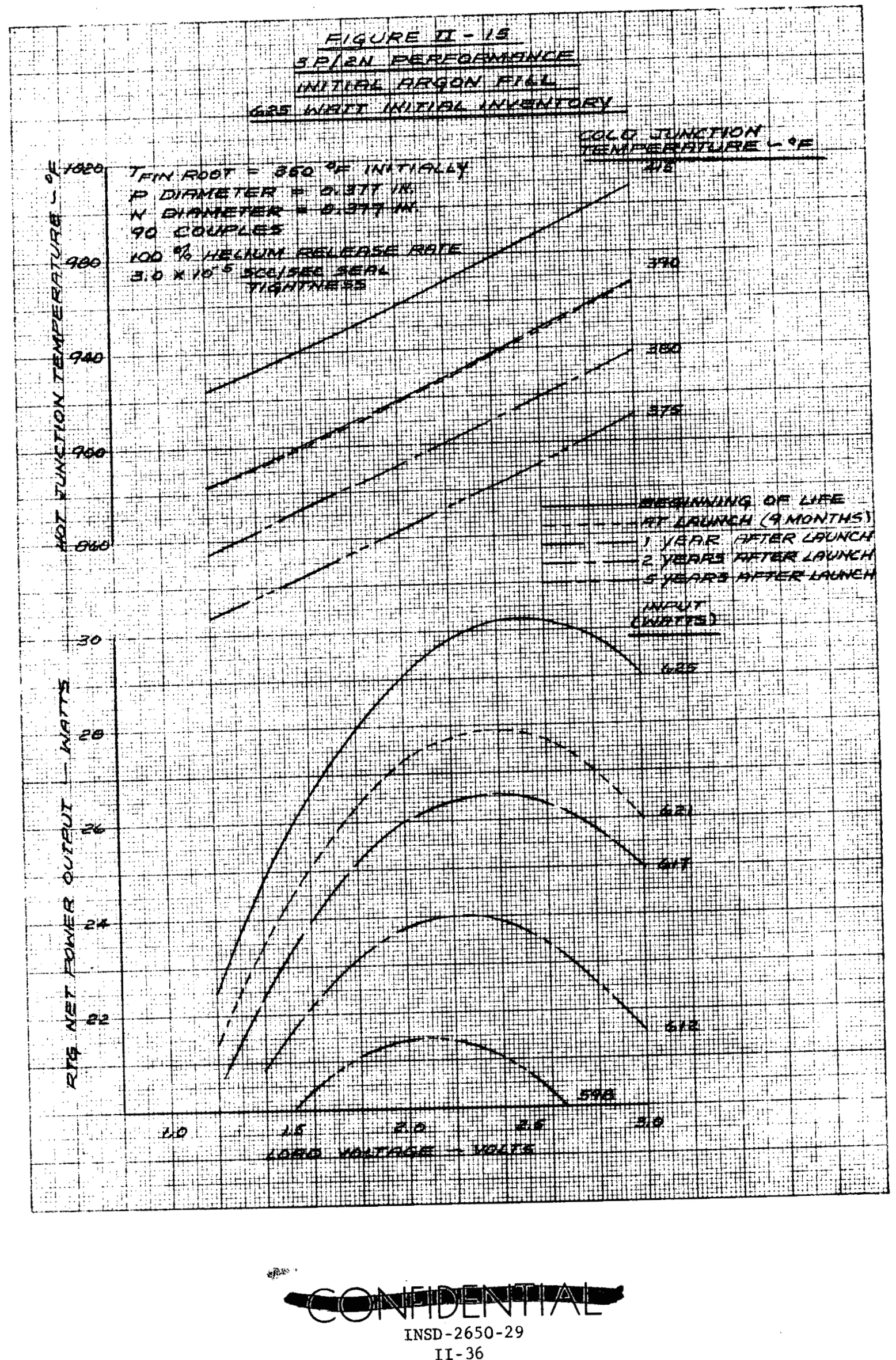


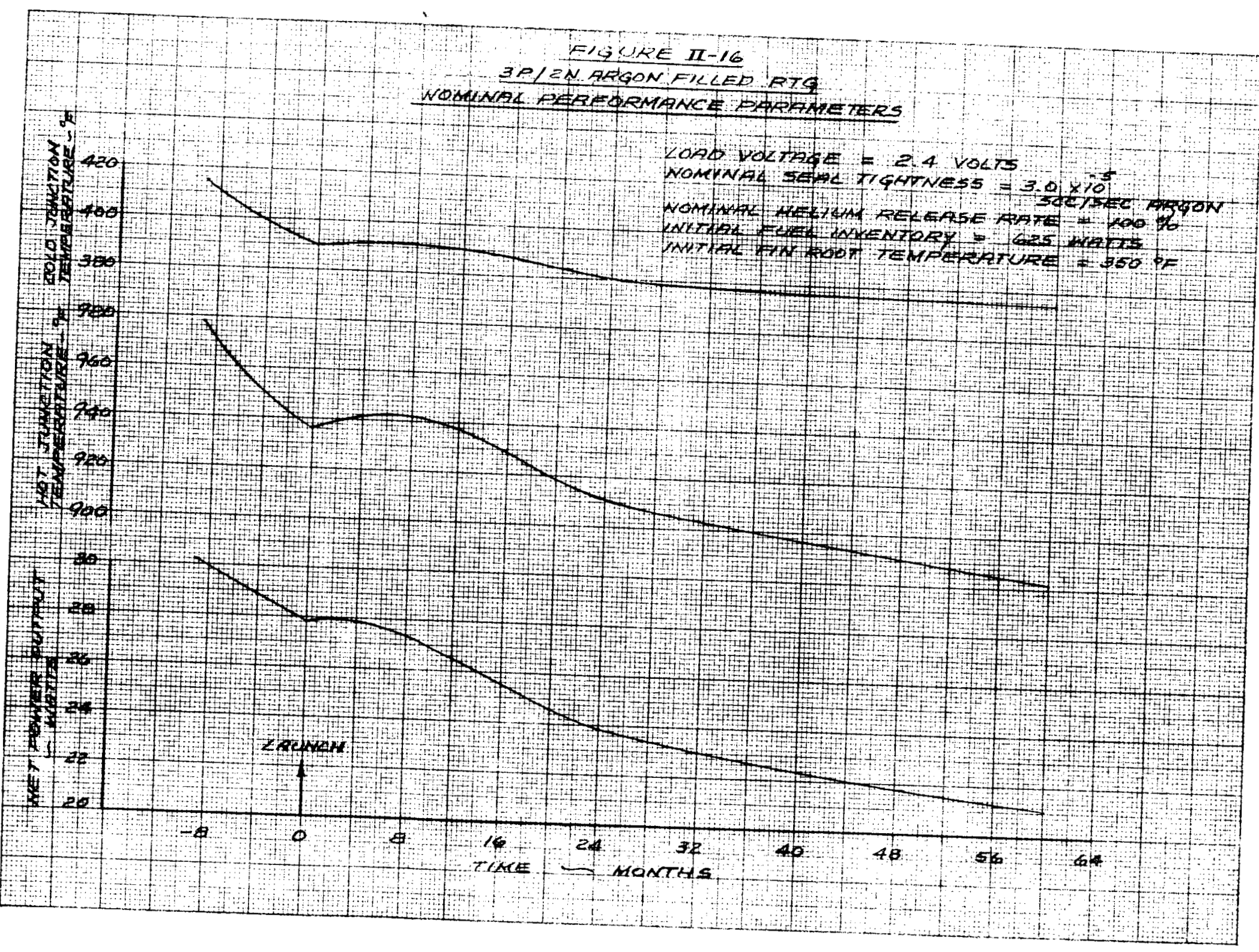




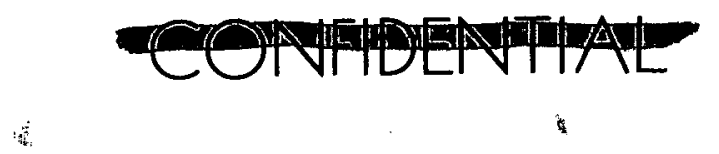

TABLE II-6

PERFORMANCE SUMMARY FOR 3P/2N RTG DESIGN

(INITIAL ARGON FILL)

$\begin{array}{lll} & \frac{\text { BOL }^{1}}{} & \frac{\text { OOM }^{2}}{} \\ \text { Nominal input power (watts) } & 625 & 617 \\ \text { Nominal output power (watts) } & 30.3 & 26.6(24.8)^{3} \\ \text { RTG efficiency (\%) } & 4.85 & 4.32 \\ \text { RTG specific power (watts/1b) } & 1.13 & 1.00 \\ \text { Load voltage (volts) } & 2.4(3.6) & 2.4(3.6) \\ \text { Load current (amps) } & 12.6(8.4) & 11.1(7.4) \\ \left.\text { Hot junction temperature ( }{ }^{\circ} \mathrm{F}\right) & 978 & 938 \\ \left.\text { Cold junction temperature ( }{ }^{\circ} \mathrm{F}\right) & 415 & 390 \\ \text { Fin root temperature }\left({ }^{\circ} \mathrm{F}\right) & 350 & 348 \\ \text { Total internal pressure }(\mathrm{psia})^{5} & 14.7 & 5.0 \\ \text { Helium concentration }(\%)^{5} & 0 & 6.1\end{array}$

1 Beginning-of-life, defined as at fueling nine months prior to launch.

${ }^{2}$ End-of-mission, defined as one year after launch.

3 output power at EOM for a 0.96 reliability shown in parentheses.

4 values in parentheses are for two series-parallel strings.

5 Based on $100 \%$ He release from capsule and $3 \times 10^{-5} \mathrm{scc} / \mathrm{sec}$ seal tightness (see Section III-C).

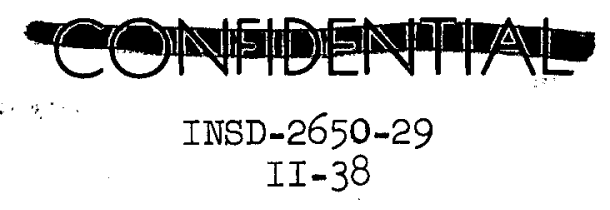




\section{PERFORMAINCE STUDIES}

\section{A. RTG OPTIMIZATION}

This section presents the results of RTG optimization studies performed for TAGS-85/2N and 3P/2N RTG concepts for the Viking Lander mission. In the studies, the radiator fin root operating temperature was varied and the resultant effect on RTG fuel inventory, specific power, electrical power output and weight determined for a fixed hot junction temperature. Two generator housing lengths, the present 8.9 inch and a longer 9.5 inch housing, were evaluated. Although the present 8.9 inch long housing will accommodate the IIHS, increasing the housing length to 9.5 inches is proposed to increase the thermal insulation thickness at the ends of the heat source. 1. Radiator Parameters

The RTG radiator consists of the outer cylindrical housing, end covers and six fins spaced at 60-degree increments around the housing. The radiator emissive coating is a zirconium oxide/sodium silicate (binder) mixture developed on the SNAP 9A program. Measured coating properties show the thermal (infrared) emissivity to be $\sim 0.83$ and the solar absorptivity to be $\sim 0.2$. Telemetered SNAP 9A S/N 04 RTG housing temperature data received from Transit Satellite 1963-49B provide evidence of the excellent stability of this coating after approximately six years of space operation. Figure III-I shows radiator temperature data for the dirst three years of operation. APL reports no apparent degradation through the present.

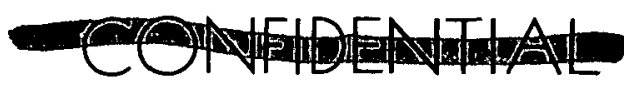

INSD-2650-29

III-I 
FIG. III-1. SNAP 9A S/N 04 ORBITAL RADIATOR TEMPERATURE STABILITY DATA 
For the Viking RTG, heat rejection was assumed to occur from the finned cylindrical housing and one end cover. The end cover adjacent to any mounting structure after installation was assumed to be adiabatic. The effective environmentalsink temperature was assumed to be $100^{\circ} \mathrm{F}$, a conservative maximum anticipated value for Martian daylight operation based on Martin Denver proposal studies. Figures III-2 through III-4 show typical heat rejection capability curves for the finned cylindrical housing where $Q / L$ is the heat rejected per inch of housing ( $f$ in) height (excludes heat rejected from end cover). 2. TAGS-85/2N RTG

The results of the optimization study for the TAGS-85/2N RTG are shown in Table III-1 and Fig. III-5. A BOL design hot junction temperature of $1050^{\circ} \mathrm{F}$ was selected based on existing thermoelectric data (see Section III-B). Thermoelectric element size was maintained constant at the present TAGS-85/2N values (P-leg 0.270 in. dia. x 0.500 lg., N-leg 0.377 in. dia. $x 0.500$ lg.) for the engineering models presently on test at Isotopes. Specific power is seen to be rather insensitive over the fin root temperature range considered ( $325^{\circ} \mathrm{F}$ to $400^{\circ} \mathrm{F}$ ), being approximately 1.6 watts per pound. These results show that the trade-off is essentially one of output power for weight and depends on the particular spacecraft requirements. The intact impact heat source (IIHS) proposed can easily accommodate the fuel inventories required for any of the cases whown.

Considering the power requirements of the Viking mission for a four RTG system (minimum of 36 watts per RTG at end-of-mission at a high

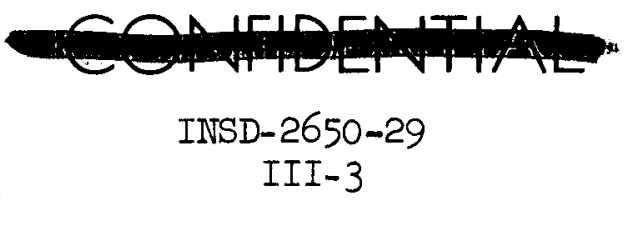




\section{"EVIDENAT:}
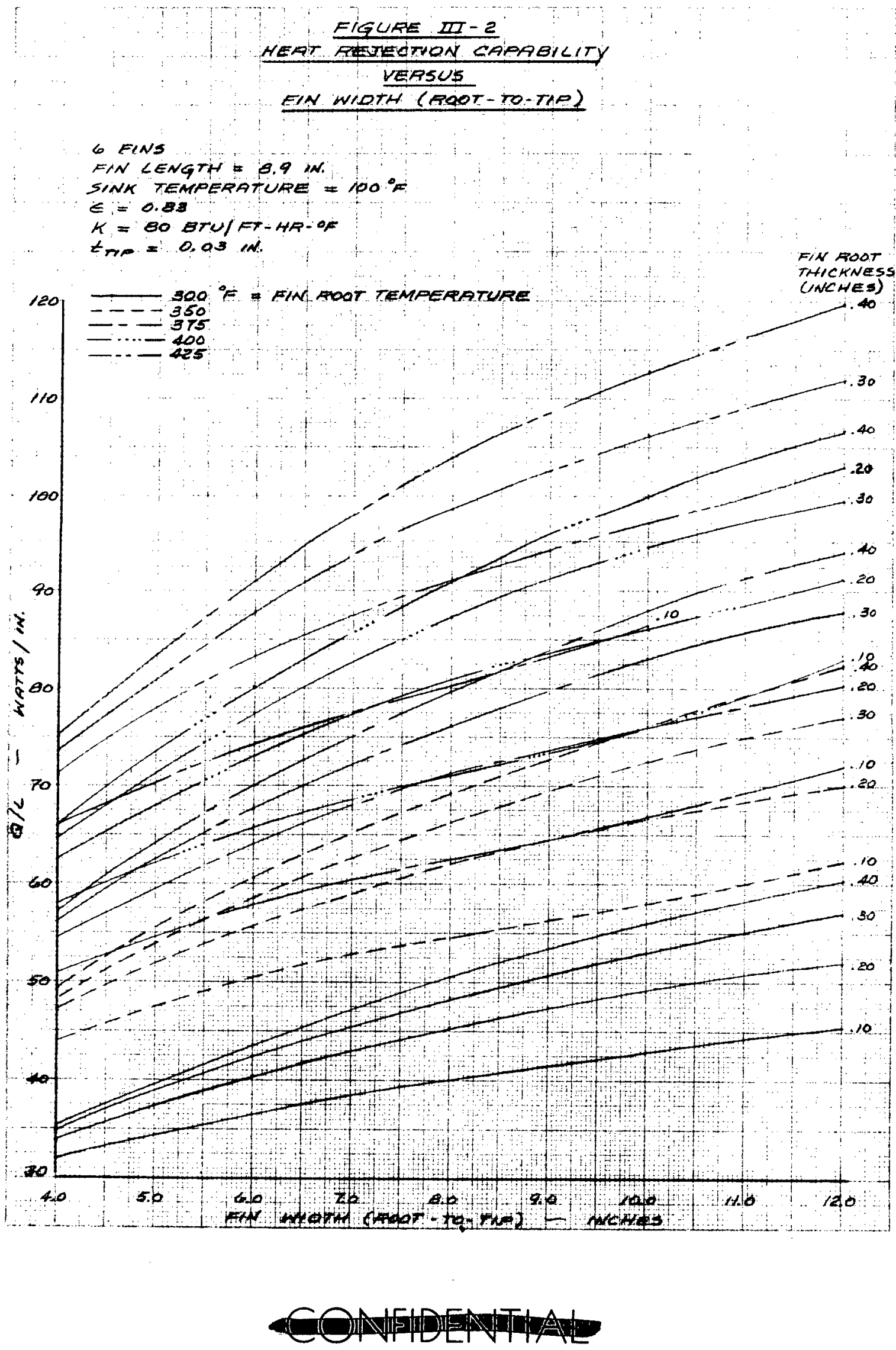

INSD- $2650-29$

III -4 
HISURE II- 3

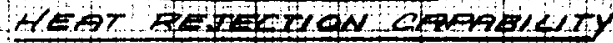

VEASUS

EN GOQT TENTOEQATUEE

6 FINS

FN LENGTH 0 O 9 IN

SINK TEMPAAATURE W 100 \%

$E=0$ os

120

H oo bruthaphes

trio $=0.00 \mathrm{vN}$

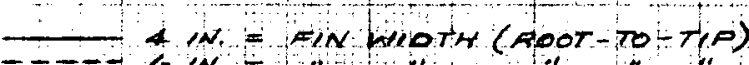

110

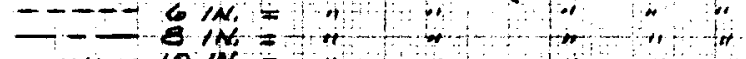

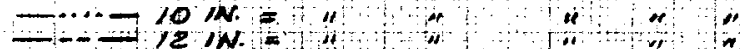

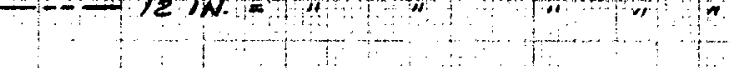

is

170

N

8

60

1

$\vdots$

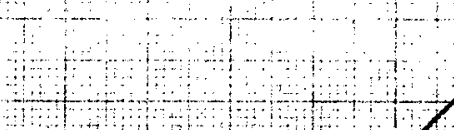

a d 

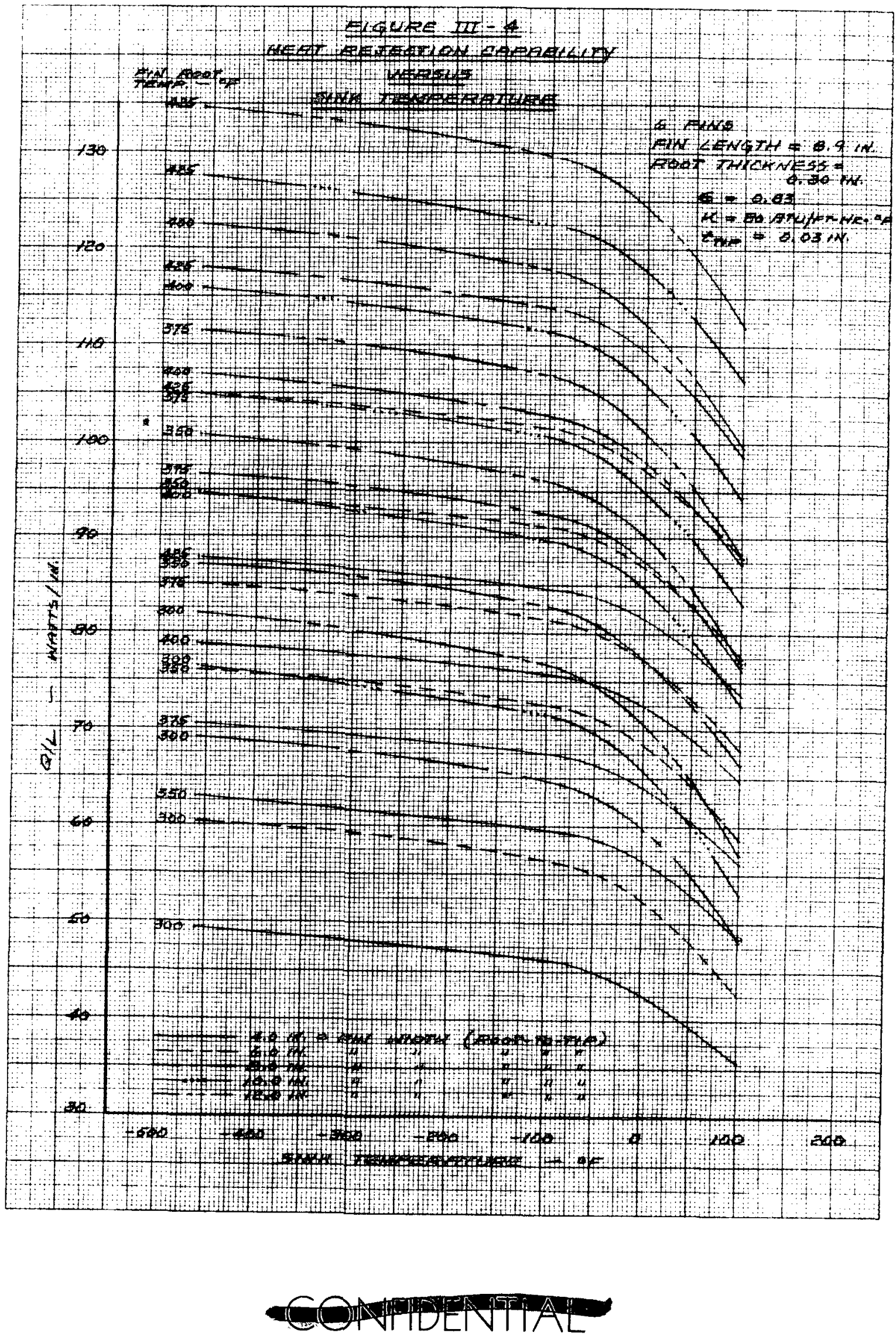

INSD- $2650-29$ 


\section{TABLE III-I}

TAGS-85/2N RTG BOL PARAMETRIC EVALUATION DATA

(Effective Sink Temp. $=100^{\circ} \mathrm{F}, 9.5$ inch housing length)

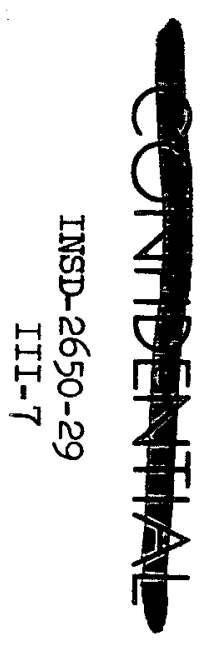

\begin{tabular}{|c|c|c|c|c|c|c|c|c|}
\hline $\begin{array}{c}\text { Fin Root } \\
\text { Temperature } \\
\left(\begin{array}{l}\mathrm{F}) \\
\end{array}\right.\end{array}$ & $\begin{array}{c}\text { Cold Junction } \\
\text { Temperature } \\
\left(\mathrm{O}_{\mathrm{F}}\right) \\
\end{array}$ & $\begin{array}{l}\text { Hot Junction } \\
\text { Temperature } \\
\left(\mathrm{O}_{\mathrm{F}}\right) \\
\end{array}$ & $\begin{array}{c}\text { Fuel } \\
\text { Inventory } \\
\text { (watts) }\end{array}$ & $\begin{array}{l}\text { Net } \\
\text { Output } \\
\text { Power } \\
\text { (watts) }\end{array}$ & $\begin{array}{l}\text { RTG } \\
\text { Weight } \\
\text { (1bs) } \\
\end{array}$ & $\begin{array}{l}\quad \text { RTG } \\
\text { Specific } \\
\text { Power } \\
\text { watts/lb } \\
\end{array}$ & $\begin{array}{l}\quad \text { Fin Si } \\
\text { Fin Root } \\
\text { to-Tip }\end{array}$ & $\begin{array}{l}\text { ize (in.) } \\
\text { Fin Root } \\
\text { Thickness } \\
\end{array}$ \\
\hline 375 & 430 & 1050 & 634 & 38.9 & 24.0 & 1.62 & 5.6 & 0.1 \\
\hline 350 & 405 & 1050 & 660 & 42.1 & 25.8 & 1.63 & $7 \cdot 3$ & 0.2 \\
\hline 330 & 390 & 1050 & 675 & 44.1 & 28.2 & 1.56 & 9.0 & 0.3 \\
\hline 325 & 385 & 1050 & 680 & 44.7 & 28.7 & 1.55 & 9.9 & 0.3 \\
\hline
\end{tabular}



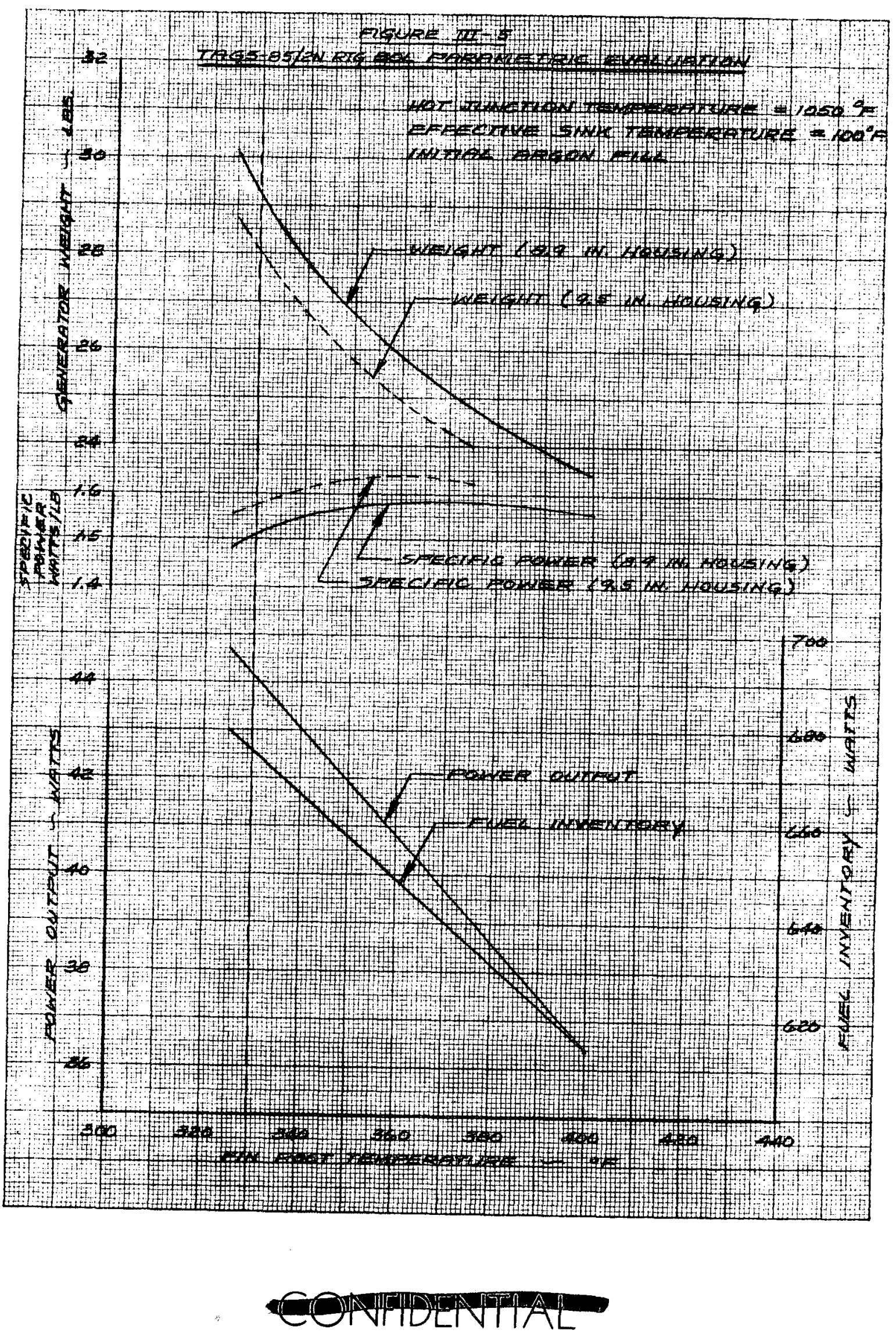

INSD-2650-29

III- 8 
reliability--see Chapter VI), a nominal fin root operating temperature of 330 was selected. As is shown in Chapter VI this design condition, with a 44.1 watt BOL power output, results in a nominal power output of 40.7 watts $(38.5$ watts at a 0.99 reliability for four units connected in parallel) EO: EOM (one year after launch). Thus, the 36 watt minimum requirement is satisfied and a 2.5 watt margin provided. The BOL fuel inventory is 675 watts, and 9.0 inch wide fins (root-to-tip) with an 0.3 root thickness are required for the proposed 9.5 inch housing length. These fins are approximately 1.5 wider than the present Nimbus III fins ( $\sim 7.5$ inches long with 0.3 inch fin root). Stress analyses performed have shown that the 1.5 inch fin length increase will not result in a structural dynamics problem for the anticipated Viking environment. 3. $3 P / 2 N$ RTG

Table III-2 and FIg. III-6 present the study results for a $3 P / 2 N$ RTG. For these studies the BOL hot junction temperature was maintained at $1000^{\circ} \mathrm{F}$. The present SNAP $193 \mathrm{P} / 2 \mathrm{~N}$ thermoelectric element dimensions, 0.377 inch diameter by 0.500 inch long, were retained, athe fin root and fuel inventory varied so as to maintain the design $1000^{\mathrm{F}}$ hot junction temperature selected after examining the thermoelectric data pret sented in Section III-B. BOL power outputs approaching 36 watts appear practical for a $3 \mathrm{P} / 2 \mathrm{~N}$ RTG with an increase in fuel inventory and fin width and root thickness over the present Nimbus III configuration. Specific power is rather insensitive at approximately 1.2 watts per pound. Comparison of the 3P/2N RTG with the TAGS-85/2N unit shows that for a 675 watt thermal input, power output is 35.3 watts and 44.1 watts at $\mathrm{BOL}$ respectively.

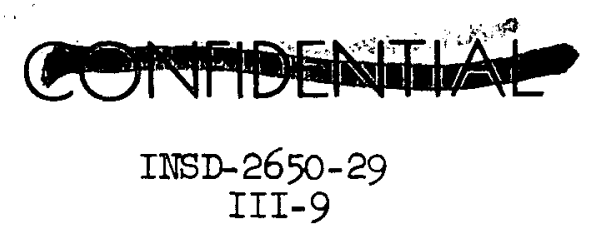


TABLE III-2

3P/2N RTG BOL PARAMETRIC EVALUATION DATA

(Effective Sink Temp. $=100^{\circ} \mathrm{F}, 9.5$ inch housing length)

\begin{tabular}{|c|c|c|c|c|c|c|c|c|}
\hline $\begin{array}{c}\text { Fin Root } \\
\text { Temperature } \\
\left(\text { OF }_{F}\right) \\
\end{array}$ & $\begin{array}{c}\text { Cold Junction } \\
\text { Temperature } \\
\left(\mathrm{O}_{\mathrm{F}}\right)\end{array}$ & $\begin{array}{l}\text { Hot Junction } \\
\text { Temperature } \\
\left(\mathrm{O}_{\mathrm{F}}\right) \\
\end{array}$ & $\begin{array}{l}\text { Fuel } \\
\text { Inventory } \\
\text { (watts) } \\
\end{array}$ & $\begin{array}{l}\text { Net } \\
\text { Output } \\
\text { Power } \\
\text { (watts) }\end{array}$ & $\begin{array}{r}\text { RTG } \\
\text { Weight } \\
\text { (lbs) } \\
\end{array}$ & $\begin{array}{c}\text { RTG } \\
\text { Specific } \\
\text { Power } \\
\text { watts/Ib } \\
\end{array}$ & $\begin{array}{l}\quad \text { Fin } \\
\text { Fin Root } \\
\text { to-Tip } \\
\end{array}$ & $\begin{array}{l}\text { Size (in.) } \\
\text { Fin Root } \\
\text { Thickness }\end{array}$ \\
\hline 봅 & 430 & 1000 & 627 & 30.5 & 24.2 & 1.26 & 5.7 & 0.1 \\
\hline 0 占 & $405=$ & 1000 & 655 & 33.2 & 25.9 & 1.28 & $7 \cdot 3$ & 0.2 \\
\hline 330 & 390 & 1000 & 671 & $34.9=$ & 28.5 & 1.22 & 9.2 & 0.3 \\
\hline 325 & 385 & 1000 & 677 & 35.5 & 30.0 & 1.18 & 9.0 & 0.4 \\
\hline
\end{tabular}




\section{(1)}
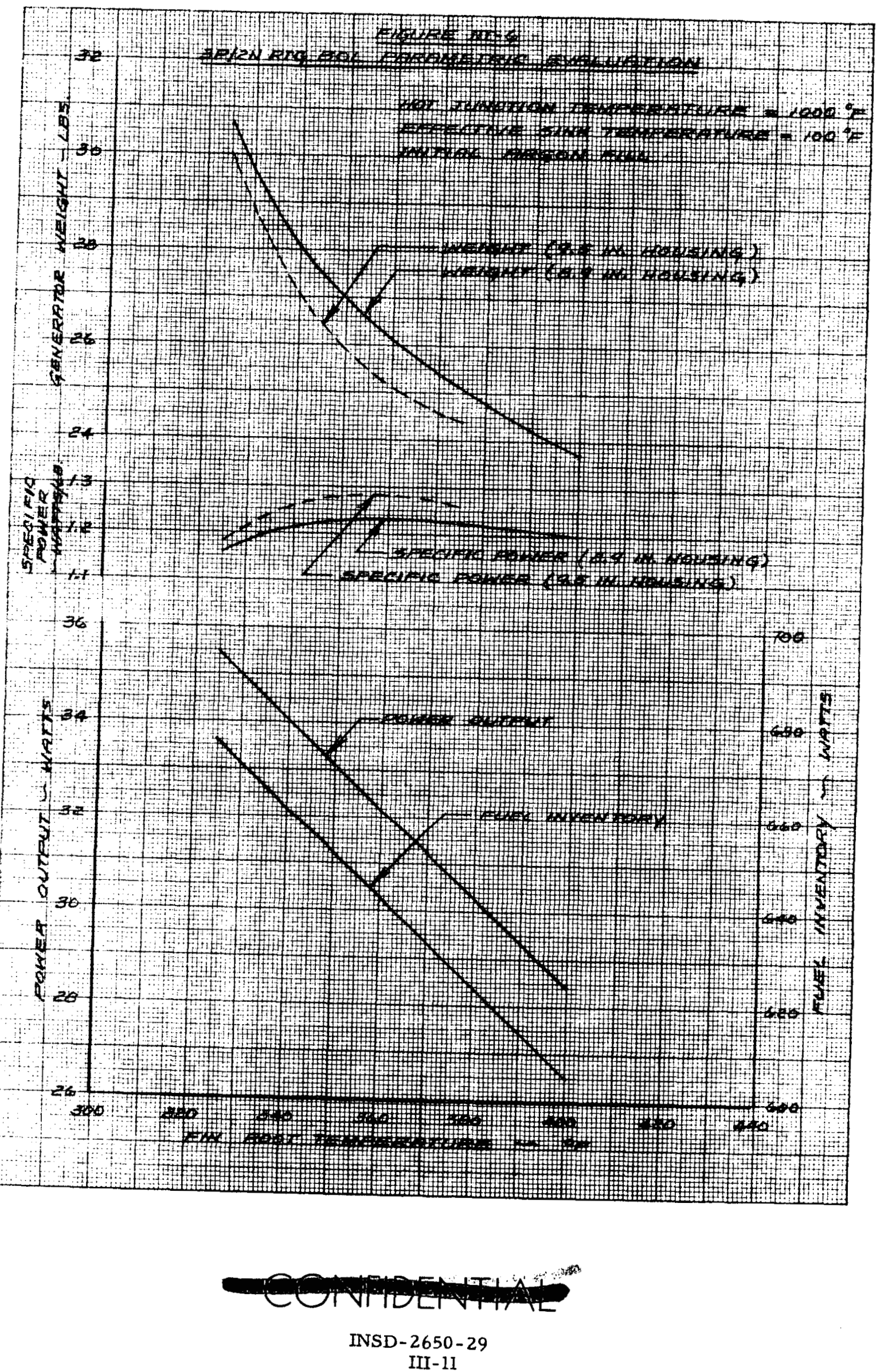


\section{B. THERMOELECTRIC SUPPORTING DATA}

\section{Property Data}

In the past several years, Isotopes has developed a new P-type thermoelectric material, TAGS-85, composed of silver, antimony, germanium and tellurium in the form $\left(\mathrm{AgSbTe}_{2}\right)_{0.15}$ (GeTe) ${ }_{0.85^{\circ}}$ This P-type material operates in the general temperature range of lead telluride with a significantly higher energy conversion efficiency. The superiority of this material, as evidenced by the test data discussed in the following sections, justifies its use for the Viking mission. The rationale that supports this recommendation of TAGS is presented by first examining initial performance and then the longer term behavior. As might be expected, the largest body of evidence illustrating the superiority of TAGS has been obtained from initial performance data. It is clearly evident from both analytical and experimental investigations that the initial and long term characteristics of TAGS are unequalled on an efficiency and output power basis.

Three principal physical properties are indicators of thermoelectric performance: Seebeck coefficient, $a$; electrical resistivity, $\rho$; and thermal conductivity, k. From these properties, a conclusion can be draw on the potential worth of a material by calculating two performance indices: figure-of-merit, $\mathrm{z}=\frac{\alpha^{2}}{\rho \mathrm{k}}$; and the $\mathrm{ZT}$ product (where $\mathrm{T}=$ temperature). Over the same temperature range, the material with the greater figure-of-merit wlll have the superior performance. The ZT Index is of particular interest in that, as rough approximation,

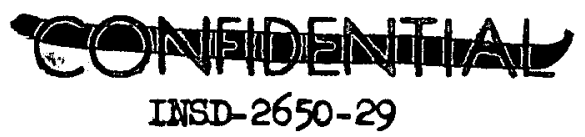


thermoelectric efficlency is related to it by the formula

$$
\eta_{\mathrm{T} / \mathrm{E}}=\frac{(\mathrm{ZT})\left(\mathrm{T}_{\mathrm{H}}-\mathrm{T}_{\mathrm{C}}\right)}{4 \mathrm{~T}_{\mathrm{H}}}
$$

where

$$
\begin{aligned}
& \eta_{\mathrm{T} / \mathrm{E}}=\text { thermoelectric efficiency } \\
& \mathrm{T}_{\mathrm{H}}=\text { hot junction temperature } \\
& \mathrm{T}_{\mathrm{C}}=\text { cold junction temperature }
\end{aligned}
$$

Figures III-7 through III-1I present $\alpha, \rho, \mathrm{k}, \mathrm{Z}$ and ZT as a function of temperature for the materials PbSnTe (3P), PbTe (2P), SnTe and TAGS-85. At all temperatures, and even after an operational time in excess of that typical of storage and the Viking mission ( $\sim$ year after launch) the ZT factor is highest for TAGS.

Figures III-12 and III-13 show the change in Seebeck coefficient and electrical resistivity with time obtained from greater than 10,000 hours of testing. Seebeck and resistivity vary linearly on a logarithmic time scale. These data are the fundamental thermoelectric property data used in performance prediction for long term operation.

\section{TAGS Performance Data}

Current hardware efforts utilizing TAGS thermoelectric material continue to demonstrate the superior performance achievable with this material over current lead telluride P-type materlals. All of Isotopes' current RTG programs have changed to TAGS as the P-leg material. The SNAP 19 Nimbus III design has been modified from 3P to TAGS on three test generators orlented towards future applications such as Viking. SNAP 29 has fabricated sufficient TAGS-85/2N couples to build 8 modules,

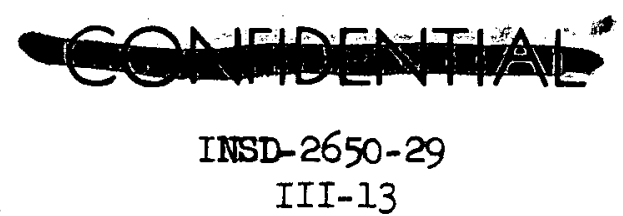




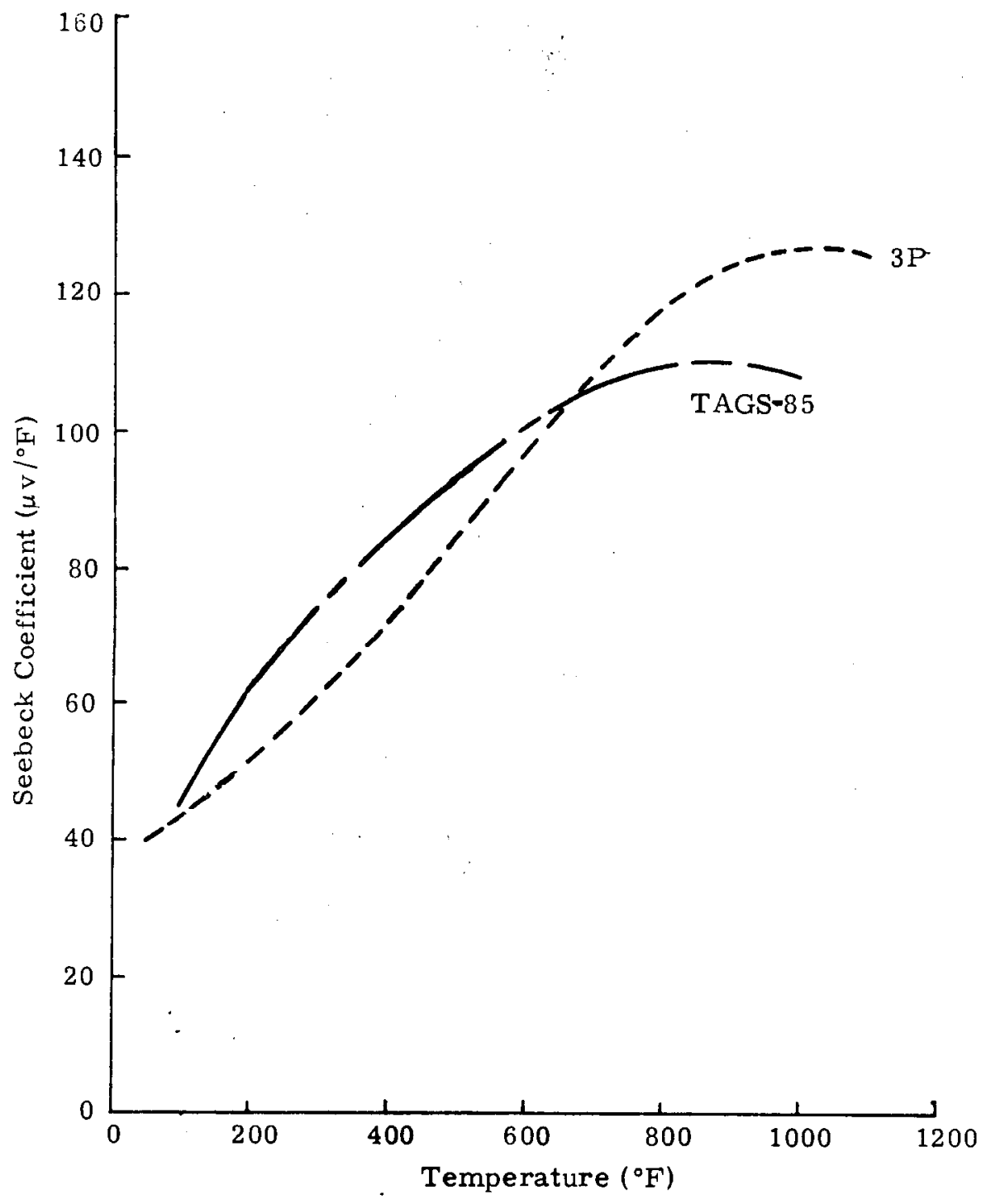

FIG. III- 7. INITIAL SEEBECK COEFFICIENT

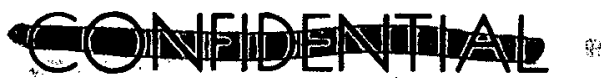

INSD-2650-26

III- 14 

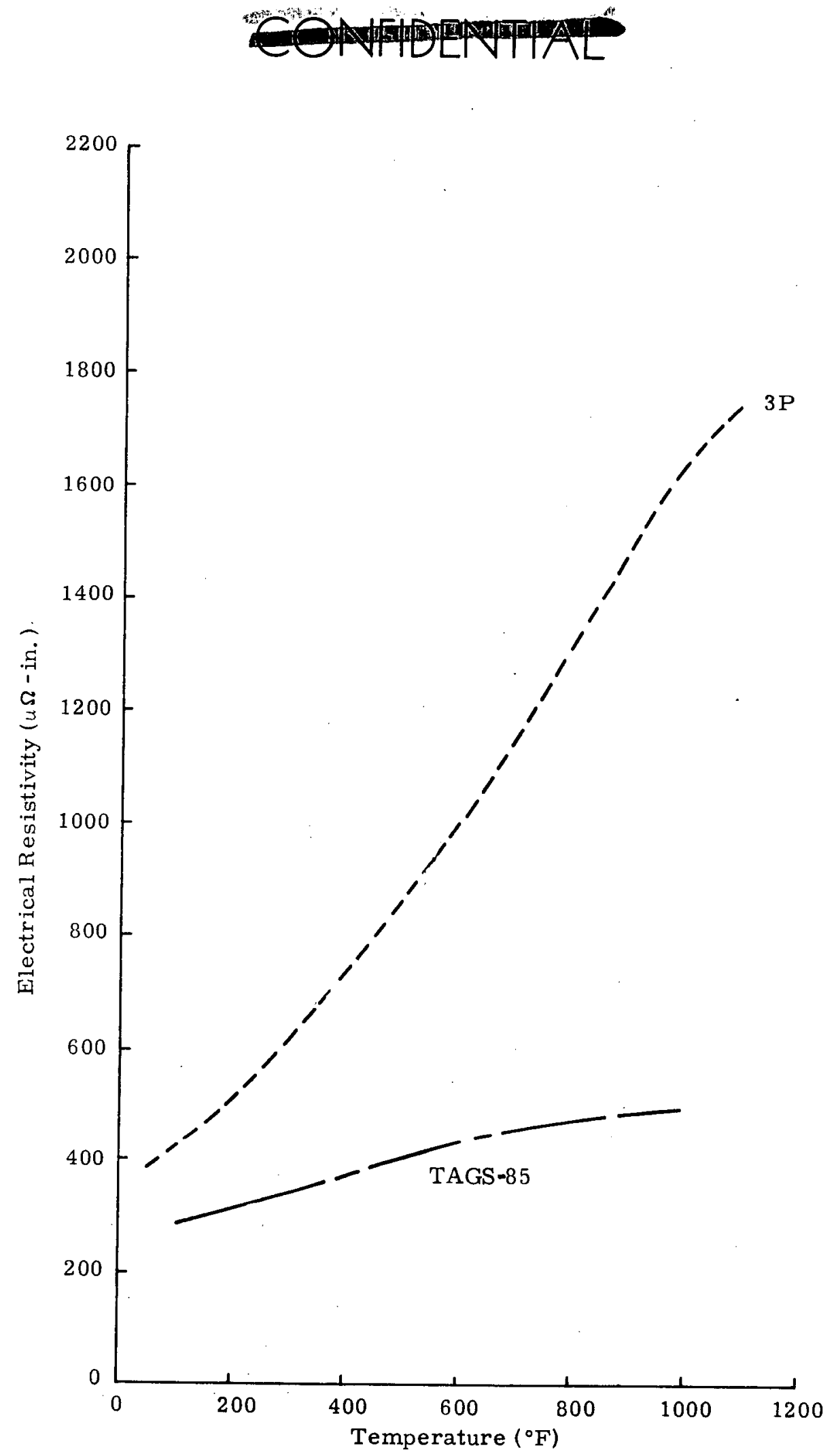

FIG. III-8. INITIAL ELECTRICAL RESISTIVITY

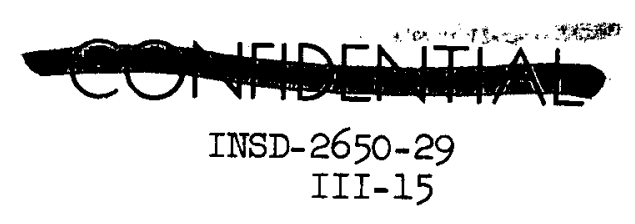



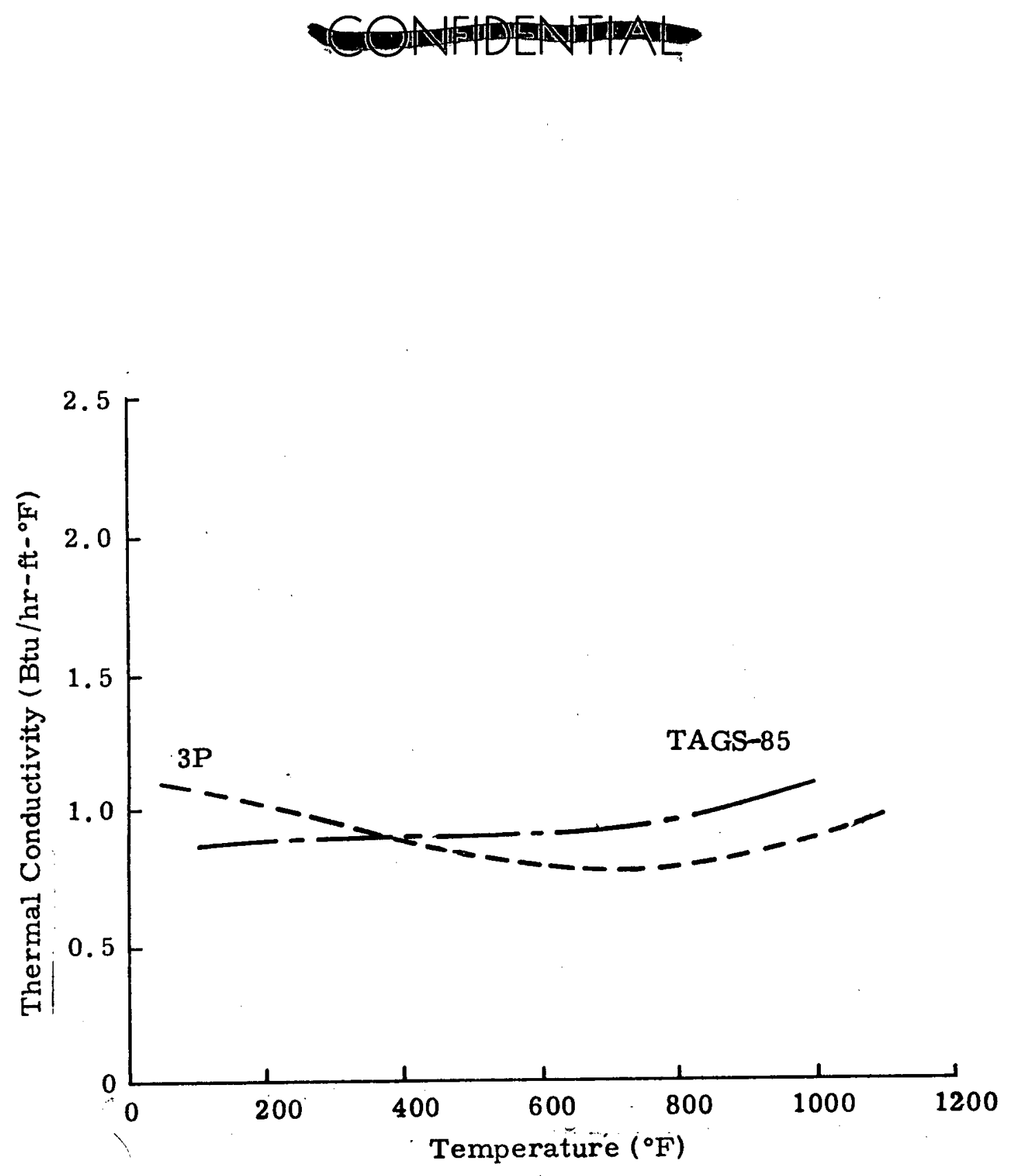

FIG. III-9. INITIAL THERMAL CONDUCTIVITY

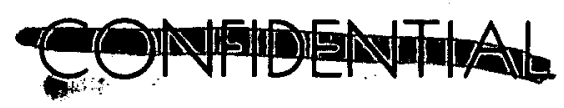

INSD-2650-29

III-16 

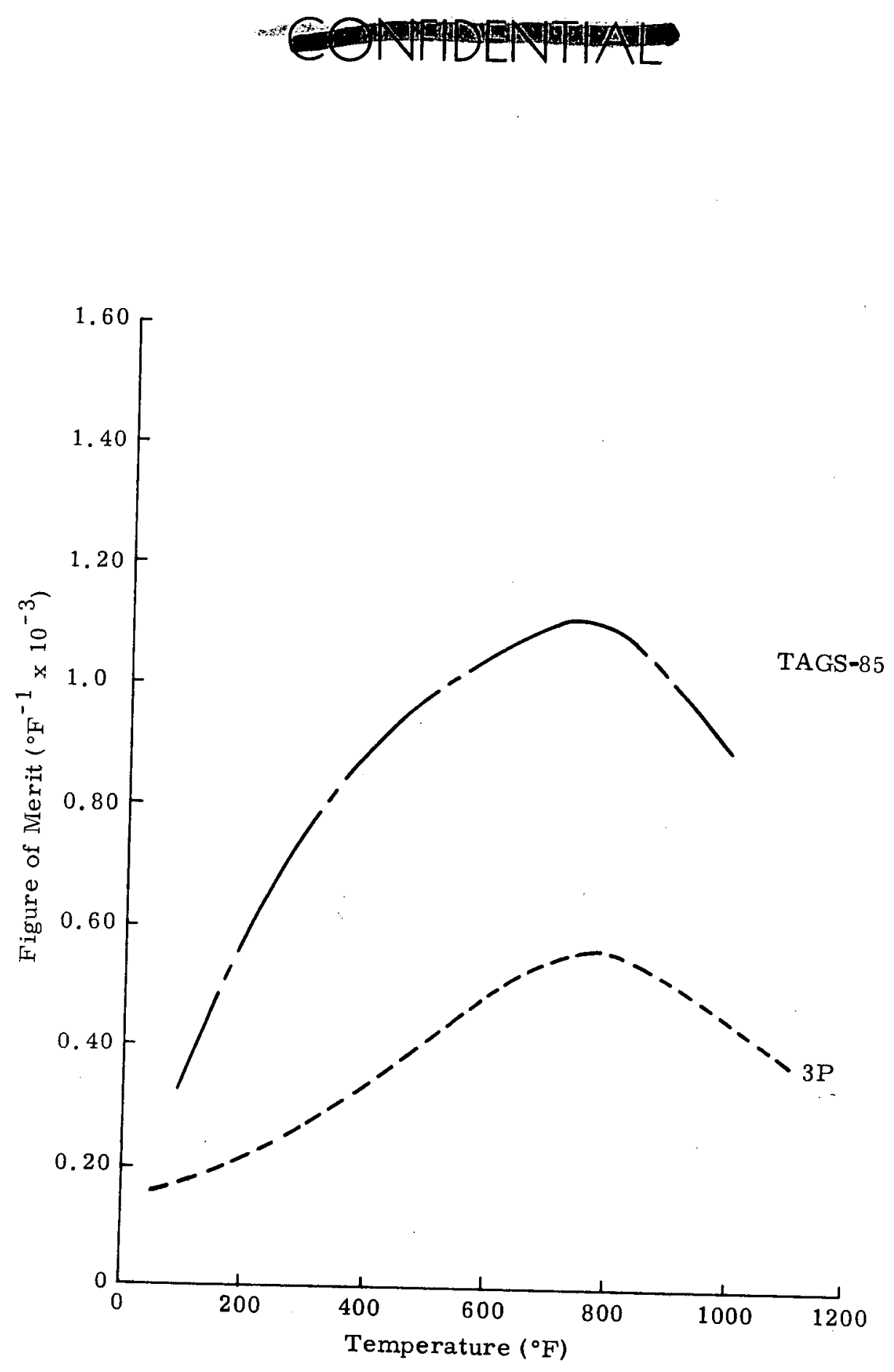

FIG. III-10. INITIAL FIGURE-OF-MERIT

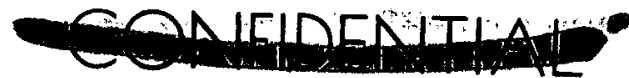

INSD-2650-29

III-17 


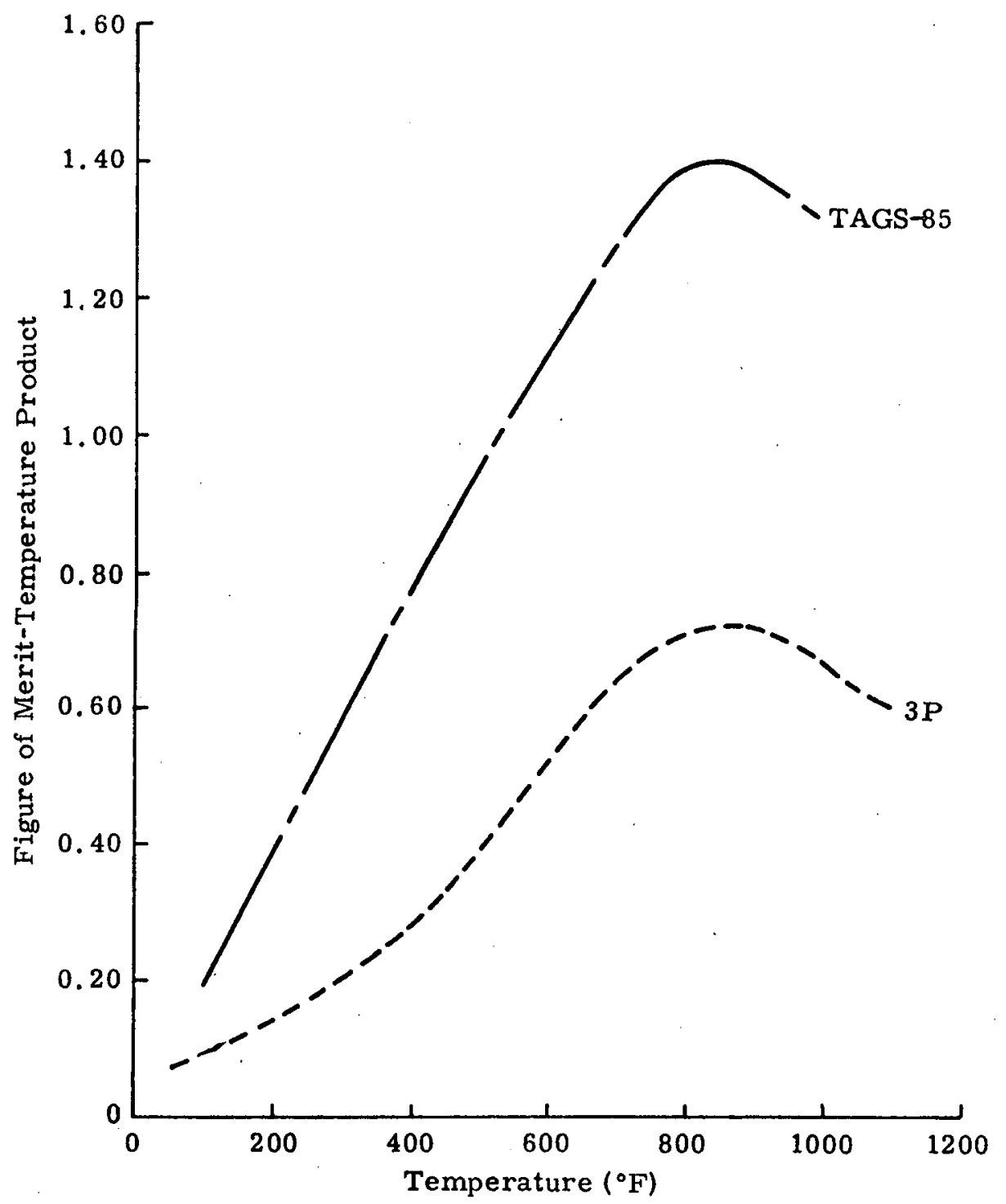

FIG. III-II. INITIAI FIGURE-OF-MERIT-TEMPERATURE PRODUCT

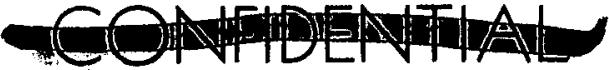

INSD-2650-29

III-18 


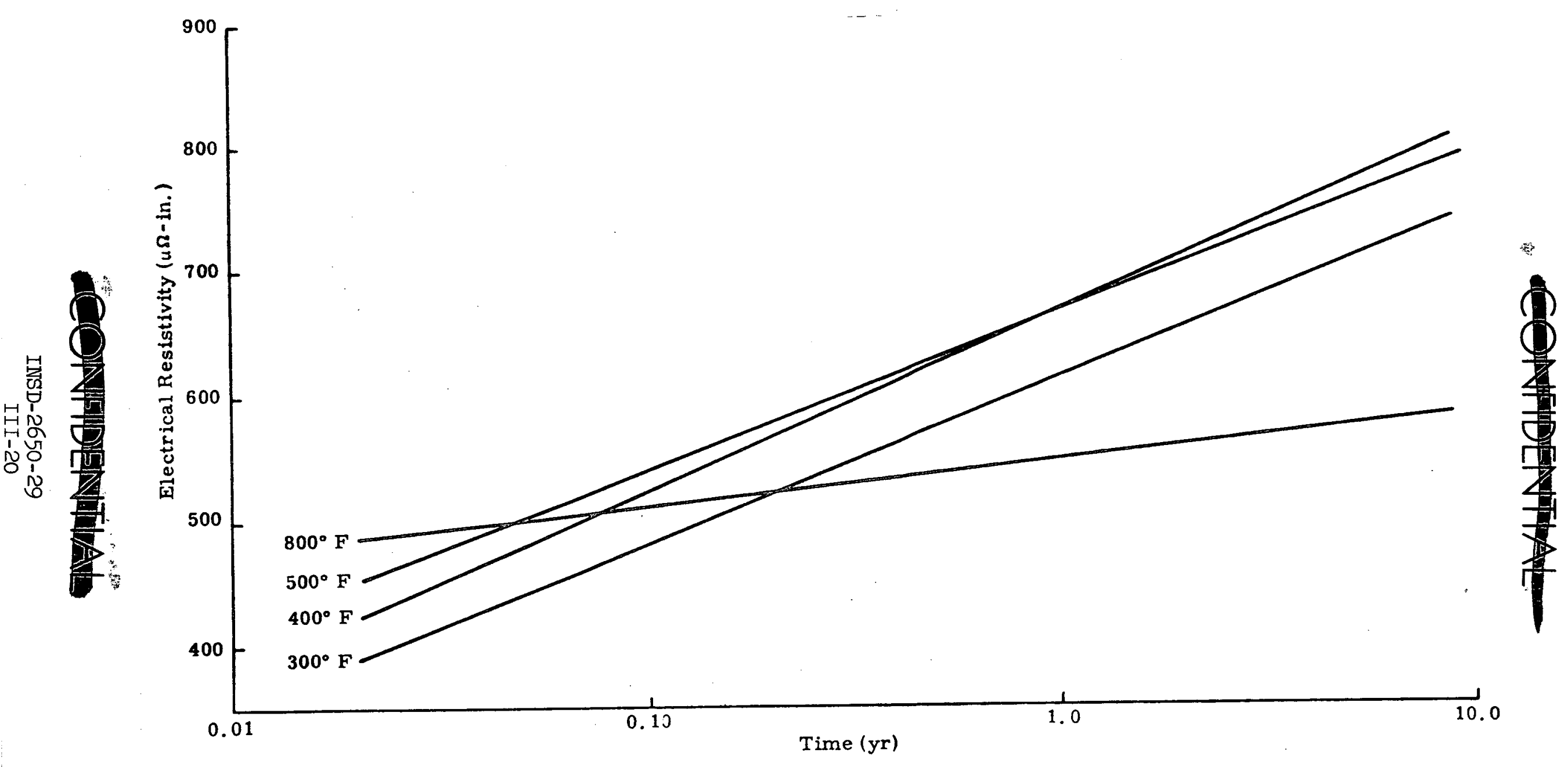

FIG. III-13. TAGS PROPERTY VARIATION WITH TIME--RESISTIVITY 
employing well over 100 watts each with 4 to be delivered as a generator and 4 to be life tested. The Sentinel terrestrial RIG program has delivered 13 modules utilizing TAGS, all of which are successfully operating in the field.

a. SIIAP 19

The SINAP 19 generator design which until recently used 3P/2N couples for energy conversion, now incorporates TAGS-85/2N couples. This change has been initiated because of the superior thermoelectric efficiency over $3 P$ over the temperature range of interest, roughly $300^{\circ} \mathrm{F}$ to $1000^{\mathrm{F}} \mathrm{F}$. Generators $\mathrm{S} / \mathrm{N} 24$ and 25 , which were fabricated late in 1968 for Nimbus III, utilized 3P/2N couples. Generators 26, 27 and 28 have very recently been built with TAGS-85/2N couples and are discussed below.

(1) Couple power check

During the fabrication of couples for use in generators, sampling techniques are employed for quality control of the process. The most meaningful performance inspection is that provided by statistically selected couple power checks. TAGS-85/2N couples are power checked at $1050 \mathrm{~F}$ hot junction, $400 \mathrm{~F}$ cold junction temperatures and matched load. From these couple power checks, the subsequent generator power may be accurately predicted after suitable corrections are made. These corrections take into consideration the additional connections and wiring in the circuit, the fact that a generator is operated at optimum efficiency: load and not matched load, and operating temperature differences, if any.

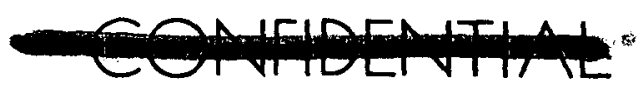

INSD-2650-29

III-2I 


\section{(1)}

As of this report, TAGS-85/2N couples have been fabricated on SNAP 19 from Lot 01 (qualification lot) and Lots 02 through 05 (production lots). These production lot couples, as well as Lot 06 for which no power check data are yet available, have been used in generators 26, 27 and 28. A summary of their performance, based on the destructive power checks, is given in Table III-3.

Based on the results of a comprehensive computer program, a power prediction of the couple was made and is shown in Fig. III-14 Noted on that figure are the voltages corresponding to maximum power (when extermal resistance matches internal resistance, hence the term matched load) and maximum efficiency (always at a higher voltage than maximum power). Values of predicted open circuit voltage and power are also listed on Table III-3 for comparison with test results. The correlation is good and thus lends credence to other predictions at the generator level.

Note from Fig. III-14 that at maximum efficiency load (.095 volts), the couple power is 0.52 watts at $10500 \mathrm{~F} / 4000 \mathrm{~F}$. With 90 couples in a SINAP generator, the gross output power (before strap and wire loss corrections) would be 46.8 watts while the RTG gross load voltage would be 2.85 volts. These values are in excellent agreement with the results observed on generators 26,27 and 28 .

(2) Generators S/N 26, 27 and 28

Generators S/N 26, 27 and 28 were the first SNAP 19's built with TAGS-85/2N thermoelectric couples. They differ from the Nimbus

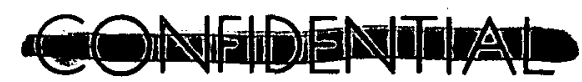

INSD-2650-29 


\section{TABLE III-3}

SNAP 19 Couple Power Test Summary

\begin{tabular}{|c|c|c|c|c|c|c|c|c|c|c|c|}
\hline \multirow{9}{*}{ 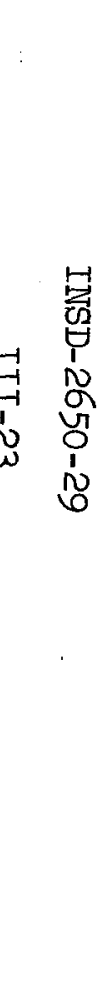 } & \multirow{9}{*}{ 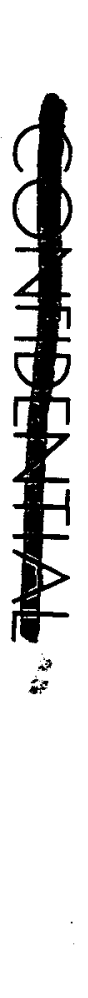 } & $\begin{array}{l}\text { Lot } \\
\text { No. }\end{array}$ & $\begin{array}{l}\text { Lot } \\
\text { Size }\end{array}$ & $\begin{array}{l}\text { Quentity } \\
\text { Power } \\
\text { Checked } \\
\end{array}$ & $\begin{array}{c}\text { Load } \\
\text { Voltage } \\
\text { (volts) } \\
\end{array}$ & $\begin{array}{c}\text { N-Leg } \\
\text { Output } \\
\text { Power } \\
\text { (watts) } \\
\end{array}$ & $\begin{array}{c}\text { P-Leg } \\
\text { Output } \\
\text { Power } \\
\text { (watts) } \\
\end{array}$ & $\begin{array}{c}\text { Couple } \\
\text { Output } \\
\text { Power } \\
\text { (watts) } \\
\end{array}$ & $\begin{array}{l}\text { N-Leg } \\
\text { Open } \\
\text { C1rcuit } \\
\text { Voltage } \\
\text { (volts) } \\
\end{array}$ & $\begin{array}{l}\text { P-Leg } \\
\text { Open } \\
\text { Circuit } \\
\text { Voltage } \\
\text { (volts) } \\
\end{array}$ & $\begin{array}{l}\text { Couple } \\
\text { Open } \\
\text { Circuit } \\
\text { Voltage } \\
\text { (volts) } \\
\end{array}$ \\
\hline & & Ol & 18 & 5 & .077 & .319 & .256 & .572 & .093 & .062 & .154 \\
\hline & & 02 & 110 & 5 & .077 & .311 & .245 & .552 & .092 & .061 & .153 \\
\hline & & 03 & 68 & $5 \cdots$ & .076 & .316 & .243 & .557 & .092 & .061 & .153 \\
\hline & & 04 & 39 & 4 & .076 & .318 & .246 & .557 & .092 & .060 & .151 \\
\hline & & 05 & 92 & 4 & .076 & .316 & .245 & .553 & .091 & .061 & .152 \\
\hline & & Average & (Test) & & & .316 & .248 & .558 & .092 & .061 & .153 \\
\hline & & Standaro & d Devia & ion (Test) & & .011 & .013 & .017 & .002 & .002 & .002 \\
\hline & & Average & Predic & & & .297 & .250 & .545 & .091 & .064 & .155 \\
\hline
\end{tabular}



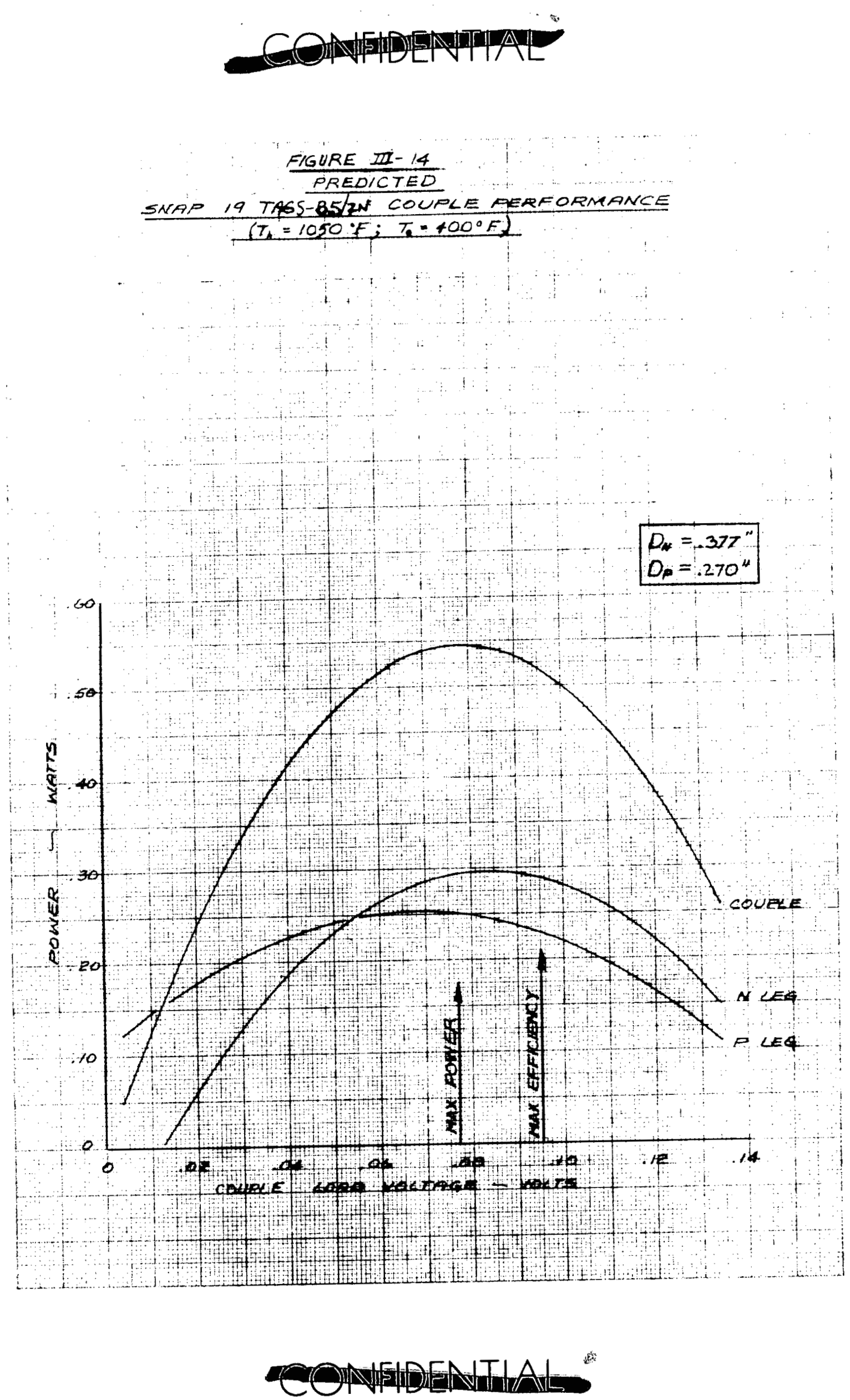

INSD-2650- 29

III- 24 
III $3 \mathrm{P} / 2 \mathrm{~N}$ configuration generators in that the 0.500 " Iong and $.377^{\prime \prime}$ diameter $3 P$ elements have been replaced with 0.400 " Iong and .270" diameter TAGS-85 elements, segmented with a .100" thick SnTe segment at the hot end. Generators $5 / \mathbb{N} 26,27$ and 28 are to be operated at hot and cold junction temperatures representative of the Viking mission. Power checks of S/N 26 at power inputs of 625 watts and 690 watts to the heaters resulted in power outputs of 36.6 and 43.0 watts, respectively. Power checks of $S / N 27$ and 28 at 700 watts to the heaters resulted in power outputs of 44.1 and 43.3, respectively. (Extra thermal losses in an electrically heated generator at the higher power inputs due to reduced insulation for vibration capability amount to 25 watts thermal.) Required power input for equivalent power outputs of a fueled unit will therefore be lower by 25 watts thermal.) Results of these tests are illustrated in Table III-4.

A parametric test in load voltage was completed on each generator (Figs. III-15, III-16 and III-17). S/N 26 was tested after 340 hours and $S / N 27$ and 28 were tested after the initial power checks and installation of pressure transducers. The peak power parameters are recorded in Table III-5 for comparison between generators.

The thermoelectric material properties change exponentially with time, with most of the change occurring early in life, as evidenced on Fig. III-18. A greater change occurs from 0 to 3 months than from 3 to 9 months. Comparisons on $S / N 26$ between the initial power check results and data from the parametric test indicate a burn-in during the

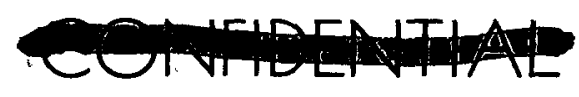


TABLE III-4

RESULTS OF POWER CHECKS ON TAGS-85/2N GENERATORS

\begin{tabular}{|c|c|c|c|c|c|c|c|}
\hline Parameter & & $\begin{array}{l}\text { Generator } \\
\mathrm{S} / \mathrm{N} 26 \\
\end{array}$ & $\begin{array}{r}\text { Gen } \\
\mathrm{S} / \\
\text { measured } \\
\end{array}$ & $\begin{array}{l}\text { rator } \\
26 \\
\text { normalized** }\end{array}$ & $\begin{array}{l}\text { Generator } \\
\text { S/N } 27\end{array}$ & $\begin{array}{l}\text { Generator } \\
\mathrm{S} / \mathrm{N} 28\end{array}$ & $\begin{array}{c}\text { Prediction } \\
\text { (peak power point) }\end{array}$ \\
\hline Date of power check & & $5 / 8 / 69$ & $5 / 9 / 69$ & $5 / 9 / 69$ & $5 / 29 / 69$ & $6 / 1 / 69$ & -- \\
\hline $\begin{array}{l}\text { Heater power } \\
\text { (equiv. fueled) }\end{array}$ & watts & 600 & 665 & 675 & 675 & 675 & 675 \\
\hline Power output & watts & 36.6 & 43.0 & 44.0 & 44.1 & 43.3 & 44.1 \\
\hline Efficiency (overall) & $\phi$ & 6.1 & 6.5 & 6.5 & 6.5 & 6.4 & 6.5 \\
\hline Loed current & amps & 14.0 & 16.2 & 16.2 & 15.5 & $15 \cdot 3$ & 15.4 \\
\hline Load voltage & volts & 2.61 & 2.66 & 2.72 & 2.84 & 2.83 & 2.85 \\
\hline $\begin{array}{l}\text { Open circuit } \\
\text { voltage }\end{array}$ & volts & 4.26 & 4.59 & 4.62 & 4.62 & 4.59 & 4.74 \\
\hline $\begin{array}{l}\text { Hot junction } \\
\text { temperature }\end{array}$ & OF & 987 & 1038 & 1048 & 1021 & 1016 & 1054 \\
\hline $\begin{array}{l}\text { Cold junction } \\
\text { temperature }\end{array}$ & $\mathrm{O}_{\mathrm{F}}$ & 395 & 404 & 408 & 361 & 360 & 390 \\
\hline $\begin{array}{l}\text { Fin root } \\
\text { temperature }\end{array}$ & $O_{\mathrm{F}}$ & 339 & 349 & 353 & 306 & 304 & -- \\
\hline $\begin{array}{l}\text { Generator argon } \\
\text { pressure }\end{array}$ & psia & 14 & 14 & 14 & 14 & 14 & 14 \\
\hline Hours of operation & & 6 & 17 & 17 & 9 & 6 & 0 \\
\hline
\end{tabular}

* Excluding outgassing time

* Normalized to 675 watts heater input 


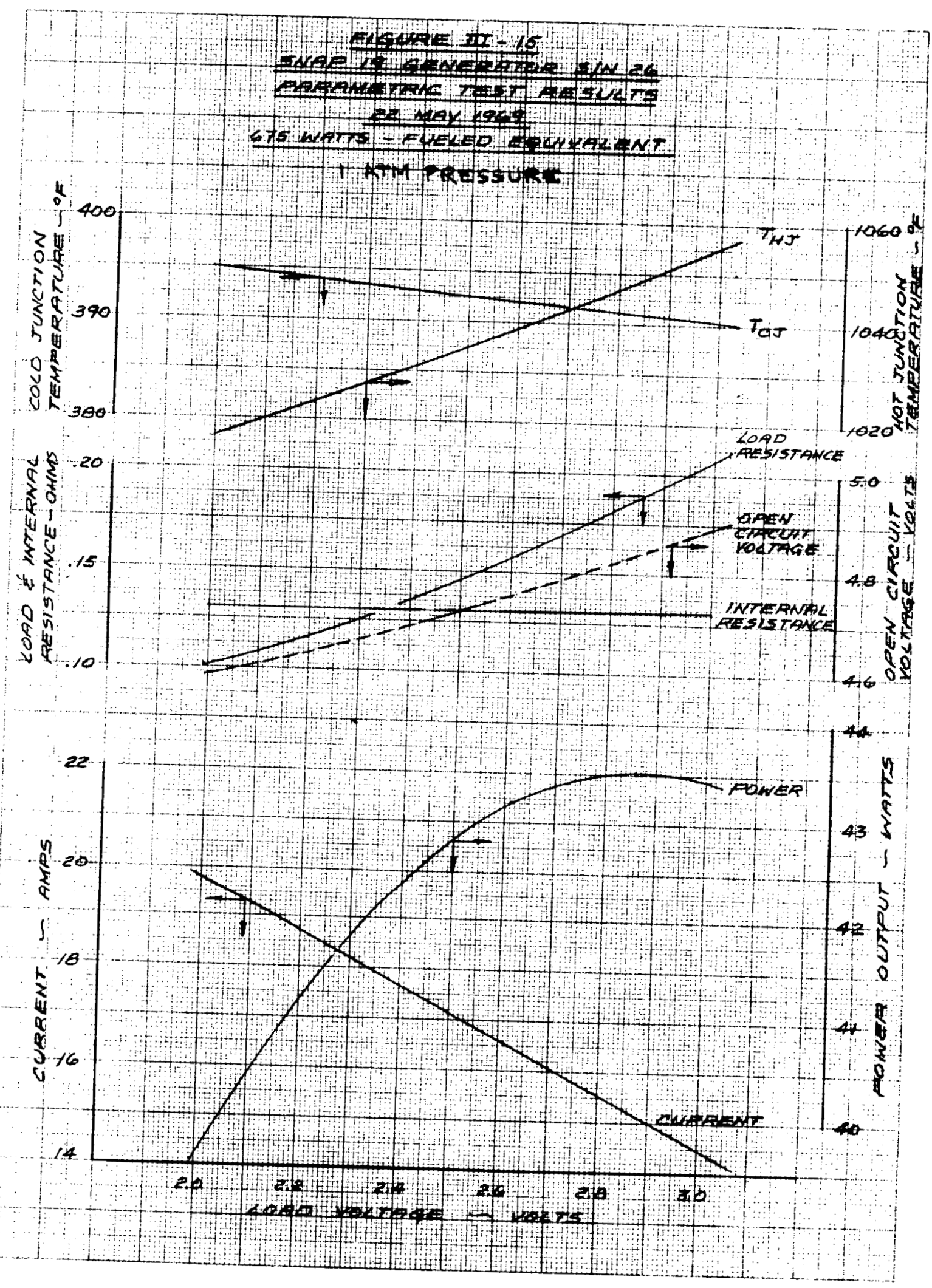



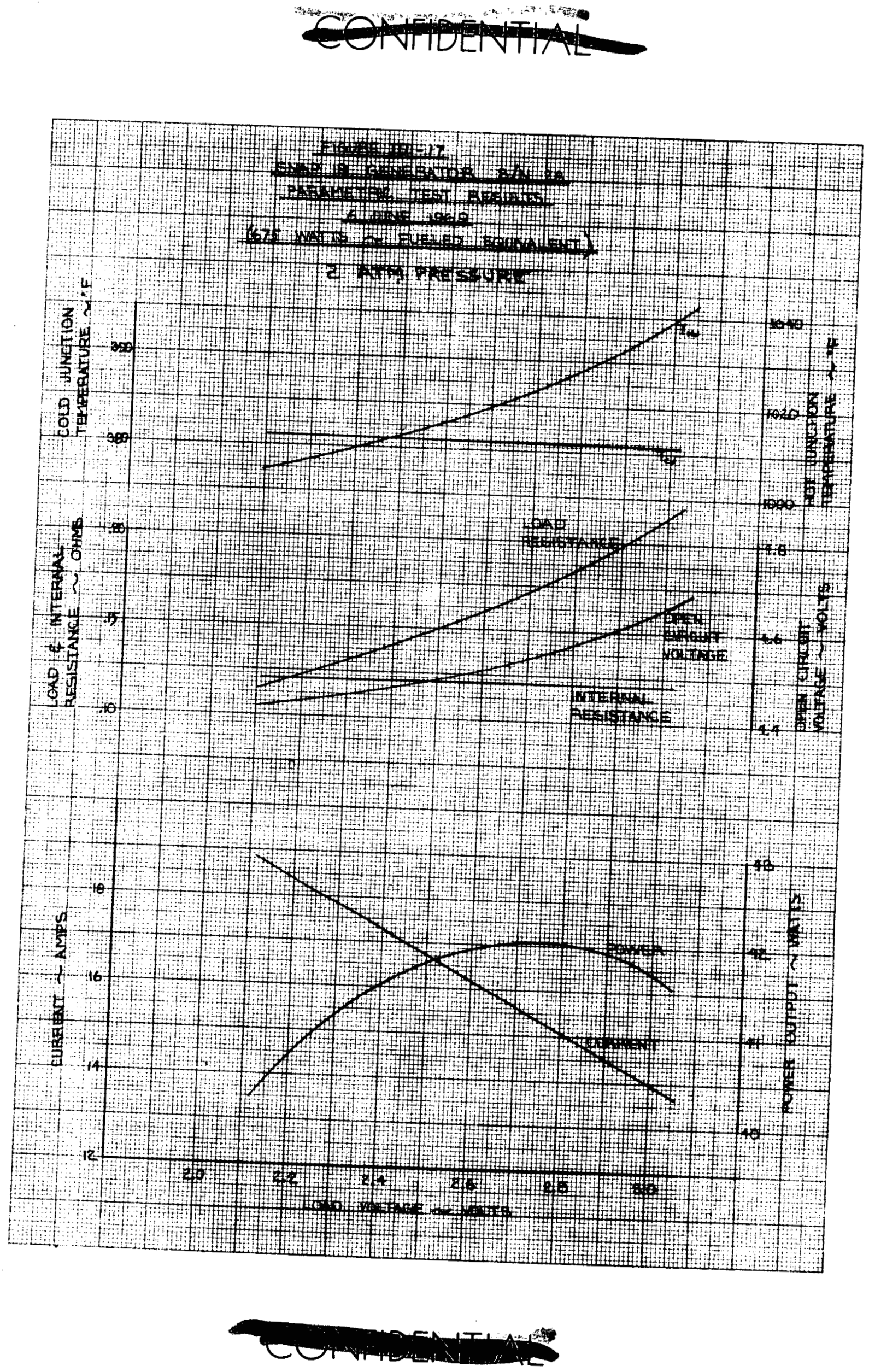


\section{TABLE III-5}

SUMMARY OF PEAK POWER POINTS OF PARAMETRIC TESTS

\begin{tabular}{|c|c|c|c|c|c|}
\hline Parameter & & $\begin{array}{l}\text { Generator } \\
\mathrm{S} / \mathrm{N} 26 \\
\end{array}$ & $\begin{array}{l}\text { Generator } \\
\mathrm{S} / \mathrm{N} 27 \\
\end{array}$ & $\begin{array}{l}\text { Generator } \\
\mathrm{S} / \mathrm{N} 28 \\
\end{array}$ & Average \\
\hline Heater power (equiv. fueled) & watts & 675 & 675 & 675 & 675 \\
\hline Power output & watts & 43.5 & 43.1 & 42.1 & 42.9 \\
\hline Efficlency (overall) & $\%$ & 6.4 & 6.4 & 6.2 & 6.4 \\
\hline Load current & amps & 15.4 & 15.4 & 15.0 & 15.3 \\
\hline Load voltage & volts & 2.88 & 2.79 & 2.81 & 2.83 \\
\hline Open circuit voltage & volts & 4.91 & 4.63 & 4.58 & 4.71 \\
\hline Hot junction temperature & $\mathrm{O}_{\mathrm{F}}$ & 1060 & 1026 & 1030 & 1039 \\
\hline Cold junction temperature & $O_{\mathrm{F}}$ & 396 & 380 & 382 & 386 \\
\hline Fin root temperature & $\alpha_{\mathrm{F}}$ & 336 & 331 & 337 & 335 \\
\hline Hours of operation & hrs & 340 & 60 & 60 & $-\infty$ \\
\hline Generator argon pressure & psia & 14 & -29 & $\sim 29$ & $\sim$ \\
\hline
\end{tabular}

(1)


Hone II-IB

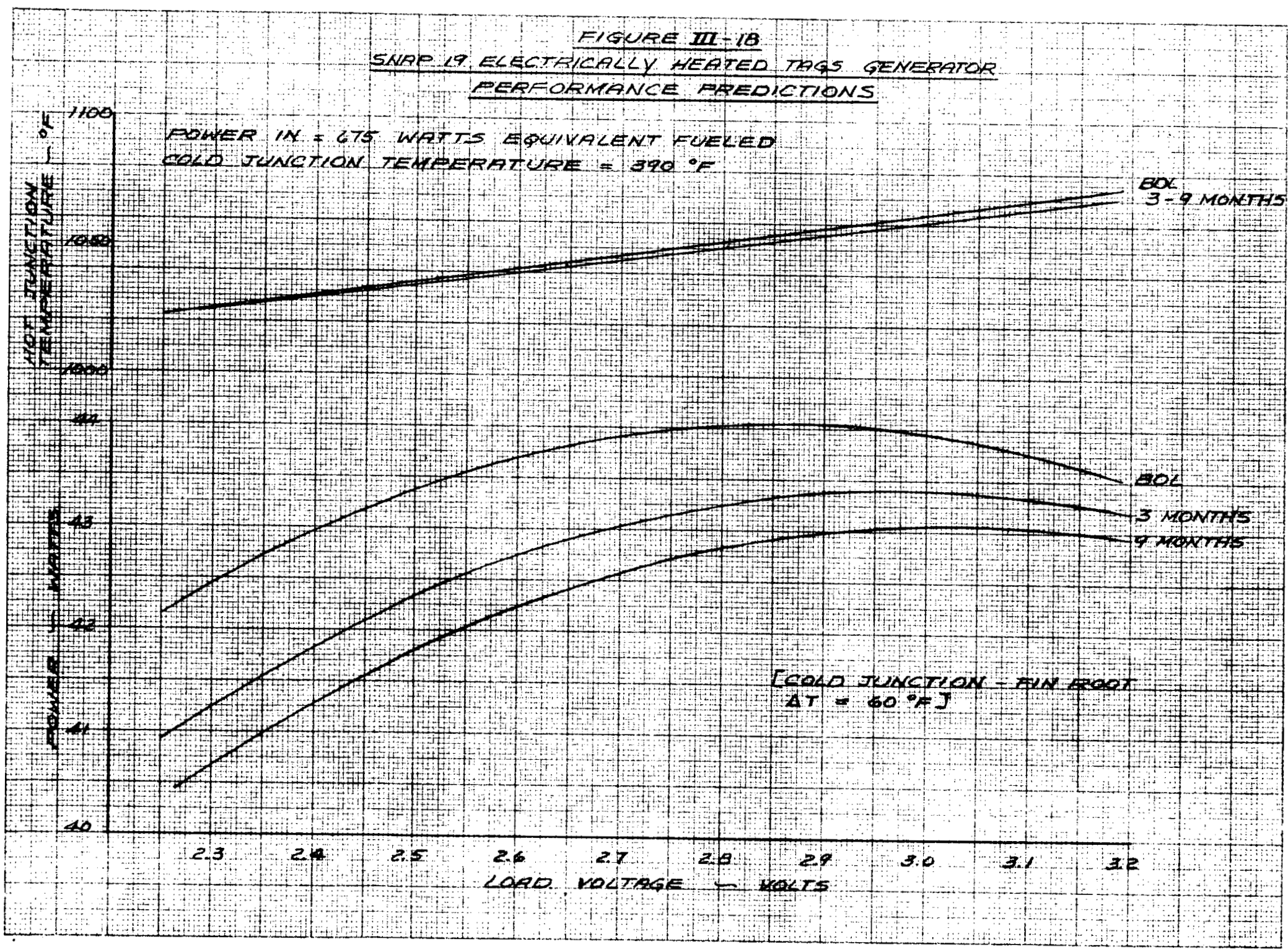


initial 340 hours on the order of 0.5 watts.

A gxeater change was observed between initial power check and parametric test over a shorter period $(\sim 60$ hours) on $S / N 27$ and $s / N$ 28. The difference was an average of 1.1 watts and is attributable to a change in generator argon pressure from 14 psia (power check) to 29 psia (parametric test). This pressure increase causes greater thermal losses through the MinK insulation. The increase in internal gas pressure was accomplished during installation of the pressure transducer, which was performed after the power check but before the parametric test.

The average power output from the first power checks of three representative TAGS-85/2N generators built to date is 43.8 watts for the 675 watt (equivalent fueled) thermal inventory. Generator S/N 26 is being maintained near initial optimum load voltage (2.86) with 675 watts (equivalent fueled) electrical input and a fin root temperature of 3250 F. Stability of significant performance parameters will continually be monitored as time accrues.

On June 12 and 13, generators S/N 27 and 28 were successfully hard-mount vibrated on load in the heated condition to the levels shown in Table III-6. Vibration was performed in all three axes with sinusoidal input first, followed by random input, in each axis. Output power was unchanged as a result of the tests.

\section{b. SNAP 29}

A

Four SNAP 29 90-couple TAGS-85/2N modules (S/N 001, 002, 007 , and 008) have been fabrlcated and placed on life test. Four

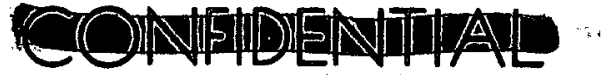




\title{
EONFTEENTIATS
}

\author{
TABLE III-6
}

VIBRATION IEVELS FOR GENERATORS S/N 27 AND 28

Sinusoidal

$$
\begin{aligned}
& \text { Direction } \\
& \text { Frequency Range Amplitude } \\
& z \text { (axial) axis } \\
& \text { (cps) } \\
& 20-500 \\
& \text { ( } g^{\prime} s, 0 \text { to peak) } \\
& 500-2000 \\
& 15 \\
& 10 \\
& x, y \text { (lateral axes) } \\
& 20-500 \\
& 10 \\
& 500-2000 \\
& 7
\end{aligned}
$$

Random

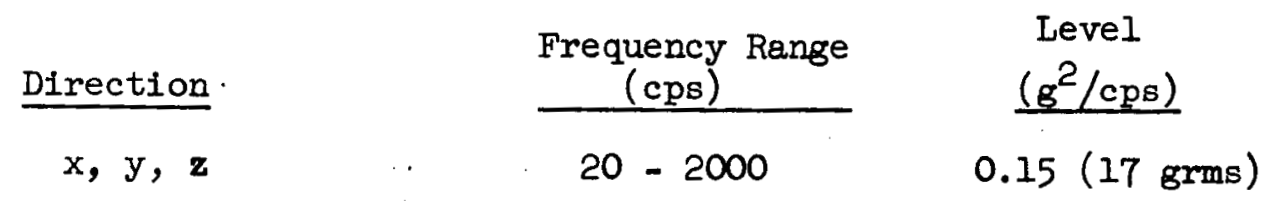

Two minutes in each axis; total, 6 minutes

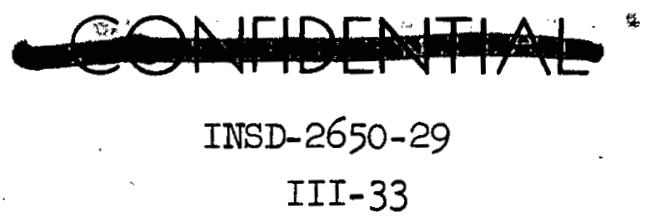


additional modules are being fabricated and will be delivered as an electrically heated thermoelectric generator (ETG) system. Couple and module performance on SNAP 29 are discussed below.

\section{(1) Couple power check}

Sampling techniques similar to those employed on SNAP 19

are üsed on SINAP 29 for quality assurance. Of this sampling, the most significant is the couple power check. The couple performance predicted by computer analysis for SNAP 29 couples operating at $\mathrm{T}_{\mathrm{h}}=1050^{\circ} \mathrm{F}$ and $\mathrm{T}_{\mathrm{C}}=350^{\circ} \mathrm{F}$ is presented in Fig. III-19. The SNAP 29 Program has fabricated 940 TAGS-85/2N couples, of which 85 were power checked at matched load. A compilation of data from these power checks is shown in Table III-7. Comparison of the analytical and test results illusi trates the excellent correlation obtainable. Good correlation between couple power checks and module performance is also obtained by subtracting the predicted strap and wire losses from the product of the average couple power and the number of couples.

The advantage of a TAGS-85/2N couple over the $3 \mathrm{P} / 2 \mathrm{~N}$ couple is indicated in Table III-8. Over the SNAP 29 temperature range $\left(1050^{\circ} \mathrm{F} /\right.$ $\left.350^{\circ} \mathrm{F}\right)$, the TAGS couples have a $24 \%$ better efficiency and $45 \%$ higher output power per unit couple area than the 3P couple. The difference is almost as great over the SNAP 19 range of temperature (1050\% $/ 400 \% \mathrm{~F})$. It should be noted that the SIIAP 29 couple is not of optimum geometry. The P-leg was sized with the existing 0.560 inch diameter N-leg to satisfy module power requirementamand thus could not be reduced in diameter to the optimum efficiency geometry.

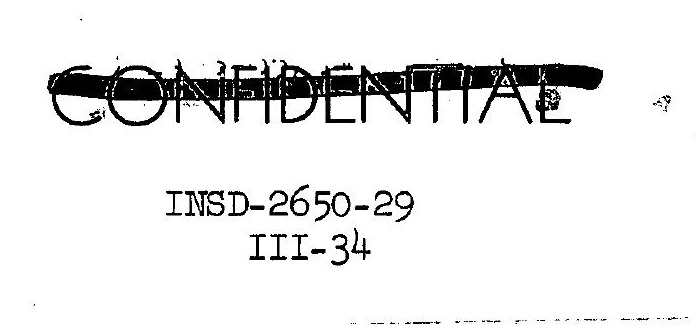



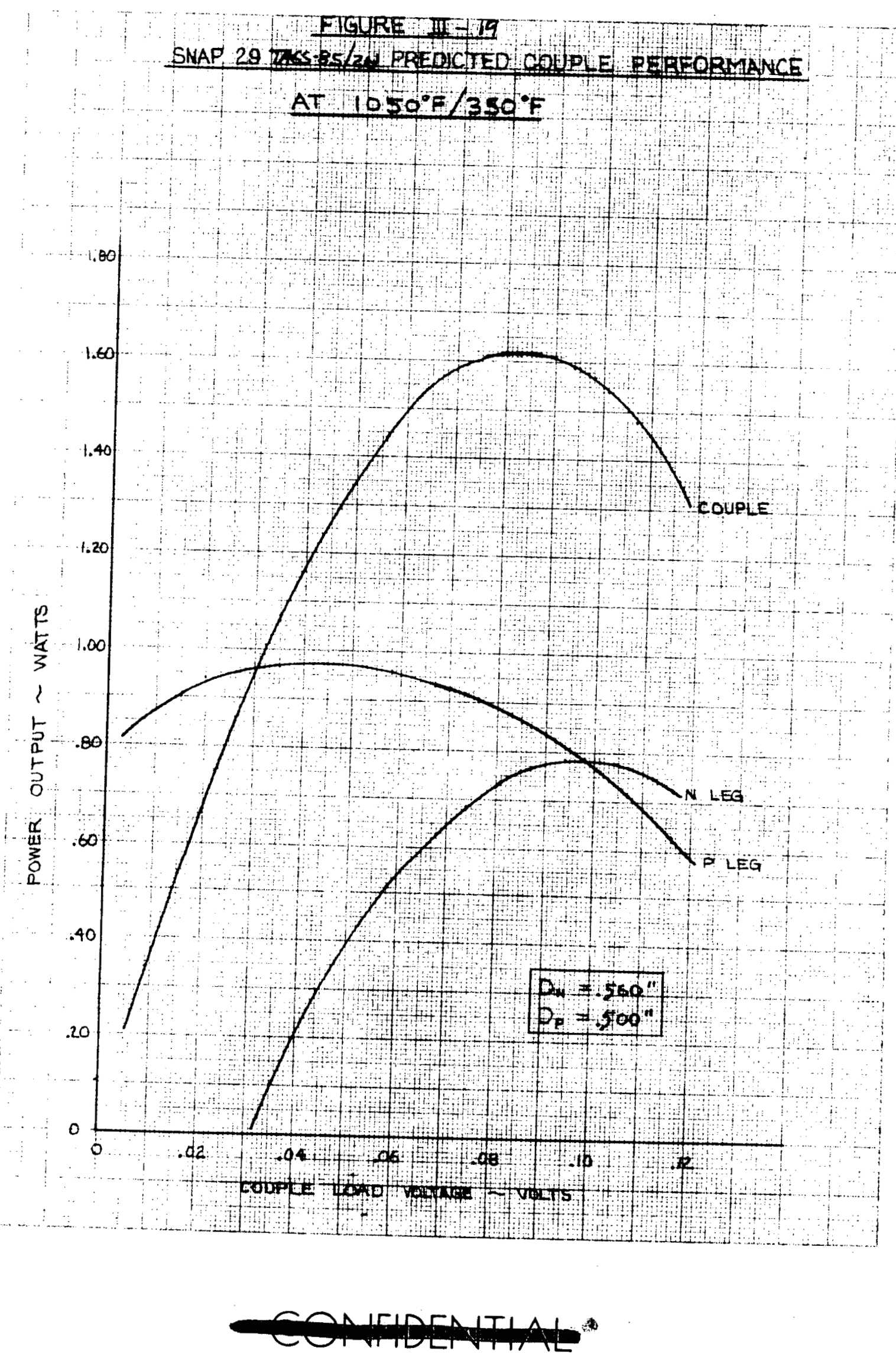

INSD- $2650-29$ 
TABLE III-7

SNAP 29 COUPLE POWER TEST SUMMARY

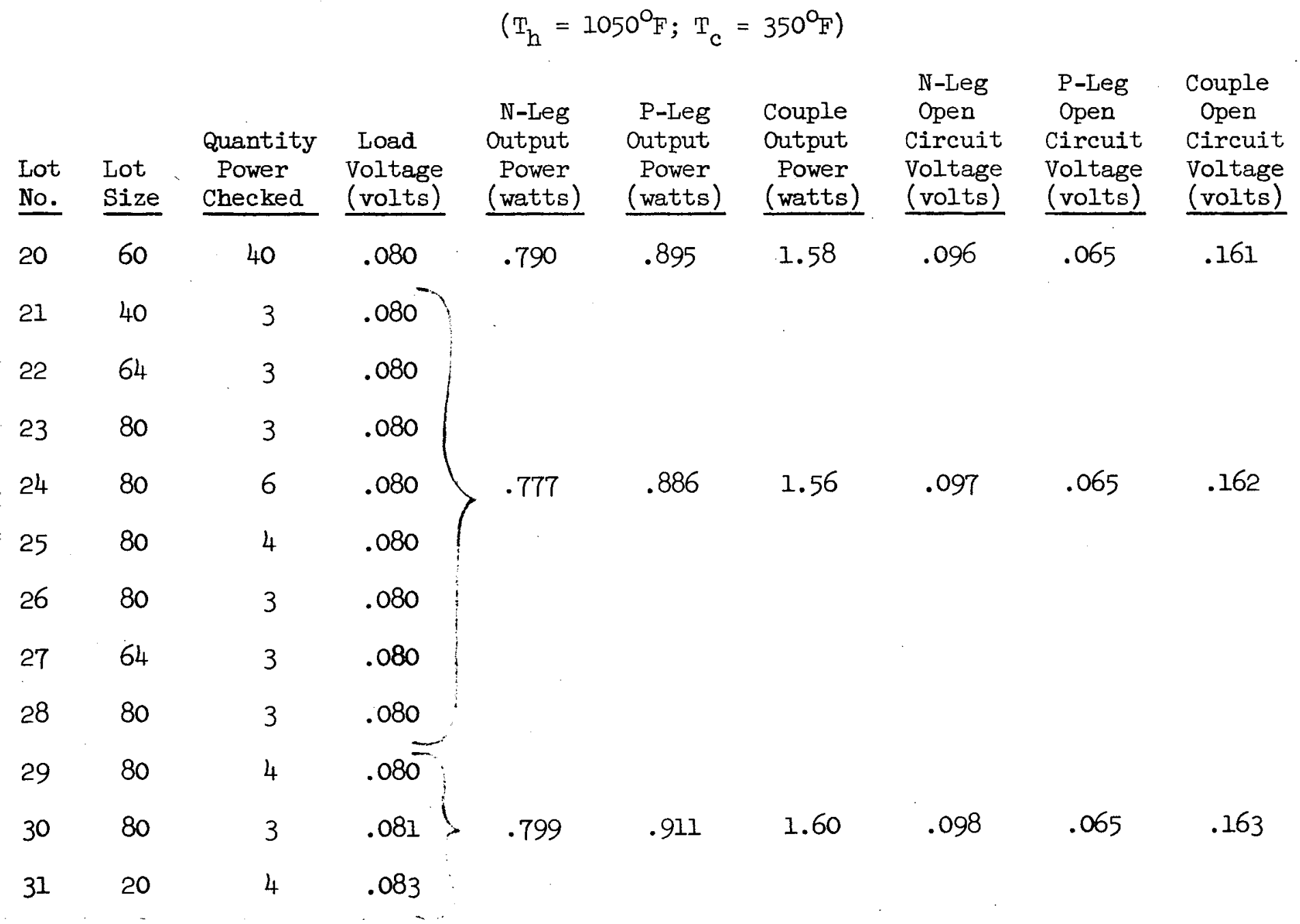

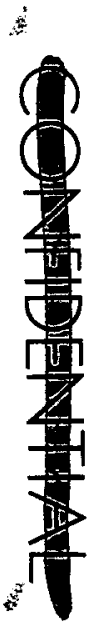




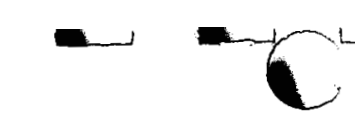

TABLE III-7 (Continued)

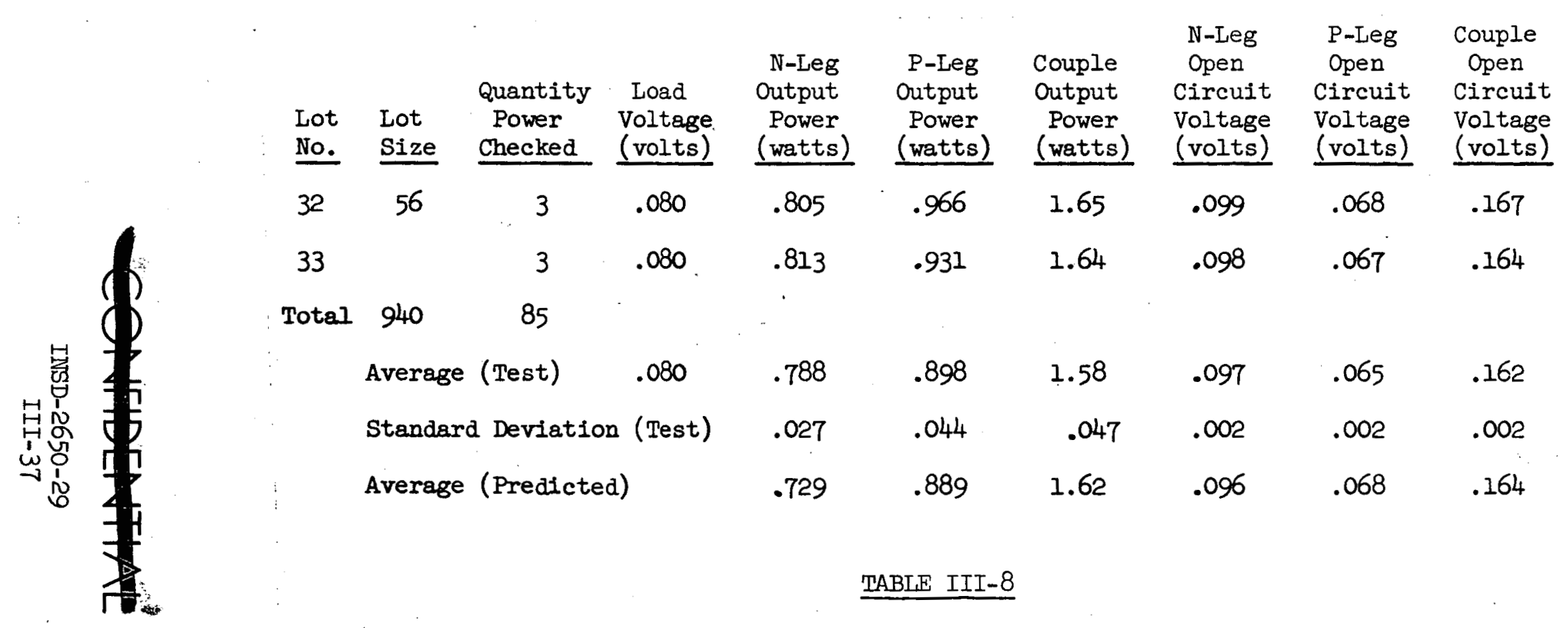

COMPARISON OF OPTIMIZED TAGS-85/2N AND 3P/2N COUPLES AT BEGINNING-OF-LIFE

\begin{tabular}{|c|c|c|c|c|c|c|}
\hline \multirow{2}{*}{$\begin{array}{c}\text { Hot/Cold Junction } \\
\text { Temperatures } \\
\left(O_{\mathrm{F})}\right.\end{array}$} & \multicolumn{3}{|c|}{$\begin{array}{c}\mathrm{T} / \mathrm{E} \text { Efficiency } \\
(\%)\end{array}$} & \multirow{2}{*}{$\begin{array}{l}\text { Output } \\
3 \mathrm{P} / 2 \mathrm{~N}\end{array}$} & $\begin{array}{l}\text { Power per Uni } \\
\left(w / i n^{2}\right.\end{array}$ & \multirow{2}{*}{$\begin{array}{l}t \text { Couple Area } \\
\text { \% Improvement }\end{array}$} \\
\hline & $3 P / 2 N$ & TAGS-85/2N & \& Improvement & & TAGS-85/2N & \\
\hline $1050 / 300$ & $7 \cdot 31$ & 9.12 & 24.8 & 2.91 & 4.26 & 46.4 \\
\hline $1050 / 350$ & 6.87 & 8.53 & 24.2 & 2.53 & 3.68 & 45.5 \\
\hline $1050 / 400$ & 6.41 & 7.91 & 23.4 & 2.17 & 3.14 & 44.7 \\
\hline
\end{tabular}


(2) Couple thermal cycle and life tests

Nineteen SNAP 29 TAGS-85/2N couples have been life tested up to 2700 hours at a cold junction temperature of $375^{\circ} \mathrm{F}$ and hot junction temperatures of 1025,1050 , and $1075^{\circ} \mathrm{F}$. These couples are being operated at matched load conditions. Five of the couples underwent three deep thermal cycles and all of the couples received a two-hour power check prior to the life test. Analytical predictions for beginning-of-life and 2160 hours ( 3 months) are illustrated in Fig. III-20 for the three temperatures of interest (1075, 1050, and $1025^{\circ} \mathrm{F}$ ). Experimental power-time maps of the individual legs and couples for each of the hot junction temperatures are presented as Figs. III-2l to III-26. In each case the mean power is indicated. In general a burn-in was experienced during the first 1000 hours, after which time virtually stable power was observed. Couple life test results are summarized in Table III-9. On all nineteen couples, the internal resistance and open circuit voltage of the TAGS leg increased, thus verifying the expected increase with time of the electrical resistivity and the Seebeck voltage as previously discussed. The five couples which underwent thermal cycling prior to the life test experienced slightly higher power reductions. Correlation between predicted and measured endurance test data is good as illustrated in Table III-10.

(3) Large TAGS module

A 90-couple 2N-TAGS module of an earlier design was endurance tested at $\mathrm{T}_{\mathrm{h}}=1015^{\circ} \mathrm{F}$ and $\mathrm{T}_{\mathrm{c}}=350^{\circ} \mathrm{F}$ for about 4200 hours. The test

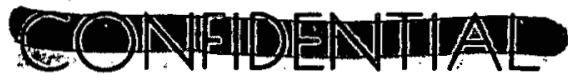

INSD-2650-29

III-38 

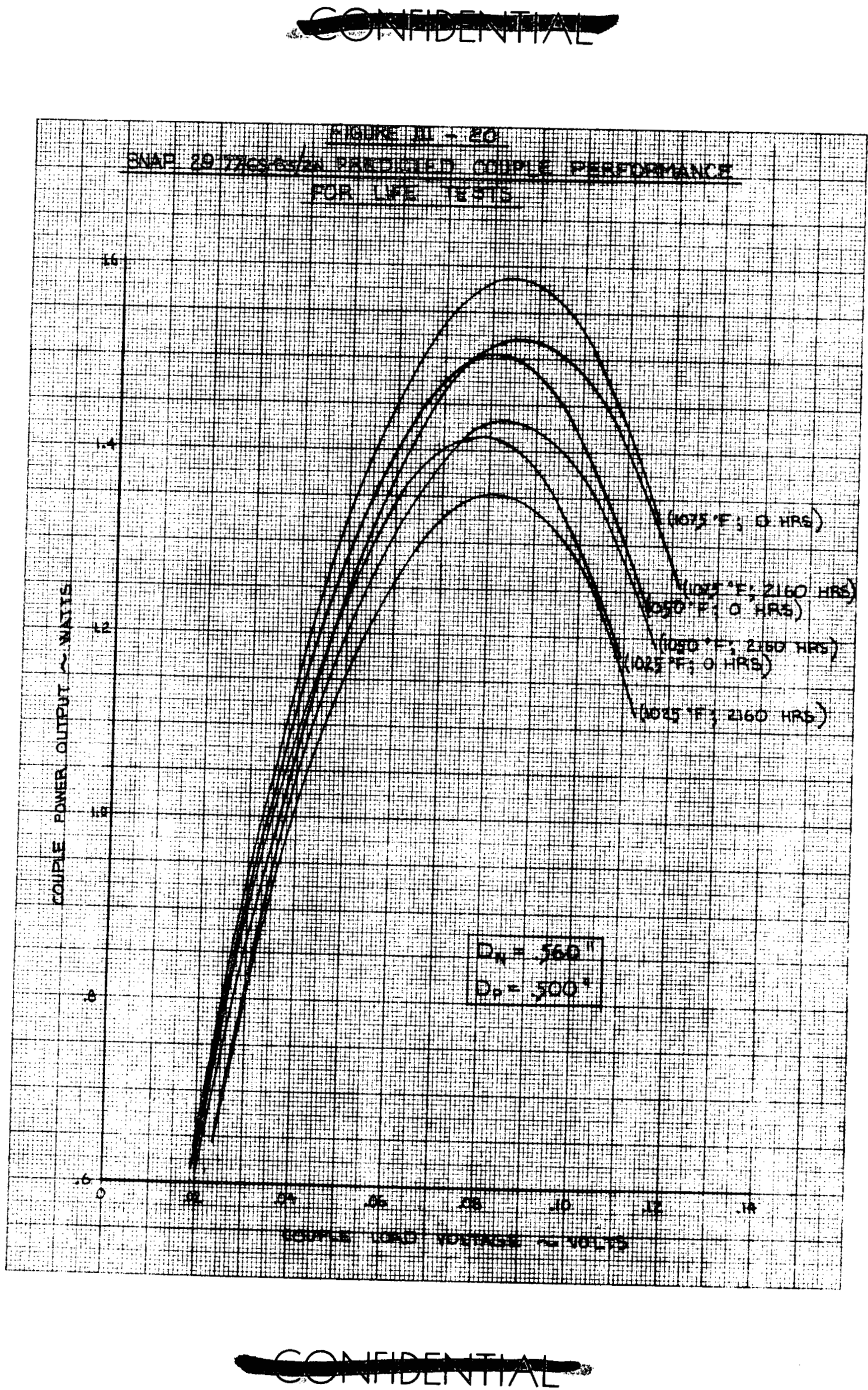

INSD $-2650-29$

III- 39 

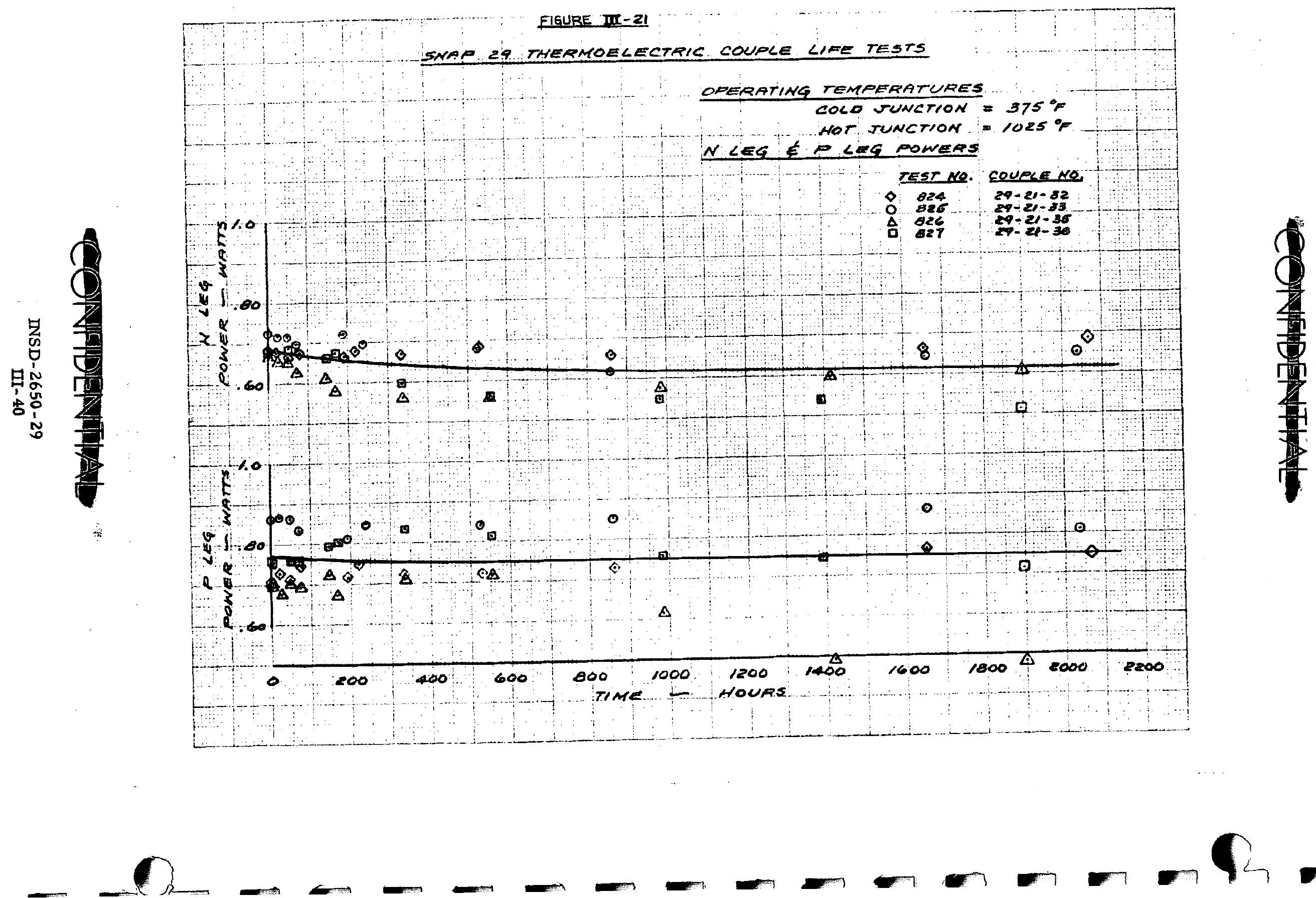


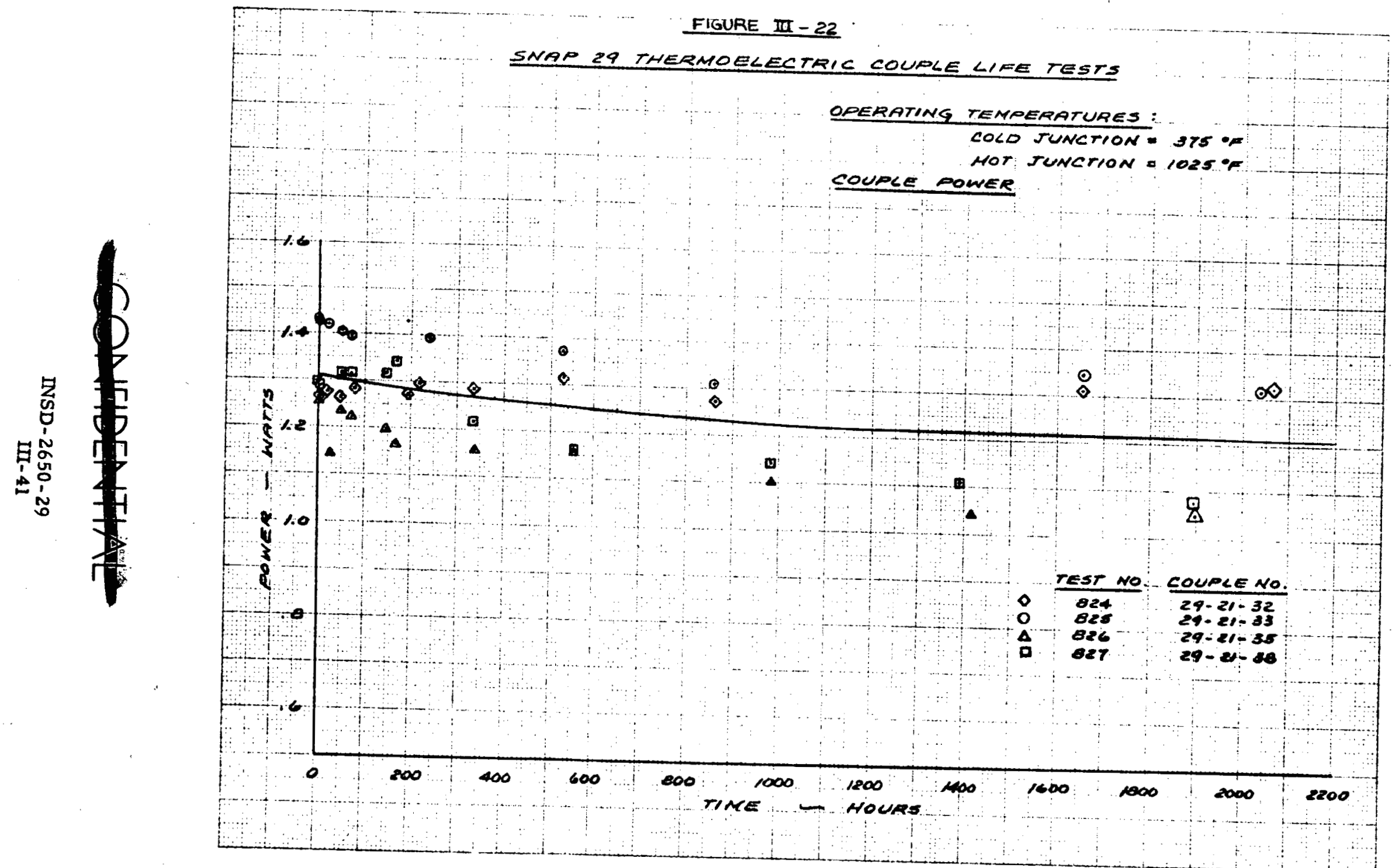



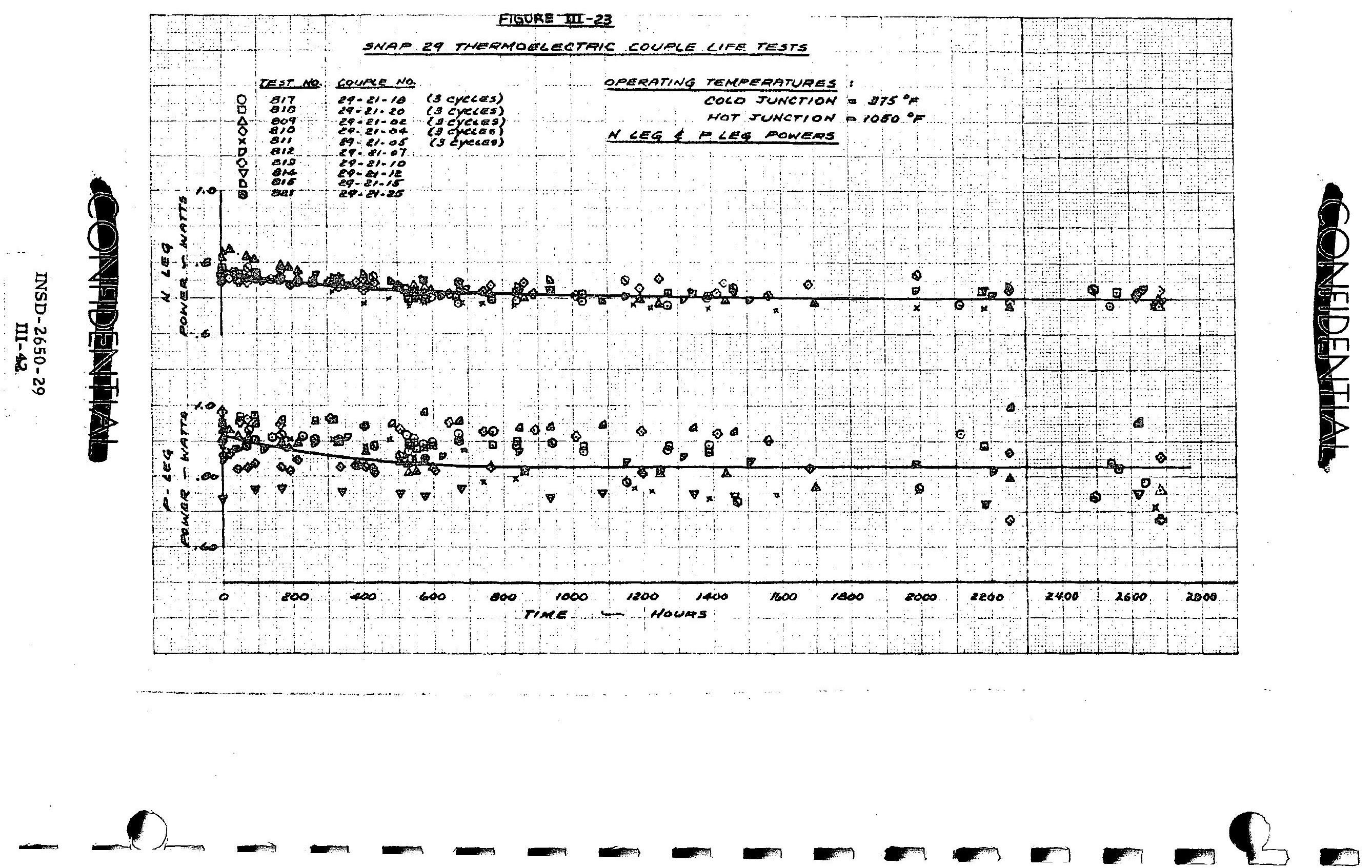


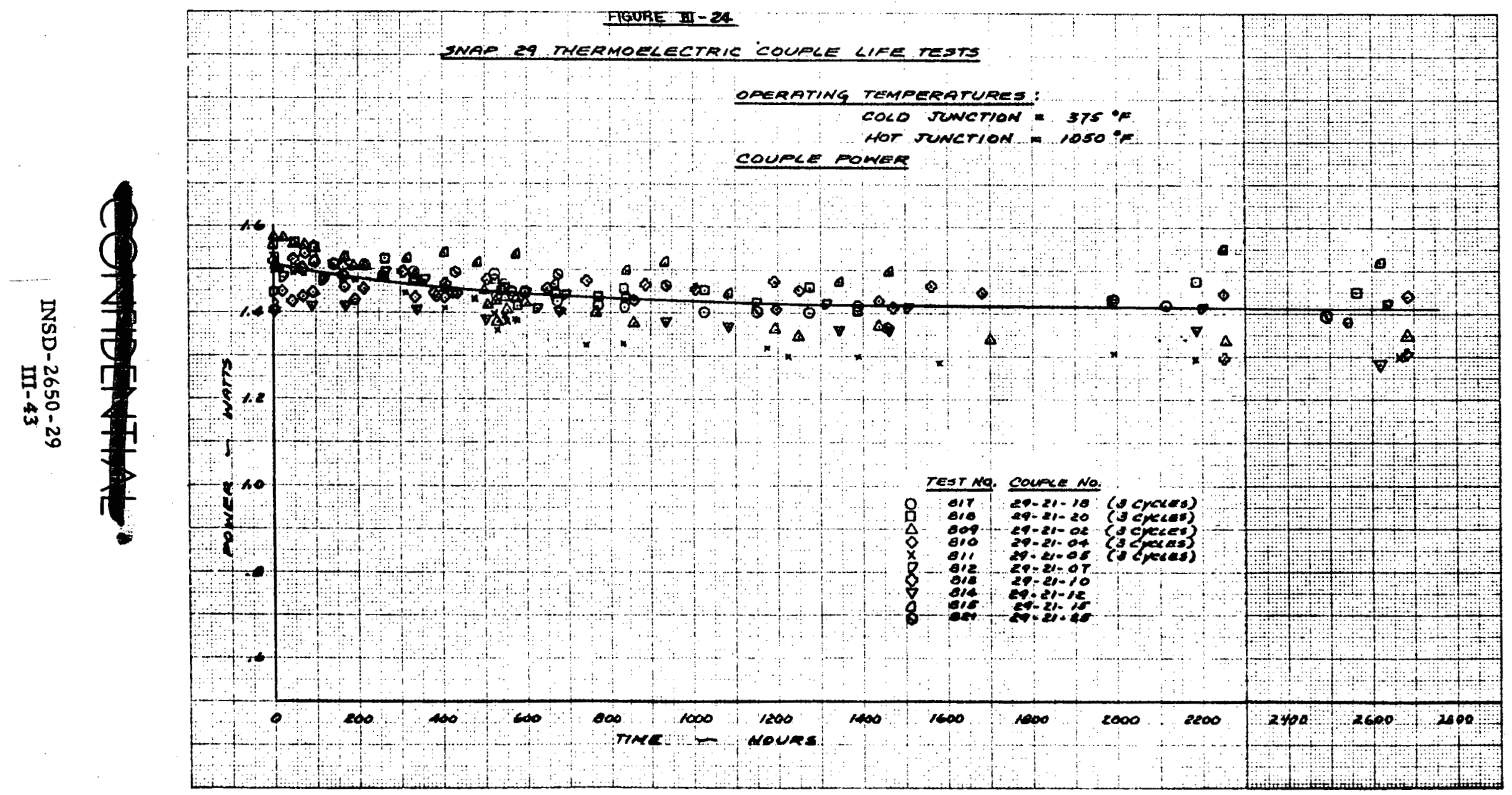




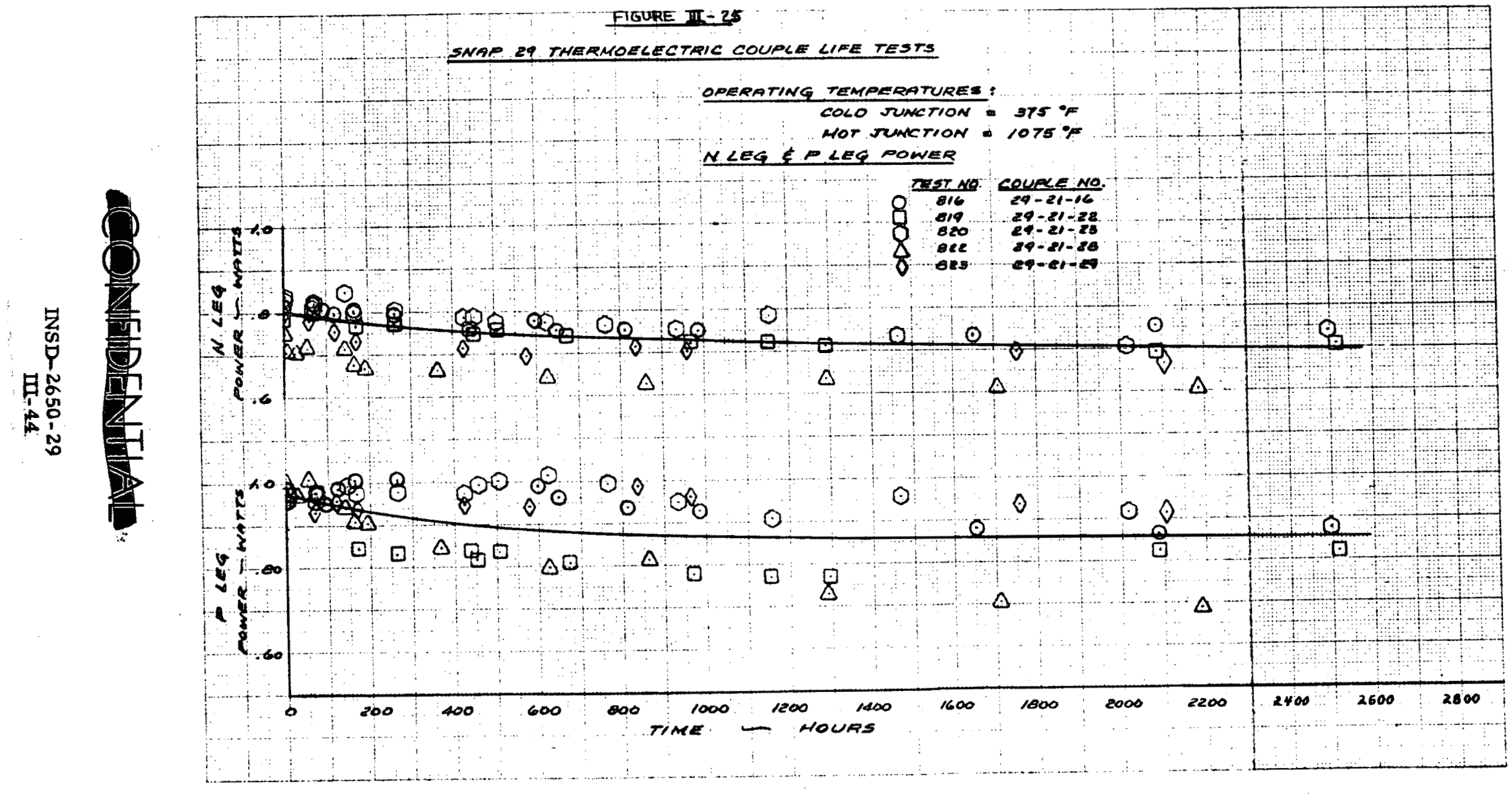


FIGURE III-26

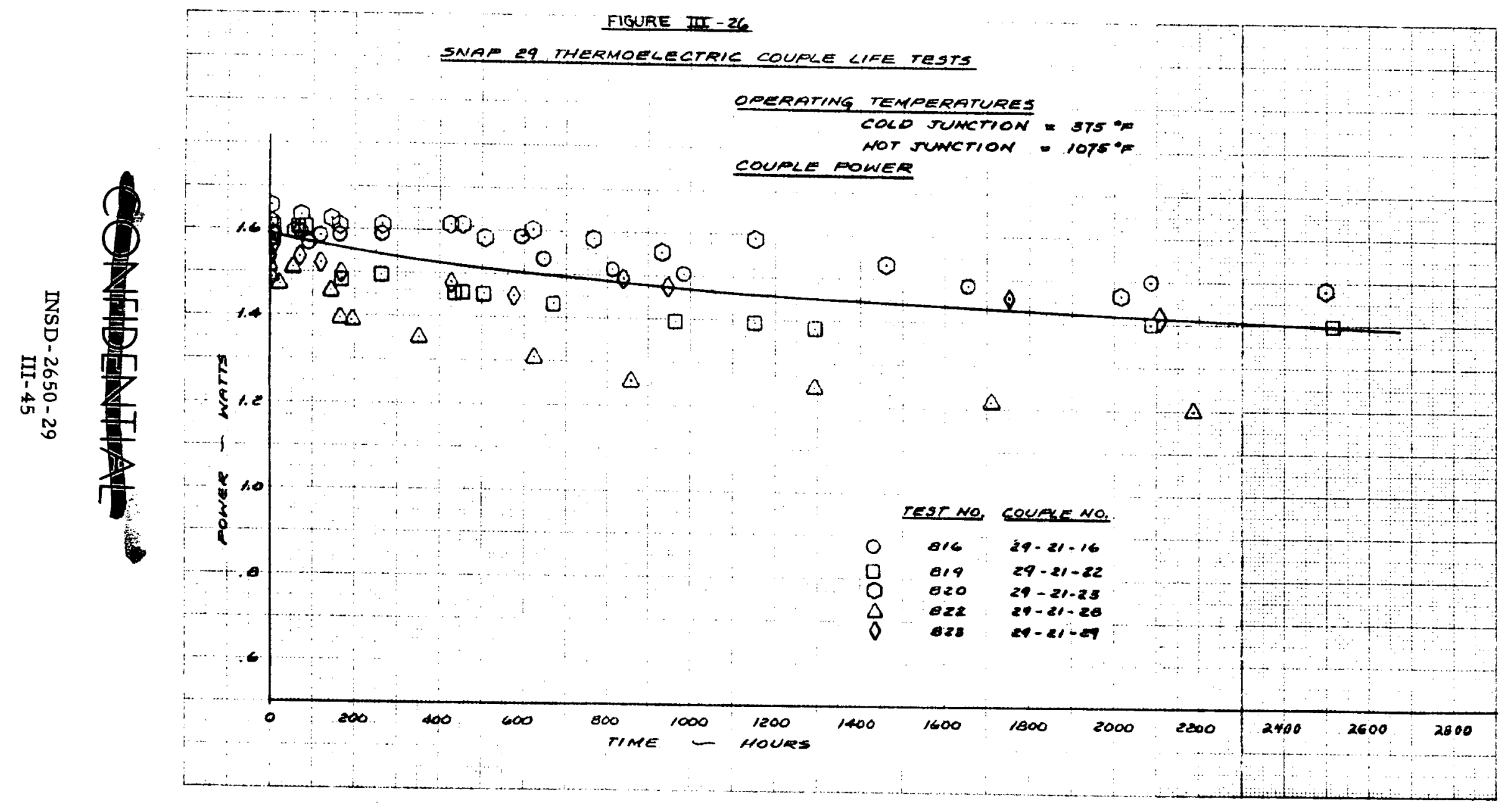


TABLE III-9

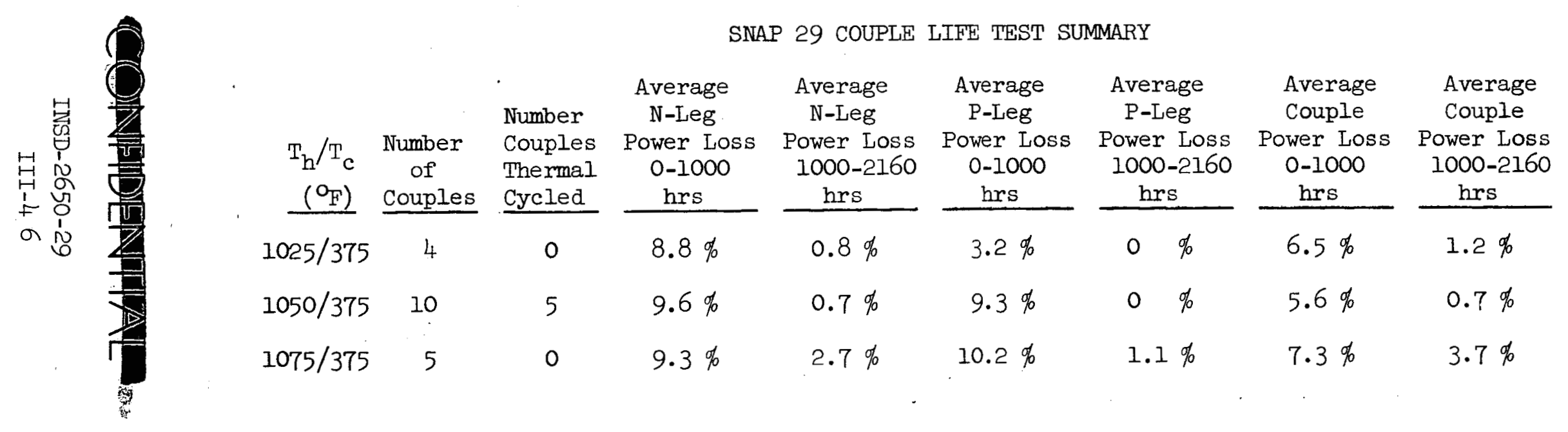


COMPARISON OF PREDICTED AND TEST RESULTS OF SNAP 29 COUPLE LIFE TESTS *

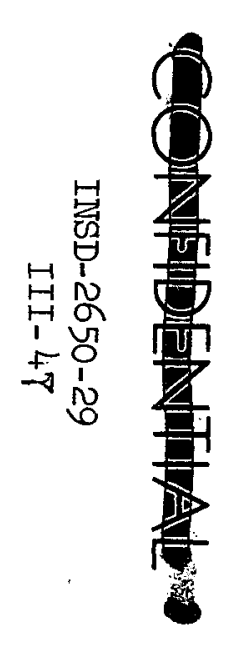

\section{Predicted}

\begin{tabular}{|c|c|c|c|c|}
\hline $\begin{array}{l}\text { Time } \\
\text { (hours) }\end{array}$ & $\begin{array}{r}\mathrm{T}_{\mathrm{h}} / \mathrm{T}_{\mathrm{c}} \\
\left(\mathrm{O}_{\mathrm{F}}\right) \\
\end{array}$ & $\begin{array}{c}\text { N-Leg } \\
\text { Output } \\
\text { Power } \\
\text { (watts) } \\
\end{array}$ & $\begin{array}{r}\text { P-Leg } \\
\text { Output } \\
\text { Power } \\
\text { (watts) } \\
\end{array}$ & $\begin{array}{l}\text { Couple } \\
\text { Output } \\
\text { Power } \\
\text { (watts) } \\
\end{array}$ \\
\hline 0 & $1025 / 375$ & .67 & .75 & 1.42 \\
\hline 0 & $1050 / 375$ & .70 & .81 & 1.51 \\
\hline 0 & $1075 / 375$ & .70 & .89 & 1.58 \\
\hline 2160 & $1025 / 375$ & .63 & .72 & 1.35 \\
\hline 2160 & $1050 / 375$ & .66 & .78 & 1.43 \\
\hline 2160 & $1075 / 375$ & .69 & .83 & 1.52 \\
\hline
\end{tabular}

Average Measured

$\begin{array}{ccc}\begin{array}{c}\text { N-Leg } \\ \text { Output } \\ \begin{array}{c}\text { Power } \\ \text { (watts) }\end{array}\end{array} & \begin{array}{c}\text { P-Leg } \\ \text { Output } \\ \text { Power } \\ \text { (watts) }\end{array} & \begin{array}{c}\text { Couple } \\ \text { Output } \\ \text { Power } \\ \text { (watts) }\end{array} \\ .69 & .77 & 1.31 \\ .78 & .92 & 1.52 \\ .80 & .98 & 1.58 \\ .62 & .75 & 1.22 \\ .71 & .83 & 1.42 \\ .71 & .87 & 1.42\end{array}$

* Note that $\mathrm{P}_{\mathrm{N}}+\mathrm{P}_{\mathrm{P}} \neq \mathrm{P}_{\text {COUPLE }}$ since individual leg powers are at their respective peak voltages. 
was interrupted by a test loop failure. Operational performance of the module, known as the large TAGS module (LTM), is illustrated on Fig. III-27. This module actually appreciated $2.4 \%$ in power over the 4200 hours tested.

\section{(4) Module life tests}

Four SNAP 29 TAGS-85/2N modules have been placed on life tests. Two of these modules, $\mathrm{S} / \mathrm{N} 001$ and $\mathrm{S} / \mathrm{N} 002$ have, at this writing, completed over 1500 hours while the other two modules, S/N 007 and S/IN 008, have just completed the initial power check. These 90-couple modules are being tested at $\mathrm{T}_{\mathrm{h}}=1050^{\circ} \mathrm{F}$ and $\mathrm{T}_{\mathrm{c}}=375^{\circ} \mathrm{F}$. Modules $\mathrm{S} / \mathrm{N} 001$ and 002 developed leaks early in the testing (following thermal cycling); were purged with argon after.S/N 001 experienced an unexpected power reduction, probably due to oxidation of the thermoelectrics. The power level of $S / \mathbb{N} 001$ appreciated after the argon purge was initiated, and the power loss after 1880 hours is $5.8 \%$. The severity of the leak in $S / \mathbb{N} 002$ was not so great as $\mathrm{S} / \mathrm{N} 001$, and the power loss is minimal, about $1.7 \%$ after 1640 hours. The performance of both modules is illustrated in Fig. III-28. The trend is toward stability.

The initial power check of modules $5 / \mathrm{N} 007$ and 008 indicate initial power outputs of 117.1 and 117.4 watts, respectively. Average initial power output of the four life test modules is 116.5 watts, which compares well with the predicted output of 114 watts.

\section{c. Sentinel}

The Sentinel commercial RTG program has fabricated and operated

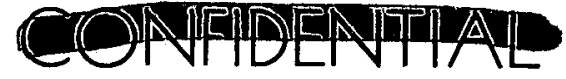




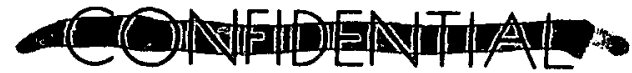
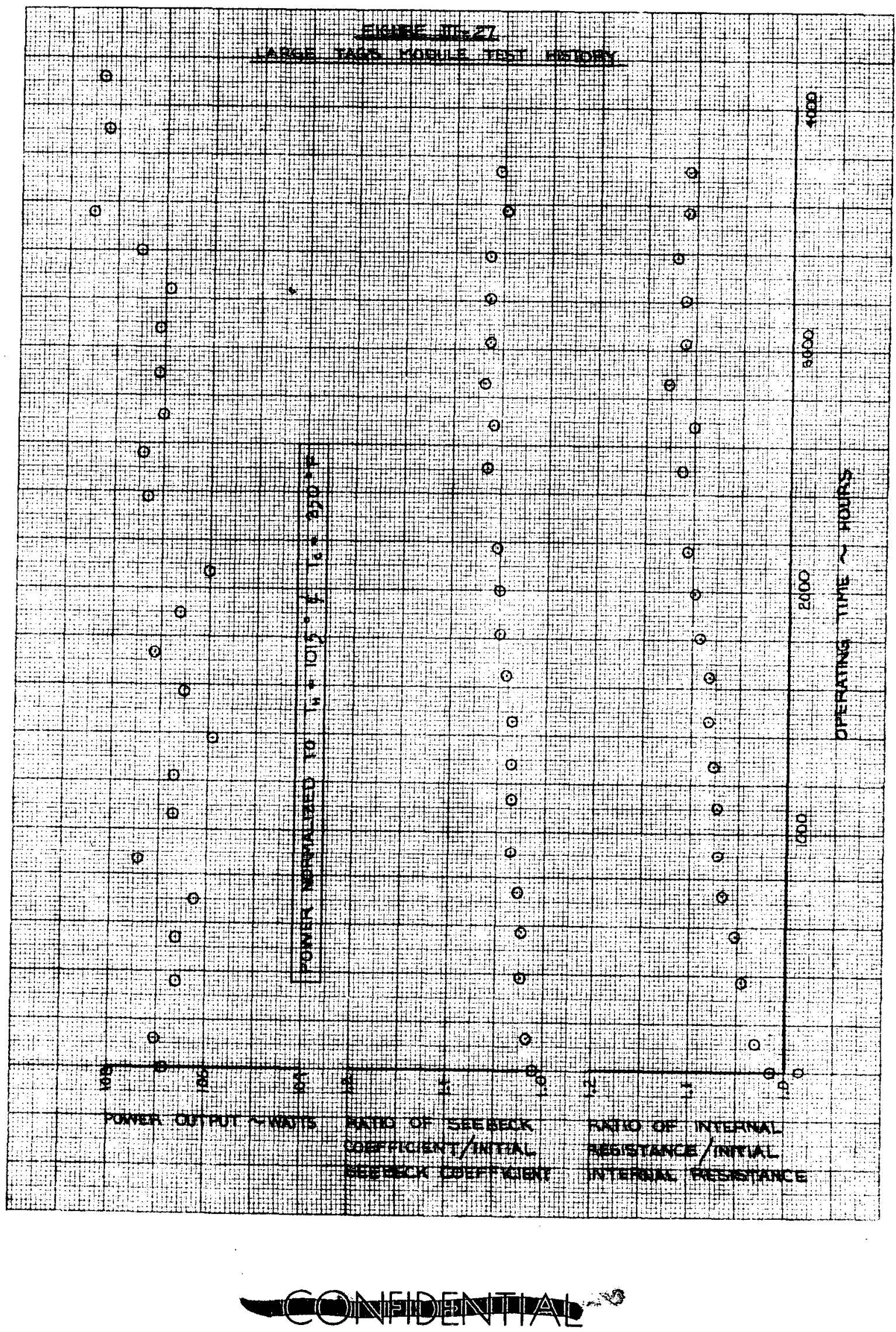

INSD $-2.650-29$ 

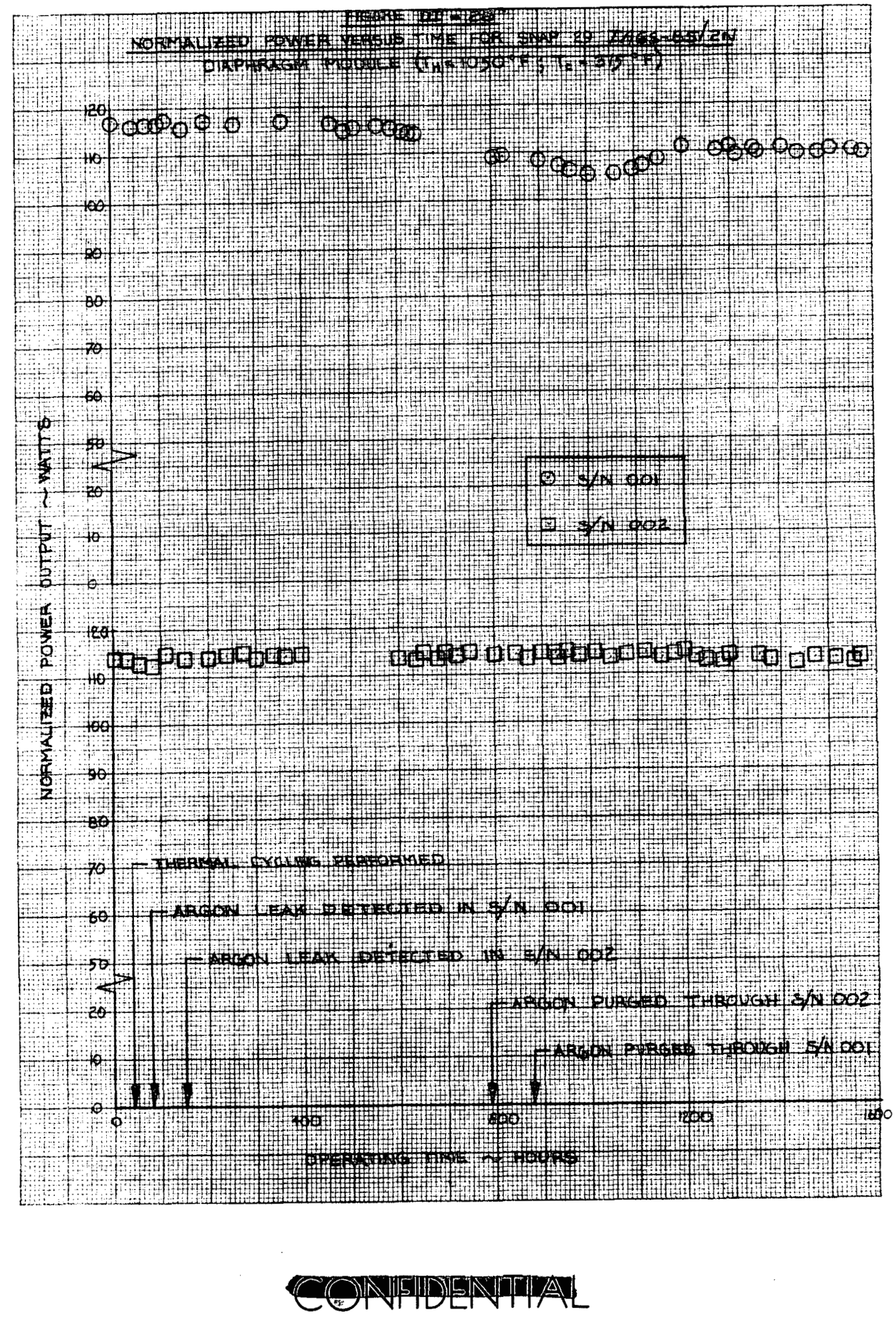


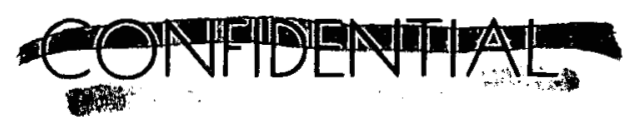

23 thermoelectric conversion assemblies ( 13 for the field and 10 for the laboratory) which utilize series-connected TAGS/Isotopes $\mathbb{N}$ couples. The TAGS assemblies have approximated, 190,000 hours (as of 6/15/69) without failure. These systems have a 5-year predicted reliability of 0.977 with a value of 0.85 or greater at a $50 \%$ confidence level being demonstrated to date.

All of the Sentinel RTG's utilize an earlier design for the couples. An improved couple using exothermic bonding techniques is now being produced. Figure III-29 presents test results of the TAGS P-leg of a preprototype exothermic bonded couple. Over the 5500 hour test, the TAGS demonstrated excellent stability after the initial burn-in period.

d. Long Eerm couple tests

Couples of various geometries utilizing TAGS as the P-leg material have been life-tested as long as 21,000 hours. The ratio of normalized couple power output to initial couple power ( $P / P o$ ) is shown as a function of time in Fig. III-30. The average ratio of $P / P o$ is presented in Table III-11. As is evident, excellent long term power stability is demons trated.

\section{TABLE III-I1}

TAGS LONG TERM STABIEIFY

\begin{tabular}{rcl}
$\begin{array}{l}\text { Time } \\
\text { (hours) }\end{array}$ & $\begin{array}{l}\text { No. of } \\
\text { Couples }\end{array}$ & $\begin{array}{l}\text { Average } \\
\text { P/Po }\end{array}$ \\
\cline { 2 - 3 } 5000 & 6 & 1.00 \\
10000 & 6 & 1.02 \\
20000 & 5 & 0.99 \\
& 3 & 0.93
\end{tabular}

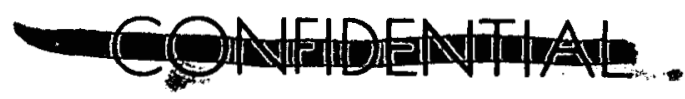

INSD-2650-29

III- 51 


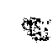
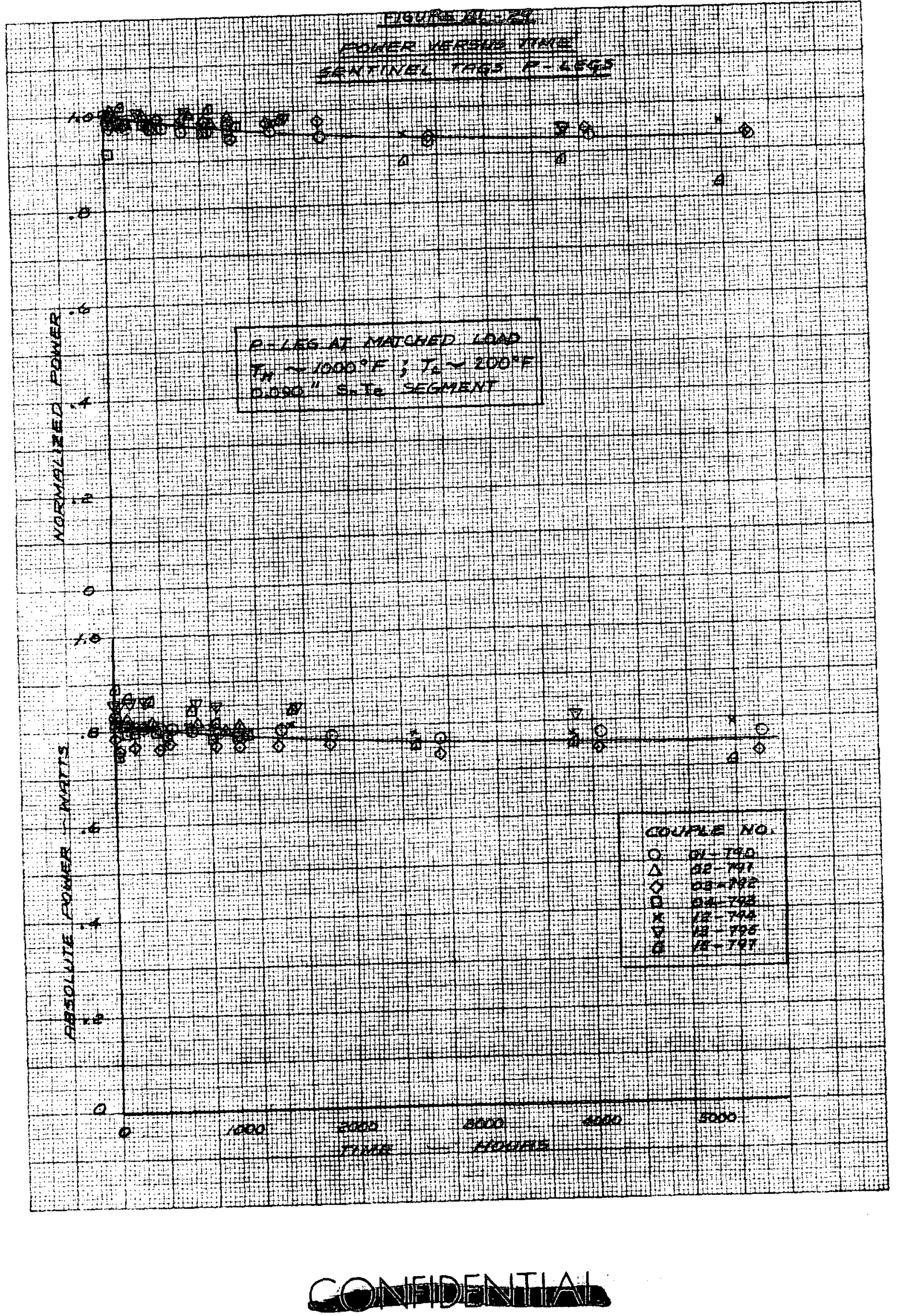

INSD- $2650-29$

III- 52 

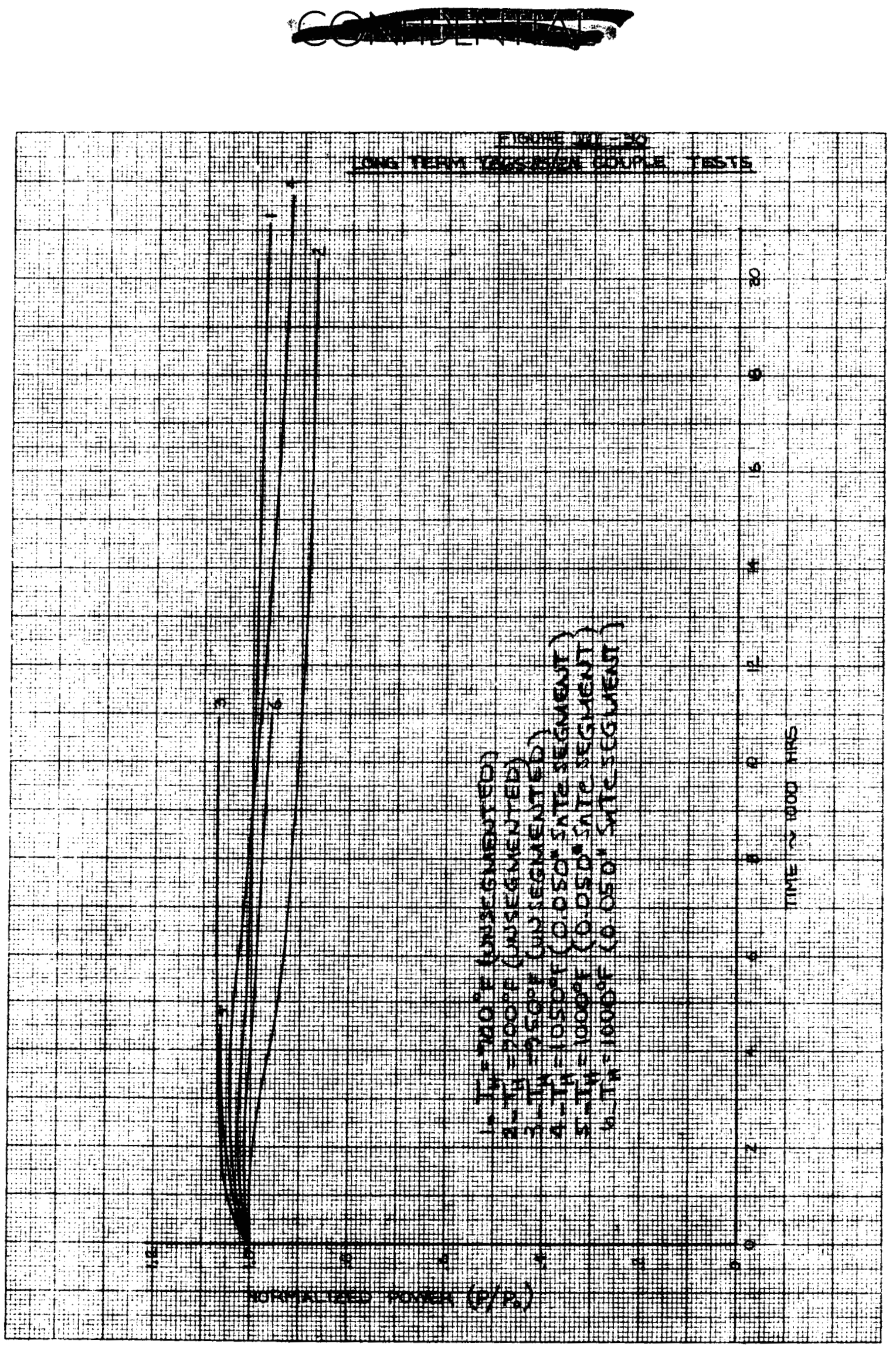

INSD-2650-29

III- 53 


\section{3. $3 P / 2 N$ Performance Data}

Data for evaluating the performance of $3 \mathrm{P} / 2 \mathrm{~N}$ thermoelectrics were primarily from the SNAP 19 S/N 20 generator and Nimbus III flight units $S / N 24$ and $S / \mathbb{N} 25$, from SIIAP 11 generator and module testing, and from SNAP 29 module testing. Currently, the SINAP $19 \mathrm{~S} / \mathrm{N} 20$ generator has operated in excess of 11,000 hours, while two $\operatorname{SNAP} 11$ generators $(Q / N-$ $I M$ and $Q / N-3$ ) have each accumulated test times in excess of 18,000 hours. Additionally, two SNAP 11 modules operating at $900^{\circ}$ and 1000\%F, respectively, have each accumulated operating time of 17,000 hours. On the SNAP 29 program, a total of five modules have been fabricated and tested with a maximum operating time of 7000 hours.

a. $\quad \operatorname{SNAP} 19 \mathrm{~S} / \mathrm{N} 20$ generator

The SNAP $19 \mathrm{~S} / \mathrm{IN} 20$ generator is an experimental unit built to evaluate $3 \mathrm{P} / 2 \mathrm{~N}$ material in a SINAP 19 configuration. Endurance testing was performed at a thermal input of 570 watts while at Isotopes, and 630 watts since shipment to JPL. The 570 watt input resulted in an operating hot junction temperature of $\sim 900^{\circ} \mathrm{F}$. With a 630 -watt input the hot junction is $\sim 960^{\circ} \mathrm{F}$.

E-I characteristics were determined initially for various thermal power inputs $\left(570,630\right.$, and 700 watts) at a $340^{\circ} \mathrm{F}$ fin root temperature. The curves are shown in Fig. III-31. The maximum power outputs for these power inputs were $26.0,31.1$ and 36.9 watts, respectively. Corresponding hot junction temperatures were $905^{\circ}, 955^{\circ}$ and $1015^{\circ} \mathrm{F}$, respectively.

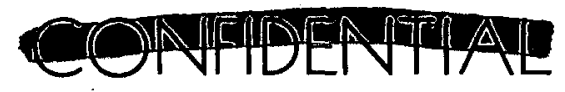



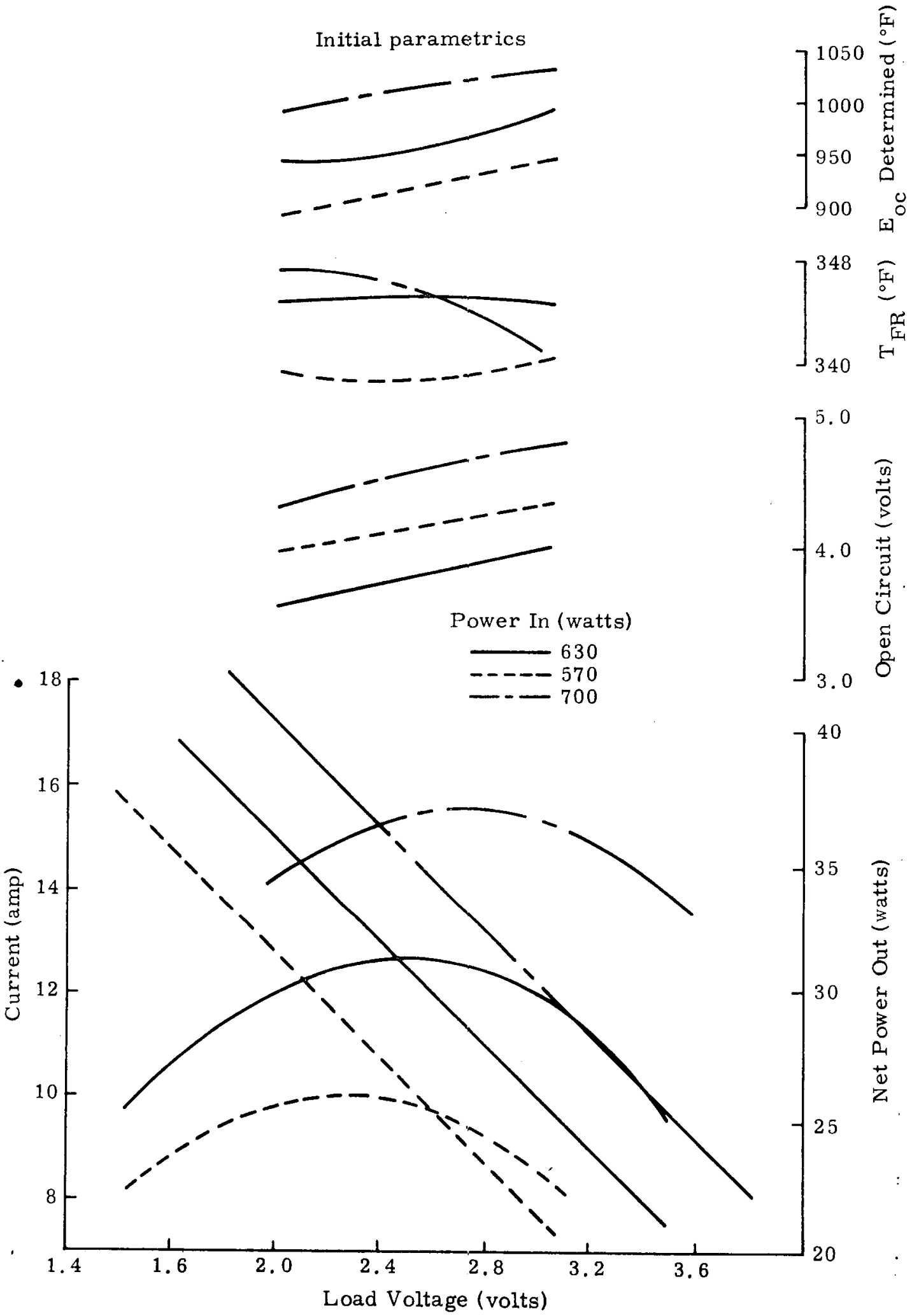

FIG. III-31. SNAP 19 GENERATOR S/N 20

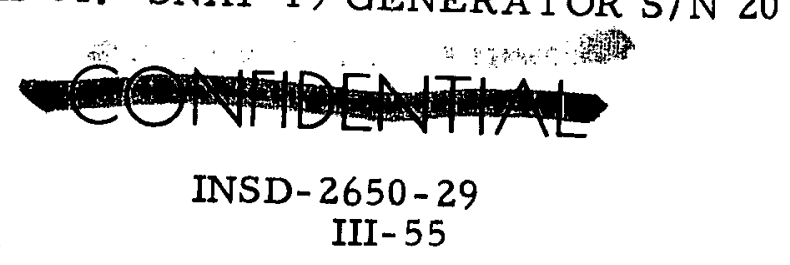


Figure III-32 is a plot of the endurance data during testing at Isotopes. The initial power output was 25.8 watts, decreasing to 24.7 watts at 5235 hours.

It is notable from the data received from JPL, that the 570-watt peak power output, 25.4 watts (Fig. III-33), is approximately that measured at Isotopes when generator testing was discontinued (24.7 watts) at $\sim 5300$ accumulated operating hours. As shown in Fig. III-33, the measured power output at 2.4 volts and a 630-watt power input (the same as that for the Nimbus III generator) is 29.9 watts.

b. SNAP $19 \mathrm{~S} / \mathrm{N} 24$ and S/N 25 generators

Figure III-34 shows the results of acceptance testing performed on the Nimbus III fueled, flight RTG units S/N 24 and S/N 25. Testing was performed in a vacuum chamber in which the chamber wall temperature was adjusted to yield the design fin root temperature of $\sim 354^{\circ} \mathrm{F}$. The peak power outputs at acceptance for the two units were 31.4 and 29.6 watts for the $S / N 24$ and $S / N 25$, respectively. At the writing of this report, S/N 24 and $S / N 25$ have been in earth orbit over two months and produce the same electrical power as just after launch ( $\sim 25$ watts per generator).

c. SINAP 11 generators

Performance data for two SINAP $113 P / 2 N$ generators, $Q / N-1 M$ and Q/N-3, currently on test at Sandia Corporation and JPL, respectively, are presented in Figs. III-35 and III-36. Neither of these generators was intended for endurance testing, thus, data comparison can be made only for instances when similar test points occurred during parametric testing.

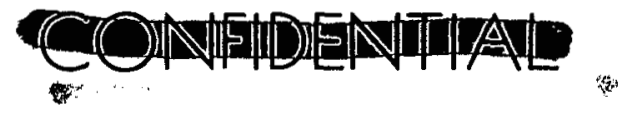

INSD-2650-29 

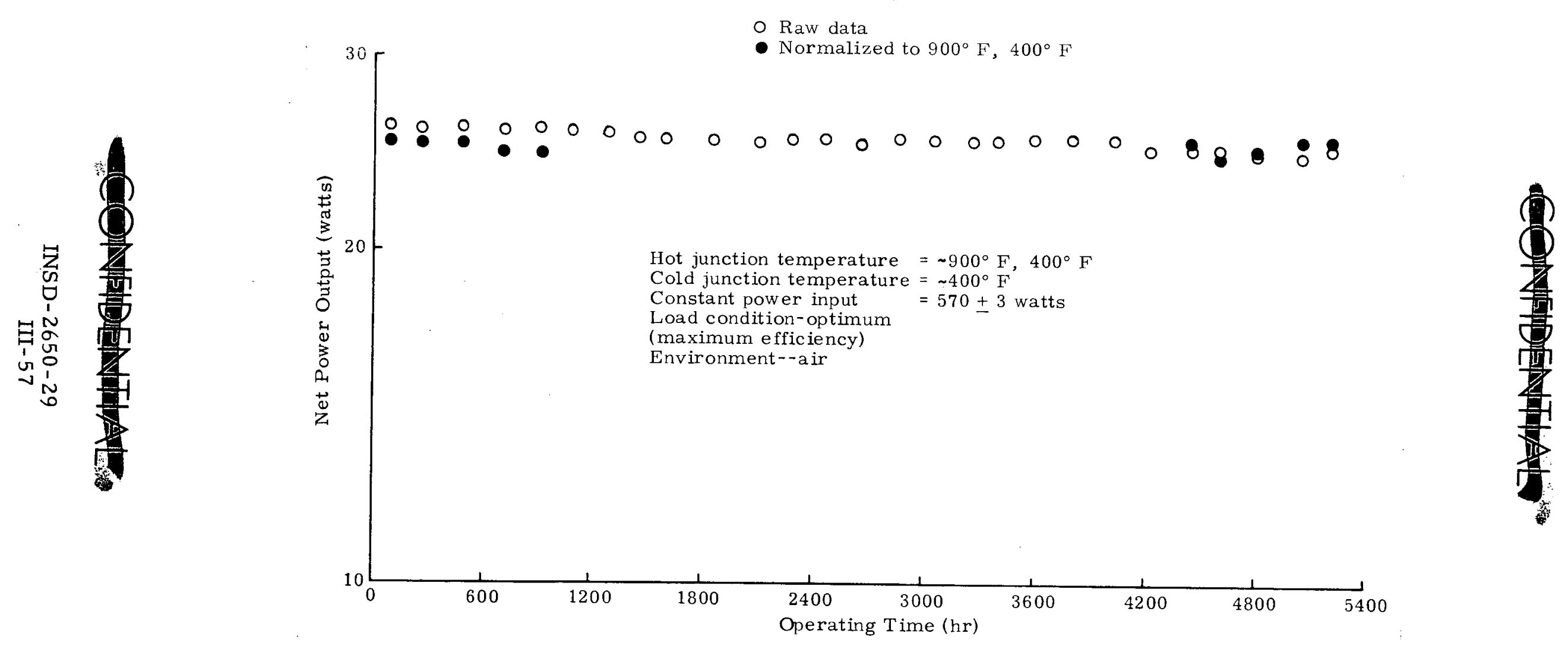

FIG. III-32, SNAP 19 GENERATOR S/N 20 AIR ENDURANCE TEST DATA 3P/2N 


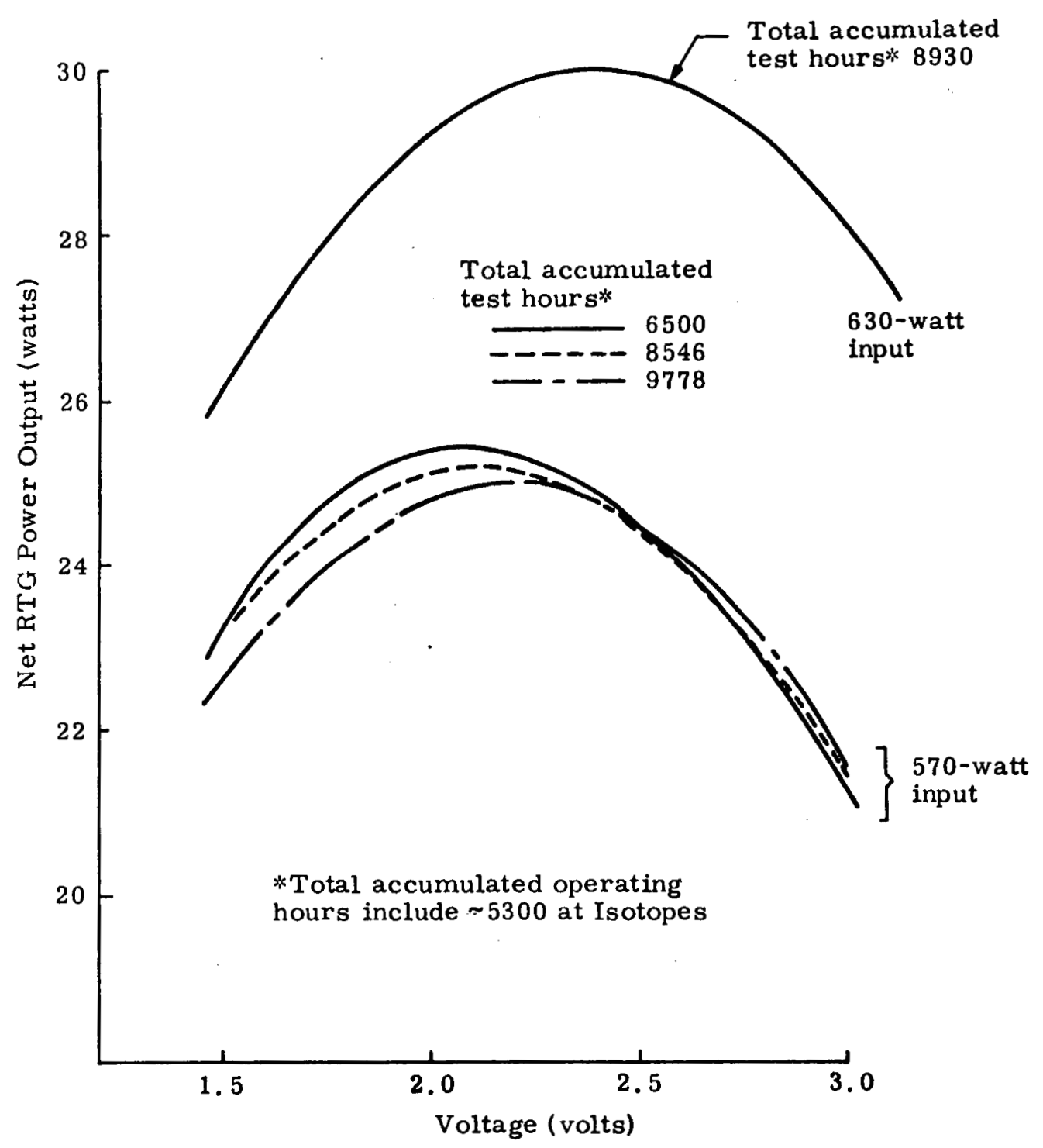

FIG. III-33. RESULTS OF JPL SNAP 19 S/N 20 TESTING

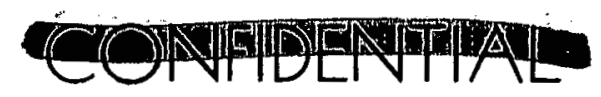

INSD- $2650-29$

III- 58 

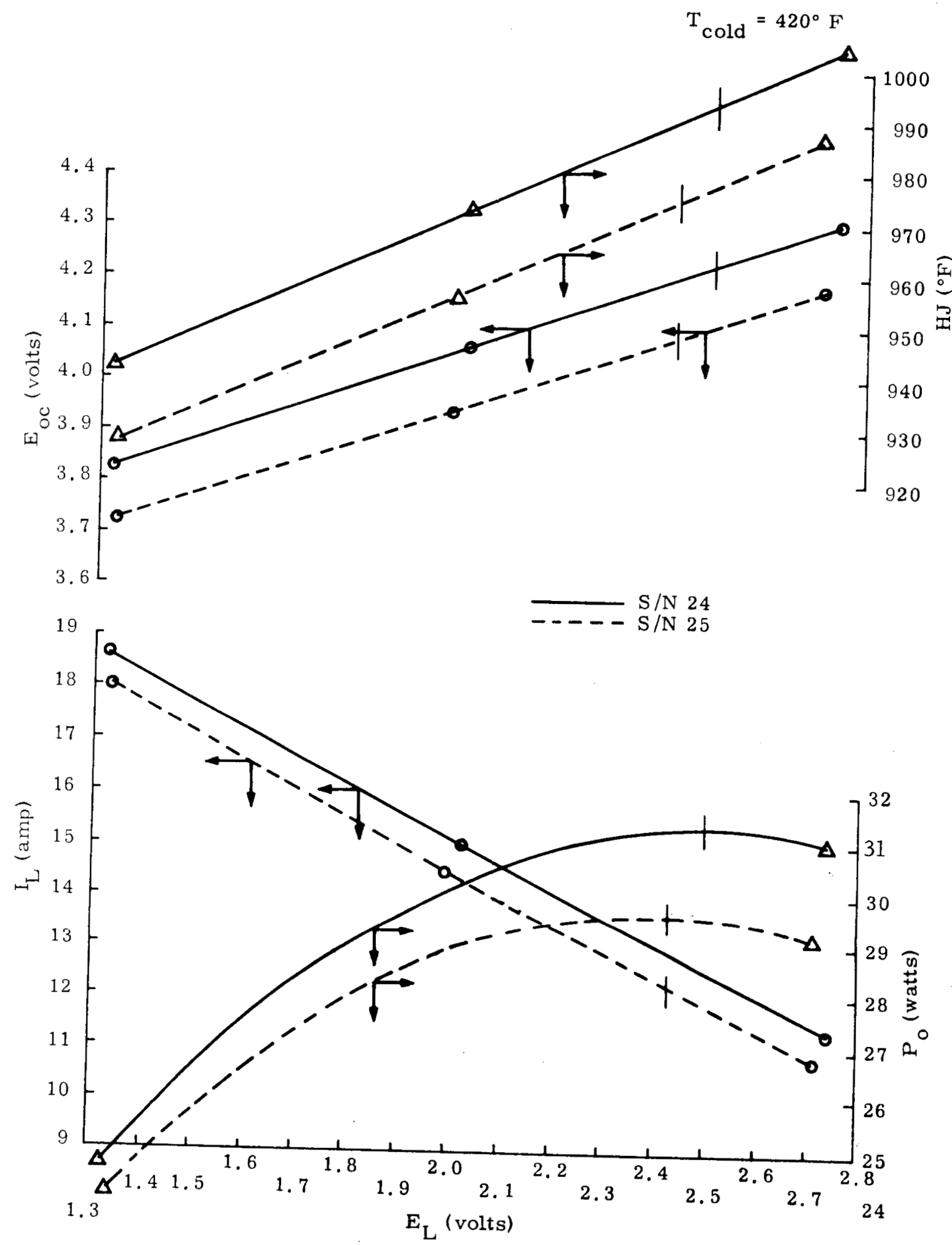

FIG. III-34. SNAP 19 VACUUM TEST E-I DATA FOR SYSTEM 9

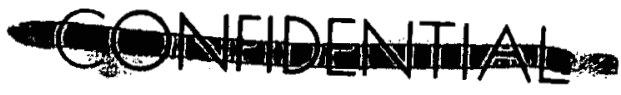

INSD $-2650-29$

III- 59 


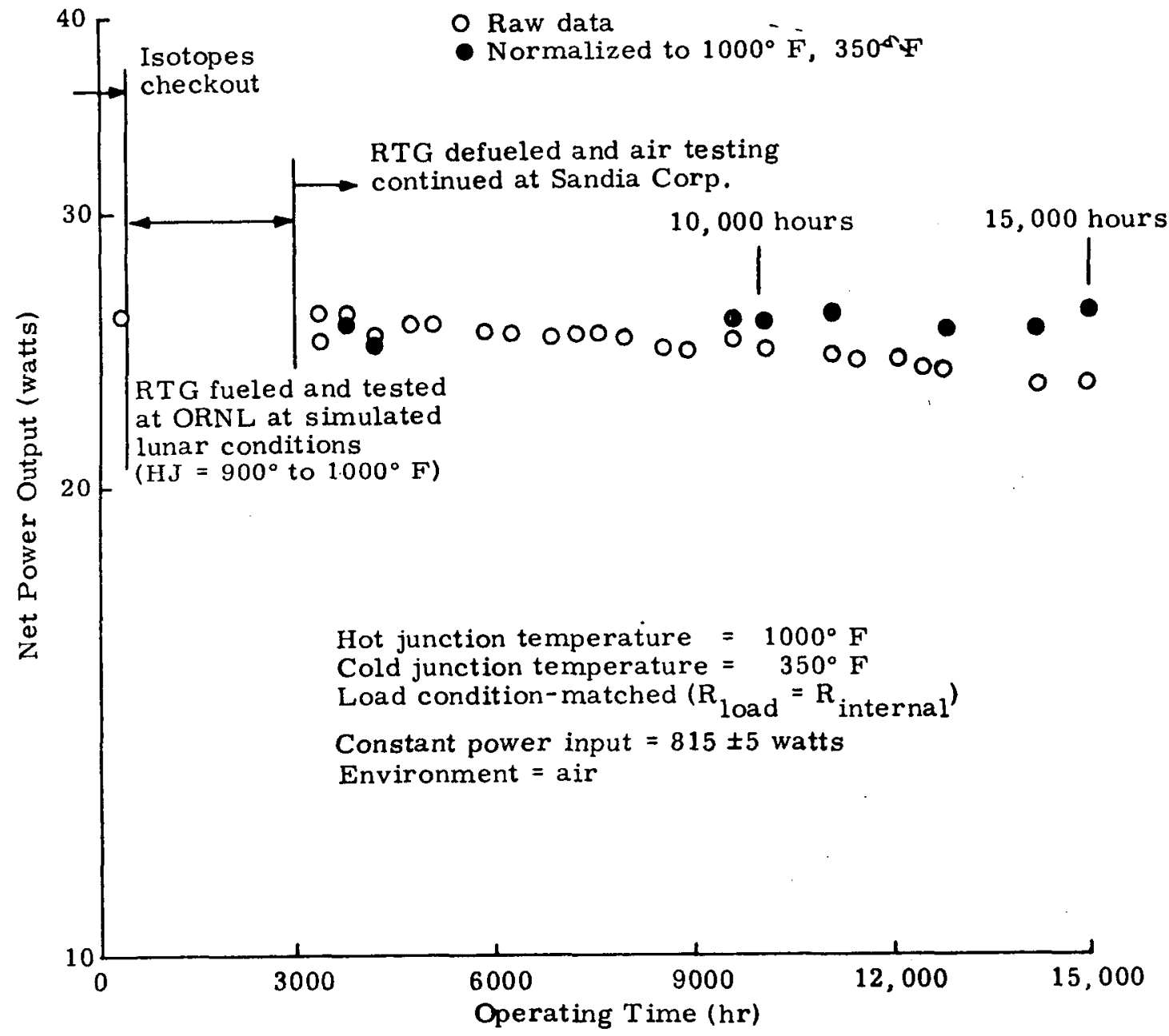

FIG. III-35. SNAP 11 GENERATOR $Q / N-1 M$ TEST DATA 3P/2N

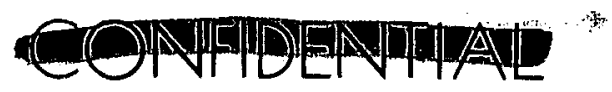

INSD $-2650-29$

III- 60 


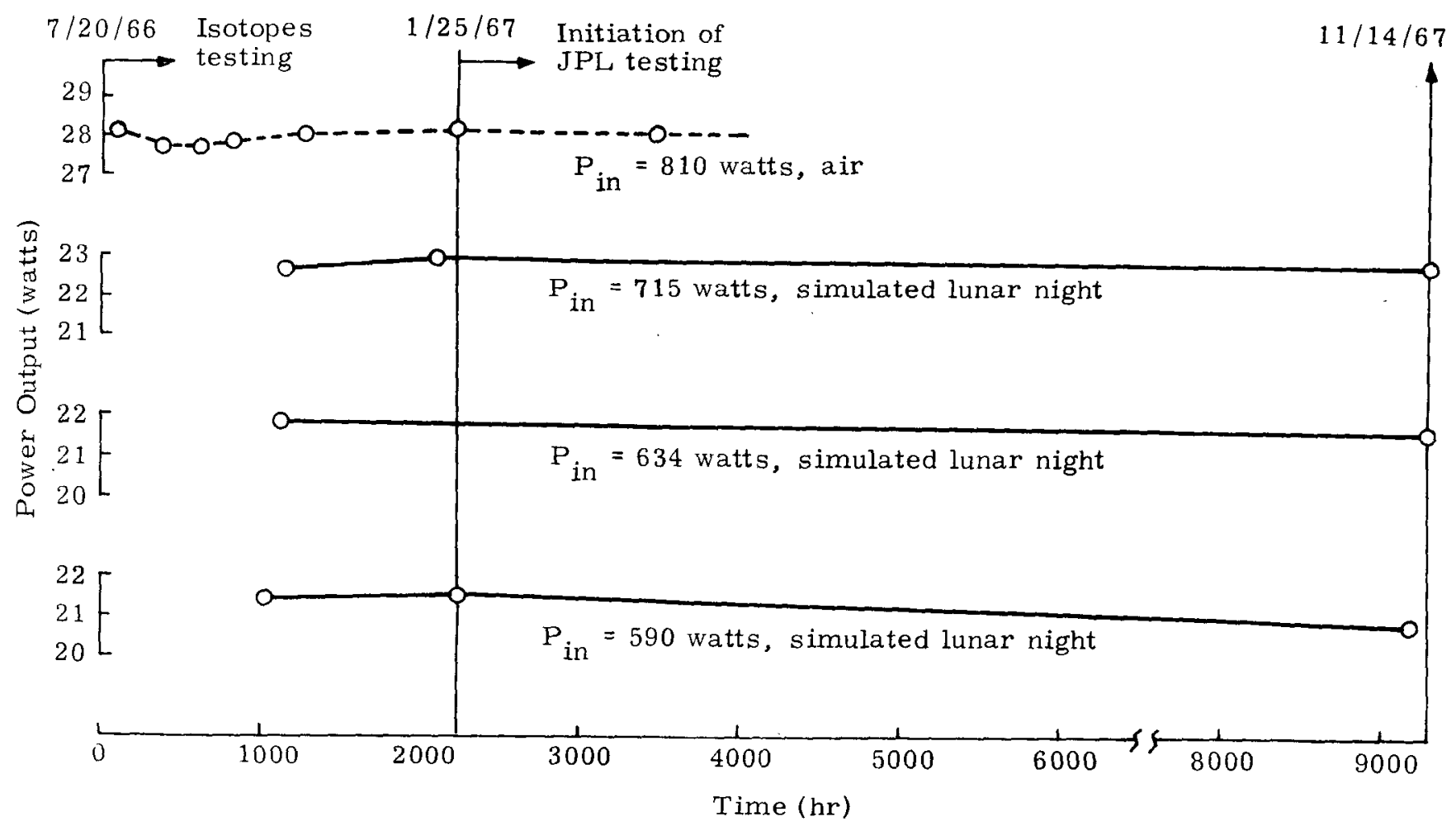

FIG. III-36. SNAP $11 \mathrm{Q} / \mathrm{N}-3$ PERFORMANCE SUMMARY - 3P/2N GENERATOR

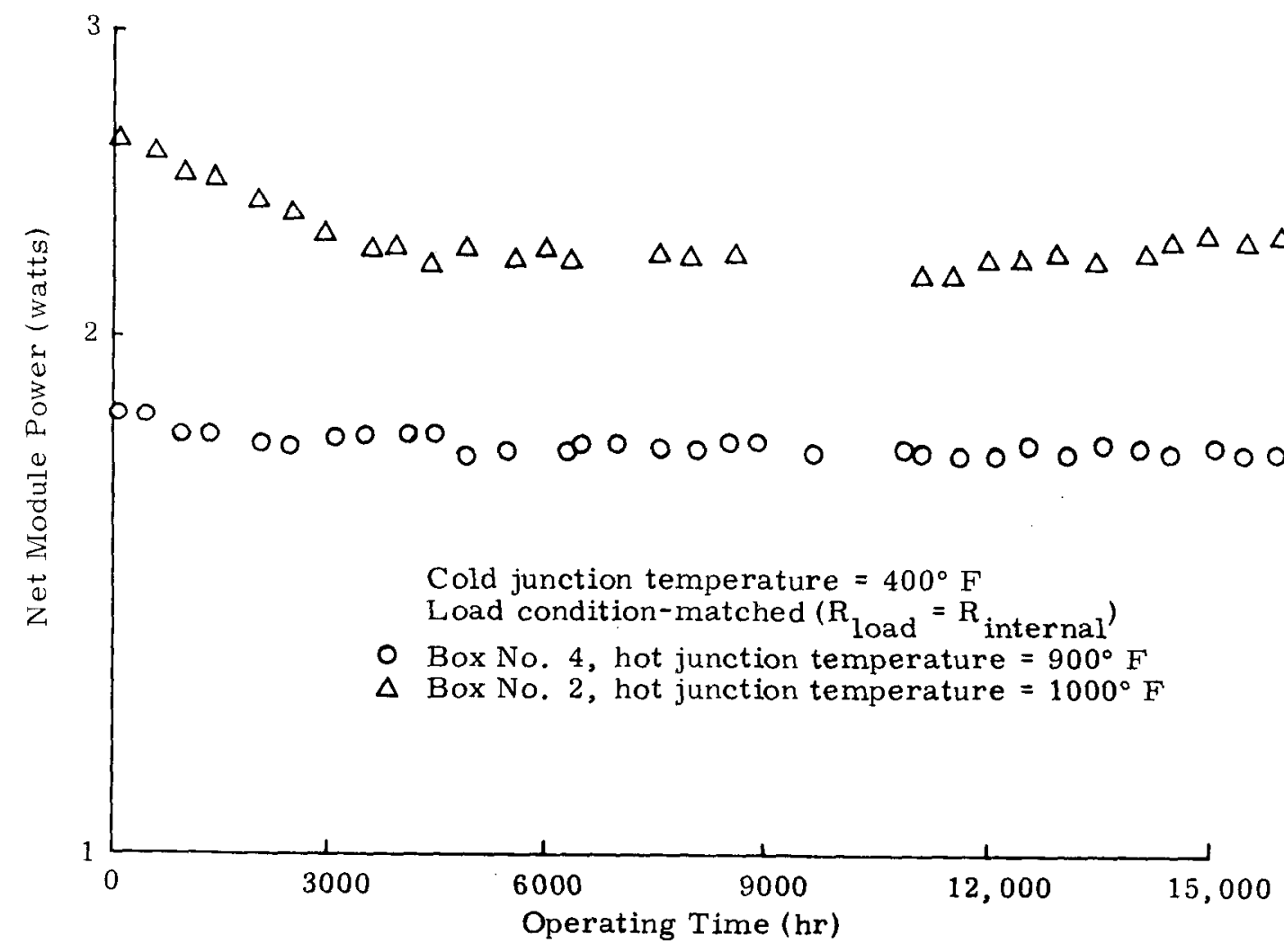

FIG. III-37. POWER VERSUS TIME FOR SNAP 11 MODULE BOXES-3P/2N

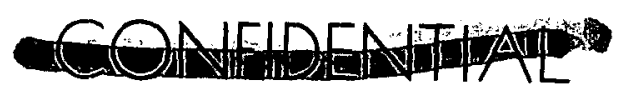

INSD-2650-29

III- 61 


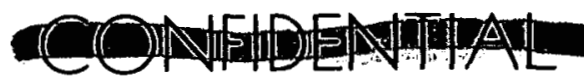

The thermoelectric elements in the SNAP 11 generator are 0.346 inch in diameter by 0.500 inch long; a generator contains a total of 72 thermoelectric couples. This compares with the 0.377 by 0.500 inch long elements and 90 couples in the 3P/2N SNAP 19 generator.

The $Q / N-I M$ generator was a demonstration unit which was fueled at ORNL with a curium-242 heat source and was subjected to a 90 -day simulated lunar mission in a vacuum environment. After successfully completing the simulated mission, the generator was defueled and sent to Sandia Corporation where it is presently on test at a hot junction operating temperature of $\sim 1000^{\circ} \mathrm{F}$ (815 watts power input). Total operating time to date, including all previous Isotopes and ORNL testing, is greater than 18,000 hours. As shown in Fig. III-35, the generator power output has decreased from $\sim 25.8$ to 23.3 watts during the 15,000 hour test time for which data have been published.

The SNAP 11 Q/N-3 generator test data are shown in Fig. III-36 for the first 9300 hours; actual test time is in excess of 18,000 hours. Initial air and vacuum testing was performed by Isotopes; the generator was then shipped to JPL, where it has been subjected to air, vacuum and dynamic testing. (As this generator is undergoing air and vacuum testing, only similar test points can be compared, thus explaining the infrequency of data points in the figure.) Examination of the test points shows that a maximum decrease in power of 0.5 watt has occurred in the generator after 9300 hours of test time. It should be noted that during $\sim 50 \%$ of this test time, the hot junction temperature operated in the $800^{\circ} \mathrm{F}$ range due to the air parametric testing performed, and at tempera-

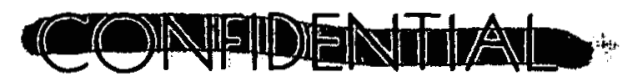


tures in excess of $900^{\circ} \mathrm{F}$ during the remaining $50 \%$ of the test time. Although data are presently not available beyond 9300 hours, communication with JPI has verified that generator performance has remained virtually unchanged during subsequent testing. Testing of this generator at JPL is continuing.

d. SNAP 11 modules

An investigation of the performance of $3 P / 2 N$ thermoelectric couples at hot junction temperatures of $900^{\circ}$ and $1000^{\circ} \mathrm{F}$ was initiated on the SNAP 11 program and later continued on the SNAP 19 program. Two modules, each containing six thermoelectric couples connected in series, were fabricated and tested. The $N$ and $P$ element size $(0.377$ in. diameter by $0.500 \mathrm{in.}$ long) of these couples are the same as for the SNAP 19 generator.

Figure III-37 shows the results of module testing for the $3 P / 2 N$ materials at hot junction temperatures of $900^{\circ}$ and $1000^{\circ} \mathrm{F}$. In these tests the hot junction is maintained at a constant temperature by controlling the power input. Initial power output for the $900^{\circ} \mathrm{F}$ module was 1.81 watts, decreasing to 1.71 watts after $\sim 17,000$ hours. However, power output remained virtually unchanged after the first 3000 hours of operation.

A comparison of the results of these $900^{\circ} \mathrm{F}$ data was made with SNAP 19 generator $S / N 20$. Based on the 5000-hour test data point from the $900^{\circ} \mathrm{F}$ module, the predicted power output of the SNAP 19 generator $\mathrm{S} / \mathrm{N} 20$ is 25.0 watts. This result is in excellent agreement with the actual $S / \mathbb{N} 20$ generator normalized power output (at $900^{\circ}$ and $400^{\circ} \mathrm{F}$ junction

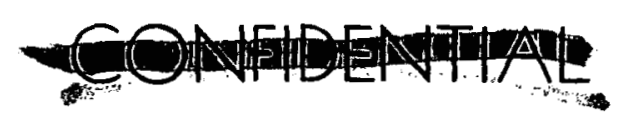

INSD-2650-29

III- 63 


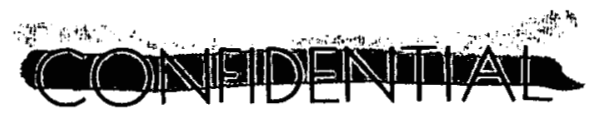

temperatures), being 25.2 watts at $\sim 5000$ hours.

Initial power output for the $1000^{\circ} \mathrm{F}$ box was 2.60 watts, decreasing to 2.25 watts after $\sim 17,000$ hours. Again, power stability was demonstrated after $\sim 4000$ hours of operation.

A comparison of the results of the $1000^{\circ} \mathrm{F}$ module data was made with SNAP 11 generator Q/N-IM. Based on the 15,000-hour test data point from the $1000^{\circ} \mathrm{F}$ module data, the predicted power output of the SIVAP 11 Q/N-IM generator is 26.1. This is in excellent agreement with the $Q / \mathbb{N}$ IM data where the normalized power output (at $1000^{\circ}$ and $350^{\circ} \mathrm{F}$ junction temperatures) is 25.8 watts after $\sim 15,000$ hours of testing.

From these discussions, the ability to correlate generator and module data for $3 \mathrm{P} / 2 \mathrm{~N}$ thermoelectrics is evident.

\section{e. SNAP 29 moduies}

The design hot and cold junction temperatures of the SNAP 29 $3 \mathrm{P} / 2 \mathrm{~N}$ modular generator are $1050^{\circ}$ and $350^{\circ} \mathrm{F}$, respectively. Figure III-38 shows the normalized (to $1050^{\circ} \mathrm{F}$ hot junction; $350^{\circ} \mathrm{F}$ cold junction) power histories of typical SNAP 29 modules. Operating times up to 7000 hours have been accumulated, with power decreases on the order of $8 \%$ noted. The data trend indicates the power output to the stabilizing in the 5000 to 6000 hour test period.

\section{Mechanical Properties}

In handling and working with TAGS elements, it is obvious that the mechanical properties of the material are superior to the P-type lead tellurides. In order to compare the mechanical strength of the two

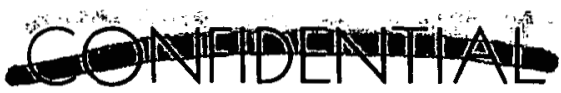

INSD-2650-29

III- 6 辛 


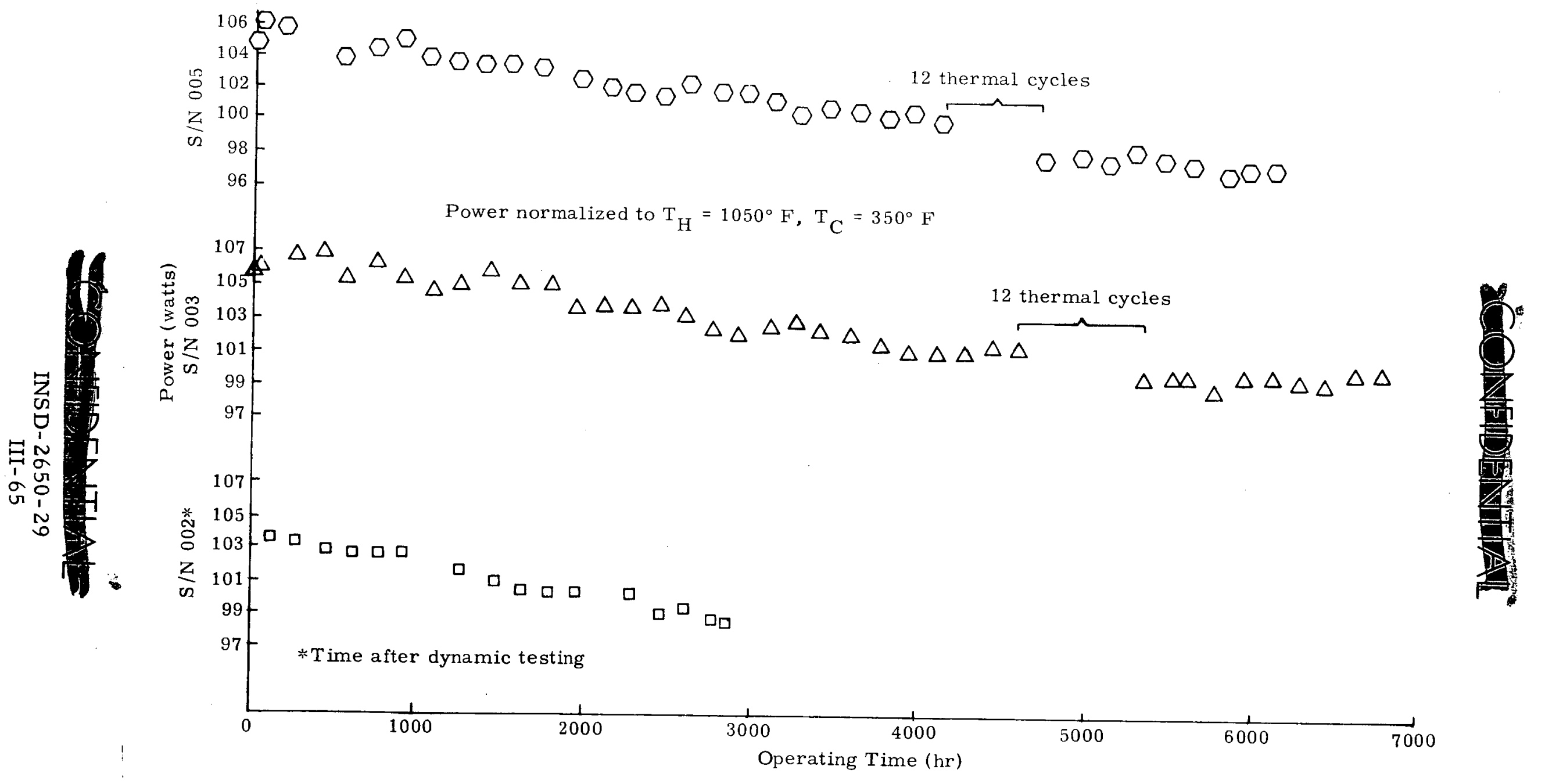

FIG. III-38. SNAP 29 SPRING PISTON MODULES TEST HISTORY 
materials more quantitatively, several tests were performed. Both cast and hot pressed TAGS samples were used while cold pressed and sintered PbTe (purchased from 3M) was used. Three types of tests, tensile tests with couples and compression and drop tests with elements, were performed. The tensile tests were performed by bonding metal hooks to the cold caps of the couple, restraining the shoe in a fixture and then applying a tensile force until the thermoeouple leg was pulled apart. The drop tests were subdivided into two types; in one case elements were dropped onto a steel ball, and in the other case the ball was aropped onto the element. The compression test consisted of placing an element between the platens of a hydraulic press and compressing it until failure occurred.

Table III-12 shows the results of the tensile tests on couples. All of the couples subjected to this test were operated 100 hours prior to testing. The couples used in these tests were from production lots, and the two groups were run at different times. The validity of the test is indicated by the near duplication of the average value of the pressure required to pull off the $\mathbb{N}$-leg of each lot. Of the twelve N-legs removed, eleven broke in the bond and only one broke in the element, indicating the relative strength of the two. There is a dramatic difference between the average strengths displayed between the TAGS and 3P, a factor of five. The difference is all the more emphasized by the fact that all six TAGS couples broke at the bond while all but one of the 3P couples broke in the elements. Further, the data

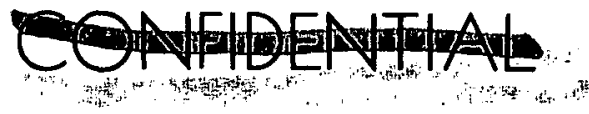




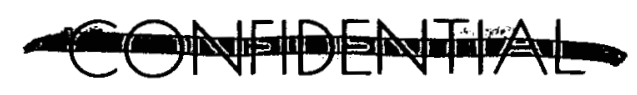

\section{TABLE III-12}

TENSILE TTESTS ON SNAP 29 COUPLES

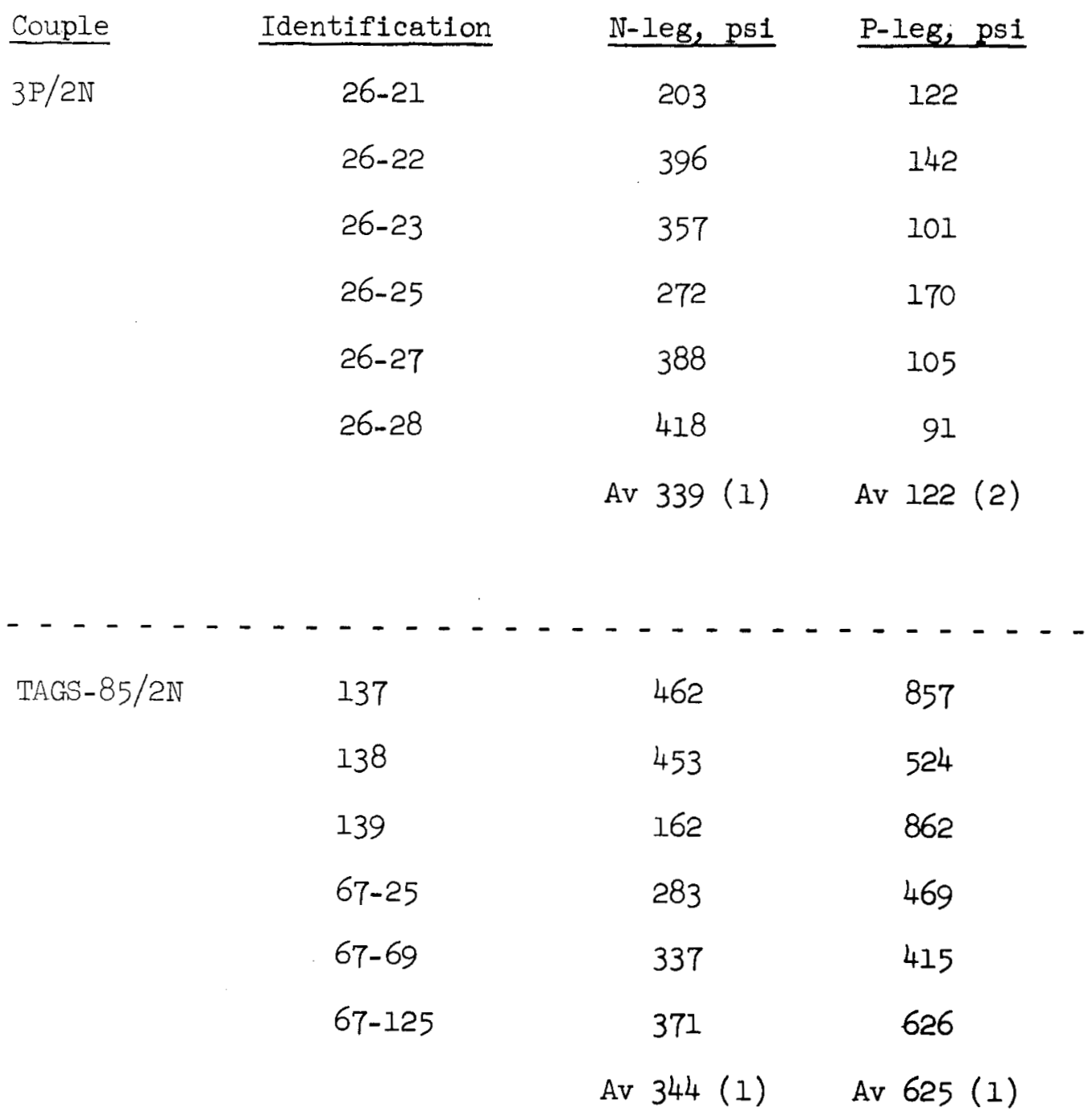

\footnotetext{
(1) Characterized by bond-failure

(2) Characterized by element-fallure
}

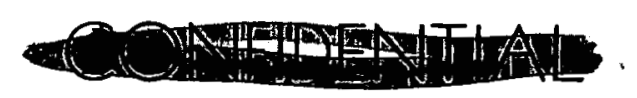

INSD-2650-29

III- 67 


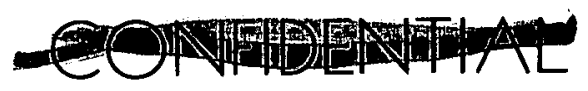

indicates that the TAGS bond is superior to the 2N bond by a factor of two. No quantitative statement about the relative strengths of TAGS and 2N can be made, but a qualitative indication results from the fact that TAGS has withstood a factor of two tensile load without failure. Finally, both TAGS and $2 \mathrm{~N}$ are clearly superior to $3 \mathrm{P}$ in tensile loads. Two types of drop tests were conducted. Type 1 consisted of dropping the element a known distance onto a steel ball embedded in a wooden block. The impact area on the element was controlled by dropping the element inside a glass tube located over the ball. Type 2 was similar to type 1 except that the ball was dropped onto the element. The steel ball weighed 24.7 grams and was dropped a distance of $4-\frac{1}{2}$ inches. The element was placed on a Transite block one inch thick.

Figure III-39 and Table III-13 show the results of the type 1 drop test. In Fig. III-39 the first hot pressed TAGS-85 sample shows the impact spots on the element surface. This element was dropped with the bottom of the tube approximately one inch above the steel ball. As a result, the element cocked as it emerged and was not struck in the center; it chipped at the edges. The other two elements were centered when they struck the ball (the impact mark is on the bottom) and no failure occurred after five drops. The element bounced when it struck the ball. The PbTe elements show impact points and fractures after only one drop. The cast TAGS-85 elements were dropped five times and only one split on the fifth drop.

New PbTe elements were used in the type 2 test, but the TAGS-85 elements which survived the type 1 test were reused. The results are

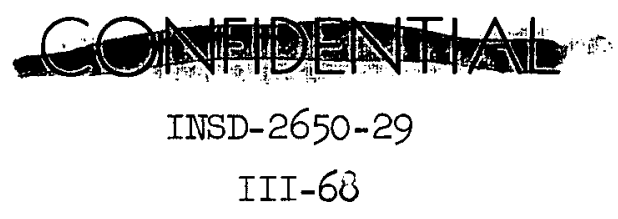


TAGS -85

Hot Pressed
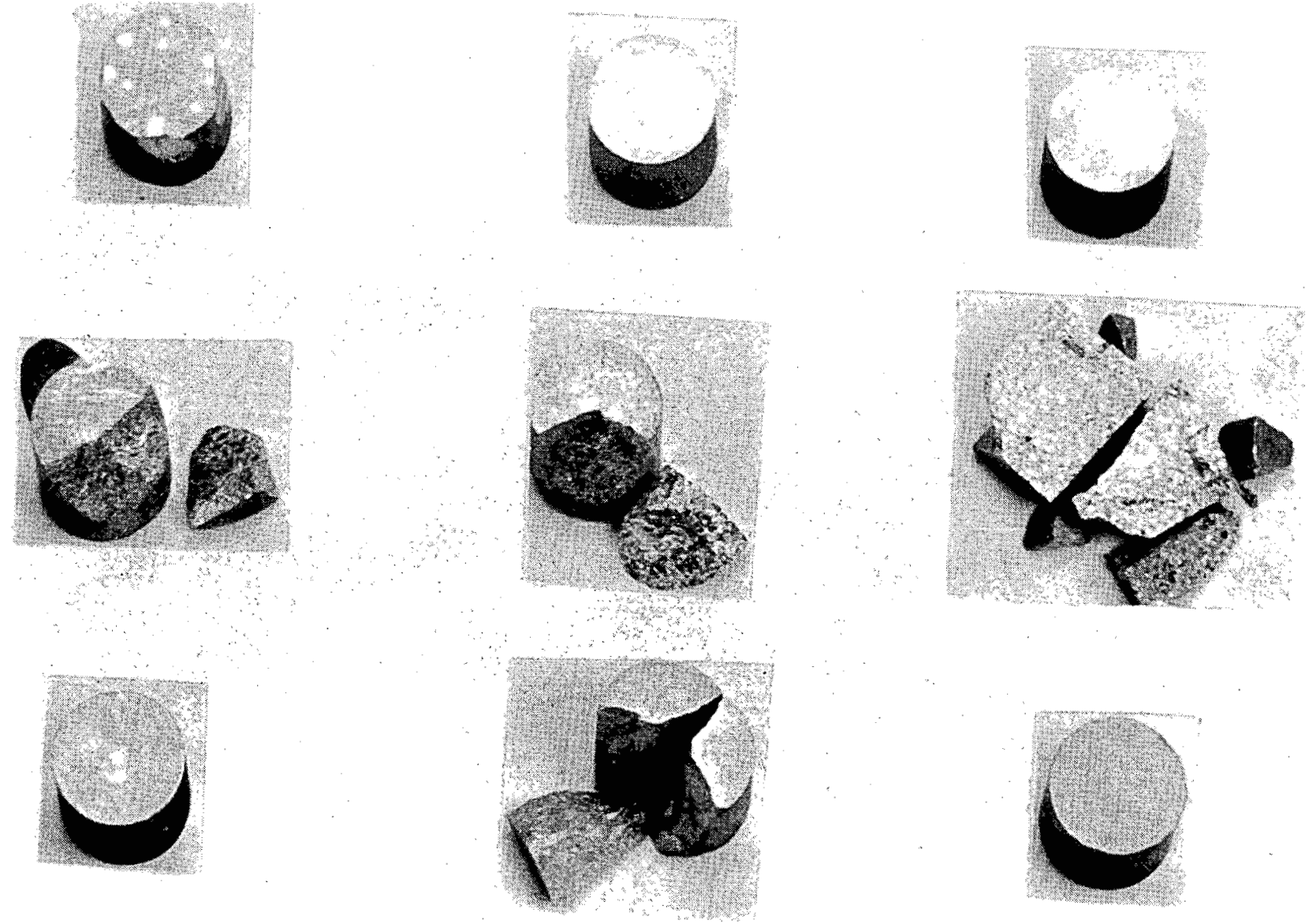

TAGS-85 Cast
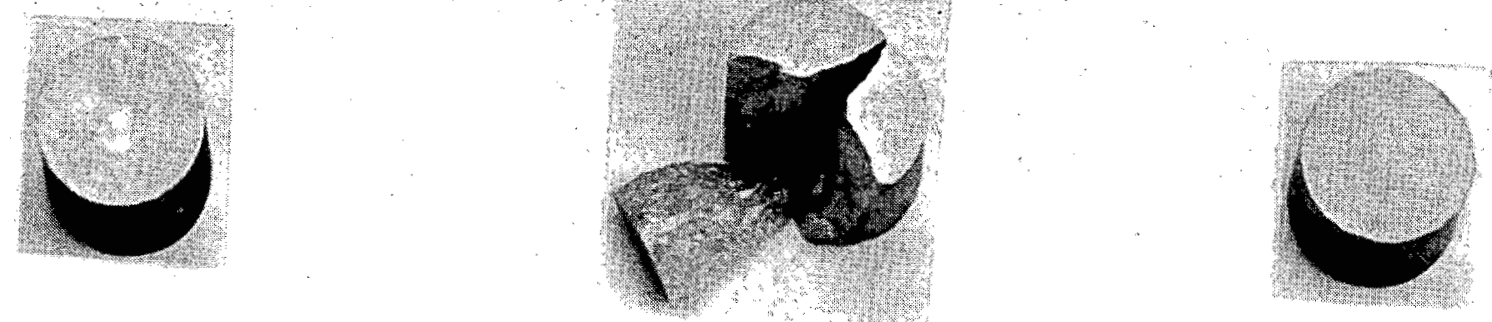

FIG. III-39. APPEARANCE OF DROP TEST SAMPLES (ELEMENT DROPPED 12 INCHES ONTOST 
TABLE III-13

DROP TESTS OF TAGS AND LEAD TELLURIDE

Element dropped on steel ball

Drop height 12 in.

Material

\begin{tabular}{|c|c|c|c|}
\hline $\begin{array}{l}\text { Diameter } \\
\text { (in.) }\end{array}$ & $\begin{array}{l}\text { Length } \\
\text { (in.) }\end{array}$ & $\begin{array}{l}\text { Drop } \\
\text { No. }\end{array}$ & Remarks \\
\hline
\end{tabular}

TAGS- 85

$0.380 \quad 0.435$

5 Chipped on edges; element

(hot

pressed)

TAGS- 85

(cast)

$0.374 \quad 0.444$

$$
\text { not hitting in center }
$$

5 No failure

5 No failure

5 No failure

5 No failure

5 No failure

5 Cracked on 5th drop

5 Cracked on 5th drop

$\mathrm{PbTe}$

0.380

0.445

5 Chipped on edge

(2P)

1 Large chip off top

1 Large chip off top

2 Cracked, then split

INSD-2650-29

III-70 


\section{TABLE III-13 (Continued)}

24.7-gm steel ball dropped on element Drop height 4.5 in.

\begin{tabular}{|c|c|c|c|c|}
\hline Material & $\begin{array}{c}\text { Diameter } \\
\text { (in.) }\end{array}$ & $\begin{array}{c}\text { Length } \\
\text { (in.) }\end{array}$ & $\begin{array}{l}\text { Drop } \\
\text { No. } \\
\end{array}$ & Remarks \\
\hline \multirow[t]{4}{*}{ *TAGS- 85} & & & 5 & No fallure (hot pressed) \\
\hline & & & 5 & No fallure (hot pressed) \\
\hline & & & 5 & No failure (hot pressed) \\
\hline & & & 1 & Split on lst drop (cast) \\
\hline \multirow[t]{4}{*}{ PbTe } & 0.380 & 0.410 & 2 & Cracked on 1st drop; split \\
\hline & & & 2 & Cracked on lst drop; split \\
\hline & & & 2 & Cracked on lst drop; splet \\
\hline & & & 2 & Cracked on lst drop; split \\
\hline
\end{tabular}

*Samples from type 1 test

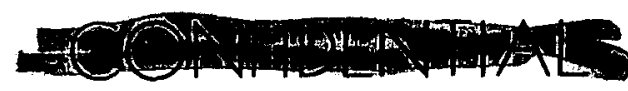

INSD-2650-29

III-7 I 
tabulated in Table III-13. The PbTe and cast TAGS-85 samples split and cracked after one or two drops of the ball. None of the hot pressed TAGS samples failed.

A rather striking difference was noted in the compressive strength of TAGS versus $2 \mathrm{P}$ and $3 \mathrm{P}$ PbTe as shown in Table III-14. In most.instances, as the pressure increased, the element chipped and fractured along the outer edges and failure occurred by massive cracking or shear.

Figure III-40 shows some of the TAGS-85 and PbTe elements after test. Note the completeness of fracture in the $\mathrm{PbTe}$ elements. These elements sheared and crushed at almost the same pressure that first indicated failure was occurring. On the other hand, the TAGS material showed large differences in pressure from the time edge cracks (usually at a pressure higher than that at which the PoTe elements failed) first appeared to the time when final failure occurred. Note also that only two samples failed in a manner similar to the PbTe elements. The other samples did not shear but chipped along the longitudinal axis. The important items to note are the much higher compressive strengths of both cast and hot pressed TAGS compared to $2 \mathrm{P}$ and $3 \mathrm{P} \mathrm{PbTe}$ and the shattering type failure of the lead tellurides to a more gradual edge-chipping failure as shown in Fig. III-40.

The semi-quantitative conclusions that can be drawn are as follows:

(1) Hot pressed TAGS-85 samples are mechanically superior to the cast TAGS-85 used in these tests. However, new casting techniques are producing elements with mechanical properties similar to hot pressed elements.

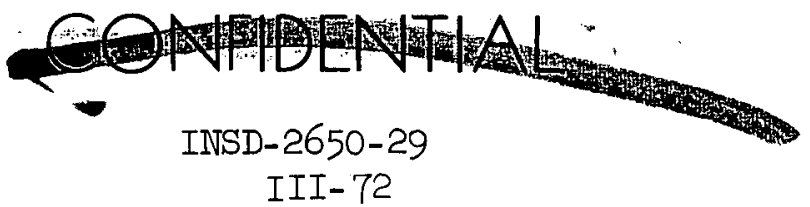




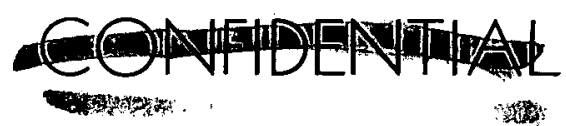

TABLE III-14

COMPRESSION TESTS OF TAGS AND LEAD TELLURIDE

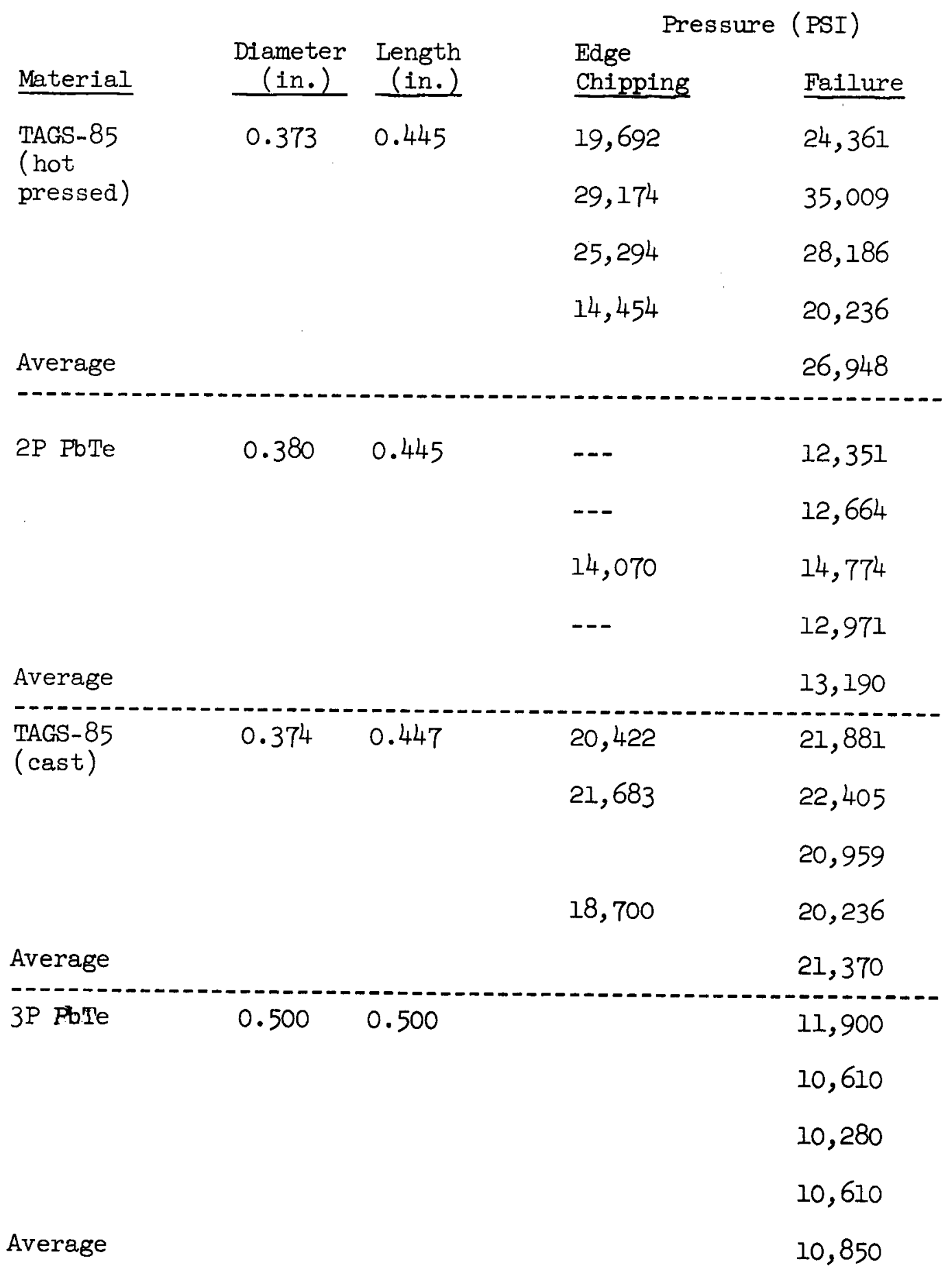



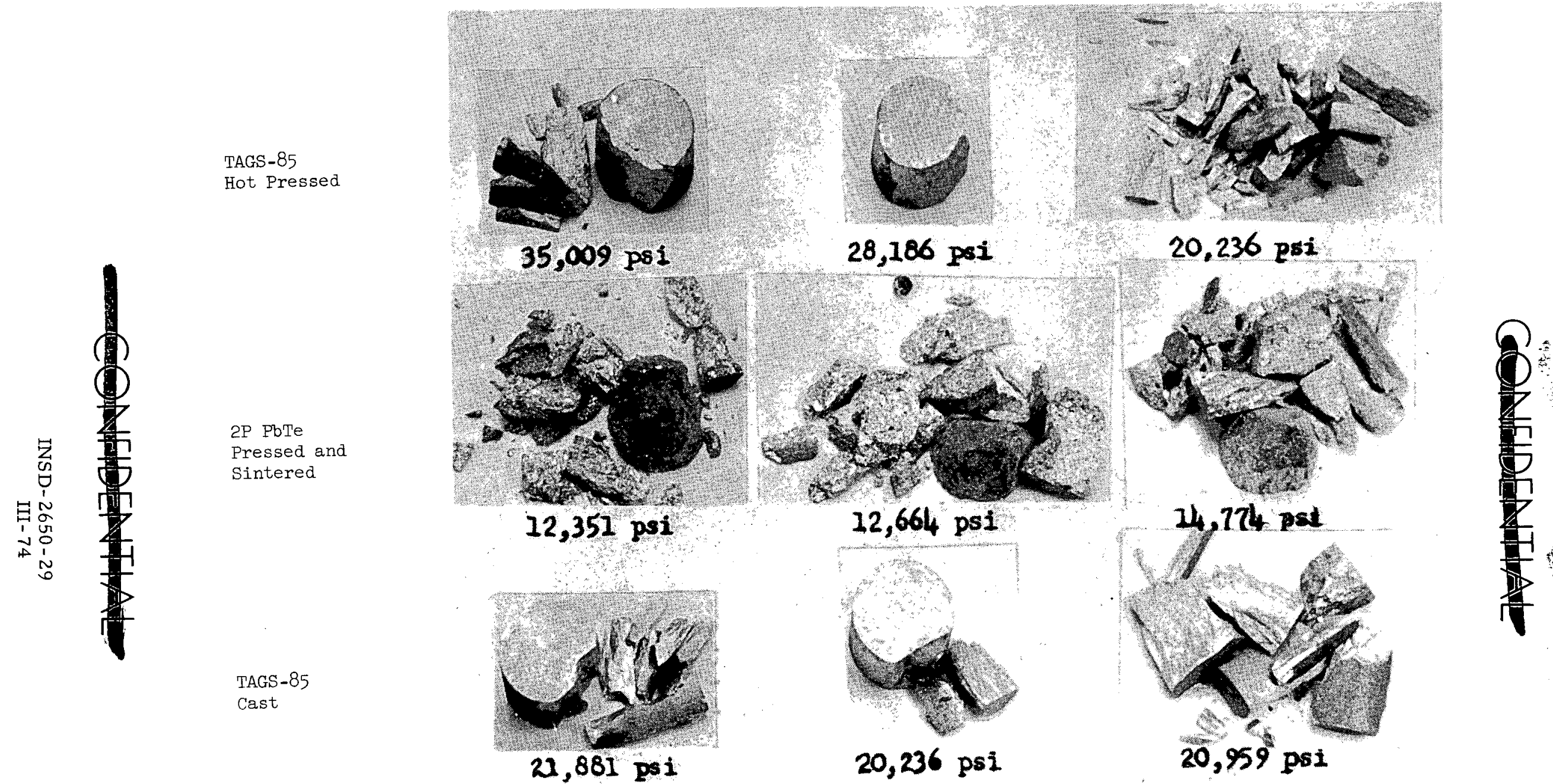

FIG. III-40. APPEARANCE OF COMPRESSION TEST SAMPLES 


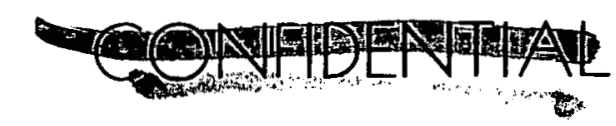

(2) Both hot pressed and cast TAGS-85 are superior to cold pressed and sintered $2 P$ and $3 P$ lead telluride.

\section{Sublimation}

The relatively high vapor pressures with attendant high sublimation rates of thermoelectric materials is a well-known phenomenon. Table III-15 provides a comparison of the vapor pressures of some thermoelectric materials of interest.

\section{TABLE III-15}

VAPOR PRESSURES OF SOME THERMOELECTRIC MATERIALS

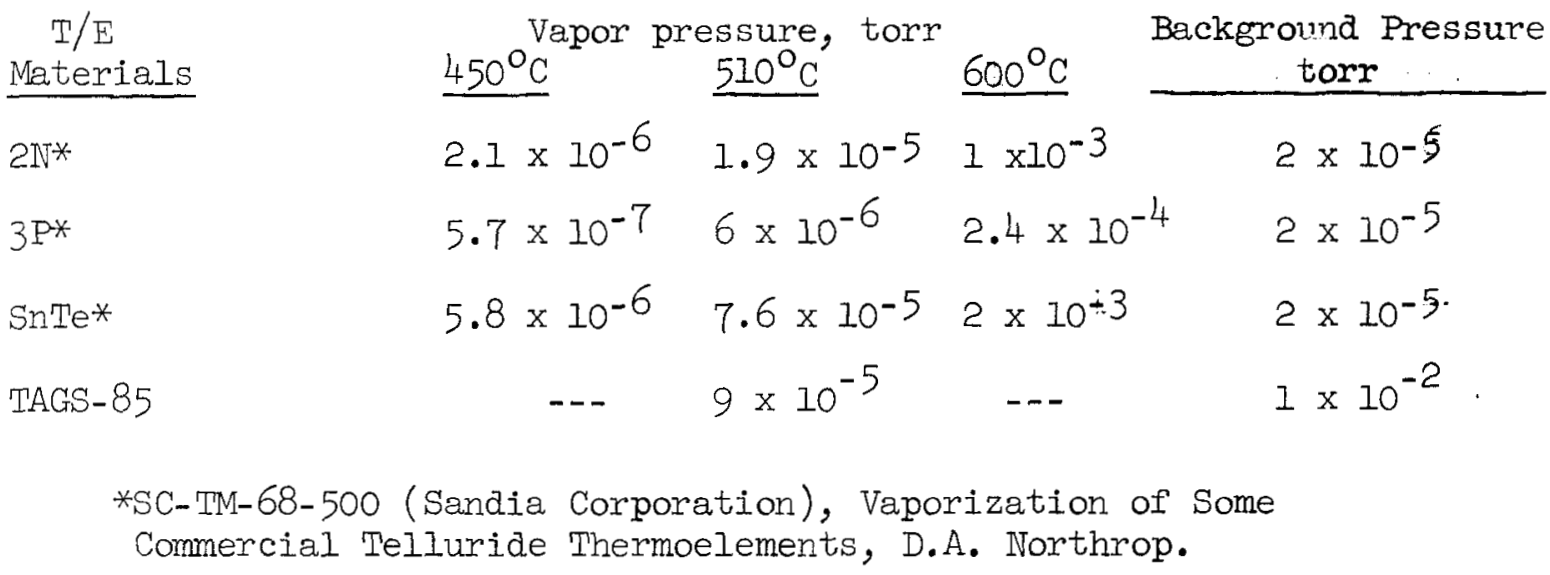

Inspection of the data shows that thermoelectric materials occupy a rather small vapor pressure range which is much higher than the ordinary structural materials at comparable temperatures. The vapor pressure of TAGS85 was determined at a higher background pressure than the other materials shown. A determination at the equivalent background pressure would show a somewhat higher vapor pressure for TAGS-85.

Control of sublimation can be effected by appropriate generator design considerations. Specifically with a minimum internal pressure

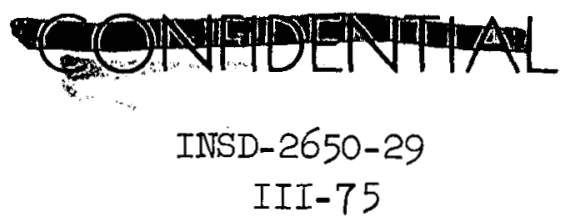




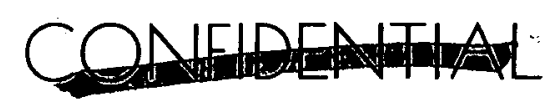

of 2 psia maintained throughout the life of the mission and with Microquartz or a similar material packed loosely into the annular spacing between the elements and the Min-K 1301 insulation, sublimation of the thermoelectric materials may be reduced to insignificance.

Atoms of the inert cover gas interfere physically with molecules escaping from the surfaces of the thermoelements by reducing the mean free path of the molecules. The path reduction is a function of the cover gas pressure and to some extent its atomic weight. A notable example of the effectiveness of this means of reducing material losses under similar conditions is the krypton filled high wattage incandescent lamp. Such a lamp has a life of about 2500 hours compared to minutes if the filament was exposed to a hard vacuum. A second and more effective means of reducing sublimation is obtained by filling the annular space with loosely packed Microquartz. In this instance a physical interference is again provided, but in this particular case the subliming species thermselves as well as the fibrous Microquartz combine to reduce the mean free path of the subliming molecules to a much greater degree than the cover gas alone.

Evidence which provides strong support for the above conclusions comes from the operational experience of the SNAP 9A generator on-board the Transit Satellite 1963-49B launched December 1963. Data from this satellite indicate the internal pressure to be a "hard vacuum" after two years in orbit. There is, however, reason to suspect that a low internal pressure still exists. Therefore, with a slight internal pressure and,

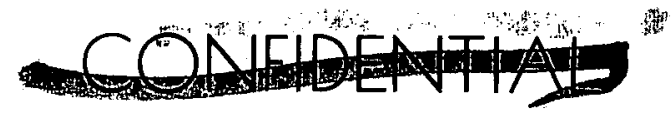




\section{HOFENTHAR}

significantly, no fibrous material packed into the annular space between the elements and the Min-K 1301 insulation, the generator remains operational $5-1 / 2$ years after launch, despite $3-1 / 2$ years at a minimal $(<1$ psi) internal pressure. 
This section presents the results of generator fill gas management studies for a Viking RTG. Fuel inventories of 625 and 675 watts were considered in conjunction with helium release rates ranging from 0 to $100 \%$ of the theoretical value generated during fuel decay. Generator seal tightness* was also varied Irom $0.01 \times 10^{-5}$ to $5.0 \mathrm{x}$ $10^{-5} \mathrm{scc} / \mathrm{sec}$. This tightness range encompasses actual SNAP 19 generator hardware ( ranges from 1 to $5 \times 10^{-5}$ ) as well as alternate generator designs with twin seals, metal seals or welded housings. The model used for these analyses is discussed below.

\section{Analytical Model}

The multi-gas permeability model used for generator pressure and gas composition predictions is illustrated in Fig. III-4l. For a given generator void volume and average gas temperature $\left(V_{G}\right.$ and $\left.T_{G}\right)$, the relationship between partial pressure of the gases considered and permeation rates across soft seals can be expressed as

$Q=B \times C \times \Delta P \quad$ where

$Q=$ rate of a permeating gas, $\mathrm{scc} / \mathrm{sec}$

$B=$ permeability constant for the gas at the seal temperature considered

$\mathrm{C}=$ installation tightness factor of the seal, $\mathrm{cm}$

$\Delta P=$ partial pressure difference across the seal, atm.

* Referenced to $337^{\circ} \mathrm{F}$ seal temperaturé and one atmosphere differential argon pressure.

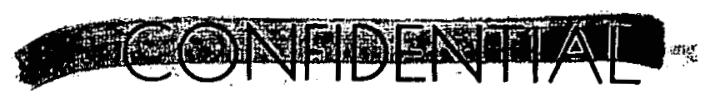



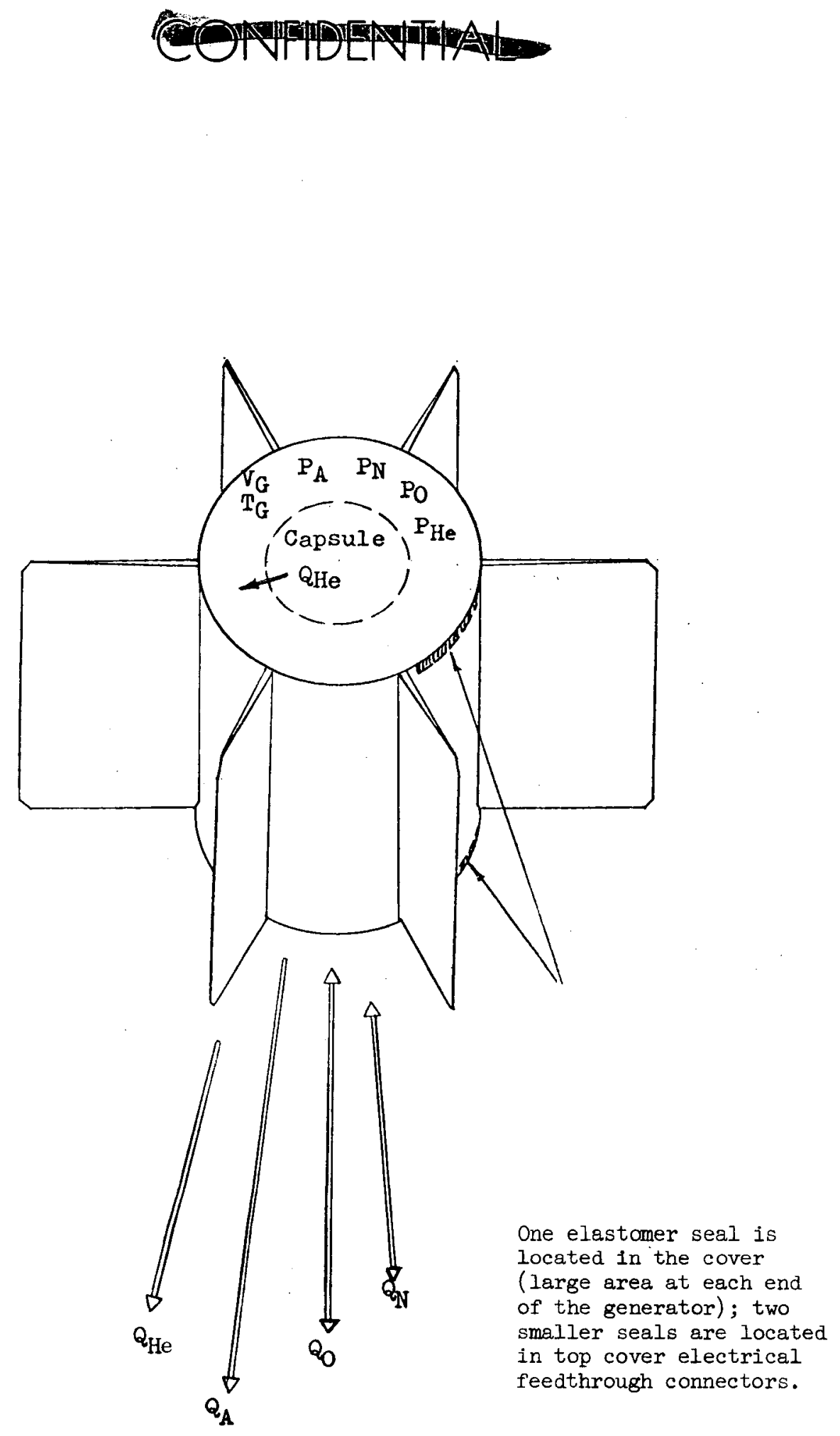

FIG. III-41. MULTIGAS PERMEATION MODEL

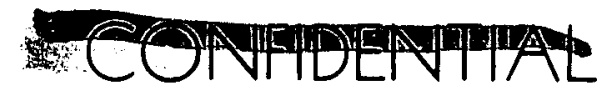

INSD-2650-29

III-79 
The resistance of the elastomer to gases is defined by $B$ whereas the configuration match between seals and grooves is given by $C$. nnly $Q$ and $\triangle P$ are time variables. The partial pressure inventories are calculated and adjusted with time by iterative computer routines which also consider the replenishment of helium gas in the generator through gas release from the fuel capsule. Possible sources of error lie in assumed relationships between permeability constants of the various gases with seal temperature, in the measurement of the seal installation tightness factor (determined from hot argon leakage tests on previous SIIAP 19 generators), and in the assumption that helium discharge from the capsule is essentially constant through the mission period. Seal permeability and seal tightness are discussed in Ref. TII-1. The excellent correlation of generator $S / N 20$ pressures by this model (using initial conditions of leak rate and pressure and the timetemperature-ambient gas history of the seal as input) is illustrated in Fig. III-42. Generator $S / N 20$ is currently undergoing thermal vacuum tests at Tet Propulsion Laboratory.

In general, correlation between data and prediction has been good for both the SNAP 19 endurance test generators (where helium leakage was not a factor) and for the flight SIAP 19 Nimbus III generators. In the latter case, good agreement was obtained by assuming a helium release rate of $96 \%$ of the theoretical helium production rate as illustrated in Fig. III-43. The 50\% release rate pressure profile is also shown. Tf the lower release rate $(50 \%)$ had been experienced, pressure would

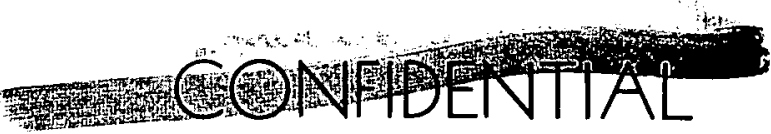




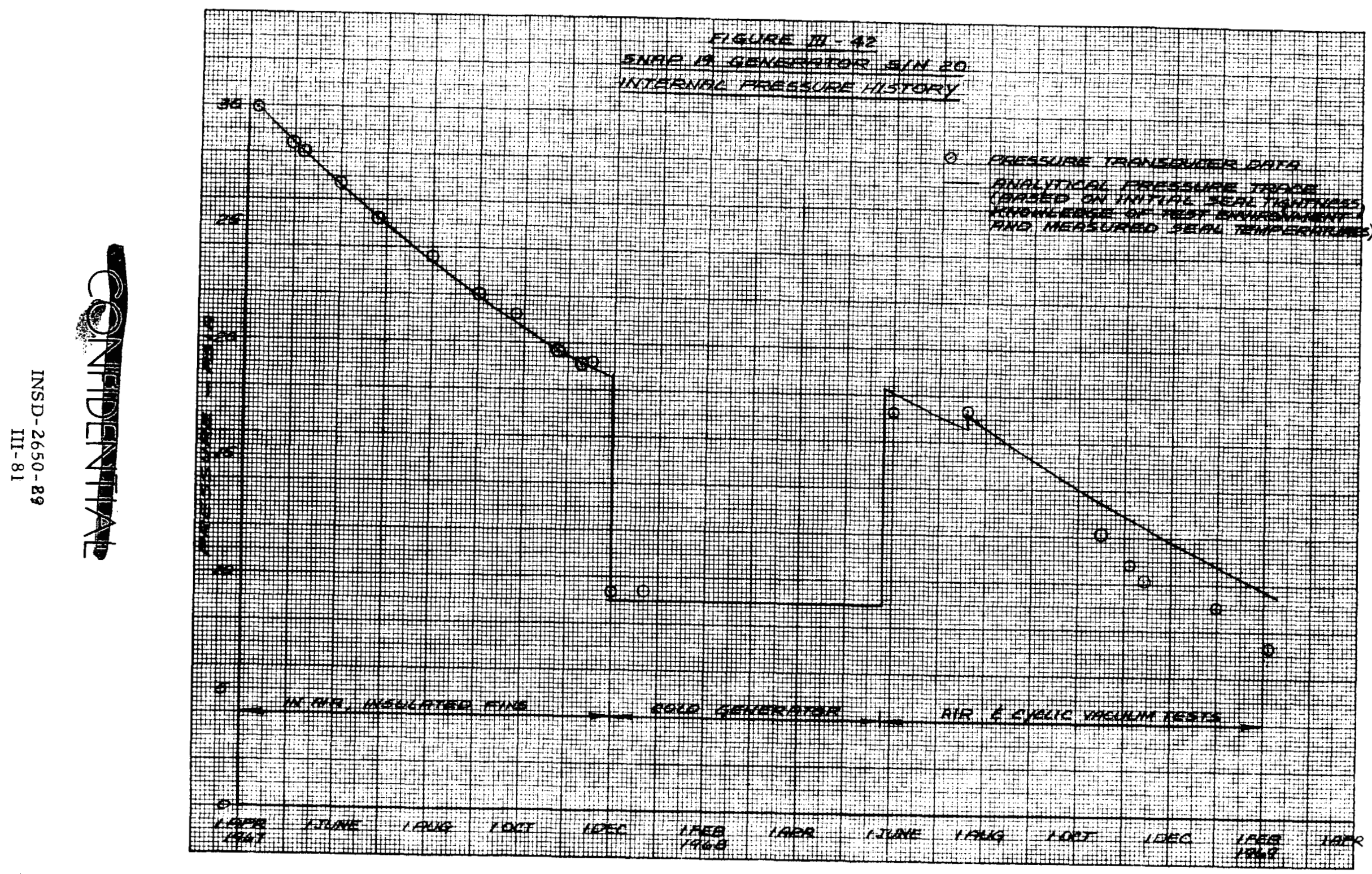


FIGURE II - 43

SNAP 19 NIMEUS III. SENERATOR

INTERNAL PRESSUAE PREDICTIONS

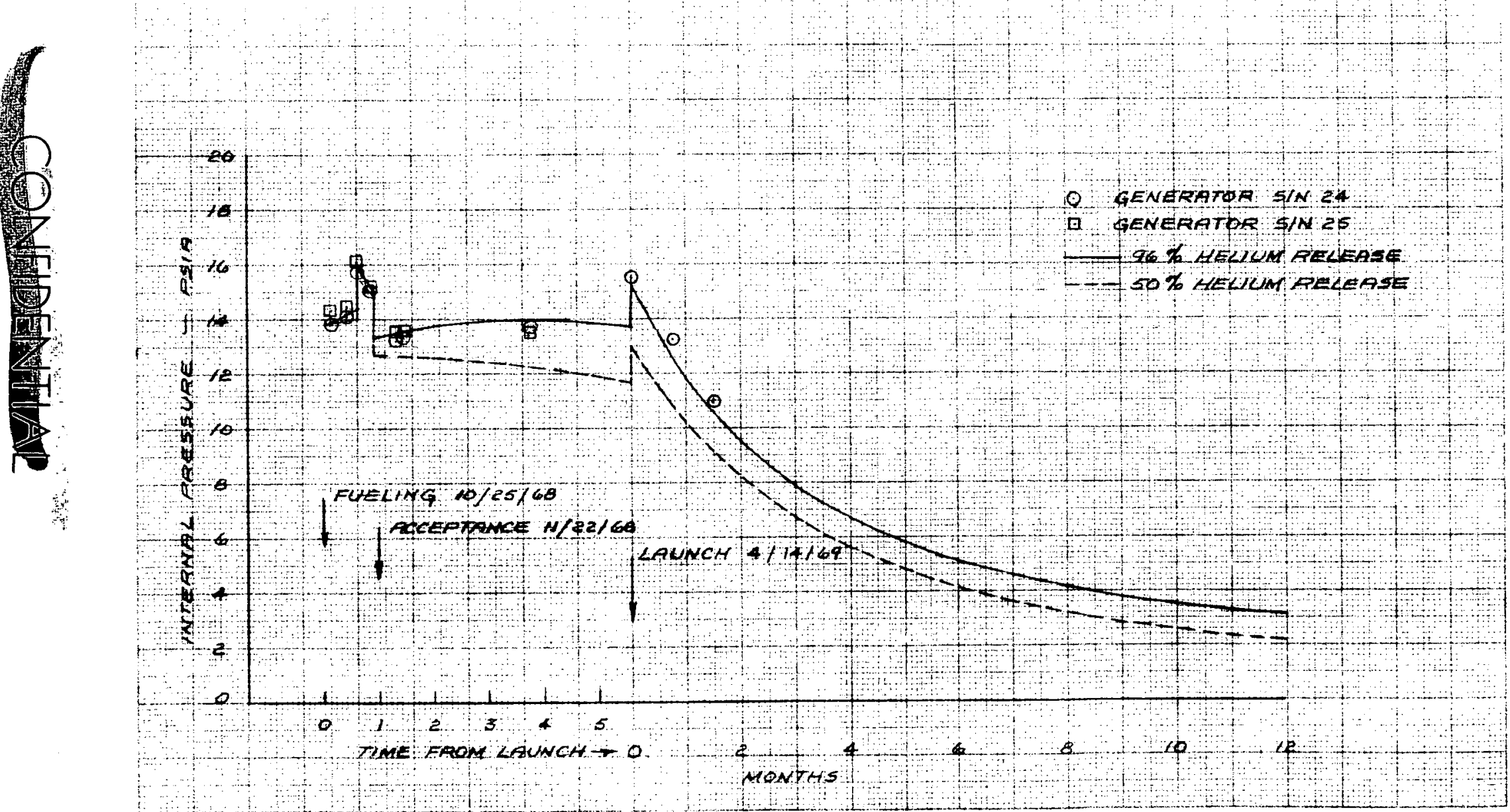




\section{-}

have been 2 psi lower than measured in the 5-1/2 months between fueling and launch. Additional support that the helium release rate of Nimbus III generators is near the $100 \%$ generation level is derived from performance considerations. The $96 \%$ level of release corresponds to a partial pressure of 4.8 psia helium in generators at the time of launch. A 50\% release level would have resulted in a helium pressure of only 2.5 psia and a generator power output nearly 3 watts greater at the system level than measured. It is this type of success in correlation of pressure and power performance which justifies the detail of pressure work presented below.

\section{Results}

a. Pressure Profiles vs Seal Tightness and Helium Release Pressure results for the parametric study in seal installation tightness and helium release rate from the fuel are plotted in Figs. III-44 through III-48 for five periods during mission life, including five years after launch. The plots are applicable to the proposed argon filled generators for the Viking mission which operate at a fin root temperature of about $330^{\circ} \mathrm{F}$. Equivalent data for RTG's initially filled with helium are presented in Table III-16.

The allowable pressure range for RTG operation is as follows. At the high limit, increasing parasitic thermal insulation losses restrict the maximum pressure to somewhat above two atmospheres. The lower pressure limit is similarly fixed by performance considerations since the thermolectrics experience accelerated losses by sublimation at

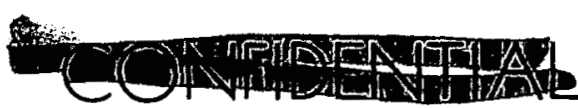

INSD-2650-29

III-83 
F/CUAEE III - 44

APGON FULED GENETFTOE

\section{INTEENAL PPESSUPE THREE MONTHS FPTED FUELING \\ LFOR COMESNATIONIS OF SEAL TIGHTNESS GNO \\ HELIUM PELEASE PATES FPOM A 675 KIATI GAPSULE)}
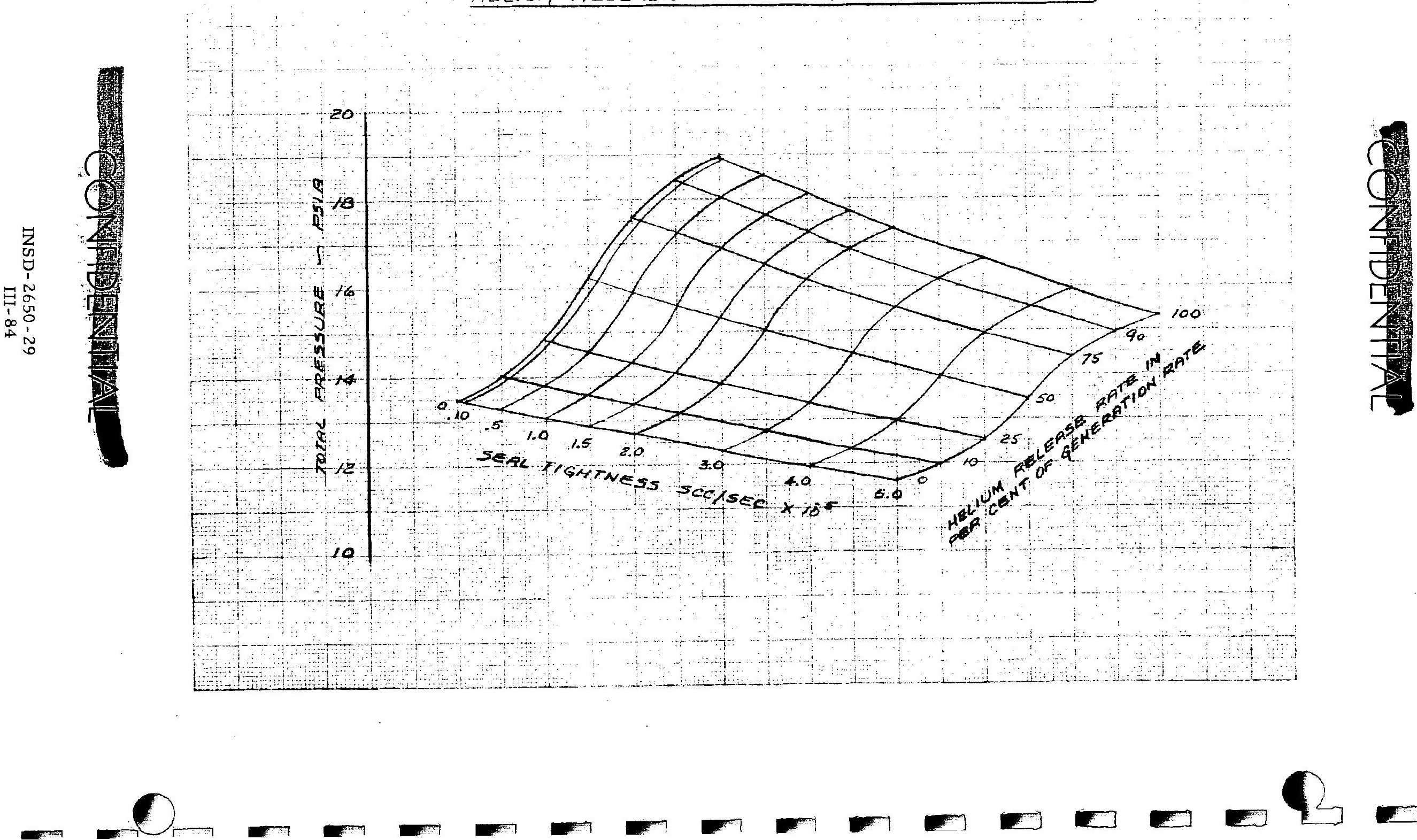


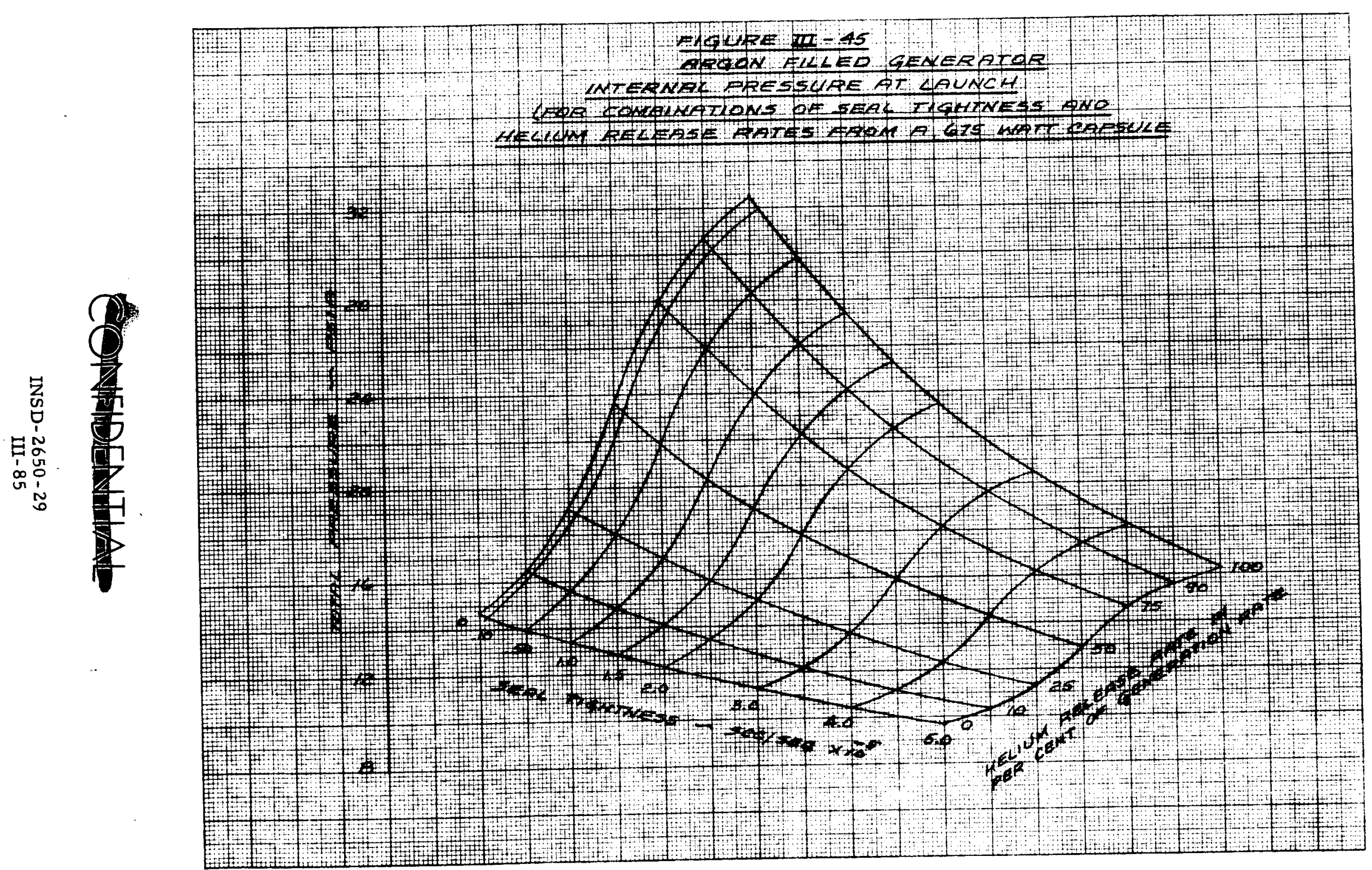




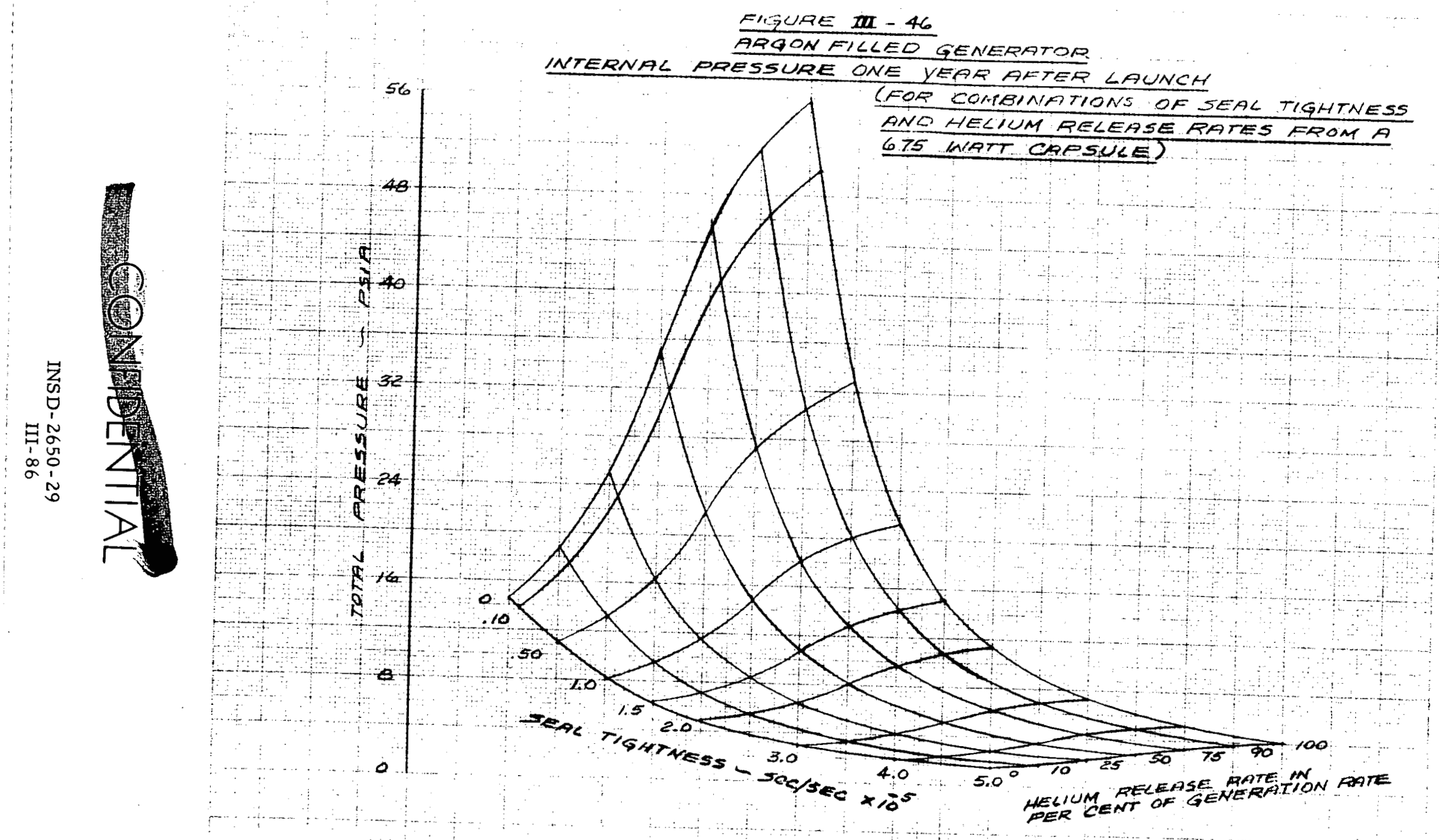




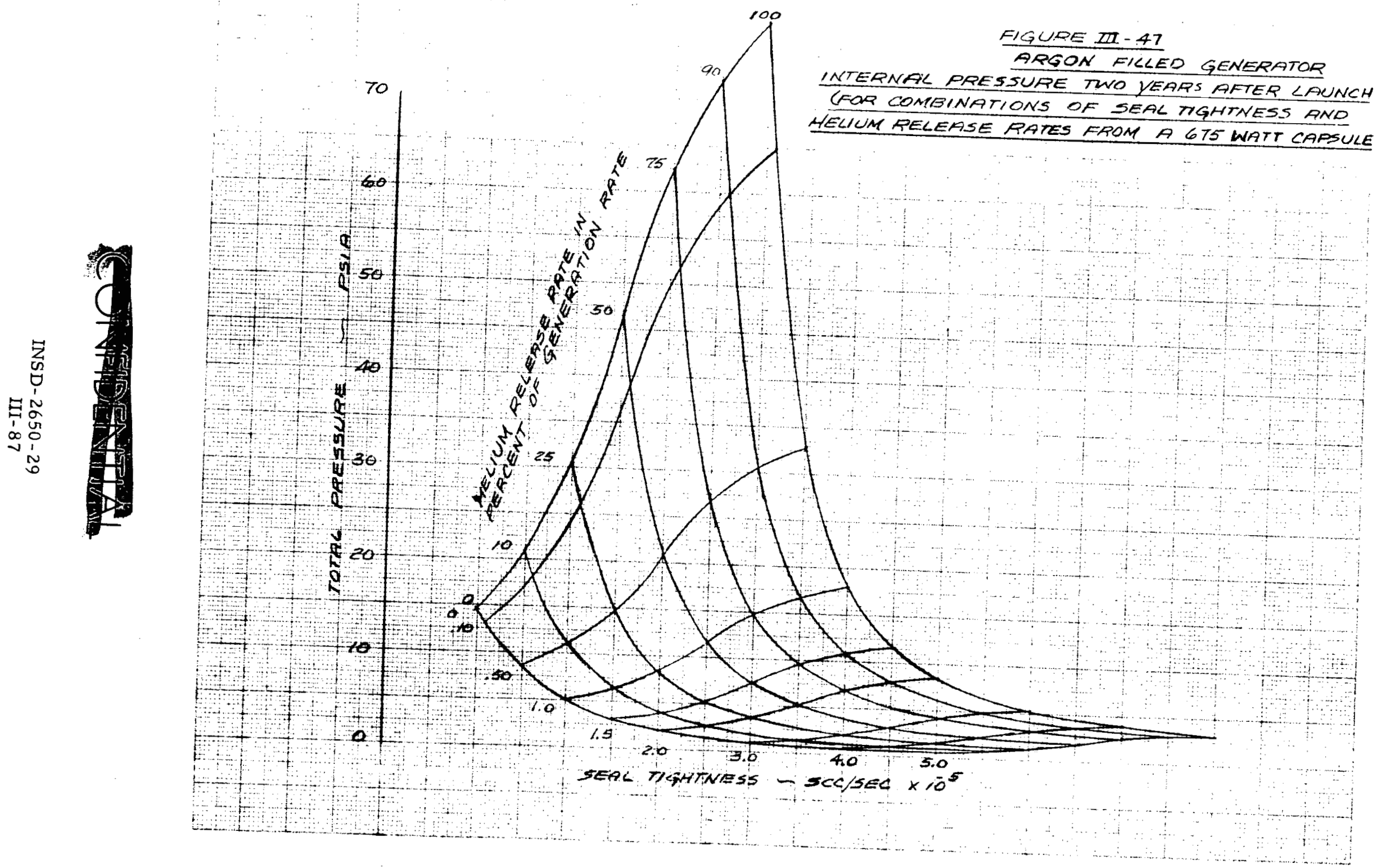



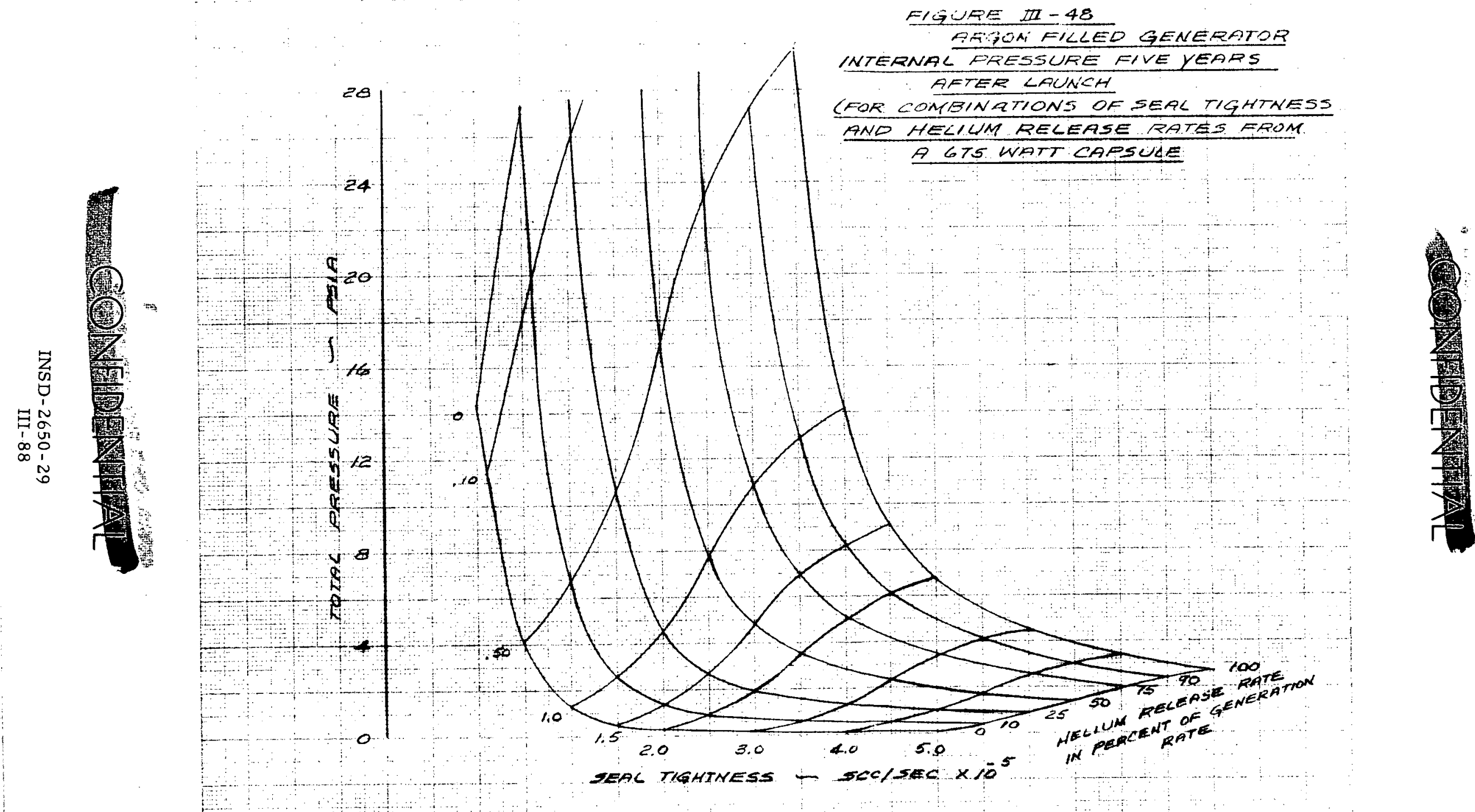

0 
TABLE III-16

SNAP 19 HELIUM FILLED GENERATOR INTERNAL PRESSURES (PSIA) FOR COMBINATIONS OF SEAL TIGHINESS AND HELIUM RELEASE RATES FIN ROOT TEMP. 330 F. INITIAL FUEL INVENTORY 675 WATTS

\begin{tabular}{|c|c|c|c|c|c|c|c|}
\hline $\begin{array}{c}\text { Seal } \\
\text { Tightness } \\
\text { Factor } \\
\text { scc/sec } \\
\end{array}$ & $\begin{array}{l}\text { Helium } \\
\text { Release } \\
\text { Rate } \\
\text { scc/sec }\end{array}$ & 0 & Time $f r$ & Fuelin & - Month & 33 & 69 \\
\hline $1.0 \times 10^{-7}$ & $\begin{array}{c}0 \\
2.80 \times 10^{-6} \\
7.0 \\
14.0 \\
21.0 \\
25.2 \\
28.0\end{array}$ & $\begin{array}{l}13.5 \\
13.50 \\
13.50 \\
13.50 \\
13.50 \\
13.50 \\
13.50\end{array}$ & $\begin{array}{l}13.48 \\
14.01 \\
14.80 \\
16.12 \\
17.44 \\
18.24 \\
18.77\end{array}$ & $\begin{array}{l}14.64 \\
16.37 \\
18.95 \\
23.27 \\
27.59 \\
20.19 \\
31.92\end{array}$ & $\begin{array}{l}14.39 \\
18.36 \\
24.34 \\
34.30 \\
44.27 \\
50.25 \\
54.24\end{array}$ & $\begin{array}{l}14.15 \\
20.32 \\
29.63 \\
45.15 \\
60.67 \\
69.98 \\
76.19\end{array}$ & $\begin{array}{r}13.45 \\
26.01 \\
44.98 \\
76.60 \\
108.22 \\
127.20 \\
139.85\end{array}$ \\
\hline $1.0 \times 10^{-6}$ & $\begin{array}{c}0 \\
2.80 \times 10^{-6} \\
7.0 \\
14.0 \\
21.0 \\
25.2 \\
28.0\end{array}$ & $\begin{array}{l}13 \cdot 50 \\
13.50 \\
13.50 \\
13.50 \\
13.50 \\
13.50 \\
13.50\end{array}$ & $\begin{array}{l}13.29 \\
13.82 \\
14.61 \\
15.92 \\
17.23 \\
18.02 \\
18.54\end{array}$ & $\begin{array}{l}14.04 \\
15.73 \\
18.26 \\
22.49 \\
26.72 \\
29.25 \\
30.95\end{array}$ & $\begin{array}{l}11.86 \\
15.41 \\
20.71 \\
29.59 \\
38.46 \\
43.79 \\
47.34\end{array}$ & $\begin{array}{l}10.02 \\
15.13 \\
22.78 \\
35.58 \\
48.38 \\
56.06 \\
61.18\end{array}$ & $\begin{array}{r}6.04 \\
14.54 \\
27.24 \\
48.51 \\
69.79 \\
82.55 \\
91.06\end{array}$ \\
\hline $5.0 \times 10^{-6}$ & $\begin{array}{c}0 \\
2.80 \times 10^{-6} \\
7.0 \\
14.0 \\
21.0 \\
25.2 \\
28.0\end{array}$ & $\begin{array}{l}13 \cdot 50 \\
13.50 \\
13.50 \\
13.50 \\
13.50 \\
13.50 \\
13.50\end{array}$ & $\begin{array}{l}12.50 \\
13.01 \\
13.77 \\
15.04 \\
16.31 \\
17.07 \\
17.58\end{array}$ & $\begin{array}{l}11.68 \\
13.22 \\
15.53 \\
19.37 \\
23.22 \\
25.53 \\
27.07\end{array}$ & $\begin{array}{r}5.08 \\
7.30 \\
10.62 \\
15.15 \\
21.69 \\
25.02 \\
27.24\end{array}$ & $\begin{array}{r}2.25 \\
4.76 \\
8.52 \\
14.78 \\
21.04 \\
24.80 \\
27.31\end{array}$ & $\begin{array}{r}0.28 \\
2.98 \\
7.05 \\
13.82 \\
20.57 \\
24.64 \\
27.34\end{array}$ \\
\hline $1.0 \times 10^{-5}$ & $\begin{array}{c}0 \\
2.80 \times 10^{-6} \\
7.0 \\
14.0 \\
21.0 \\
25.2 \\
28.0\end{array}$ & $\begin{array}{l}13.50 \\
13.50 \\
13.50 \\
13.50 \\
13.50 \\
13.50 \\
13.50\end{array}$ & $\begin{array}{l}11.57 \\
12.06 \\
12.80 \\
14.02 \\
15.24 \\
15.97 \\
16.46\end{array}$ & $\begin{array}{r}9.34 \\
10.71 \\
12.77 \\
16.21 \\
19.63 \\
21.70 \\
23.07\end{array}$ & $\begin{array}{r}1.91 \\
3.28 \\
5.33 \\
8.74 \\
12.15 \\
14.20 \\
15.56\end{array}$ & $\begin{array}{r}.53 \\
1.90 \\
3.94 \\
7.35 \\
10.76 \\
12.80 \\
14.16\end{array}$ & $\begin{array}{r}.17 \\
1.54 \\
3.58 \\
6.99 \\
10.40 \\
12.44 \\
13.80\end{array}$ \\
\hline $1.5 \times 10^{-5}$ & $\begin{array}{c}0 \\
2.8 \times 10^{-6} \\
7.0 \\
14.0 \\
21.0 \\
25.2 \\
28.0\end{array}$ & $\begin{array}{l}13.50 \\
13.50 \\
13.50 \\
13.50 \\
13.50 \\
13.50 \\
13.50\end{array}$ & $\begin{array}{l}10.73 \\
11.20 \\
11.90 \\
13.08 \\
14.26 \\
14.96 \\
15.43\end{array}$ & $\begin{array}{r}7.52 \\
8.75 \\
10.60 \\
13.68 \\
16.76 \\
18.61 \\
19.84\end{array}$ & $\begin{array}{r}.91 \\
1.85 \\
3.25 \\
5.58 \\
7.92 \\
9.32 \\
10.25\end{array}$ & $\begin{array}{l}.35 \\
1.26 \\
2.63 \\
4.91 \\
7.18 \\
8.55 \\
9.46\end{array}$ & $\begin{array}{l}.20 \\
1.11 \\
2.47 \\
4.75 \\
7.02 \\
8.38 \\
9.29\end{array}$ \\
\hline
\end{tabular}

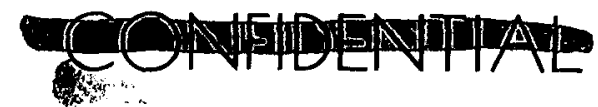




\section{-}

TABLE III-16 (Continued)

\begin{tabular}{|c|c|c|c|c|c|c|c|}
\hline $\begin{array}{c}\text { Seal } \\
\text { Tightness } \\
\text { Factor } \\
\text { scc/sec }\end{array}$ & $\begin{array}{l}\text { Helium } \\
\text { Release } \\
\text { Rate } \\
\text { scc/sec } \\
\end{array}$ & 0 & Time fr & Fuelin & Months & 33 & 69 \\
\hline \multirow[t]{2}{*}{$2.0 \times 10^{-5}$} & $2.8 \times 10^{-6}$ & $\begin{array}{l}13.50 \\
13.50\end{array}$ & $\begin{array}{r}9.95 \\
10.40\end{array}$ & $\begin{array}{l}6.12 \\
7.23\end{array}$ & $\begin{array}{r}.64 \\
1.33\end{array}$ & $\begin{array}{r}.38 \\
1.06\end{array}$ & $\begin{array}{l}.21 \\
.90\end{array}$ \\
\hline & $\begin{array}{r}7.0 \\
14.0 \\
21.0 \\
25.2 \\
28.0\end{array}$ & $\begin{array}{l}13.50 \\
13.50 \\
13.50 \\
13.50 \\
13.50\end{array}$ & $\begin{array}{l}11.08 \\
12.21 \\
13.34 \\
14.02 \\
14.48\end{array}$ & $\begin{array}{r}8.90 \\
11.68 \\
14.45 \\
16.12 \\
17.23\end{array}$ & $\begin{array}{l}2.38 \\
4.12 \\
5.86 \\
6.90 \\
7.60\end{array}$ & $\begin{array}{l}2.08 \\
3.79 \\
5.49 \\
6.52 \\
7.20\end{array}$ & $\begin{array}{l}1.92 \\
3.62 \\
5.32 \\
6.35 \\
7.03\end{array}$ \\
\hline $3.0 \times 10^{-5}$ & $\begin{array}{c}0 \\
2.8 \times 10^{-6} \\
7.0 \\
14.0 \\
21.0 \\
25.2 \\
28.0\end{array}$ & $\begin{array}{l}13.50 \\
13.50 \\
13.50 \\
13.50 \\
13.50 \\
13.50 \\
13.50\end{array}$ & $\begin{array}{r}8.57 \\
8.99 \\
9.62 \\
10.67 \\
11.72 \\
12.35 \\
12.77\end{array}$ & $\begin{array}{r}4.24 \\
5.15 \\
6.53 \\
8.81 \\
11.10 \\
12.47 \\
13.38\end{array}$ & $\begin{array}{l}.63 \\
1.09 \\
1.77 \\
2.91 \\
4.06 \\
4.74 \\
5.20\end{array}$ & $\begin{array}{r}.46 \\
.91 \\
1.60 \\
2.73 \\
3.87 \\
4.55 \\
5.00\end{array}$ & $\begin{array}{r}.20 \\
.65 \\
1.34 \\
2.47 \\
3.61 \\
4.29 \\
4.74\end{array}$ \\
\hline $4.0 \times 10^{-5}$ & $\begin{array}{c}0 \\
2.8 \times 10^{-6} \\
7.0 \\
14.0 \\
21.0 \\
25.2 \\
28.0\end{array}$ & $\begin{array}{l}13.50 \\
13.50 \\
13.50 \\
13.50 \\
13.50 \\
13.50 \\
13.50\end{array}$ & $\begin{array}{r}7.41 \\
7.80 \\
8.39 \\
9.37 \\
10.34 \\
10.93 \\
11.23\end{array}$ & $\begin{array}{r}3.17 \\
3.94 \\
5.09 \\
7.01 \\
8.92 \\
10.07 \\
10.84\end{array}$ & $\begin{array}{l}.73 \\
1.07 \\
1.59 \\
2.44 \\
3.29 \\
3.80 \\
4.14\end{array}$ & $\begin{array}{l}.50 \\
.84 \\
1.36 \\
2.21 \\
3.06 \\
3.57 \\
3.91\end{array}$ & $\begin{array}{r}.17 \\
.51 \\
1.02 \\
1.87 \\
2.72 \\
3.23 \\
3.57\end{array}$ \\
\hline $5.0 \times 10^{-5}$ & $\begin{array}{c}0 \\
2.8 \times 10^{-6} \\
7.0 \\
14.0 \\
21.0 \\
25.2 \\
28.0\end{array}$ & $\begin{array}{l}13 \cdot 50 \\
13 \cdot 50 \\
13 \cdot 50 \\
13 \cdot 50 \\
13 \cdot 50 \\
13 \cdot 50 \\
13 \cdot 50\end{array}$ & $\begin{array}{r}6.44 \\
6.80 \\
7.35 \\
8.26 \\
9.17 \\
9.71 \\
10.08\end{array}$ & $\begin{array}{l}2.61 \\
3.26 \\
4.24 \\
5.87 \\
7.50 \\
8.48 \\
9.14\end{array}$ & $\begin{array}{l}.82 \\
1.10 \\
1.50 \\
2.19 \\
2.87 \\
3.28 \\
3.55\end{array}$ & $\begin{array}{l}.52 \\
.79 \\
1.20 \\
1.88 \\
2.56 \\
2.97 \\
3.24\end{array}$ & $\begin{array}{r}.13 \\
.40 \\
.81 \\
1.49 \\
2.17 \\
2.58 \\
2.85\end{array}$ \\
\hline
\end{tabular}


very low pressures. An exact lower limit has not been established, but pressures greater than 2 psia are considered acceptable for stable performance.

As shown in the previous section, evidence from Nimbus III is that helium telease from the fuel approaches 100\%. This value corresponds to a helium production rate of $2.81 \times 10^{-5} \mathrm{scc} / \mathrm{sec}$ for a 675 watt source, a quantity not to be confused with seal tightness rates. As shown in Fig. III-46 for the expected seal tightness range of $1 \times 10^{-5} \mathrm{scc} / \mathrm{sec}$ to $5 \times 10^{-5}$ (the present RTG design with one Viton 0 -ring for each sealed surface has produced seal tightnesses within this range on all generatos built to date), the generator pressure at the end of the Viking mission will be approximately 2 psia or greater even for $0 \%$ release from the fuel. For the expected release $(\sim 100 \%)$ and seal tightness $\left(\sim 3 \times 10^{-5} \mathrm{scc} / \mathrm{sec}\right)$ the pressure will be approximately 7 psia. At 2 years after launch (Fig. III-47) the expected pressure is approximately 5 psia.

For ease of interpretation of Figs. III-44 through III-48, pressure profiles of the initial argon filled RIG are presented in Fig. III-49 for various seal tightnesses and for helium pelease rates of $100 \%$ and $50 \%$.

b. Effect of Launch Scheduling on RTG Performance Post fueling generator test and storage periods of 9 months were assumed for the pressure and performance analyses previously presented. An extension or abbreviation of the nine-month prelaunch period will have minimal effects on pressure levels at encounter but will generally

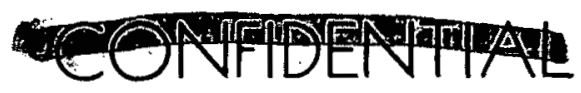




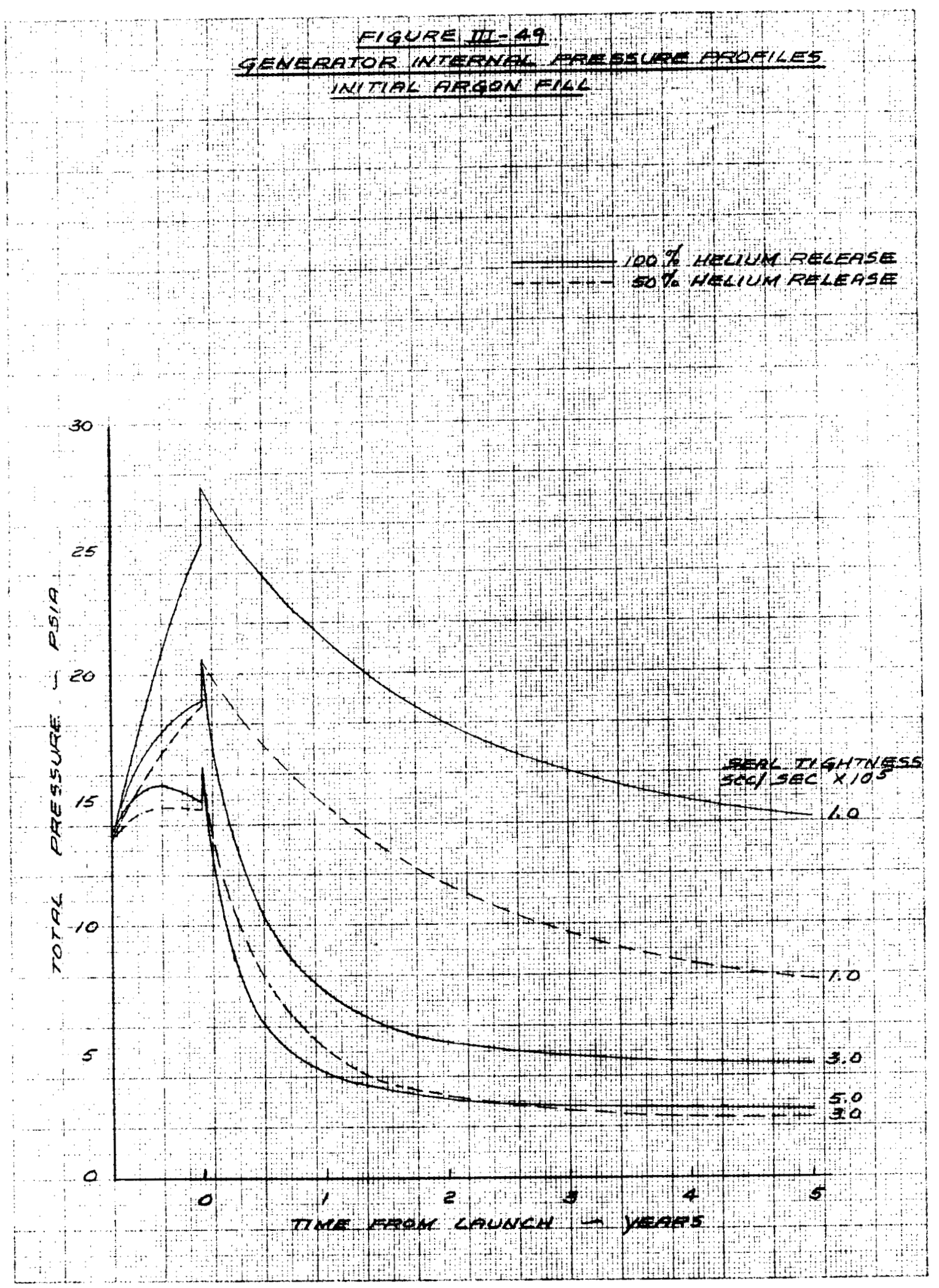




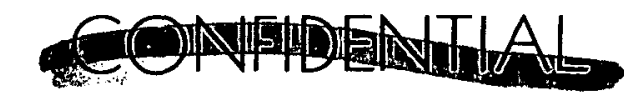

be evident at launch. Each combination of seal tightness and release rate is unique. This is illustrated in Fig. III-50 for test and storage periods of 3 and 15 months and release rates of $100 \%$ and $50 \%$. A seal tightness of $3 \times 10^{-5} \mathrm{scc} / \mathrm{sec}$ was assumed. Excessive internal pressure rise in generators with tight seals and maximum helium rates during prolonged storage periods can effectively be halted by raising seal temperatures above the nominal storage value $\left(230^{\circ} \mathrm{F}\right.$ to $260^{\circ} \mathrm{F}$ ) by insulating the fins. Impact on initial power performance can thereby be minimized.

Figure III=51 shows the effect of the prelaunch storage and hold period for fueling-to-launch-periods of 3 months and 15 months (at $100 \%$ and $50 \%$ release rates and a seal tightness of $3 \times 10^{-5} \mathrm{scc} / \mathrm{sec}$ ). The variation in performance at end-of-mission (EOM) is approximately one watt for a given helium release rate, with the shorter storage time resulting in the higher power output due to the lower helium pressure in the RTG.

c. Helium Gas Concentration

The change in percentage of helium gas at known pressures during mission life is of prime interest for performance predictions. A rising helium content will depress generator thermal efficiencies after fueling by raising the effective thermal insulation conductivity. Seal tightness and helium release rates were again combined in parametric studies versus helium concentration at various mission times. Results are presented in the carpet plots of Flgs. III-52 through III-56. It is of interest that for mission durations up to 2 years

\section{CONFEENTIATE}

INSD-2650-29

III-93 
EIGUAE TIT-SO

EFAECT AF LAUNCH SCHEOUKING ON GENERATOR NTRARNAL PRESSUPE
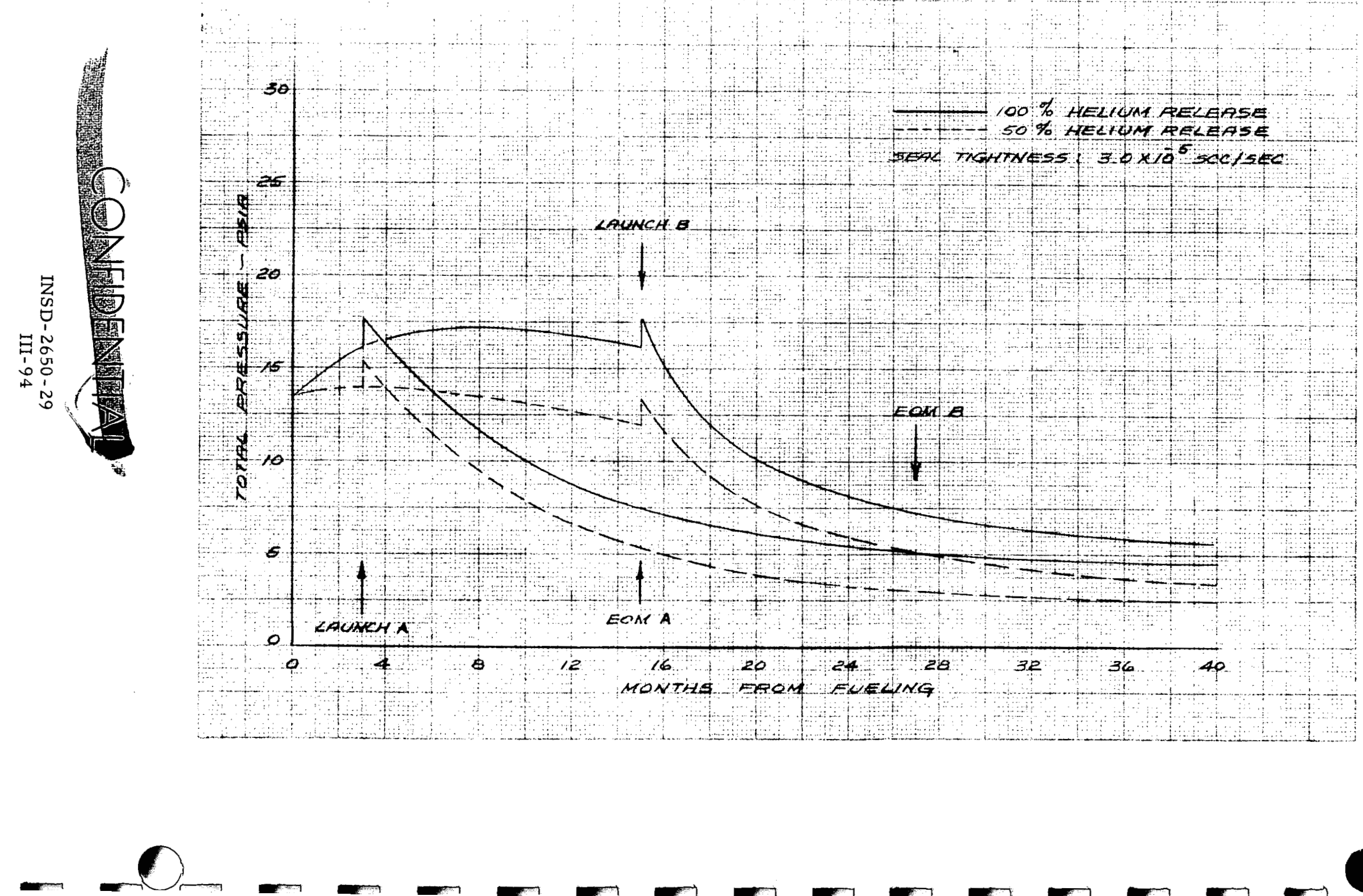
FiqueE II - SI

EFFECT ON LAUNCM SLHEOULNG ON GEMERATOR POWER
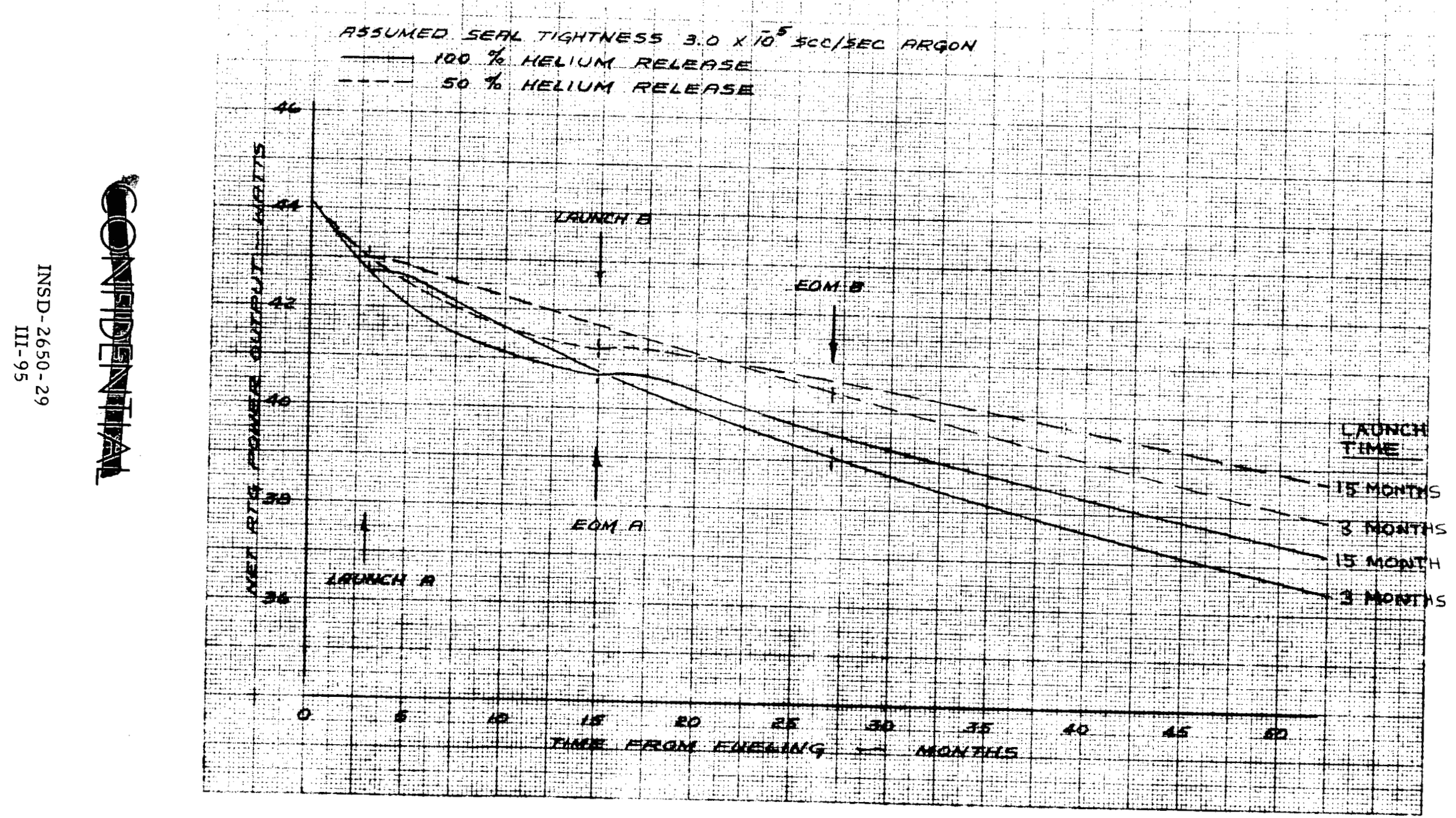

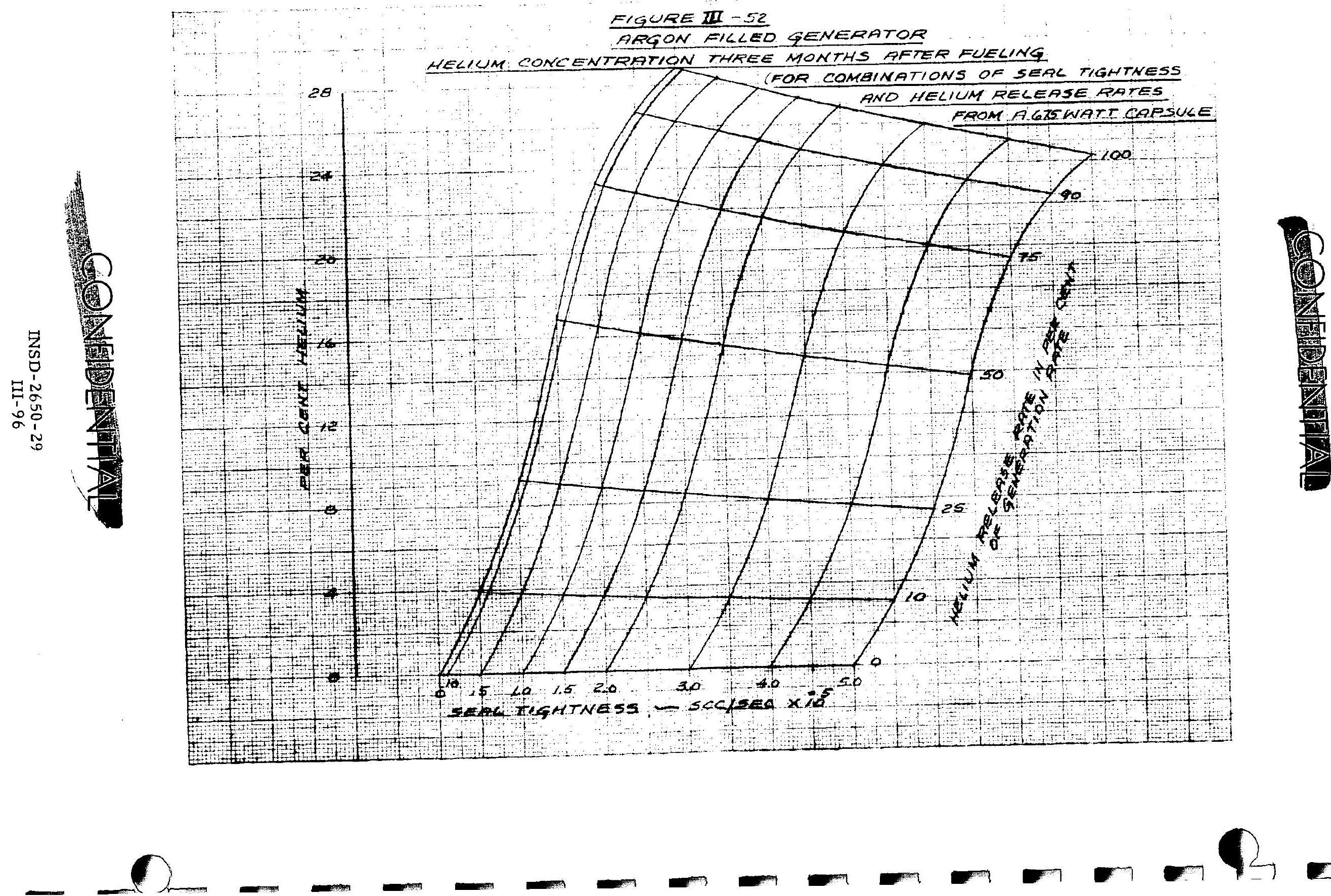

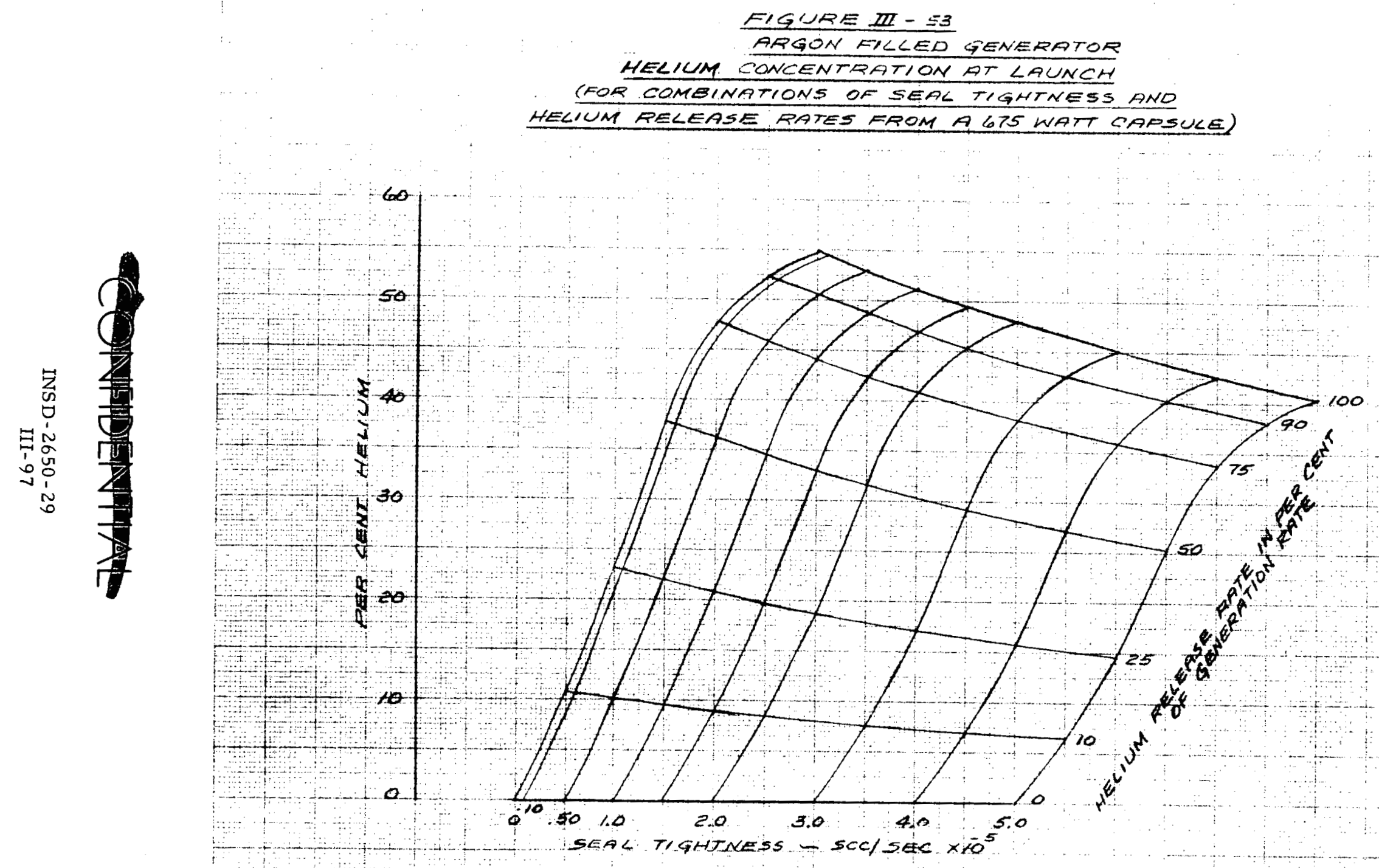

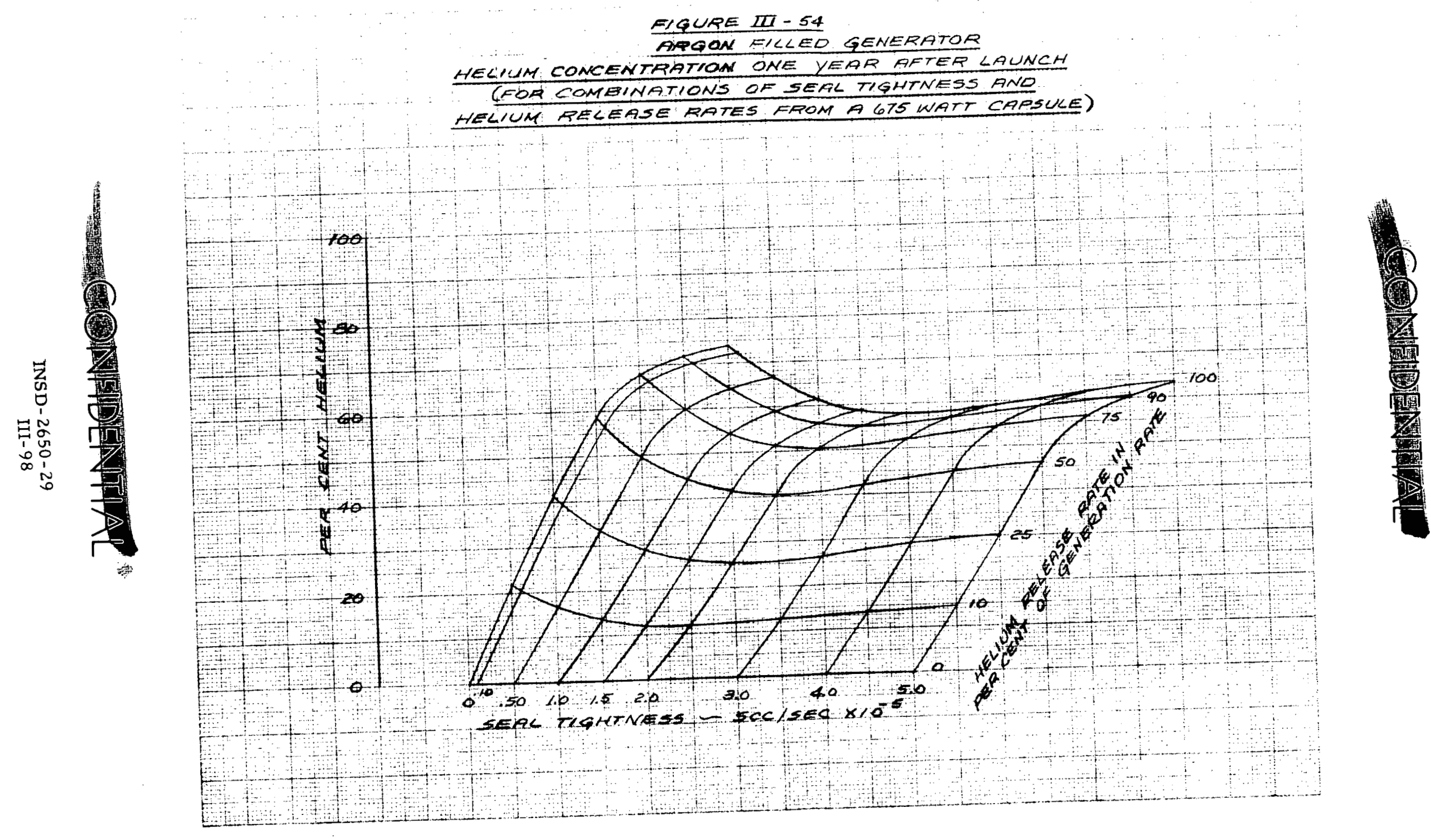


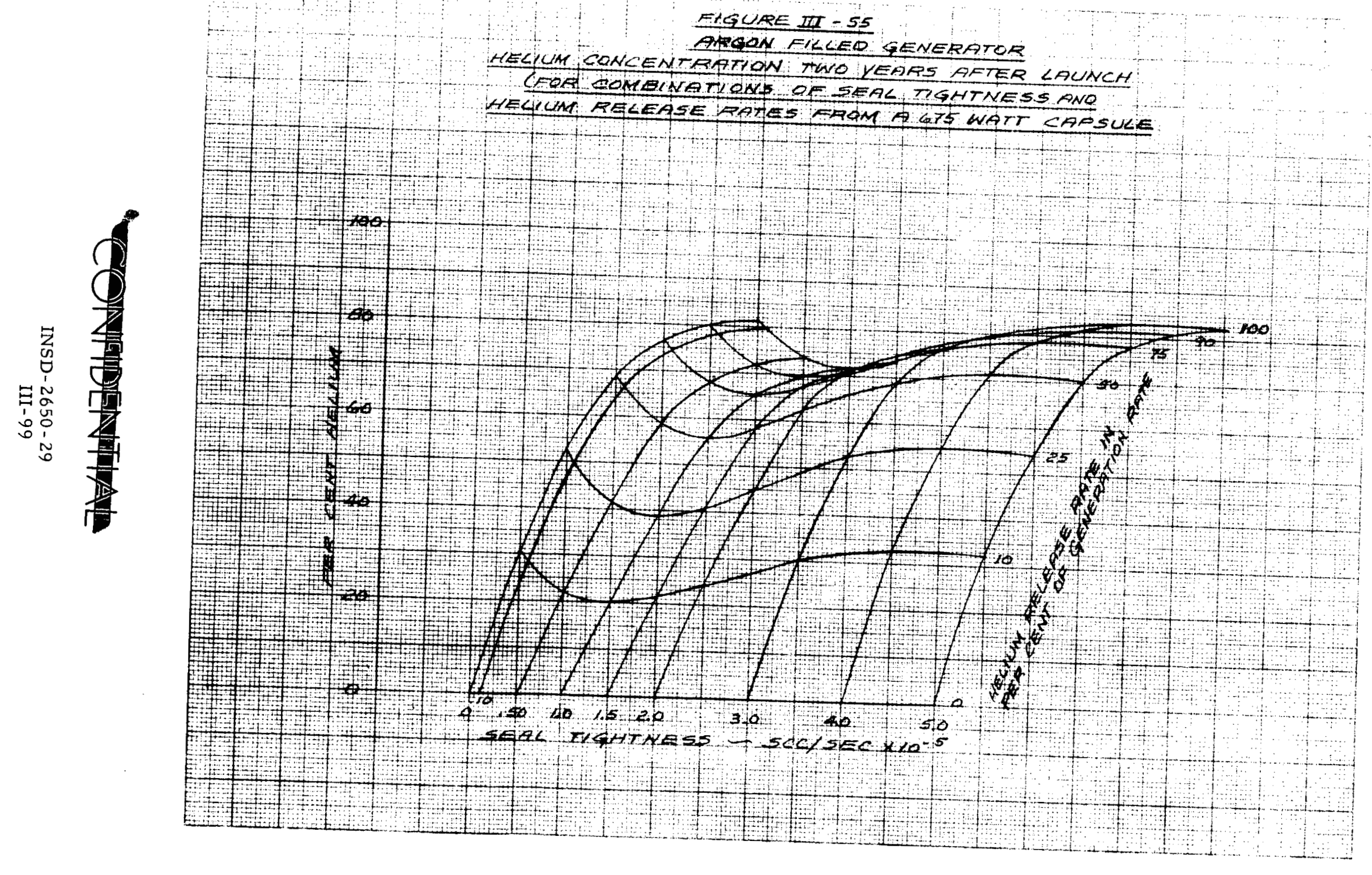



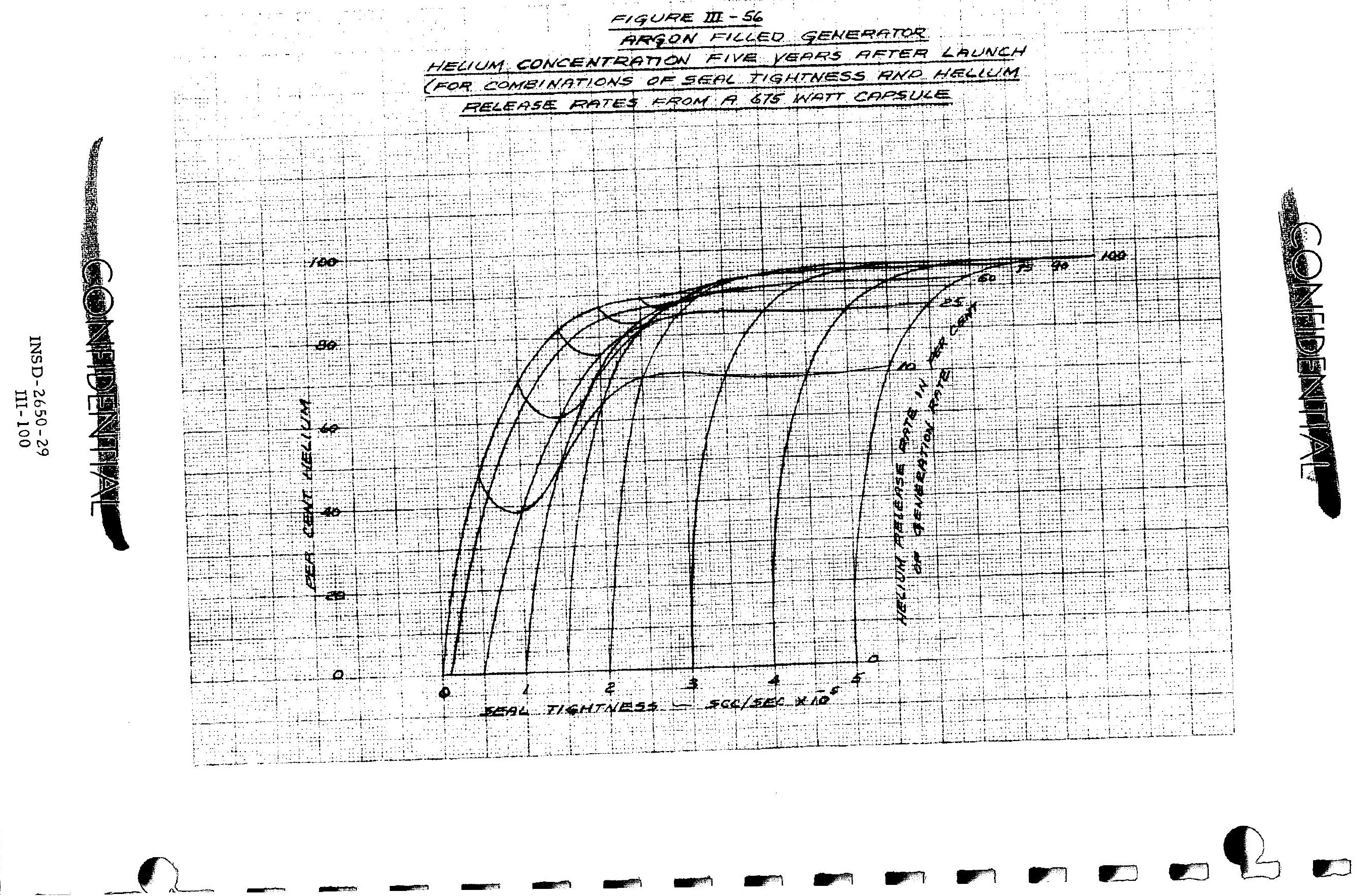
the seal tightness has a rather minor influence on helium concentration.

d. Effect of fuel inventory and temperature

Figure III-57 presents the total pressure for a Nimbus III configuration generator with a 625 watt thermal inventory and $350^{\circ} \mathrm{F}$ fin root (seal) operating temperature. At the EOM, the generator nominal pressure is $\sim 5$ psia. Thus, the effect of the higher fin root temperature and lower fuel inventory is to reduce the EOM pressure 2 psia below the 675 watt, $330^{\circ} \mathrm{F}$ design previously discussed.

e. Generators with initial helium fill

Pressure changes with time for a helium filled generator are illustrated as a function of seal tightness and helium release rate in Table III-16. The current elastomeric seals are more permeable to helium than to argon. To retain a supporting pressure in the generator, the helium filled unit must rely on gas replenishment from the capsule to a greater extent than the argon filled unit. Pressures approach levels dictated by release rates soon after launch whereas equilibrium values are approached more gradually by the argon filled generator. Representative pressure time profiles are presented in Fig. III-58.

In general, the helium filled RTG will produce a somewhat flatter power profile over the mission than the argon RIG but somewhat less integrated power. Either. RTG will meet the Viking requirements, although the argon RTG has been selected for emphasis in this study because of the greater power output available at EOM.

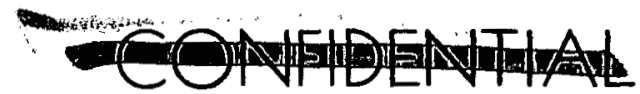

INSD-2650-29

III-10I 
FIQUFE III-5T

VIKING GENERATOR PRESSUAE PROKILE

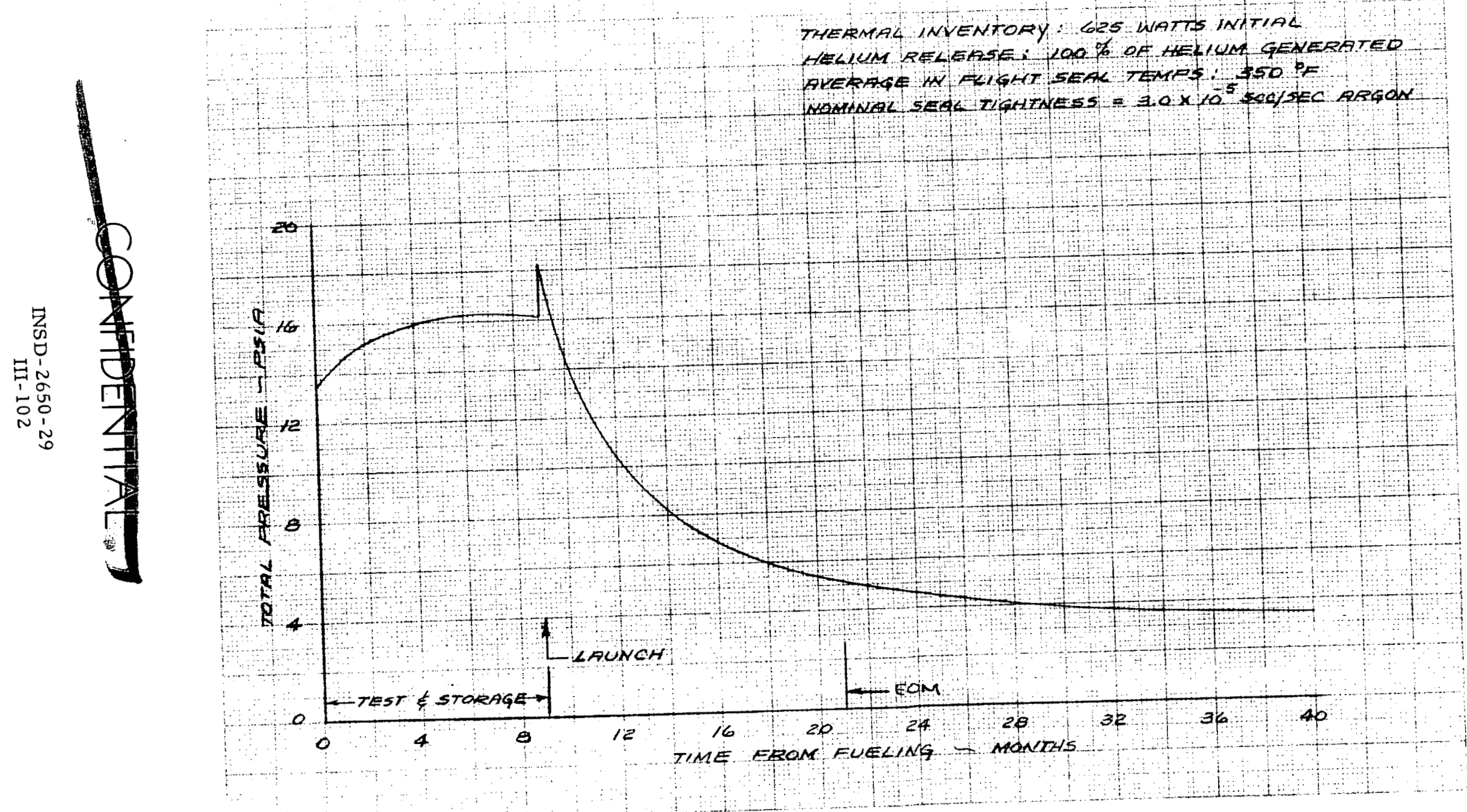



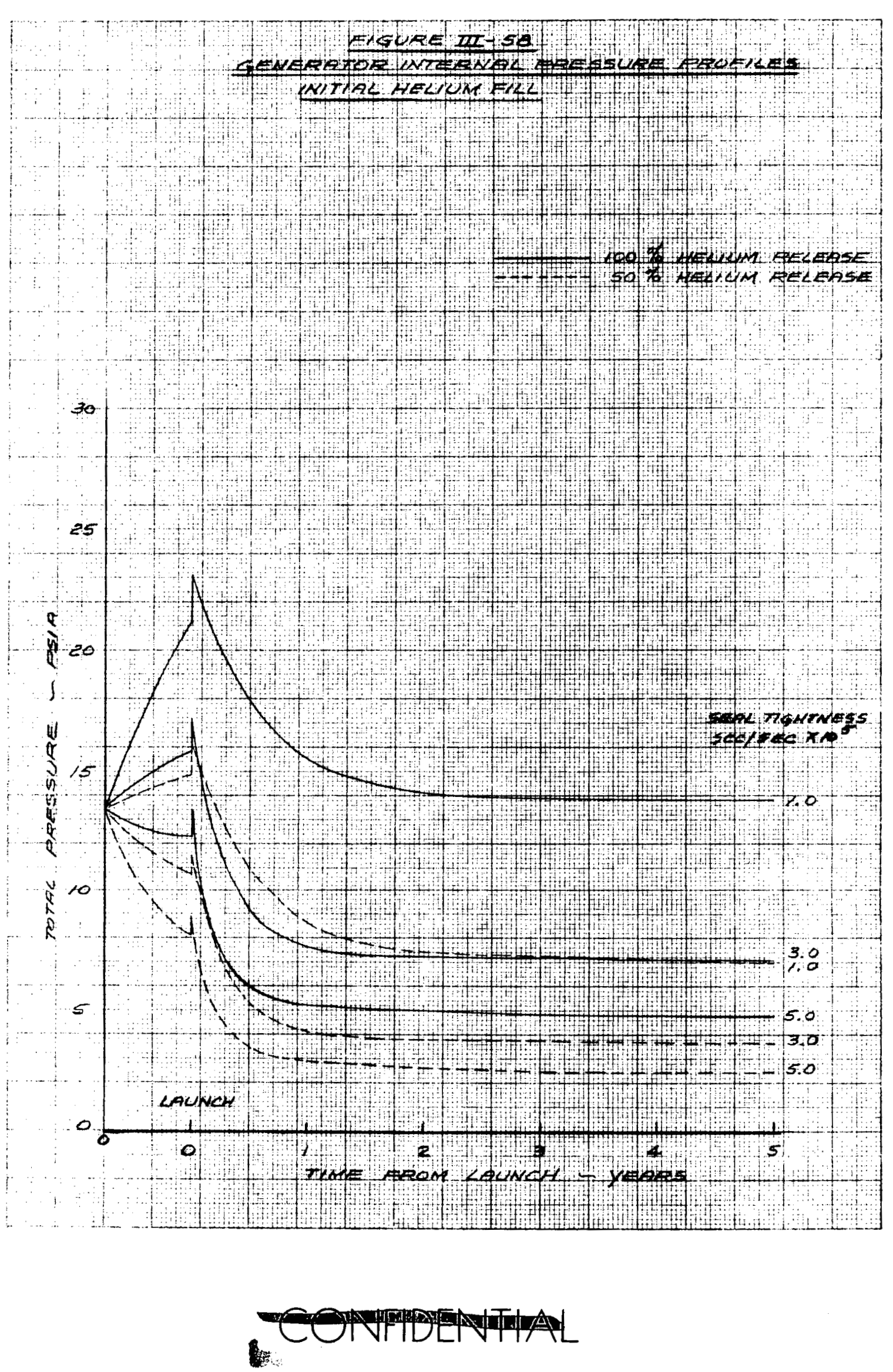

INSD-2650-29

III - 103 


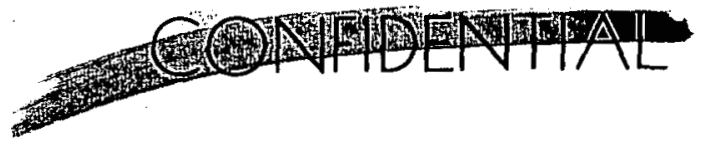

\section{Viton O-Ring Summary}

Pressure profiles and $\%$ helium concentration as presented above are supported by six years of elastomeric seal evaluation on SIAP programs. The Viton A compound V77-545 0-rings as procured from Parker Seal Company are carefully inspected for compliance with dimensional and integrity specifications. Similar inspections are made on generator sealing and groove surfaces prior to installation. The seals are held tight by rigid covers and flanges which virtually eliminate seal motion during vibration or handing of the generators. The integrity of seals is determined through helium and hot argon leakage tests of completed assemblies.

The performance of the installed seal depends on its resistance to surface deterioration and on the memory of the seal compound at time and temperature. Viton A unlike some elastomers, is superior in resistance to surface cracking and sublimation under high vacuum (Ref. III-2). The memory of the compound, which relates to the capability to maintain a seal by compressive forces is good at sustained temperatures up to $375^{\circ} \mathrm{F}$. Iiterature claims capability to withstand short-time exposures to $1000^{\circ} \mathrm{F}$.

Viton A has widely been üsed in sealing applications for space. It has been operated at temperatures in excess of $380^{\circ} \mathrm{F}$ during the qualification cycle of SNAP 19 generators and has successfully sealed the SNAP 9A S/N 4 generator which has orbited since 1963. Moreover the seals in the current configuration have been temperature cycled from 


\section{-}

350.F to room temperature at various occasions during the SNAP 19

endurance test generator program. Some of these RTG tests are still

in progress. A summary of Viton A seal applications with SIIAP RTG's is presented in Table III-17. Seal performance in a.l. instances has been satisfactory.

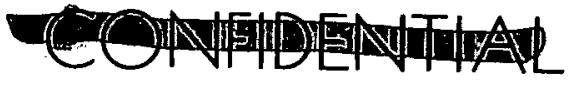

INSD-2650-29

III-105 
TABLE III-I7

VITON SEAL USAGE SUMMARY IN ISOTOPES PROGRAMS

$$
\text { Generator Program - SNAP } 19
$$

\begin{tabular}{|c|c|c|c|c|}
\hline $\begin{array}{l}\text { Serial } \\
\text { Number }\end{array}$ & $\begin{array}{l}\text { Operating } \\
\text { Time } \\
\text { (hrs) } \\
\end{array}$ & (as of) & $\begin{array}{l}\text { Nominal } \\
\text { Seal Temp. } \\
\left(\mathrm{O}_{\mathrm{F}}\right) \\
\end{array}$ & Status \\
\hline 1 & 4,000 & $9 / 66$ & $230-270$ & Terminated \\
\hline 2 & 4,000 & $7 / 67$ & $230-270$ & Terminated \\
\hline 3 & 3,800 & 1965 & $230-350$ & Terminated \\
\hline 4 & 3,800 & 1965 & $230-350$ & Terminated \\
\hline $4 \mathrm{~A}$ & 10,400 & $1 / 1 / 68$ & 350 & Terminated \\
\hline 5 & 11,900 & $12 / 67$ & 350 & Terminated \\
\hline 6 & 13,400 & $12 / 67$ & 350 & Terminated \\
\hline 7 & 4,300 & $6 / 8 / 67$ & $270-350$ & Terminated \\
\hline 8 & 4,400 & $6 / 8 / 67$ & $270-350$ & Terminated \\
\hline 9 & 800 & $5 / 68$ & 230 & At Goddard for Magnetic Testing \\
\hline 10 & 800 & $5 / 68$ & 230 & At Goddard for Magnetic Testing \\
\hline $11,11 \mathrm{~A}$ & 5,700 & $1 / 10 / 68$ & $270-350$ & Terminated \\
\hline $12,12 \mathrm{~A}$ & 5,700 & $1 / 10 / 68$ & $270-350$ & Terminated \\
\hline 13 & 4,600 & $1 / 16 / 68$ & $270-350$ & Terminated \\
\hline 14 & 4,600 & $1 / 16 / 68$ & $270-350$ & Terminated \\
\hline 15 & 1,000 & $5 / 68$ & 230 & Terminated \\
\hline 16 & 1,000 & $5 / 68$ & 230 & Terminated \\
\hline 17 & 5,800 & $12 / 67$ & 350 & Terminated \\
\hline 18 & 9,000 & $4 / 68$ & 350 & On test at NSRDC \\
\hline 19 & 16,000 & $4 / 69$ & 350 & $\begin{array}{l}\text { First } 5460 \text { hours at Isotopes; } \\
\text { remainder at NASA-MSFC; test } \\
\text { continuing. }\end{array}$ \\
\hline
\end{tabular}

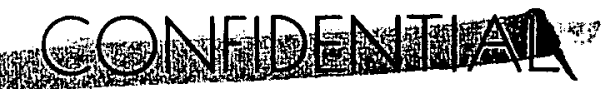




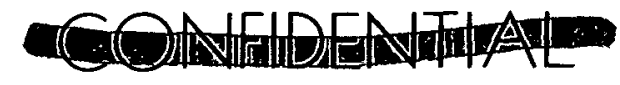

TABLE III-I7 (Continued)

Generator Program - SINAP 19 (Cont'a)

\begin{tabular}{|c|c|c|c|c|}
\hline $\begin{array}{l}\text { Serial } \\
\text { Number }\end{array}$ & $\begin{array}{l}\text { Operating } \\
\text { Time } \\
\text { (hrs) } \\
\end{array}$ & (as of) & $\begin{array}{l}\text { Nominal } \\
\text { Seal Temp. } \\
\text { (oF) } \\
\end{array}$ & Status \\
\hline 20 & 10,150 & $2 / 69$ & 350 & At JPL \\
\hline 21 & 8,300 & $3 / 5 / 69$ & 350 & At JPL \\
\hline $\begin{array}{l}22 \mathrm{~A} \\
23 \mathrm{~A}\end{array}$ & $\begin{array}{l}5,000 \\
5,000\end{array}$ & $\begin{array}{l}5 / 68 \\
5 / 68\end{array}$ & $\begin{array}{l}240-365 \\
240-365\end{array}$ & $\begin{array}{l}\text { Numbus B Flight System } 8 \text { A } \\
\text { Generators - Terminated }\end{array}$ \\
\hline $\begin{array}{l}24 \\
25\end{array}$ & $\begin{array}{l}5,500 \\
5,500\end{array}$ & $\begin{array}{l}6 / 69 \\
6 / 69\end{array}$ & $\begin{array}{l}240-375 \\
240-375\end{array}$ & $\begin{array}{l}\text { Nimbus III Flight System } \\
\text { Generators - in Orbit }\end{array}$ \\
\hline 26 & 1,200 & $6 / 69$ & 330 & Life Test \\
\hline 27 & 200 & $6 / 69$ & 330 & Awaiting Disposition \\
\hline 28 & 200 & $6 / 69$ & 330 & Awaiting Disposition \\
\hline \multicolumn{5}{|c|}{ Generator Program - SNAP 11} \\
\hline$Q / N-I M$ & 15,000 & $9 / 68$ & $250-400$ & Test continuing at Sandia \\
\hline$Q / N-3$ & 17,000 & $2 / 69$ & $250-400$ & Test continuing at JPL \\
\hline$Q / N-4$ & 8,351 & $\begin{array}{l}12 / 20 / 67 \\
\text { Generat }\end{array}$ & $\begin{array}{l}250-400 \\
\text { or Program - }\end{array}$ & $\begin{array}{l}\text { Unknown history at MSC (Houston) } \\
\text { SNAP } 9 A\end{array}$ \\
\hline $\begin{array}{l}\text { Transit } \\
5 \mathrm{BN}-1 \\
(\mathrm{~S} / \mathrm{N} 6)\end{array}$ & $>6,000$ & $6 / 1 / 64$ & 275 & $\begin{array}{l}\text { Satellite memory failure termin- } \\
\text { ated generator data; pressure was } \\
6 \text { psia. }\end{array}$ \\
\hline $\begin{array}{l}\text { Transit } \\
5 \mathrm{BN}-2 \\
(\mathrm{~S} / \mathrm{N} 4)\end{array}$ & 41,000 & $8 / 68$ & 275 & $\begin{array}{l}\text { On } 3 / 66 \text { ( } 20,000 \text { hours) indicated } \\
\text { pressure reached zero; RTG is } \\
\text { still functioning. }\end{array}$ \\
\hline$S / N 2$ & 20,300 & -- & $215-275$ & Terminated \\
\hline$S / N 3$ & 10,800 & -- & $215-275$ & Terminated \\
\hline$S / \mathbb{N} 5$ & 13,900 & -- & $215-275$ & Terminated \\
\hline
\end{tabular}

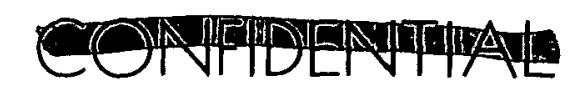


5

$E$

反

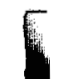

ઈ

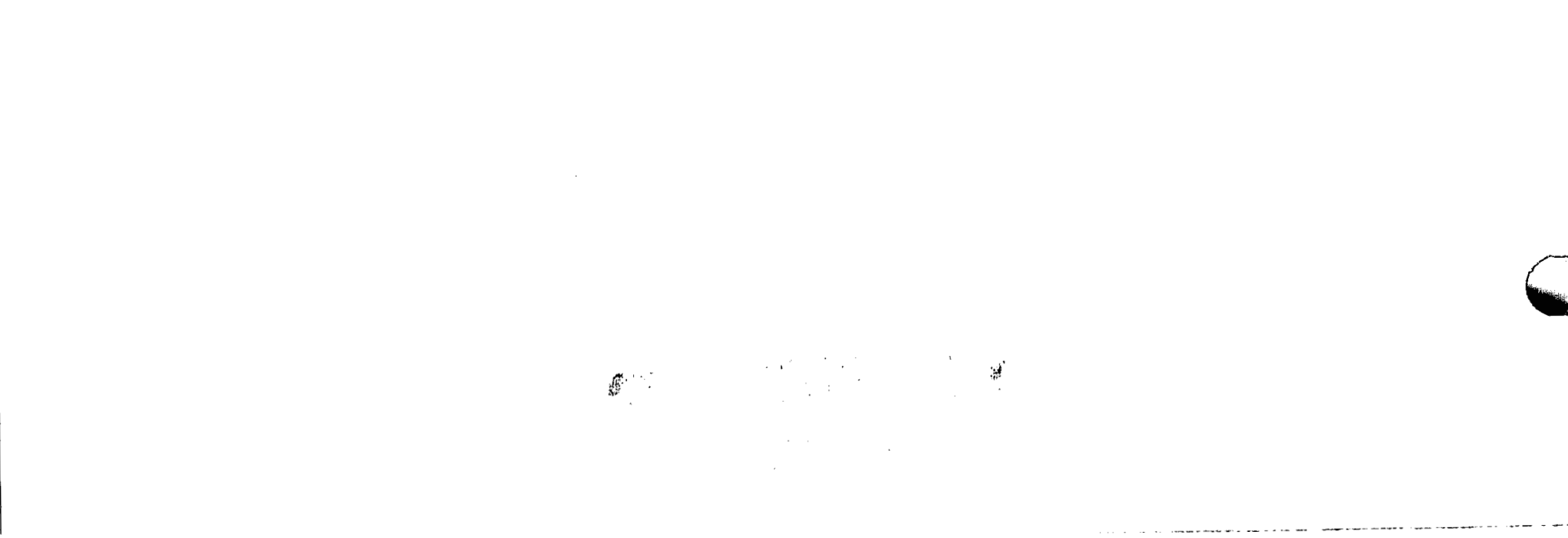




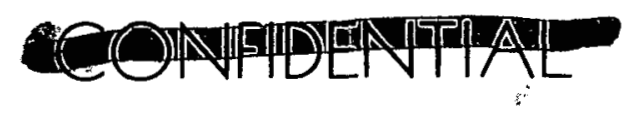

IV. HEAT SOURCE

The design of an Intact Impact Heat Source (IIHS) for an RTG is most strongly influenced by nuclear safety requirements. Accordingly, analyses of the heat source reported in this chapter are developed in a way that facilitates a preliminary safety evaluation and permits rational decisions with regard to design selection.

\section{A. GENERAT}

The primary purpose of nuclear safety analysis is to provide component design criteria for the nuclear system. The objectives of these criteria are twofold:

1. that the system will satisfy total safety requirements, and

2. that the resulting design will be balanced so that no component is unintentionally over-designed.

The safety function must be comprehensive to be useful. Failure of the fuel containment is a matter of concern, whatever the cause. Although the magnitude of the nuclear assessment varies with conditions under which fuel release occurs, that is no single event, such as the re-entry process, which so dominates with respect to nuclear safety significance that all other considerations may be suppressed in designing the nuclear system.

Preliminary analyses were performed of all postulated malfunctions which have a dominant influence on the design of the heat source. Two candidate heat shields for an intact impact heat source were examined

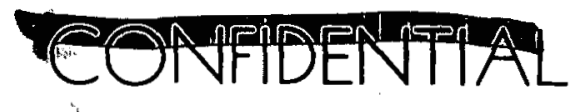

INSD-2650-29

IV-I 
in this study. The design options are defined and discussed in section B. Equilibrium temperature profiles for these configurations are presented in Section $\mathrm{C}$.

Malfunction analysis was separated into three categories -- launch pad and flight aborts (Sections $D$ and $E$ ) and impact-post impact containment (Section F). In each case, environments consequent to the malfunction were considered as well as the response of each candidate configuration. The specific objective of this analysis is to estimate fuel release probabilities for each environment and candidate heat shield.

In the final section (Section $G$ ) release probabilities are combined with indices which are measure of the resultant nuclear safety assessment and summed for each candidate heat shield. When this is accomplished, it is possible to select the safest design and deduce further modifications, if required.

\section{B. INTACT IMPACT HEAT SOURCE (IIHS) DESIGN}

The ultimate requirements of the heat source are that it maintain fuel containment under all normal conditions of transportation, handling, checkout, launch, re-entry and Earth impact as well as certain abnormal (but credible) postulated conditions which may occur due to terrestrial accidents or launch or flight aborts. The fuel capsule must be made of materials that are chemically compatible with the fuel, resist oxidation and seawater corrosion, and have sufficient strength and ductility to resist shock, vibration, shrapnel penetration, and Earth impact at component temperatures associated with these environments.

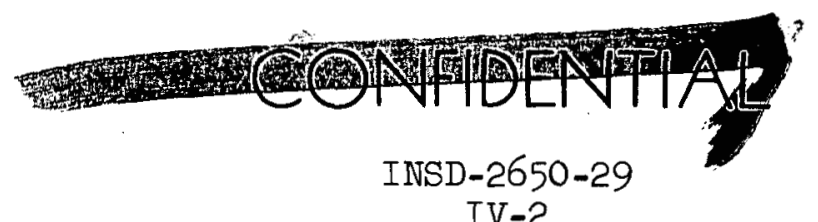




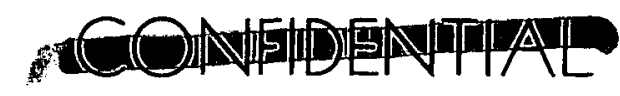

Two types of capsule fabrication have been adequately explored in past programs and are directly applicable for Viking use. The first concept available is one utilizing the combination of refractory metals for strength and impact resistance and refractory/noble metals for fuel compatibility, corrosion and oxidation resistance. The significant advantages of this type of design are that steady state capsule operation temperatures of $2000^{\circ} \mathrm{F}$ may be tolerated. This approach has been used in SNAP 11 and is currently being developed for SNAP 19 type RTG's.

The second concept uses a superalloy capsule having the capability of operating at steady state temperatures of $1400^{\circ} \mathrm{F}$ or slightly higher. This type of fuel capsule is well developed and was used successfully in SNAP 3B, 9A, 19, and 27. All of these RTG systems except SNAP 27 were developed by Isotopes, Nuclear Systems Division.

Design of the SNAP 19 heat source for intact re-entry and intact impact is constrained by the hexagonally-shaped central cavity of the thermoelectric core. On the SNAP 19 Nimbus program, the six thermoelectric modules were supported around this cavity by a graphite heat accumulator block that accepted heat from the centrally located heat source. It has been found that by utilizing this externally configured hexagonal graphite heat accumulator block as an integral addition to the previously developed cylindrical SNAP 19 graphite heat shield, three direct improvement effects on re-entry are obtained:

1. Additional graphite thickness on the order of $160 \mathrm{mils}$ is provided for ablation resistance.

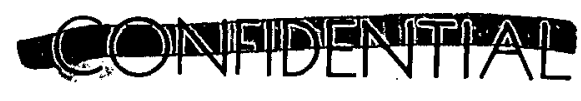

INSD-2650-29

IV -3 
2. Hypersonic ballistic drag coefficient $\left(W / C_{D} A\right)$ is decreased from 37 to $34 \mathrm{lb} / \mathrm{ft}^{2}$ due to the larger effective radius and corners, thereby reducing stagnation aerodynamic heating.

3. Subsonic drag coefficient is increased from 0.34 to 0.67 therefy reducing the calculated impact velocity from 335 to 245 fps.

These effects play a large part in assessing postulated fuel release probabilities. They affect safety margins with respect to heat source melt and ablation temperatures during potential re-entry and capsule rupture at Earth impact, two of the primary modes of potential fuel release.

\section{Capsule Design}

As indicated in Fig. IV-I, the high temperature fuel capsule has the configuration of a short cylinder with hemispherical ends. It is fabricated in two layers, an inner layer (25 mils thick) made of molybdenum 50 weight percent rhenium alloy which constitutes the primary containment vessel for the radioisotopic fuel, and an outer layer (nominally 60 mils) of TZM which provides resistance to any mechanical environments (impact, blast, shrapnel, crushing, etc.) which result from potential transportation, handling or flight accident, or from Earth impact after re-entry. The TZM strength member may be coated with rhodium, if required, to minimize the effect of oxidation after such an unlikely accident. The capsule is designed to contain up to 755 watts( $t$ ) of $\mathrm{Pu}-238 \mathrm{O}_{2}$ at a bulk power density of 2.7 watts per 


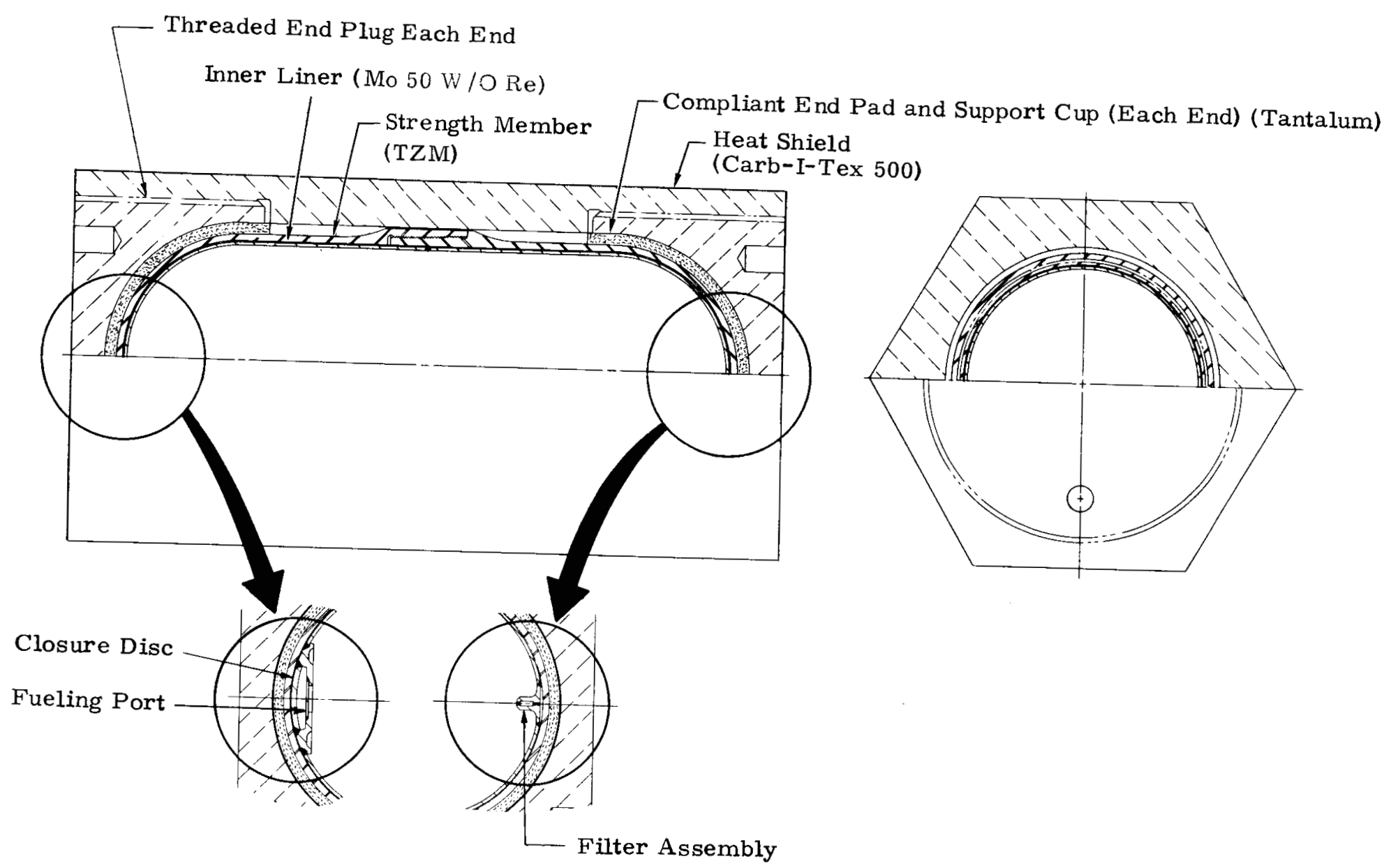

FIG. IV-I. INTACT IMPACT HFAT SOURCE (IIHS) 
cubic centimeter, although only 675 watts are required for the Viking RTG design.

\section{a. Primary container (liner)}

The primary container (liner) has a major function, that of fuel containment under all normal operating conditions without undue interaction with or reduction of the fuel form. Other important characteristics of the capsule liner which bear on material evaluation and form the bases for selection trade studies include:

(1) Fabricability

(2) Mechanical properties

(3) Melting temperature

(4) Availability and cost

(5) Oxidation/barrier coating applicability

The liner consists of two spun molybdenum 50\% rhenium, 25 mil thick cups, joined by a circumferential weld joint. Machined fueling port and filter-vent housing details, as shown in Fi. IV-I, are welded at opposite internal locations in the closed cup ends prior to making the central weld joint closure.

Fuel loading with $\mathrm{Pu}-238 \mathrm{O}_{2}$ microspheres is facilitated by the dual liner closure at the fueling port so that complete decontamination of the liner can be done after the initial seal weld and prior to performance of the outer closure cap structural TIG weld. This design concept was utilized in SNAP 19 IRHS ( 8 capsules of this design have previously been fueled) in which a small amount of $\mathrm{ZrO}_{2}$ particles was 
poured in over the fuel to occupy the remaining void volume. It was found that by performing the first closure weld over the $\mathrm{ZrO}_{2}$ particles, weld contamination was minimal and decontamination prior to the outer structural weld was made with ease.

Thin gauge materials are used to construct the liner, and it is anticipated that special handling tools will be required during the fuel loading operation. Similar handing tools were recently designed and built for the SNAP 19 IRHS program, although they were utilized with a heavier gauge superalloy capsule. With proper planning of handling operations and appropriate tool and fixture design, capsule loading problems can be reduced to a minimum. It should be pointed out that the TIG welds at the two fueling port closures (seal weld followed by structural weld) are the only welds required during the fuel loading and heat source assembly operation.

b. Strength member

The outer strength member is machined from stress-relieved TZM rod to obtain a hard, rupture-resistant shell around the liner. To facilitate assembly at the fueling facility, a threaded, two-piece assembly is used. Strength members using this technique have been successfully fabricated and tested including impact (16 tests), plasma $\operatorname{arc}(7$ tests), and solid propellant contact fire tests (2 tests). A recent series of impact and plasma arc test results are given in Tables IV-I and IV-2, respectively. The plasma arc test simulations for orbital decay and $36 \mathrm{~K} \mathrm{ft} / \mathrm{sec}$ superorbit re-entry are given in Figs. IV-2 and IV-3.

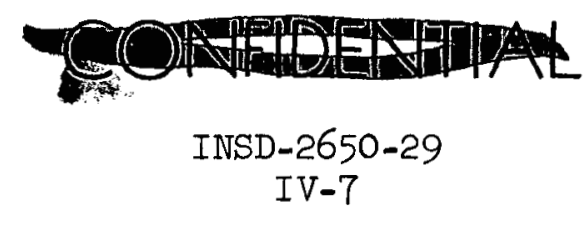


TABLE IV-I

IIHS IMPACT TEST PROGRAM*

Test No. Date

$16 / 12 / 69$

6/16/69 Taper Thread-2.47" dia.

6/19/69 Taper ${ }^{* *}-2.56^{\prime \prime}$ dia.

6/23/69 Taper Thread-2.56" dia.

6/27/69 Plasma Are Tested Taper Thread-2.56" dia.

6/27/69 Taper Thread-2.56" dia.

6/27/69 Taper Thread-2.56" dia.

$6 / 28 / 69$

$6 / 28 / 69$

$6 / 28 / 69$

$6 / 29 / 69$

$6 / 29 / 69$

$6 / 30 / 69$

$6 / 30 / 69$

$7 / 1 / 69$

Plasma Arc Tested Taper Thread-2.56" dia.

Taper Thread-2.56" dia.

Plasme Are Tested Taper rhread-2.56" dia 358 oxidazed (2 times)

Bare ${ }^{* * *}$ Taper Thread-2.56" dia. oxidized (3 times)

Taper Thread-2.56" dia.

352

349

394

350

\section{Impact Angle}

$60^{\circ}$ Female End

$60^{\circ}$ Female Find

$60^{\circ}$ Female fnd

$60^{\circ}$ Female fnd

$60^{\circ}$ Female End

$10^{\circ}$ Female End

$90^{\circ}$ Female End

$60^{\circ}$ Female End

$30^{\circ}$ Male End

$60^{\circ}$ Female End

$45^{\circ}$ Female End

$60^{\circ}$ Femrle Fnd

$10^{\circ}$ Male End

$60^{\circ}$ Female End

$60^{\circ}$ Female Find

\section{Result}

Failure in male thread relief; fuel released

Successful

Successful

Successfu工

Successful

Successful

Successful

Successful

Successful

Successful; 2 fine cracks in TZM; fuel retained

Successful

Successfu工

SuccessfuI

SuccessfuI

Successful; one fine crack in TZM; fuel retrined

* All samples prebeated to $1900^{\circ} \mathrm{F}$ prior to impact

** No threads, using interference fit

*** Impacted without graphite heat shield 
IIHS PIASMA ARC TEST SIMULATING RE-ENTRY FROM EARTH ORBIT

TEST SUMMARY

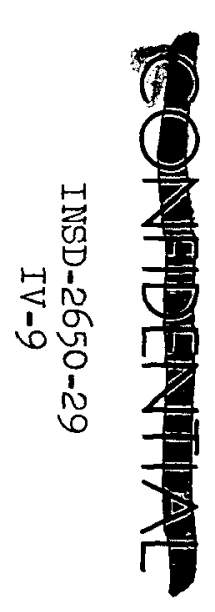

\begin{tabular}{|c|c|c|c|c|c|c|c|c|c|}
\hline $\begin{array}{l}\text { Test } \\
\text { No. }\end{array}$ & $\begin{array}{l}\text { Test } \\
\text { Date }\end{array}$ & $\begin{array}{c}\text { Heat Shield } \\
\text { Configuration } \\
\end{array}$ & $\begin{array}{l}\text { Dimensions } \\
\text { (in.) }\end{array}$ & $\begin{array}{c}\text { Test } \\
\text { Attitude } \\
\end{array}$ & \begin{tabular}{l}
\multicolumn{1}{r}{ Test } \\
Condition \\
Simulation \\
\end{tabular} & Test Facility & $\begin{array}{l}\text { Weight } \\
\text { Loss } \\
\text { (1b) } \\
\end{array}$ & $\begin{array}{c}\text { Maximum } \\
\text { Surface } \\
\text { Recession } \\
\text { (in.) } \\
\end{array}$ & Results \\
\hline 1 & $6 / 24 / 69$ & Hex Prism & $\begin{array}{l}6.75 \text { long } x \\
3.5 \text { between } \\
\text { flats }\end{array}$ & $\begin{array}{l}\text { Corner facing } \\
\text { flow }\end{array}$ & $\begin{array}{l}\text { Superorbit } \\
36 \mathrm{~K} \mathrm{ft} / \mathrm{sec} \\
\gamma_{1}-6^{\circ}\end{array}$ & NASA -MSC & -- & .083 & $\begin{array}{l}\text { Failure in heat shield } \\
\text { thread relief due to } \\
\text { over torquing of } \\
\text { threaded end plug; } \\
\text { capsule undamaged }\end{array}$ \\
\hline 2 & $6 / 24 / 69$ & Hex Prixm & $\begin{array}{l}6.75 \text { long } x \\
3.5 \text { between } \\
\text { flats }\end{array}$ & $\begin{array}{l}\text { Corner facing } \\
\text { flow }\end{array}$ & $\begin{array}{l}\text { Superorbit } \\
36 \mathrm{~K} \text { ft/sec } \\
\gamma_{i}-6^{\circ}\end{array}$ & NASA-MSC & .048 & .083 & Successful \\
\hline 3 & $6 / 25 / 69$ & Hex Prism & $\begin{array}{l}6.75 \text { long } x \\
3.5 \text { between } \\
\text { flats }\end{array}$ & $\begin{array}{l}\text { Corner facing } \\
\text { flow }\end{array}$ & $\begin{array}{l}\text { Superorbit } \\
36 \mathrm{~K} \mathrm{ft} / \mathrm{sec} \\
\gamma_{i}-6^{6}\end{array}$ & NASA-MSC & .046 & .090 & Successful \\
\hline 4 & $6 / 26 / 69$ & Hex Prism & $\begin{array}{l}6.75 \text { long } x \\
3.5 \text { between } \\
\text { flats }\end{array}$ & $\begin{array}{l}\text { Corner facing } \\
\text { flow }\end{array}$ & Orbital Decay & Martin-Baltimore & .16 & .077 & Successful \\
\hline 5 & $6 / 27 / 69$ & Hex Prism & $\begin{array}{l}6.75 \text { long } x \\
3.5 \text { between } \\
\text { flats }\end{array}$ & $\begin{array}{l}\text { Corner facing } \\
\text { flow }\end{array}$ & Orbital Decay & Martin-Baltimore & .16 & .082 & Successful \\
\hline 6 & $6 / 28 / 69$ & Hex Prixm & $\begin{array}{l}6.75 \text { long } x \\
3.5 \text { between } \\
\text { flats }\end{array}$ & $\begin{array}{l}\text { Corner fecing } \\
\text { flow }\end{array}$ & Orbital Decay & Mertin-Baltimore & .16 & .082 & Successful \\
\hline
\end{tabular}




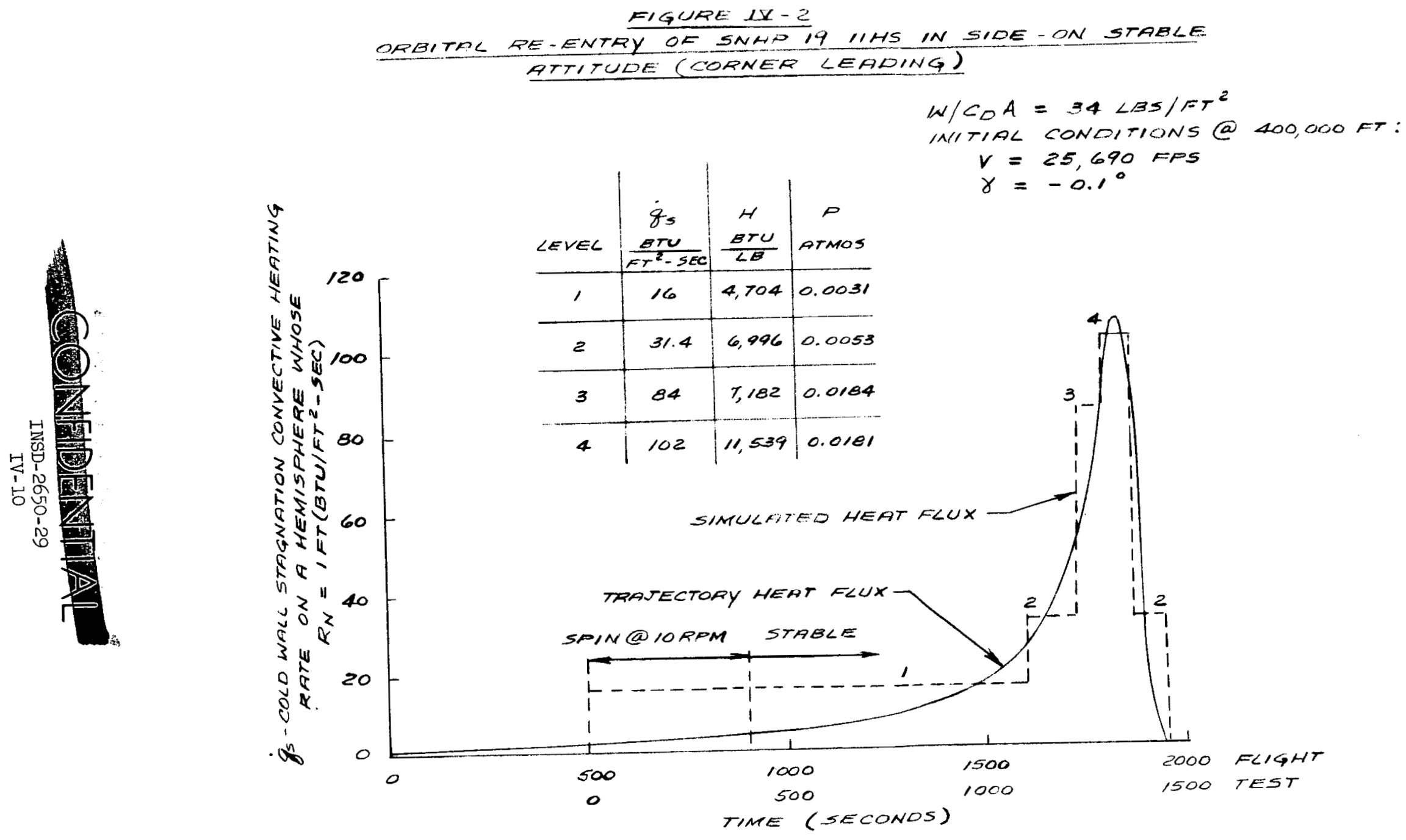



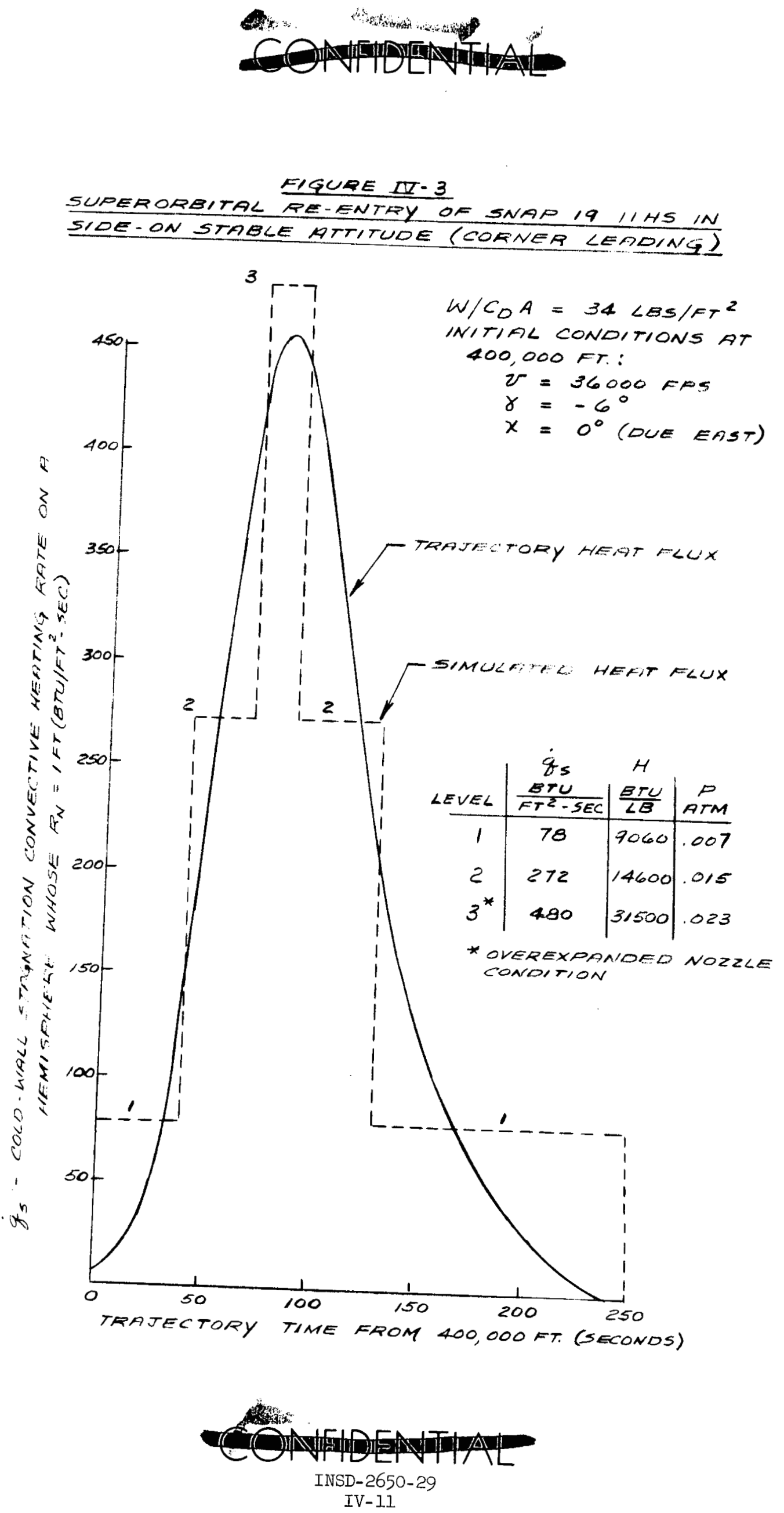
The TZM strength member is composed of two mating cups which are machined at the open ends with a tapered threaded joint. Assembly is completed by merely inserting the fueled liner into the female strength member cup and then threading the male component into final engagement. The completed capsule will then be ready for installation into the heat shield.

There is always some concern over whether threaded parts may be cross-threaded during assembly. Cross-threading is caused by improper alignment at the start of the threading operation by at least one-half a thread lead. In the present design, as the male half of the strength member is lowered over the fuel capsule liner, it will slide over the cylindrical surface of the liner a distance of approximately 1.5 inches before contact with the mating threads is made. If it is assumed that a maximum diametrical tolerance of 0.005 inch is provided, this will result in a maximum angular misalignment of 0.0033 inch or 0.19 degree. This corresponds to less than half a thread lead. This illustrates that cross-threading of the TZM strength member is not possible because of the alignment provided by the internal capsule liner. Because of tapered thread torquing and the preload applied to the capsule during assembly into the heat shield, the threads will not back off as a result of vibration loading.

c. Filter

A one-stage ceramic vent is provided at one end of the liner to allow the helium generated within the capsule to escape. The vent

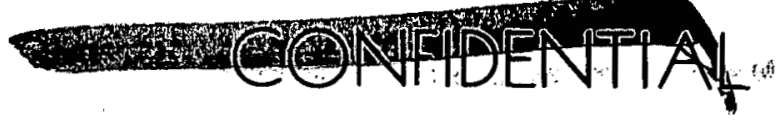


serves to contain the fuel particles within the capsule and gives low pressure arop to the flow of helium. This stage is similar to materials and identical in construction to that used in SNAP 19 IRHS, for which fuel compatibility and filtration properties with production grade Pu-238 $\mathrm{O}_{2}$ microspheres have already been tested and proven.

An additional flow-regulating feature can be obtained by the application of a high density, vitreous oxide filter-vent to directly replace the lower density material as used in the SNAP 19 IRHS capsule. The use of the higher density material will provide a controlled pressure drop across the filter-vent on the order of 10 psi at the nominal helium production rate of the decaying $\mathrm{Pu}-238 \mathrm{O}_{2}$ fuel. As a result of the maintained helium gas pressure in the fuel cavity, fuel centerline temperatures will be minimized.

Assembly of the filter element into the vent receptacle will be performed in a manner similar to that developed for SIAP 19 IRHS. It involves the process of platinum plating the outer cylindrical surface of the ceramic filter element, then machining and installing it into the machined filter housing receptacle and diffusion bonding the element into place. Evidence from impact tests performed with SNAP 19 IRHS indicates that this vent configuration is impact resistant without swaging or staking the element into place. A pierce disc is utilized outside the vent to permit complete decontamination subsequent to fueling as well as to protect the vent element from the influx of dirt or cleaning solution. The disc is pierced prior to installing the liner into the strength member to activate filter venting of helium gas.

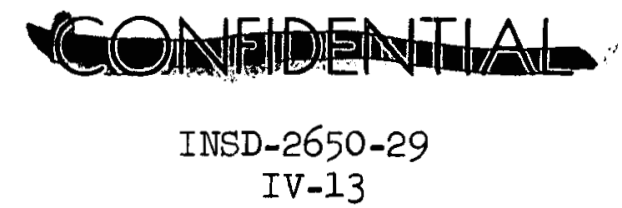

IV-13 
a. Coatings

A zirconium oxide coating will be required on the external hemispherical surfaces of the TZM structural member to provide a diffusion barrier to the tantalum felt compliance pad at both ends when installed in the graphite heat shield. Application of coating on the external surface of the TZM strength member is performed as a routine process prior to fueling.

It should be noted that compatibility between the TZM strength member and the graphite heat shield is no problem since the materials do not contact.

\section{Heat Shield Design}

The graphite heat shield, when fits within the existing RTG heat source cavity, has an external configuration of a right hexagonal prism, 6.75 inches long and 3.50 inches across opposing flats. Fabrication of the heat shield is accomplished by boring out a Carb-I-Tex 502 tube and machining the outside to the hexagonal shape. Two threaded end caps of Carb-I-Tex 500 are fabricated with spanner wrench holes to permit ease of installation (Fig. IV-I).

\section{Capsule Suitability to Solid Fuel Forms}

To facilitate fueling operations with solid fuel forms, design of the liner for edge-type TIG weld closure at the hemispherical cap can be provided (Fig. IV-4). This liner configuration permits the final weld to be performed at a remote location from the fuel. It would also allow the use of right cylindrical pellets having one diameter only, with the exception of the hemispherical ends.

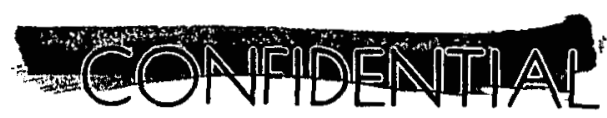

INSD-2650-29

IV-14 


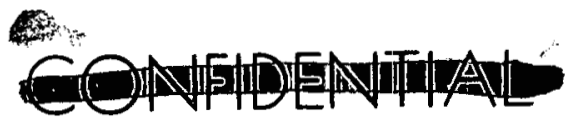

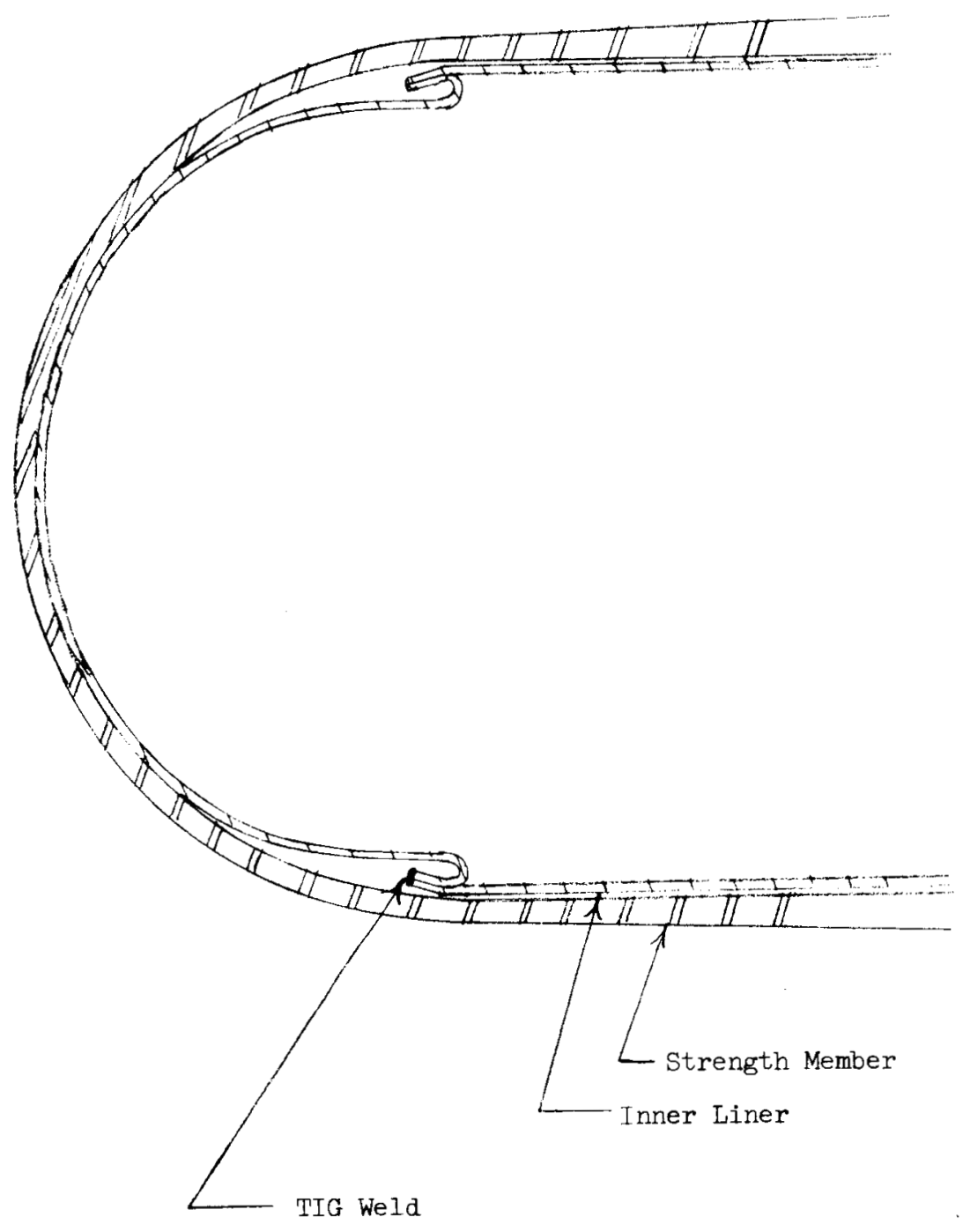

FIG. IV-4. WEID CLOSURE IJETAIL

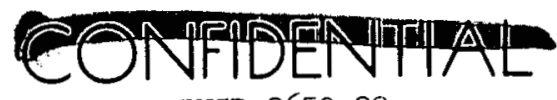

INSD-2650-29

IV- 15 


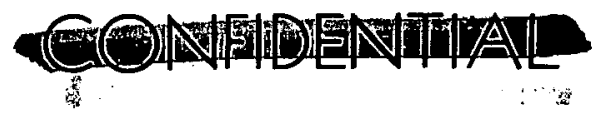

\section{STEADY STATE TEMPERATURE PROFILES}

The baseline heat source design employs a Carb-I-Tex 500/502 graphite heat shield. Alternate designs have been considered which employ a superalloy, vibration-isolation metal sleeve between the heat shield and thermoelectrics and which consider POCO graphite for the heat shield. These various combinations have been thermally analyzed for both beginning-of-life (BOL) normal operation and launch time ( 9 months after BOL) normal operation at steady state conditions inside the RTG. In addition, the launch phase was studied for two malfunction conditions - open circuit and normal load electrical operation, both with an RTG internal vacuum to simulate loss of fill gas at launch.

An 85 node thermal model of the heat source was constructed, as shown in Fig. IV-5, for solution with a digital computer code. The model is a $10^{\circ}$ pie-slice from one-half of a heat source, since circumferential and axial symetry can be assumed.

Material properties are handled by the code as constants; values used are given in Table IV-3. The actual thermal fuel loading will be 675 watts per RTG. For conservatism, this analysis assumed complete loading of the capsule - 755 watts.

Results of the code runs are summarlzed in Table IV-4. The use of a metal sleeve around the heat shield adds 50 to $150^{\circ} \mathrm{F}$ to all heat source temperatures, and a Carb-I-Tex heat shield results in temperatures about $70^{\circ} \mathrm{F}$ higher than with a POCO graphite shield. The conductivity of gas contained within the generator changes with time due

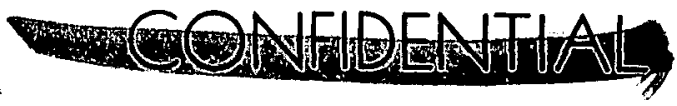




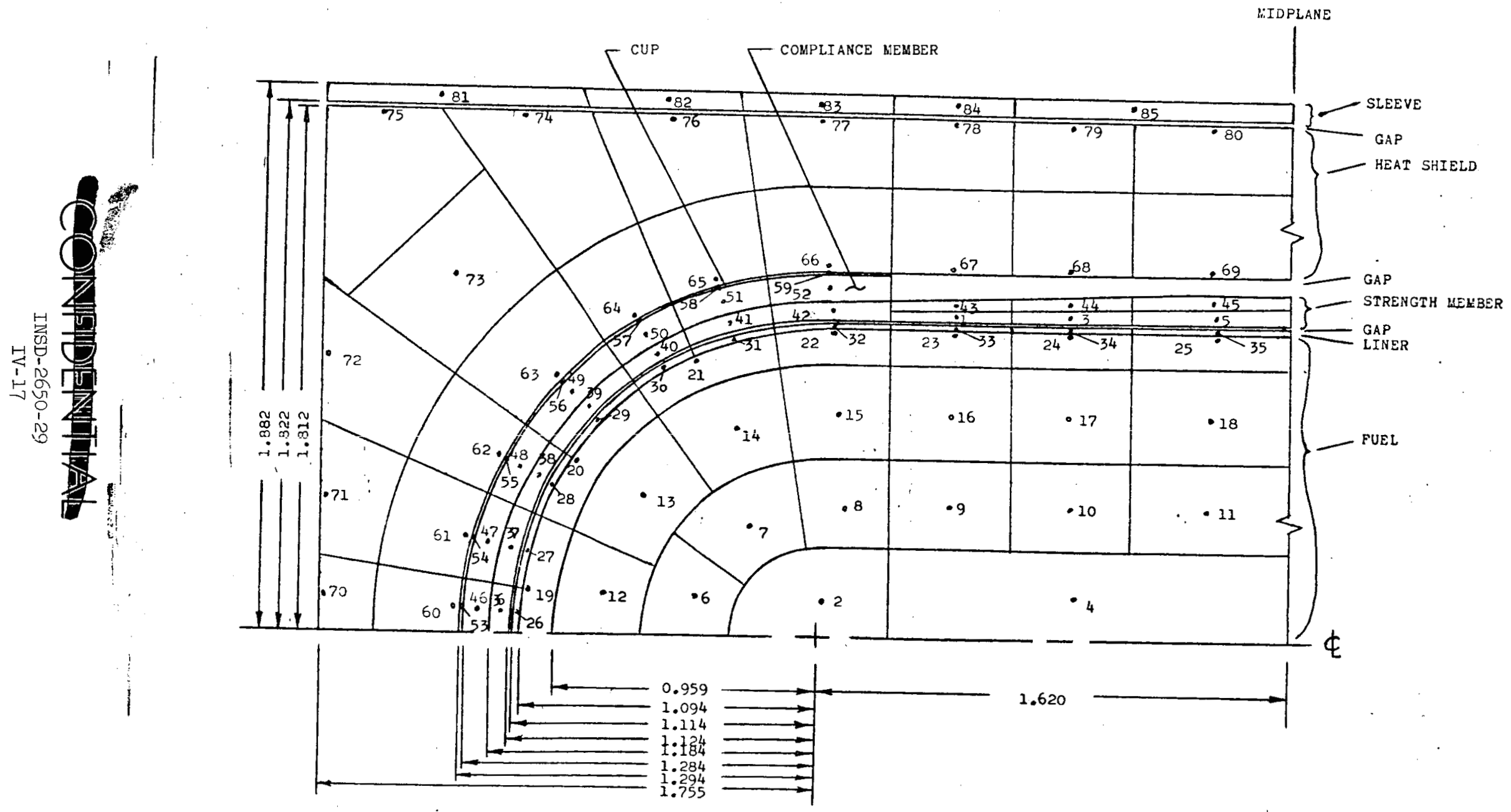

FIG. IV-5. VIKING THERMAL MODEL 
TABLE IV-3

MATERIAI PROPERTIES OF VIKTNG HEAT SOURCE

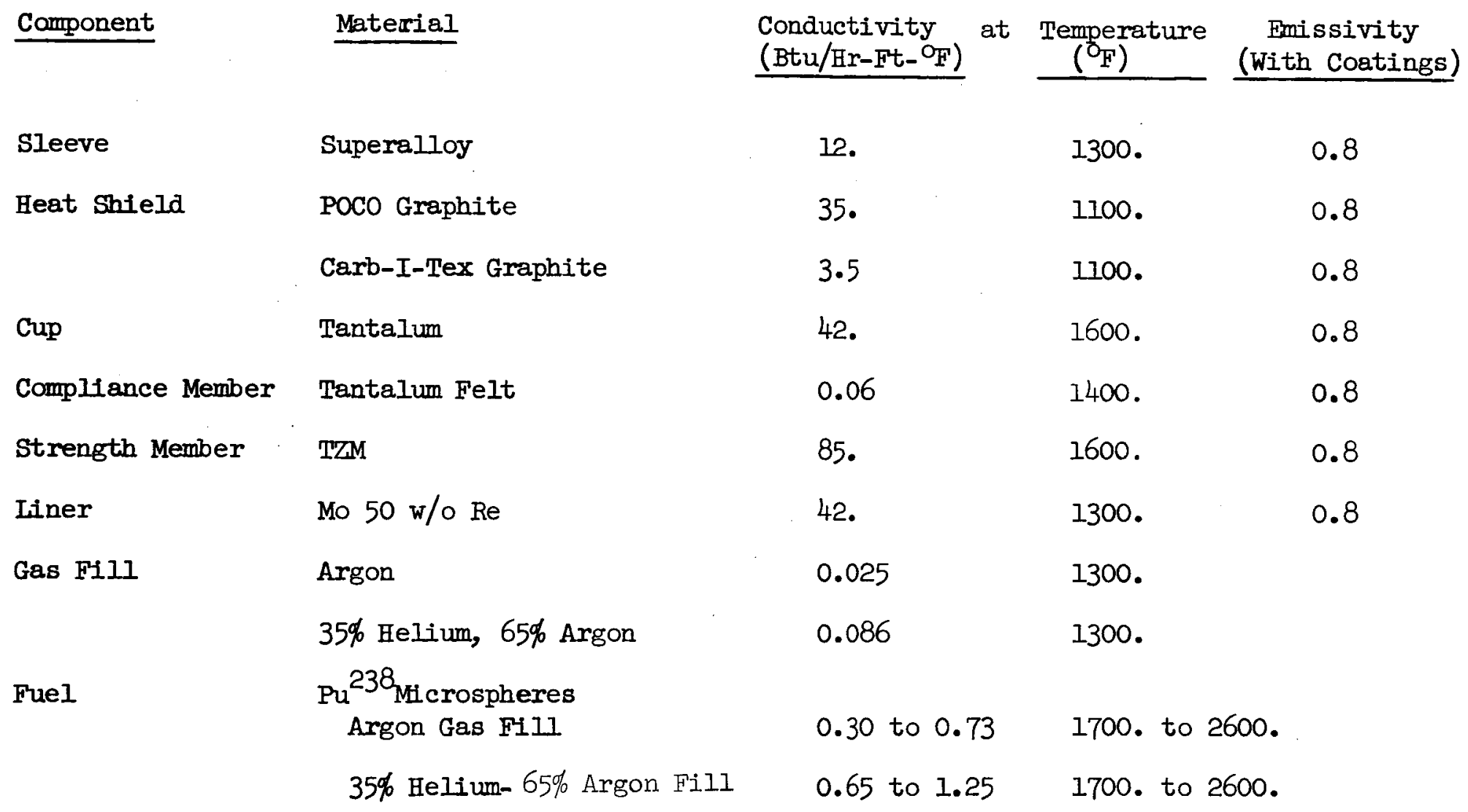

\section{Component}

Sleeve 
TABLE IV-4

MAXIMUM STEADY STATE TEMPERATURES OF VIKING HEAT SOURCE

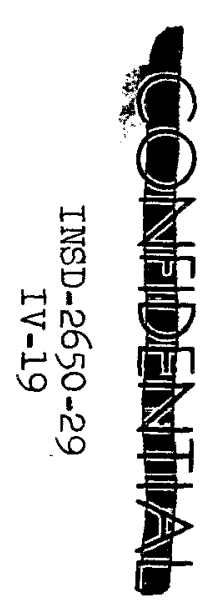

Configuration
Poco heat shield
with sleeve
Poco heat shield
without sleeve
Carb-I-Tex heat shield
with sleeve
Carb-I-Tex heat shield
without sleeve
Carb-I-Tex heat shield
without sleeve; vacuum
gaps; normal elec. load
Carb-I-Tex heat shield
without sleeve; vacuum
gaps; open circuit

\begin{tabular}{|c|c|c|c|c|c|c|c|}
\hline Time & $\begin{array}{c}\text { Sleeve } \\
\left(\mathrm{O}_{\mathrm{F}}\right)\end{array}$ & $\begin{array}{c}\text { Heat } \\
\text { Shield } \\
\left(\mathrm{O}_{\mathrm{F}}\right) \\
\end{array}$ & $\begin{array}{l}\left.\operatorname{Cup}_{(\mathrm{F}}\right) \\
(\mathrm{O}\end{array}$ & $\begin{array}{c}\text { Compliance } \\
\text { Member } \\
\left(\mathrm{O}_{\mathrm{F}}\right)\end{array}$ & $\begin{array}{c}\text { Strength } \\
\text { Member } \\
\left(\mathrm{O}_{\mathrm{F}}\right) \\
\end{array}$ & $\begin{array}{r}\text { Liner } \\
\left({ }_{\mathrm{F}}\right)\end{array}$ & $\begin{array}{l}\text { Fuel } \\
\left(O_{F}\right)\end{array}$ \\
\hline $\begin{array}{l}\text { BOL } \\
\text { Launch }\end{array}$ & $\begin{array}{l}1114 \\
1065\end{array}$ & $\begin{array}{l}1231 \\
1188\end{array}$ & $\begin{array}{l}1204 \\
1158\end{array}$ & $\begin{array}{l}1434 \\
1365\end{array}$ & $\begin{array}{l}1708 \\
1615\end{array}$ & $\begin{array}{l}1814 \\
1662\end{array}$ & $\begin{array}{l}2776 \\
2618\end{array}$ \\
\hline $\begin{array}{l}\text { BOL } \\
\text { Launch }\end{array}$ & -- & $\begin{array}{l}1129 \\
1085\end{array}$ & $\begin{array}{l}1108 \\
1061\end{array}$ & $\begin{array}{l}1355 \\
1279\end{array}$ & $\begin{array}{l}1642 \\
1539\end{array}$ & $\begin{array}{l}1733 \\
1588\end{array}$ & $\begin{array}{l}2721 \\
2548\end{array}$ \\
\hline $\begin{array}{l}\text { BOL } \\
\text { Launch }\end{array}$ & $\begin{array}{l}1177 \\
1134\end{array}$ & $\begin{array}{l}1512 \\
1396\end{array}$ & $\begin{array}{l}1311 \\
1204\end{array}$ & $\begin{array}{l}1554 \\
1438\end{array}$ & $\begin{array}{l}1833 \\
1706\end{array}$ & $\begin{array}{l}1911 \\
1753\end{array}$ & $\begin{array}{l}2903 \\
2726\end{array}$ \\
\hline $\begin{array}{l}\text { BOL } \\
\text { Launch }\end{array}$ & -- & $\begin{array}{l}1332 \\
1295\end{array}$ & $\begin{array}{l}1163 \\
2115\end{array}$ & $\begin{array}{l}1424 \\
1358\end{array}$ & $\begin{array}{l}1717 \\
1634\end{array}$ & $\begin{array}{l}1806 \\
1682\end{array}$ & $\begin{array}{l}2801 \\
2658\end{array}$ \\
\hline Launch & -- & 1441 & 1259 & 1489 & 1757 & 1889 & 2891 \\
\hline Launch & -- & 1677 & 1492 & 1699 & 1948 & 2048 & 3042 \\
\hline
\end{tabular}

Launch

1677


to the addition of helium from fuel decay. This change in gas composition results in lower temperature drops across gaps at launch time than exist immediately after fueling.

All resultant component temperatures for normal generator operation are acceptable for an IIHS. The vacuum malfunction cases appear to be acceptable, even for superorbital re-entry, but further analysis and test are necessary for confirmation. Fuel centerline data for the vacuum cases presumes the use of a finite pressure drop filter in the liner in order to retain a gas environment in the fuel.

\section{IAUNYCH PAD ABORT STUDY}

An analysis was performed to evaluate the response of the nuclear system to the more severe environments resulting from accidents occurring after booster fueling and RTG payload installation. A Titan IIIC/ Centaur Vehicle was assumed for the analysis. A representative failure probability of $1 / 100$ was assumed for those failure modes leading to propellant explosion and a subsequent fireball. The objective was to determine the total probability of fuel release in the launch pad environs, taking into account the more severe environments threatening fuel containment and the capability of the system to withstand these environments.

The analysis employed techniques developed during the SIIAP 29 program and utilized in the PSAR (Ref. IV-I) for that system. Included in this study were the effects of blast and shrapnel environments,

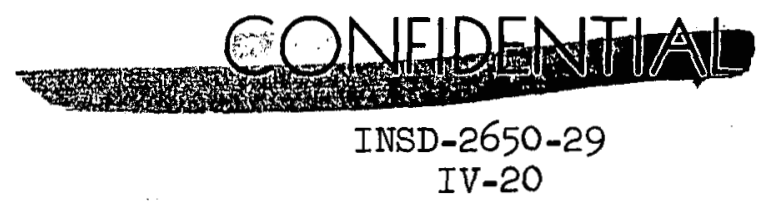


impact of fuel-bearing systems on the surface of the pad, and the thermal environment. The analyses were separated into two phases: environment characterization and system response.

1. Environment Characterization

Each environment considered depends, in part, upon one or more of the vehicle parameters including propellant weight, propellant type, and the separation distance between payload and fuel-oxidizer interfaces. These parameters are shown in Table IV-5.

\section{TABLE IV -5}

VEHICLE PARAMETERS-TITAN IIIC/CENTAUR

\begin{tabular}{|c|c|c|c|c|c|}
\hline Vehicle & Stage & Propellant & $\begin{array}{l}\text { Propellant } \\
\text { Weight } \\
\text { (1bs.) } \\
\end{array}$ & $\begin{array}{c}\text { Stage } \\
\text { Dimension } \\
\text { (ft) } \\
\end{array}$ & $\begin{array}{l}\text { Distance-RTG } \\
\text { to Fuel/Oxidizer } \\
\text { Interface(ft) }\end{array}$ \\
\hline \multirow[t]{3}{*}{ Titan } & 0 & UTP-3001(solid) & 843,000 & 83 & 86 \\
\hline & 1 & $\mathrm{~N}_{2} \mathrm{H}_{4} / \mathrm{N}_{2} \mathrm{H}_{2} / \mathrm{IDMH}$ & 251,000 & 73 & 96 \\
\hline & 2 & $"$ & 66,000 & $23 \cdot 3$ & 50 \\
\hline Centaur & - & $\mathrm{IO}_{2} / \mathrm{LH}_{2}$ & 29,858 & 30 & 25 \\
\hline$P / I$ & - & - & - & 20 & - \\
\hline
\end{tabular}

The mechanical and thermal environments are treated chronologically in the following sections.

a. Blast

Reference IV-I presents a review and statistical analysis of data pertaining to blast overpressures, including dependence on fuel weight, separation distance, and the relationship between rocket propellants

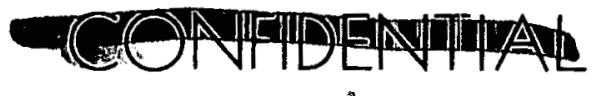

INSD-2650-29

IV-21 
and TNI. An empirical equation for TNT explosions was determined relating maximum overpressure (psi) to distance and explosive weight of the form:

$$
P=10^{3} \frac{W_{f}^{2 / 3}}{R^{2}},
$$

where $\mathrm{W}_{\mathrm{f}}=$ weight of TNT (Ibs)

and $R=$ separation distance $(f t)$

It was further determined that the same equation could be employed to describe overpressures from detonation of liquid rocket propellants provided that $W_{f}$ is interpreted as the weight equivalent of TNT for each type of propellant. Statistical treatment of test data showed mean weight equivalency factors of $4.5 \%$ for cryogenic fuels and $0.51 \%$ for hypergolics. Statistics were consistent with "one-sided" normal distributions with standard deviations of 5.6 and $1.2 \%$, respectively. These equivalence factors and variances were employed to determine peak overpressure values at the payload for the appropriate stages of the reference vehicle. Table IV- 6 shows the mean, 90 percentile and 99 percentile TNT equivalence for each stage. Table IV-7 presents the calculated overpressures, the percentile values here indicating the probability of not exceeding the tabulated overpressure.

It is seen that the Centaur stage yields the predominant overpressures because of its cryogenic fuel and proximity to the payload region. The percentiles indicate the probability of not exceeding a given overpressure. Thus the probability of not exceeding 500 psi within the payload from a Centaur explosion is 0.99 .

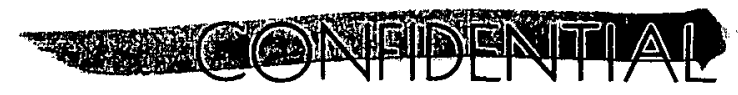




\section{TABLE IV-6}

TNT EQUIVAIENTS FOR VEFICULAR STAGES

Stage

Centaur

Titan (2)

Titan (1)
Mean

1340

337

1280
TNT Equivalence (lbs.)

$\begin{array}{ll}\frac{90 \%}{3500} & \underline{99 \%} \\ 1317 & 5280 \\ 5005 & 2122 \\ & 8060\end{array}$

TABLE IV -7

OVERPRESSURES AT PAYIJOAD (psi)

\section{Stage}

Centaur

Titan (2)

Titan (1)
Mean

200

20

13
$90 \%$

386

49

32
$99 \%$

500

68

45

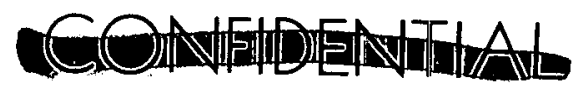

INSD-2650-29

IV -23 
b. Shrapnel

The shrapnel environment during a launch pad explosion is not well defined. An estimate of the environment was obtained (Ref. IV-I) from data derived from the command destruct of 2 solid rocket motors. The environment was represented by about 230 pieces of aluminum about I foot square by $1 / 4^{\prime \prime}$ thick with a speed of about $300 \mathrm{ft} / \mathrm{sec}$, each piece of shrapnel therefore having a kinetic energy of about $5 \times 10^{3} \mathrm{ft}-1 \mathrm{~b}$ at impact.

The probability of shrapnel impacting a given configuration (RTG, heat source, or capsule) was determined by assuming the shrapnel to be distributed isotopically in space from the point of explosion. The impact probability then, is given by:

$$
P=\frac{N A}{4 \pi R^{2}}
$$

where $\mathrm{N}$ = number of fragments

$$
\mathrm{R} \quad \text { = distance from source of explosion }
$$

and

A = interaction area for a particular configuration; i.e., the total area such that if the center of mass of a fragment penetrates this area, impact with the target will occur.

The number of fragments, N, for the Centaur vehicle was assumed to be about 70 . Under the above assumptions, the Centaur vehicle contributed the largest shrapnel impact probability in the payload region.

\section{c. Impact}

It is shown in the next section that the most likely result of a postulated blast with overpressure as described above would be to free

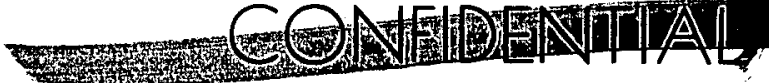

INSD-2650-29

IV-24 
the heat source, leading to subsequent impact in the launch pad vicinity. An analysis based on a survey of locations of the payload after 30 launch aborts was coupled with estimates of the relative fractions of these areas comprising sand, concrete and structure. The resulting probability estimates (Ref. IV-1) were $0.65,0.3$ and 0.05 , respectively, for these impact media. The impact speed was calculated to be about $100 \mathrm{ft} / \mathrm{sec}$.

The calculated fall time was about 2.8 seconds. Therefore, for any case in which the fuel capsule is protected by a heat shield until impact, the capsule is assumed to be exposed to the thermal environment at 2.8 seconds from the fireball initiation.

\section{d. Thermal environment}

The thermal environment considered in this study comprises three parts, the fireball contributed by liquid propellants and to a lesser extent by solids, the residual solid fire characterized by localized chunks of burning propellant, and the residual liquid fires fed by pools of liquid propellant not consumed in the fireball. The distribution of thermal fluxes in time for each source is discussed below.

\section{(1) Fireball}

Kite and Bader (Ref. IV-2) have presented a thermal flux model as a function of a dimensionless temporal argument scaled according to the cube root of the propellant weight involved. Their results are given in Table IV-8.

The model on which this heat flux distribution was derived assumed that all available energy in the propellant quantity, $W$, is

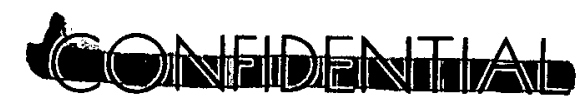


TABLE IV -8

HEAT FLUX MODEL

$$
t *=\frac{22 t(\mathrm{sec})}{w(1 \mathrm{bs})^{1 / 3}}
$$

0

0.2

0.4

0.6

0.8

0.9

1.0

1.2

$1.5-$

$1.5+$

1.7

1.9 $\dot{q}(t *) B t u / f t^{2}-s e c$

400

332

290

267

247

242

225

197

165

43

26

13

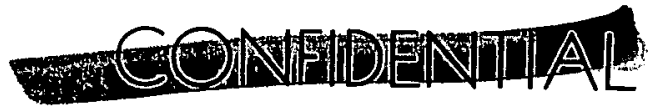

INSD - 2650-29

IV-26 
consumed. It, therefore, represents a maximum heat flux distribution for a given amount of propellant. Results of recent tests completed under the PYRO Program (to be reported by Bader) tend to confirm the maximal nature of this thermal distribution.

Based on a qualitative review of these results we have assumed a model in which a scaling factor, $f$, is defined such that $t^{*}=\frac{22 t}{f \mathrm{w}^{1 / 3}}$, and the density for $f$ is uniformly distributed between 0.2 and 1.0 . According to this assumption the heat flux distribution corresponding to any percentile thermal profile decreases more rapidly in time than the maximal profile.

The contribution of solid propellants to the fireball has been treated previously by assuming an equivalence of solid and liquid propellants. A recent analysis (Ref. IV-3) of data developed under Project SOPHY yielded an equivalence factor, derived from the effect of solid propellants on fireball duration, of 0.25 . We have used this equivalency in predicting heat flux distributions characterizing the Titan IIIC/Centaur fireball.

(2) Residual Iiquid fires

The analytical model incorporates a constant heat flux following the conclusion of the fireball of $13 \mathrm{Btu} / \mathrm{ft}^{3}-\mathrm{sec}$ for a 30 minute interval.

(3) Residual solid fires

Solid propellant ignition tests conducted under the SNAP 29

Program yielded heat fluxes of about $50 \mathrm{Btu} / \mathrm{ft}^{2}-\mathrm{sec}$. incident on typical

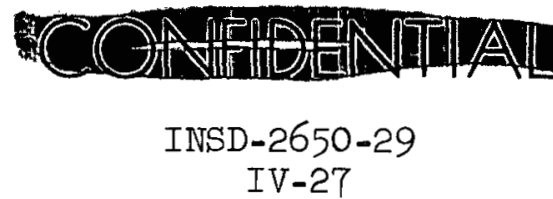


heat source and capsule configurations. This value applies to the heat transferred through the surface of specimens, which surfaces were observed to be coated with varying thicknesses of aluminum oxide. Burn times for the one cubic foot propellant samples were quite uniform at about 4 minutes.

While the propellant used in these tests was AlGOl-IIB (Scout vehicle propellant), the Titan solid (UTP-3001) is not expected to present a more severe environment. The heat flux is expected to increase by about $40 \%$, however, the burning rate is about 3 times as great. Thus the integrated heat for the same size propellant block would be reduced for the Titan fuel.

From an analysis of propellant fragments from an SRM detonation (described in Ref. IV-I), the most probable propellant thickness to be encountered (if at all) by a heat source falling to launch pad would be about one foot, the same thickness used in the SNAP 29 tests.

The fragmentation analysis was also used to estimate the probability that a falling heat source or capsule would impact in close proximity to a burning fragment. The distribution of fragments was represented by a spatial distribution of the form $r e^{-\alpha r^{2}}$, where $r$ is the distance measured from the base of the vehicle. The parameter, $\alpha$, was determined from the expected separation distance for a fragment of a given mass.

This distribution was then combined with the aforementioned information on payload depositions following aborts to determine the

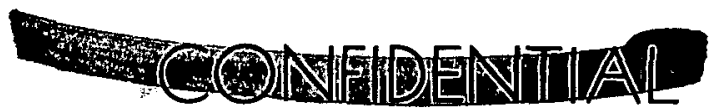




\section{a}

proximity probability. The result was 0.1 , which did not depend sensitively on the choice of the parameter $\alpha$. It was further estimated that in only one case out of ten the impacted fragment would be ignited. The total probability of depositing a heat source on a burning propellant fragment was therefore about $1 / 100$.

Based on these arguments the thermal environment to which a capsule or heat source would be exposed if it impacted on or near a chunk of solid propellant was assumed to be a heat flux of $50 \mathrm{Btu} / \mathrm{ft}^{2}$-sec for a four minute interval.

The total thermal environment is summarized in Fig. IV-6. The fireball heat fluxes occurring less than about five seconds after detonation are shown as 50 and $99 \%$ percentile curves. The 99 percentile curve was formed from the "maximum" heat flux curve described by Kite and Bader using the 55\% equivalence evaluated for solid propellants contributing to the fireball. The variance in this equivalence factor led to its being considered 99 percentile (rather than 100 percentile). 2. Heat Source Response

The reference system selected for analysis in response to the aforementioned environments consists of a fuel capsule enclosed in a hexagonal prism of Carb-I-Tex 500/502 graphite and inserted in the RTG. The fuel capsule is a cylindrical element 3.16 inches long with an OD of 2.4 inches, and hemispherical end caps 2.4 inches in OD. The hexagonal heat source has a projected area of $3.5 \times 6.75$ in. ${ }^{2}$. The projected area for the generator is about $6.5 \times 10 \mathrm{in.}^{2}$.

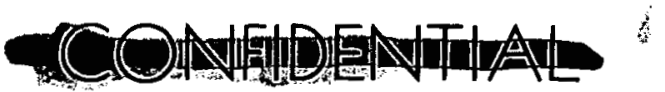

INSD-2650-29

IV-29 

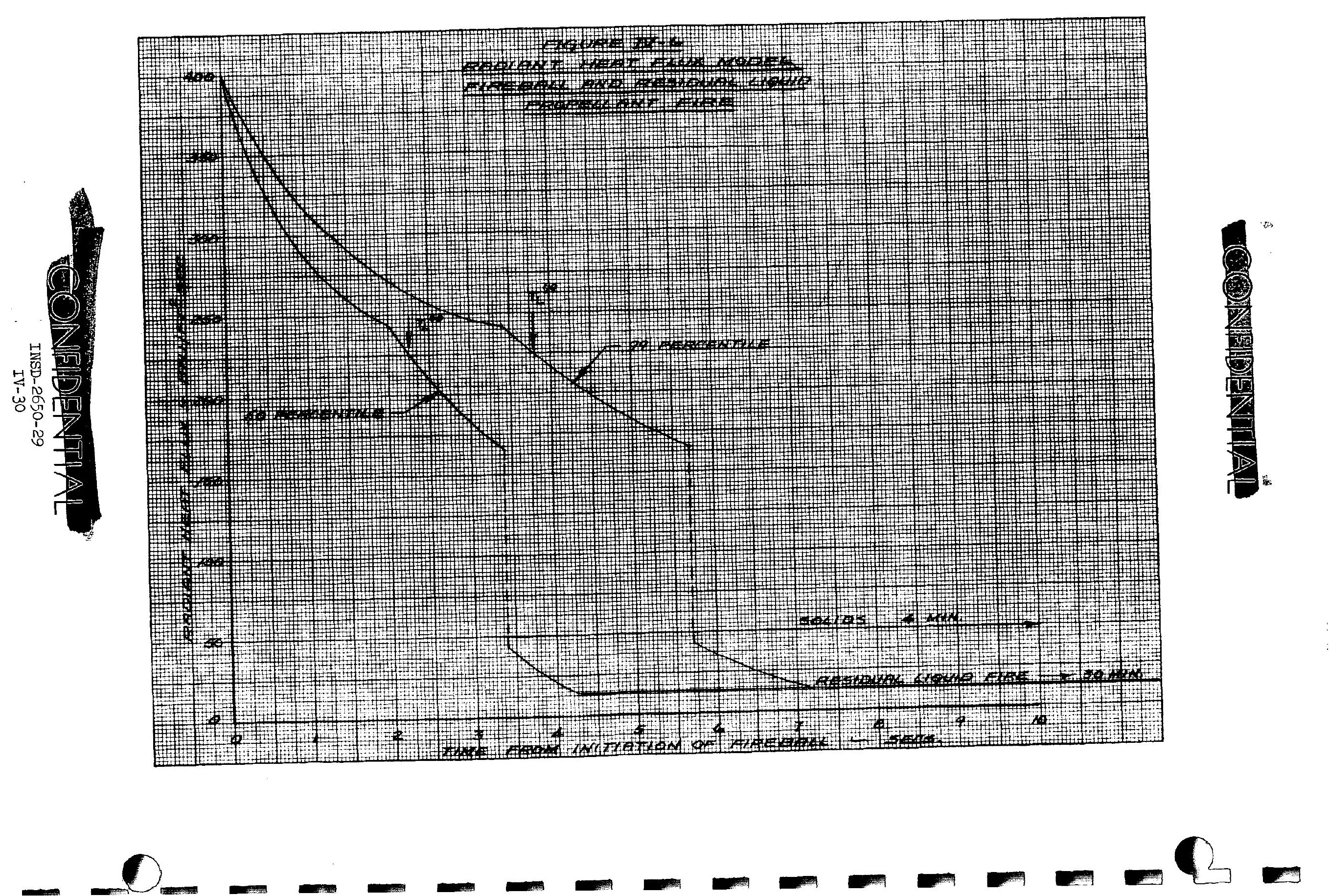
Table IV-9 lists materials and approximate thicknesses used in evaluating resistance to mechanical environments, particularly shrapnel impact.

TABLE IV-9

RTG COMPONENTS CHARACTERISTICS

\begin{tabular}{|c|c|c|c|c|}
\hline Component & Material & Thickness (in) & $\begin{array}{l}\text { Density } \\
\left(1 \mathrm{~b} / \mathrm{n}^{3}\right)\end{array}$ & $\begin{array}{l}\text { Modulus of } \\
\text { Elasticity } \\
\text { Psi x } 10^{-6}\end{array}$ \\
\hline Ifiner & Mo $50 \mathrm{w} / 0 \mathrm{Re}$ & 0.030 & 0.494 & 40.0 \\
\hline Strength Member & TZM & 0.080 (avg.) & 0.37 & 32.0 \\
\hline Heat Shield & $\begin{array}{l}\text { Graphite } \\
\text { Carb-I-Tex 500/502 }\end{array}$ & $2^{0.450}$ & 0.051 & 1.9 \\
\hline Hot Shoes & NI with Fe insert & 0.050 & 0.321 & 30.0 \\
\hline$T / E$ elements & TAGS/PbTe & 0.500 & 0.252 & 10.0 (avg.) \\
\hline Cold End Hardware & $\mathrm{A} I$ & 0.80 & 0.098 & 10.0 \\
\hline Housing & $\mathrm{Mg}$ & 0.1 & 0.064 & 6.2 \\
\hline
\end{tabular}

\section{a. Blast response}

To evaluate structural response to a blast loading, the pressure history must be defined. From the detonation, a shock wave is formed consisting of a mass of compressed air propagating toward the target or structural configuration. When the blast wave encounters the structure, the wave is diffracted. The pressure loadings developed by reflected shock waves during this diffraction phase are considerably higher than the side-on overpressure. The time duration of the diffraction phase is very short and often is a cause of failure in high frequency structures.

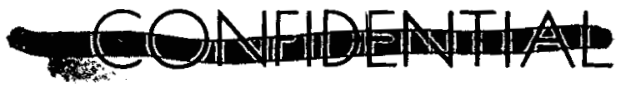

INSD-2650-29

IV -31 


\section{a}

After the blast wave has enclosed the structure, the pressure differential between front and back faces of the structure decreases considerably. This loading is a function of the dynamic pressure and is termed the drag phase. The time duration is relatively long and damage is primarily to low frequency structures.

For this study, interest is directed toward potential blast effects on the generator, fuel block and capsule. Table IV-lo constain the considered overpressures and their probabilities of not being exceeded.

\section{TABLE IV-10}

\section{SELECTED OVERPRESSURES}

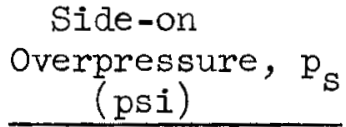

500
Probability

(\%)

50

90

99

By applying the conservation of mass, energy, and momentum at the shock front, the reflected pressure, $p_{r}$, and dynamic pressure, $q$, may be obtained as a function of side-on overpressure, $p_{s}$, and ambient pressure, $p_{0}$.

$$
\begin{aligned}
& P_{r}=2 p_{s}\left[\frac{7 p_{0}+4 p_{s}}{7 p_{0}+p_{s}}\right] \\
& q=\frac{5 p_{s}^{2}}{2}\left[\frac{1}{7 p_{0}+p_{s}}\right]
\end{aligned}
$$

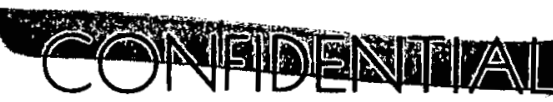

INSD-2650-29

IV-32 
since we are interested in launch pad accidents, $p_{0}=14.7$ psi. Table IV-II below presents $p_{r}$ and $q$ for each overpressure of interest.

TABLE IV-Il

REFLECTED AND DYNAMIC PRESSURES

$\begin{array}{lcc}\mathrm{p}_{\mathrm{S}} & \mathrm{p}_{\mathrm{r}} & \mathrm{q} \\ (\underline{\mathrm{psi}}) & \underline{(\mathrm{psi})} & \underline{(\mathrm{psi})} \\ 200 & 1192 & 350 \\ 386 & 2601 & 762 \\ 500 & 2488 & 1037\end{array}$

To determine whether or not structural damage is expected from a blast loading, Fig. IV-7 from Ref. IV-4 is used. It is seen that potential structural damage is a function of the structural frequency, $f$, depth or lateral dimension of the structure, D, side-on overpressure, $p_{S}$, and structural density, $\rho$. From the structure of interest with $f, D$, and $\rho$ known, the chart indicates the minimum side-on overpressure to initiate failure. Table IV-12 presents properties of the components of interest.

From Fig. IV-T and the calculated frequencies and characteristic lateral dimensions, all three components represent diffraction targets; that is, potential failure would be due to the reflected pressure. For the heat shield it can be seen that the critical side-on overpressure is about $150 \mathrm{psi}$. The housing properties yield a critical side-on overpressure of approximately $70 \mathrm{psi}$.

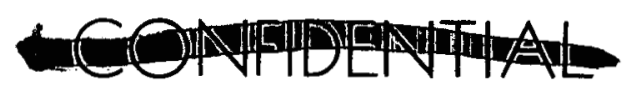

INSD-2650-29

IV -33 


\section{TABLE IV - I2}

PROPERTIES FOR BLAST DAMAGE DETERMINATION

\begin{tabular}{|c|c|c|c|c|c|}
\hline Item & Material & Frequency & $\begin{array}{c}\text { Characteristic } \\
\text { Dimension } \\
\end{array}$ & $\begin{array}{c}f-D \\
\text { Product }\end{array}$ & $\begin{array}{l}\text { Structural Density } \\
\text { (Wt/Volume Envelope) }\end{array}$ \\
\hline & & $\begin{array}{c}\mathrm{f} \\
(\mathrm{cps})\end{array}$ & $\begin{array}{c}D \\
(f t)\end{array}$ & $\begin{array}{l}\mathrm{fD} \\
(\mathrm{fps})\end{array}$ & $\left(\# / \mathrm{ft}^{3}\right)$ \\
\hline $\begin{array}{l}\text { Capsule Strength } \\
\text { Member }\end{array}$ & TZM & 908 & .1875 & 170 & $.35 \times 10^{-3}$ \\
\hline Heat Shield & Carb-I-Tex 500/502 & 5930 & 0.5 & 2965 & 39.8 \\
\hline Housing & MgTh & 10,300 & 0.66 & 6790 & 6.53 \\
\hline
\end{tabular}

TRANSITION PROBABILITIES FOR BLAST ENVIRONMENT

Initial-State

RTG

$$
\text { RTG }
$$

0

$\frac{\text { Heat Source }}{\sim 0.99} \frac{\text { Final State }}{\text { Bare Capsule }}$

$\sim 0.01$
Fuel Release 

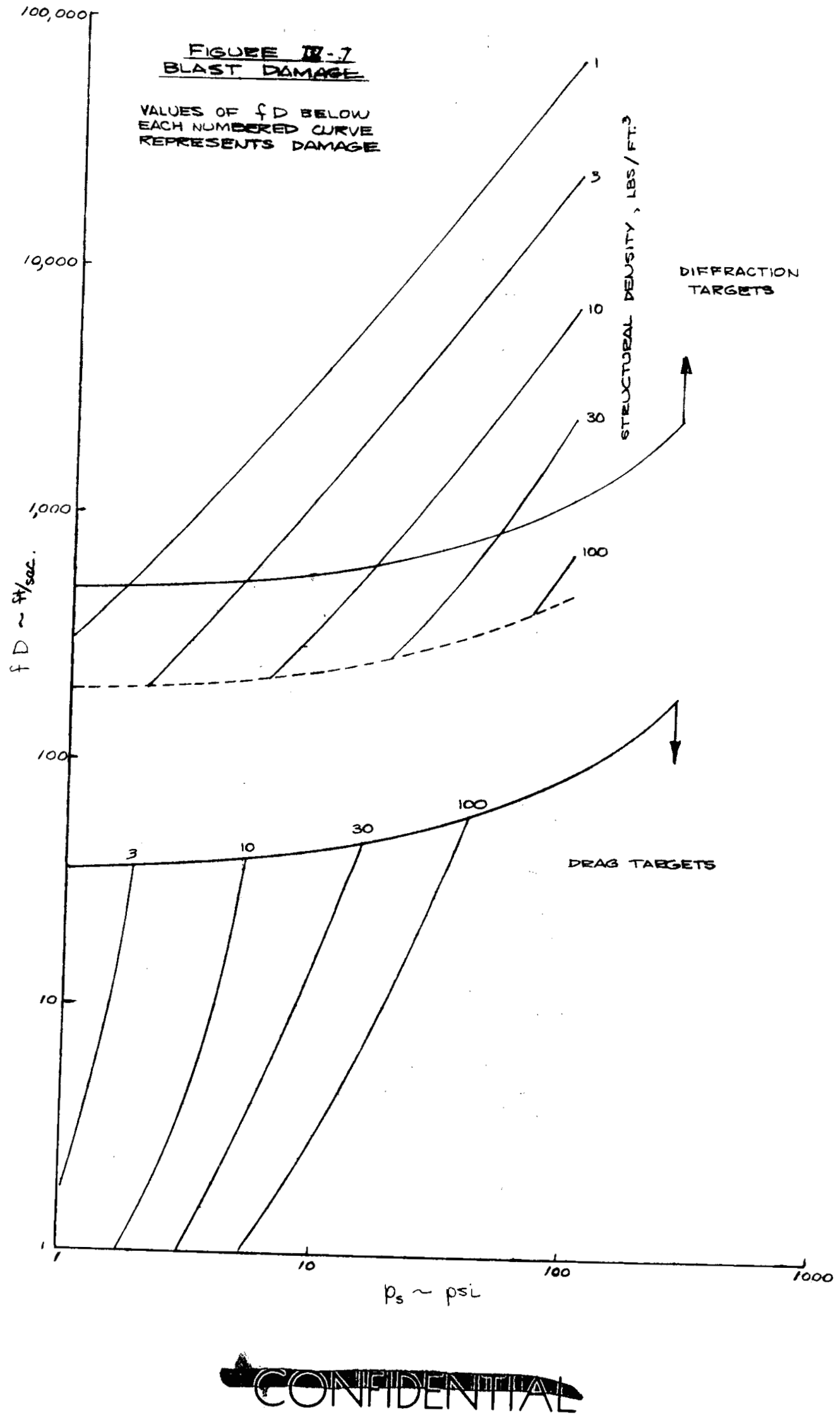

INSD-2650-29

IV-35 
It does not appear that this criterion of blast damage is applicable for the capsule strength member. The calculated natural frequency is assumed very conservative (low) since the liner enhances the capsule rigidity and the fuel provides a highly effective elastic foundation to restrict vibrational response. Therefore, a more realistic approach involves estimation of material yielding. The TZM shell at temperature has a yield strength of approximately $40000 \mathrm{psi}$ and the maximum $\mathrm{R} / \mathrm{t}$ of the shell is 14.5. Thus, the applied pressure prior to yielding is

$$
p=\frac{40000}{14.5}=2760 \mathrm{psi}
$$

The maximum amplitude for a triangular acceleration-time pulse is about 1.4. Therefore, the critical reflected pressure is greater than 2760/1.4 or $1970 \mathrm{psi}$. This value corresponds to a side-on overpressure of $321 \mathrm{psi}$. This value is conservative (low) for three important reasons:

(1) The ratio of model frequency to the impulse frequency must be a unique value to warrant the maximum amplitude response.

(2) The material has sufficient ductility to indicate significant plastic flow or deformation prior to failure.

(3) The fuel will respond to the loading imposed.

From these calculations we conclude that the result of exposing the initially intact RTG would be to fracture the external housing.

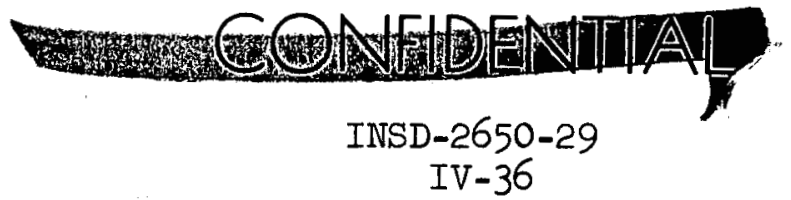


It is further assumed that by virtue of the laminar construction of the Carb-I-Tex 500/502 heat shiela member, and the expected attenuation of the shock pulse, that this member would remain intact after the blast except in about $1 \%$ of the potential blast magnitudes. The capsule was assumed to have a nil probability of failure from blast effects. From these arguments the transition-probability matrix for the blast environment has the form of Table IV-13.

b. Shrapnel penetration

Shrapnel penetration probabilities were determined using the model developed in Ref. IV-1. Fragments selected as the most likely to cause penetration by virtue of their number and kinetic energy were $12 \times 12 \mathrm{x}$ I/4 inches in size and were assumed to be aluminum.

Two impact orientations were considered, "wedge" and "edge," defined by sketch in Fig. IV-8. Wedge impact was defined for impact orientations such that $\theta=45^{\circ} \pm 22.5^{\circ}$. Edge impact corresponds to $\theta$ less than $22.5^{\circ}$ and greater than $67.5^{\circ}$. The critical impact angle assumed for penetration of the heat source and capsule were limited to planar angles, $\phi$, within $22.5^{\circ}$ of $90^{\circ}$. All shrapnel orientation at impact were assumed equally likely so that both wedge and edge impact had equal probabilities at about $1 / 8$ (1/2 for either edge or wedge and 1/4 for critical angles) if the fragment's center of mass were directed within the projected area of the target. An additional interaction area was defined as shown in Fig. IV-9 so that, if the center of mass of the projectile were directed within this area, proper impact for penetration would occur in about $1 / 16$ of the cases.

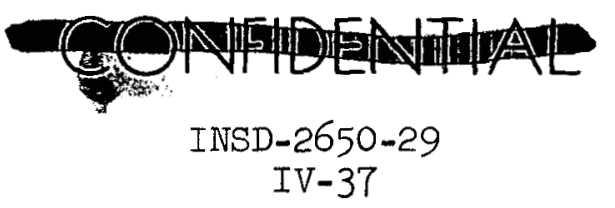



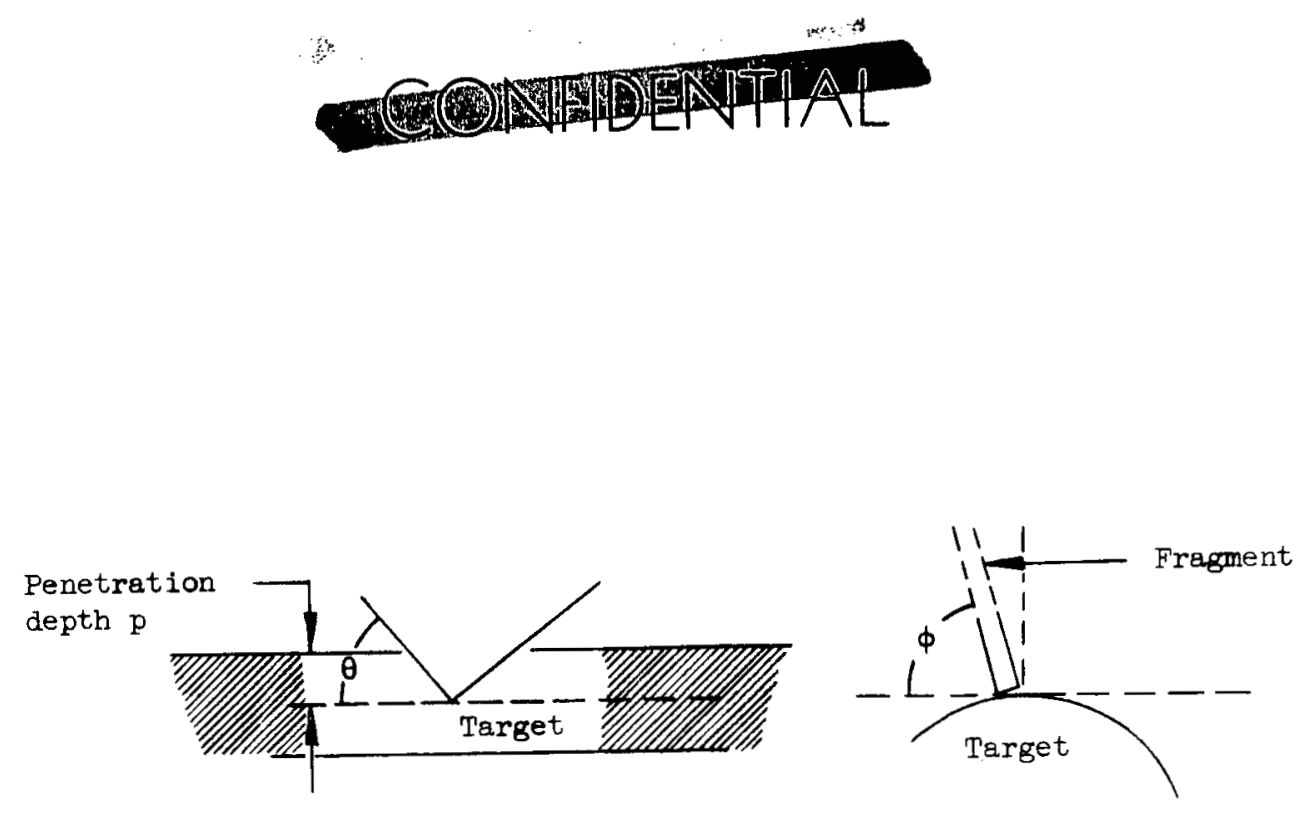

FIG. IV-8. IMPACT ORI ENTATIONS

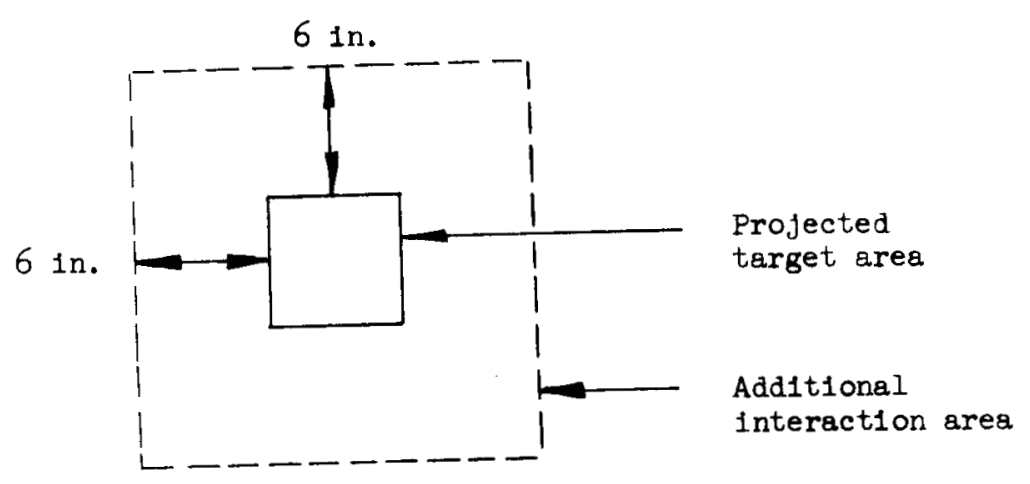

FIG. IV-9. TARGET AND INTERACTION AREAS

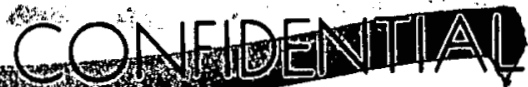

INSD-2650-29

IV -38 


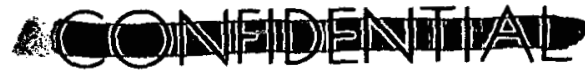

From these hypotheses and the 70 shrapnel fragments assumed for the Centaur vehicle, the probability of impacting the capsule or heat source with proper orientation for penetration is about $1.0 \times 10^{-3}$. The probabilities for generator and heat source impact without regard to fragment orientation are about 0.03 and 0.02 , respectively.

Energy requirements for penetrating the materials comprising each configuration of interest (RTG, heat source and capsule) were determined using the following expressions for impact penetration for the wedge and edge orientations from Ref. IV-I:

$$
\begin{aligned}
& \text { (Wedge) } \quad P=8.2\left(\frac{\rho_{\mathrm{p}}}{\rho_{\mathrm{t}}}\right)^{\frac{1}{4}}\left(\frac{\epsilon}{E_{t}}\right)^{\frac{1}{2}}\left(\frac{1}{t}\right)^{\frac{1}{2}} \\
& \text { (Edge) } \quad P=68\left(\frac{\rho_{\mathrm{p}}}{\rho_{\mathrm{t}}}\right)^{\frac{1}{2}}\left(\frac{\epsilon}{\mathrm{E}_{\mathrm{t}}}\right) \cdot\left(\frac{1}{\mathrm{~A}}\right)
\end{aligned}
$$

where

$$
\begin{aligned}
& P=\text { penetration (in.) } \\
& t=\text { projectile thickness (in) }=0.25 \\
& \epsilon=\text { kinetic energy of projectile }(\mathrm{ft}-\mathrm{lb})=5 \times 10^{3} \\
& \rho_{p}=\text { projectile density }(\mathrm{g} / \mathrm{cc})=2.7 \\
& \rho_{t}=\text { target density } \\
& A=\text { length of projectile edge } \mathrm{x} \text { thickness }\left(\mathrm{in}^{2}\right)=0.6 \\
& E_{t}=\text { modulus of elasticity of target }(\mathrm{psi})
\end{aligned}
$$

Equivalent graphite thicknesses for each component were obtained by scaling actual component thicknesses by density and elastic modulus correction ratios. The equivalent graphite thicknesses and energy

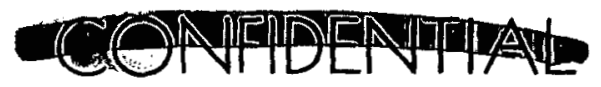


requirements to penetrate the several configurations are given in Table IV-14.

\section{TABLE IV-14}

ENERGY REQUIREMENTS FOR RTG COMPONENT PENETRATION

Component

$\frac{P \text { Equivalent (in) }}{\text { Wedge }}$

$\frac{\text { Energy Required (ft-lb) }}{\text { Wedge }}$

Capsule

0.79

5.6

$3.2 \times 10^{3}$

$6.7 \times 10^{4}$

Heat Shield

0.45

0.45

$1.0 \times 10^{3}$

$5.4 \times 10^{3}$

RTG (without Heat 4.26 Source)
$14.19 .2 \times 10^{4} \quad 1.7 \times 10^{5}$

From these results and the characteristic shrapnel energy of $5 \times 10^{3} \mathrm{ft-lbs}$, it was concluded that capsule or heat source impact in the wedge orientation would most likely cause fuel release, whereas an initially intact RTG would provide ample protection for the capsule and heat shield. Impact at any orientation on the RTG was assumed to release the intact heat source.

These results were used to determine the transition probability matrix for shrapnel impact, given in Table IV-15.

\section{TABLE IV-I5}

TRANSITI ON MATRIX - SHRAPNEL

Initial state

RTIG

Heat Source

Capsule
Final state

RTG Heat Source Capsule Fuel Release

0.97

0.03

$\sim 0$
0.02

$\sim 1$
$1 \times 10^{-3}$

$1 \times 10^{-3}$

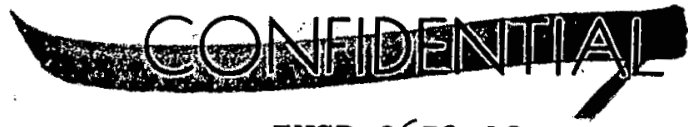

INSD-2650-29

IV -40 


\section{c. Impact response}

No analyses were performed for impact response of the possible configurations. It is believed, however, that the following conclusions are intuitively reasonable.

If the generator impacts any of the target media (sand, concrete, or structure), it is assumed that the housing will fail and deform, exposing the heat source. The Carb-I-Tex 500/502 heat shield is assumed to remain intact. From the results of the preceding shrapnel penetration analysis, these same results would apply even if the RTG were to impact sharp structure.

If the heat source impacts sand or concrete, it is assumed that the Carb-I-Tex 500/502 heat shield will survive the impact except in one out of 10 cases. Failure of the capsule is assumed if it encounters sharply pointed structure. This probability was estimated at one in a thousand, using the total structural impact probability of five in one hundred and assuming a one in fifty chance for impact on sharp structure at other than glancing orientations.

Impact of the bare capsule would produce failure only in the event of impacting sharp structure; its probability is the same as that for the heat source, $10^{-3}$.

The transition matrix derived from these considerations is given in Table IV-16.

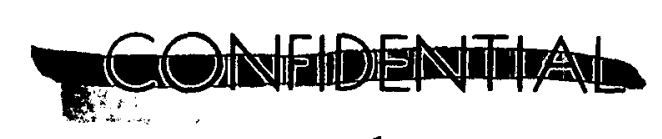

INSD-2650-29

IV -41 
TABLE IV-16

TRANSITION MATRIX - IMPACT

Initial state

RIG

Heat Source

Capsule

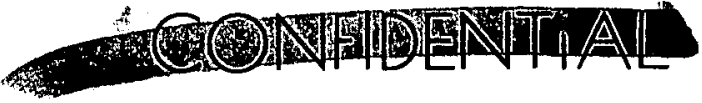

\section{d. Thermal response}

Calculations have been performed for the bare capsule and heat source configurations. The thermal profile used in the calculations was a compination of the 99 percentile fireball, residual solid propellant burning and the residual liquid propellant environment. According to the statistical model, a more severe environment than this would occur in only 1 out of 10,000 cases.

The results of calculations for the unprotectel capsule are shown in Fig. IV-10. The maximum liner temperature was about $3250^{\circ} \mathrm{F}$, occurring shortly after the fireball ignition. The effect of the solid propellant environment was to produce a peak liner temperature of about $2750^{\circ} \mathrm{F}$. The equilibrium liner temperature during the residual liquid fuel fire was about $2050^{\circ} \mathrm{F}$.

Calculations performed for the same environment but with a CarbI-Tex shielded capsule resulted in a maximum liner temperature of $2640^{\circ} \mathrm{F}$ following the solid propellant environment and an equilibrium temperature of $2140^{\circ} \mathrm{F}$ in the liquid propellant residual fire.

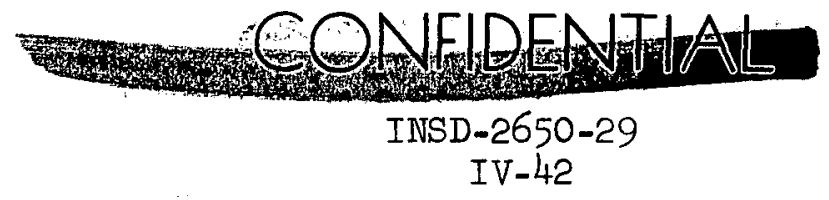




\section{Composite Launch Pad Abort Probabilities}

a. Summary results

The transition matrices may be combined multiplicatively to determine the probabilities for each possible state; i.e., RTG, heat source, capsule, or fuel release. The formalism employed for any sequential arrangement of environments is:

(1) Determine probabilities for each final state from the previous environment.

(2) Calculate probabilities for final states of the present environment according to:

$$
P_{j}^{i}=P_{k}^{i-1} T_{k j}^{i}
$$

where $P_{j}^{i}$ is the probability of final configuration, $j$, from environment $i, \mathrm{P}_{k}^{i-1}$ is the probability of final state $k$ from the preceding environment $(i-1)$ and $T_{k j}^{i}$ is the transition probability from configurations $k$ to $j$ during environment. Applying this formalism and including the launch pad abort probability of $10^{-2}$,

(1) The probability of exposing a heat shield capsule to the full launch pad thermal environment is $8 \times 10^{-3}$.

(2) The probability of exposing a bare capsule to the full thermal environment is $3 \times 10^{-4}$.

(3) The probability of exposing a bare capsule to the post impact thermal environment only (after 2.8 seconds) is $1 \times 10^{-3}$.

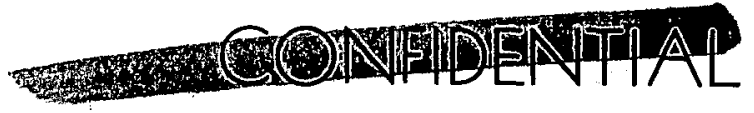




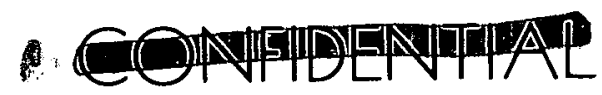

(4) The probability of fuel release prior to the thermal environment is about $2 \times 10^{-5}$.

(5) The probability of fuel release resulting solely from the thermal environment is negligible.

\section{b. Discussion}

The total fuel release probability resulting from the launch pad abort environments was calculated to be about $2 \times 10^{-5}$. This resulted from shrapnel penetration considerations and estimates of failure due to impacting sharp structure. The models used to derive these results are believed to be conservative. However, particular attention should be devoted to improving models for shrapnel flux, size and shape distributions and penetration characteristics at the relatively small impact speeds of 300 to 600 feet per second.

Blast effects will similarly require investigation. However, it is believed that attenuation afforded by structure surrounding the RTG, ignored in this study, tends to make these results conservative. There apparently is little threat to fuel capsule integrity imposed by thermal environments based on the results of calculations under environments more severe than are anticipated for this vehicle. Effects of impairment of the mechanical properties of the fuel capsule by the blast, shrapnel and impact environments prior to thermal exposure and chemical effects will require further study.

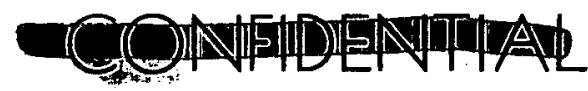

INSD-2650-29

IV -45 


\section{E. FLIGHT ABORT STUDY}

The effects of abort flight conditions on the RTG environment and subsequent heat source performance are evaluated in this section to insure heat source integrity. The presentation is in chronological event order, so that first the Viking flight conditions are studied to define the range of abort re-entry angles and velocities, and subsequently the re-entry environment and thermal effects on the RTG are analyzed over the appropriate parametric fields.

\section{Flight Profile Analysis}

The most severe flight environment (not including the launch pad abort) for heat source integrity consideration is thrust misalignment during transfer from Earth orbit to interplanetary trajectory. Thus, a range of altitudes and thrust misalignments are applied to the "escape" rocket stages. These calculations yield the re-entry angles and velocities for heat source environment evaluations.

a. Launch vehicles, events and conditions

A Titan IIIC/Centaur launch vehicle configuration is to be used for the Mars/Viking mission. The Centaur vehicle is an improved version with two separate burns being planned. The Titan IIIC along with the first burn of the Centaur will be used to place the vehicle into an earth circular orbit. The second burn of the Centaur then supplies the necessary velocity increment to escape the gravitational pull of Earth.

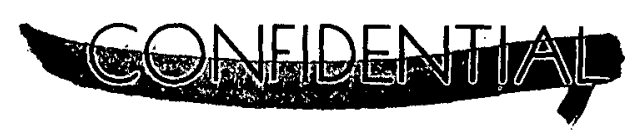




\section{(1)}

For these studies, the following initial conditions for the second Centaur burn have been assumed:

$$
\begin{aligned}
& \text { Circular Orbit } \\
& \text { A1titude, } h=559,506 \text { feet } \\
& \text { Inertial Velocity, } v_{i}=25,597 \text { fps } \\
& \text { Inertial Flight Path Angle, } \gamma_{i}=0 \text { degree } \\
& \text { Weight, } w_{0}=34,350 \text { lbs. }
\end{aligned}
$$

In addition, the following thrust characteristics are assumed.

Thrust, $\mathrm{T}=30,0001 \mathrm{bs}$.

Specific Impulse, $I_{s p}=442 \mathrm{sec}$.

Fuel Mass Flow Rate, $M=-2.11$ slugs per sec.

Burn Time, $\mathrm{T}_{\mathrm{b}}=322$ seconds

The above values of initial condition and thrust characteristics are believed to be typical of current launch plans. A Centaur vehicle drag area (C ${ }_{D}$ ) of 157 square feet representing a nose on orientation was used for all re-entry trajectory computations.

b. Thrust misalignment analysis

Thrust misalignment failures such as considered here may be largely prevented by launch constraints which prevent continuation of the mission when abnormal conditions are detected. An example of such control might be a case where the second Centaur burn is not initiated unless the vehicle is aligned within certain angular limits. However, the availability and/or reliability of such a launch program is not known at this time, and thus an investigantion of superorbital re-entry is pertinent.

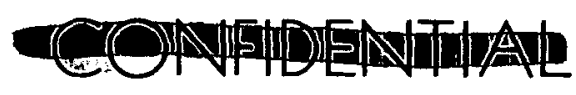

INSD $-2650-29$

IV -47 
This study is limited in scope and thus should be treated only as a preliminary survey. An initial circular orbit in a direction due east about the Earth's equator is assumed. In a complete analysis, a range of orbital directions and locations would be investigated for an oblate earth. Other simplifying assumptions include the positioning of the thrust misalignment angle in a plane normal to the Earth's surface, as well as the passing of the thrust vector through the vehicle center of gravity. Variations to such constraints can produce significant changes in the results and might result in conditions more severe than those currently being obtained.

Figures IV-11 and IV-12 present re-entry trajectory values resulting from the occurrence of various thrust misalignments during a Centaur second burn. Relative re-entry velocities and flight path angles are described for altitudes ranging from 400,000 feet through 100,000 feet. The thrust misalignment angles are measured relative to the body $\mathrm{x}$-axis which is initially aligned with the zero degree flight path angle axis. Negative values of thrust misalignment indicate directions towards the Earth's surface while positive values indicate directions away from the Earth's surface. The data of Fig. IV-11, which are for negative values of thrust misalignment, occur while the Centaur is still thrusting. For all calculations, the heat source is assumed still attached to the Centaur vehicle. Figure IV-12 presents trajectory data for positive values of thrust misalignment angle. These data describe a coast re-entry following an elliptical flight path about the Earth.

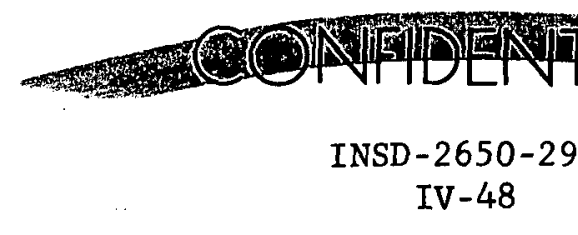




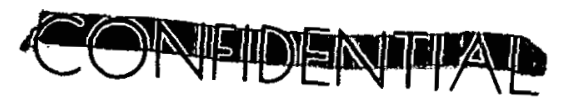

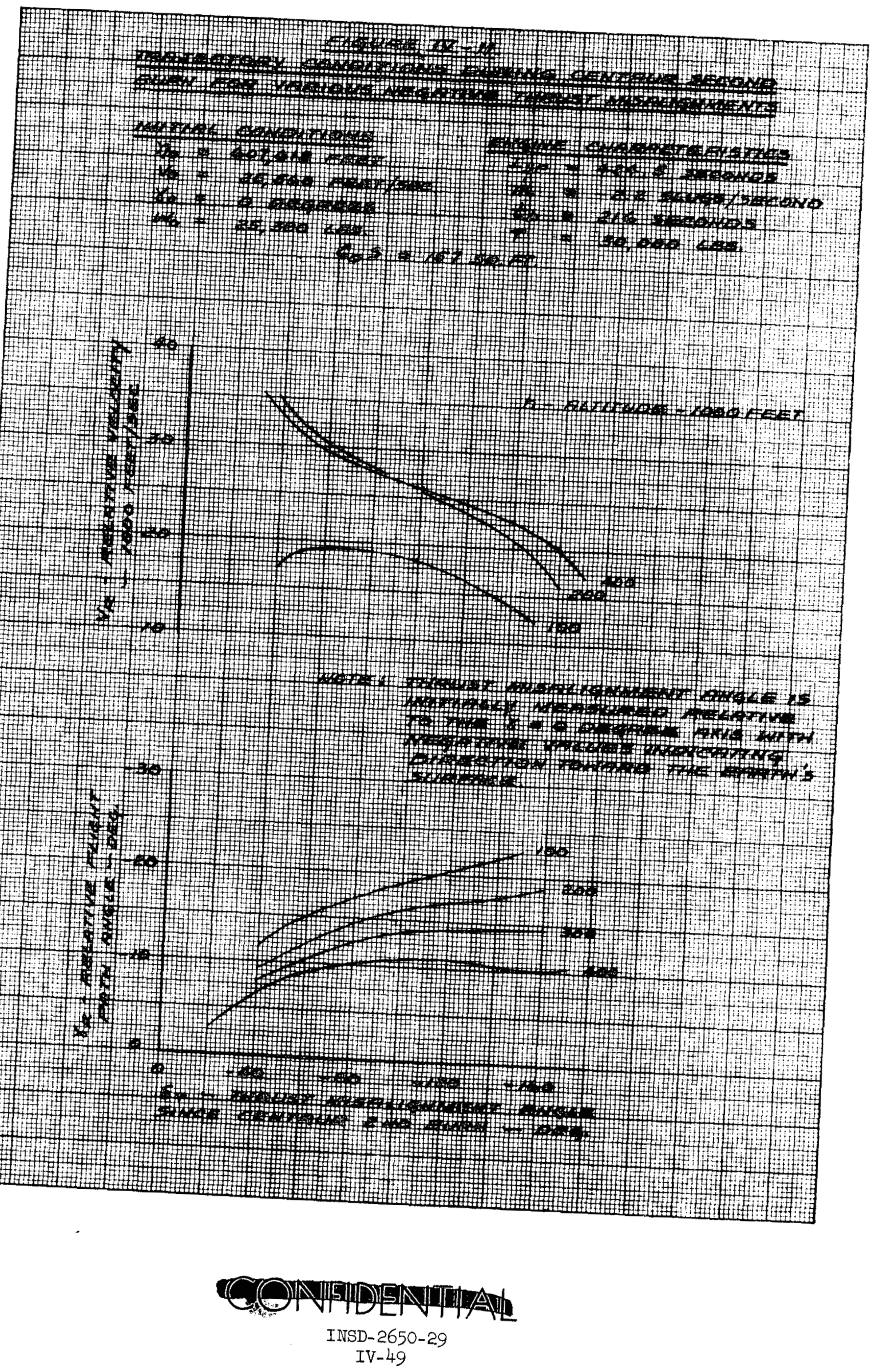




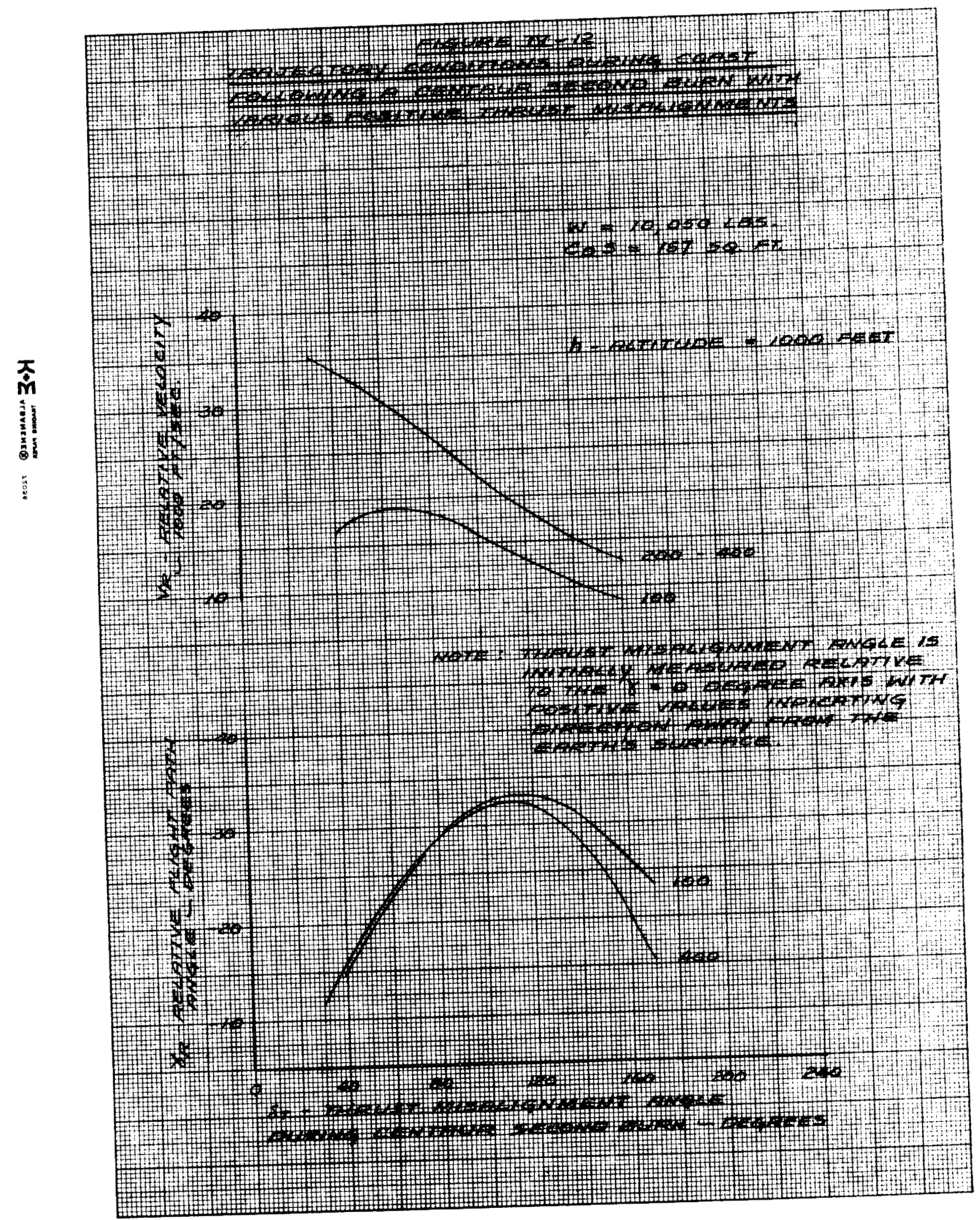




\section{(1)}

\section{Re-entry Trajectory Evaluation}

The re-entry studies include the range of flight conditions caused by orbital decay, thrust misalignment, and an estimate of terminal impact velocity. Since detailed investigation of the separation of the RTG from the vehicle and subsequent exposure of the heat source was not performed, the heat source is assumed to re-enter bare and unattached to other spacecraft components. This assumption is believed conservative, but confirming calculations are required.

\section{a. Orbital decay trajectory}

Orbita1 decay trajectory results are shown in Fig. IV-13. The initial conditions at $400 \mathrm{~K}$ feet were: inertial velocity $=25,690 \mathrm{fps}$, inertial flight path angle $=0.1$ degree, and inertial heading $=120$ degrees (measured clockwise from the North Pole). The beginning of continuum flow regime for the hexagonal heat source is shown to occur at an altitude of approximately $200 \mathrm{~K}$ feet and was based on the criterion described in Ref. V-2:

$$
\mathrm{N}_{\mathrm{Kn}} \leq 0.1 /\left(\rho_{\mathrm{s}} / \rho_{\infty}\right)
$$

where $\mathrm{N}_{\mathrm{Kn}}$ is the free stream Knudsen number and $\rho_{\mathrm{S}} / \rho_{\infty}$ is the density ratio across the shock wave. Since maximum heating rate occurs at approximate1y $200 \mathrm{~K}$ feet, the IIHS spends 1850 seconds out of 1950 seconds of heating pulse in free molecule and transitional flow regimes.

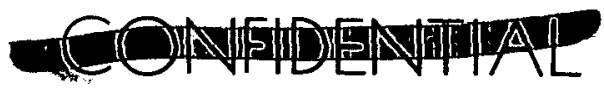

INSD $-2650-29$

IV -51 


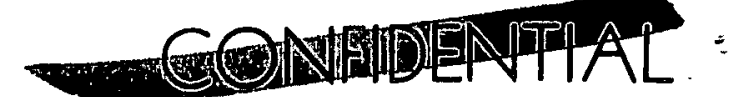

a. Histories of $h, V_{R}, \gamma_{R}$ and $M$
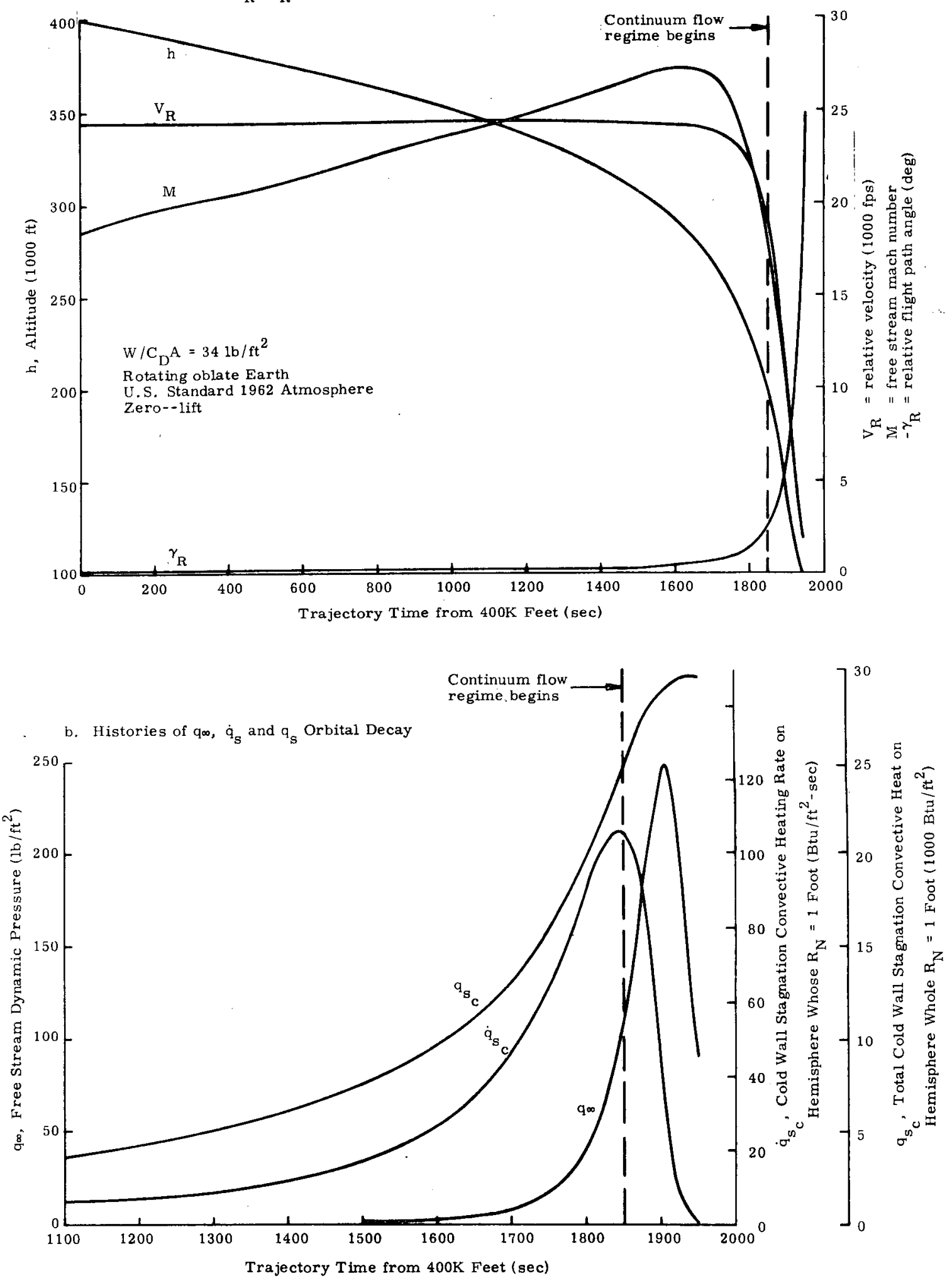

FIG. IV-13. TRAJECTORY HISTORIES FOR AN ORBITAL DECAY

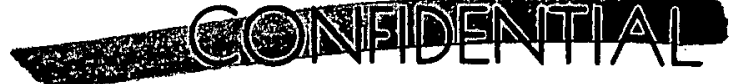

INSD-2650-29

IV -52 


\section{b. Superorbital re-entry}

Because of time constraints, the superorbital re-entry studies were performed concurrently with flight profile predictions. Thus, parametric investigations of trajectory variables were made to include the values obtained from thrust misalignment conditions. The initial relative velocities $\left(V_{R}\right)$ and relative flight path angles $\left(\gamma_{R}\right)$ ranged between 26,000 and $48,000 \mathrm{ft} / \mathrm{sec}$ and -10 and -3 degrees, respectively. (It should be noted that these represent the most severe re-entry conditions.) A11 trajectories were initiated at 400,000 feet and zero latitude and longitude with a heading of due East.

The hypersonic ballistic coefficient $\left(W / C_{D} A\right)$ for the SNAP 19 heat source in side-on stable attitude is $34 \mathrm{psf}$ and this value was held constant throughout the trajectory down to a Mach number of 2.0 where aerodynamic heating becomes sma11.

Figure IV-14 shows the trajectories investigated and those that re-entered directly. The trajectories that skipped out were not studied further. It should be noted that, although only discrete points were studied, limitations on the skip-out and direct trajectories may be deduced.

The maximum convective heating rates and the total stagnation convective energies for the parametric range are depicted in Figs. IV-15a, 15b and 15c. The unusual boundaries (cusps) on the total heating curves are a result of the skip-out cutoff conditions. It is apparent that the maximum tota 1 heat supplied is between 60,000 and

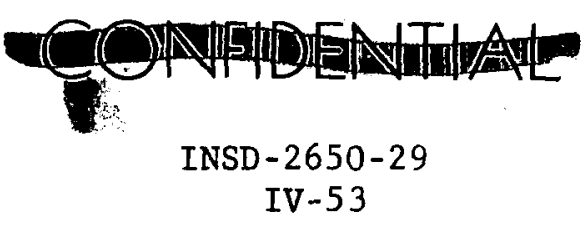



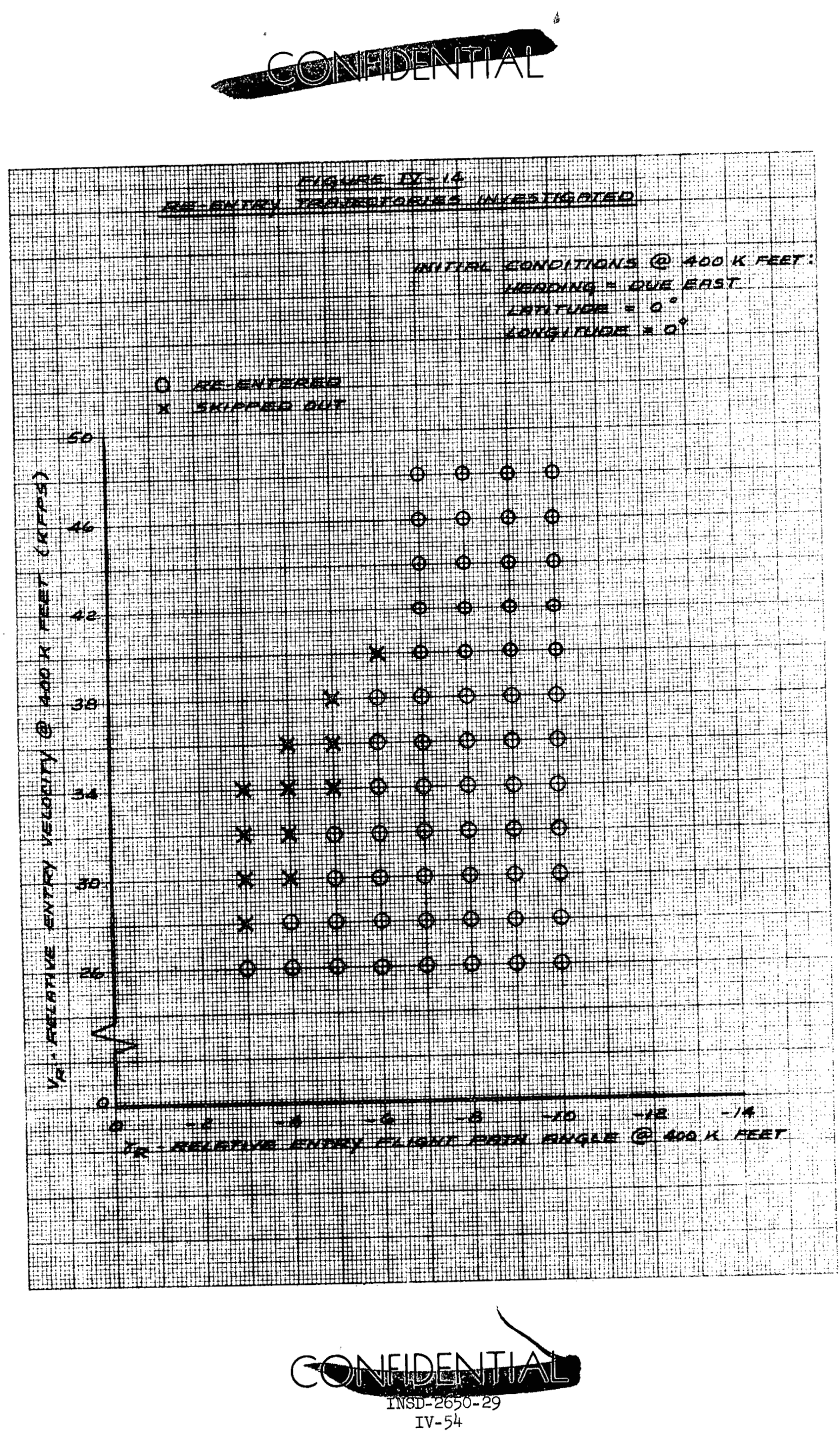


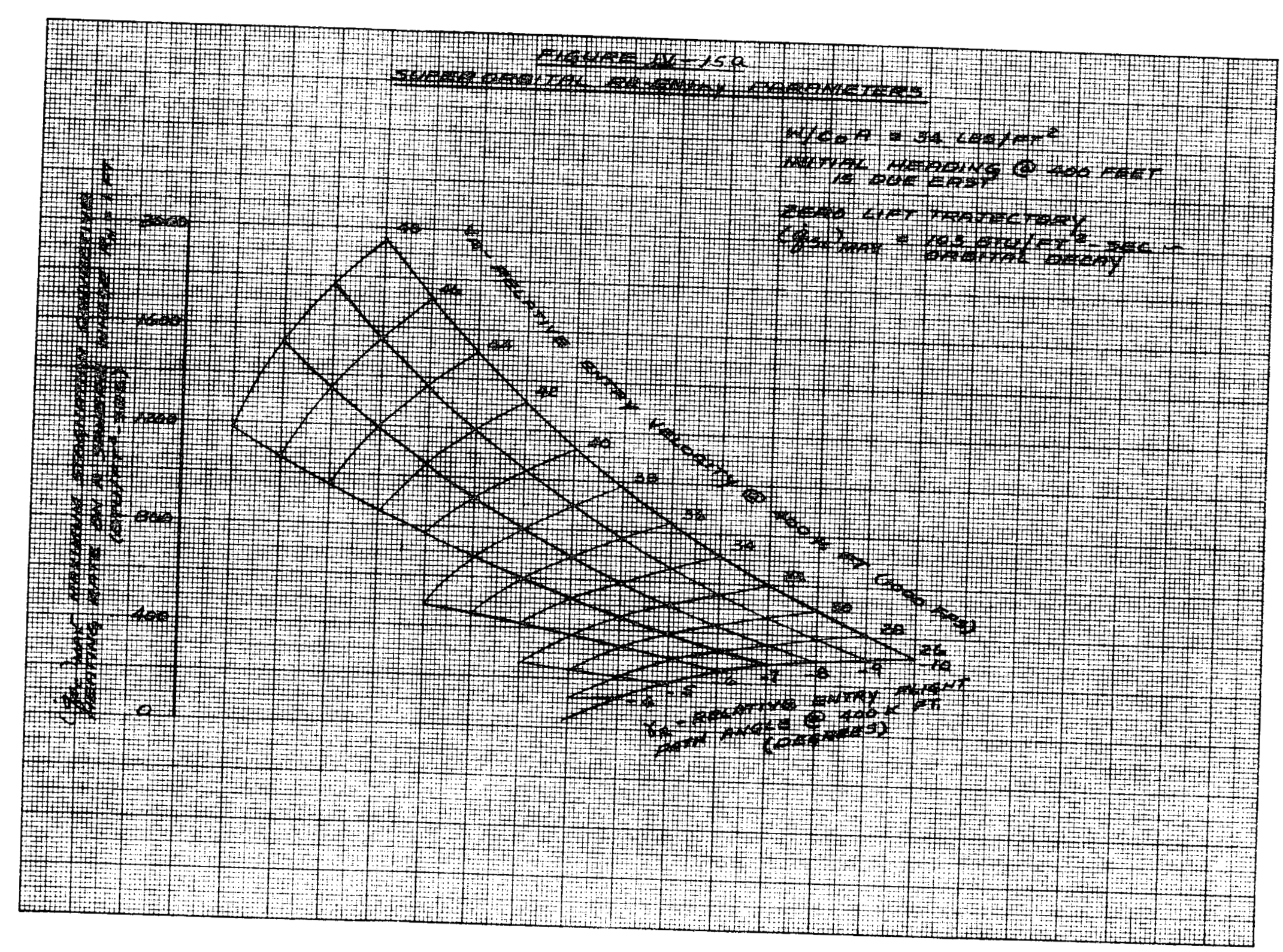

3 


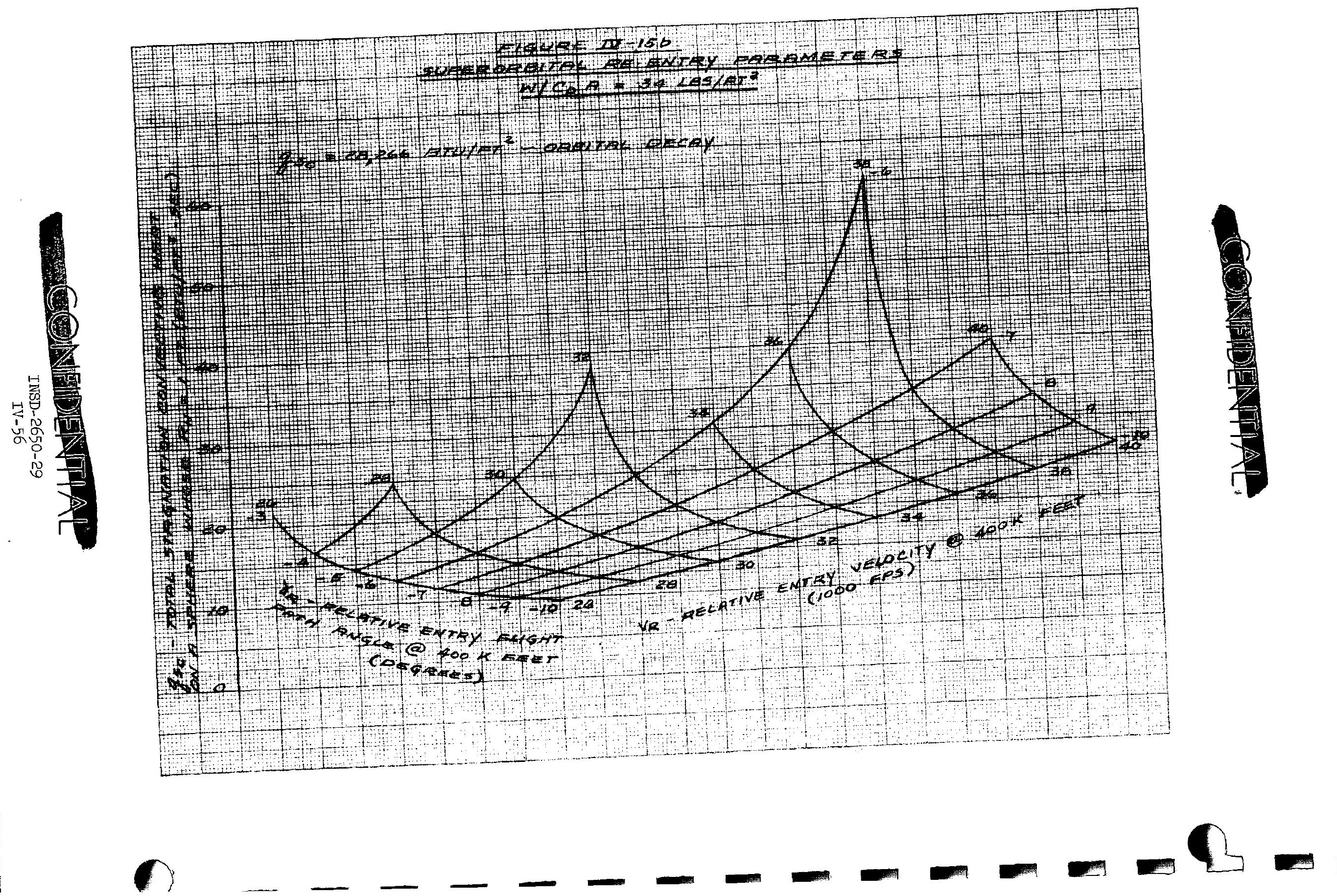




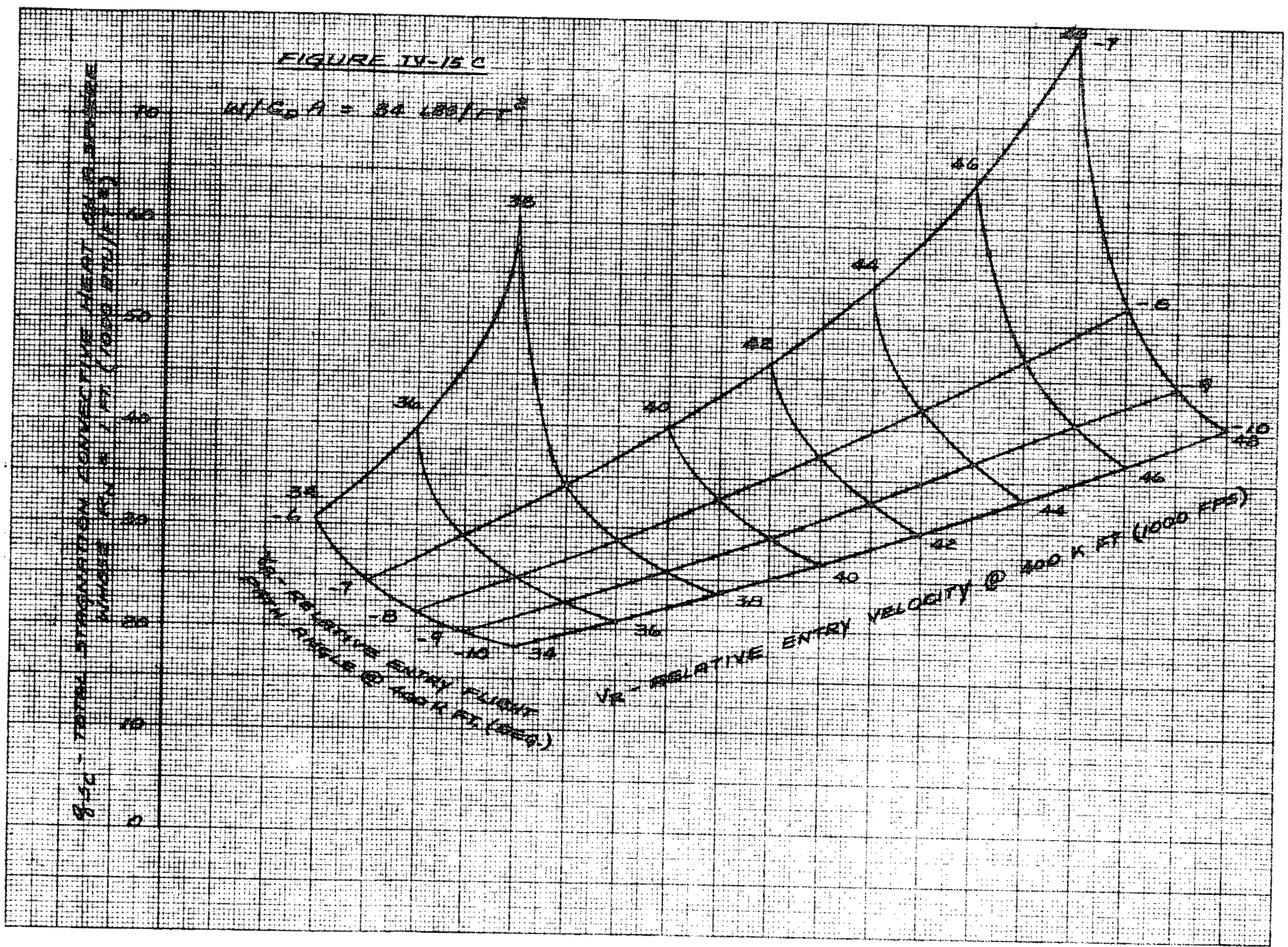


$80,000 \mathrm{Btu} / \mathrm{ft}^{2}$ while the maximum rate reached about $2000 \mathrm{Btu} / \mathrm{ft}^{2}-\mathrm{sec}$. A brief investigation of radiation heating divulged that 1 ess than $10 \%$ of the total heat is contributed by radiation. This small magnitude together with time constraints justified omission of further study of radiation heating and its effect on heat source temperature during re-entry.

c. Termina1 impact velocity

Re-evaluation of the subsonic drag coefficient for the heat source yields an estimated impact speed, $245 \mathrm{ft} / \mathrm{sec}$. The technique involved circular cylindrical data with a surface roughness factor to adjust for the hexagonal cross section. Although this technique is quite approximate, recent preliminary drop tests conducted at Tonapah Test Range by Sandia Corporation indicate a terminal velocity quite close to the calculated value.

\section{Heat Source Therma1 Response}

a. Analysis

The two-dimensional heat source thermal model used in this study is shown in Fig. IV-16. The model is suited for studies in which the re-entry mode is side-on-spin or side-on-stable edge leading. For conservatism, only the stable mode was evaluated since this mode yields higher temperatures and termperature gradients than the spinning mode. Two different thermal shield materia1s, POCO, type AXF (AS)-Q1, and Carb-I-Tex, type 500, were evaluated.

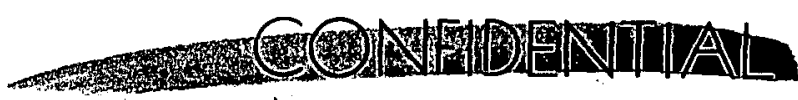


EIGURE IQ -16

2 DIMENSIONAL THERMAL MODEL HEX FUEL BLOCK

$$
W / C_{D} A=34 \text { PSF }
$$

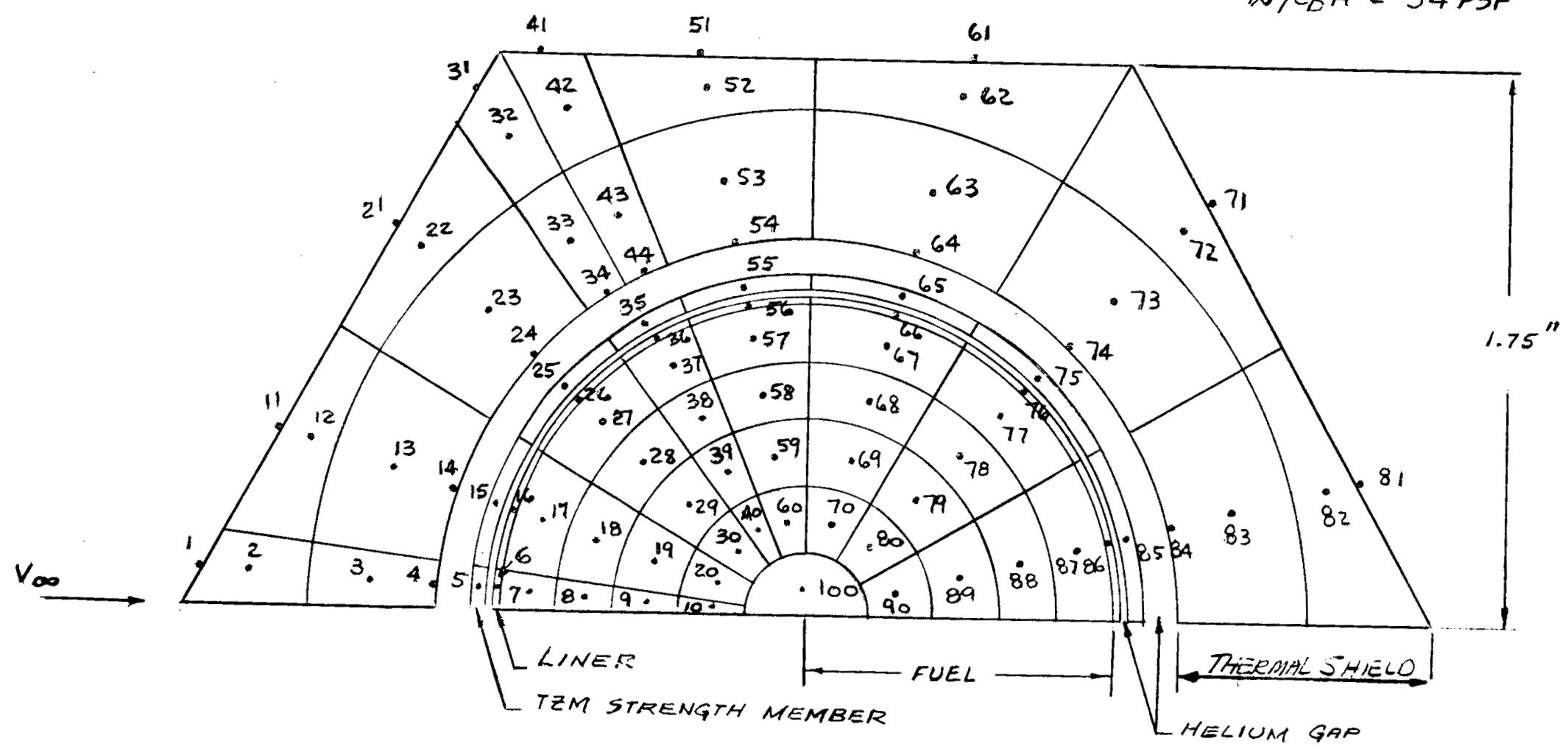


The thermal model was programmed for the TAP III computer code and solutions were obtained using an IBM 360-50 computer. The initial temperature varied from $1050^{\circ} \mathrm{F}$ at the external surface to $1825^{\circ} \mathrm{F}$ at the fuel core (Node 100). Surface recession rates caused by oxidation were evaluated but the resultant dimensional change of the configuration was not factored into the temperature distribution calculations. Further study is required to determine the effects of surface recession on predicted temperatures.

The heating distribution for the side-on stable attitude of the heat source was obtained from the re-entry trajectory studies described above together with test data from the SNAP 29 program. Figure IV-17 shows this distribution.

\section{b. Results}

Temperature histories of heat source components during an orbital decay re-entry $\left(-0.1^{\circ} ; 25,690 \mathrm{ft} / \mathrm{sec}\right)$ are shown in Figs. IV-18 and IV-19 for POCO and Carb-I-Tex 500/502 thermal shields, respectively. For either shield material, the fuel capsule liner is maintained below the me1ting temperature. Hence, either thermal shield material is considered adequate for orbital decay re-entries.

Peak liner temperatures as a function of initial path angle and velocity for superorbital re-entry are presented in Figs. IV-20 and IV-21, respective1y, for POCO and Carb-I-Tex heat shields. It is clear by comparing these figures that a Carb-I-Tex thermal shield provides substantially lower liner temperatures than a POCO shield. In fact,

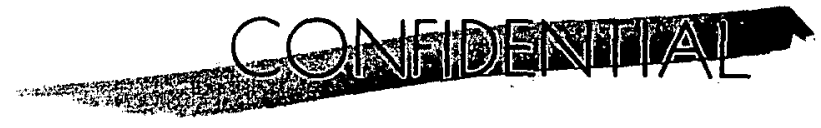

INSD $-2650-29$

IV- 60 


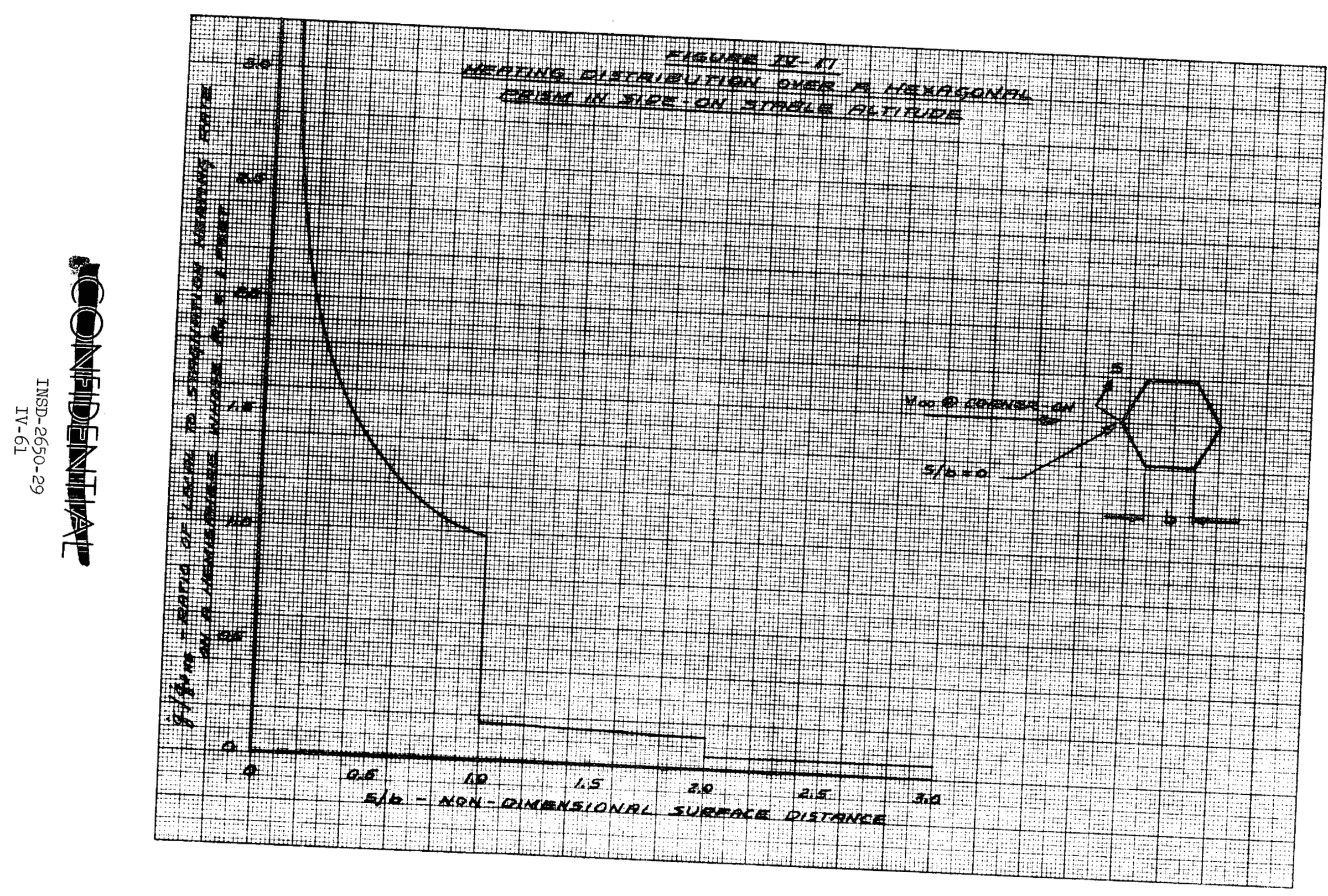



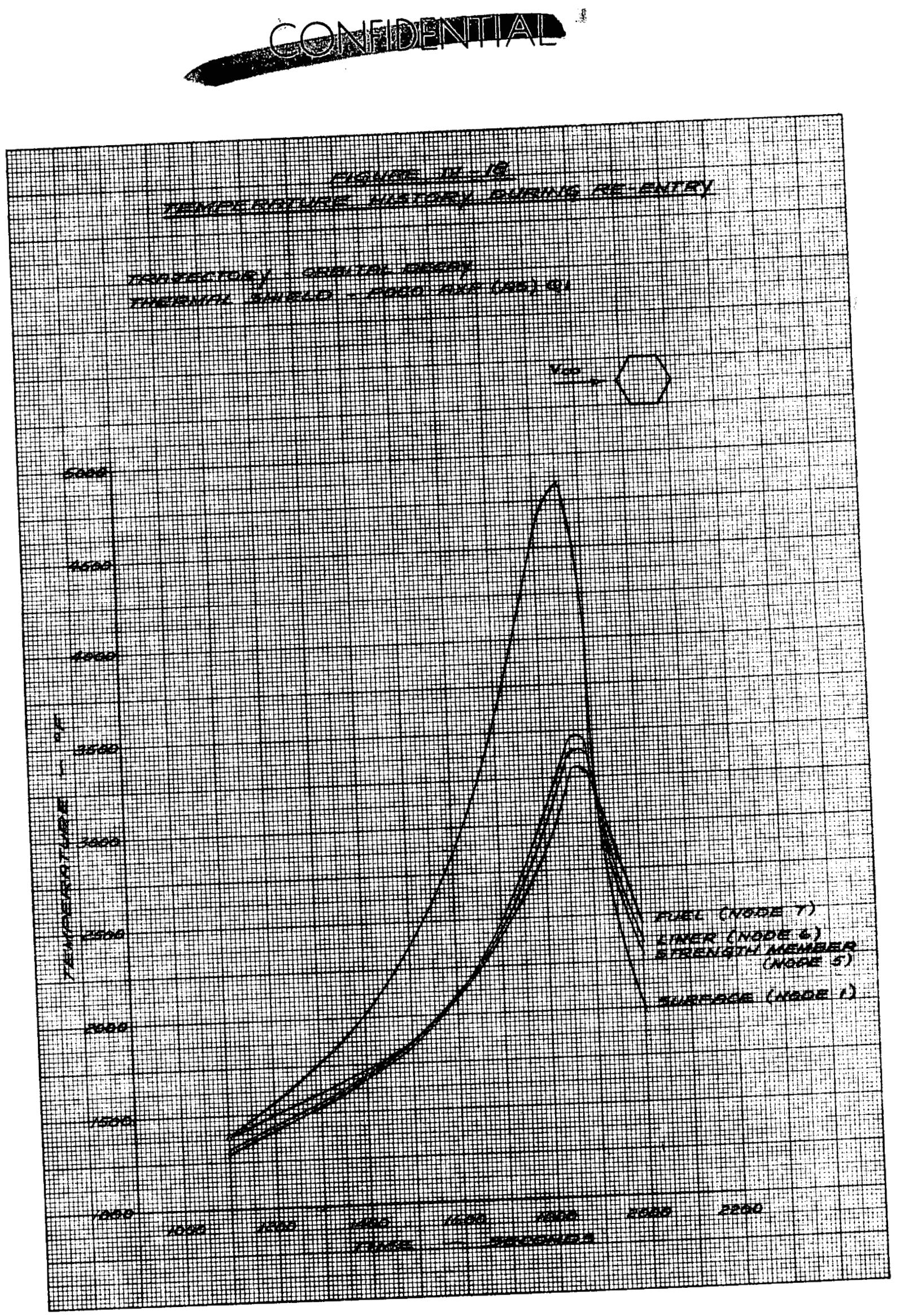

$B$

I

I

I

I

I

I 


\section{EOAFIDEFTHAT}
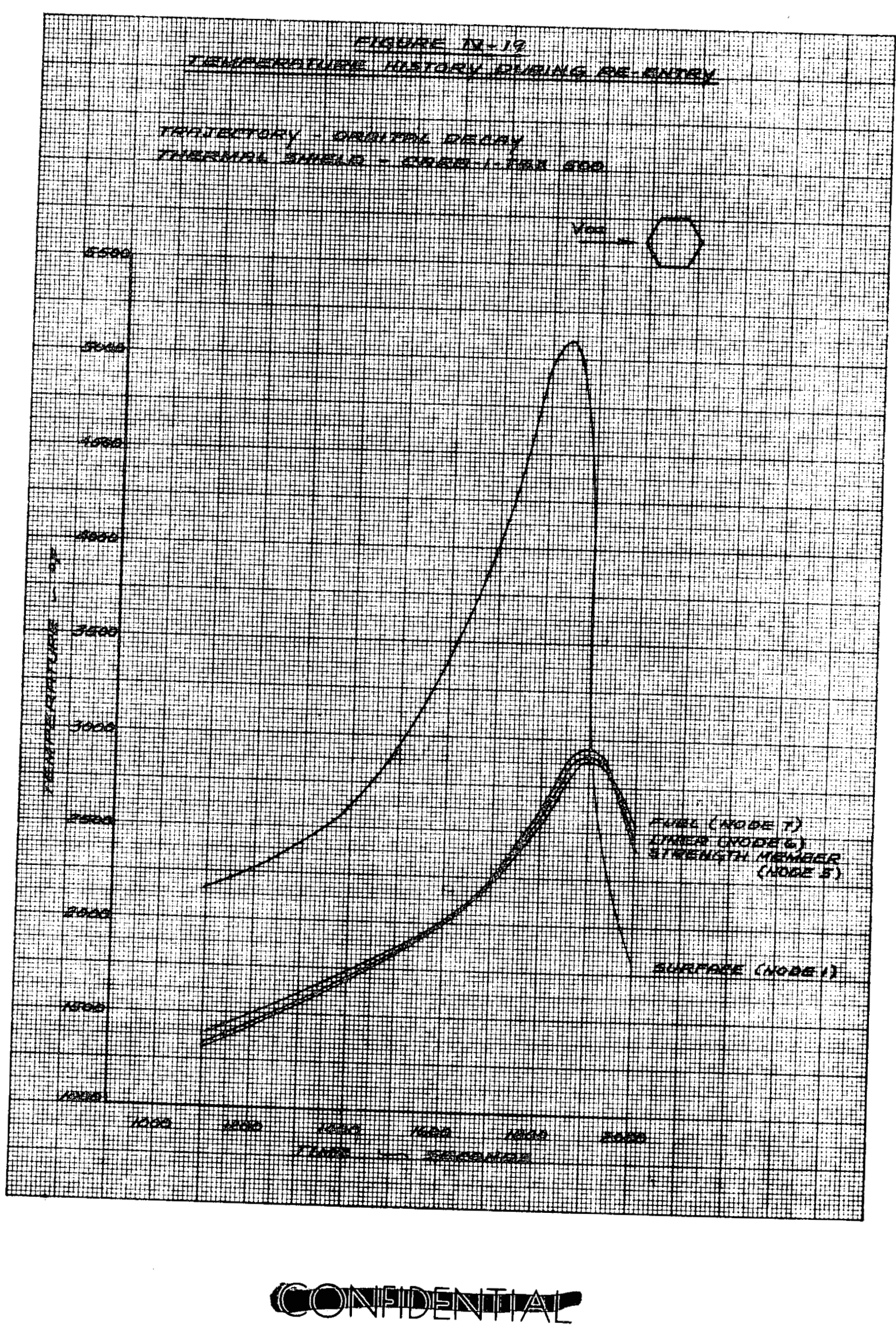

INSD-2650-29

IV-63 


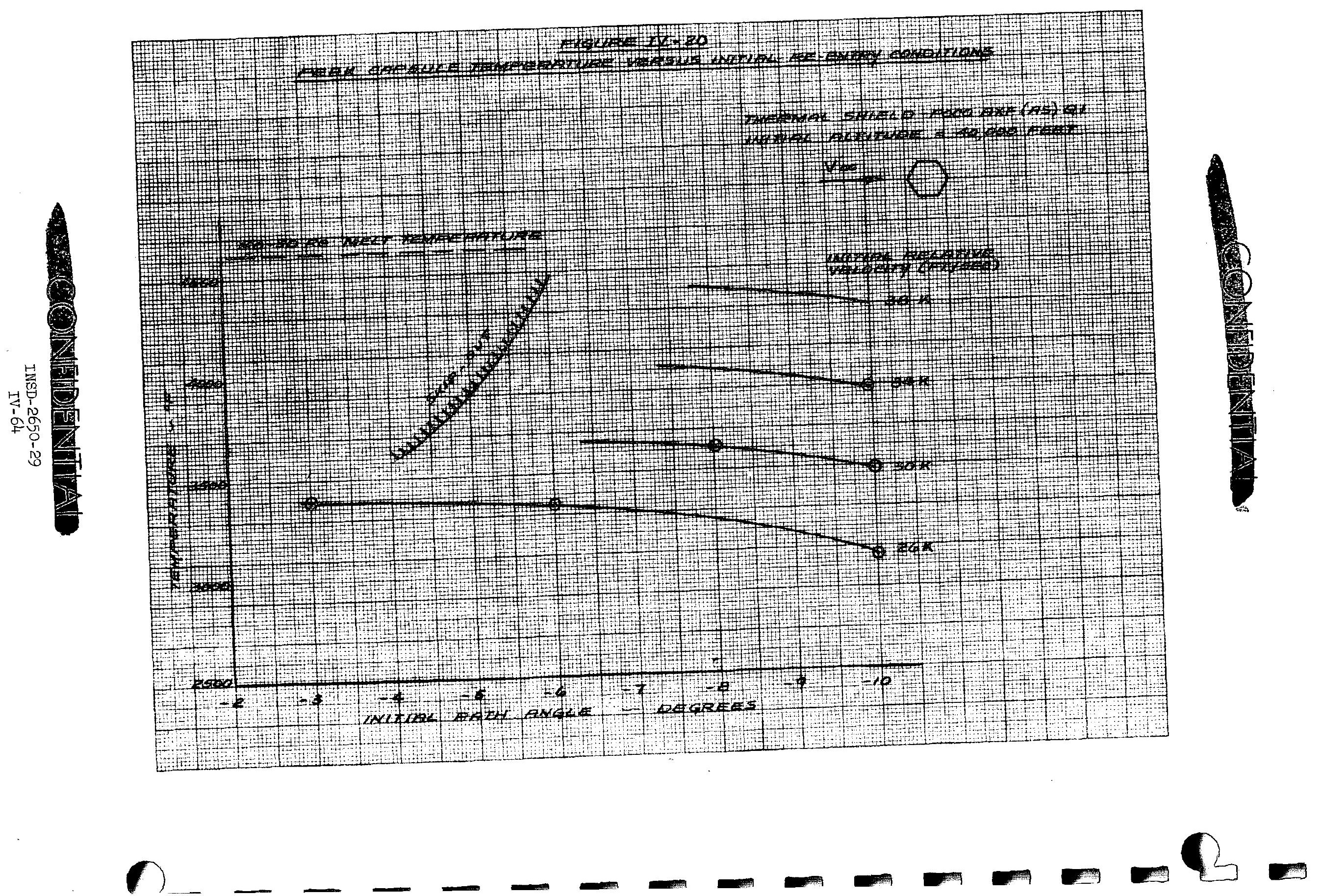




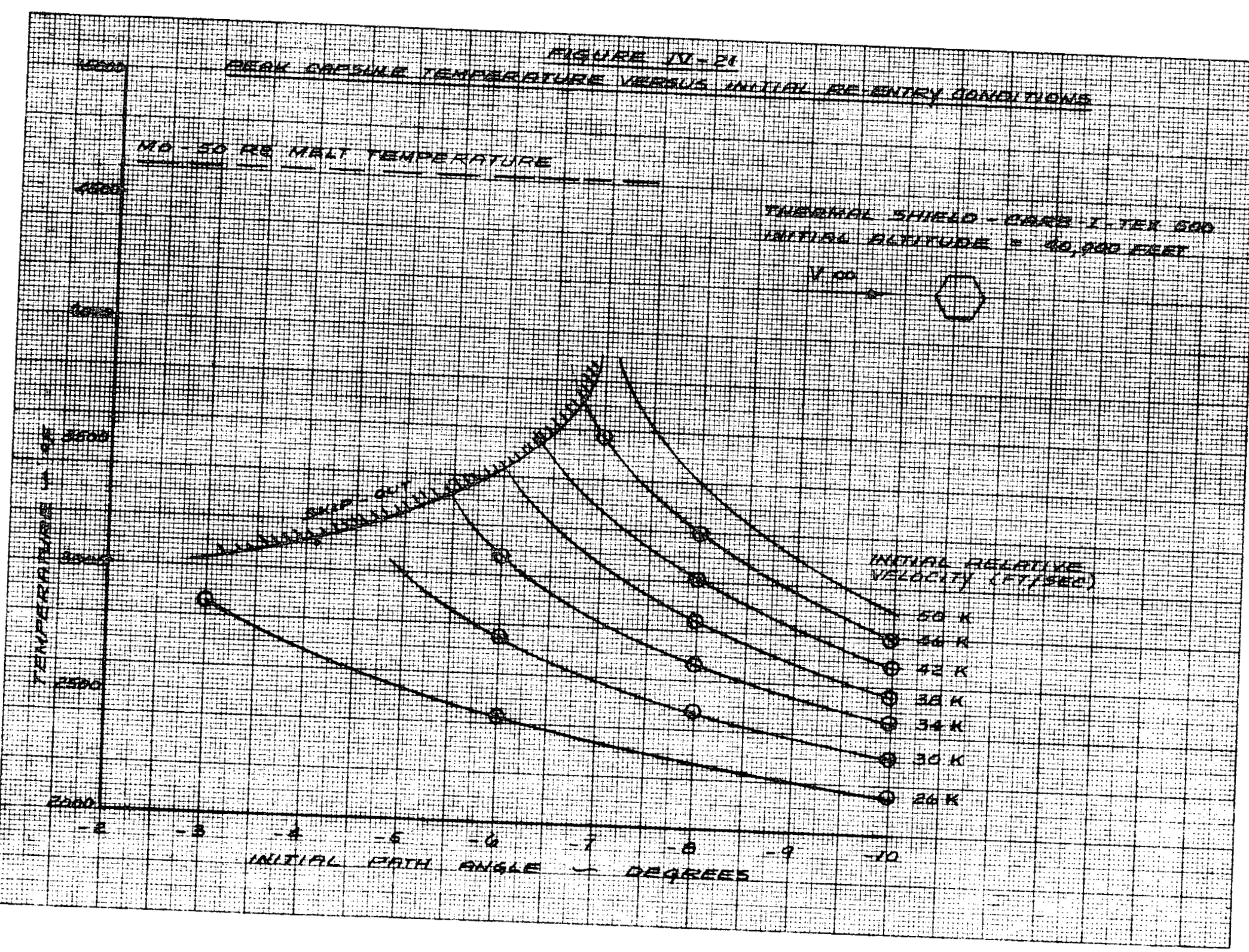




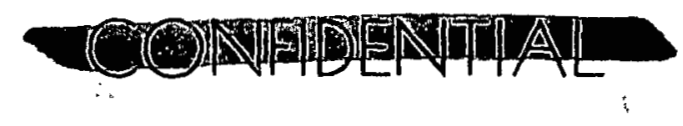

the Mo-50\% Re capsule liner has no apparent temperature restrictions for any of the orbital and superorbital re-entry conditions investigated if a Carb-I-Tex thermal shield is used (Fig. IV-21).

Temperature distributions through Carb-I-Tex and POCo therma1 shields are presented in Figs. IV-22 and IV-23 for a superorbital trajectory (initial flight path angle $=-10^{\circ}$; initial velocity $=30,000$ $f($ sec).

4. Heat Shie1d Therma1 Stresses

As a result of the geometric complexity associated with a hexagonal heat shield and the thermal gradients in both the radial and circumferential directions, the precise determination of thermal stresses resulting from re-entry heating requires development of a digital computer program. However, by assuming a circular cross-section and approximating the temperature profile, an estimate of the maximum thermal stress is obtainable from simpler analytic methods.

The hexagonal heat shie1d investigated has a distance across the flats and an inside diameter of 3.5 inches and 2.37 inches, respectively. The superorbital re-entry condition assumed for evaluation is based upon an initial velocity of $30,000 \mathrm{ft} / \mathrm{sec}$, and an initial flight path angle of $-10^{\circ}$ at an altitude of 400,000 feet (the same conditions used in Figs. IV-22 and IV-23). The orientation is related to a mode of side-on-stable. Two graphitic heat shield materials were investigated: Poco (type AXF), and Carb-I-Tex 500. The solid lines in Fig. IV-24 present the inside and outside surface temperature profiles at the

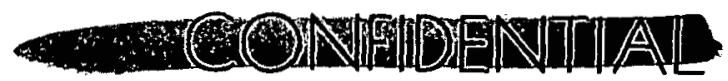




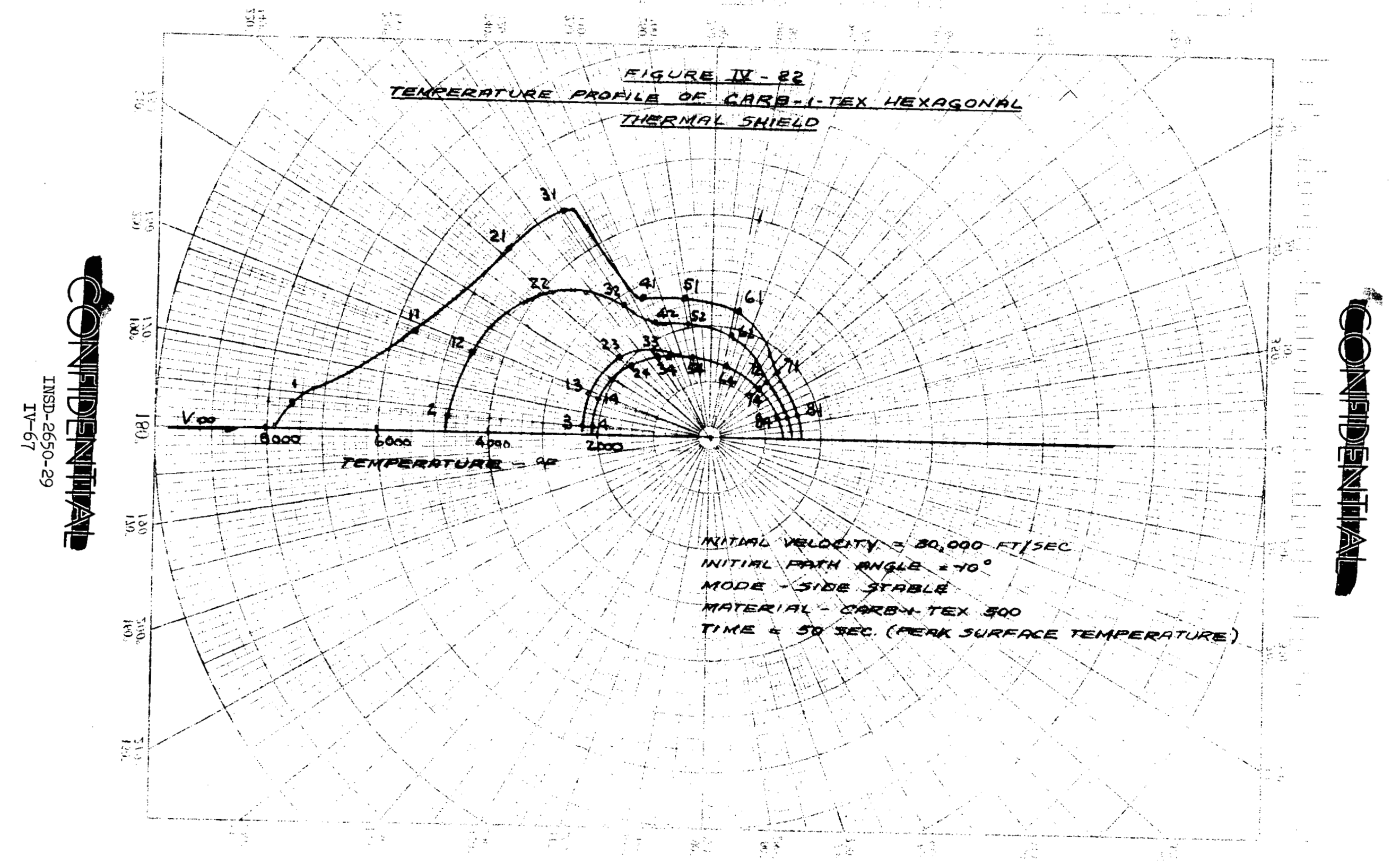




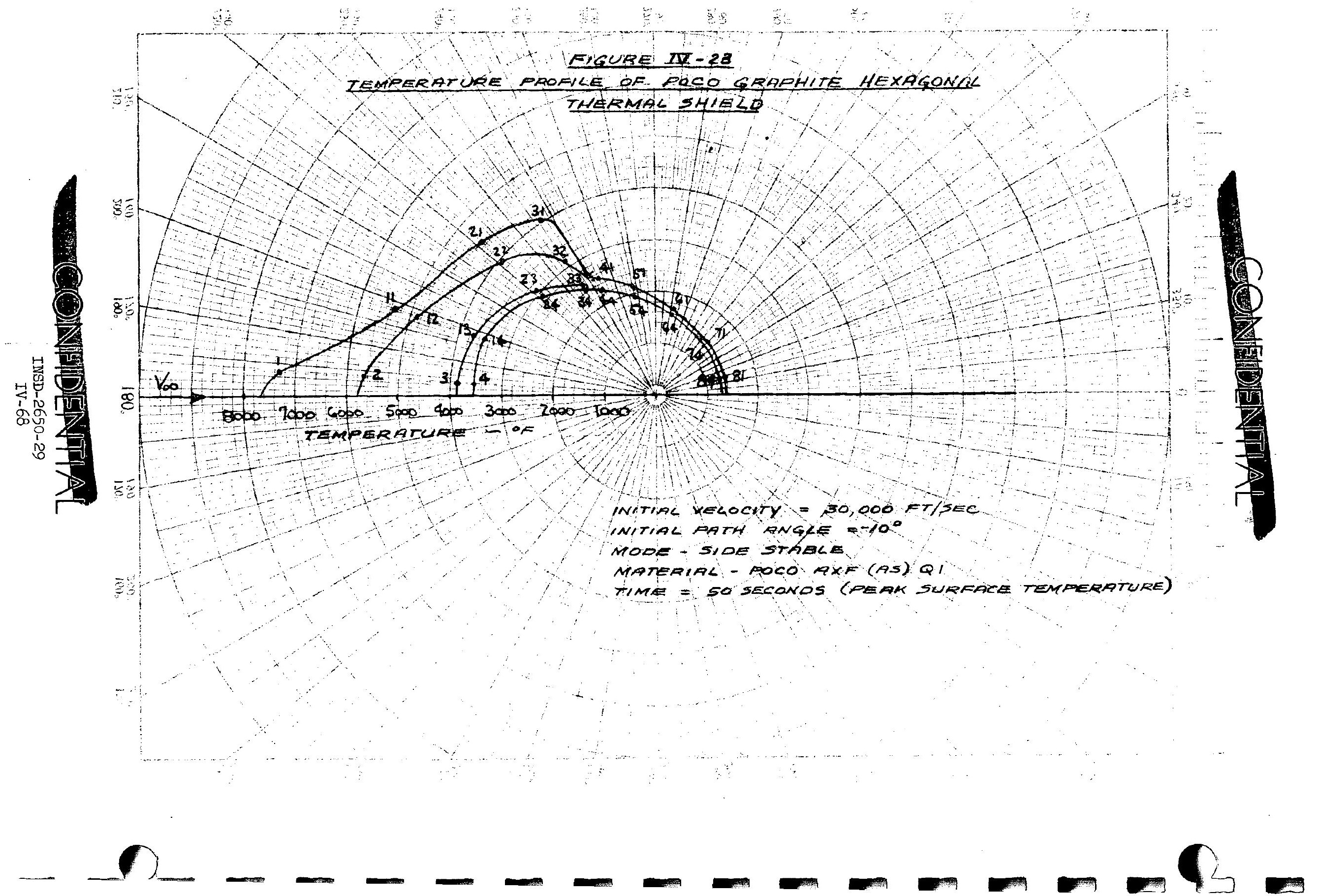




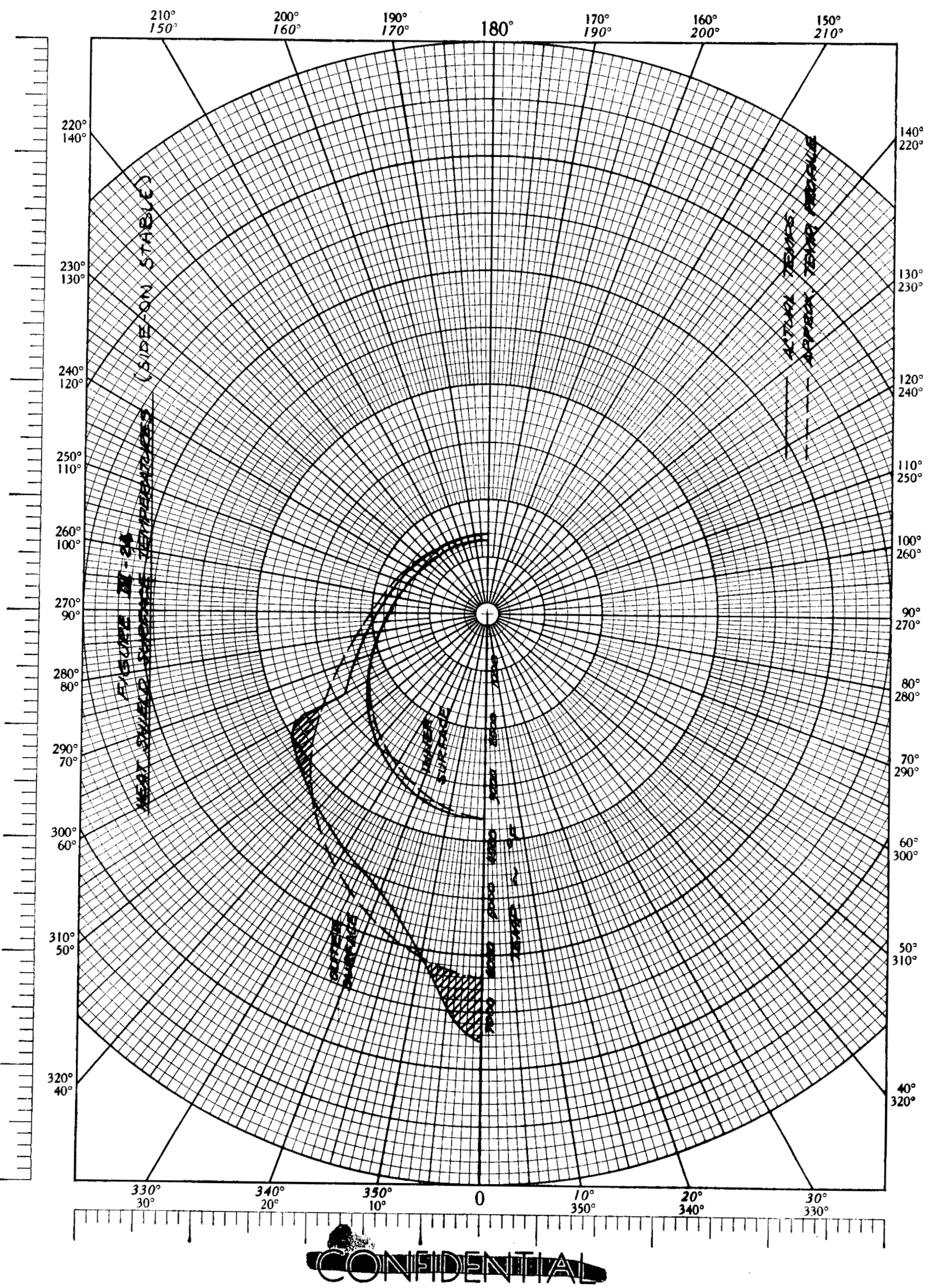

INSD-2650-29 
time of peak surface temperatures for the POCO graphite as determined from the results in the previous section. The surface temperatures for the structural model used here are also represented in the figure by the dashed lines. Note that temperature and geometric symmetry exists about the center line in the direction of the velocity vector.

Upon investigating the two temperature profiles shown in Fig. IV-24 (i.e., solid and dashed lines), the major difference is seen to exist at the shaded areas. Fortunate1y, these two locations are at the corners where:

a. Surface recession will round off the corners, hence reducing the slopes of the temperature gradients presented for these regions.

b. The peak temperatures are very local in nature and should not have any significant thermal stress effect.

The maximum thermal stress may be obtained for a cylindrical she11 where the temperature varies around the section and through the thickness. Goodier's approach (Ref. IV-5) is to represent the surface temperatures by simple Fourier series where the temperatures are,

$$
\begin{array}{ll}
\mathrm{T}_{1}=\mathrm{A}_{0}+\mathrm{A}_{1} \cos \theta+\mathrm{B}_{1} \sin \theta & 0 \leq \theta \leq \pi \\
\mathrm{T}_{0}=\mathrm{A}_{0}^{\prime}+\mathrm{A}_{1}^{\prime} \cos \theta+\mathrm{B}_{1}^{\prime} \sin \theta & 0 \leq \theta \leq \pi
\end{array}
$$

where $\mathrm{T}_{1}$ and $\mathrm{T}_{0}$ are the inside and outside temperatures $\left({ }^{\circ} \mathrm{F}\right)$, respectively. The extreme circumferential bending stress (psi) is given by the equation,

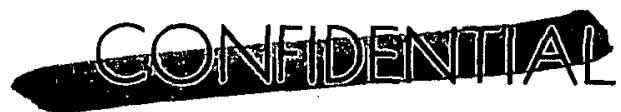

INSD $-2650-29$

IV -70 


$$
\sigma= \pm \frac{E \alpha}{2(1-\nu)}\left[A_{0}-A_{0}^{\prime}+\left(A_{1}-A_{1}^{\prime}\right) \cos \theta+\left(B_{1}-B_{1}^{\prime}\right) \sin \theta\right]
$$

From the approximated temperature distributions shown in Fig. IV-24, the mathematical representation becomes,

$$
\begin{aligned}
& \mathrm{T}_{1}=2450+1150 \cos \theta-750 \sin \theta \\
& \mathrm{T}_{0}=3900+2500 \cos \theta-1900 \sin \theta
\end{aligned}
$$

Substituting into equation (IV-3),

$$
\sigma= \pm \frac{E \alpha}{2(1-\nu)}[-1450-1350 \cos \theta+1150 \sin \theta]
$$

For POCO AXF at a mean temperature of $\sim 5000^{\circ} \mathrm{F}$,

$$
\begin{aligned}
& \mathrm{E}=0.9 \times 10^{6} \mathrm{psi} \\
& \alpha=4.8 \times 10^{-6} \mathrm{in} / \mathrm{in} .{ }^{\circ} \mathrm{F} \\
& \nu=0.3
\end{aligned}
$$

The maximum stress occurs at $\theta=0^{\circ}$ where the stress magnitude is 8640 psi.

This stress value is of similar magnitude with the anticipated flexural capability of the material at elevated temperature. For example, the ultimate tensile strength at $6500^{\circ} \mathrm{F}$ is reported to be approximately $4000 \mathrm{psi}$, and the ultimate flexural strength of POCO graphite is usually about 2 or 3 times greater.

A similar temperature profile was developed for a heat shield manufactured from Carb-I-Tex 500 with the same initial conditions of

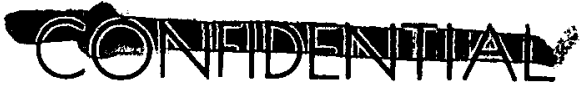

INSD - 2650-29

IV -71 


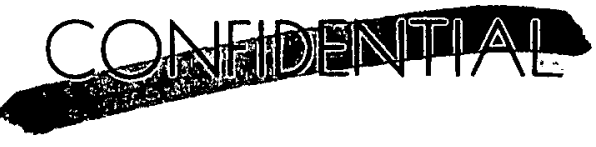

$30,000 \mathrm{ft} / \mathrm{sec}$. velocity and $-10^{\circ}$ path angle. The comparison of front and back face temperatures is given in Table IV-17.

\section{TABLE IV-17}

FRONT AND BACK FACE TEMPERATURES OF HEAT SHIELDS

$\begin{array}{lcr} & \text { Carb-I-Tex } & \text { POCo } \\ \text { Outside-Front } & 7900^{\circ} \mathrm{F} & 7500^{\circ} \mathrm{F} \\ \text { Inside-Front } & 4750^{\circ} \mathrm{F} & 3600^{\circ} \mathrm{F} \\ \text { Outside-Back } & 1600^{\circ} \mathrm{F} & 1400^{\circ} \mathrm{F} \\ \text { Inside-Back } & 1230^{\circ} \mathrm{F} & 1300^{\circ} \mathrm{F}\end{array}$

From the temperatures shown, the $\Delta T$ profile is more severe for the Carb-I-Tex with a mean front face temperature for Carb-I-Tex of $6325^{\circ} \mathrm{F}$ as opposed to $5550^{\circ} \mathrm{F}$ for POCO AXF-Q1.

At room temperature, $\mathrm{E} \alpha$ is $\left(2.7 \times 10^{6}\right)\left(.61 \times 10^{-6}\right)$ or $1.65 \mathrm{psi} /{ }^{\circ} \mathrm{F}$ for Carb-I-Tex versus approximately $7.7 \mathrm{psi} /{ }^{\circ} \mathrm{F}$ for POCO. Although values wil1 be significantly lower at the temperatures of interest, equation IV-3 indicates that the stress levels should be considerably lower in the Carb-I-Tex.

There are many forms of Carb-I-Tex where the cloth layup may have various orientations. Additional flexure capability is conceivable by including cross-grain needles to increase the ability to transfer shear across the laminates in flexure.

From the preliminary calculations provided, it appears that the heat shield of either material must be further investigated since little

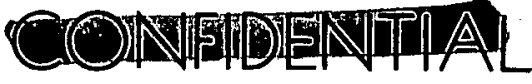


is known of the mechanical properties of the two materials at elevated temperature. Thus, test programs are necessary to establish thermal shock capability of the configuration and determine elevated temperature strength.

\section{Flight Abort Event Probabilities}

The previous sections contain parametric data on the response of the heat source to orbital and superorbital aborts. Suborbital aborts were not investigated owing to:

(1) the lesser severity of the re-entry heating pulse compared with superorbital entry, and

(2) the small probability of impacting land after exposure to re-entry heating.

a. Orbita1 decay

For orbital decay conditions, the temperature histories contained in Figs. IV-18 and IV-19 may be utilized to estimate failure probabilities. It should be noted that the conservative assumption implicit in using these results is that stable, corner-on entry occurs. This is believed not to be the 1ikely case; however, a detailed study beyond the present scope is required to prove this point. Orbital decay occurrence probability was taken as $10^{-2}$.

The maximum temperatures of the capsule liner during entry are about $3400^{\circ} \mathrm{F}$ and $2900^{\circ} \mathrm{F}$ for the POCO and Carb-I-Tex heat shields. Use of the error analysis results presented in Chapter $V$ of Ref. IV-6 yields negligible failure probabilities for the $\mathrm{TZM} / \mathrm{molybdenum} 50 \mathrm{w} / 0$ rhenlum capsule shielded by POCO AXF and Carb-I-Tex 500 graphite.

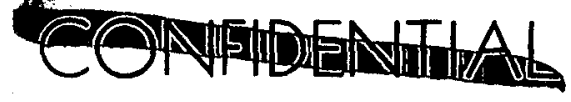

INSD $-2650-29$

IV -73 


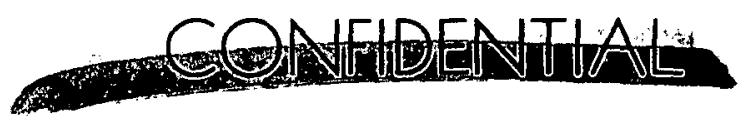

The calculated thermal stress in the graphite for either heat shield is about a factor of 3 or 4 lower than the estimated failure stress (10 to 12 thousand psi). It is concluded, therefore, that disintegration of the heat shield, potentially permitting the release of fuel at high altitude, is quite unlikely under orbital decay reentry conditions.

The probability of mechanical failure of the POCO heat shield was taken as $10^{-4}$ in accordance with the results of the IRHS analysis (Ref. IV-7). For Carb-I-Tex, an improvement factor of 10 (failure probability $=10^{-5}$ ) was assumed owing to its better mechanical properties.

b. Superorbital re-entry

Superorbital entry conditions expose the heat source to more severe thermal/mechanical environments. From analysis of physically possible re-entry modes, it is apparent that risk assessment depends very strongly on occurrence probabilities for the necessary combinations of speed and re-entry angle to produce these severe conditions. Again, a11 calculations were done for a stable entry mode (corner-on) so that results, particularly for thermal stresses in the heat shield, are conservative.

Figure IV-18 presents results for the heat source containing a shield of POCO graphite. For re-entry speeds in excess of 38,000 fps and re-entry angles steeper than about -7 degrees, the Mo-Re melt temperature is approached. These latter conditions also cause temperatures close to the melt point of the TZM strength member. Use of the

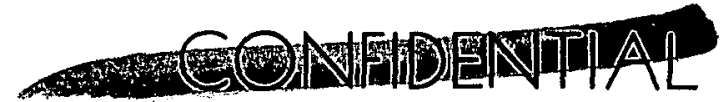




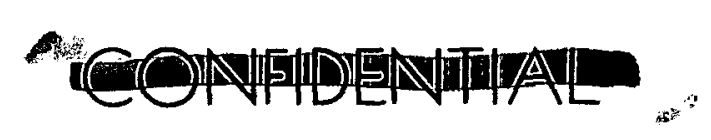

Carb-I-Tex heat shield, however, limits the TZM strength member and the Mo-Re liner temperatures such that little probability of approaching melting conditions occurs.

Another requirement for additional research pertains to the response of graphite materials to thermal stresses. Data plotted in Figs. IV-22 and IV-23 indicate temperature gradients of more than 5,000 and $4,000^{\circ} \mathrm{F}$ for the Carb-I-Tex and POCo heat shields, respectively, and the stress calculations are in the marginal range for each material.

While this condition occurs for the conservative assumption of stable, corner-on entry, the re-entry speed and angle combination to produce these temperature differences was not maximal. Therefore accurate, quantitative evaluation of the superorbital re-entry condition depends upon:

(1) the probability of achieving superorbital re-entry conditions,

(2) the probability of stable or near-stable re-entry motion, and

(3) the response of the heat shield to stresses originating from radial temperature differences ranging from 4,000 to more than $5,000^{\circ} \mathrm{F}$.

A final consideration is the high surface temperature of the heat shield. The requirement exists to verify calculated recession rates for POCO and Carb-I-Tex graphites at surface temperatures approaching $8,000^{\circ} \mathrm{F}$. 
c. Summary

The flight abort results reviewed above may now be summarized in terms of probabilities of occurrence and system response leading primarily to one of two situations:

(1) heat shield failure leading to release of fuel at high altitudes, and

(2) 1oss of strength member prior to impact.

The results are presented in Table IV-18 as the estimated negative logarithms (base 10) of probabilities. Therefore a large, positive number indicates an estimated smal1 probability.

The quantity $\mathrm{N}_{1}$ represents the negative logarithm of the unknown probability of achieving the combination of re-entry speed and flight path angle designated as the super orbital re-entry range. $\mathrm{N}_{2}$ represents the event of exceeding the melt point of the Mo-Re liner.

It is believed that the numbers $\mathrm{N}_{1}$ and $\mathrm{N}_{2}$ are very large compared with unity (small probabilities), based on the previous discussion of flight mechanics. This contention must be verified by a detailed study of abort modes for the launch vehicle and their consequences.

The composite failure probabilities according to a given mode for a specified system is $10^{-(Q+R)}$ where $Q$ and $R$ are the negative logarithms of occurrence and response probabilities.

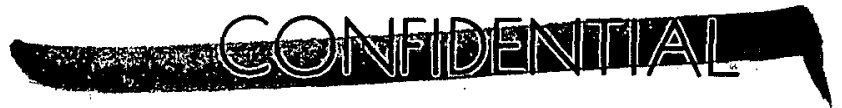

INSD - 2650-29

IV -76 
TABLE IV-18

IN-FLIGHT ABORT PROBABILITIES

Negative Logarithm (base 10) of Probability

\begin{tabular}{|c|c|c|c|c|c|}
\hline Failure Mode & Environment & Flight Condition & Occurrence & POCO & Carb-I-Tex \\
\hline Loss of heat shield & Mechanical & Orbital & $2^{(1)}$ & $4^{(2)}$ & $5^{(3)}$ \\
\hline Loss of heat shield & $\begin{array}{l}\text { Thermo- } \\
\text { mechanica1 }\end{array}$ & Superorbital & $\mathrm{N}_{1}$ & 0.3 & 0.3 \\
\hline $\begin{array}{l}\text { Loss of strength } \\
\text { nember }\end{array}$ & Thermal & Superorbital & $\mathrm{N}_{1}$ & $\mathrm{~N}_{2}$ & $>\mathrm{N}_{2}$ \\
\hline
\end{tabular}

NOTES: (1) An occurrence probability of $10^{-2}$ is assigned for aborts leading to short orbits.

(2) Estimated failure probability for IRHS heat shield (Ref. IV-7).

(3) The mechanical failure probability for the Carb-I-Tex heat shield was assumed to be smaller by a decade than that for $\mathrm{POCO}$, by virtue of its better strength properties. 


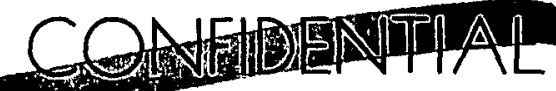

\section{F. IMPACT AND POST-IMPACT STUDY}

\section{Impact Containment}

Impact survival characteristics are not, at the present time, predictable on a strictly theoretical basis. Therefore, no attempt was made to determine impact failure probability. However, heat sources comprising a TZM strength member, liner and fuel simulators and a POCO graphite shield have been impacted at speeds of 297 to 394 fps without failure of the selected strength member (Table IV-1).

The predicted terminal speed at impact is about $245 \mathrm{fps}$ so that if survival of the heat source is demonstrated at $300 \mathrm{fps}$, the failure probability would be small, indeed. We have assumed a strength member failure probability of $10^{-2}$ which takes into account in a general sense:

(a) The 1lkelihood of exceeding $245 \mathrm{fps}$ on impact owing to corner recession in the hex heat shield.

(b) Impact under conditions more severe than tested (sharp objects, e.g.)

(c) Variability inherent in materials and capsule fabrication process

The liner is assumed to fail if the strength member suffers breakup or piercing.

The likelihood of fuel release following burial of the heat source must also be considered. To this end we have assumed that burial to a depth sufficient to melt the encapsulating materials occurs in one out of ten random impacts. As will be seen below, we assume a further

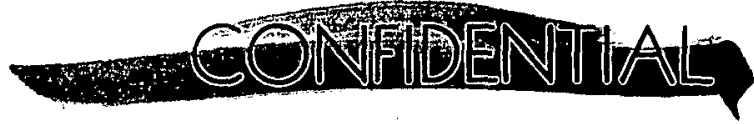

INSD $-2650-29$

IV -78 


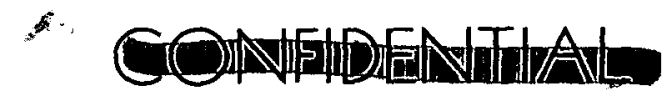

mitigation of the subsequent hazard owing to the immobilization of the fuel after its release.

\section{Post-Impact Containment}

The successful design of an IIHS implies that the most likely happening following an abort and capture of the nuclear system in the Earth's gravitational field is intact deposition of the heat source either on land or in the ocean. The advantage accruing to an intact impact heat source is thus intrinsically associated with the time period during which it remains intact after impacting land.

If we assume conservatively that the probability of recovery by a search team following land impact is small ( 0.1 or 1 ess), then the value associated with a given containment duration is that of "accidentally" finding and recovering the heat source if there are people in the region of deposition, or diminished hazard if the heat source is not found by virtue of only a few people being in the region.

Evaluation of the safety advantage derived from use of the IIHS as opposed to the IRHS is performed herein by computing a probabilistic hazard measure. The model used takes into account random discovery of the heat source (accidental recovery). The advantage factor is evaluated as a function of containment time; i.e., the advantage factor is evaluated under the condition that the heat source remains intact for a time $\mathrm{T}$.

It is found that, while the recovery probability is increased only by a factor of about two for 100-day containment as compared

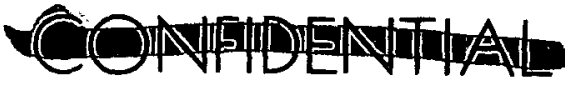

INSD $-2650-29$

IV -79 


\section{(2)}

to instantaneous release, the hazard measure is improved by nearly 2 orders of magnitude.

a. Model description

Assume deposition of the heat source occurs in a region having population density $\rho$ (persons $/ \mathrm{ft}^{2}$ ). It is further assumed that recovery is accomplished if any person approaches the heat source within a distance $a / 2$. If the average speed of persons located within the deposition region is $v$ (feet/day), then the rate of sweeping out area by each person is av( $\mathrm{ft}^{2} /$ day).

Now the area "reserved" for each person in the region is $1 / \rho$. Therefore, the incremental probability of finding the heat source in time increment $d t$ is $\frac{a v}{1 / \rho} d t=\rho$ av $d t$. The differentlal equation satis fied by the recovery probability, $p$, is therefore $\frac{d p}{d t}=(1-p) \rho$ av yielding $p=1-e^{-\rho \text { av } t}$

Thus, the non-recovery probability for a region having density $\rho$ and elapsed time $\mathrm{T}$ is the simple exponential:

$$
\mathrm{p}_{\mathrm{NR}}=\mathrm{e}^{-\rho_{\mathrm{av} T} \mathrm{~T}} .
$$

Now if the population density spectrum is defined by $g(\rho)$ such that $\int_{0}^{\infty} g(\rho) \mathrm{d} \rho=1.0$, then the total probability of not finding the source in time $T$ is

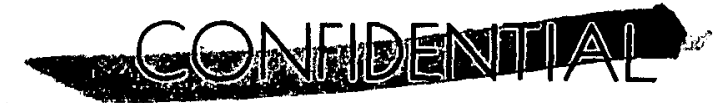




$$
\mathrm{P}_{\mathrm{NR}}(\mathrm{T})=\int_{0}^{\infty} \mathrm{g}(\rho) \mathrm{e}^{-\rho_{\mathrm{av}} \mathrm{T}} \mathrm{d} \rho
$$

This probabllity is not the sole measure of safety in that a nonrecovered source which ultimately releases fuel constitutes no hazard if there are no people in the region. Previous analyses have shown that a reasonable risk measure is proportional to the population density; therefore, an appropriate risk index can be calculated in the form

$$
R(T)=\int_{0}^{\infty} \rho g(\rho) e^{-\rho a v T} d \rho
$$

In previous studies (Ref. IV-8) we have derived an exponential representation for the probability density function of worldwide population density based on Edrington's data (Ref. IV-9). It has the form:

$$
g(\rho)=\sum_{i=1}^{3} A_{i} e^{-\alpha_{1} \rho_{1}},
$$

where the parameters $A_{1}$ and $\alpha_{1}$ are given in Table IV-19.

Substituting the exponential representation of $g(\rho)$ into the expressions for $P_{N R}(T)$ and $R(T)$ we find

$$
\mathrm{P}_{\mathrm{NR}}(\mathrm{T})=\sum_{1=1}^{3} \frac{A_{1}}{\alpha_{1}}\left(1+\frac{\mathrm{av}}{\alpha_{1}}\right)^{-1}
$$

\section{-eonitionatar}




\section{CONELEENTIHAL}

TABLE IV-19

POPULATION DENSITY FUNCTION PARAMETERS

$\underline{\mathbf{1}}$

1

2

3
$\alpha_{1}\left(\mathrm{ft}^{2}\right)$
$2.9 \times 10^{7}$
$7.08 \times 10^{5}$
$8.78 \times 10^{4}$ 
and $R(T)=\sum_{i=1}^{3} \frac{A_{1}}{\alpha_{i} 2}\left(1+\frac{a v}{\alpha_{i}} T\right)^{-2}$

b. Results

Approximate results were calculated for $\mathrm{P}_{\mathrm{NR}}$ and $\mathrm{R}$ for $1,10,100$, and 1000 days. These are given in the Table IV-20. The average speed $\mathrm{v}$ was taken as about $1 \mathrm{mile} /$ day and the comblnation av was taken as $5 \times 10^{4} \mathrm{ft}^{2} /$ day.

This, if one can be assured of containment for 10 days following impact, the estimated advantage is a reduction of a factor of 10 in the risk magnitude. For each decade increase in containment time, thereafter, the hazard decreases by about one decade. Eventually, for long containment times, the risk decreases like $\mathrm{T}^{-2}$.

The results are sensitive to the quantities $a$ and $v$ only in the combination avT. Thus, if $v$ were taken to be $1 / 10$ of its present value while a and $T$ were fixed, the result would be the same as evaluated at $\mathrm{T}^{\prime}=0.1 \mathrm{~T}$ :

$R(T, 0.1 a, v)=R(0.1 T, a, v)$

While the values assumed for $a$ and $v$ are only estimates, it seems unreasonable that the product av would differ by as much as a factor of 10 from its assumed value. 


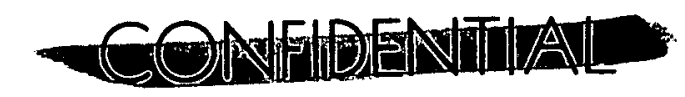

TABLE IV-20

EFFECT OF CONTAINMENT TIME

ON FUEL RELEASE PROBABILITY AND RISK

Tota 1

Non-Recovery

Contaiment

Time, $T$

(days)

Probability

$\mathrm{P}_{\mathrm{NR}}(\mathrm{T})$

Risk Index $R(T)$

Normalized Risk Index $R(T) / R(0)$

1

0.93

$1.0 \times 10^{-6}$

0.50

10

0.75

$1.9 \times 10^{-7}$

0.095

100

0.53

$2.08 \times 10^{-8}$

$1.04 \times 10^{-2}$

1000

0.22

$2.79 \times 10^{-9}$

$1.39 \times 10^{-3}$ 
We conclude from this approximate analysis that design of an IIHS heat source for 100-days' containment affords a risk reduction of about 2 orders of magnitude. If the source is likely to be recovered shortly after deposition owing either to the efforts of a search team or from sighting during re-entry, the relative advantage as a function of time remains because of the non-zero probability of non-recovery. However, if early recovery is very probable, non-recovery obviously poses a smaller risk and other hazards become more dominant in influencing design.

is:

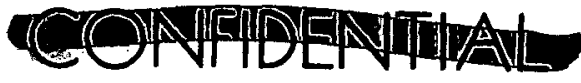

INSD - 2650-29

IV -85 


\section{G. DESIGN CONSIDERATIONS}

The results of the preceding sections of this chapter may now be summarized. The resulting probabilities of malfunctions and system response are considered the best available for decision making with respect to the design of the heat source. Where occurrence probabilities have been roughly estlmated based upon past experience, e.g., in the case of orbital abort frequencies or impact containment of the capsule and liner, it should be recognized that substantial effort is required to provide significantly improved estimates.

The results, shown in Table IV-21, are grouped according to consequences of malfunctions and system fallure--high altitude release and ground release at times varying from the instant of impact to 100 days after impact* Also included are hazard indices indicating the relative severity of the types of events considering the quantity and nature of released fuel and the extent of population exposures (Ref. IV-7).

The hazard indices were derived for the microsphere fuel form. Release at high altitude was estimated to cause degradation in size of the original particles, increasing inhalation exposures. Its relative value is taken as 1.0 . The remaining indices pertain to ground release and vary depending upon location of the release (random or in the launch pad environs). Ground releases have smaller indices by about 2 or 3 decades than release at high altitude.

*100-day containment was conservatively assumed based on Isotopes' and vendor test data - actual containment time would be in excess of this value.

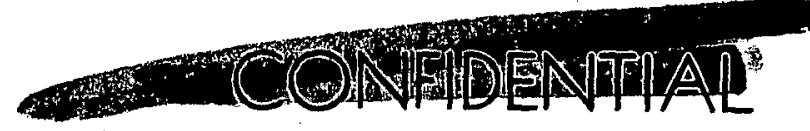


TABLE IV-21

MALFUNCTION (NET RELEASE) PROBABILITIES

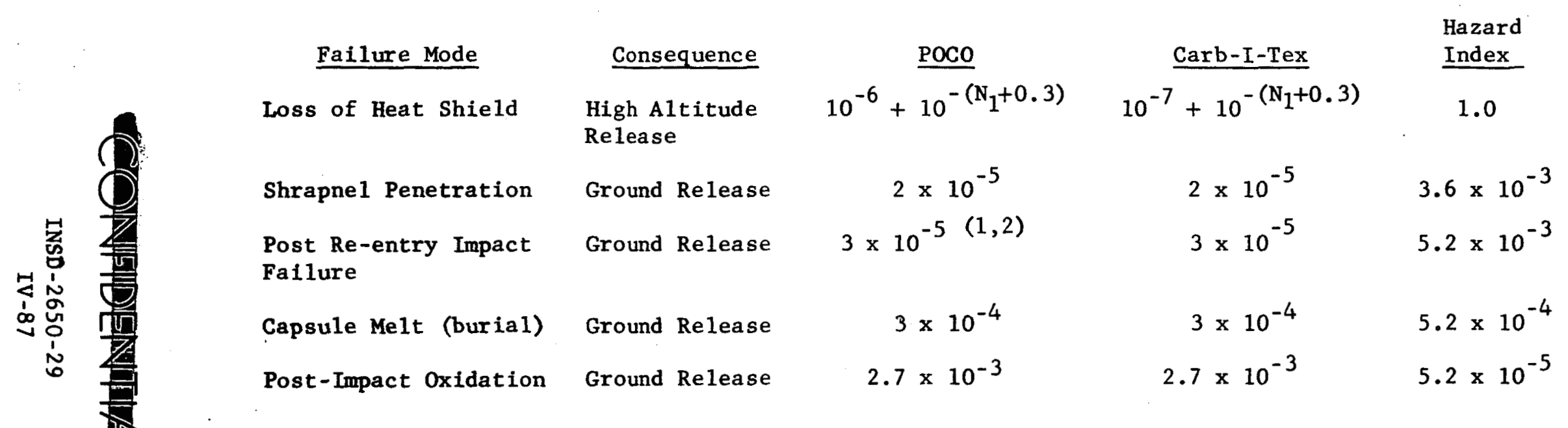

Nore: (1) Includes probabilities of $10^{-2}$ for in-flight aborts and 0.3 for land impact. The same is true for a11 entries below and to the right.

(2) Ignores superorbital melting of strength member. Same is true for other elements in this row. 


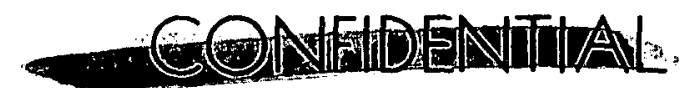

The first row in Table IV-21 indicates the estimated probability and consequences of loss of the heat shield during re-entry. The first term in the release probabilities derives from mechanical failure of the graphite owing to accelerations possible prior to peak heating for orbital aborts. These include the flight malfunction probability $\left(10^{-2}\right)$ and the system response probabilities $\left(10^{-4}\right.$ or $10^{-5}$ for Poco and Carb-I-Tex) taken from Table IV-18. Composite indices (ref. Table IV-22), formed by multiplying release probabilities for each system and the 1isted hazard index, are on the order of $10^{-6}$ and $10^{-7}$ depending upon the heat shield material, provided superorbital entry is quite improbable $\left(\mathrm{N}_{1}>7\right)$. In any case, this failure mode yields one of the largest composite hazard indices for heat sources with POCO heat shields.

Shrapnel penetration probabilities were discussed previously and a release probability on the order of $2 \times 10^{-5}$ was derived. The hazard index in this case pertains to fuel release in the launch pad environs and is somewhat smaller than for ground release in uncontrolled areas. This fallure mode has an estimated composite index which is smaller than the major contributors. Identical results are estimated for all systems by virtue of nearly identical penetration characteristics for each capsule.

Post re-entry impact failure owes to fallure of the strength member and liner elements of the capsule. The capsule was assumed to have a single fallure probability $\left(10^{-2}\right)$, regardless of heat

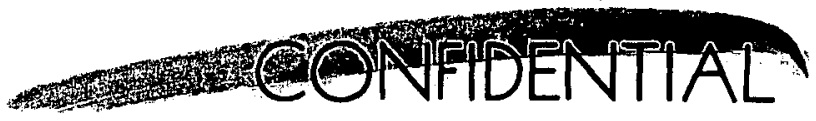




\title{
CONFFIDENTWA
}

\author{
TABLE IV -22
}

COMPOSITE INDICES

Failure Mode

Loss of Heat Shield

Shrapne1 Penetration

Impact Failure

(post re-entry)

Capsule Me1t

(buria 1)

Post Impact Oxidation

Total (excluding superorbital thermal stress failure of heat shield)
POCO
$10^{-6}+10^{-\left(\mathrm{N}_{1}+0.3\right)}$
$10^{-7}+10^{-\left(\mathrm{N}_{1}+0.3\right)}$
$7 \times 10^{-8}$
$7 \times 10^{-8}$
$1.5 \times 10^{-7}$
$1.5 \times 10^{-7}$
$1.5 \times 10^{-7}$
$1.5 \times 10^{-7}$
$1.4 \times 10^{-7}$
$1.4 \times 10^{-7}$
$1.5 \times 10^{-6}$
$6.1 \times 10^{-7}$ 
shield differences. The composite hazard magnitude of about $10^{-7}$ appears to be realistic and represents the lower limft of design capability. (It would be difficult to demonstrate an impact failure probability much smaller than $10^{-2}$ ). At this leve1, assuming a 11 other failure modes gave smaller indices, the intact impact design would be safer by about two decades than the IRHS (used for Nimbus III).

The burial probability, as indicated above, includes, in addition to abort $\left(10^{-2}\right)$ and land impact $(0.3)$, a probability of 0.1 for burial at sufficient depth to melt the capsule. The hazard index is also mitigated by a factor of 10 owing to expected immobilization of the fuel particles by resolidified soil and capsule materials. The composite index is about the same as that for impact failure.

In evaluating relative hazards from post-impact oxidation of the capsule, the results of Section IV-F-2 were used. Thus the hazard indices for ground release of fuel after 100 days was assumed to be smaller than for instantaneous release $\left(5.2 \times 10^{-3}\right)$ by a factor of 100 . The 100-day containment time was conservatively assumed based on Isotopes' and vendor test data which shows the probable containment time to be in excess of this value. As containment periods in excess of 100 days do not significantly effect the risk index (see Table IV-20), 100 days was conservatively assumed for this preliminary evaluation.

The composite indices in Table IV-22 may be used to derive conclusions from present estimates and to indicate emphasis required in future work. The conclusions are as follows:

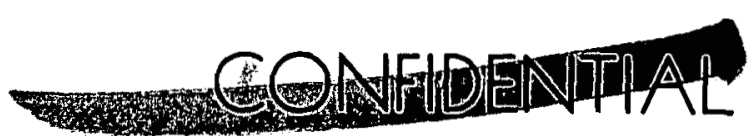




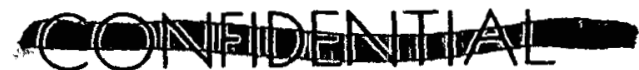

1. The minimum achievable level of risk expressed in the relative units presented above is about $10^{-7}$. This level results from failure of the capsule on impact with an estimated probability of $3 \times 10^{-5}\left(10^{-2}\right.$ for orbital abort, 0.3 for land impact, and $10^{-2}$ for capsule failure).

2. Present estimates indicate that best source candidates have comparable risk levels within about a factor of two.

3. Key assumptions made in deriving these results include:

a. For the heat shields, the occurrence probability of superorbital conditions and stable entry and thermal stress failure is smaller than $10^{-7}$; mechanical failure of heat shield during orbital re-entry is $10^{-6}$ (POCO) or $10^{-7}$ (Carb-I-Tex).

b. Impact failure of strength member and liner materials has a probability of $10^{-2}$.

c. A containment period in excess of 100 days is expected following post-re-entry impact.

Future work should address itself to the validity of assumptions as well as the refinement of all significant probabilistic mode1s.

4. With the above assumptions, performance approaching the estimated lower $11 \mathrm{mit}$ of about $10^{-7}$ would require demonstration of:

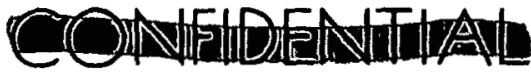


a. Greater heat shield integrity during re-entry.

b. Decreased probability of melting or burying on impact; somewhat reduced shrapnel penetration probability.

c. Post-impact capsule integrity.

5. Finally, and significantly, a risk level decreased by 1 to 2 orders of magnitude, compared with the SNAP 19 IRHS launched on Nimbus III, appears achievable.

In these considerations, we have ignored compatibility requirements between fuel and liner materials. At the present time it is considered that the molybdenum alloys are sufficiently compatible with $\mathrm{PuO}_{2}$ so that contalnment is not jeopardized based on tests conducted at Los Alamos Scientific Laboratory, Battelle Memorial Institute, and Mound Laboratory. The results of this study suggest that either candidate may be utilized and provide a significant safety advantage over the flight-qualified SNAP 19 IRHS.

We have further assumed in this analysis that the physica 1 characteristics of the fuel are those estimated for $\mathrm{PuO}_{2}$ microspheres. If it is shown that present estimates for microspheres are unduly pessimistic, or if a safer form is utilized, the estimated hazard index will be further reduced.

The formulation of safety design criteria for an IIHS was the indicated goal of the safety evaluation. Achievement of this goal requires:

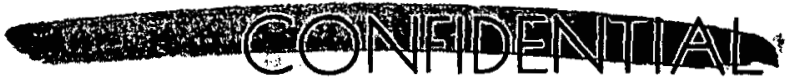




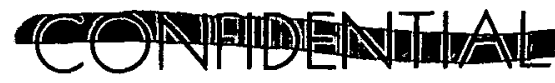

1. Finalization of probability models particularly in the areas of blast response, shrapnel environment and penetration, impact media and their consequences, capsule burial, superorbita1 re-entry, and re-entry rotationa 1 states.

2. Definition of the relationship between release probabilities and the materials and dimensions of candidate configurations.

3. Specification of a criterion for the composite index described above (or as an improvement factor relative to the IRHS).

With these requirements satisfied, the establishment of design criteria and specifications follows in a straightforward manner.

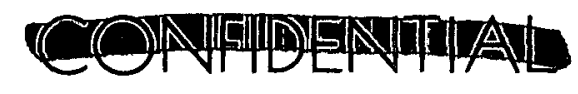

INSD $-2650-29$

IV-93 
V. RTG/VLC INIEGRATION CONSIDERATIONS

This chapter presents the spacecraft integration considerations associated with incorporating multiple RTG's as the Viking Lander Capsule (VLC) prime power source. The Martin Denver proposal study, as well as studies presently being performed at that facility, were used to establish baseline VLC configurations. Figure V-1 shows the Viking Lander Model built by Martin Denver based on the Viking proposal configuration which employed two RTG units.

\section{A. MECHANICAL}

\section{Installation}

A Viking RTG unit. may be mounted in any orientation on the VLC by attachment to the VLC structure at either one or both of the RTG end closure flanges. At present the mounting bolt circle pattern in each end flange (and associated end cover) consists of six equally spaced holes on a 7.5-inch diameter circle (see Fig. V-2). Attachment to the structure is with 0.25 -inch diameter bolts

For a two RTG unit stacked installation (similar to the existing SNAP 19 Nimbus III RTG subsystem configuration), the RTG units are bolted end-to-end at the six attachment holes in the mating flanges. Again, mounting in any orientation on the VLC may be accomplished at either one or both of the RTG stack outer end cover flanges or at the mating flange interface.

The mounting provisions and end cover design shown in Fig. V-2 should be considered as typical and can be altered to the VLC de-
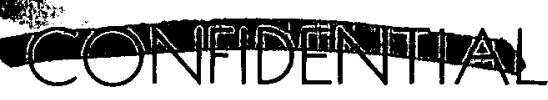

INSD-2650-29

$\mathrm{V}-1$ 


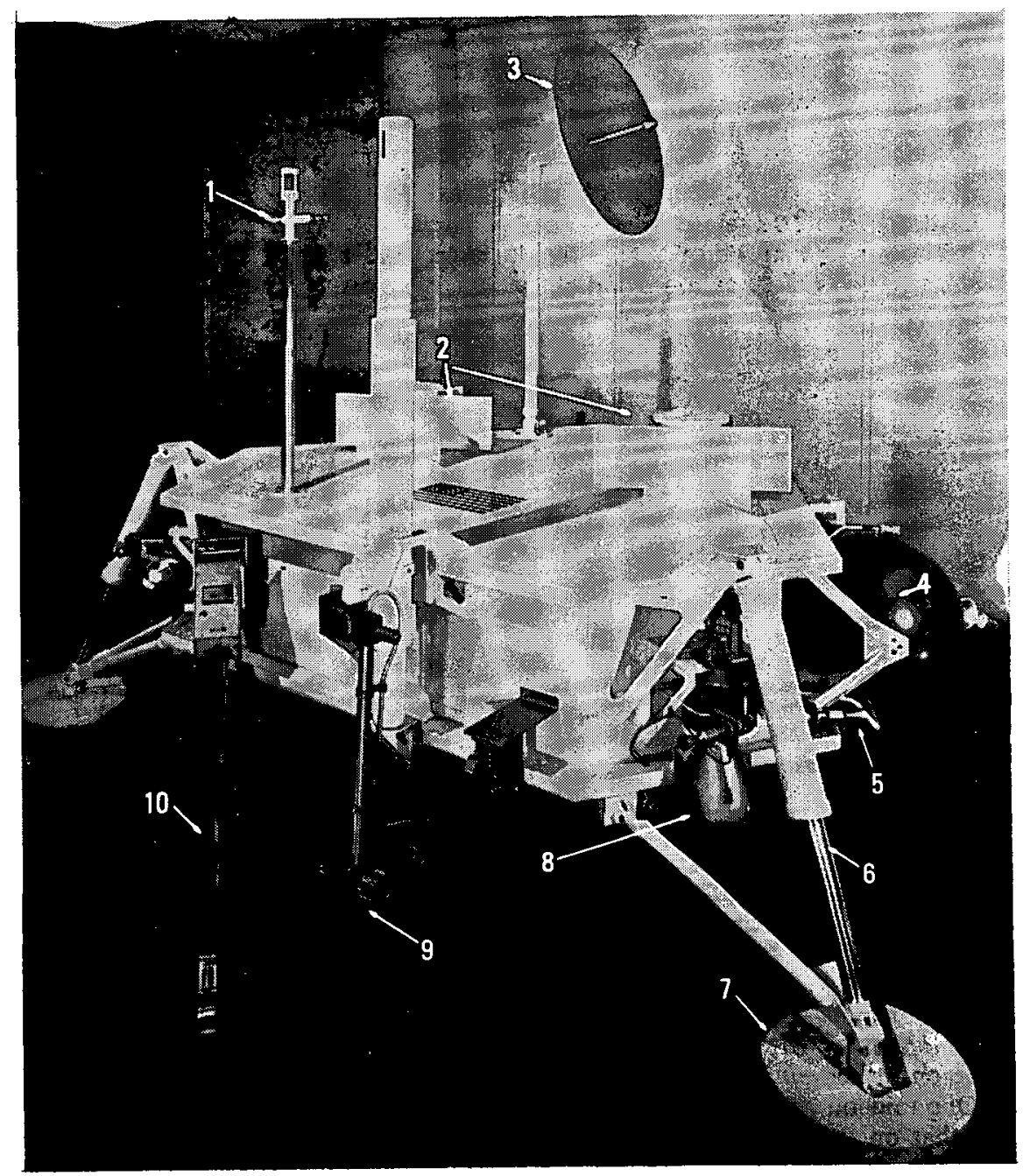

FIG. V-1. VIKING LANDER MODEL
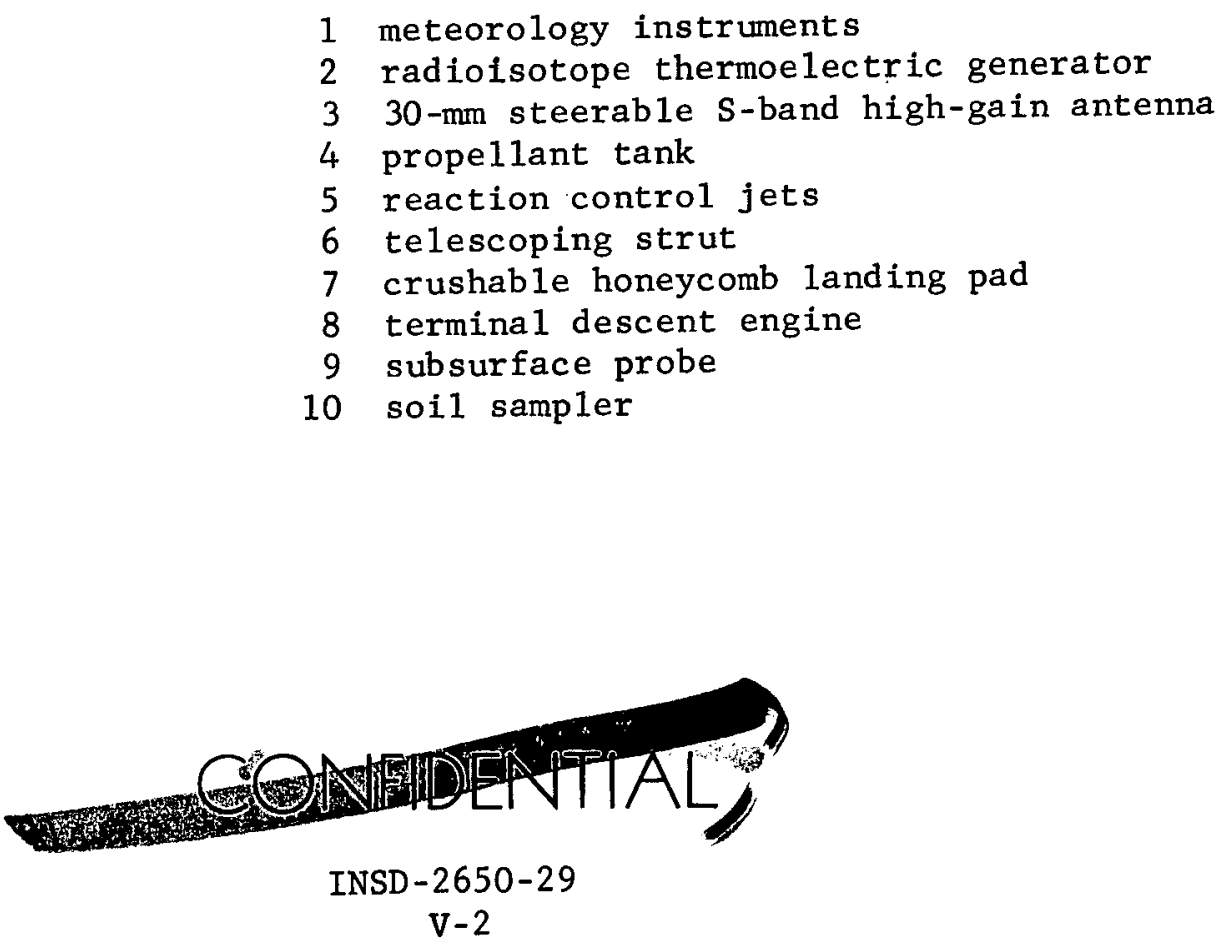


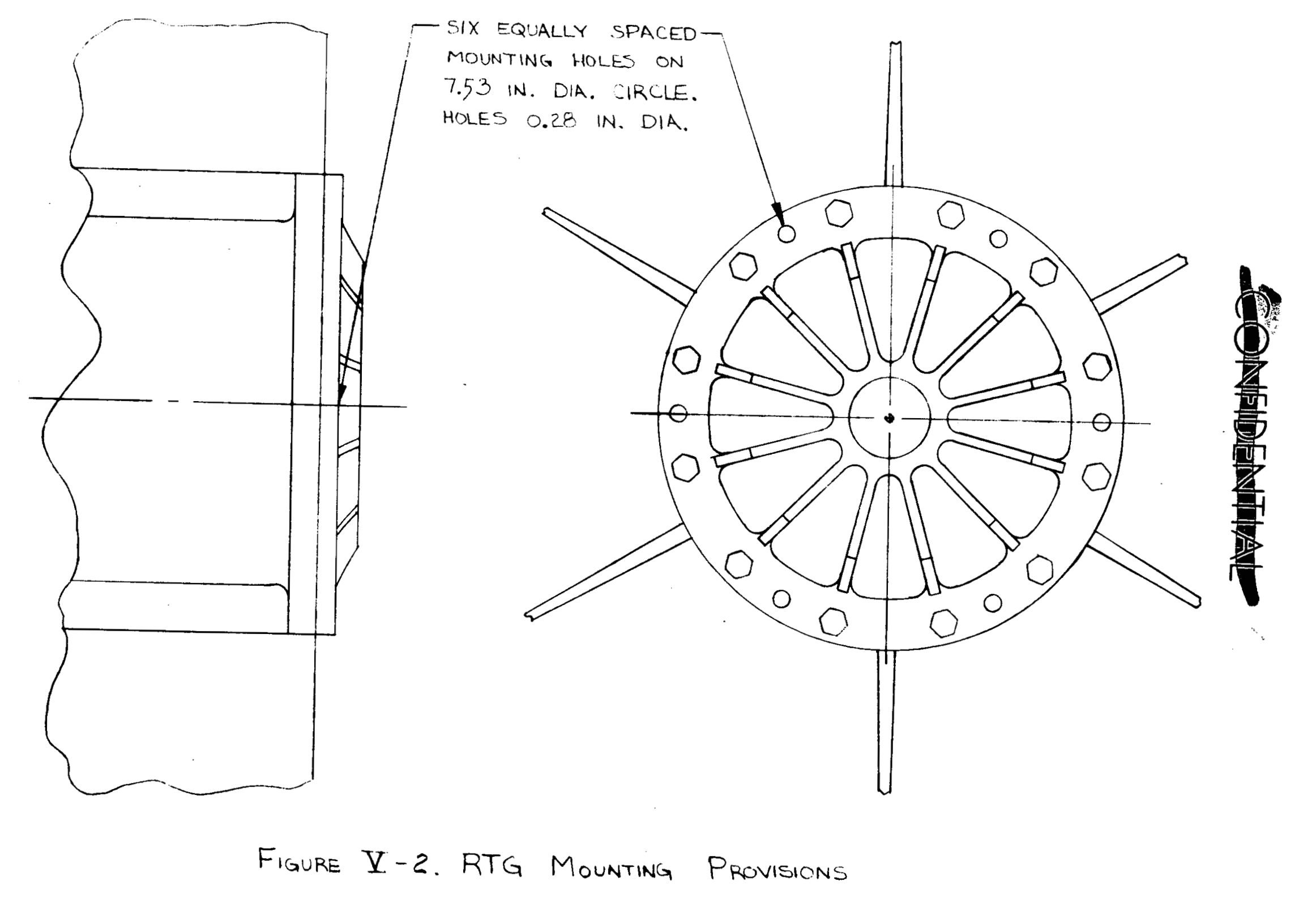


signer's specific requirements. This may include a variation in mounting hole geometry as well as an attendant change in the end cover design. Such changes may be desired to permit mating with VLC thermal control devices designed to extract heat from the RTG during "cold" periods such as during the Martian night. A specific contact area at the RTG/thermal control device interface may be required to achieve the desired heat flow into the spacecraft. The present Martin Denver design employs the RTG mounted directly to the VLC structure with a thermal control device which maintains contact with the RTG in the area of the lower cover during periods when heat flow to the VLC is desired. When heat is not required the device retracts away from the RTG surface, thus opening the heat transfer path from the RTG.

The single RTG unit envelope is 10.75 inches high by 24.4 inches across the fin tips. For a two unit, stacked configuration the height is approximately doubled, 21.50 inches, and the dimension across the fin tips increases approximately 2 inches. An increase in $f$ in width over the single unit is required to compensate for (I) loss of heat dump capability from the end cover of one RTG and (2) loss of view factor to the environment due to the presence of both RTG's.

2. Dynamic Considerations

The proposed Viking baseline design is similar to that of SNAP 19 generators $S / \mathbb{N} 27$ and $S / \mathbb{N} 28$ which were dynamically tested on June 12 and 13, 1969. These generators were hard-mounted to the vibration table and dynamically tested in the heated, operational condition to the levels shown in Table III- 6 of section III-B. These dynamic test levels were determined for the RTG from Viking launch environment

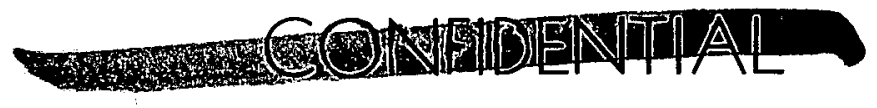




\section{GONFIDENTIAND}

specifications. Results of these tests showed no change in power output in either generator. Although preliminary in nature, the results of these tests, in conjunction with the considerable SNAP 19 Nimbus test experience on similar type units, demonstrate the basic RTG configuration is capable of satisfying the Viking dynamic requirements.

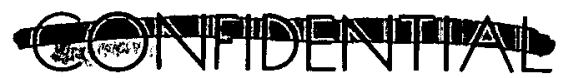

INSD-2650-29 
B. THERMAL

The RTG's will be subjected to a wide spectrum of thermal environments during the course of the Viking mission. Prelaunch environments include those associated with normal ground handling activities of the RTG's prior to installation on the VLC, and operations subsequent to installation, including VLC sterilization within the sterilization canister. After sterilization, the VLC (with RTG's installed) remains in the sterilization canister during subsequent launch preparation, launch and interplanetary cruise. Just prior to deorbiting for entry into the Martian atmosphere the sterilization canister is ejected. Subsequent to Mars landing, RTG operation will be in the sun-shade cycle characterized by the Martian diurnal cycle.

In this section, the thermal limitations for the RTG are presented and operation in the various environments evaluated in light of these limitations.

\section{RTG Temperature Limitations}

The RTG temperature limitations may generally be categorized as either those concerned with the thermoelectric degradation rate or those associated with component failure. In the RTG, the primary cause of an increase in the thermoelectric degradation rate is any significant increase in the hot junction temperature above the design value. The component failures of concern are the melting of the PbTn solder used for bonding the thermoelectric couples at the cold junction to the copper electrical connector straps, and a relaxation of the 0-ring seals which

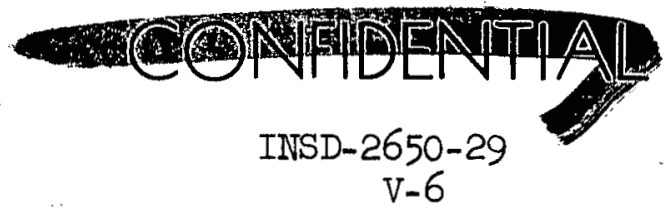


could result in increased gas leakage from the generator.

The hot junction temperature limitations for the baseline TAGS-85/ 2N design are defined as $1060^{\circ} \mathrm{F}$ for continuous operation and $1075^{\circ} \mathrm{F}$ for short-term operation (on order of a month). Life test data are presentIy being obtained on the SNAP 19 and 29 programs for generators, modules and couples operating in the 1025 to $1075^{\circ} \mathrm{F}$ temperature range (see Section III-B). Results to date show that long-term operation up to $1075^{\circ} \mathrm{F}$ may be allowable; however, for purposes of this study, $1075^{\circ} \mathrm{F}$ is assumed to be the upper limit for short-term operation until additional data are available.

The PbIn solder used to bond at the cold end melts at approximately $530^{\circ} \mathrm{F}$. Since the $\Delta \mathrm{T}$ from this solder joint to the radiator fin root is approximately $60^{\circ} \mathrm{F}$, a fin root temperature of $470^{\circ} \mathrm{F}$ would result in solder melt. A fin root temperature of $450^{\circ} \mathrm{F}$ has been selected as the limitation to prevent melting at this joint.

Operation of the Viton 0-ring seals at a temperature in excess of $400^{\circ} \mathrm{F}$ for extended periods of time could result in excessive set of the Viton o-ring seals and accelerated leakage of the generator internal cover gas. Thus, it is desirable to maintain the seal temperature at about $400^{\circ} \mathrm{F}$ or lower for short-term, high temperature operations such as sterilization. No extensive data are presently available above $400^{\circ} \mathrm{F}$ to accurately predict the resulting seal integrity for longterm operation. However, component testing is scheduled to be initiated at Isotopes in this calendar year to determine the effect of O-ring

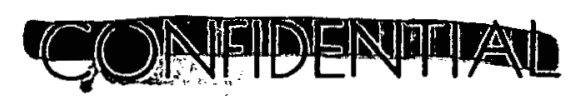

INSD-2650-29 
temperature on the seal tightness. Results of these tests will permit selection of a more accurate temperature limitation than is possible with existing data.

Table V-I summarizes the RTG temperature limitations. Evident is that the o-ring seal is the limiting factor for the fin root temperature.

\section{Viking Stuajy Results}

During the Viking proposal effort, Martin Denver performed extensive VLC thermal integration studies for various mission thermal environments. However, these studies were performed using the existing Nimbus III type generator design parameters (625 watts fuel loading, $350^{\circ} \mathrm{F}$ design fin root temperature) and the two-RTG VLC configuration shown in Fig. V-1. Table V-2 presents the results of these evaluations. The worst case for the RTG fin root temperature, $415^{\circ} \mathrm{F}$, as expected occurs during sterilization. This temperature is considered marginal for the short term sterilization period, as the $400^{\circ} \mathrm{F}$ limit is exceeded and must be evaluated further in the aforementioned seal tests to be performed. Since the RTG is on short circuit during this operation, the resulting hot junction temperature, $1019^{\circ} \mathrm{F}$, is well within limits (see Table V-2).

The maximum RTG fin root temperature at Mars occurs when the VLC is descending to the Martian surface. The fin root temperature during this short time period is $365^{\circ} \mathrm{F}$ and the corresponding hot junction temperature $1045^{\circ} \mathrm{F}$. This is the worst thermal case for Mars operation

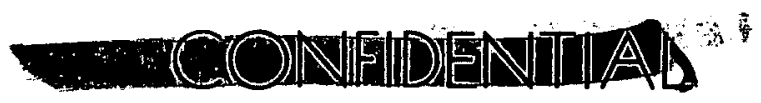




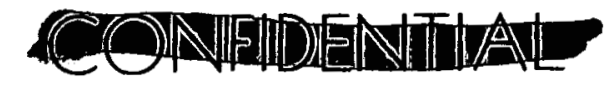

since the RTG is on load and at the maximum fin root value. From Table V-2 it is evident that no thermal problems associated with the RTG are anticipated for any operations subsequent to sterilization. Verification of seal integrity at sterilization temperatures requires demonstration testing.

It should be noted that the temperature data given in Table V-2 assumes the baseline TAGS-85/2N operational characteristics are similar to those for the Nimbus III generators for which the analysis was performed. This assumption is permissible for a two-RTG VLC configuration, but may be in error for the present four-RTG configuration due to the higher total thermal inventory present. Martin Denver is presently preparing thermal models for the four-RTG configuration, and data will be available shortly to permit evaluation of this VLC concept.

\section{TABLE V-1}

RTG TEMPERATURE LIMITATIONS

\begin{tabular}{|c|c|c|}
\hline Item & Comment & Iimitation \\
\hline $\begin{array}{l}\text { Hot junction } \\
\text { temperature }\end{array}$ & $\begin{array}{l}\text { Thermoelectric power degra- } \\
\text { dation generally increases } \\
\text { at hot junction values sig- } \\
\text { nificantly in excess of the } \\
\text { selected design value }\end{array}$ & $\begin{array}{l}1060 \text { (continuous } \\
\text { operation) } \\
1073 \text { (short-term } \\
\text { operation--up to } \\
\text { one month) }\end{array}$ \\
\hline $\begin{array}{l}\text { PbIn cold end } \\
\text { solder }\end{array}$ & Melts at $530^{\circ} \mathrm{F}$ & $\begin{array}{l}\text { Fin root tempera- } \\
\text { ture limited to } \\
450^{\circ} \mathrm{F}^{*}\end{array}$ \\
\hline o-ring seals & $\begin{array}{l}\text { Operation at elevated tem- } \\
\text { perature for extended per- } \\
\text { iods of time causes relax- } \\
\text { ation of the O-ring and a } \\
\text { potential increase in gas } \\
\text { leakage from the RTG }\end{array}$ & $\begin{array}{l}\text { Fin root tempera- } \\
\text { ture limited to } \sim \\
400^{\circ} \mathrm{F} \text { for short-term } \\
\text { operation (up to } 200 \\
\text { hrs) and } 375^{\circ} \mathrm{F} \text { for } \\
\text { continuous operation* }\end{array}$ \\
\hline
\end{tabular}

*The limitation on fin root temperature is controlled by the o-ring since its limitation is less than that for the solder.

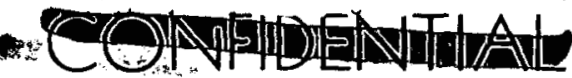




\section{TABLE V-2}

PREDICTED RTG FIN ROOT TEMPERATURES FOR VIKING MISSION ENVIRONMENT (Two-RIG Configuration)

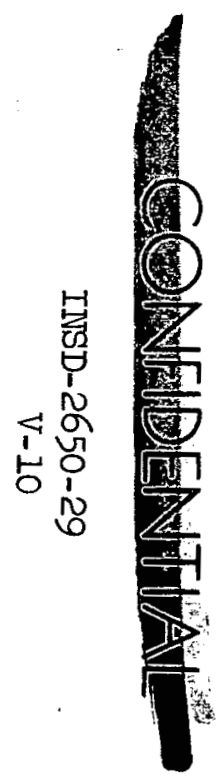

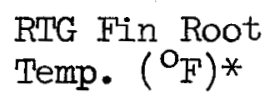

415

279

370

363

365

Descent to Mars Surface

Mars Surface Operation

$\begin{array}{ll}\text { Extreme Hot } & 340 \\ \text { Extreme Cold } & 194\end{array}$

$\begin{array}{lcc}\begin{array}{c}\text { Load } \\ \text { Condition }\end{array} & \begin{array}{c}\text { Hot Junction } \\ \text { Operating Temp. }\end{array} & \left.{ }^{{ }} \text {F }\right) \\ \text { Shorted } & & 1019 \\ \text { Shorted } & 863 \\ \text { Shorted } & 954 \\ \text { On Load } & 1043 \\ \text { On Load } & 1045 \\ & \\ \text { On Load } & 1020 \\ \text { On Load } & 874\end{array}$

*The SNAP 19 Nimbus III parameters were assumed in the Martin Denver proposal studies

( 625 watt thermal inventory, $350^{\circ}$ F design fin root temperature, two-RTG VLC configuration). 


\section{CONFDENATE}

\section{ELECTRICAL}

As was stated in the guidelines in section I-B, the electrical interface between the RTG and Viking Lander Capsule (VLC) is assumed to be at the RTG electrical output connector. This assumption is based on the recognition that in present program plans, Martin Denver will provide the associated power system wiring and power conditioning equipment (e.g., DC-DC converters and voltage regulator). The content of this section is oriented primarily toward describing the RTG electrical characteristics and their influence on mission planning. However, a discussion on related electrical equipment and instrumentation is also presented.

1. Load Condition

a. Normal operation

As is typical with most power sources, the performance capability of an RTG is directly related to the load condition under which it is operated. Figure V-3 shows the predicted nominal operational characteristics of the baseline Viking RTG at various times during the mission. A fixed operating load voltage of 2.9 volts has been selected as the design point since the maximum generator power at the end-of-mission (one year after launch) is realized at this value. As the RTG output is by itself unregulated, a voltage regulation device is required at some point in the circuit, such as at the RTG output or at the VLC power bus, to maintain this voltage.

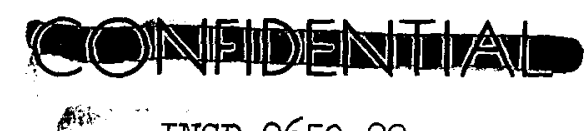

ANA " INSD-2650-29

$\mathrm{V}-11$ 


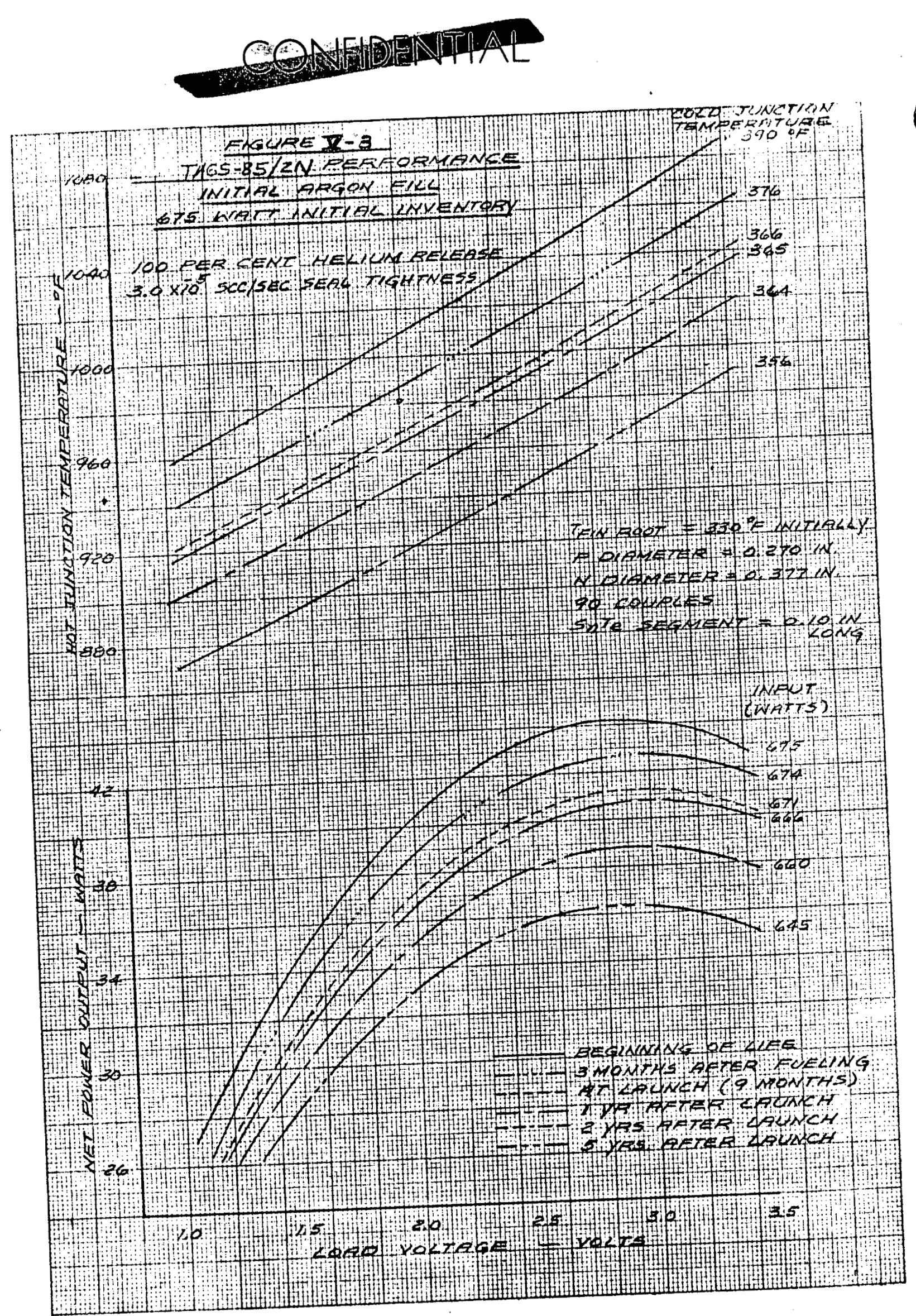




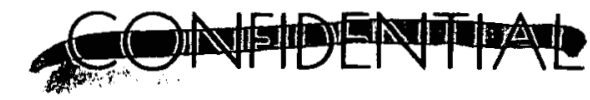

In Fig. V-3 it is seen that the hot junction operating temperature variation with load voltage is virtually linear, increasing with increasing load voltage. Thus, as the load voltage is decreased toward short circuit from the 2.9 volt design point the hot junction temperature drops. Conversely, as the load voltage is increased above the design point, the hot junction increases. Since the fraction of heat converted to electrical energy (RTG conversion efficiency) is relatively low (approximately $6 \%$ ) the effect of load voltage variation on the cold junction and fin root temperatures is small. Both temperatures change less than $15^{\circ} \mathrm{F}$ from the nominal design values for the extreme load conditions of open circuit and short circuit. At these loads, the RTG power output is essentially zero and the heat to be radiated to space increases approximately $6 \%$ above that at nominal operating conditions.

b. Short circuit operation Operation of the RTG on short circuit at any time desired during the mission is permissible. Unlike batteries, operation with the output shorted does not result in a discharged condition and will not significantly effect subsequent performance. As discussed above, operation at short circuit results in a lower hot junction temperature and thus is desirable, though not necessary, when electrical power is not required. For example, preVious SNAP 19 units have been operated on short circuit during prelaunch storage periods. Short circuiting the RTG output reduces the hot junction temperature approximately $100^{\circ} \mathrm{F}$ below the nominal load value for the same radiator fin root temperature.

The current Martin Denver mission operations call for the RTG's to

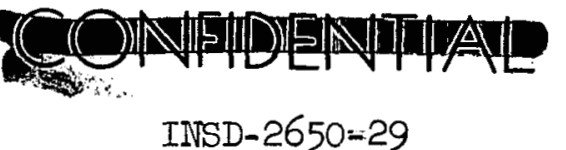

$\mathrm{V}=13$ 


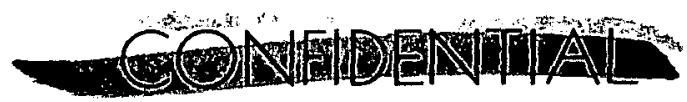

be maintained on short circuit during storage, sterilization and interplanetary cruise.. As indicated in Table V-2, sterilization is the only operation necessitating short circuit operation to assure subsequent satisfactory operation (temperature would exceed $1100^{\circ} \mathrm{F}$ if maintained on load). In Mars orbit, prior to Mars entry, the RTG's will be switched on load for VLC activation and checkout, and will remain on load throughout the remainder of the mission.

\section{c. Open circuit operation}

Extended operation of the RTG at the open circuit condition is not allowable due to the high hot junction operating temperatures incurred. A temperature increase above the nominal value on the order of $100^{\circ} \mathrm{F}$ results at steady state open circuit conditions. However, the RTG output may be open eircuited momentarily (on the order of 30 seconds) to obtain instantaneous voltage readings for purposes of RTG performance evaluation or load switching. The rate of hot junction temperature increase after open circuiting is closely related to the thermal capacity of the heat source, and this characteristic thermal inertia permits short-term open circuit operation.

2. Environmental Effects

a. Fin root temperature variation

Operation of the RTG in the Martian environment results in a varying RTG fin root temperature which influences the RIG power output. The maximum fin root temperature range during operation on the Martian surface predicted by Martin Denver proposal studies was presented in

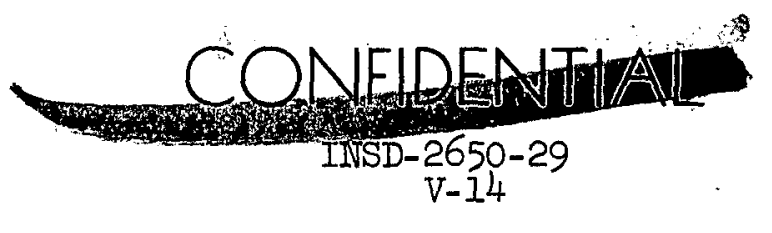


Table V-l. However, as the Martin Denver proposal studies are based on test results and thermal models employing two RTG's of the SITAP 19 Nimbus III design ( 625 watt thermal inventory, $350^{\circ} \mathrm{F}$ nominal fin root temperature), the results are not directly applicable to the proposed TAGS-85/2N Viking RTG design (675 watts thermal inventory, $330^{\circ} \mathrm{F}$ design fin root temperature) and four-RTG VLC configuration. Thus, only a qualitative evaluation is possible at present.

Figure V-4 shows the effect of fin root temperature variation on power output for the Martin Denver predicted operating temperature range. The results shown are for the VLC configuration presented in the Martin Denver proposal studies (two Nimbus III type RTG's). On the Martian surface, a maximum power decrease of approximately 2 watts was predicted from nominal operation to either the coldest or hottest Martian environment. Although no substantiating data are presently available, it is anticipated that for the proposed TAGS-85/2N RTG, the power fluctuation curve will be similar to that shown in the figure, and the maximum power decrease on the order of 2 watts.

To quantitatively determine the influence of fin root temperature variation, Martin Denver is presently conducting integration studies on the current VLC concept employing four baseline TAGS-85/2N RTG's. The results of these studies, in conjunction with scheduled thermal tests in the near future on this type RTG by Isotopes in which power output as a function of fin root temperature will be determined, will permit a comprehensive evaluation.

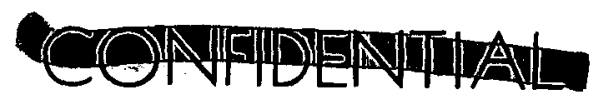

INSD-2650-29

$\mathrm{V}-15$ 


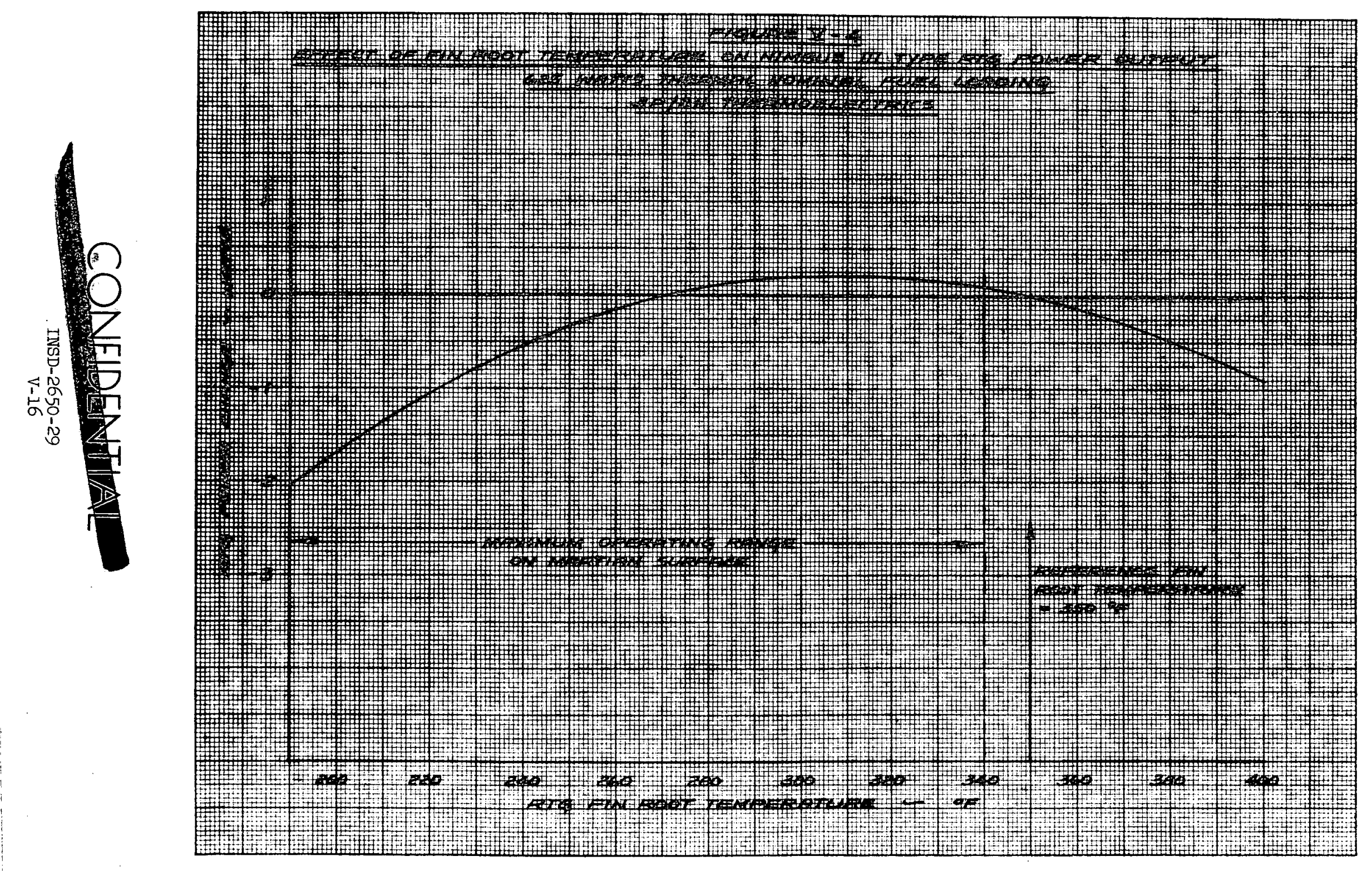

O 


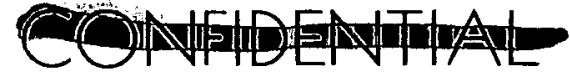

b. Housing thermal gradient

The Martin Denver thermal control concept for the VLC requires extracting heat from the RTG at the base mounted to the VLC structure. Thus, during the Martian night (and other possible mission environments where heat is required) a thermal gradient is imposed on the RTG due to the axial heat flow to the mounting base. Martin Denver proposal studies have shown the maximum housing temperature gradient and heat conducted to the VLC to be on the order of $50^{\circ} \mathrm{F}$ and 100 watts respectively. This magnitude gradient is expected to have no significant effect on RTG performance, but may conservatively be assumed to be $I$ watt for preliminary studies.

Scheduled thermal tests to be performed by Isotopes will result in more accurate design values for power fluctuation. These tests will involve determining the effect on power output of extracting up to 200 thermal watts at the RTG mounting base.

c. Emissive coating deterioration

The operating environment on the Martian surface is expected to be hostile toward VLC component coatings and finishes. The radiator surface of the RTG is especially susceptible since it by necessity is exposed directly to the environment. Thus, the RTG radiator coatings could potentially be subjected to severe sandblasting by sandstorms. As the effect of coating deterioration on RTG power output depends on the aforementioned planned thermal tests that will determine the effect of fin root temperature variation on power output, only a qualitative evaluation is possible in this study.

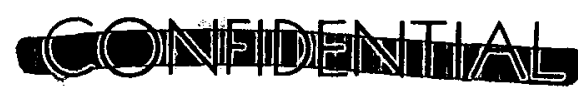

INSD-2650-29 
Figure V-5 presents the results of studies performed for the Martin Denver Viking proposal effort. The VLC configuration presented in the proposal employed two RTG's of the SNAP 19 Nimbus III design. The emissivity $\left(\epsilon_{t}\right)$ and solar absorptivity $\left(\boldsymbol{K}_{\mathrm{s}}\right)$ values were determined from preliminary spectral reflectance tests performed at Isotopes on both coated and bare, sandblasted test samples fabricated from the present SIVAP 19 radiator and coating materials, MgTh and zirconium oxide/sodium silicate respectively. As-sprayed coating properties were $\epsilon_{t}=0.83, \alpha_{S}=0.20$. Value for both bare and bare sanablasted MgTh samples were $\epsilon_{t}=0.3$ to 0.4 and $\alpha_{S}=0.5$ to 0.5 (values for both bare and sandblasted samples were virtually identidal). As is shown in Fig. V-5, loss of $50 \%$ of the coating $\left(\epsilon_{t}=0.6, \alpha_{\mathrm{S}}=0.4\right.$ ) increases the fin root temperature approximately $65 \% \mathrm{~F}$. Thus, the $340^{\circ} \mathrm{F}$ maximum Martian surface operating temperature shown in Fig. V-4 would increase to $405^{\circ} \mathrm{F}$, with an associated power decrease of approximately 1 watt. This decrease is less than the 2 watt value previously determined for operation from extreme hot to extreme cold.

The results above may be qualitatively applied to the TAGS-85/2N RTG. As the nominal design fin root temperature is lower, $330^{\circ} \mathrm{F}$ as compared to $350^{\circ} \mathrm{F}$, the fin root temperature for a comparable coating condition will be lower, although the power decrease will be approximately that shown for the Nimbus III configuration. However, as the 2 watt power decrease due to fluctuation between the anticipated extreme hot and cold environments is greater than the $I$ watt decrease due to coating 


\section{COAMUENATA}

deterioration, only the former value need be considered for determining minimum RTG power requirements.

RTG radiator emissive coating evaluations are scheduled to be performed by Isotopes in the near future. These evaluations will include tests to determine the effect of sandblasting as well as humidity and other gas environments on the stability and thermal properties of the present as well as other candidate coatings.

d. Results

The Martian environmental effects on the RTG will result in a maximum power decrease of approximately 3 watts from the nominal value. Two watts are due to fin root temperature variation, (including effects due to both extreme hot and cold environments and deterioration of the coating), and one watt due to the thermal gradient imposed on the RTG during the VLC thermal control function. The Martin Denver determined RTG power requirements for the Viking mission stated elsewhere in this report consider the above effects. Performance testing on TAGS-85/2N generators and coating evaluation studies to be performed at Isotopes in this calendar year will provide substantiating data for the performance extrapolations made from the Nimbus III RTG test data assumed in the above discussions.

\section{Related Equipment}

Practical limitations in the mechanical and electrical design of the RTG dictate that it operate at an inherently low output voltage, and into a load which is sufficient to prevent RTG damage due to thermal stress. These two RTG constraints require the employment of power

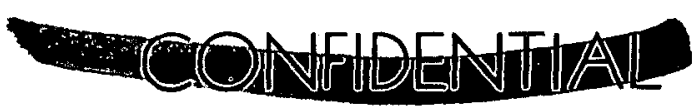

INSD-2650-29 
conditioning equipment ( $P C E$ ) to convert the low voltage RTG output to a higher and more functional level, and to maintain a constant load on the RTG. The power conditioning equipment consists generally of a DC-DC converter (to convert the voltage) and a shunt regulator (to maintain the load).

In this section a discussion on PCE requirements and typical design approaches are presented. Specifics of the PCE design and integration will be performed by Martin Denver.

a. DC-DC converter

The DC-DC converter changes the low voltage DC output of the generator to an alternating voltage, amplifies it to the level required for the system load, and then rectifies and filters it to provide the required DC output. In general, the static converter accomplishes this by utilizing three subcircuits: a power stage, an oscillator-driver, and a rectifier-filter. The oscillator-driver is utilized to control solid-state switching devices contained in the power stage, such that they alternately deliver the generator voltage to a step-up transformer also contained in the power stage. The stepped-up output voltage of the transformer is then rectified, filtered and delivered to the load. In order to obtain a high conversion efficiency, the power stage must operate in the switching mode. In this type of operation, the semiconductor device is switched repetitively from the saturated (high current, low voltage) condition to the cut-off (high voltage, low current) condition. Switching is accomplished very rapidly through the inter-

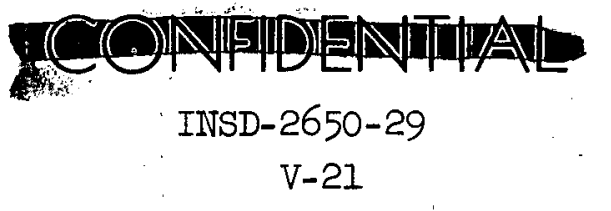


mediate, high-dissipation region, and the average power dissipated is very small compared to the total power switched.

The transistor is perfectly suited for utilization in low voltage DC-DC converters in that it approximates the operation of an ideal switch. This is a result of the low collector-emitter saturation resistance and the relatively high blocking capability (collectoremitter voltage) of the transistor. There are two basic types of power transistors: germanium and silicon. The germanium unit has a collectoremitter saturation resistance lower than that of the silicon, and for this reason it yields the most efficient converter. The silicon unit, however, has some advantages over the germanium such as higher temperature ratings, faster switching times, and high collector-emitter voltage capabilities. For the Viking mission silicon transistors will be required due to the high sterilization temperature $\left(\sim 125^{\circ} \mathrm{C}\right)$. Selection of high current silicon transistors with a low collector-to-emitter saturation voltage for the converter has resulted in a predicted converter efficiency of approximately 85\% for the Viking application with an RTG input of 2.9 volts.

Figure V-6 shows a typical converter circuit of the type previously utilized for the Nimbus application which was designed and developed by Isotopes as a part of the SINAP 19 RTG Power Supply System. Thie DC-DC converter consists of, in part, a current feedback driven power oscillator represented by switching transistors Q2 and Q3, feedback transformer T2, power transformer T1, saturable reactor L3, and the base peaking inductors LI and I2. The power osclilator chops the RTG low DC voltage into a square wave and transformat to the higher required bus

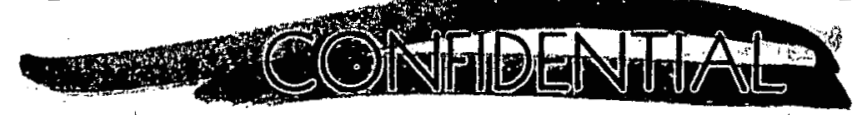




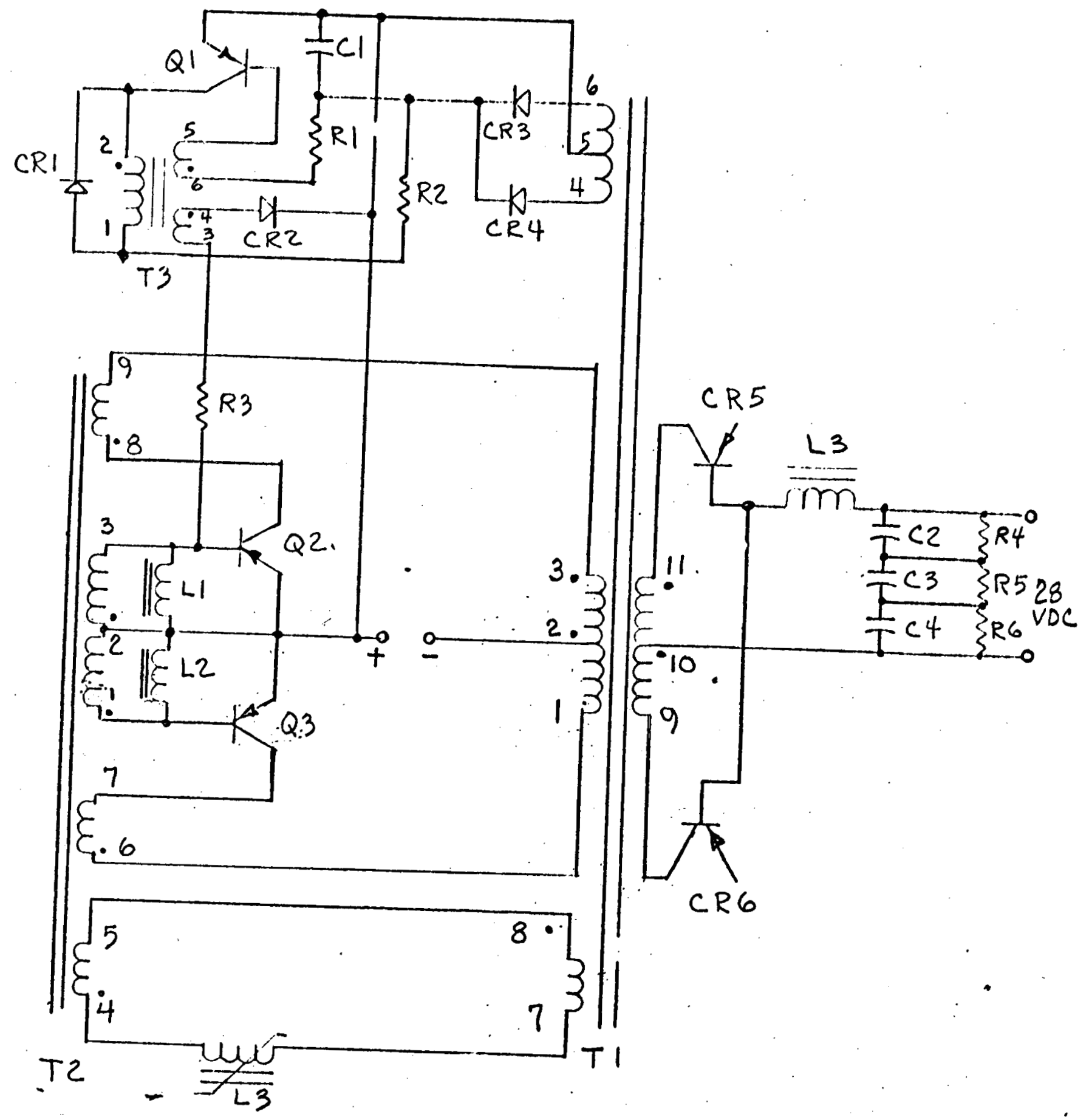

FIG. V-6. TYPICAL DC-DC CONVERTER DESIGN

INSD-2650-29
V-23 


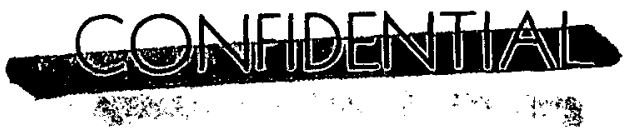

voltage at the secondary of transformer $M$. When $Q 2$ is reversed biased (off), Q3 is forward biased (on) to saturation and vice versa. They therefore alternately apply voltages of opposite polarity to the primary windings (terminals 1,2 , and 3 ) of the power transformer $T 1$. Since the switching times are of the order of a few microseconds, a square wave voltage is induced on the secondary (terminals 9, 10, and 11) windings of $\mathrm{Tl}$ at a stepped-up level. The transistors are driven alternately into saturation by the current induced in the base drive windings (terminals 1,2 , and 3 ) of $T 2$ by the feedback winding (terminals 6 and 7) of T2. The frequency at which the transistors are switched is controlled by the saturable reactor, L3. Efficient switchover of the transistors is caused by negative voltage feedback from winding 7-8 of TI which is applied to winding $4-5$ of T2 after L3 saturates. The time required for I3 to saturate determines the switching frequency of the converter (for the SNAP 19, Nimbus converter design, I3 saturates in 1.7 milliseconds thus giving a switching frequency of approximately $600 \mathrm{htz}$ ). Neither $\mathrm{Tl}$ or Th are driven into saturation, which enables them to operate efficiently. Both transformers and the saturable reactor contain a nickel-iron alloy toroidal core which provides high initial permeability and low losses. The base drive current is proportional to the transistor collector current by the ratio of the feedback winding to the base drive winding. The switching transistors àre therefore always operating at their optimum power loss condition regardless of load current.

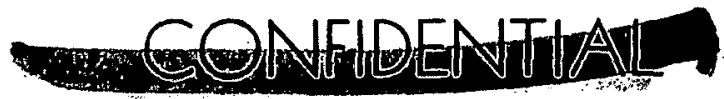




\section{LCONDIDENTTIAL}

To insure reliable starting of the converter circuit for any environmental condition, a blocking oscillator consiting of transformer T3, transistor QI, diodes CRI through $\mathrm{CR} 4$, resistors $\mathrm{RI}$ and $\mathrm{R} 2$, and capacitor $\mathrm{Cl}$ is employed. The blocking oscillator applies a pulse through $\mathrm{CR} 2$ and $\mathrm{R} 3$ to the base emitter junction of the switching transistor Q2. A bias voltage from a winding (terminals 4, 5, and 6) of $\mathrm{TI}$ and diodes $\mathrm{CR} 3$ and $\mathrm{CR} 4$ is applied to the blocking oscillator once the power oscillator operation is initiated. The bias voltage shuts off the blocking oscillator and renders it inoperable as long as the power oscillator is operating. The blocking oscillator is capable of starting the power oscillator with a generator voltage as low as 0.8 VDC.

The base peaking inductors, II and I2, are incorporated to decrease the turn-on and turn-off times of the power switching transistors. This reduces their switching loss and thus increases the converter efficiency.

The square wave output voltage of transformer TI is full wave rectified by the diodes CR5 and CR6. (In the Nimbus converter design these are actually the base-collector junctions of germanium transistors which exhibit a forward voltage drop lower than the conventional silicon rectifier, and thus enhanced efficiency.) The rectified voltage is filtered by capacitors $\mathrm{C} 2, \mathrm{C} 3$, and $\mathrm{C}_{4}$ and inductor $\mathrm{L} 4$. The capacitors are series connected in order to divide the voltage imposed on them. The series connection enhances the reliability of the circuit since the capacitor failure mode is a short circuit. The resistors, $R 4, R 5$, and $R 6$ help maintain equal voltage sharing by the three capacitors. 
b. Constant voltage regulator

For the Viking application the power output from the RTG will be regulated at the RTG output to provide a 28 VDC power bus. The shunt regulator schematic shown in Fig. V-7 is a typical circuit which might be employed. The shunt regulator maintains the output voltage of the RTG at the desired value throughout the mission by varying the effective resistance of a current controlled shunting element placed across the RTG output. The shunting element dissipates any power (in excess of that demanded by the system load) necessary to maintain the RTG (and bus) voltage at the fixed design values.

The shunt regulator shown acts as a feedback control system. A differential amplifier $\left(Q_{1}\right.$ and $\left.Q_{2}\right)$ is used as a comparator which samples a portion of the RTG voltage (through resistors $R I$ and $R 2$ ) and compares it to the reference provided by a zener diode $\mathrm{xI}_{1}$. If the output voltage attempts to go above the design voltage, a difference voltage $V_{D}$ is developed by the differential amplifier, which is converted to a proportional current $I_{D}$ by the transistor $Q 3$. (Variable resistor $\mathrm{Rl}$, is set such that $I_{D}$ is zero when the RTG output is at its design value.) $I_{D}$ is amplified by transistors $Q 4$ and $Q 5$ and supplied to the base of the shunting transistor QS. The base current is sufficient to enable QS to shunt the necessary current to maintain the fixed RTG output. Through the DC-DC converter, the bus boltage is thus maintained at 28 VDC.

The shunt regulator concept discussed above should be considered as typical since the regulator could also be placed across the DC-DC converter output. However, the present Martin Denver design approach is to

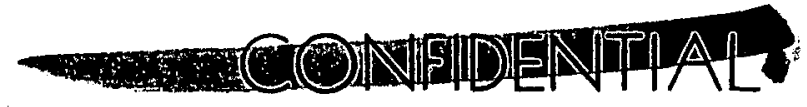




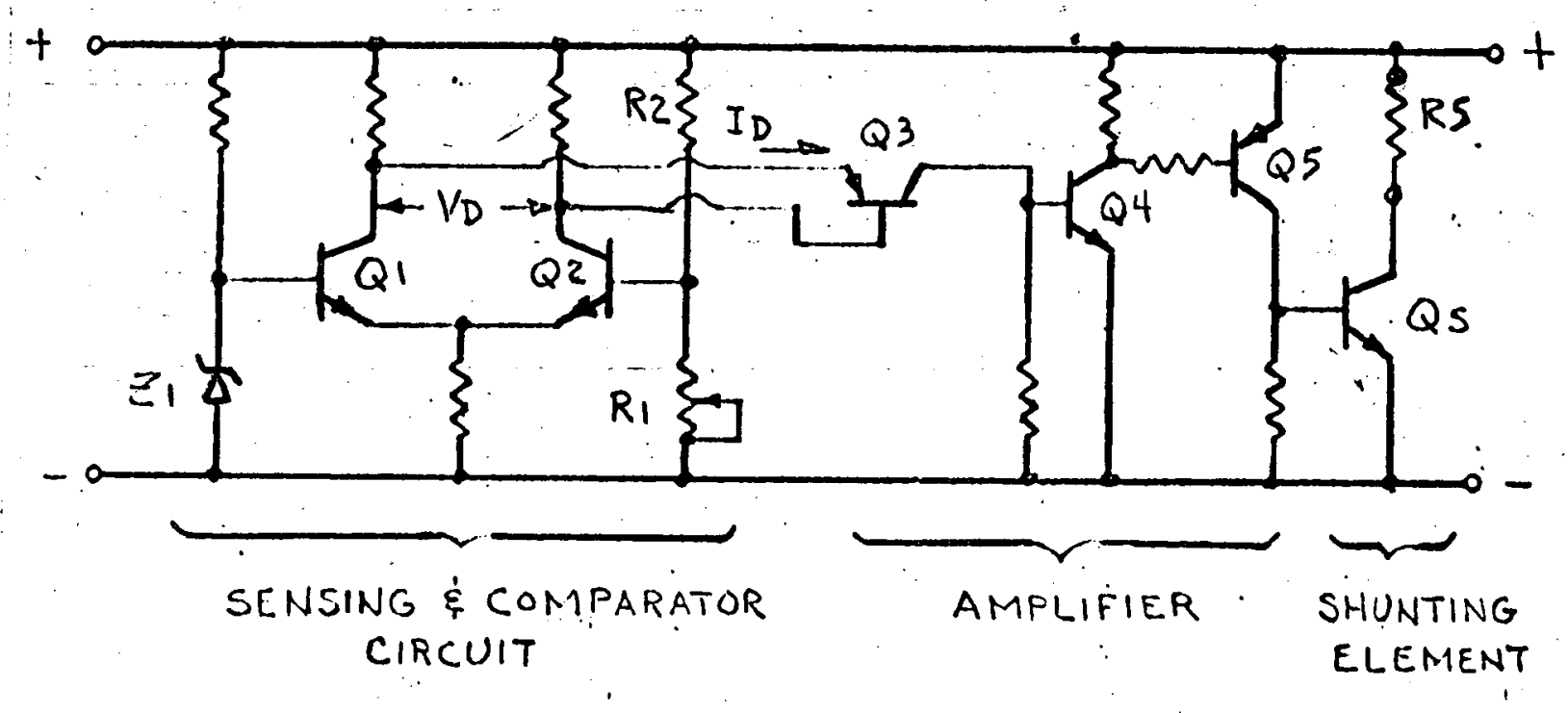

FIG. V-7. SHUNT REGULATOR CONCEPTUAL SCHEMATIC

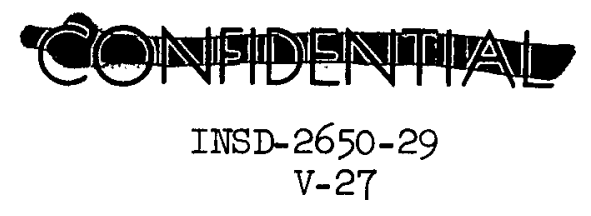




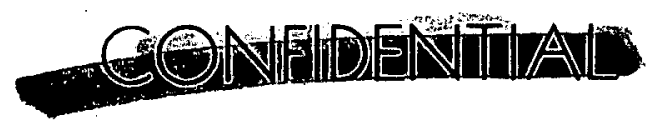

regulate the RTG output prior to the converter to decrease the current load on the converter, thereby enhancing converter reliability. 4. Instrumentation

In order to determine the performance of various subsystems during the mission, the VLC will employ a telemetry system which transmits various data, in digital form, to a ground station. The telemetry system will contain an analog-to-digital converter in order to transdate the data into a transmittible form. If monitoring of the RTG and power conditioner equipment performance is desired, a telemetry signal conditioner unit (TSCU) will be necessary to condition the measurements of the various RTG power supply parameters into analog signals which are compatible with the VLC analog-to-digital converter.

The TSCU would receive its power from the VLC 28 VDC bus and would monitor RTG parameters such as temperature and voltage and power conditioning equipment parameter's. such as temperature, voltages, and currents. It would then condition these measurements to analog outputs in the form of voltages within a desired range and impedance level as dictated by the analog-to-digital converter constraints. Each of the analog outputs delivered by the TSCU woudd have an associated calibration curve or conversion factor from which the measured parameter represented. by the output could be derived.

Figure V-8 is a typical block diagram of the functions which would be performed by a TSCU for the Viking system. In order to accomplish these functions, the TSCU would contain various subcircults as described below.

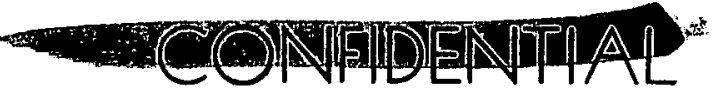

INSD-2650-29 

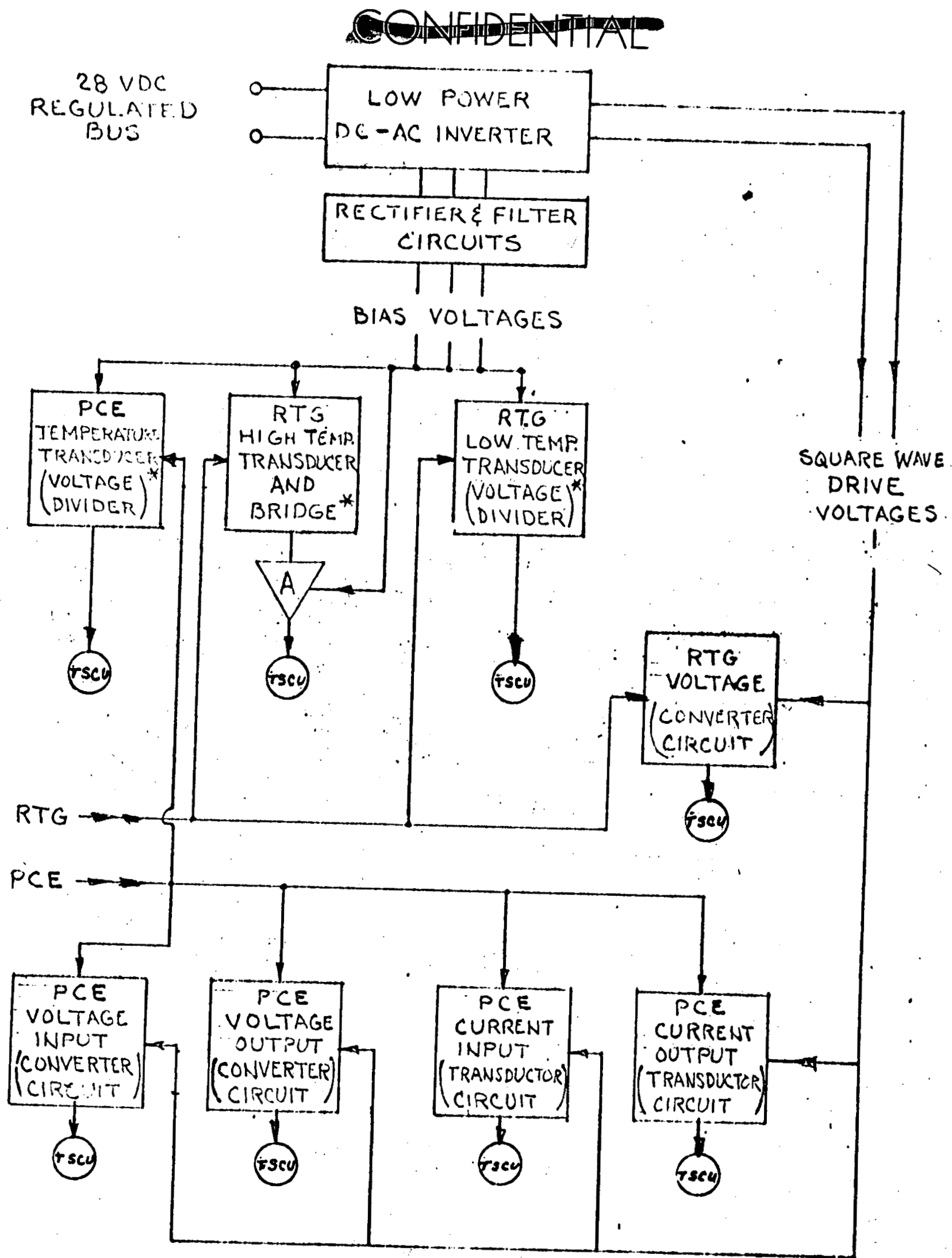

*Thermocouples may be employed in lieu of voltage dividers.

FIG. V-8. TSCU FUNCTIONAL BLOCK DIAGRAM

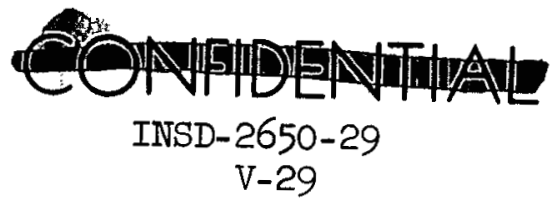




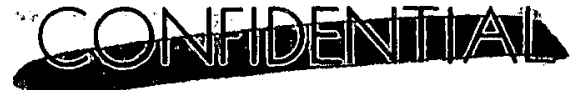

\section{a. Temperature measurement}

There are three basic devices which can be utilized for measuring temperature and senting changes; the thermistor, the resistor, and the thermocouple. For measuring low temperatures (A.e., temperatures below $\left.700^{\circ} \mathrm{F}\right)$ the thermistor should be used, in that it provides a very large resistance change for a relatively small change in temperature. The TSCU signal can therefore be provided directly, with a small power drain, by aonnecting the thermistor in a voltage divider circuit such as the one shown in Fig. V-9.(a).

The thermistor cannot be reliably used for measuring temperatures in excess of $700^{\circ} \mathrm{F}$, which precludes their use for measurement of high RTG temperatures such as the thermoelectric hot junction. High temperatures may be sensed by a platinum resistance sensor. This type of sensor is accurate, repeatable, and reliable if mounted properly and electrically isolated from its environment. The change in the resistance of a platinum resistor due to a temperature change is very small in comparison to a thermistor and, therefore, aditional circuitry may be required if order to obtain a desired TSCU output voltage while maintaining power drain at a minimum. The resistance change, for example, could be converted to a proportional voltage change by a lower power bridge circuit which would then be amplified by an operational amplifier if a high ISCU voltage output is desired. Such a circuit is sketched in Fig. V-9 (b).

The bias voltages for the previously mentioned valtage dividers, amplifiers, etc. will be supplied by the rectified outputs of a low

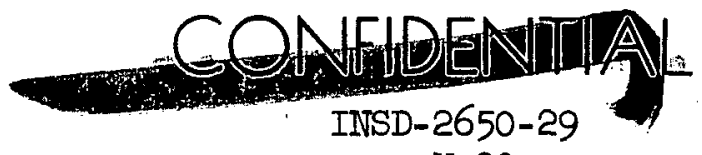




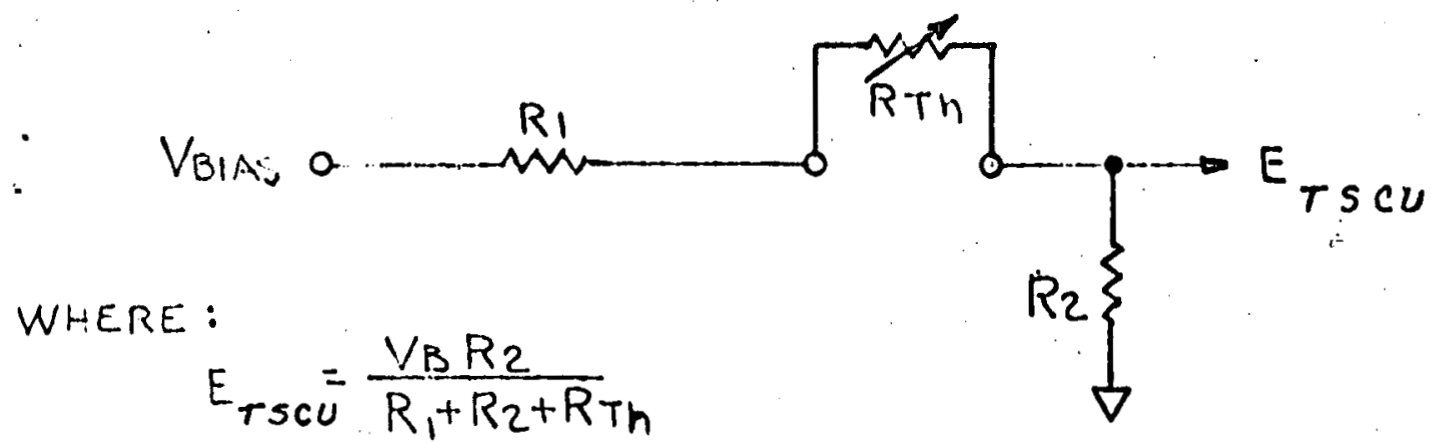

ANTS RTh $\propto \frac{1}{\text { TEMP }}$

FIG. V-9(a). LOW TEMPERATURE MEASURING AND CONDITIONING CIRCUIT

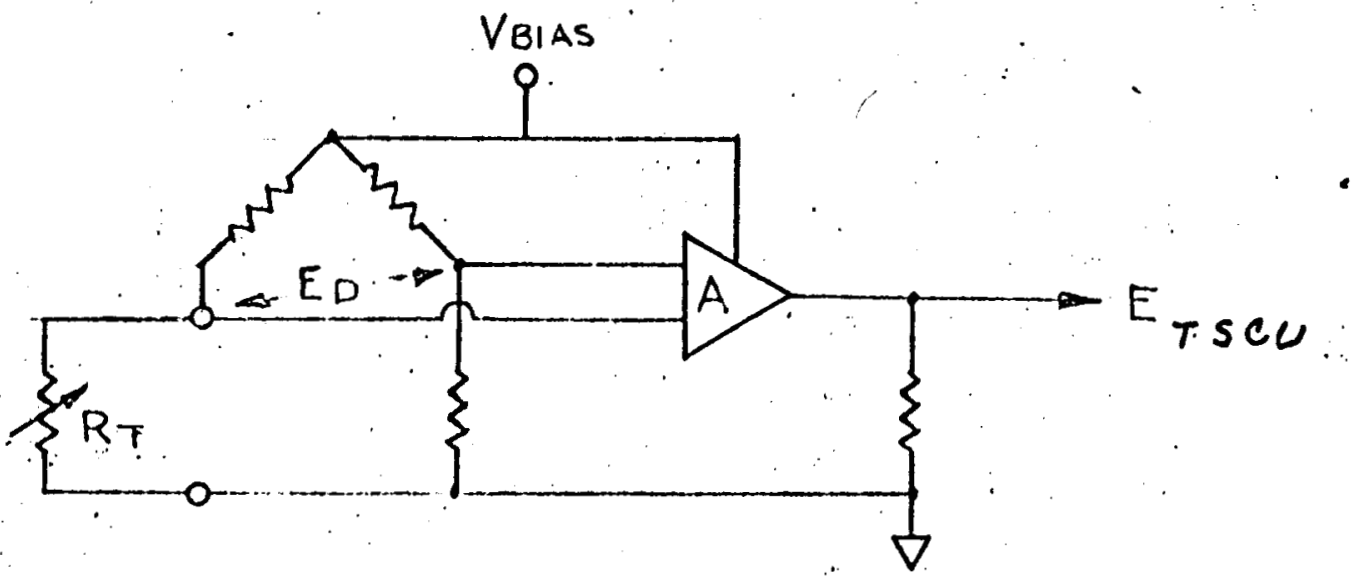

WHERE : $E_{T S C U}=A E D$

- AND ED \& RT \& TEMP.

FIG. V-9(b). HIGH TEMPERATURE MEASURENG AIND CONDITIONING CIRCUTT

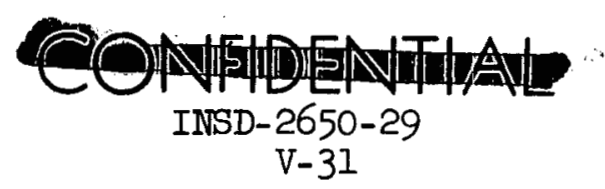




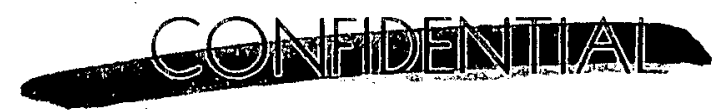

power DC-AC inverter (refer to Fig. V-8).

Alternately the thermocouple may be used as a temperature measurement device. However, it requires a more complex conversion system in that a reference temperature or compensating circuit must be provided.

b. Voltage measurements

The RTG output voltage and power conditioning equipment voltages can be measured and conditioned by a simple voltage divider circuit if isolation and/or polarity reversal is not required with respect to the VLC analog-to-digital converter. If isolation is required, these voltages may be measured and conditioned by the DC-DC converter circuit sketched in Fig. V-10. The base drive for transistors $Q 1$ and $Q 2$ is maintained at a constant frequency and voltage level by a square wave output from the low power DC-AC inverter. The square wave is coupled to $Q 1$ and $Q 2$ through transformer T2, and is sufficient to alternately drive Q1 and Q2 into saturation for every half-cycle of the square wave. Resistor Rl provides base drive current limiting. The TSCU output voltage is pro fortional to the measured voltages by the turns ratio of Tl (minus the various series voltage drops). Diodes $\mathrm{CRI}$ and CR2, inductor $\mathrm{Ll}$ and capacitor Cl form a full-wave rectifier and filter circuit with the center-tapped transformer Tl.

c. Current measurement

The input and output currents of the conditioning equipment may be measured and conditioned by the transductor circuit shown in Fig. V-II. This circuit enables isolated current monttoring with very small power drain. Transformers $T$ and $T 2$ have torroldal cores, through which the current carrying conductor w1ll pass. The AC windings $\mathbb{N}$ and $\mathbb{N} 2$ are

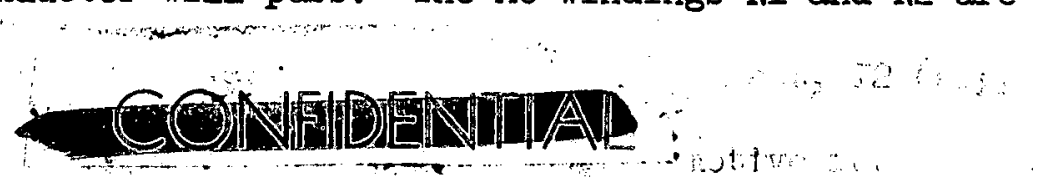

INSD-2650-29

$v-32$ 


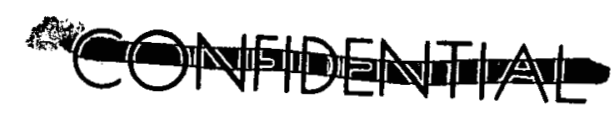

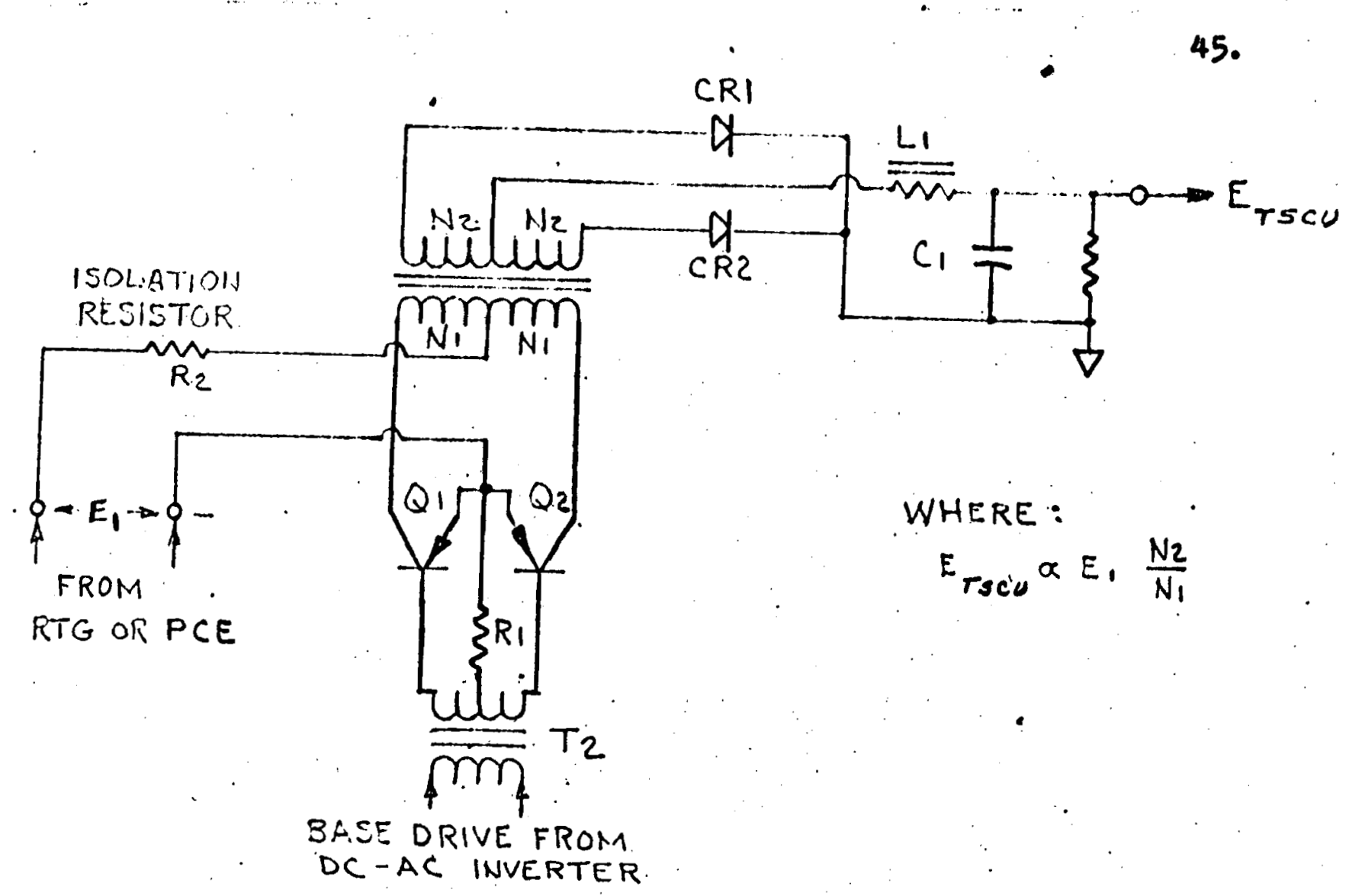

FIG. V-10, PCE \& RTG VOLTAGE MEASURIING AND CONDITIONING CIRCUIT

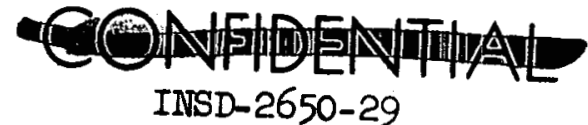

$\mathrm{V}-33$ 


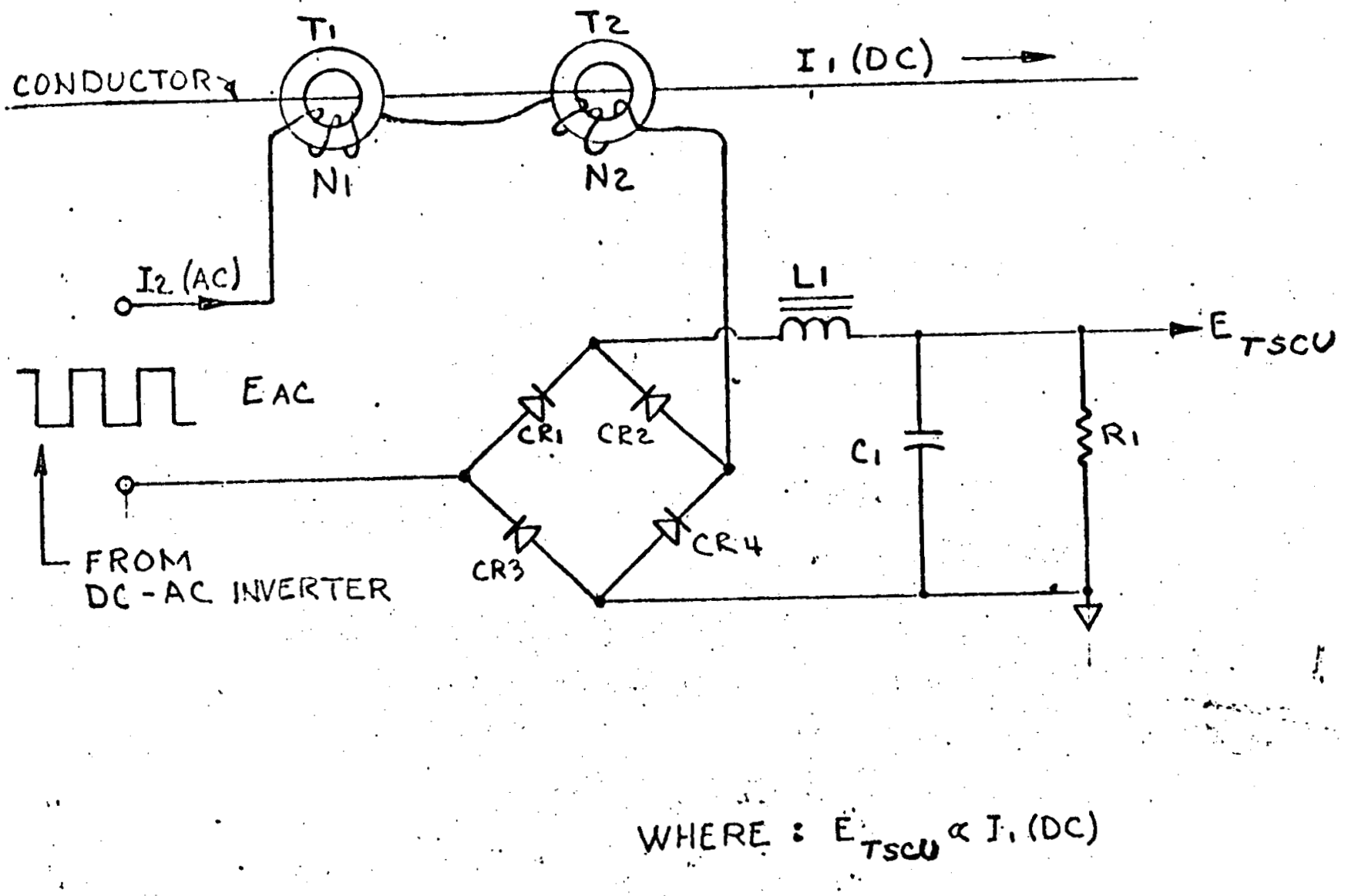

FIG. V-11. PCE INPUT AND OUTPUT CURRENT MEASURING AND CONDITIONING TRANSDUCTOR CIRCUIT 
connected in series in such a way that when the AC current, I/ (supplied by the low power DC-AC inverter) assists the magnetomotive force of the measured current, II in one core, it opposes that magnetomotive force in the other core. The AC current, $I_{2}$, is full-wave rectified and filtered to produce a TSCU output voltage which will vary linearly with the DC current being measured.

d. Low power DC-AC inverter

The DC bias voltages for the amplifiers, bridges, and voltage dividers, and the $A C$ driving voltage for the voltage and current measuring circuits is supplied by a low power DC-AC inverter such as the one shown in Fig. $\mathrm{V}-12$. The DC-AC inverter operates from the $28 \mathrm{VDC}$ bus and delivers a square wave voltage to each of the secondary windings (S1 through S7). Windings SI and S2, for example would provide the AC voltage for the current measuring transductor circuits. Windings S3, S4, and S5 would provide the base drive power for the circuits measuring the RTG output voltages. The output of windings 56 and 57 would be full-wave rectified and filtered to provide the various necessary bias voltages.

A conceptual schematic of a I'SCU operating from the 28 VDC bus and supplying typical measurement and conditioning circuits is shown in Fig. V-13.

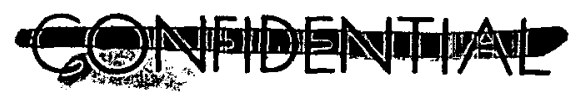

INSD-2650-29 


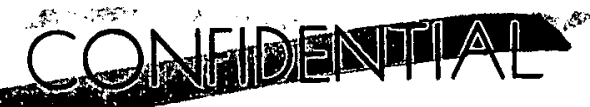

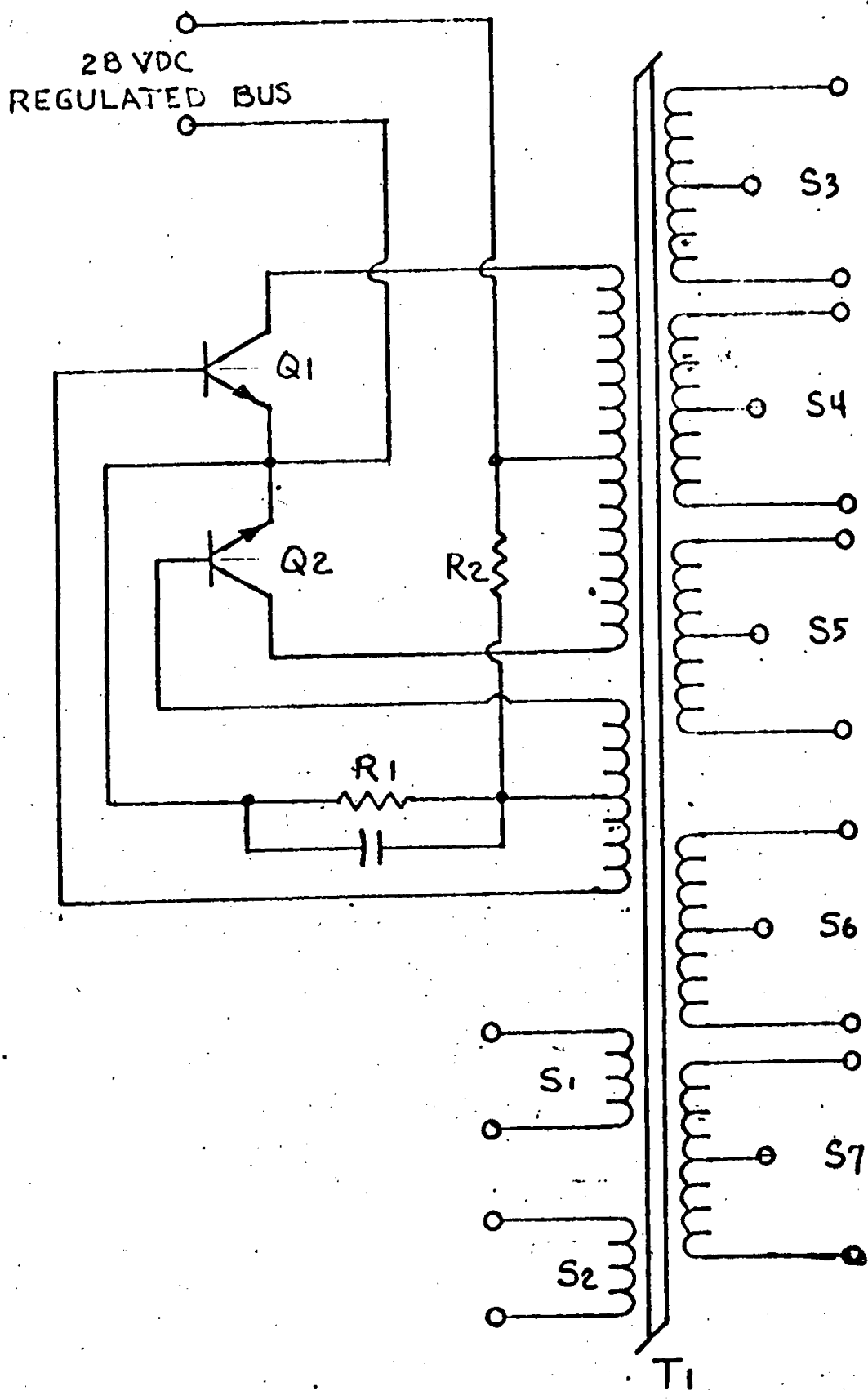

FIG. V-12. LOW POWER DC-AC INVERTER CIRCUIT 


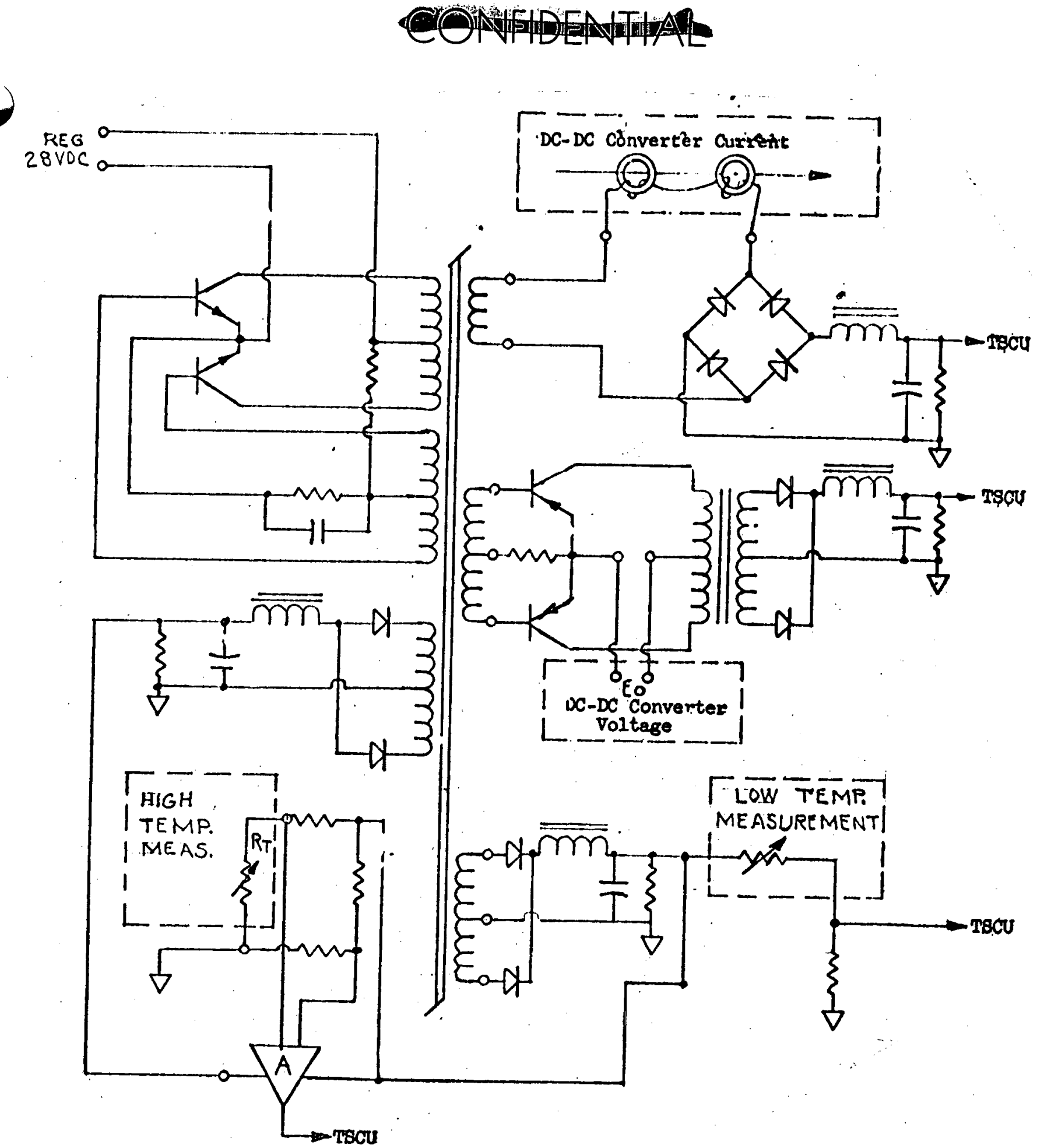

FIG. V-13. CONCEPTUAL TSCU SCHEMATIC, SHOWING TYPICAL MEASUREMENT AND CONDITIONING CIRCUITS

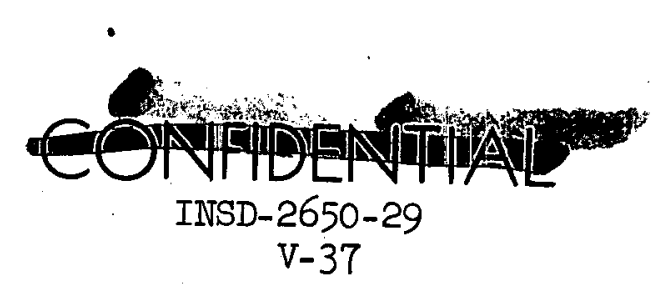




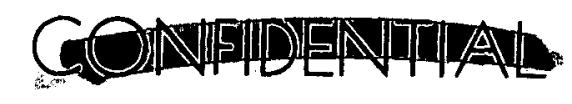

\section{NUCLEAR RADIATION}

This section evaluates unshielded radiation fluxes and biological dose rates at points in the vicinity of a spacecraft employing one or more single generators or double generator (stacked) systems. Flux and dose attenuation data for typical shielding materials are included. The flux attenuation data have been used to develop near optimum (with respect to weight) shield configurations for attenuation of total flux to some prespecified limit. Total shield weight for gamma flux attenuation is given. For situations where personnel access into the vicinity of the RTG's is required, access times and temporary shielding requirements may be estimated from the data herein.

1. Unshielded Fluxes

Penetrating nuclear radiation from plutonium dioxide fueled RTG's consists primarily of neutrons and gammas. Neutrons are produced from $(\alpha, n)$ reactions in oxygen and fuel impurities and from spontaneous and induced fission. The dominant characteristics of the energy spectrum indicate that the primary source is the $\mathrm{O}^{18}(\alpha, \mathrm{n}) \mathrm{Ne}^{21}$ reaction. Measured emission rates for small samples of $\mathrm{PuO}_{2}$ produced with natural oxygen show a maximum of $2.5 \times 10^{4}$ neutrons/sec-gram of Pu-238. Combined with a conservative estimate of neutron multiplication within a distributed source $\left(k_{\text {eff }}=0.25\right)$, the corresponding source strength is $3.33 \times 10^{4}$ neutrons/ sec-gram of Pue238 or a total source of $3.96 \times 10^{7}$ neutrons/sec for a capsule with a loading of 675 watts thermal. Table V-3 presents the neutronssource spectrum.

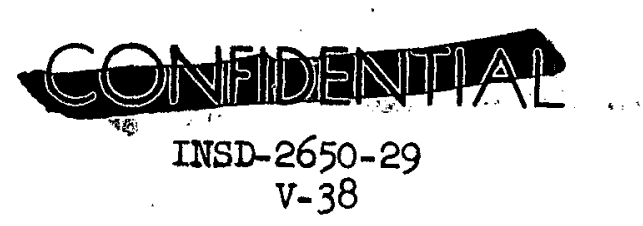




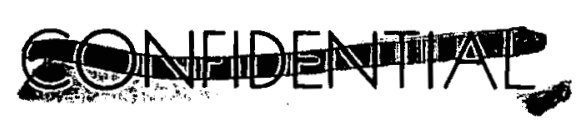

Gammas are emitted from the fission process, fission product decay, decay of fuel and impurity isotopes and from decay of compound nuclei

formed in the $(\alpha, n)$ process. Results presented herein are based on the twenty energy group spectrum of Table V-3. This spectrum was derived from the data of Stoddard and Albenesius.*

\section{TABLE-V- -3}

GAMMA SOURCE SPECTRUM

\begin{tabular}{l}
$\begin{array}{c}\text { Energy Range } \\
(\text { Mev) }\end{array}$ \\
\hline $0.0-0.044$ \\
0.0440 .2 \\
$0.2-0.3$ \\
$0.3-0.4$ \\
$0.4-0.5$ \\
$0.5-0.6$ \\
$0.6-0.7$ \\
$0.7-0.8$ \\
$0.8-0.9$ \\
$0.9-1.0$ \\
$1.0-1.2$ \\
$1.2-1.4$ \\
$1.4-1.6$ \\
$1.6-1.8$ \\
$1.8-2.0$ \\
$2.0-3.0$ \\
$3.0-4.0$ \\
$4.0-5.0$ \\
$5.0-6.0$ \\
$6.0-7.0$ \\
\end{tabular}

Gamma s/sec-gram of $\mathrm{Pu}^{238}$

$2.36 \times 10^{8}$

$5.65 \times 107$

$2.56 \times 10^{4}$

$1.30 \times 10^{4}$

$2.50 \times 10^{3}$

$6.04 \times 10^{2}$

$5.38 \times 10^{2}$

$3.15 \times 10^{5}$

$1.86 \times 10^{5}$

$3.81 \times 10^{2}$

$1.21 \times 10^{2}$

$3.19 \times 10^{3}$

$1.12 \times 10^{3}$

$8.50 \times 10^{2}$

$7.84 \times 10^{2}$

$2.29 \times 10^{3}$

$2.30 . \times 10^{2}$

$6.97 \times 10^{1}$

$2.33 \times 10^{1}$

$5.85 \times 100$

*D.H. Stoddard, E.I. Albenesius, "Radiation Properties of Pu-238 Produced for Isotopic Power Generators", DP-984, July 1965.

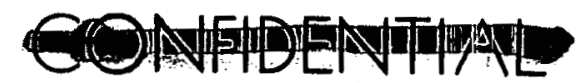

INSD-2650-29

V-39 
TABLE V-3 (Continued)

NEUTRON SOURCE SPECTRUM

\begin{tabular}{|c|c|c|c|c|c|}
\hline $\begin{array}{l}\text { Point } \\
\text { Index, } \\
\quad i \\
\end{array}$ & $\begin{array}{l}\text { Energy } \\
\text { (Mev) }\end{array}$ & $\frac{\text { Lethargy }_{U}^{(1)}}{\mathrm{U}}$ & $\begin{array}{c}\mathrm{A} \\
(\boldsymbol{\alpha}, \mathrm{n}) \text { Neutrons } \\
(\mathrm{n} / \mathrm{sec}-\mathrm{gm} \text { of } \mathrm{Pu}-238) \\
\end{array}$ & $\begin{array}{c}\text { B } \\
\text { Fission Neutrons } \\
\end{array}$ & $\begin{array}{c}\text { Composite } \\
\text { Spectrum } \\
\mathrm{A}+\mathrm{B} \\
\end{array}$ \\
\hline 1 & 14.09 & 0 & 0 & $5.50 \times 10^{0}$ & $5.50 \times 10^{0}$ \\
\hline 2 & 10.97 & 0.25 & 0 & $5.49 \times 10^{1}$ & $5.49 \times 10^{1}$ \\
\hline 3 & 8.55 & 0.50 & 0 & $2.97 \times 10^{2}$ & $2.97 \times 10^{2}$ \\
\hline 4 & 6.66 & 0.75 & 0 & $9.76 \times 10^{2}$ & $9.76 \times 10^{2}$ \\
\hline 5 & 5.18 & 1.00 & 0 & $2.05 \times 1.0^{3}$ & $2.05 \times 10^{3}$ \\
\hline 6 & 4.46 & 1.15 & $0.93 \times 10^{3}$ & $3.12 \times 10^{3}$ & $4.05 \times 10^{3}$ \\
\hline 7 & 4.04 & 1.25 & $1.19 \times 10^{4}$ & $0.37 \times 10^{4}$ & $1.56 \times 10^{4}$ \\
\hline 8 & 3.14 & 1.50 & $2.85 \times 10^{4}$ & $0.52 \times 10^{4}$ & $3.37 \times 10^{4}$ \\
\hline 9 & 2.45 & 1.75 & $2.10 \times 10^{4}$ & $0.60 \times 10^{4}$ & $2.70 \times 10^{4}$ \\
\hline 10 & 1.91 & 2.00 & $0.80 \times 10^{4}$ & $0.62 \times 10^{4}$ & $1.42 \times 10^{4}$ \\
\hline $1 i$ & 1.49 & 2.25 & $0.56 \times 10^{4}$ & $0.57 \times 10^{4}$ & $1.13 \times 10^{4}$ \\
\hline 12 & 1.16 & 2.50 & $2.43 \times 10^{3}$ & $4.99 \times 10^{3}$ & $7.42 \times 10^{3}$ \\
\hline 13 & 0.900 & 2.75 & $1.32 \times 10^{3}$ & $4.09 \times 10^{3}$ & $5.41 \times 10^{3}$ \\
\hline 14 & 0.702 & 3.00 & $0.71 \times 10^{3}$ & $3.23 \times 10^{3}$ & $3.94 \times 10^{3}$ \\
\hline 15 & 0.546 & 3.25 & $0.39 \times 10^{3}$ & $2.47 \times 10^{3}$ & $2.86 \times 10^{3}$ \\
\hline 16 & 0.331 & 3.75 & $0.18 \times 10^{3}$ & $1.35 \times 10^{3}$ & $1.53 \times 10^{3}$ \\
\hline 17 & 0.201 & 4.25 & $0.80 \times 10^{2}$ & $6.94 \times 10^{2}$ & $7.74 \times 10^{2}$ \\
\hline 18 & 0.122 & 4.75 & $0.31 \times 10^{2}$ & $3.44 \times 10^{2}$ & $3.75 \times 10^{2}$ \\
\hline 19 & 0.0449 & 5.75 & 0 & $8.10 \times 10^{1}$ & $8.10 \times 10^{2}$ \\
\hline
\end{tabular}

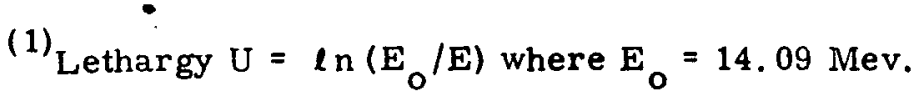

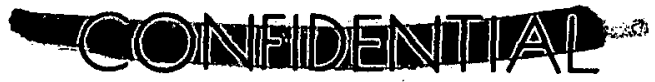




\section{CONIFPOENATINAN}

Neutron and gamma fluxes were evaluated in the vicinity of two RTG's coupled as shown in Fig. V-14 and for a single generator as shown in Fig. V-15. Fluxes were determined by first evaluating the neutron and gamma dose rates at points along the lines shown in these figures. Dose rates were evaluated by use of a point kernel technique employing cylindrical geometry (computer program SPEND). A brief description of this technique and associated uncertainties are given later in the section. Transport calculations for a spherical source of $\mathrm{PuO}_{2}$ in air provide the appropriate dose rate-to-particle flux conversion factors. These calculations are the results of program DTF ( $S n$ discrete ordinates technique) for a spherical source of plutonium dioxide (radius $=4.4 \mathrm{~cm}$ ) surrounded by thin regions of materials which approximate the actual capsule geometry. Computed flux-to-dose rate ratios at various distances in air from the spherical source are given in Table V-4. The data of this table indicates an approximate constancy in the flux-to-dose ratios. The variance in the gamma ratio is, in part, due to the angular nature of the flux which effects a hardening of the spectrum at large distances. Constant flux-to-dose rate ratios of $8.15 \mathrm{n} / \mathrm{cm}^{2} \mathrm{sec} / \mathrm{mrem} / \mathrm{hr}$ and 1300 photons $\mathrm{cm}^{2} \mathrm{sec} / \mathrm{mrem} / \mathrm{hr}$ were used to scale the computed dose rates and obtain flux.

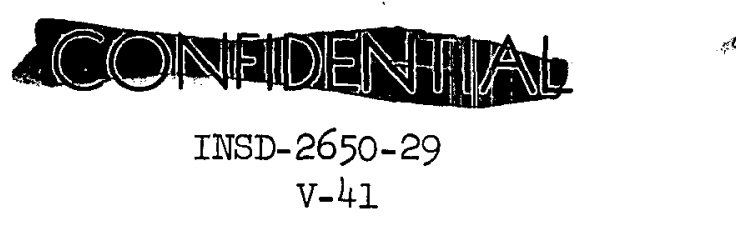




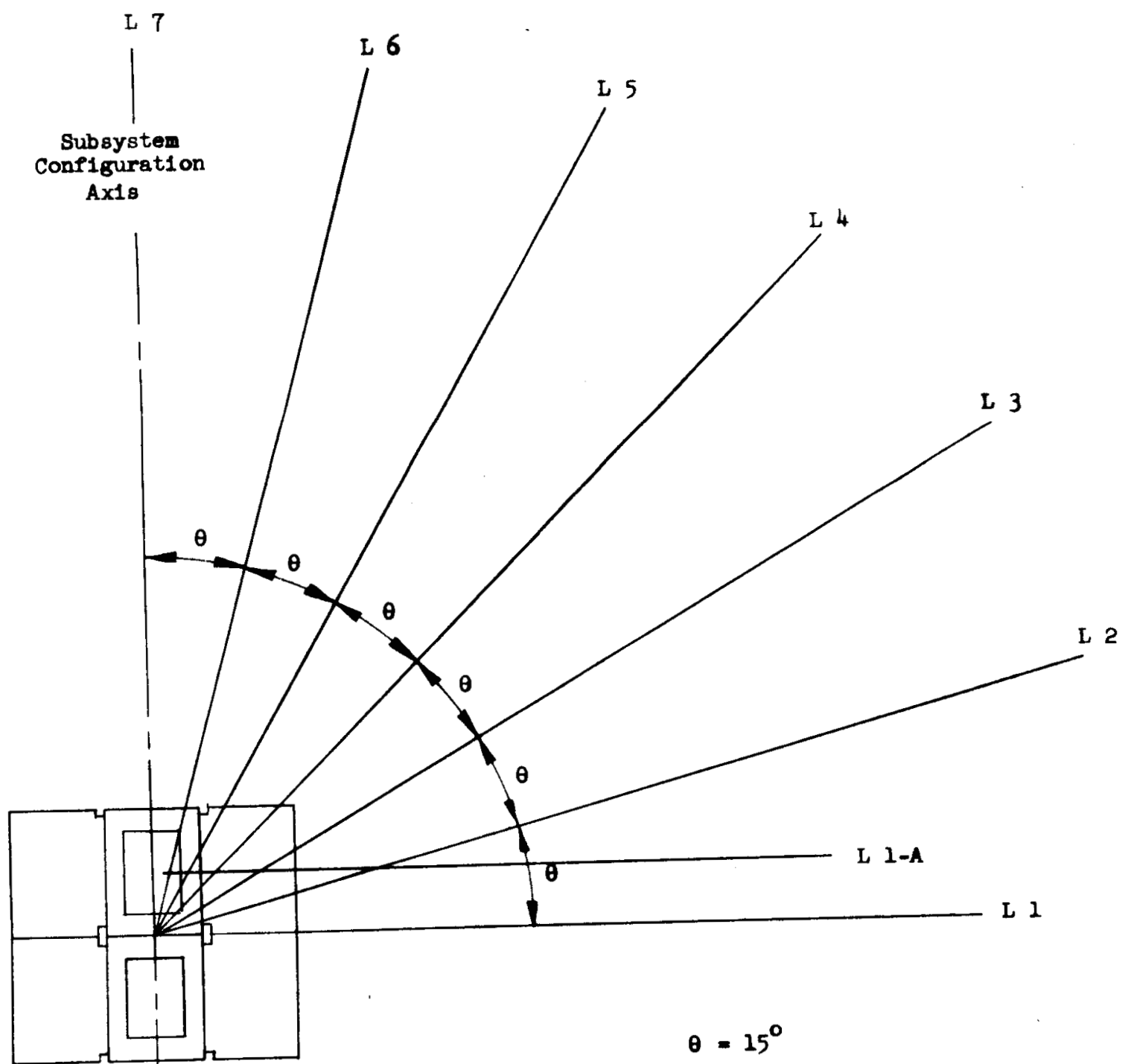

F16. V-14. Oeneretor conflourntion Bhorlns Limen

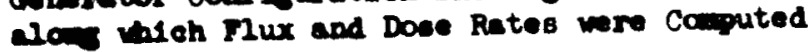

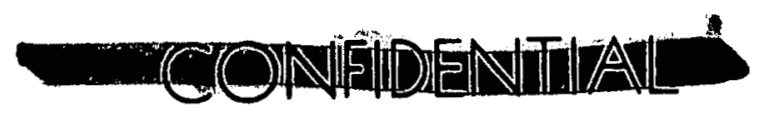

INSD-2650-29

V -42 


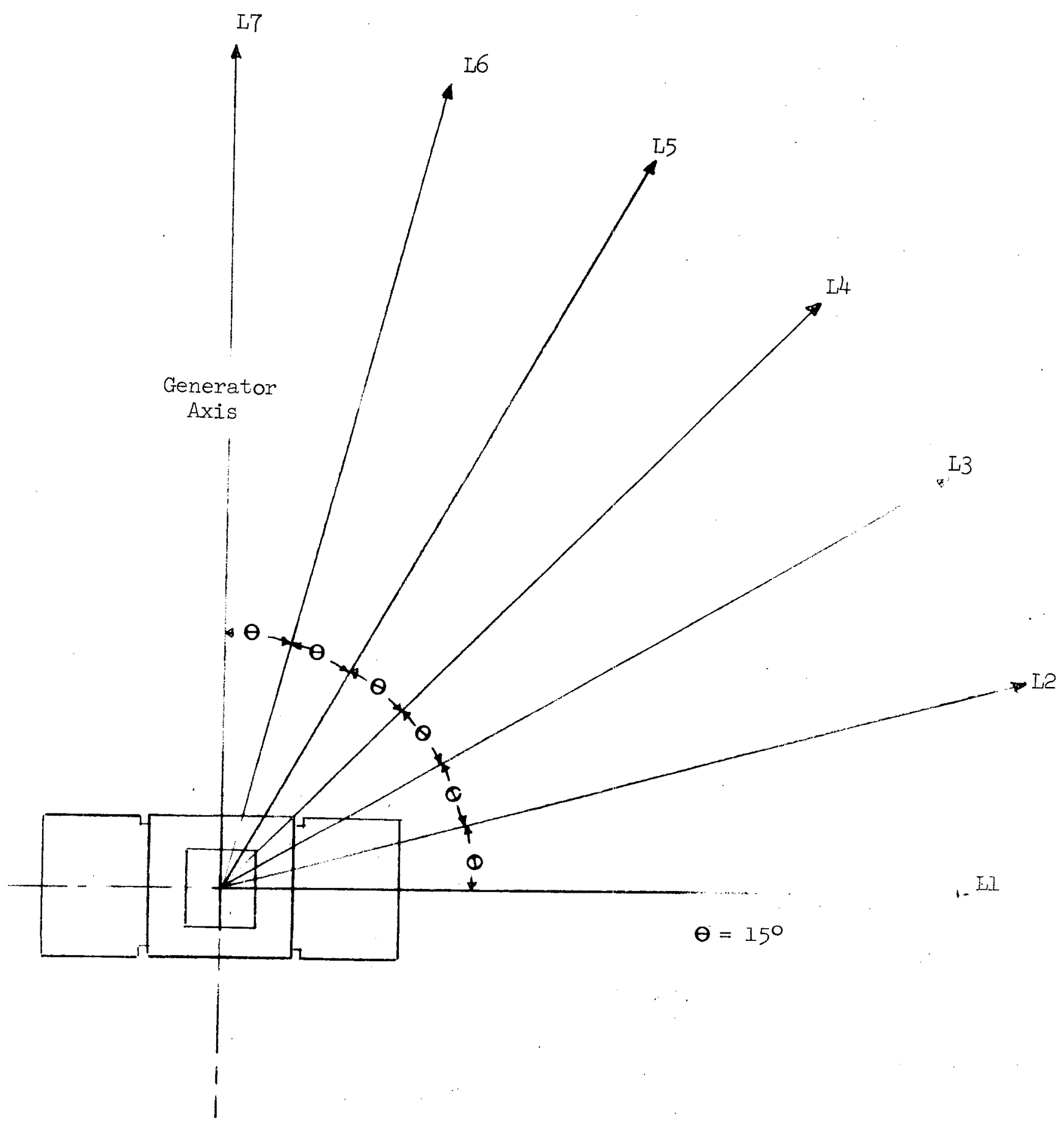

FIG. V-15. SINGIE GENERATOR CONFIGURATION SHOWING LINES ALONG WHICH FLUX AIND DOSE RATES WERE COMPUTED.

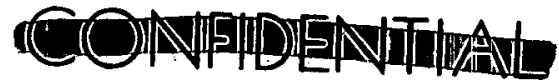




\section{TABLE V4}

FLUX AND DOSE RATES FROM A SPHERICAL SOURCE OF PLUTONIUM DIOXIDE (1024 THERMAL WATTS)

A. Neutrons

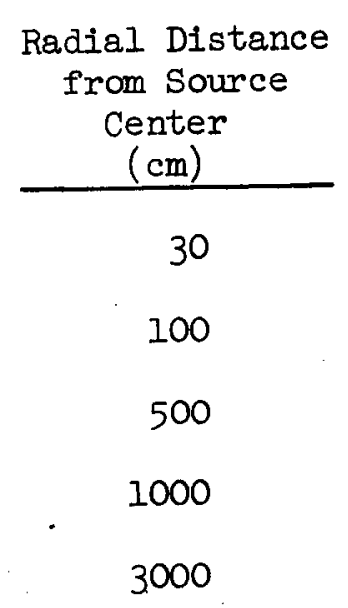

$\begin{array}{ccc}\begin{array}{c}\text { Flux } \\ \phi\end{array} & \begin{array}{c}\text { Dose Rate } \\ \left.\dot{\mathrm{D}} / \mathrm{cm}^{2}-\mathrm{sec}\right)\end{array} & \frac{\phi}{(\mathrm{mrem} / \mathrm{hr})} \\ 4790 & 590 & \frac{\left.\frac{\mathrm{n} / \mathrm{cm}^{2}-\mathrm{sec}}{\mathrm{mrem} / \mathrm{hr}}\right)}{8.12} \\ 447 & 55.0 & 8.13 \\ 18.7 & 2.29 & 8.17 \\ 4.85 & 0.591 & 8.21 \\ 0.590 & 0.0711 & 8.30\end{array}$

B. Gamma

\begin{tabular}{c}
$\begin{array}{c}\text { Radial Distance } \\
\text { from Source } \\
\text { Center } \\
(\mathrm{cm})\end{array}$ \\
\hline 30 \\
100 \\
500 \\
1000 \\
3000
\end{tabular}

\begin{tabular}{|c|c|c|}
\hline $\begin{array}{c}\text { Perticle Flux } \\
\phi \\
\left(\gamma / \mathrm{cm}^{2}-\mathrm{sec}\right) \\
\end{array}$ & $\begin{array}{c}\text { Dose Rate } \\
\dot{\mathrm{D}} \\
\text { (mrem/hr) }\end{array}$ & $\frac{\phi}{\phi}\left(\frac{\gamma / \mathrm{cm}-\mathrm{sec}}{\mathrm{mrem} / \mathrm{hr}}\right.$ \\
\hline 49900 & 39.5 & 1260 \\
\hline 4640 & 3.64 & 1280 \\
\hline 294.0 & .145 & 1340 \\
\hline 50.1 & .0355 & 1410 \\
\hline 5.99 & .00381 & 1572 \\
\hline
\end{tabular}




\section{COANFPEAPPAN}

Neutron and gamma fluxes are given in Tables $V-5$ and $V-6$ at various points along lines LI thru LT (Figs. V-14 and V-15). Since the configurations exhibit near radial svmmetry about their axes and symmetry about the mid-plane, results may be interpolated to obtain the fluxes at any point exterior to the $\mathrm{FTG}$ 's. For distances greater than those given in Tables $V-5$ and $V-6$ the $r^{2}$ relationship may be used; i.e.,

$$
\phi\left(r_{2}\right)=\frac{r_{1}^{2}}{r_{2}^{2}} \phi\left(r_{1}\right)
$$

where $r_{1}$ is a point at which the flux is tabulated $\left(r_{1}\right.$ greater than $\left.3.0 \mathrm{ft}\right)$. 


\section{TABLE V -5}

NEUTRON AND GAMMA FLUXES IN THE VICINITY OF

A 2-RTG TANDEM CONFIGURATION

(See F1g. V-14 for Location of Lines)

Distance from Geometric Center of Configuration (ft)

0.27

0.42

0.50

0.75

1.0

2.0

3.0

5.0

8.0

10.0

15.0

20.0

30.0

0.27

0.42

0.5

0.75
Particle Flux $\left(/ \mathrm{cm}^{2}-\mathrm{sec}\right)$

Ine

Il

Neutron

$1.92 \times 10^{4}$

Gamme

L1

$1.38 \times 10^{4}$

$1.14 \times 10^{4}$

$6.63 \times 10^{3}$

$4.18 \times 10^{3}$

$1.18 \times 10^{3}$

$5.35 \times 10^{2}$

$1.95 \times 10^{2}$

$7.60 \times 10^{1}$

$4.85 \times 10^{1}$

$2.14 \times 10^{1}$

$1.19 \times 10^{1}$

$5.23 \times 10^{0}$

LI

$3.35 \times 10^{4}$

$1.61 \times 10^{4}$

$1.19 \times 10^{4}$

$6.19 \times 10^{3}$
$1.82 \times 10^{5}$

$1.46 \times 10^{5}$

$1.25 \times 10^{5}$

$7.90 \times 10^{4}$

$5.16 \times 10^{4}$

$1.51 \times 10^{4}$

$6.89 \times 10^{3}$

$2.50 \times 10^{3}$

$9.72 \times 10^{2}$

$6.16 \times 10^{2}$

$2.71 \times 10^{2}$

$1.51 \times 10^{2}$

$6.88 \times 10^{1}$

$4.17 \times 10^{5}$

$2.02 \times 10^{5}$

$1.47 \times 10^{5}$

$7.63 \times 10^{4}$ 
TABLE V-5 (continued)

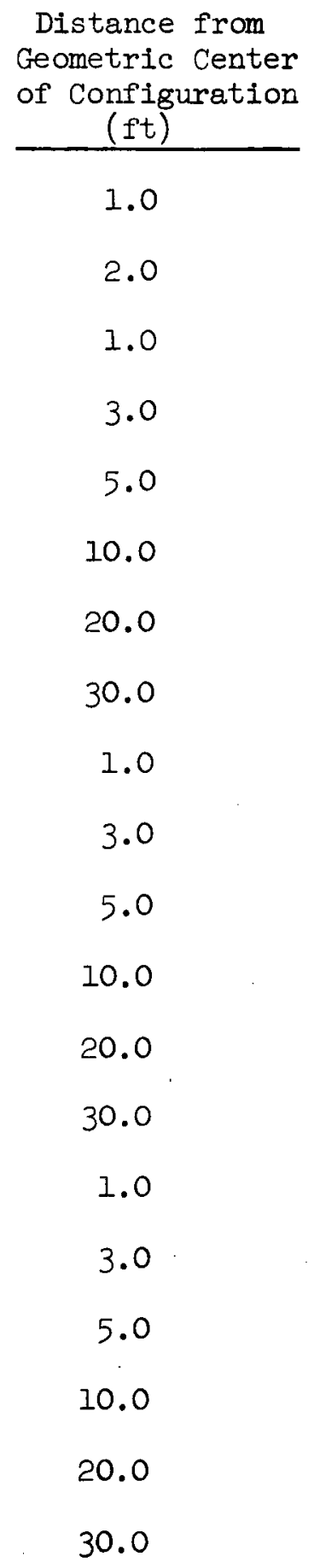




\section{COAfFHOENTIIIAL}

TABLE V-5 (continued)

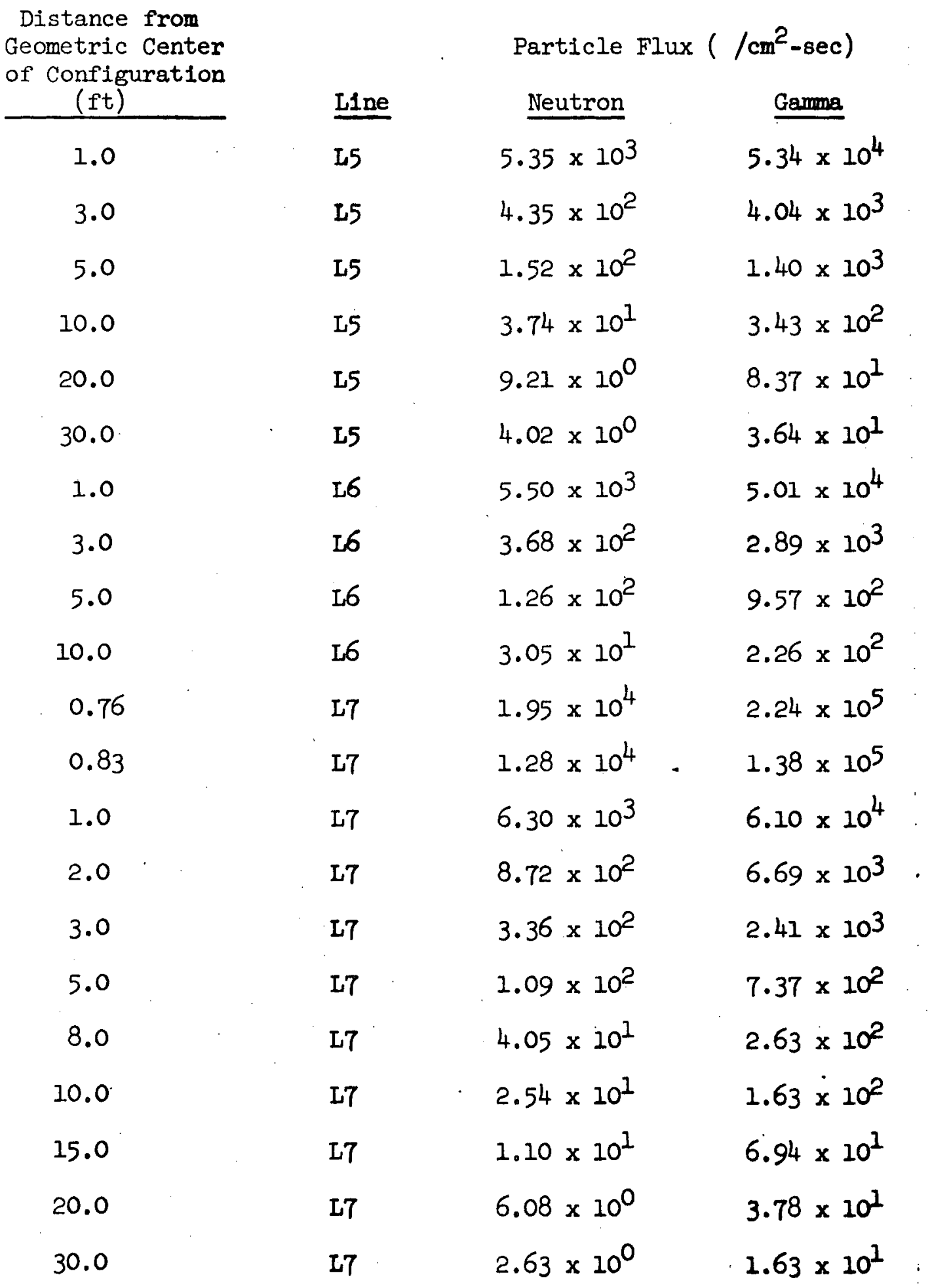




\section{TABLE V-6}

INEUTRON AIND GAMMA FLUXES IN THE VICINITY OF A SINGLE GENERATOR CONFIGURATION

(See Fig. V-15 for Location of Lines)

Distance from Geometric Center of Configuration

\begin{tabular}{l} 
(ft) \\
\hline 0.27 \\
0.42 \\
0.50 \\
0.75 \\
1.0 \\
2.0 \\
3.0 \\
5.0 \\
8.0 \\
10.0 \\
15.0 \\
20.0 \\
30.0
\end{tabular}

1.0

3.0

5.0

10.0

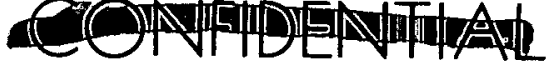




\section{TABLE V-6 (Continued)}

Distance from Geometric Center of Configuration

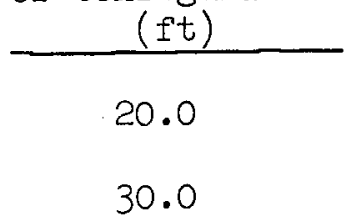

1.0

3.0

5.0

10.0

20.0

30.0

1.0

3.0

5.0

10.0

20.0

1.0

3.0

5.0

10.0

20.0

30.0

$$
\text { Particle Flux ( } \left./ \mathrm{cm}^{2}-\mathrm{sec}\right)
$$

Line

Neutron

Gamma

L2

5.86

72.9

L2

2.56

31.7

L3

$2.30 \times 10^{3}$

$2.69 \times 10^{4}$

L3

$2.54 \times 10^{2}$

$2.99 \times 10^{3}$

I3

91.3

$1.08 \times 10^{3}$

L3

22.7

$2.67 \times 10^{2}$

I3

5.58

65.3

L3

2.44

28.3

$2.12 \times 10^{3}$

$2.22 \times 10^{4}$

$2.35 \times 10^{2}$

$2.50 \times 10^{3}$

84.5

$8.98 \times 10^{2}$

21.0

$2.22 \times 10^{2}$

5.17

54.7

$1.98 \times 10^{3}$

$1.89 \times 10^{4}$

$2.16 \times 10^{2}$

$2.05 \times 10^{3}$

77.5

$7.35 \times 10^{2}$

19.2

$1.82 \times 10^{2}$

44.6

4.73

2.07

$19 \cdot 3$
L5

L5

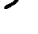


TABLE V-6 (Continued)

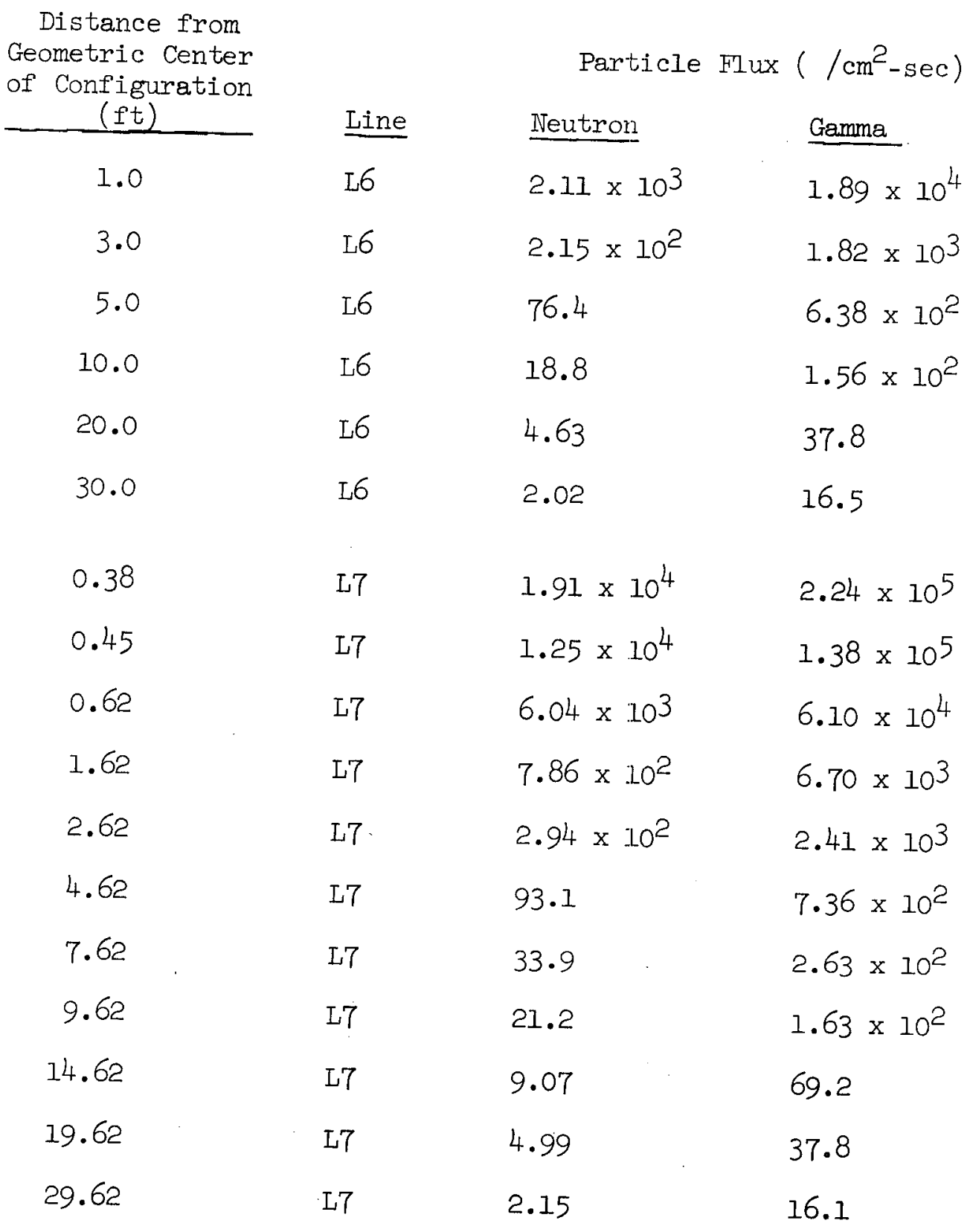




\section{Shield Attenuation and Weight Optimization}

In the final analysis, reduction of flux levels, if required, must consider the total weight associated with placement of the RTG's and shielding within the configuration. The flux levels could obviously be reduced by the use of booms to increase the source-to-detector separation distance. Another option would be the placement of "shadow" shielding between the RTG sources and the areas where radiation sensitive equipment may be located. The problem of optimized shielding (minimum total system weight) would be solved by consideration of all factors such as boom weight and shield weight (including canning and support structure). This section discusses shield attenuation for reduction of the total flux or gamma flux. For a fixed configuration, and given a flux design criteria, the data of this section provide the nearly optimum shielding required.

Neutron and gamma flux attenuation data were developed by use of the previously mentioned spherical source of $\mathrm{PuO}_{2}$. The DTF code was used to compute the neutron and gamma fluxes and dose rates at various distances in air beyond the source surrounded with varying thicknesses of typical neutrons and gamma shielding materials which are suitable for space applications. The gamma and neutron source spectra used in these calculations is that of Table V-3. Fluxes and dose rates at varying distances in air from 30 to $3000 \mathrm{dm}$ from the center of the source were compared to those computed for the unshielded source to obtain attenuation factors.

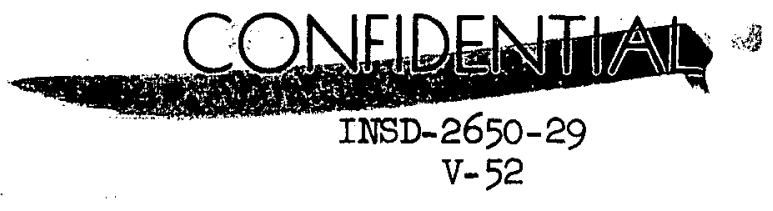




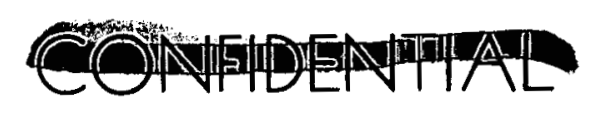

For distances greater than 3.0 ft from the source, attenuation factors were found to be nearly constant. The attenuation factors are shown in Figs. V-16 through $\mathrm{V}-19$. These results may be considered applicable for points of interest greater than 3 feet from the RTG sources. Differences in attenuation factors as a function of distance between shielded and unshielded configurations are due to differences in the angular spectral distribution for shielded and unshielded cases. (At distances less than 3 feet, the attenuation factors would be somewhat less than those shown.) Shield material densities are as given below:

Shield Material

$$
\underline{\left(\mathrm{g} / \mathrm{cm}^{2}\right)^{\text {Density }}\left(1 \mathrm{~b} / \mathrm{in}^{3}\right)}
$$

Neutron:

$$
\begin{array}{lll}
\text { Polyethylene } & 0.92 & 0.0332 \\
\text { Lithium Hydride } & 0.82 & 0.0296
\end{array}
$$

Gamma:

$$
\begin{array}{lll}
\text { Lead } & 11.4 & 0.412 \\
\text { Tungsten (W1O) } & 15.3 & 0.553 \\
\text { Platinum } & 21.5 & 0.777
\end{array}
$$

For a given flux criterion, the attenuation data of Fig. V-16 through V-19 coupled with the unshielded flux at the point of interest (obtained from the data of Tables V-5 and V-6)may be used to determine a near optimum shield configuration. Two types of criterion 

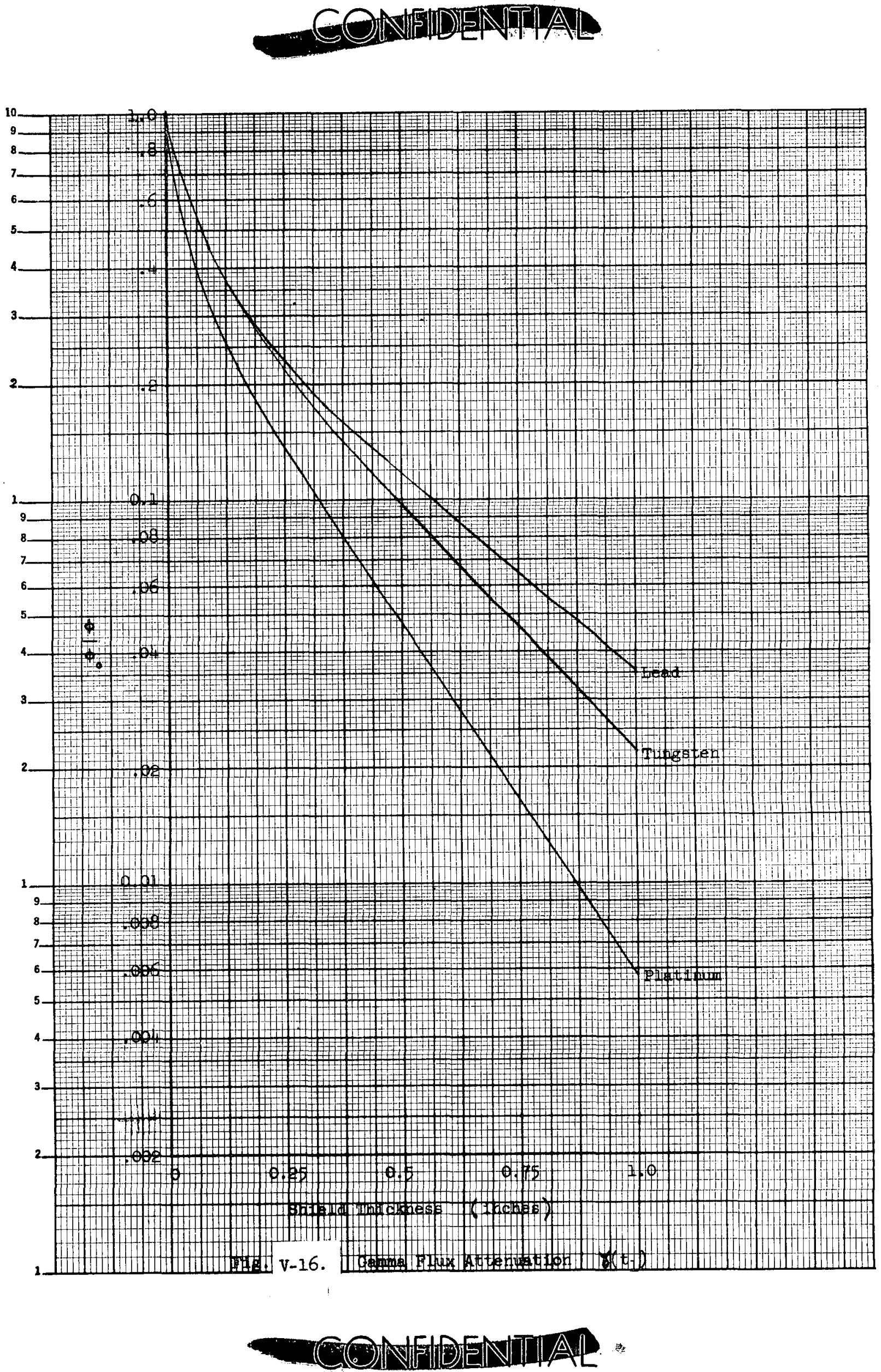


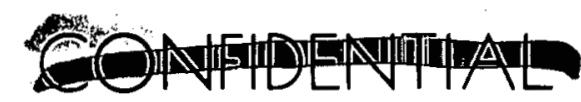

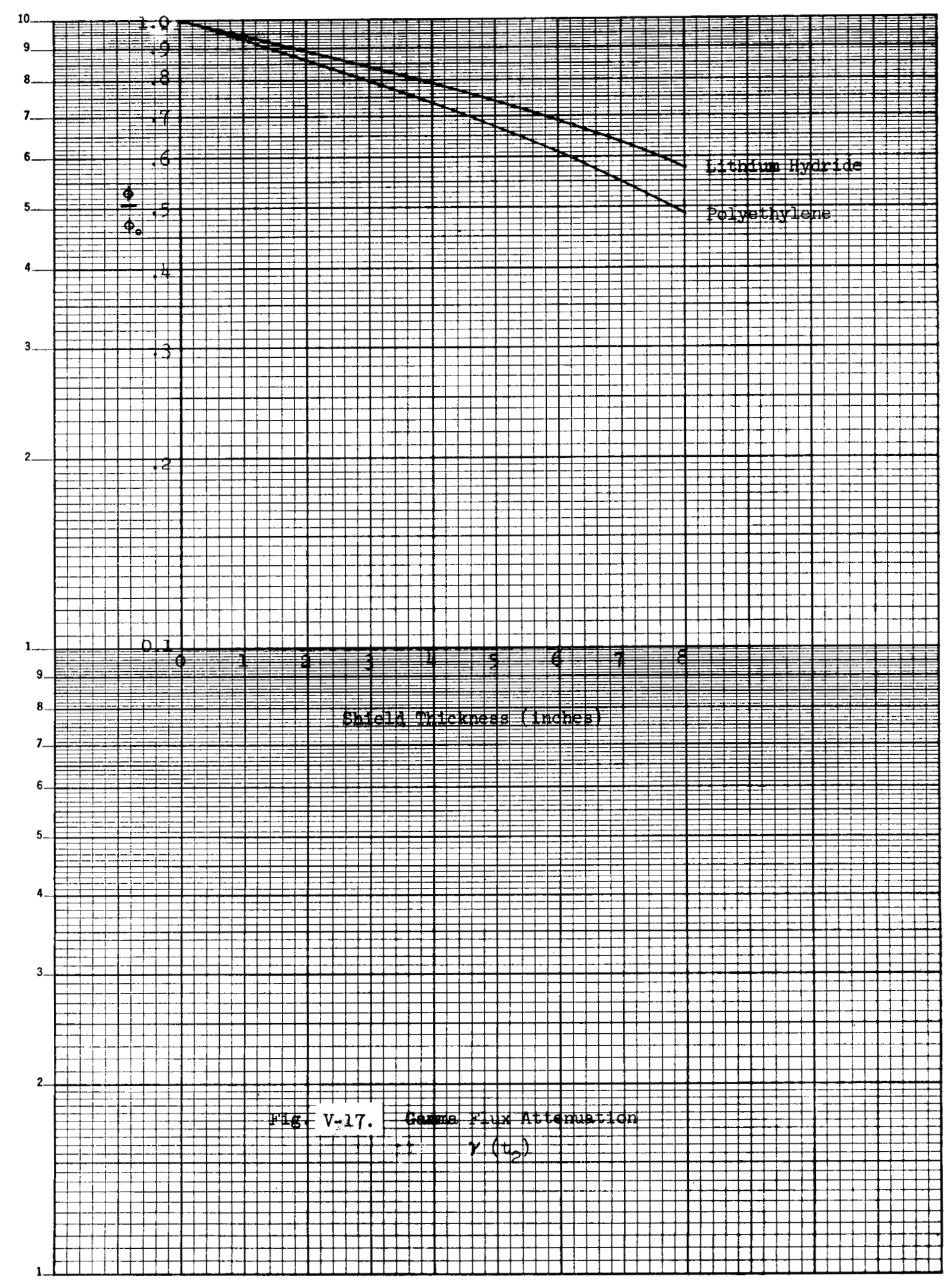

COAFIIDENTIIAAL

INSD-2650-29

V-55 


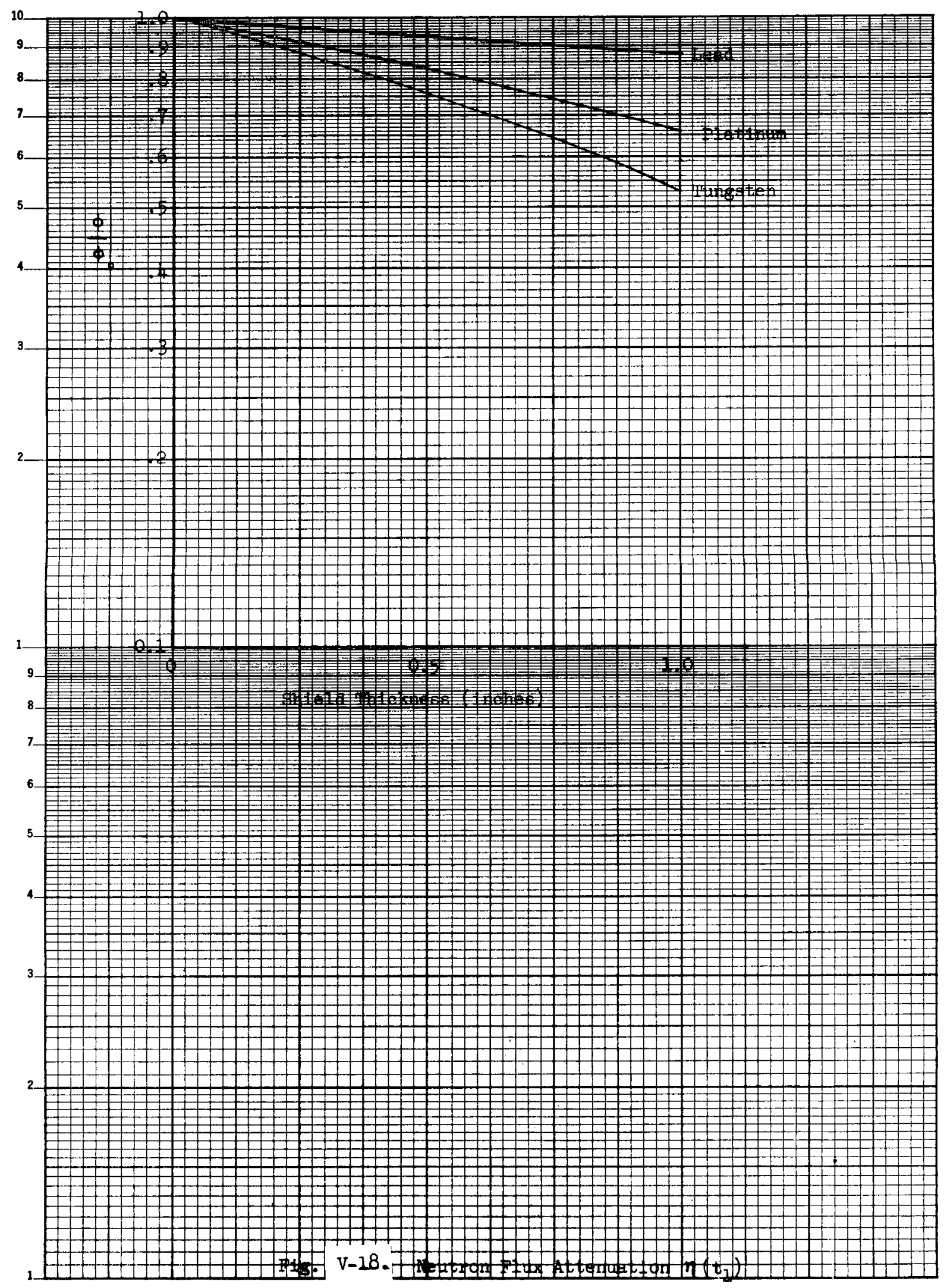



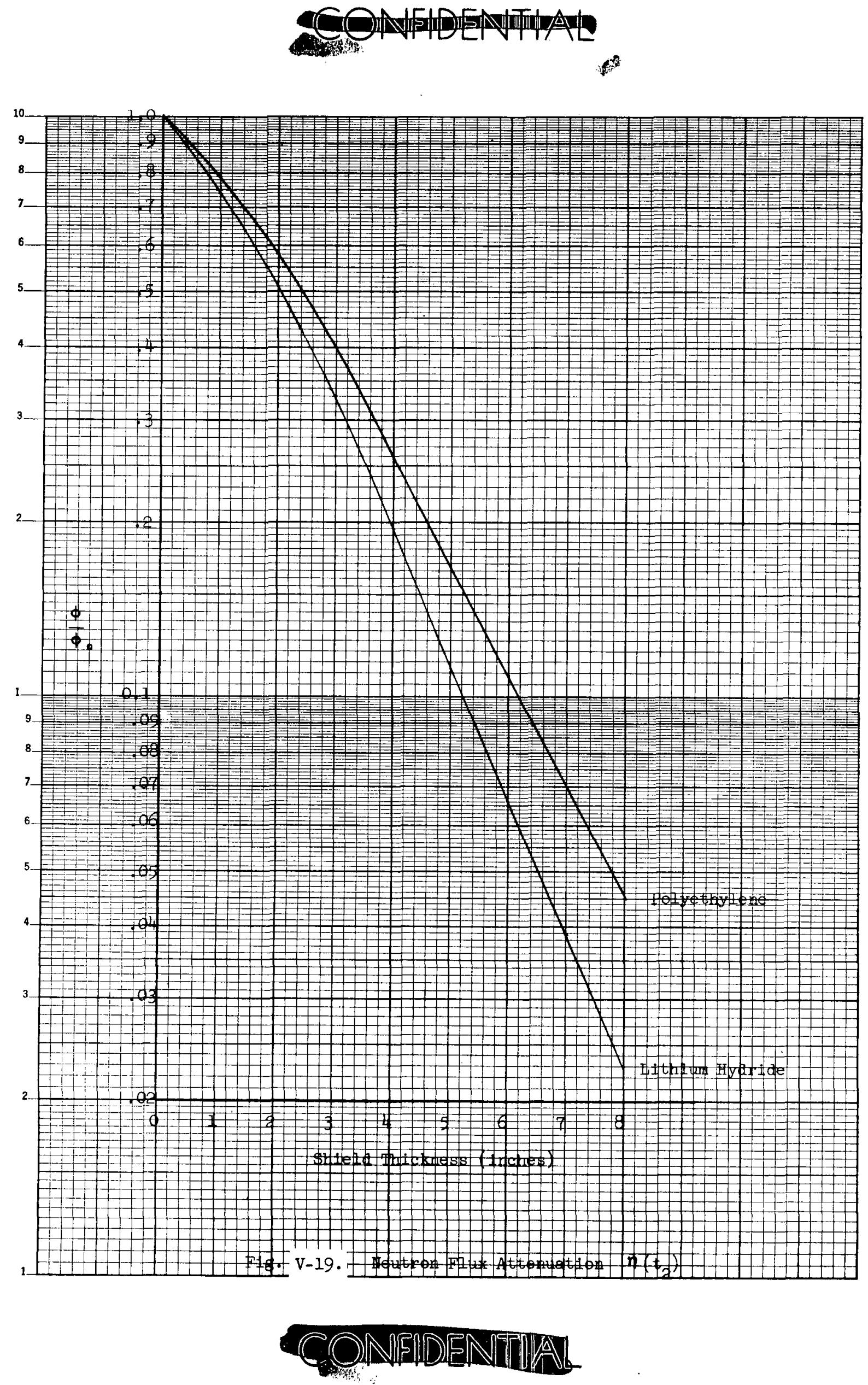

INSD-2650-29

$\mathrm{V}-57$ 


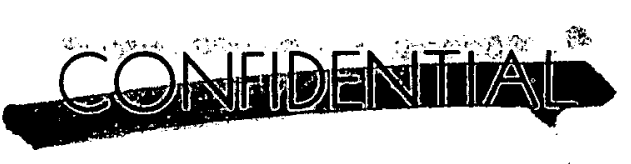

are considered: (1) the total (neutron plus gamma) flux and, (2) the gamma flux. In case (1), a minimum shield weight is found which reduces the total flux at the point of interest to some prespecified absolute limit. No restriction is made on the relative number of neutrons and gammas reaching the point. In case (2), only the gamma flux is to be reduced to a specified limit. The neutron flux at the point is of no concern.

3. Total Flux Criterion

Where the criterion is in terms of total (neutron plus gamma) flux, we first observe (from the data of Tables V-5 and V-6) that, for distances greater than two feet from the center of either the single or tandem configurations, the unshielded gamma-to-total flux ratios are approximately constant as shown below:

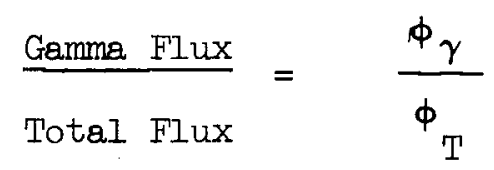

\begin{tabular}{lcccc} 
& $\begin{array}{c}\text { Distance } \\
\text { Feet }\end{array}$ & Single Generator & Tandem Genera \\
\cline { 2 - 2 } Radial & 2 & & 0.93 & 0.93 \\
(Line 1, & 5 & 0.93 & 0.93 \\
Fig.V-14, or V-15) & 8 & 0.93 & 0.93 \\
& 10 & 0.93 & 0.93 \\
& 20 & 0.93 & 0.93 \\
Axial & 30 & 0.93 & 0.93 \\
(Line 1, & 2 & 0.88 & 0.88 \\
Fig. V-14 or V-15) & 5 & 0.89 & 0.87 \\
& 10 & 0.88 & 0.87 \\
& 20 & 0.87 & 0.87 \\
& 30 & 0.88 & 0.86
\end{tabular}


For a given ratio $\phi_{\gamma} / \phi_{T}$, the optimized shield configurations may be determined as a function of the attenuation factor $f=\phi_{c} / \phi_{0}$ (the ratio of the total flux criterion to the unshielded total flux) which are valid for all separation distances greater than three feet from the source. This is accomplished by finding solutions of the equation:

$$
f=\left[\gamma\left(t_{1}\right) \gamma\left(t_{2}\right)+c n\left(t_{1}\right) n\left(t_{2}\right)\right] /(1+c)
$$

where:

$f$ is the attenuation factor, $f=\phi_{c} / \phi_{0}$ where $\phi_{c}$ is the desired total flux level, $\phi_{0}=\phi_{n_{0}}+\phi_{\gamma_{0}}$;

$\phi_{n_{0}}$ and $\phi \gamma_{0}$ are the unshielded neutron and gamma fluxes at the point of interest

$\gamma\left(t_{j}\right)$ is the gamma attenuation factor for material $j$

$n\left(t_{j}\right)$ is the neutron attenuation factor for material $j$

$c=\phi_{n_{0}} / \phi_{\gamma_{0}}$

The attenuation factors $\gamma\left(t_{1}\right), \gamma\left(t_{2}\right), n\left(t_{1}\right)$ and $n\left(t_{2}\right)$ are obtained from Figs. V-16 through V-19. Here $\gamma$ refers to garma flux attenuation factor, $n$ refers to neutron flux attenuation factor and $t_{1}$ and $t_{2}$ are the gamina and neutron shield material thicknesses, respectively. After finding a set $\left(t_{1}, t_{2}\right)$, which satisfied the condition of Eq. (V-1) for a given $T$, shield weights per unit area are computed as:

$$
W_{i}=\rho_{1} t_{I_{i}}+\rho_{2} t_{2_{i}}
$$

where $\rho_{1}$ and $\rho_{2}$ are the gammas and neutron shield densities, respectively.

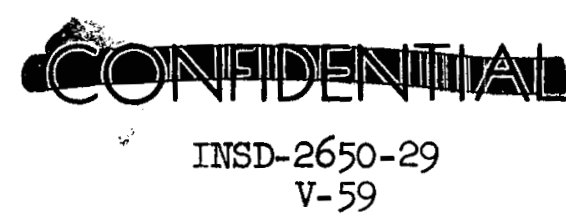


Several sets $\left(t_{1}, t_{2}\right)$ are found which satisfy the condition of Eq. (V-I). Either $t_{1_{i}}$ or $t_{2_{i}}$ are then plotted versus $w_{i}$ to select the set $\left(t_{1}, t_{2}\right)$ which gives the minimum weight.

Solutions of Eq. (V-I) were found for combinations of neutron and gamma shield materials. Jptimum weights as a function of $f$ for an unshielded gamma-to-total flux ratio of about 0.87 are given in Fig. V-20. Corresponding shield thicknesses are given in Fig. V-2l. These results are applicable for placement of shielding in axial regions. Tptimum weights for an unshielded gamma-to-total flux ratio of about 0.93 are given in Fig. V-22 with corresponding shield thicknesses in Fig. V-23. These results are applicable for shielding placed radially. 4. Gamma Flux Criterion

Where the criterion is in terms of gamma flux only, shield weights may be found by applying the appropriate densities to the gamma attenuation data of Fig. V-16. Shield weight per unit area for gamma shielding is given in Fig. V-24. It is obvious from this figure that the use of lead will give the minimum weight shield. (The feasibility of use of lead would have to be determined from consideration of the environment for a specified mission.)

\section{Discussion of Results}

It should be noted that the attenuation analysis reported herein applies only to primary radiation. Complete analyses would consider production of secondary produced mainly by neutron capture in the shield and ther spacecraft components. Preliminary analysis indicates that secondary radiation becomes significant when considering attenuation factors of less than 0.01 . The user is warned against extensive extrapolations of the results.

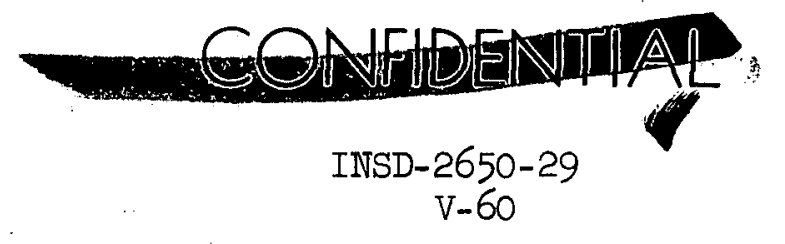




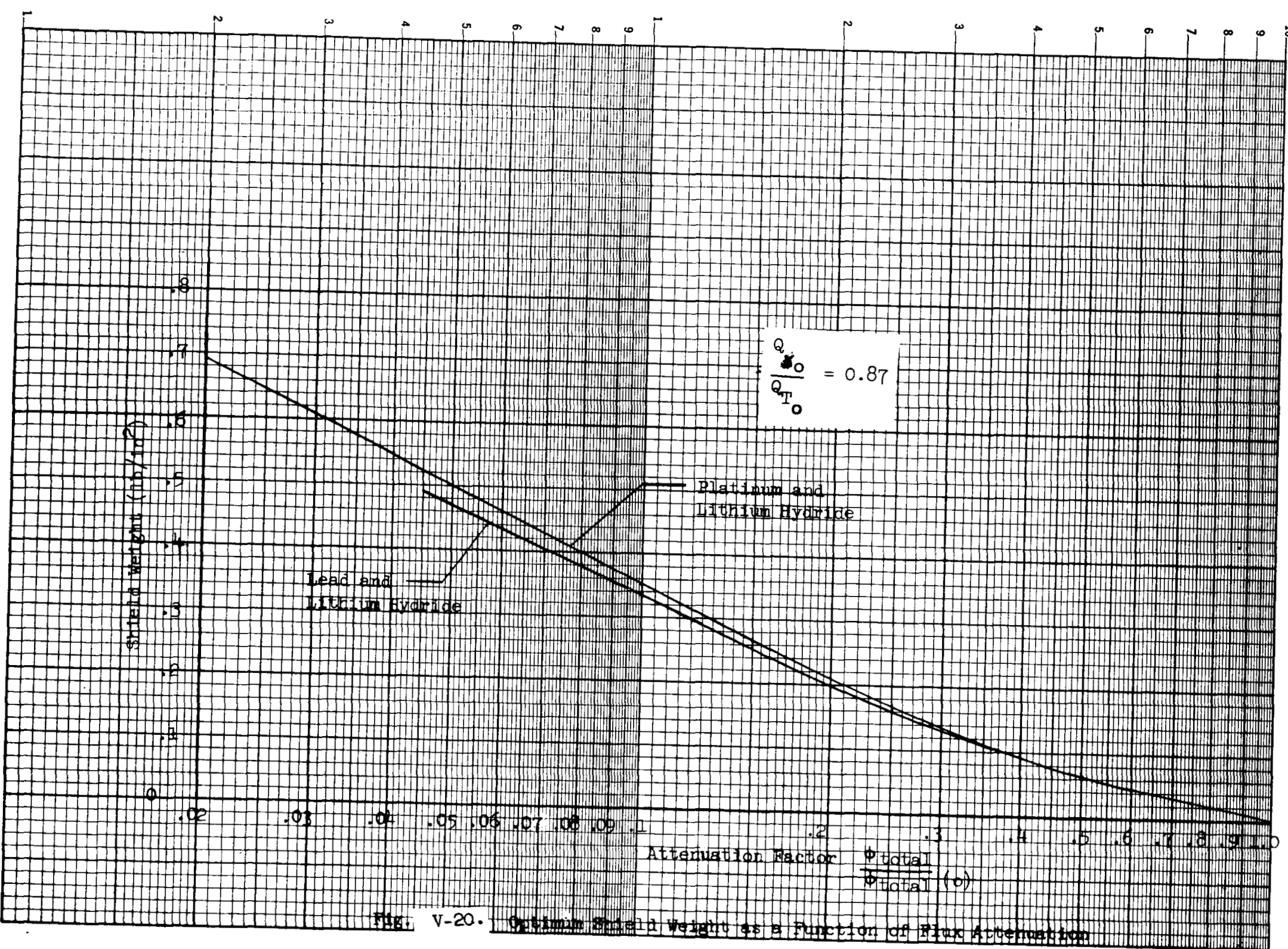




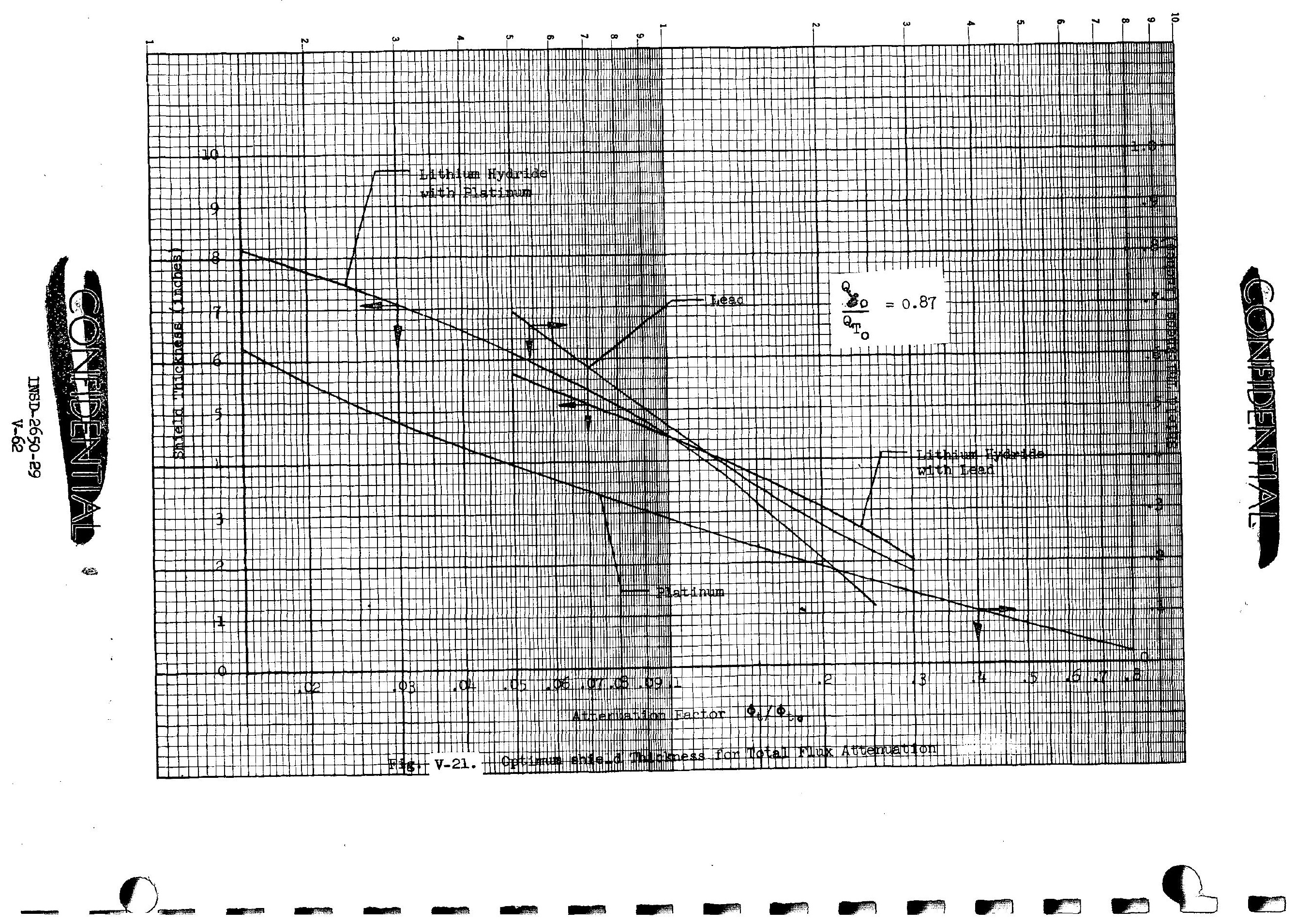




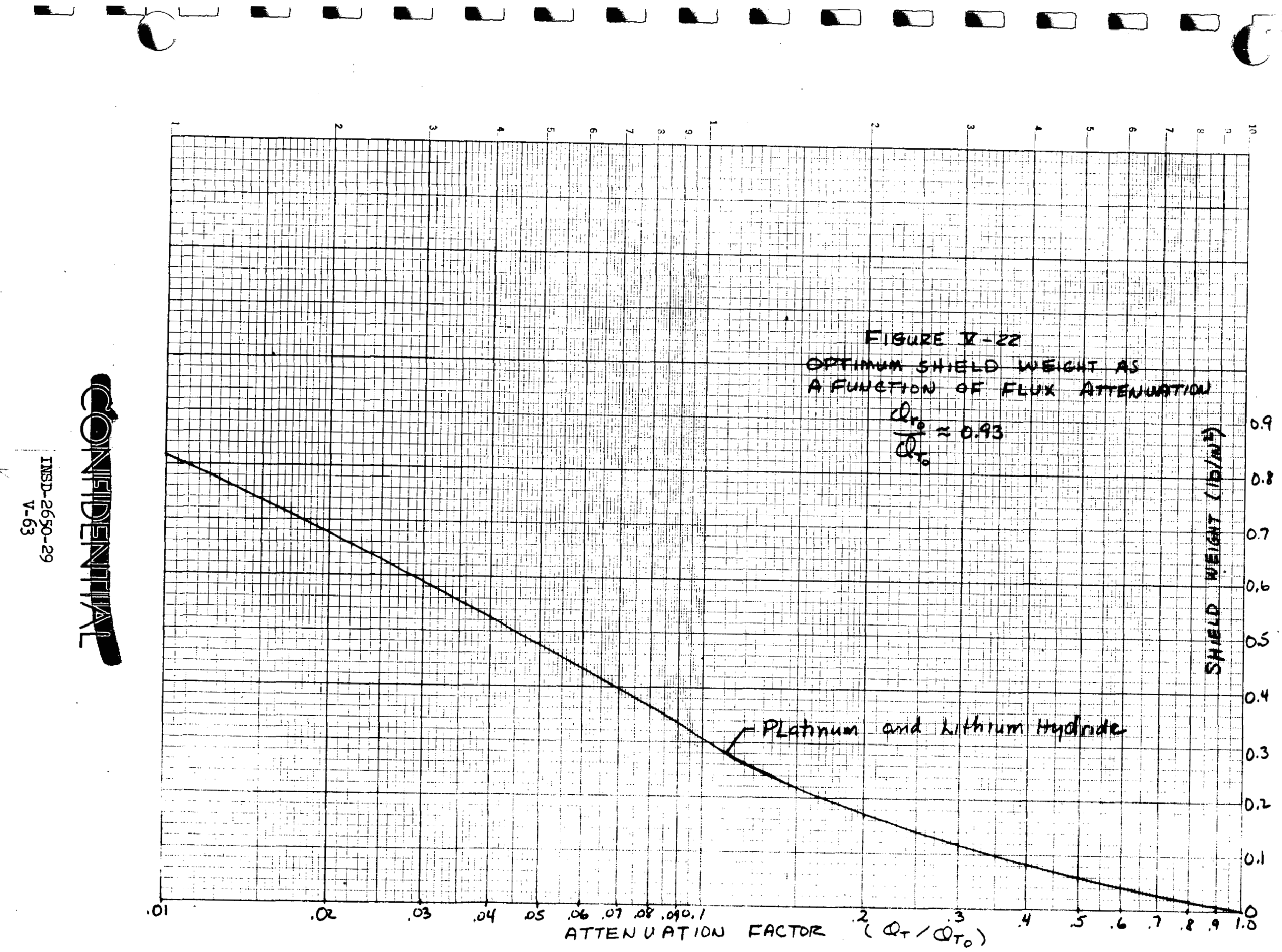




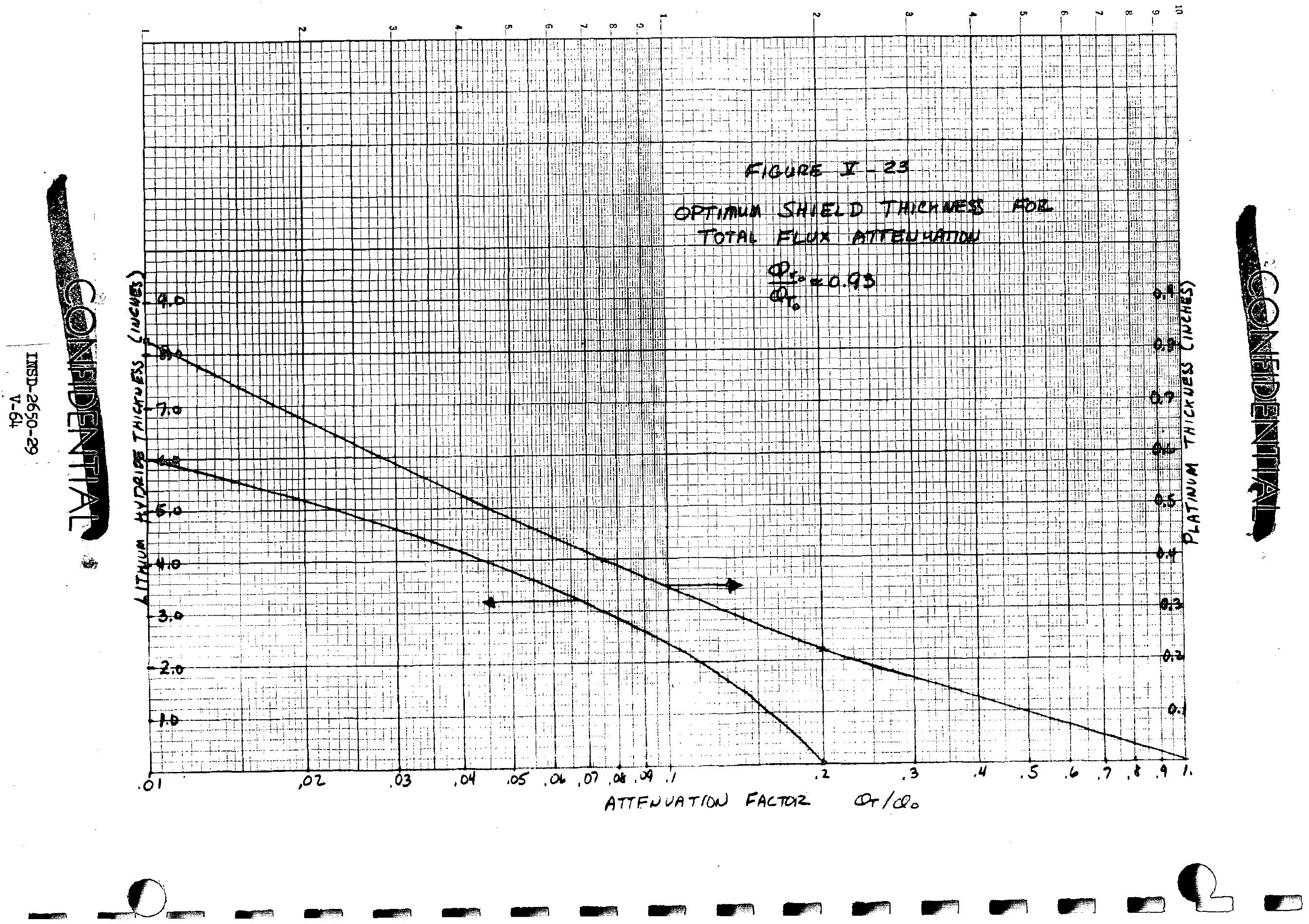



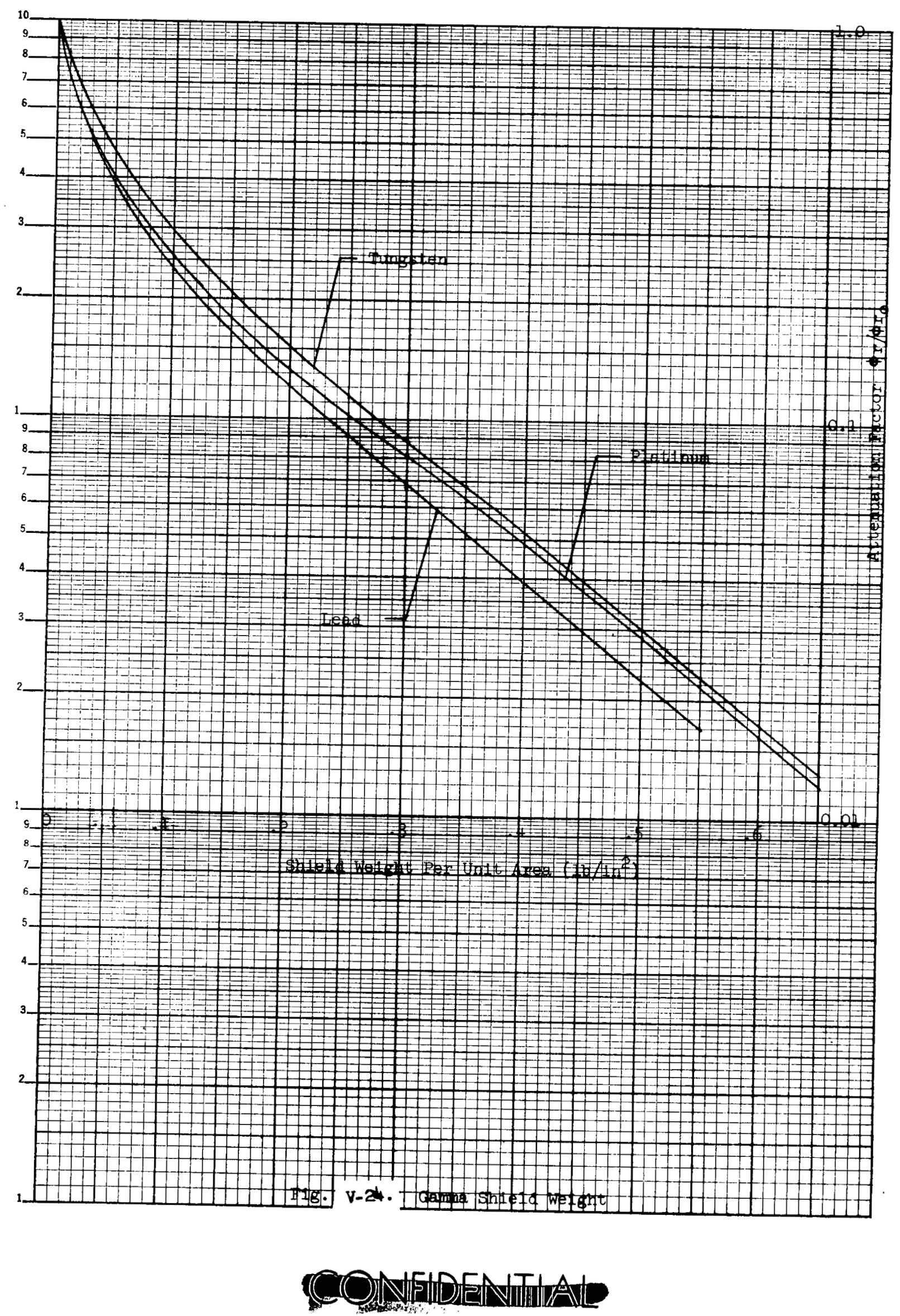


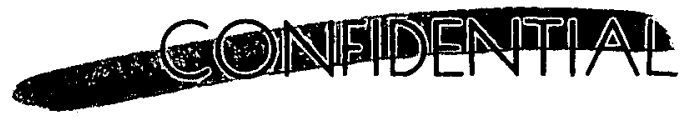

Another problem to be considered in the final analysis is radiation which reaches the points of interest by scattering and thus by-passing the shadow shield. Here, very preliminary analysis indicates that for configurations of the type considered herein, the scattered radiation is roughly two to three orders of magnitude less than the unshielded, direct flux.

The lateral extent of the shield is a function of the angles subtended by the source and the area to be shielded. Obviously, minimum weight for the RTG system plus shielding is attained by aligning the RTG axis to pass through the detector points. For shielding large regions, the optimum placement would be a shield near the source. For shielding small areas, placement of the shield near the point of interest may lead to reduced weight.

\section{Biological Dose Rates}

The biological dose rate fields around the single and tandem mounted generators were computed for purposes of evaluation of radiation hazards to personnel involved in ground handling operations. The data may be used to estimate the dose rates for any arbitrary system of one or more single or tandem generator configurations.

Dose rates were evaluated by use of the SPEND computer program. This code is written in cylindrical geometry (with symmetry about a central axis) and uses the point kernel technique to integrate over the cylindrical annuli source regions. For gamma calculations, the twenty group spectrum (Table V-3) and appropriate bulldup factors were used. Neutron dose rates were evaluated by the use of effective removal cross sections.

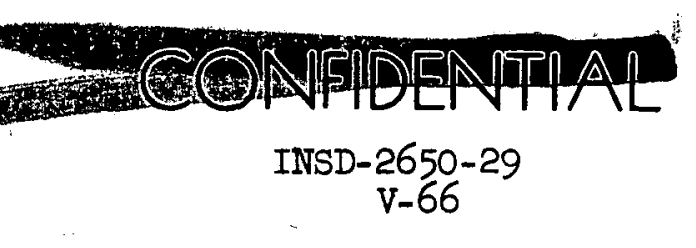


To check the validity of the method, calculations were performed for a similar system (SNAP 19 - Subsystem 9 used for Nimbus III) composed of two generators in tandem with a fuel loading of approximately 628 watts/capsule. Calculations are compared to measured values in Table V-7. Neutron measurements were made with a Texas Nuclear - Nemo Neutron Dosimeter. This instrument is regarded as having a standard error of $\pm 5 \%$ for measurement of dose rates from a standard Pu-239 Be source. Frror associated with the different fast neutron spectrum is unknown. Gamma measurements were made with an Eberline E-500B--GM Survey Meter calibrated with a $1 \mathrm{mg}$ Ra-276 source.

Several factors may account for the variations between measurement and calculation:

a) The computational model was in cylindrical geometry. This affects calculations on the axis since the actual fuel capsule has spherical ends.

b) Since the thermoelectrics do not represent solid shielding material, they were not included in the calculational model. This tends to yield an overestimate in the calculations.

c) Although the use of removal cross sections for heavy elements with the appropriate conversion factor appears reasonably correct, their use with light elements such as carbon may lead to significant error for thin slabs. The calculation included a removal cross section for the graphite surrounding the fuel capsule. Transport calculations for this thickness of graphite 
TABLE V-7

SNAP 19 IRHS SUBSYSTEM 9 (NIMBUS III)

CALCULATED AND MEASURED DOSE RATES

Distance from Geometric Center of System

(ft)

Radial

1

3

6

Axial

$$
\begin{aligned}
& 2-1 / 2 \\
& 5-1 / 2 \\
& 9-1 / 2
\end{aligned}
$$

Neutrons

(mrem $/ \mathrm{hr}$ )

measured calculated

$600 \quad 472$

80

25

60.6

22.1

59.3

10.4

3.29

4.6
Dose Rate

$\frac{\text { measured }}{\text { calculated }}$

1.3

1.3

1.1

1.5

1.4

1.4
Gammas

Dose Rate

(mrem/hr)

measured calculated

measured

calculated

$\begin{array}{lll}33 & 42.6 & 0.77 \\ 5 & 5.66 & 0.88 \\ 1.1 & 1.43 & 0.77\end{array}$

3.41

1.5

0.6

0.535

1.1

0.11

0.163

0.68 


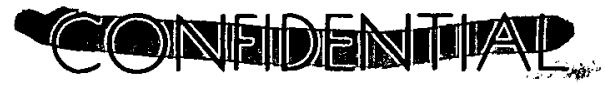

indicate essentially no removal of neutrons. If this is

correct, the use of the removal cross section yielded

neutron dose rates which are roughly $20 \%$ low.

Calculated neutron and gamma dose rates in the vicinity of the tandem RTG configuration are given in Table V-8. Neutron and gamma dose rates for the single generator are given in Table V-9. The data may be interpolated (inverse square law) to obtain the dose rates at any point. For estimates of required temporary shielding, dose attenuation factors are given in Figs. V-25 through V-28. (The attenuation factors were derived from the spherical source calculations.)

As an example of the use of this data, consider the generator arrangements in Figs. V-29 and V-30 which are typical of present Martin Denver configurations. The data of Table V-9 were used to evaluate dose rates at various points, and thus obtain the isodose curves. In the event that personnel access in the vicinity of this system is required, the following biological dose rate criteria* are considered:

(1) An allowable dose of 1.25 rem to the whole body, head and trunk, active blood forming organs, eyes or gonads.

(2) An allowable dose of $18.75 \mathrm{rem}$ to the hands and forearm, feet and ankles.

These criteria are based on the maximum allowable per calendar quarter of a year. Consideration of matters such as an individual's previous radiation history, work requirements in other radiation areas, and/or con*USAEC Rules and Regulations, Title 10-Atomic Energy, Part 20, Standards for Protection Against Radiation, paragraph 20.101.

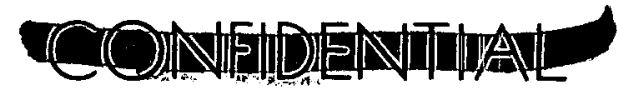

INSD-2650-29 


\section{TABLE V-8}

NEUTRON AND GAMMA DOSE RATES IN THE VICINITY

OF THE TANDEM RTG CONFIGURATION

(See Fig. V-14 for location of lines)

\begin{tabular}{|c|c|c|c|}
\hline $\begin{array}{l}\text { Distance from } \\
\text { Geometric Center }\end{array}$ & & Dose $R \varepsilon$ & $\mathrm{em} / \mathrm{hr}$ ) \\
\hline (ft) & Iine & Neutron & Gamma \\
\hline 0.27 & LI & 2360 & 140 \\
\hline 0.42 & Ll & 1690 & 112 \\
\hline 0.50 & LI & 1400 & 96.5 \\
\hline 0.75 & LI & 814 & 60.8 \\
\hline 1.0 & LI & 513 & 39.7 \\
\hline 2.0 & $\mathrm{LI}$ & 145 & 11.6 \\
\hline 3.0 & LI & 65.7 & 5.30 \\
\hline 5.0 & LI & 23.9 & 1.92 \\
\hline 8.0 & $\mathrm{LI}$ & 9.33 & .748 \\
\hline 10.0 & L1 & 5.95 & .474 \\
\hline 15.0 & LI & 2.63 & .209 \\
\hline 20.0 & LI & 1.47 & .116 \\
\hline 30.0 & L1 & .642 & .0529 \\
\hline 0.27 & LI-A & 4110 & 321 \\
\hline 0.42 & LI-A & 1980 & 155 \\
\hline 0.5 & LI-A & 1462 & 113 \\
\hline 0.75 & $L 1-A$ & 760. & 58.7 \\
\hline
\end{tabular}


TABLE V-8 (continued)

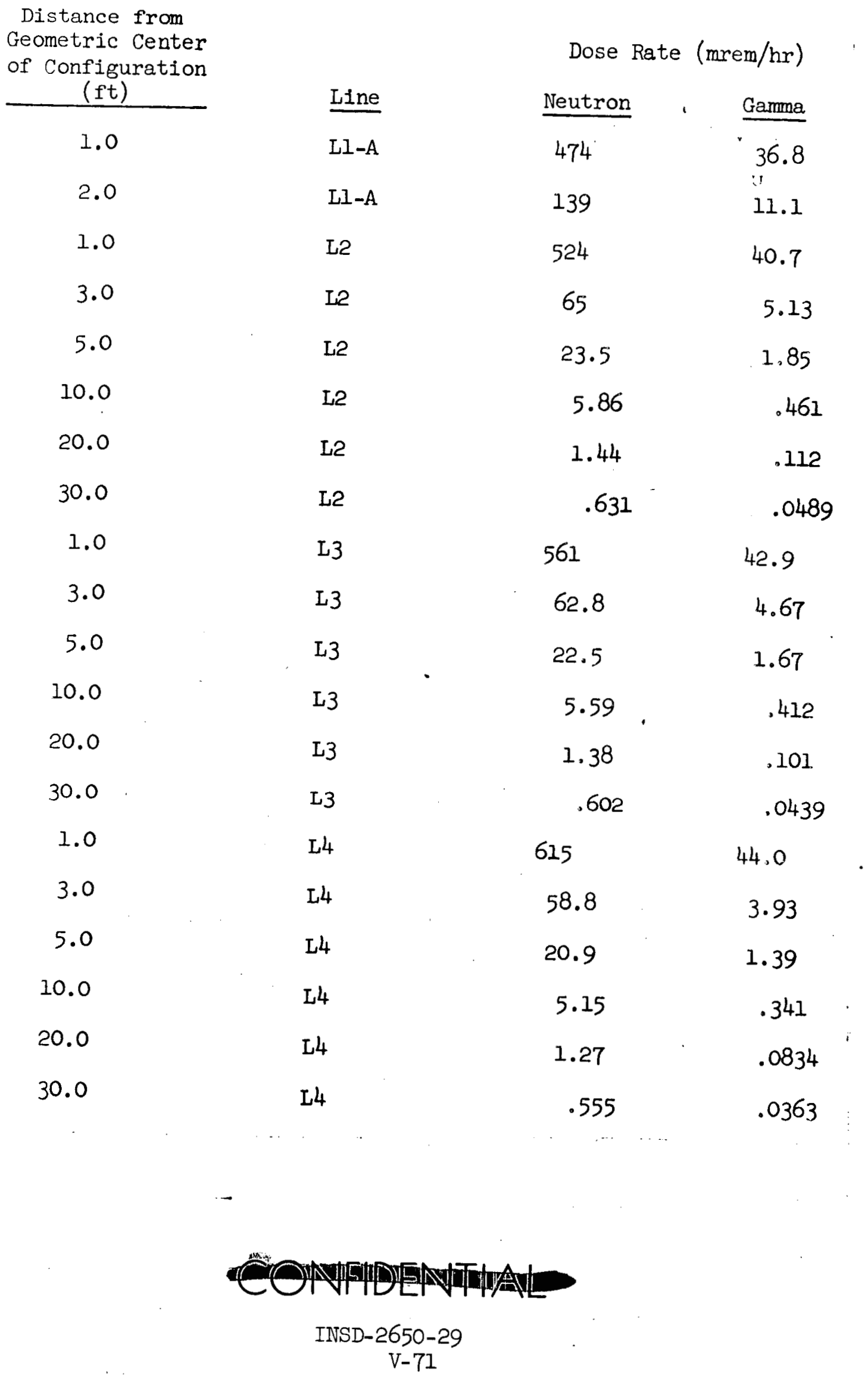


TABLE V-8 (cont1nued)

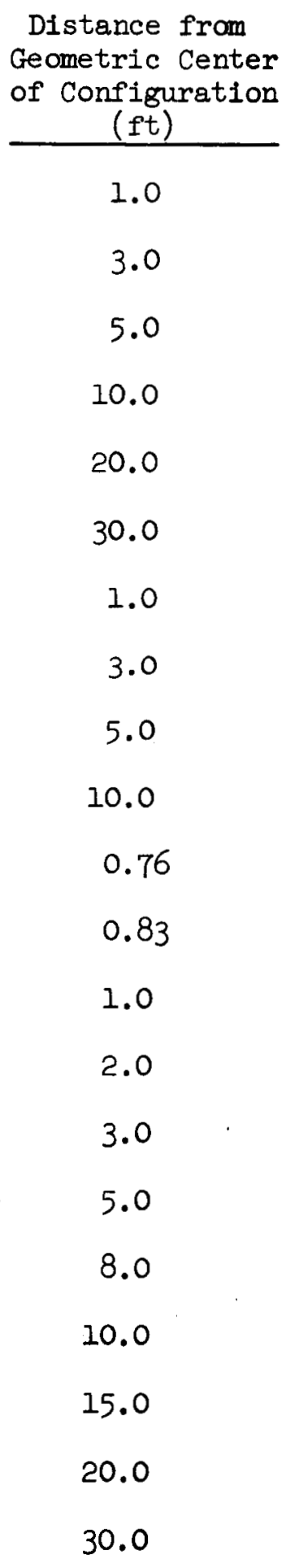

$$
\text { Dose Rate (mrem/hr) }
$$

Line Neutron Gamma

L5

657

41.1

L5

53.4

3.11

I5

18.7

1.08

L5

4.59

.264

I. 5

1.13

.0644

I5

L6

.493

.0280

675

38.5

I6

I6

45.2

2.22

15.5

.736

3.75

.174

L7

I7

IT

IT

I7

IT

I7

2390

172

1570

106

773

46.9

107

5.15

41.2

1.85

13.4

.567

4.97

.202

IT

3.12

.125

L7

1.35

.0534

L7

.746

.0291

I7

.0125 
TABLE V-9

NEUTRON AND GAMMA DOSE RATES IN THE VICINTTYY

OF THE SINGLE GENERATOR CONFIGURATION

(See Figure V-15 for Location of Lines)

\begin{tabular}{|c|c|c|c|}
\hline $\begin{array}{c}\text { Distance from } \\
\text { Geometric Center } \\
\text { of Configuration } \\
\text { (ft) }\end{array}$ & Line & \multicolumn{2}{|c|}{ Dose Rate (mrem/hr } \\
\hline 0.27 & LI & 3780 & 905 \\
\hline 0.42 & $\mathrm{LI}$ & 1670 & 138 \\
\hline 0.50 & $I I$ & 1180 & 97.2 \\
\hline 0.75 & $\mathrm{~L} 1$ & 531 & 43.7 \\
\hline 1.0 & L1 & 300 & 24.6 \\
\hline 2.0 & II & 75.2 & 6.11 \\
\hline 3.0 & LI & 33.4 & 2.70 \\
\hline 5.0 & II & 11.9 & 0.965 \\
\hline 8.0 & $\mathrm{~L} 1$ & 4.65 & .373 \\
\hline 10.0 & $\mathrm{~L} 1$ & 2.97 & 0.238 \\
\hline 15.0 & $\mathrm{Ll}$ & 1.31 & 0.104 \\
\hline 20.0 & LI & .731 & .0580 \\
\hline 30.0 & LI & $\cdot 320$ & .0252 \\
\hline 1.0 & L2. & 296 & 23.6 \\
\hline 3.0 & L2 & 32.8 & 2.59 \\
\hline 5.0 & L2 & 11.8 & 0.925 \\
\hline 10.0 & L2 & 2.92 & 0.230 \\
\hline 20.0 & L2 & .718 & .0561 \\
\hline 30.0 & I2 & .314 & .0244 \\
\hline
\end{tabular}

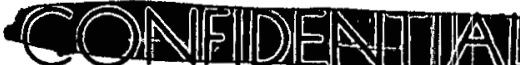

INSD-2650-29

$\mathrm{V}-73$ 
TABLE V-9 (Continued)

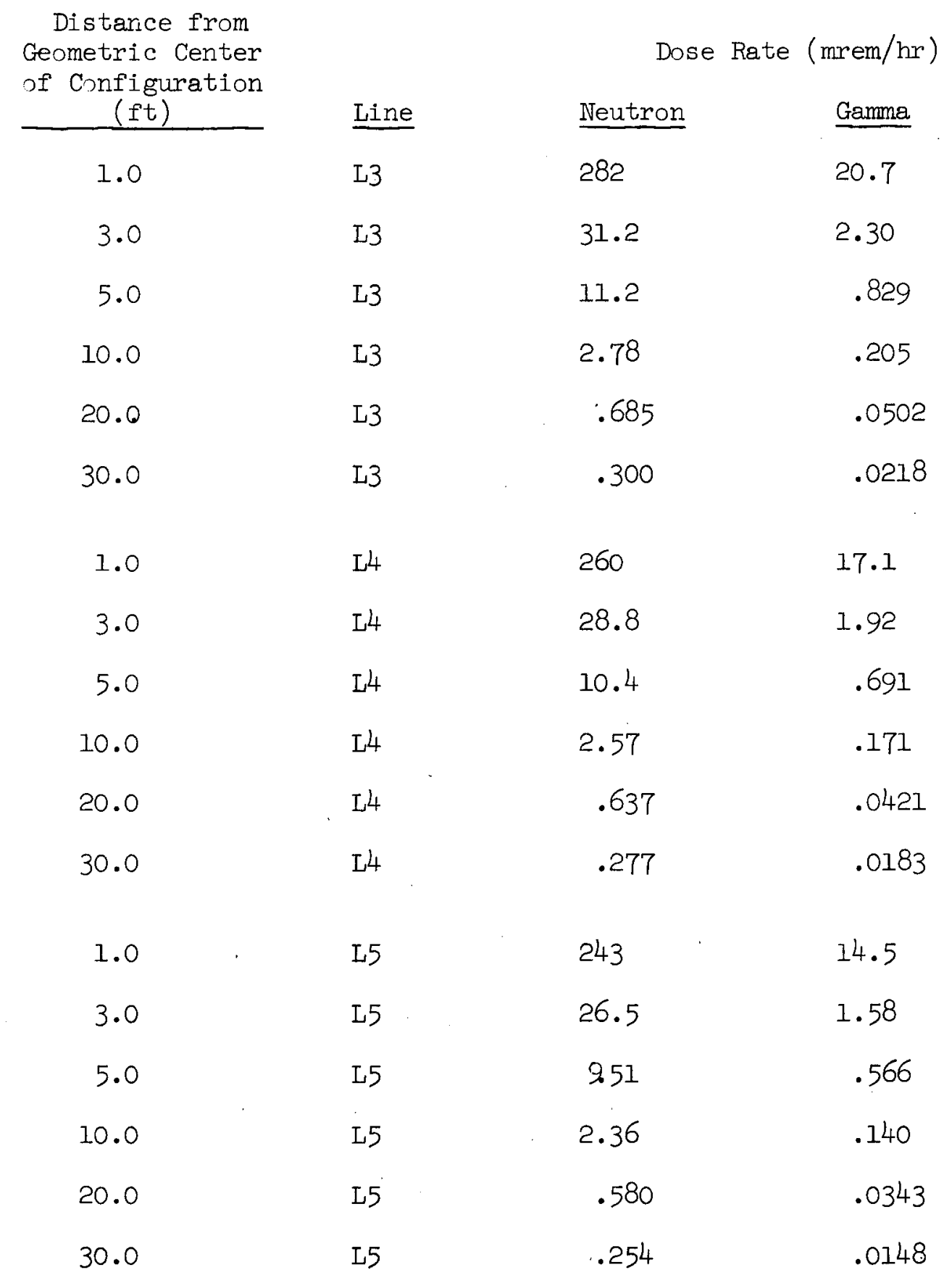

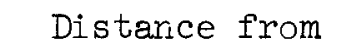

Geometric Center

of Configuration

1.0

30.0

1.0

3.0

10.0

20.0

30.0

30.0

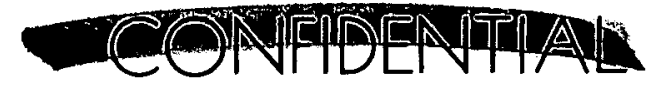




\section{CONFWEANTHA}

TABLE V-9 (Continued)

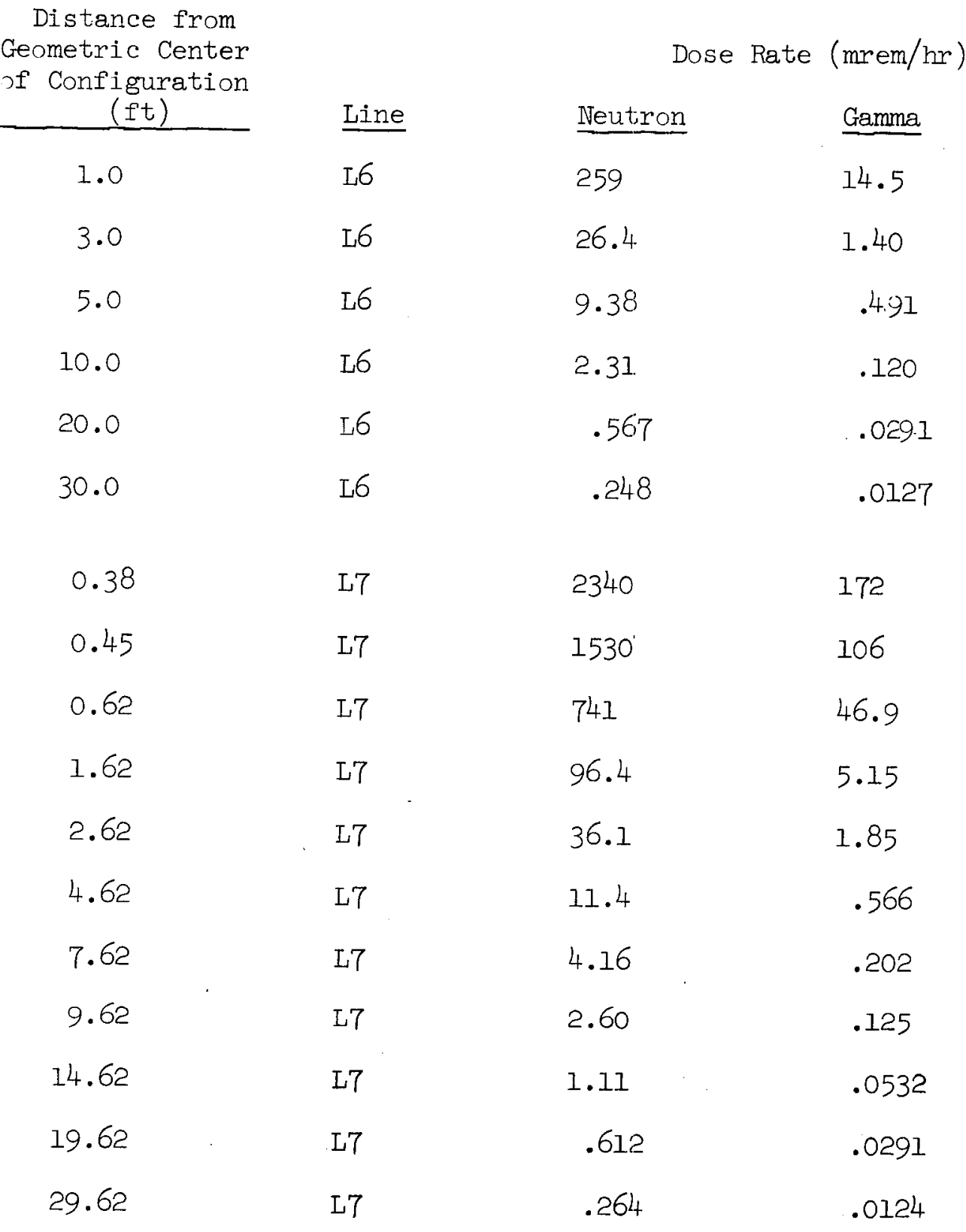

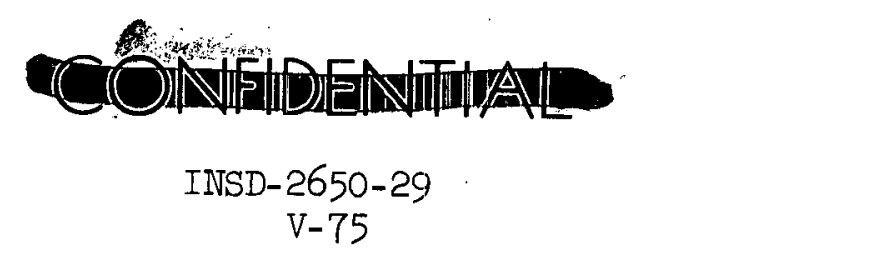



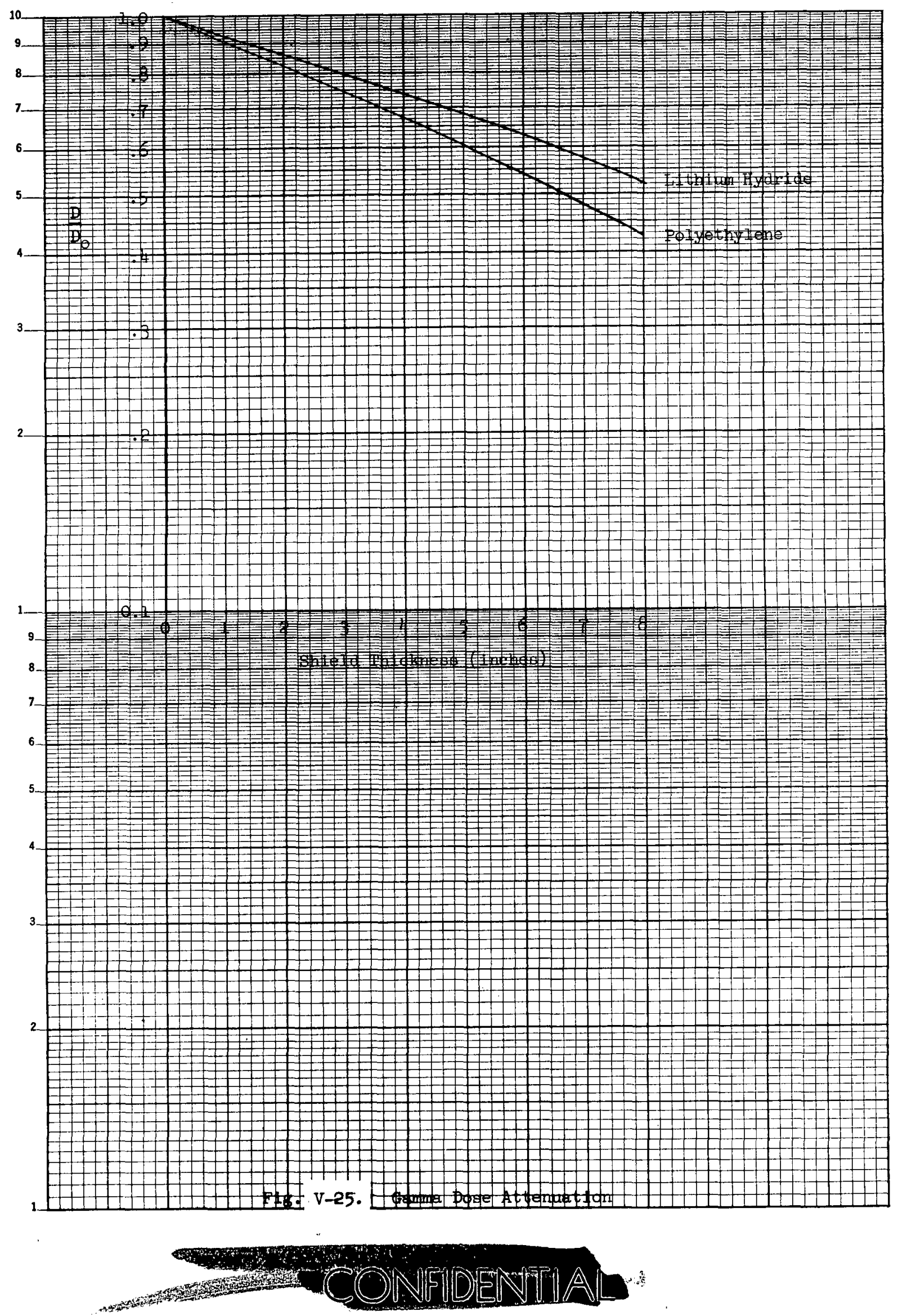


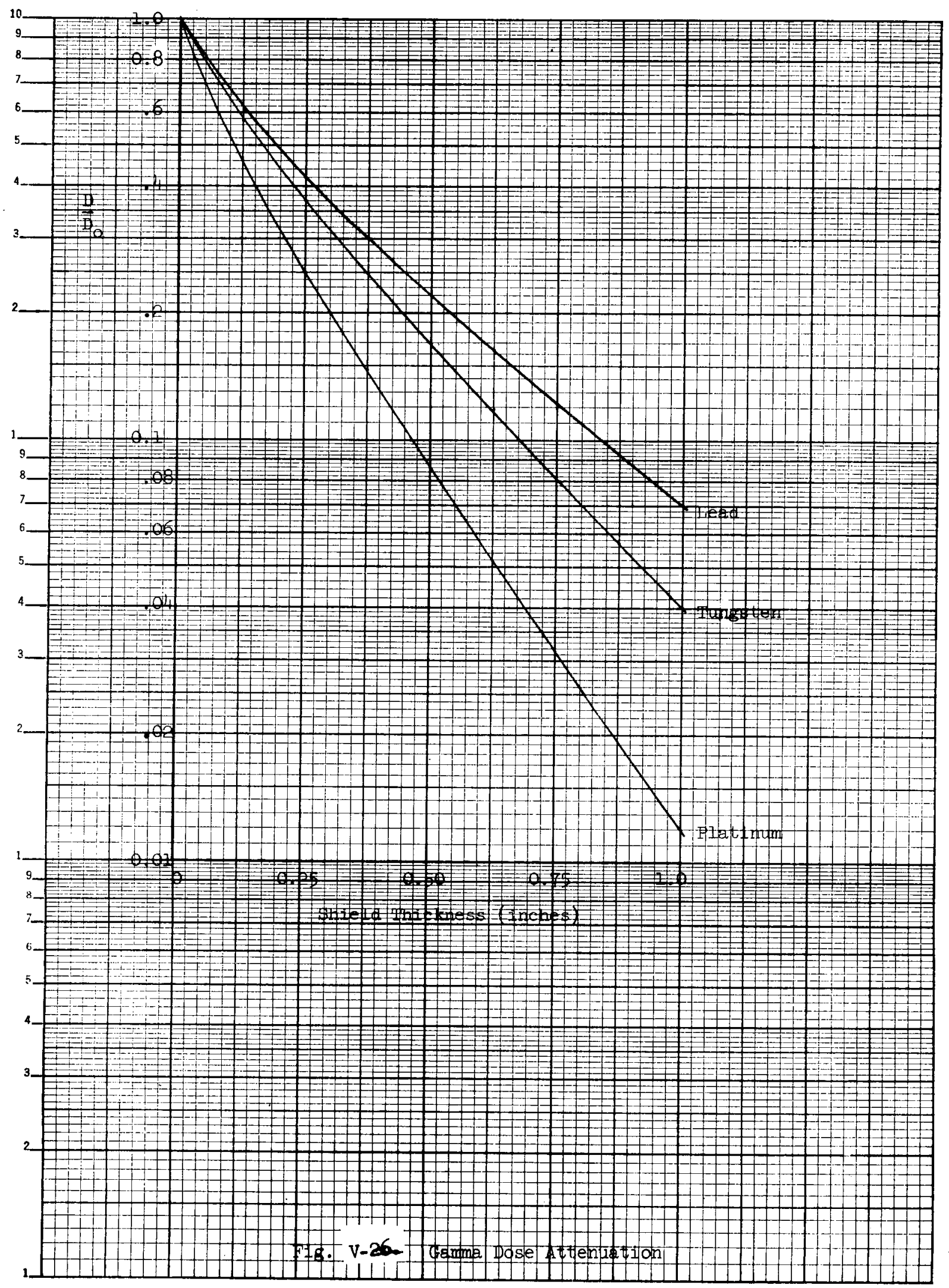



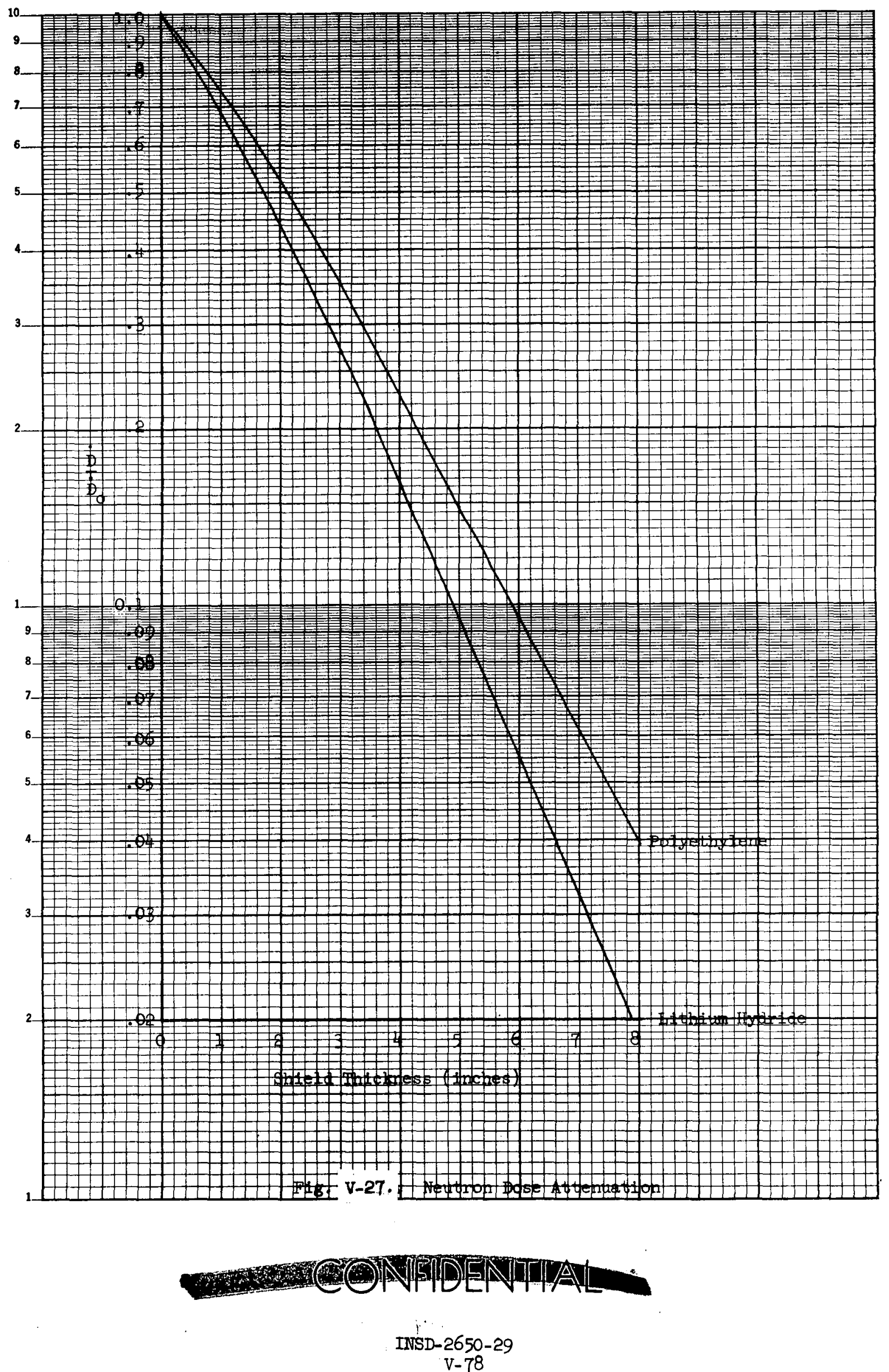

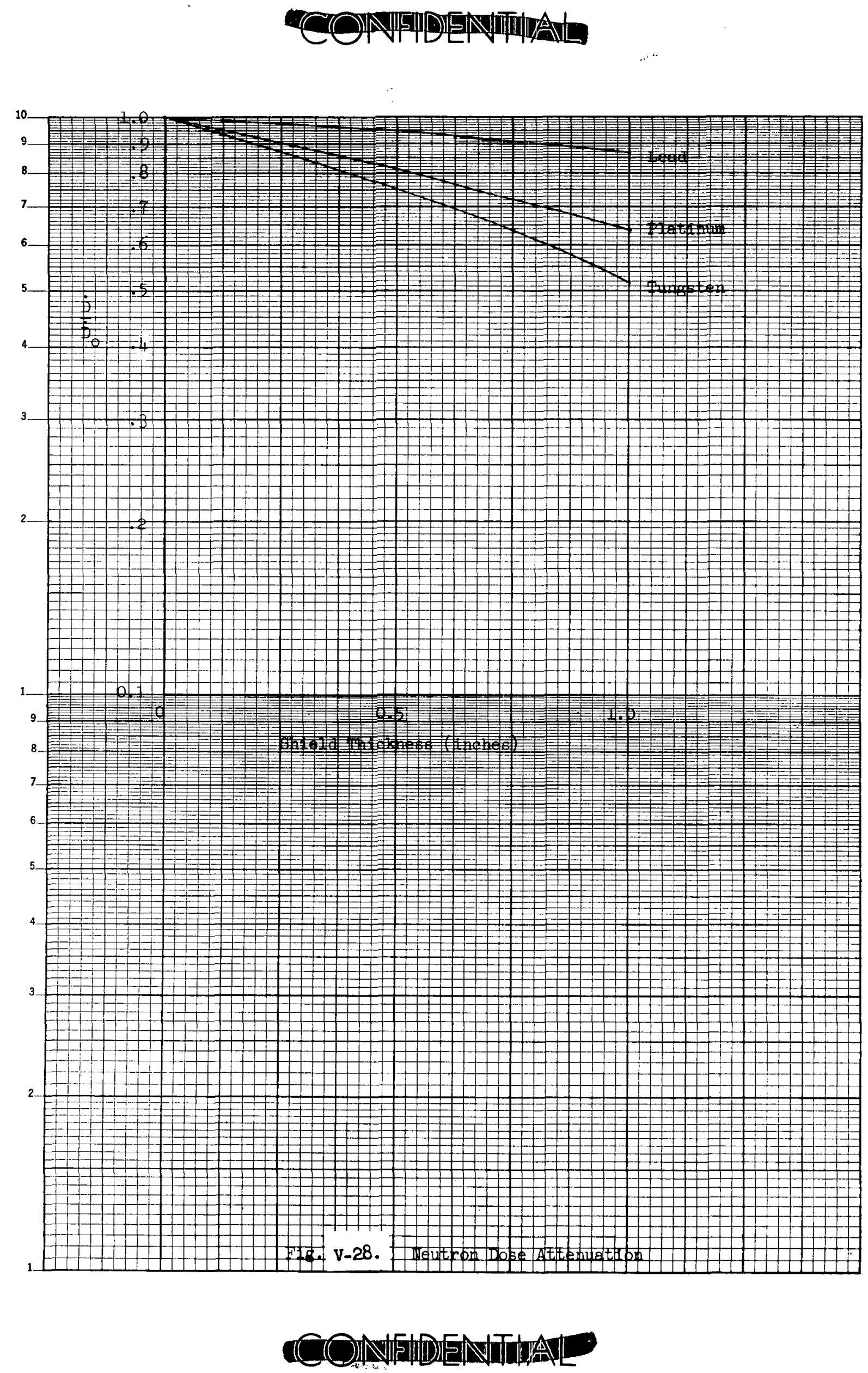
FIG. Z- 29

RADIATION DOSE RATES

FOR VIKING TWIN-RTG INSTALLATION

ISODOSE CURVES ARE SYMMETRIC

ABOUT BOTH AXES
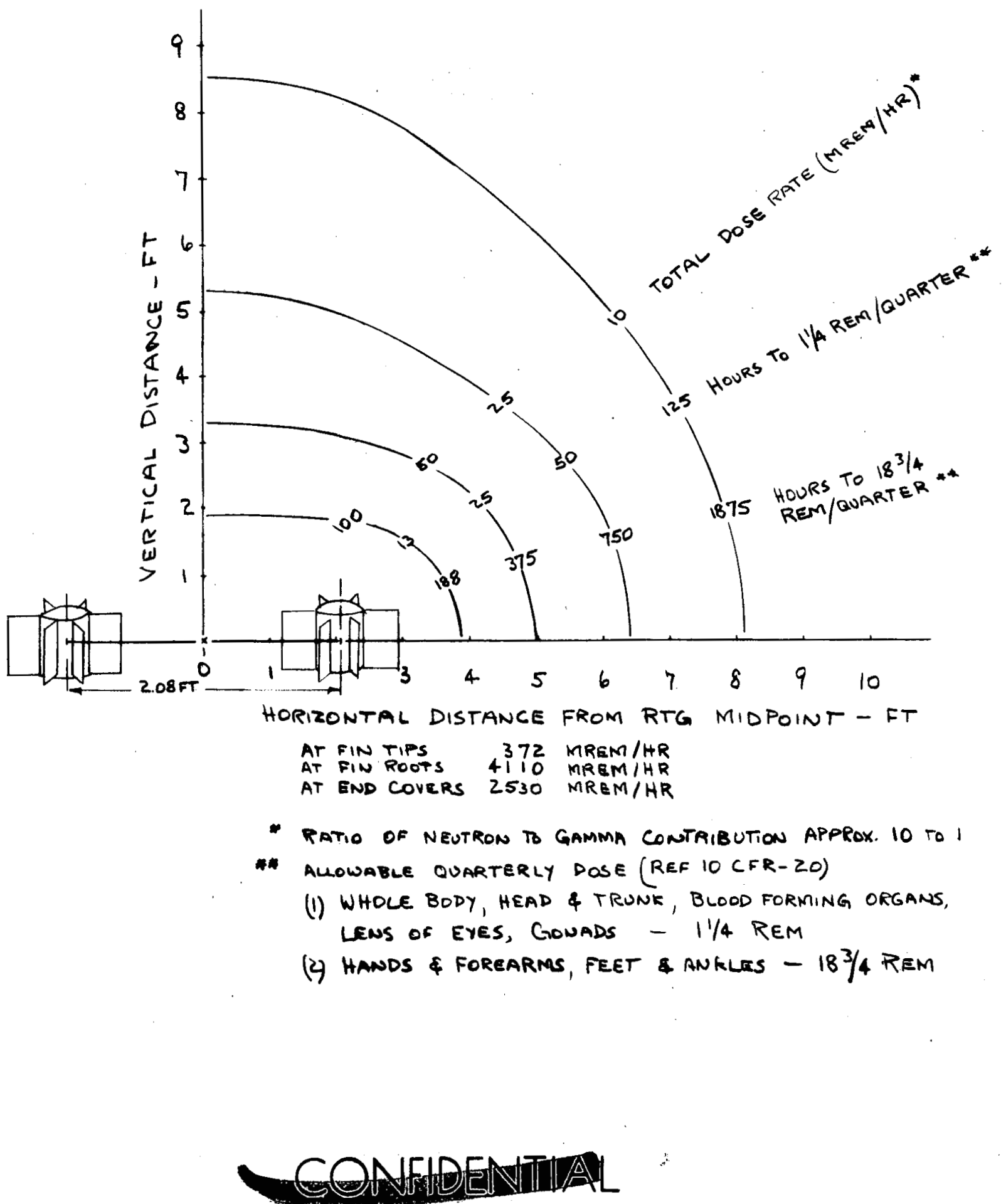
FIG, $\mathbf{Z}-30$

Radiation dose Rates

FOR VIKING FOUR-RTG INSTALLATION

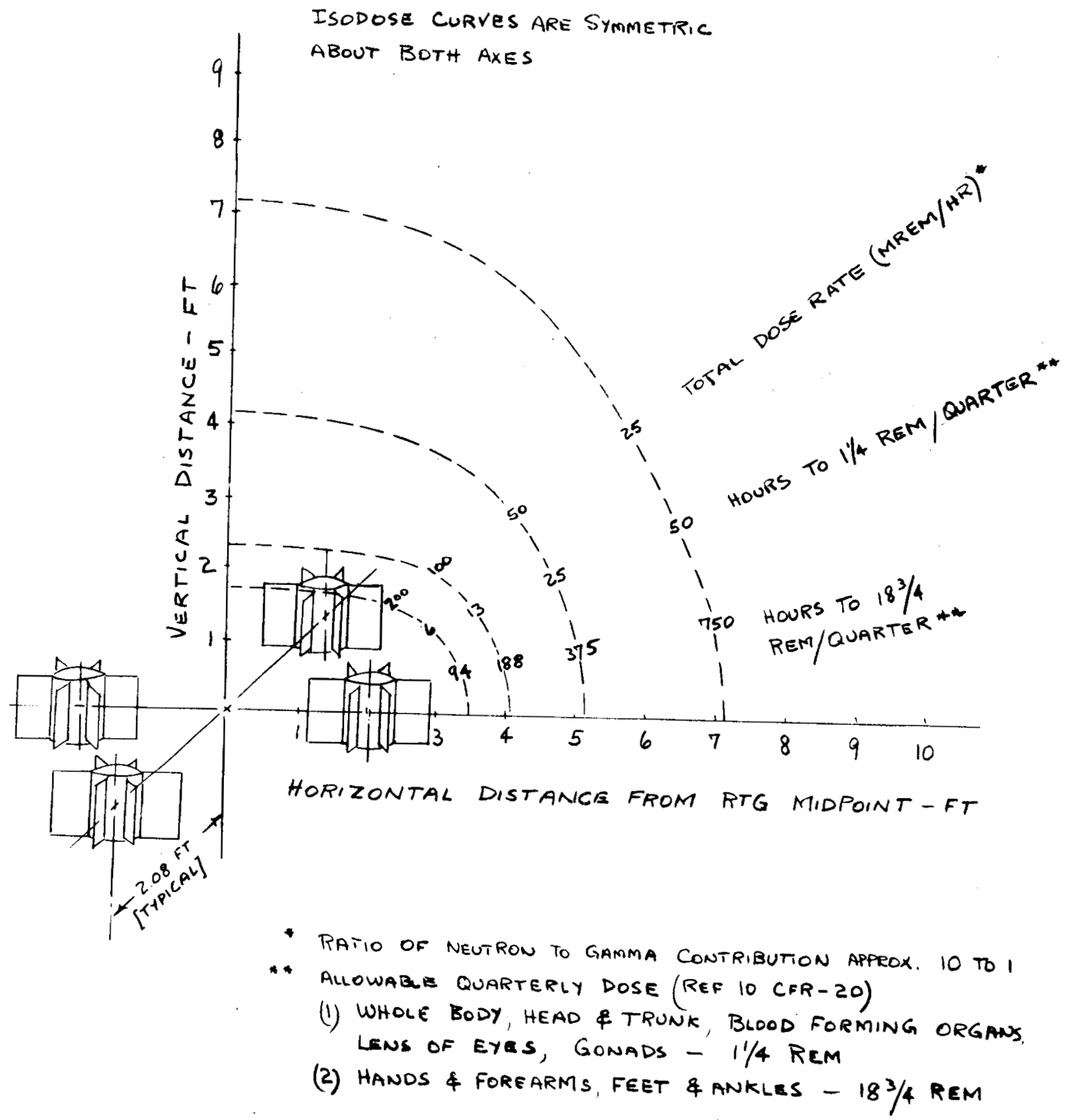


tingency for delayed launch may require criteria revisions. Allowable working times for these two criteria are shown in the figures for each isodase curve.

Dose rates may be reduced considerably by the use of temporary shielding. For example, the placement of 5 inches of polyethylene between the source and the work area will reduce the neutron dose rate by a factor of 0.15 and the gamma dose rate by a factor of 0.6 (from Figs. V-25 and V-27).

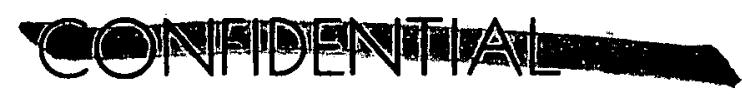

INSD-2650-29

$\mathrm{V}-82$ 


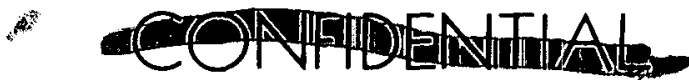

\section{E. MAGNETICS}

The magnetic field of an RTG exerts two effects on spacecraft performance: (1) the field may interfere with experiment sensors such as magnetometers and (2) interaction of the RTG field with other magnetic fields in space may yield a torque which must be compensated to preserve spacecraft orientation. Since the field strength and magnetic moment constraints are in general, very restrictive, measurements of these levels in the presence of extraneous fields (such as exist on earth) are subject to uncertainty, thus experimental determination of the RTG characteristic is very difficult. Nevertheless, facilities such as the Goddard Magnetic Test Facility and Jet Propulsion Laboratory have attempted such measurements.

In addition to experimental data, theoretical depictions of the SNAP 19 generator configuration are presented to yield basic characteristics such as attenuation dependance upon distance and magnetic moment. Before presenting the results of these calculations and comparison with experiment, a brief discussion of units, equivalent circuits, and general generator configuration is given.

1. Units

The basic electromagnetic units in this discussion are for the cgs system, where the permeability $\left(\mu_{\mathrm{v}}\right)$ of free space (vacuum) is taken as unity and electrical quantities are labeled abamperes and abvolts. The unit of magnetic induction or flux density (B) is the gauss, and its surface integral ( $f l u x)$ is the maxwell. One other quantity is necessary, the magnetic intensity or field strength (H) labeled the oersted. This

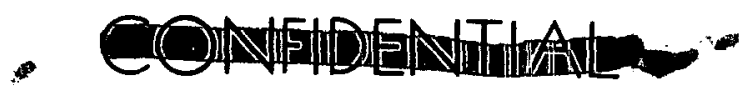


leads to the definition of the gamma $(\gamma)$ which is an intensity of $10^{-5}$ sersted. Consequently, in this system where $\mu_{V}=1, \beta_{F}=\mu_{v i} H=H$ and B may be expressed in gamma units also.

The magnetic moment of a current loop (or magnet) is a measure of the maximum torque exterted in a magnetic field in vacuum. A magnetic dipole moment is a mathematical entity which is the product of one of the two dipole charges by the very small distance separating the two charges. Since one of the characteristics of the dipole is a potential proportional to the inverse square of distance (and hence from a magnetic dipole a field proportional to the inverse cube) one must be careful in ascribing a purely. dipole moment to an arbitrary circuit whose characteristics may not be primarily dipoles. A non-dipolar example below is the equivalent circuit of two SIAP 19 generators stacked with opposing current flow. In any event, the cgs magnetic moment has the unit dyne-cm/oersted or in basic magnetic notation is the product of unit poles acting at one centimeter $\left(\right.$ pole-cm). In this discussion, the moment unit will be $\gamma-\mathrm{m}^{3}$ where for conversion purposes, pole-cm $=10\left(\gamma-\mathrm{m}^{3}\right)$.

2. Equivalent Circuit of RTG

The current path in a SNAP 19 is a complicated, three-dimensional arrangement requiring much computational effort to precisely calculate the magnetic field. The formulation of such a procedure using computer technique is currently underway, but results are not available for this report. Therefore, in order to provide a tractable hand calculation method the simplified circuit depicted in Fig. V-3I was formulated for single and double generator arrays. In practice, actual wire lengths

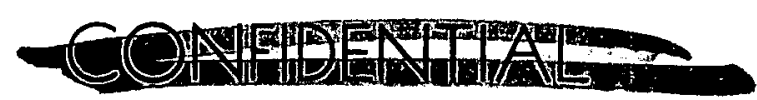

INSD-2650-29

$\mathrm{V}-84$ 


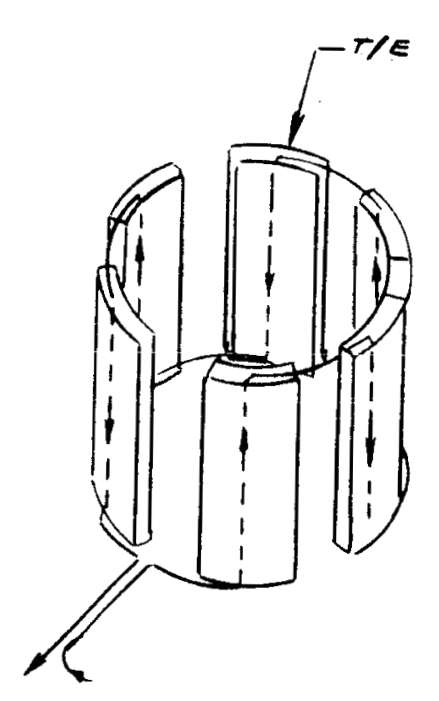

SINGLE GENERATOR
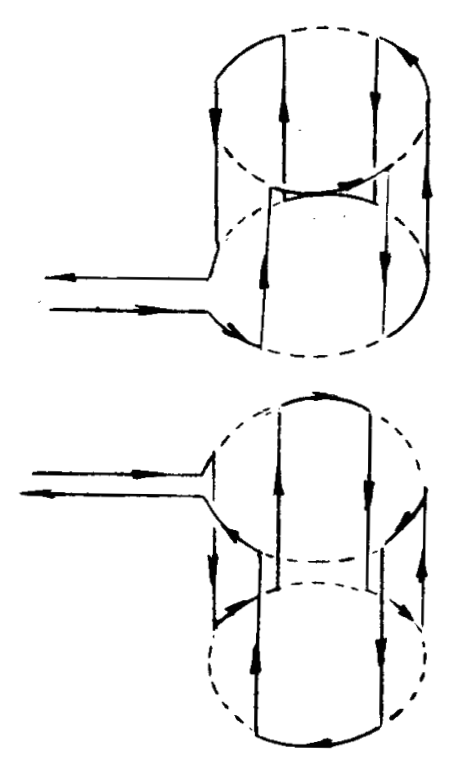

DOUGLE GENERATOR CIPCUIT LOOP

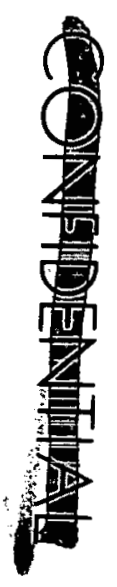




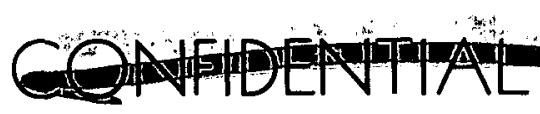

which are chords of the circle insibead of arcs are used at the top and bottom and the effective fractional loop length is approximately 0.5 for the latest SNAP 19 design.

The formulae used for the radial and tangential loop contributions in the directions of increasing $r$ and $\theta$, are

$$
\begin{aligned}
& F_{r}=\frac{\text { IAf }}{\left(a^{2}+r^{2}\right)^{3 / 2}} \operatorname{cós} \theta \\
& H_{\bar{\theta}}=\frac{\text { IAf }}{\left(a^{2}+r^{2}\right)^{3 / 2}} \sin \theta
\end{aligned}
$$

where $I=$ current in abamperes

$\mathrm{a}=100 \mathrm{p}$ diameter in $\mathrm{cm}=12.4 \mathrm{~cm}$

$A=100 p$ area in $\mathrm{cm}^{2}$

$r=$ distance from center of system to the observer and $F$ is vector from center to observer

$f=$ fractional loop length

$\theta=$ angle between vertical axis and observer

a. Single generator field

The single generator, being represented by two loops whose currents move in the same direction (complementing), exhibits the following intensity component along its vertical(Z) axis, where the origin is at 
the center of the RTG.

$$
\begin{aligned}
H_{Z}(Z) & =\frac{2 \operatorname{IAf}}{10}\left[\frac{1}{\left[(z-7.6)^{2}+a^{2}\right]^{3 / 2}}+\frac{1}{\left[(z+7.6)^{2}+a^{2}\right]^{3 / 2}}\right] \\
& \approx \frac{\operatorname{2IAF}}{10}\left[\frac{1}{(z-7.6)^{3}}+\frac{1}{(z+7.6)^{3}}\right] \approx \frac{2 I A f}{5 z^{3}}
\end{aligned}
$$

where $I$ is now in amperes.

However, in the direction perpendicular to its vertical axis the vector sum of radial and tangential components from the loops yields a vertical (Z) resultant only as illustrated in Fig. V-32(a).

This vertical resultant is given by:

$$
\mathrm{H}_{\mathrm{Z}}(r)=2 \mathrm{H}_{\theta} \cos \boldsymbol{\alpha}-2 \mathrm{H}_{r} \sin \alpha
$$

Noting that $\sin \alpha=\cos \theta$ and $r_{1}=r_{2}$ yields

$$
\mathrm{H}_{Z}(r)=\frac{\text { IIAf } \cos ^{2} \alpha}{10\left(r_{1}^{2}+a^{2}\right)^{3 / 2}}-\frac{\text { 4IAf } \sin ^{2} a^{3 / 2}}{10\left(r_{1}^{2}+a^{2}\right)^{3 / 2}}
$$

which after substituting the appropriate trigonometric relationships yields:

$$
\mathrm{H}_{Z}(r)=\frac{\operatorname{IAF}}{5}\left[\frac{r_{1}^{2}-3(7.6)^{2}}{\left(r_{1}^{2}+a^{2}\right)^{3 / 2} r_{1}^{2}}\right] \approx \frac{\text { IAf }}{5 r^{3}}
$$

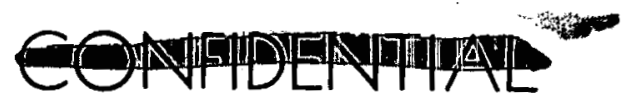




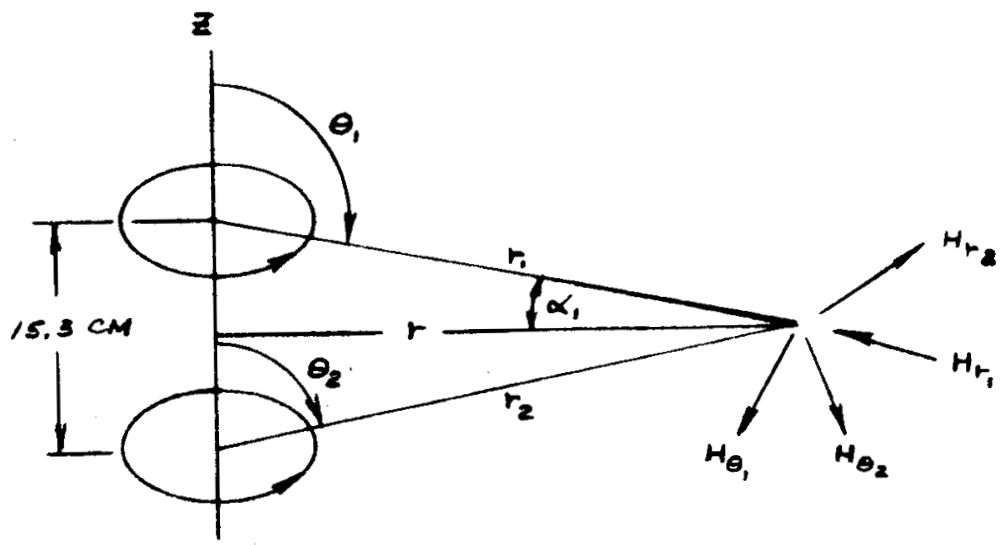

Elgure ㅍ. $-32(a)$

MAGNETIC VECTOR CONVENTION TOR SINGLE GENERATOR

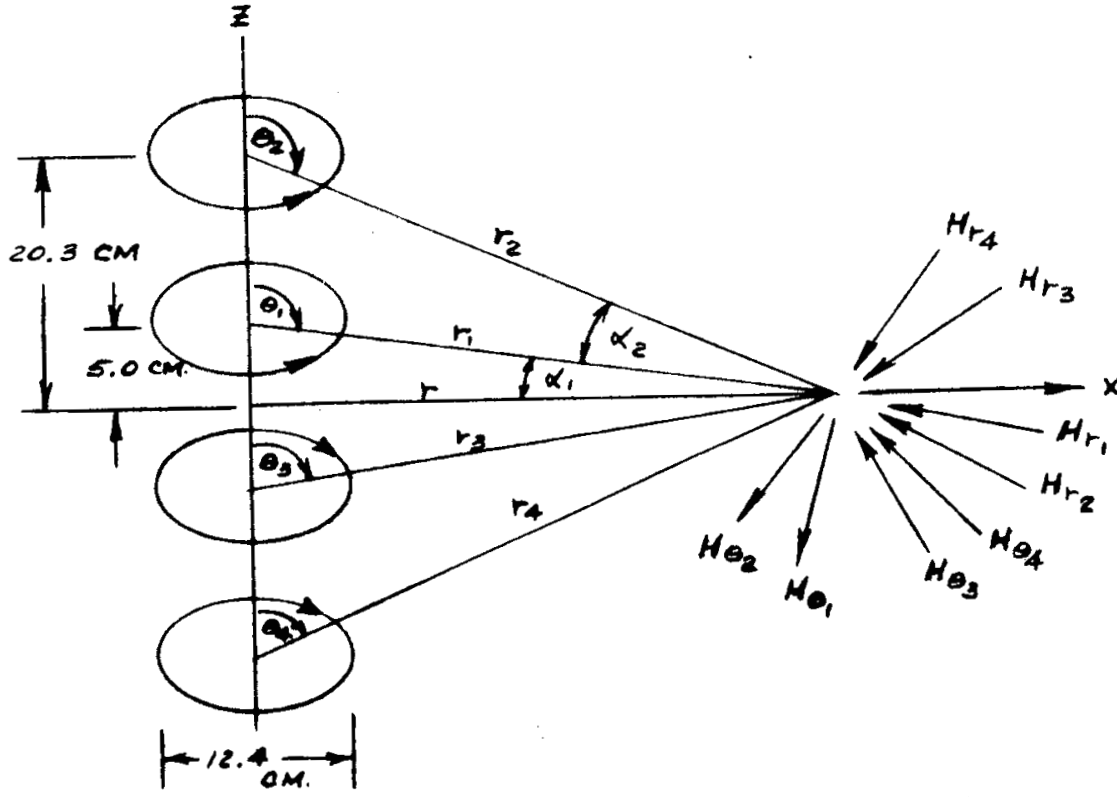

aiguar I.32(b)

MAGNETIC VECTOR CONVENTION FOR DOUELE GENERATOR

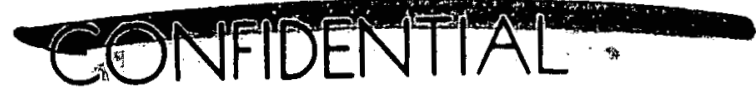

IIISD-2650-29

V -88 
For a single RTG, the equivalent dipole moment, ${ } Z$, is given by:

$$
M_{Z}=\frac{I A F}{5} \approx H_{Z}^{(x) x^{3}} \approx \frac{H_{Z^{(Z) ~} z^{3}}}{2}
$$

and its cgs units are pole-cm.

Note that since $\mathrm{H}_{Z}(r)$ and $\mathrm{H}_{Z}(Z)$ are inverse cube functions at large distances, $M_{Z}$ remains approximately a constant.

\section{b. Double generator field}

Formulation of the double generator equation proceeds as with the single generator, but with two additional current loops opposing the previous pair (see Fig. V-32(b)). Thus, taking the origin at the new system center, the vertical axis intensity is:

$$
H_{Z}(Z)=\frac{2 \text { IAf }}{10}\left[\frac{1}{(Z-20.3)^{3}}+\frac{1}{(z-5.0)^{3}}-\frac{1}{(Z+5.0)^{3}}-\frac{1}{(z+20.3)^{3}}\right]
$$

Although the equation is of similar form to the single loop pair case, the subtracting terms cause a $1 / \mathrm{Z}^{4}$ variation of $\mathrm{H}$ at large distances. This can be verified readily by taking a binomial expansion of each term and noting that the $1 / \mathrm{Z}^{3}$ terms cancel and the $1 / \mathrm{Z}^{4}$ terms predominate at large $\mathrm{Z}$.

The perpendicular axis vector sum is also somewhat more complicated than for the single pair. For this case, the vertical component ( $Z$ ) vanishes, yielding only a horizontal $(\mathrm{X})$ direction field.

$$
\mathrm{H}_{\mathrm{x}}=2 \mathrm{H}_{\mathrm{r}_{1}} \cos \sigma_{1}+2 \mathrm{H}_{\mathrm{r}_{1}} \cos \alpha_{2}+2 \mathrm{H}_{\theta_{1}} \sin \alpha_{1}+2 \mathrm{H}_{\theta_{2}} \sin \alpha_{2}
$$

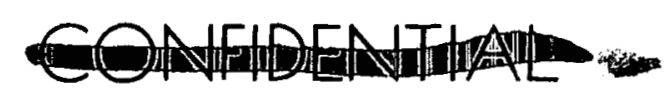


which after much algebra yields:

$$
H_{x}=\frac{6 \text { IAf }}{10} r\left[\frac{5}{\left(r^{2}+25\right)^{5 / 2}}+\frac{20.3}{\left[r^{2}+(20.3)^{2}\right] 5 / 2}\right]
$$

It is apparent that this equation also exhibits a $1 / \mathbf{r}^{4}$ behavior at large $r$. 3, Evaluation of Experimental and Calculational Results

a. Experimental results

Measurements of the magnetic fields and magnetic moments of single and double generator configurations have been performed in detail at the Goddard Magnetic Test Facility and at the Jet Propulsion Laboratory. At Goddard, a relatively field-free environment is provided by a 42-foot diameter tri-axial Braunbek coil system. A sevenfoot diameter region at the center exhibits $.001 \%$ uniformity in an external field of $60,000 \gamma$ while $0.1 \%$ uniformity exists over a 22 -foot diameter region. The Jet Propulsion Laboratory does not possess this field compensating arrangement, but careful magnetic field measurements were made in an East-West Earth direction and mathematical analysis of the results performed.

The tests of a 2P/2N SNAP 19 double generator subsystem (Subsystem 2) at Goddard have revealed that the power conditioning unit (PCU) is a major contributor to the magnetic field and magnetic moment of such an arrangement. The fact that from sixty to eighty percent of the magnetic field emanates from the PCU makes the results of previous measurements of double RTG arrangements of little value in determining

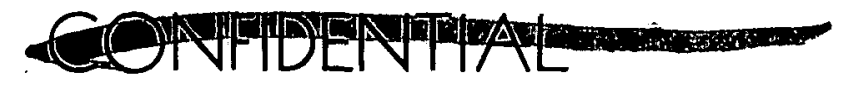

. INSD-2650-29 
the field produced by the RTG's alone. This finding has prompted an expanded test plan on Subsystem 2 to enable determination of the fields produced by the double generator configuration as well as from individual SNAP 19 units. As of this writing, measurements have just begun and results are not yet available.

At JPL, a single SNAP 19 generator (S/N 21) was studied and its equivalent dipole magnetic moment determined. It was found that a moment of about $18 \gamma-$ meter $^{3}$ is exhibited by a flight unit. Interestingly, this value is about $60 \%$ of the total $\mathrm{S} / \mathrm{N} 21$ measurement of $30 \gamma-\mathrm{m}^{3}$ which includes the effect of the steel heater core not present in a flight system. This finding lends support to the desire for future measurements at Goddard without extraneous, non-flight components such as the PCU, electrical heater, and other accessories of the test system.

b. Calculational results and comparison with measurements

The calculated fields and dipole moment for the original SNAP 19 design containing $2 \mathrm{P} / 2 \mathrm{~N}$ couples (on which measurements were made) as well as for the new SNAP 19 containing TAGS-85/2N couples is presented in Table V-10. The original SNAP 19 current at design power is $\sim 12$ amperes while that for the newer version is $\sim 15$ amperes. However, a compensating shortening of module interconnecting wires yields a net reduction in magnetic field for the TAGS-85/2N generator. The dipolar nature of a single generator is illustrated by the $1 / r^{3}$ dependence of field on distance. However, as stated previously, the double generator configuration cannot be represented by a single dipole, as evidenced by the $1 / 4^{4}$ variation of field with distance.

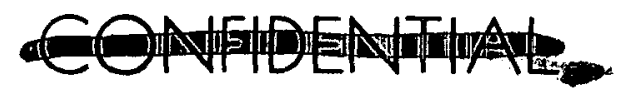

INSD-2650-29 
TABLE V - 10

MAGNETIC PROPERTIES OF SNAP 19 GENERATOR CONFIGURATIONS

A. Original SNAP $192 \mathrm{P} / 2 \mathrm{~N}-12$ amps $* * *$

\begin{tabular}{|c|c|c|c|c|c|}
\hline \multirow[b]{2}{*}{$\begin{array}{c}\text { Distance from } \\
\text { System Center } \\
\text { (m) }\end{array}$} & \multirow[b]{2}{*}{$\begin{array}{l}M_{z} \\
\left(\gamma-m^{3}\right) \\
\end{array}$} & \multicolumn{2}{|c|}{ ingle Generator } & \multicolumn{2}{|c|}{ Double Generator } \\
\hline & & $\begin{array}{l}\text { Mid-Plane } \\
\mathrm{H}(\mathrm{r}) \\
\text { (gamma) }\end{array}$ & $\begin{array}{l}\text { Axial } \\
H_{Z}(Z) \\
\text { (gamma) } \\
\end{array}$ & $\begin{array}{l}\text { Mid-Plane } \\
\mathrm{H}_{\mathrm{r}}(\mathrm{r}) \\
\text { (gamma) } \\
\end{array}$ & $\begin{array}{l}\text { Axial } \\
\mathrm{H}_{\mathrm{z}}(\mathrm{Z}) \\
\text { (gamma) }\end{array}$ \\
\hline & $20 .(18) *$ & & & & \\
\hline 1.0 & & 19. $(18) *$ & $40 .(38) *$ & .14 .1 & 35. \\
\hline 2.0 & & 2.5 & 5.0 & 0.92 & 2. 0 \\
\hline 4.0 & & 0.31 & 0.61 & 0.060 & 0.12 \\
\hline 10.0 & & 0.0201 .01 & 0.03910 & 0.0015 & 0.0030 \\
\hline
\end{tabular}

B. New SNAP 19 TAGS-85/2N - 15 amps ***

18. $(16) * *$

$\begin{array}{rllll}1.0 & 18 .(16 .) * * & 37 .(35 .) * * & 12.5 & 31.0 \\ 2.0 & 2.2 & 4.4 & 0.83 & 1.8 \\ 4.0 & 0.28 & 0.55 & 0.055 & 0.11 \\ 10.0 & 0.018(0.016) * * & 0.036(0.033) * * & 0.0013 & 0.0027\end{array}$

*JPL measurements

**JPL measurements adjusted for shorter module interconnecting straps

***F or RTG's on short circuit, the values shown are approximately doubled 
Comparison of calculational results with the experimental data for a single generator (also shown in Table $\mathrm{V}-10$ ) yields excellent agreement. This lends confidence to the analytical model for the double generator configuration as well. Apparently, the main contribution to the field is from the horizontal partial current loops.

c. Summary of results

The measurements and calculations show that both the single and double SNAP 19 flight configurations yield magnetic fields of less than 0.05 gamma at 10 meters from the system in any direction. Moreover, the $1 / r^{4}$ dependence for the double generator arrangement assures much lower field contribution than from a single generator at distances greater than 2 meters. It should be noted also that for both configurations the magnetic field along the vertical axis is about twice that along the transverse direction.

\section{Conclusion}

It has been determined that the magnetic field from a degaussed SNAP 19 flight generator arises primarily from current flow. Further, the absence of significant induced field contributions indicates that the present materials of construction are satisfactory.

Other significant findings concern spacecraft auxiliary equipment such as the power conditioning unit and the necesisity for degaussing to remove induced magnetization incurred during exposure of the generator to very high magnetic fields such as from vibration testing machines. The power conditioning unit used in the SNAP 19 Nimbus application

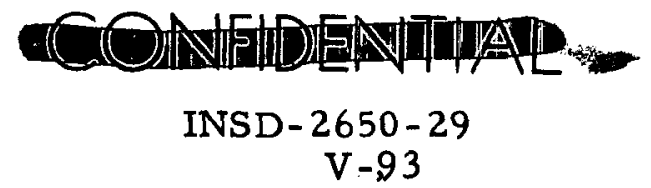


contributes more magnetic field than the two generators. This fact illustrates the necessity of examination and special design of all spacecraft current carriers to preserve magnetic integrity. One must conclude that the use of a SNAP 19 on a spacecraft involves total integration with the magnetic constraints applied so that an optimum arrangeme nt can be obtained without undue penalty to particular components.

The preceding results of generator magnetic properties will be amplified by future measurements of flight and mock-up units. As stated, detailed experiments are planned at the Goddard Magnetic Test Facility which will yield more information on single and double generator arrays. At present no magnetic limitations have been imposed on the Viking RTG, and no conclusions as to the acceptability of the numbers given herein are possible. 


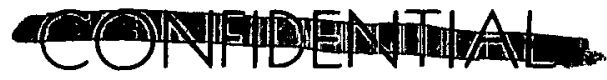

F. GROUND HANDLING

The ground handling of RTG's presents two distinct personnel safety considerations. The first involves normal safety precautions associated with the handling of hardware weighing in excess of $50 \mathrm{lbs}$. and having a surface temperature greater than $200^{\circ} \mathrm{F}$ under normal ambient conditions. The second covers ionizing radiation exposure. Radiological safety imlies minimizing the radiation dose absorbed by personnel. Since the radiation from a fueled RTG exists continuously, the primary methods of minimizing the personnel dose rates are:

a. Shield the source whenever possible.

b. Work as far from the source as practical since the dose rate diminishes rapidly with distance from the source.

c. Do not remain in a radiation area any longer than required to perform a specified work function.

d. Rehearse handling procedures using a non-fueled RTG to minimize the time required to perform each operation.

Health physics safety programs should be established at the spacecraft integrator's facility and at the launch site (Ref. V-1). These programs should incorporate a training program for all personnel who will be involved with handling the RTG's, the participation in formulating test and handling procedures to incorporate health physics operations and considerations, and the normal protection mechanisms such as dose rates and contamination surveys, air-monitoring, and personnel metering.

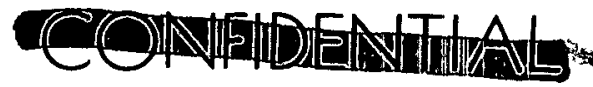

INSD-2650-29 


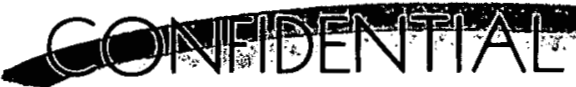

In addition to the radiological safety program, detailed handling procedures should be prepared with the cooperation of the spacecraft integrator, the RTG supplier, the AEC and NASA to cover all handling operations at the integrator's facility and at the launch site. At the integrator's facility these would include:

(a) Receiving an RTG from an external shipper.

(b) Storage of the RTG (including monitoring procedures).

(c) Movement of the RTG within the integrator's facility.

(d) Shipping of the RTG to an external receiver.

Typical handling procedures that would be required at the launch site are:

(a) Receipt and storage of the RTG's.

(b) Installation of the RTG's on the Viking Lander Capsule (VLC).

(c) Subsequent operations with the RTG's installed.

(d) Removal of the RTG's from the VLC if required.

These procedures should include identification and administration of health physics operations, RIG handing restraints, and emergency procedures.

A significant portion of the ground handling equipment which was built for SNAP 19 Nimbus B could be utilized for the Viking program with little or no modification. Table V-ll itemizes the ground handling equipment used on the Nimbus program and lists the modification status required to utilize this equipment for the Viking program.

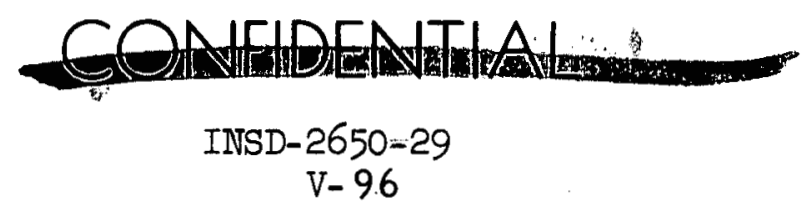


TABLE V-II

SNAP 19 NTMBUS GRרUND HANDLING EQUTPMENT

Component

Ground Support Test Console

P)wer Supply Rack

Fuel Capsule Shipping Cask

Generator Handling Adaptor

Mobile Carriage

M)bile Carriage Handling Sling

RTG Subsystem Shipping Container

ETG Subsystem Shipping Container

ETG Shipping Container

Shipping Pallet

Shipping Container Handling Sling

P)rtable Monitor Package
Status

Modification required (if used)

No modification necessary

Modification required

Modification required

Modification required

No modification necessary

Modification required

Modification required

Modification required

No modification

necessary

No modification

necessary

Modification required
Qty. Avail. (As of $5 / 20 / 69$ )

3

1

3

3

3

1

2

0

0

2

2

2

A summary description of these ground handling items follows. A complete description can be found in Ref. V-2.

1. Ground Support Test Console

The ground support test console (GSTC) shown in Fig. V-33 contains all the equipment necessary for complete functional testing and monit ring of the SNAP 19 system. The GSTC capability includes:

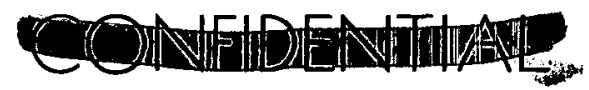

NSD-2650-29 

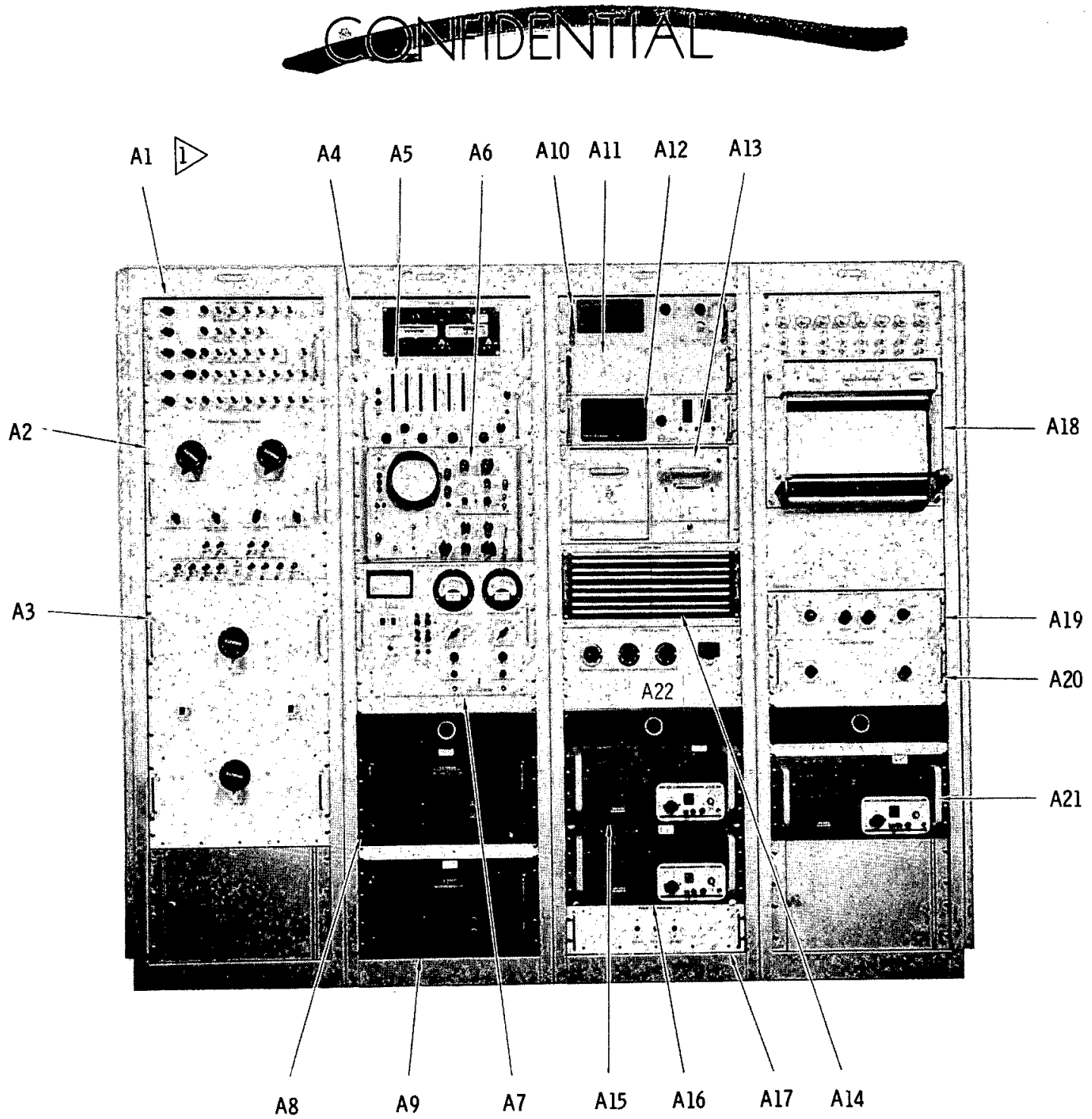

Al Telemetry Test Panel

A.2 Power Conditioner Test Panel

RTG Load Panel

Ditital Clock

Universal Eput and Timer

Oscilloscope

Heater Power Supply Control Panel

Regulated Power Supply

Regulated Power Supply

AlO Digital Voltmeter

Al1 Input Converter

Al2 Input Scanner

Al3 Data Printer

Al 4 Monitor Panel

A15 Power Supply

Al6 Power Supply

Al7 Power Distribution Panel

Al8 Recording System

Al9 Variable Power Control Panel

A20 Bus Power Control Panel

A21 Power Supply

A22 AC Receptacle Panel

Fig. V-33. Ground Support Test Console

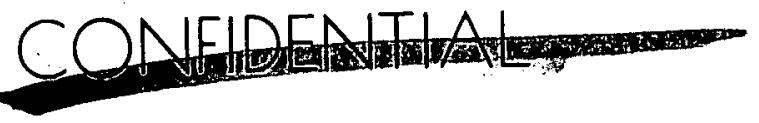


(1) Testing of the power supply subsystems (e.g. RTG, DC-DC converter) either individually or collectively.

(2) Testing of the power supply system either as a whole or with one or more subsystems simulated.

(3) Calibration of the telemetry unit.

(4) Monitoring of power supply system performance.

Consisting of four racks of equipment integrated to form a single unit, the GSTC is mounted on casters for limited mobility. The console is designed for indoor use in a protected, area, such as a launch complex assembly building or an industrial environment. Current Viking requirements do not dictate a need for the GSTC. However, if required, the GSTC would require minor modifications to be useful in monitoring the RTG's and system qualification and acceptance tests.

\section{Power Supply Rack}

The caster-mounted power supply rack is smaller and more mobile than the GSTC and provides a convenient method of supplying power to electrically heated generators (ETG's). The rack is used when ETG's are tested individually. To use the power supply rack, the power supply panel (A15, Al6, or A21) and the heater power supply control panel (A7) are removed from the GSTC and installed in the rack, as illustrated in Fig. V-34.

\section{Fuel Capsule Shipping Cask}

The fuel capsule shipping cask is used to transport the heat source from the Monsanto Research Laboratory fueling facility in Miamisburg, Ohio, to the Isotopes, Inc., plant in Middle River, Maryland. The cask ensures

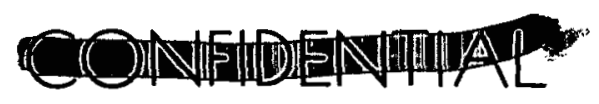

INSD-2650-29 

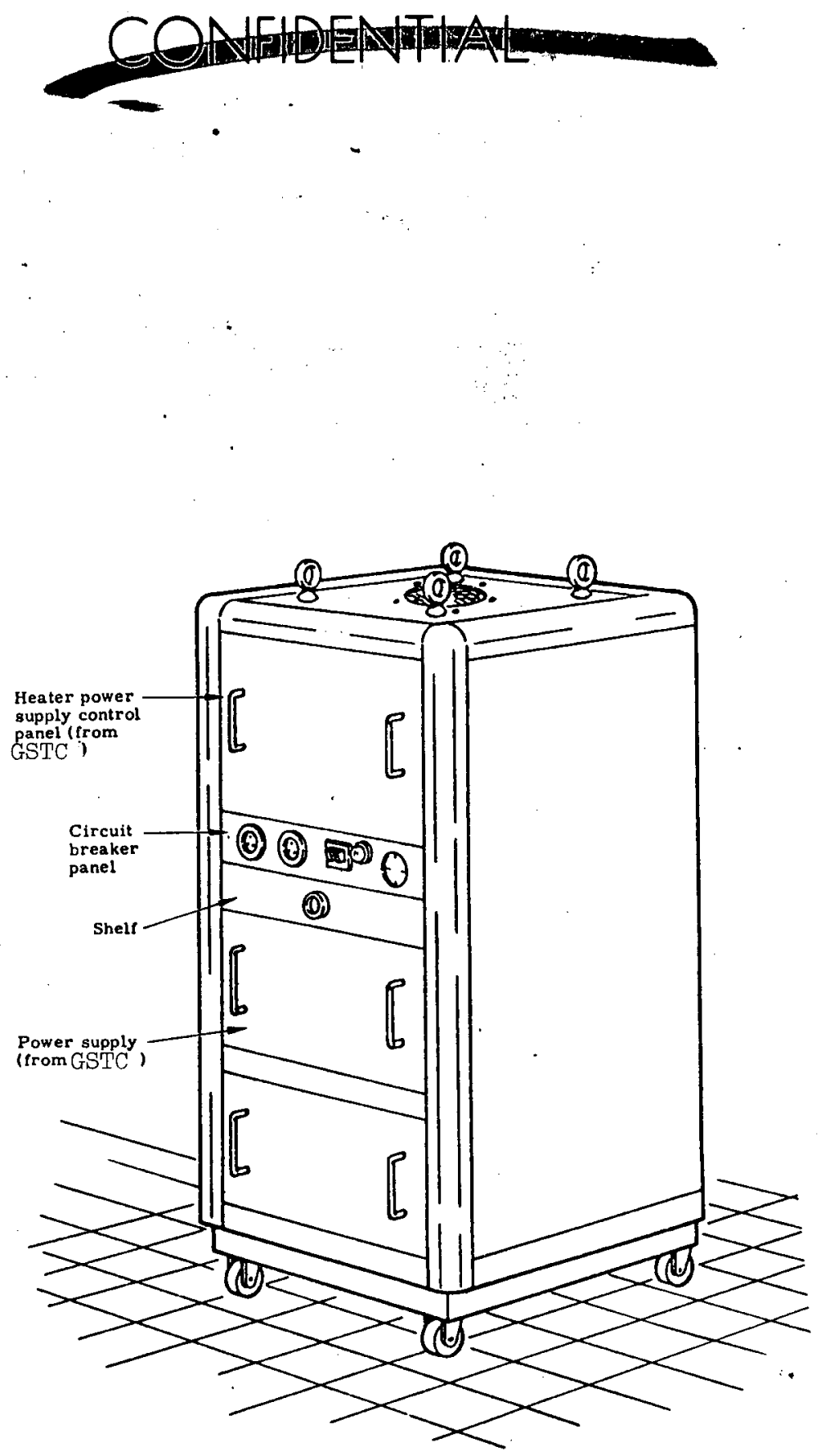

FIG. V-34. Power Supply Rack Arxangement 
safety during transportation and meets the requirements of $\mathrm{AEC}, \mathrm{B} \cap \mathrm{E}$, DOT, and ICC. In addition to maintaining an inert atmosphere around the oxidation susceptible heat source, the cask allows sampling of the inert blanket gas. A cutaway view of the present IRHS shipping cask is shown in Fig. V-35. Natural convective cooling is sufficient to maintain fin root temperatures at $90^{\circ} \mathrm{F}$ in $70^{\circ} \mathrm{F}$ ambient air. Modifications required to adapt to the larger intact impact heat source (IIHS) which is planned for the Viking mission include reworking the stainless steel primary container, boring a larger hole in the aluminum cask body biological shield to accept the enlarged container, and modifying the shielding to further attenuate the fast neutrons.

4. Generator Handling Adaptor

The generator handling adaptor is required for lifting an individual generator or generator stack. A quick release handling adaptor interfaces between the generator and the adaptor to reduce exposure times around fueled units to a minimum.

5. Mobile Carriage and Handling Sling

The mobile carriage (see Fig. V-36) is a lightweight dolly for inplant transporting both RTG's and ETG's between working areas, and for storage of ETG's. The carriage consists of a protected mounting for the generator and a lower shelf for the battery-powered heater power control assembly used with ETG's. ETG's are moved in the heated condition to minimize thermal cycling. The heater power control assembly supplies 1140 watts of heater power for at least 30 minutes. Minor modifications would alter the mounting structure to the Viking configuration.

The mobile carriage handing sling facilitates lifting the carriage

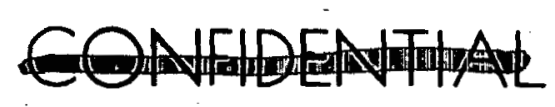




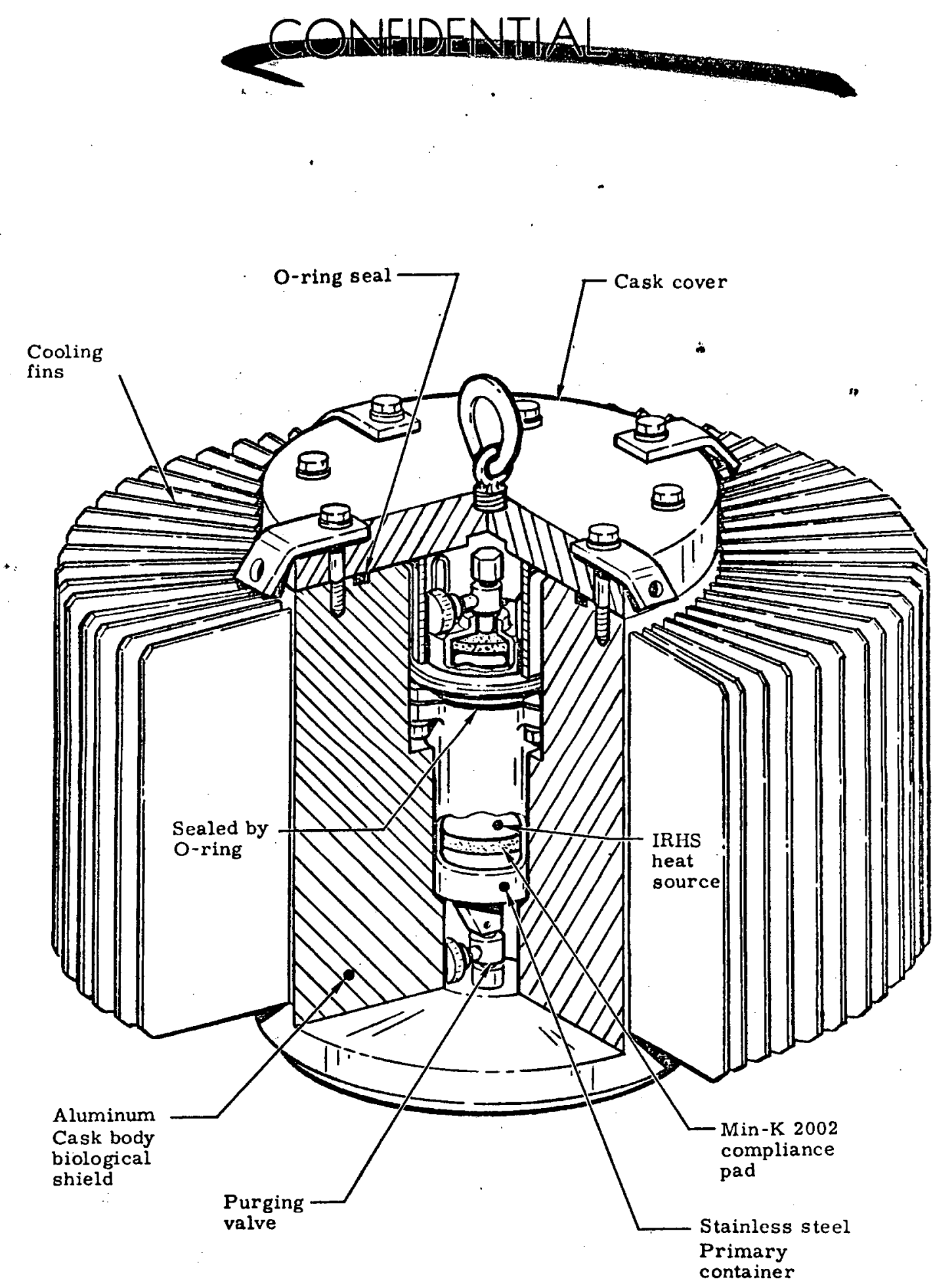

FIG. $V-35$. CUTAWAY VIEW OF IRHS SHIPPING CASK

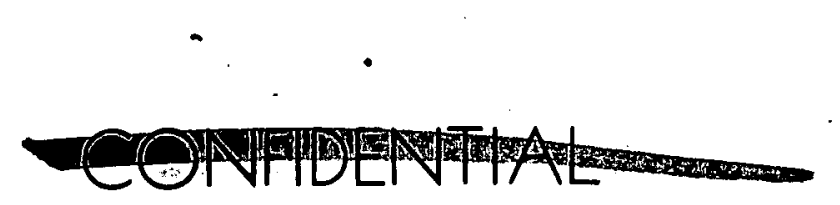




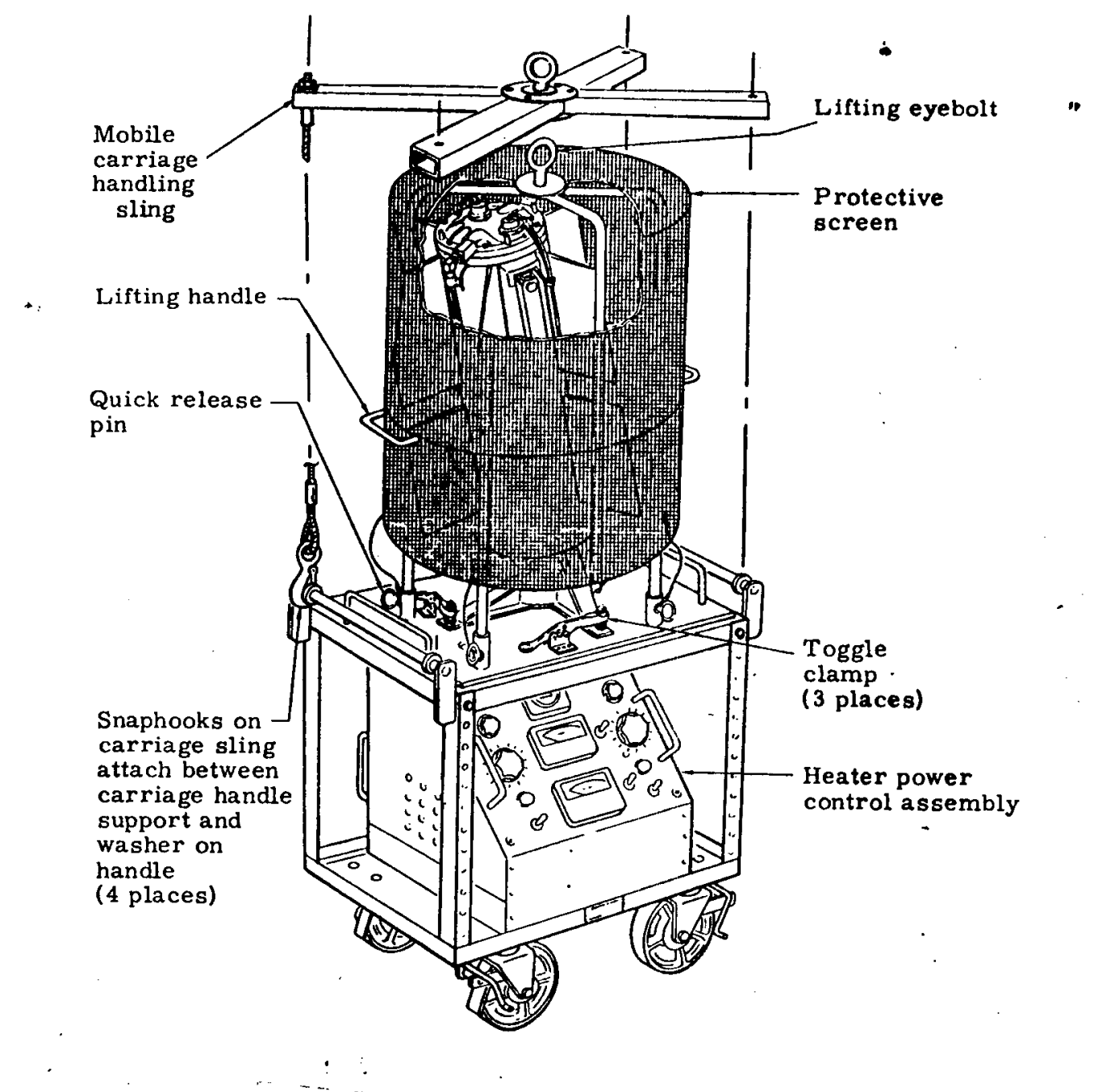

FIG. $\mathrm{v}$-36. MOBILE CARRIAGE ARRANGEMENT
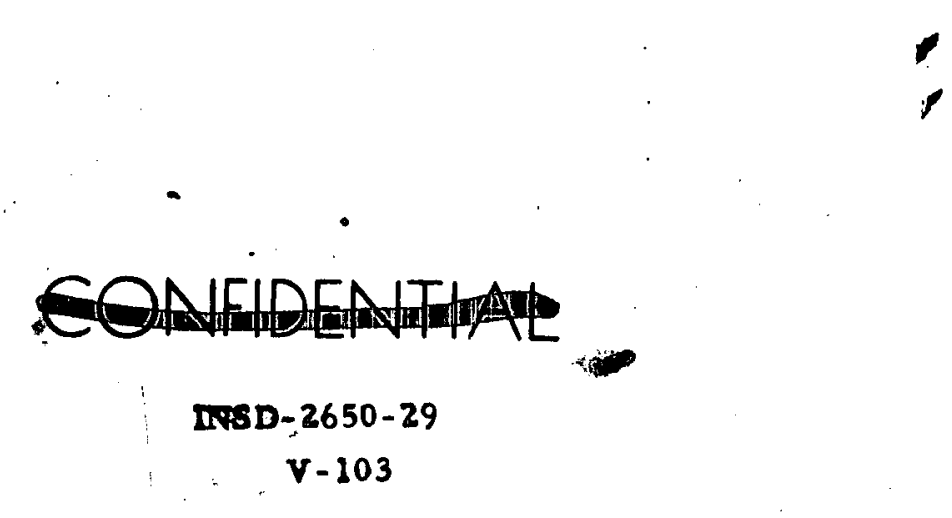


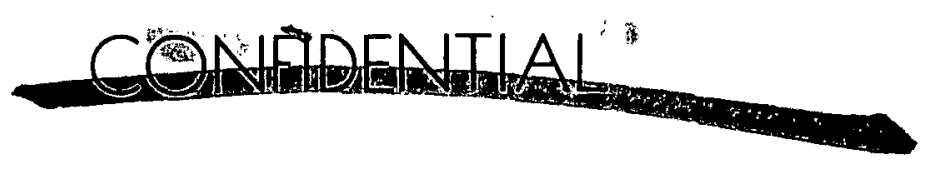

with an installed RTG from ground level. The sling is attached to the mobile carriage handles at four points and has a single point pickup attachment for an overhead crane hook. 6. RTG Subsystem Shipping Container

The RTG subsystem shipping container (see Fig. V-37) provides the necessary protective shipping enclosure and ionizing radiation shielding for shipping and storing an RTG subsystem. The container meets applicable $\mathrm{AEC}, \mathrm{B} O \mathrm{E}, \mathrm{DOT}$, and ICC regulations and specifications. The pallet mounted unit consists of an aluminum encased paraffin shield, which is crenelated circumferentially top and bottom to permit natural convective cooling of the RTG. Minor modifications to the RTG mounting structure and the electrical junction box will be required for Viking usage.

The shipping container handling sling is used to lift the shipping container when a fork lift truck is unavailable, to lift the container from the shipping pallet for limited mobility of the caster mounted shipping container, and to lift the shipping container shield body from the base for installation or removal of an RTG.

\section{ETG Shipping Containers}

A rectangular wooden box is the ETG shipping container. It is approximately 33 inches square at the base by 4 feet high. Attached to the bottom of the container are rugged wooden skids that permit handling by fork lift truck. The ETG is shipped cold. ETG mounting structure modification is required for the Viking application.

\section{Portable Monitor Package}

Each SNAP 19 RTG and ETG will, at a minimum, be instrumented to monitor

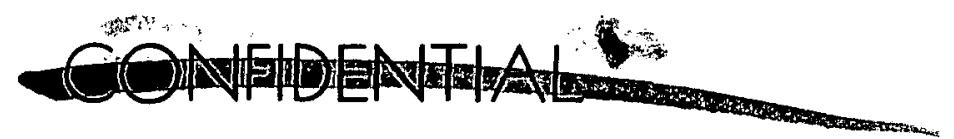



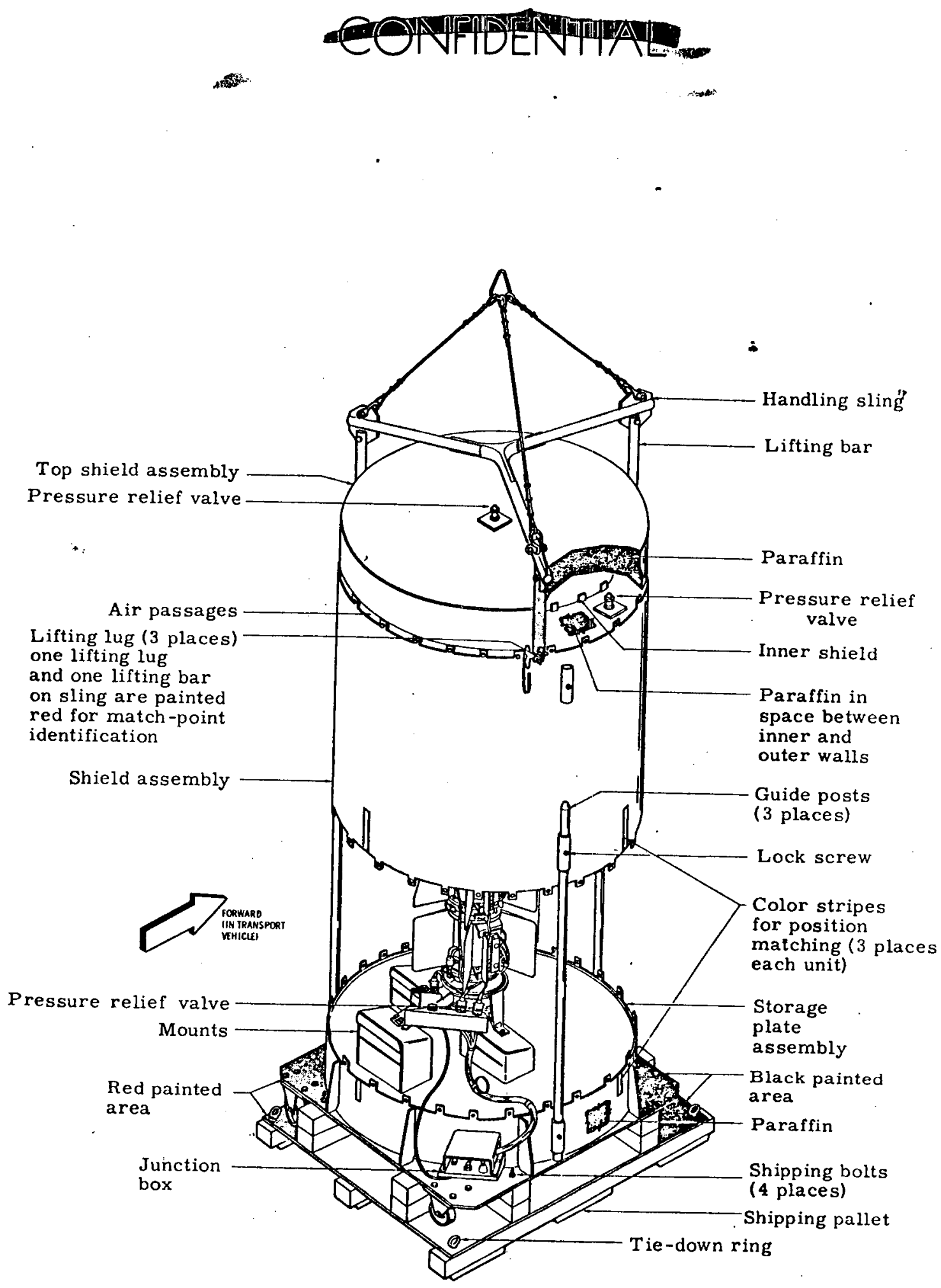

FIG. V-37. INSTALLATION OF GENERATOR SUBSYSTEM IN SHIPPING CONTAIN

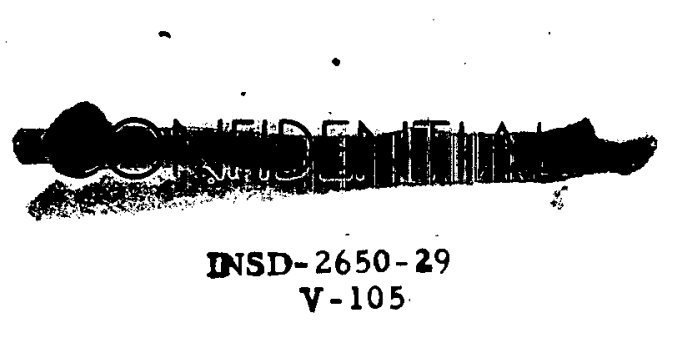




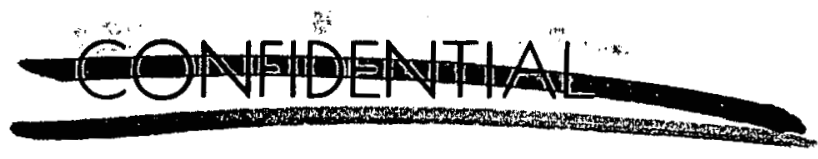

temperatures, voltage, and current. The portable monitor package contains suitable instrumentation to monitor these parameters and thus verify the generator status. The portable monitor package is used during transportation and storage of the RTG and is useful in monitoring RTG and/or ETG performance in bench tests, breadboard tests, and other engineering tests. Minor modifications may be necessary for Viking usage pending selection of desired instrumentation.

Transportation and handling procedures were prepared for the SNAP 19 Nimbus program. These procedures (Refs. V-3, V-4, V-5 and V-6) are applicable to the Viking program and will be useful to the spacecraft integrator and the launch site in preparing their handling procedures.

For long-term storage of a fueled generator, the shipping container must be kept in a biologically shielded area as specified in Ref. V-7. Also, this area must meet $A E C$ security requirements. It is also recommended that the RTG temperatures be monitored and recorded on a regular basis during storage periods.

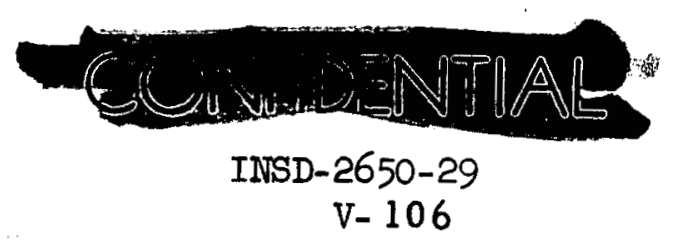




\section{RELIABILITY}

\section{A. PERFORMANCE CRITERIA}

\section{Objective}

The primary design objective for any spacecraft electrical power system is to maximize the probability of delivering a level of electrical power that will assure the accomplishment of the greatest number of experiments throughout the life span and environments dictated by the mission. Many factors enter into the selection of such a power system and, thus, trade-off studies must be performed in order to select an optimum design. On this basis, the user requires an option to select from alternate available designs the one best suited for accomplishing any given mission.

With this in mind, the emphasis, from a reliability aspect, has been placed (1) on the analysis and prediction of the RTG and (2) on the development of reliability-power distribution characteristics for those configurations considered most adaptable to the Viking Lander Capsule (VLC). Two selected configurations containing RTG's in parallel are presented. The impact of connecting RTG's in series or seriesparallel has been indicated. Overall power system reliability-power distributions, which include the consideration of associated power system components and wiring, have not been included by reason of the guidelines of the Viking study presented in Section I-B. However, the effect of these system components on the distributions are indicated.

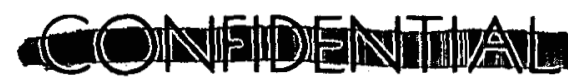


2. Criteria

The preliminary results of Martin-Denver power system studies presently being performed indicate that the power requirements for the VLC are 36 watts minimum from each of four RTG's or 25 watts minimum from each of two RTG's for the all-RTG and RTG/battery hybrid systems respectively at the end-of-mission. Thus, the minimum power requirements for the four and two generator systems are 144 and 50 watts, respectively. The operational life span for the VLC RTG approaches $1-3 / 4$ years duration. Ground operation consumes approximately nine months and covers the period from fabrication at Isotopes through launch complex integration and checkout. The mission starts with countdown, extends through launch and up to 229 days of interplanetary travel to Mars, Mars landing and a subsequent 90-day minimum surface operation for a total mission time of approximately 319 days. For the purpose of this study, the mission is conservatively assumed to be of one-year duration. It further assumes that the RTG's have an availability of one (1) at launch since their operational characteristics are known at the time of launch commitment. The mission reliability required for the VLC is assumed to be in the order Of 0.80 or better with an apportioned 0.95 or better for the lander power supply subsystem. These assumptions are consistent with current Martin-Denver estimates. Since no reliability apportionment has been established specifically for the RTG, a value of 0.96 or greater has been assumed. This assumption appears realistic for a power system design which incorporates redundancy in the electronic equipment of the of the power supply subsystem.

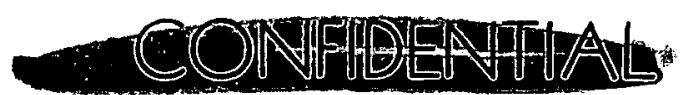

INSD-2650-29

VI -2 
Since the four-RTG system appears to be the present preferred design, it is emphasized and used as the basis for this study. The assumed reliability-power requirements for this preferred design may thus be stated, "The predicted probability shall be a minimum of 0.96 that the Viking Lander Capsule four-RTG configuration will produce a minimum of 144 watts under the environmental conditions encountered during a one year mission including travel to and operation on the surface of Mars."

3. Approach

Total reliability-power distribution characteristics at end-ofmission are developed for an initial fuel loading of 675 thermal watts for the TAGS-85/2N generator and for 625 thermal watts for the 3P/2N generator. These distributions have been prepared for both the fourand two-generator configurations. The selected parallel combinations may not reflect all possible arrangements. They do, however, provide information for performing tradeoff studies involving a range of mission power requirements up to 160 watts.

The distribution characteristics were formulated on the existing Nimbus generator design in which the thermoelectric couple network contains three parallel couples in a series-parallel circuit configuration. The effect on the reliability-power distribution due to a change to a two parallel couple scheme in this network is indicated. Such a change constitutes a technical option within the scope of the study.

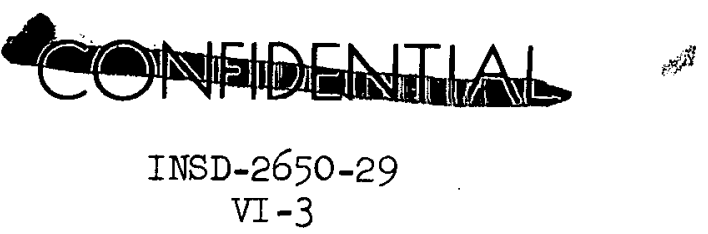


The approach utilized in presenting the RTG reliability-power distribution was based on combining failure probabilities associated with the various operational states of the system with the parameter variations which influence the distribution of the power output. In implementing this approach, a nominal electric power level for the RTG was established based on the RTG designs presented in the study. This power level was then combined with the failure probability and power distribution to develop the reliability-power distribution characteristics.

Section $B$ of this chapter provides a detail analysis and prediction of the failure probabilities and parameter variations of the RTG along with the rationale and supporting data. Section $C$ presents the reliability-power distribution characteristics for the two configurations and two types of RTG's based on the combination of failure probabilities and distribution characteristics.

\section{B. RTG ANALYSIS AND PREDICTION}

The SNAP 19 Nimbus RTG was utilized as the primary data source for the reliability analysis and prediction of the RTG designs considered for the VLC power supply system. The RTG proposed for the mission employs state-of-the-art component parts for which known performance histories have been established. Thus, reliability-power distribution characteristics may be predicted with a degree of accuracy that permits meaningful program decisions. 


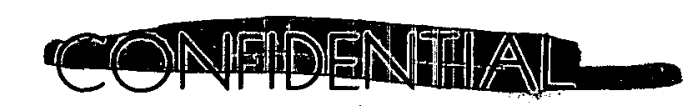

The breakdown for presenting the reliability analysis and predictions considered the three functions inherent in an RTG represented by the Viking design, namely: thermal, mechanical and electrical. Within each of these functions, the predictions considered failure probabillties and parameter variations. Failure probabilities are characterized by abrupt decrease in performance or total (catastrophic) failure, while parameter variations consider the probability associated with exceeding specification values due to the distributions associated with the parameters of interest. 1. Thermal Reliability

The isotopic heat source provides the thermal energy necessary for the thermoelectric conversion process. It is composed of the isotopic fuel, fuel capsule, strength member and heat shield. The heat source exhibits a very low failure probability insofar as it contributes to loss or reduction of electric power output. The low probability results from the high inherent safety margins built into the design as a result of nuclear safety design criteria. The safety-dictated design criteria require fuel containment under extremely more rigorous conditions than those encountered during normal mission conditions, and are established primarily by environments which include launch accidents, atmospheric re-entry and earth impact. A failure probability of 10 parts/million has been allowed for this function.

From a performance viewpoint, the thermal output exhibits a decrease with time which is predicatable to a high degree of accuracy.

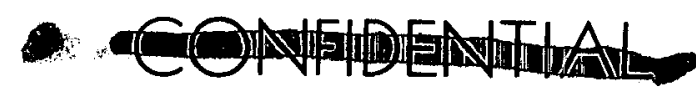

INSD-2650-29

VI -5 
There is, however, a variation associated with this output due to tolerances associated with capsule fuel loading and accuracy of calorimetric measurements. Measured fuel inventories show a standard deviation of $1.6 \%$ of the mean thermal watts based on an assumed normal distribution.

2. Mechanical Reliability

The mechanical functions relate to the structural integrity of the housing and the capability of the housing and seals to retain the internal fill gas. The need here is to design the structure primarily for the short-term, high load launch environment of vibration, acceleration and shock, after which time, structural loads are influenced primarily by thermal considerations (creep) while mechanically induced loads are of negligible consequence. The concern relates to the probability that the housing and seals will preclude the total loss of internal gas pressure which can occur due to failure of the o-ring seals or punctures in the housing due to a meteoroid penetration.

a. Structural reliability

The RTG housing has been designed with a structural strength margin of safety sufficiently high that its failure probability may be considered to approach zero for the expected levels of environments encountered during launch, booster staging, operation in space and landing on Mars. Reliability predictions have been prepared using established reliability safety margin techniques. The stress analyses, coupled with material temperature characteristics such as Larson-Miller

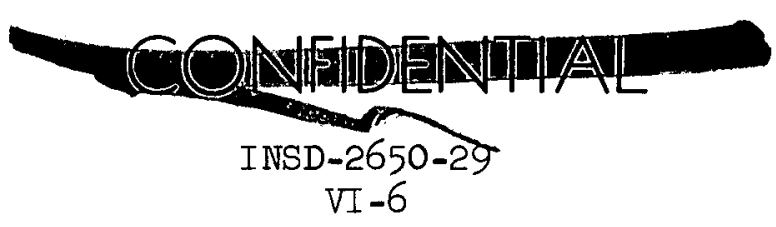


plots, provide the principal basis of such analyses. The identical safety margins have been applied to the housings selected for the Viking generator configuration. A failure probability of 10 parts/million has been allowed for the structure.

b. O-ring seal reliability

Once fueled, the generator contains an inert gas (argon) which serves to inhibit sublimation of the thermoelectric couples and to provide for heat transfer at various interfaces. The failure probability for the O-ring is directly related to the catastrophic loss of the generator internal gas for the mission duration. A best estimate of the failure rate for O-rings has been developed by applying an experience factor to the generic data obtained from industry sources (Ref. VI-I).

The reliability has been computed using the exponential equation:

$$
R=\exp (-n \lambda t)
$$

where $n=$ number of O-rings (3)

$$
\begin{aligned}
& \lambda=0 \text {-ring failure rate }\left(0.030 \times 10^{-6} / \mathrm{hr}\right) \\
& t=\text { time of mission ( } 8760 \text { hours) }
\end{aligned}
$$

This equation assumes that the failure rate is constant for the mission. Substituting the above values yields a failure probability of 79 parts/ million or a reliability of 0.99921 .

Variation of generator electrical power due to seal leak rates was computed using the data presented in Section II-A, Fig. II-8. Here, the effects on power for various helium release rates and housing seal

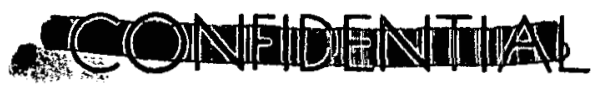

INSD-2650-29

$\mathrm{VI}-7$ 
tightnesses are presented. The 100\% helium release is considered most representative (and conservative) based on actual operating experience with Nimbus III generators. A variation (standard deviation divided by the mean) due to initial generator fill gas charge and seal leak rate for the mission is $0.42 \%$ for $100 \%$ helium release based on the premise that the seal tightness range $\left(1 \times 10^{-5}\right.$ to $\left.5 \times 10^{-5} \mathrm{scc} / \mathrm{sec}\right)$ represents the three sigma limits and that the distribution is normal.

c. Meteoroid penetration

Another potential failure mode for the Viking generator is loss of fill gas resulting from penetration of the generator housing by meteoroids. In estimating unreliability from this cause, we conservatively assume that failure is catastrophic, although the information available at this time is insufficient to make such a judgment, as experienced with generators operating at low pressure.

Three elements make up the computational model used to estimate unreliability resulting from meteoroid penetration. The first deals with the determination of meteoroid mass required to penetrate the housing, assuming a nominal relative speed between generator and meteoroid. The present calculations assume no uncertainty in this calculation although it is possible to include this source of variance in a more detailed model.

The second element of the model is the nominal mass spectrum of the flux and its estimated uncertainty. The nominal flux was taken from Ref. VI-2 for the composite* spectrum near Earch, at $1.25 \mathrm{AU}$ and * cometary plus asteroidal meteoroids

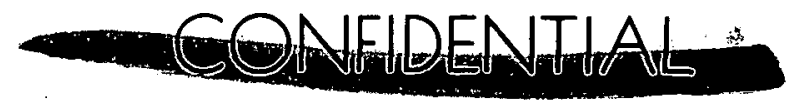




\section{\$}

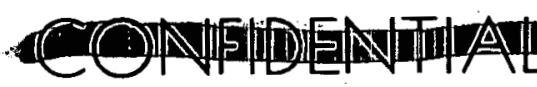

near Mars. The effects on unreliability of the uncertainty of this spectrum was included by assuming a log normal density function for the flux exceeding any mass and evaluating the overlap integral for the flux and penetration probability densities.

The final element deals with the probability of incurring a penetration in a specified flux, $\Phi$. The probability of one or more penetrations is determined from the expected number of penetrations using Poisson statistics.

The detailed model and results derived from it are described in the following sections:

(1) Analytical Model

(a) Penetration

The expression relating depth of penetration in a target material by a meteoroid of diameter, $d_{m}$, used in this work was the new Aerospace Corporation equation Ref. VI-3:

$$
t=0.65 \frac{\mathrm{d}_{\mathrm{m}}^{19 / 18}}{\epsilon_{\mathrm{T}} 1 / 18}\left(\frac{\rho_{\mathrm{m}}}{\rho_{\mathrm{T}}}\right)^{1 / 2} \mathrm{v}^{7 / 8}
$$

where $t=$ thickness of target material, $\mathrm{cm}$

$$
\begin{aligned}
d_{m} & =\text { meteoroid diameter }, \mathrm{cm} \\
V & =\text { relative impact speed, } \mathrm{km} / \mathrm{sec} \\
\rho_{\mathrm{m}} & =\text { meteoroid density, } \mathrm{gm} / \mathrm{cm}^{3} \\
\epsilon_{\mathrm{T}} & =\text { elongation of target material, } \% \\
\rho_{\mathrm{T}} & =\text { target material density }, \mathrm{gm} / \mathrm{cm}^{3}
\end{aligned}
$$

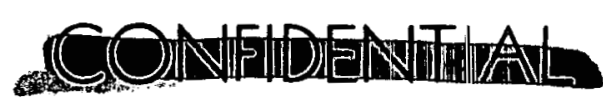

INSD-2650-29

$\mathrm{VI}-9$ 
Values assumed for the density and speed characterizing the meteoroid flux were selected for the composite flux model given in Ref. VI-2 for the environments at $1.25 \mathrm{AU}$ and near Mars. The impact speed, $V$, was taken as $25 \mathrm{~km} / \mathrm{sec}$, somewhat greater than the nominal speed of $10 \mathrm{~km} / \mathrm{sec}$ estimated for particles with mass greater than $10^{-9} \mathrm{gm}$. The density was taken as $3.5 \mathrm{gm} / \mathrm{cm}^{3}$, the maximum of the range of nominal densities given in Ref. VI-2. Target parameters were: A thickness of 0.1 in., the nominal thickness of the generator housing, a density of $1.8 \mathrm{gm} / \mathrm{cm}^{3}$ and an elongation of $10 \%$ for the magnesium-thorium alloy at $350^{\circ} \mathrm{F}$.

The threshold diameter and mass just sufficient to penetrate the housing were determined to be $0.0232 \mathrm{~cm}$ and $2.3 \times 10^{-5} \mathrm{gm}$, respectively. This value was assumed to be precisely known in spite of the variances associated with the parameters used, principally impact speed, meteoroid mass and, perhaps, with the validity of the penetration equation itself. The total variance, however, inherent in the determination of the threshold mass for penetration is small compared with that assumed for the flux, discussed next. Accordingly, omission of these former variances will not affect the conservatism of the computed reliability.

(b) Flux spectrum

The spatial region of concern in the present work includes the near-earth region, the region varying from 1.0 to $1.5 \mathrm{AU}$ in the ecliptic plane, and the near-Mars region. Figures 4-16, 4-19 and 4-22, of Ref. VI-2, indicate that variation of the nominal flux among these three regions is small compared with the uncertainties represented by the upper and lower 95 percentile regions.

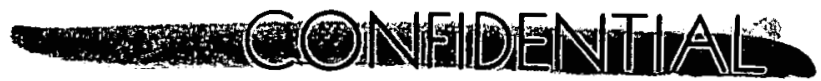




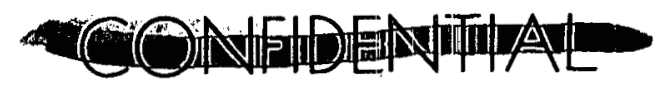

The specific values for the nominal cumulative flux for meteoroids exceeding $2.3 \times 10^{-5}$ gms and its uncertainty are presented in Table VI-I. It is seen that the nominal fluxes are consistent, within a factor of four, for the three regions. For the present estimate of unreliability, we will assume a nominal flux of $1.6 \times 10^{-10} \mathrm{~m}^{-2} \mathrm{sec}^{-1}$, since most of the transit and mission time will be spent in the $1.25 \mathrm{AU}$ and near-Mars regions.

\section{TABLE VI-1}

$$
\text { CUMULATIVE FLUX AND UNCERTAINTIES ( } \left.\mathrm{m}=2.3 \times 10^{-5} \mathrm{gms}\right)
$$

$\begin{array}{lcccc}\text { Region } & \frac{\text { Nominal Flux }\left(\mathrm{m}^{-2} \mathrm{sec}^{-1}\right)}{\text { Near Earth }} & 6.3 \times 10^{-10} & \frac{95 \text { Percentile Limits }\left(\mathrm{m}^{-2} \mathrm{sec}^{-1}\right)}{\text { Upper }} & \frac{\text { Lower }}{6.3 \times 10^{-7}} \\ 1.25 \mathrm{AU} & 1.6 \times 10^{-10} & 7.9 \times 10^{-9} & 1.6 \times 10^{-11} \\ \text { Near Mars } & 1.3 \times 10^{-10} & 6.3 \times 10^{-11} & 1.6 \times 10^{-11}\end{array}$

The upper and lower 95 percentile limits are seen to be quite large with differences on the logarithm (base 10) scale amounting to 3.9, 2.7 and 3.6 for the near-Earth, $1.25 \mathrm{AU}$ and near-Mars regions, respectively.

The means of evaluating penetration probability require an estimate of the density function for the penetrating flux. To this end we follow Dixon's approach (Ref. VI-4) and represent the flux, $\phi$, by a density function of the form:

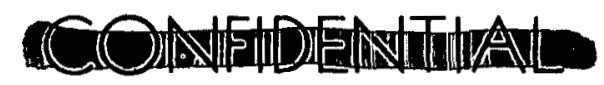

INDS-2650-29

VI -11 
$p(\phi)$ a $\ln \phi=\frac{1}{\sqrt{2 \pi} \ln \sigma} \exp \left[-\frac{\left.\ln \phi / \phi_{0}\right)^{2}}{2(\ln \sigma)^{2}}\right]$ a $\ln \phi \quad(V I-3)$

where $\sigma=$ the geometric standard deviation of the distribution

$\phi_{0}=$ nominal or 50 percentile flux $\left(\mathrm{m}^{-2} \mathrm{sec}^{-1}\right)$

and $\phi=$ flux of particles exceeding any given mass $\left(\mathrm{m}^{-2} \mathrm{sec}^{-1}\right)$

Since the distance between 95 percentile points on normal distribution is approximately 3.3 times the standard deviation*, the indicated values of in range from $0.8,\left(\frac{2.7}{3.3}\right)$ to about $1.2,\left(\frac{3.9}{3.3}\right)$. We have assumed a value of 1.0 for $\ln \phi$ in the present calculations.

(c) Penetration probability

Meteoroid fluxes are small in general and random in nature; whether or not a given target is hit during transit is a matter of chance. Lacking information on the detailed nature of the randomness, we assume the Poisson statistics describe the variation about the expected number of hits.

* We have assumed a symetric distribution (in logarithmic space) for the flux densities. Actually, the skewness implicit in the upper and lower tolerance curves about the mean, makes this a somewhat unconservative approximation. This is believed to lead to a relatively unimportant underestimate of the penetration probability.

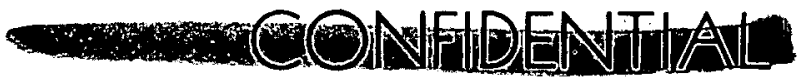


If the exposed area of the target is $A_{T}$, and the time duration of exposure, T, the expected number of penetrations is:

$$
\mathrm{X}=\mathrm{A}_{\mathrm{T}} \mathrm{T} \phi \simeq \lambda \phi
$$

where $\phi$ is the flux exceeding the mass threshold for penetration.

According to Poisson statistics, the probability of zero hits is $\mathrm{e}^{-\mathrm{x}}$, and the penetration probability is $\mathrm{P}=1-\mathrm{e}^{-\mathrm{x}}$.

The total failure probability may be written as the integral of the density function for penetration in a $y^{3} l u x, \phi$, weighted by the probability of exceeding that flux. For convenience the integral is evaluated in terms of the logarithmic variable:

$$
u=\frac{\ln \phi / \phi_{0}}{\ln \sigma}
$$

so that the failure integral becomes

$$
U=\int_{-\infty}^{\infty} \frac{d p}{d u} G(u) d(u)
$$

where $G(u)=\frac{1}{\sqrt{2 \pi}} \int_{-\infty}^{\infty} \exp -y^{2} / 2 d y$, the cumulative normal

The density, $\frac{d p}{d u}$, is given by:

$$
\frac{d p}{d u}=\lambda \phi_{0}(\ln \sigma) \sigma^{u} \quad \exp \left[\begin{array}{ll}
-\lambda \phi_{O} & \sigma^{u}
\end{array}\right]
$$

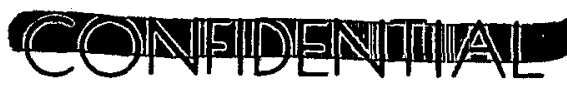




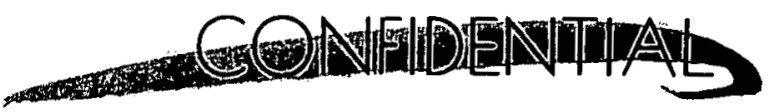

so that $U$ may be written as:

$$
U=\frac{\lambda \phi_{0} \ln \sigma}{\sqrt{2 \pi}} \int_{-\infty}^{\infty} d u \sigma^{u} \exp \left[-\lambda \phi_{0} \sigma^{u}\right] \int_{u}^{\infty} e^{-y^{2} / 2} d y .
$$

This integral cannot be evaluated in closed form. It has been evaluated by numerical integration as a function of $\lambda \phi_{0}$ for four values of In: $1.00,1.50,1.96$, and 2.50 . The results are shown in Fig. VI-1.

In the present case the exposed area of the generator is $1.25 \mathrm{ft}^{2}$ or about $0.12 \mathrm{~m}^{2}$, assuming an isotropic distribution-in-angle for the meteoroid flux. The transit and Mars surface operation time combine to about one year or about $3 \times 10^{7}$ seconds. Thus the product, $\lambda \phi_{0}=A_{T} T \phi_{0}$ is about $5.8 \times 10^{-4}$.

From Fig. VI-I we find an associated unreliability of about $1 \times 10^{-3}$. Thus, the reliability with respect to surviving the meteoroid environment was estimated at 0.999 .

3. Electrical Reliability

a. Wiring network reliability

Figure VI-2 illustrates the salient features associated with the electrical circuit within the generator. The area of interest involves the interconnections between the modules and the housing feedthrough electrical connector. The failure probability for the wiring network is related to the open and short circuit mode. There are three factors that have been considered with relation to these modes: (1) mechanical strength of the wire in relation to the routing and

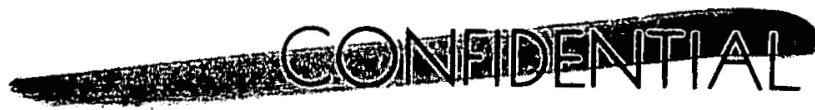




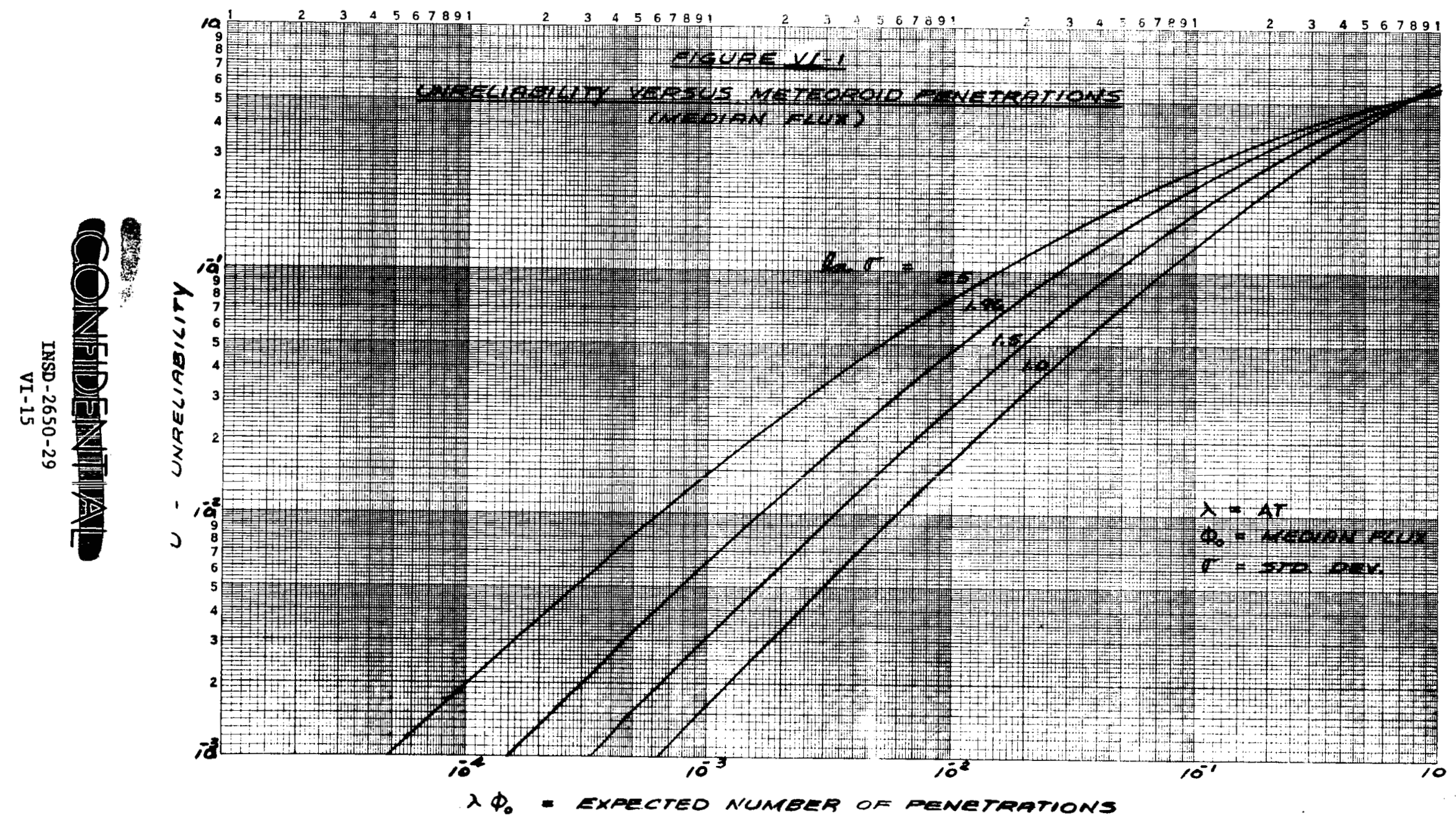



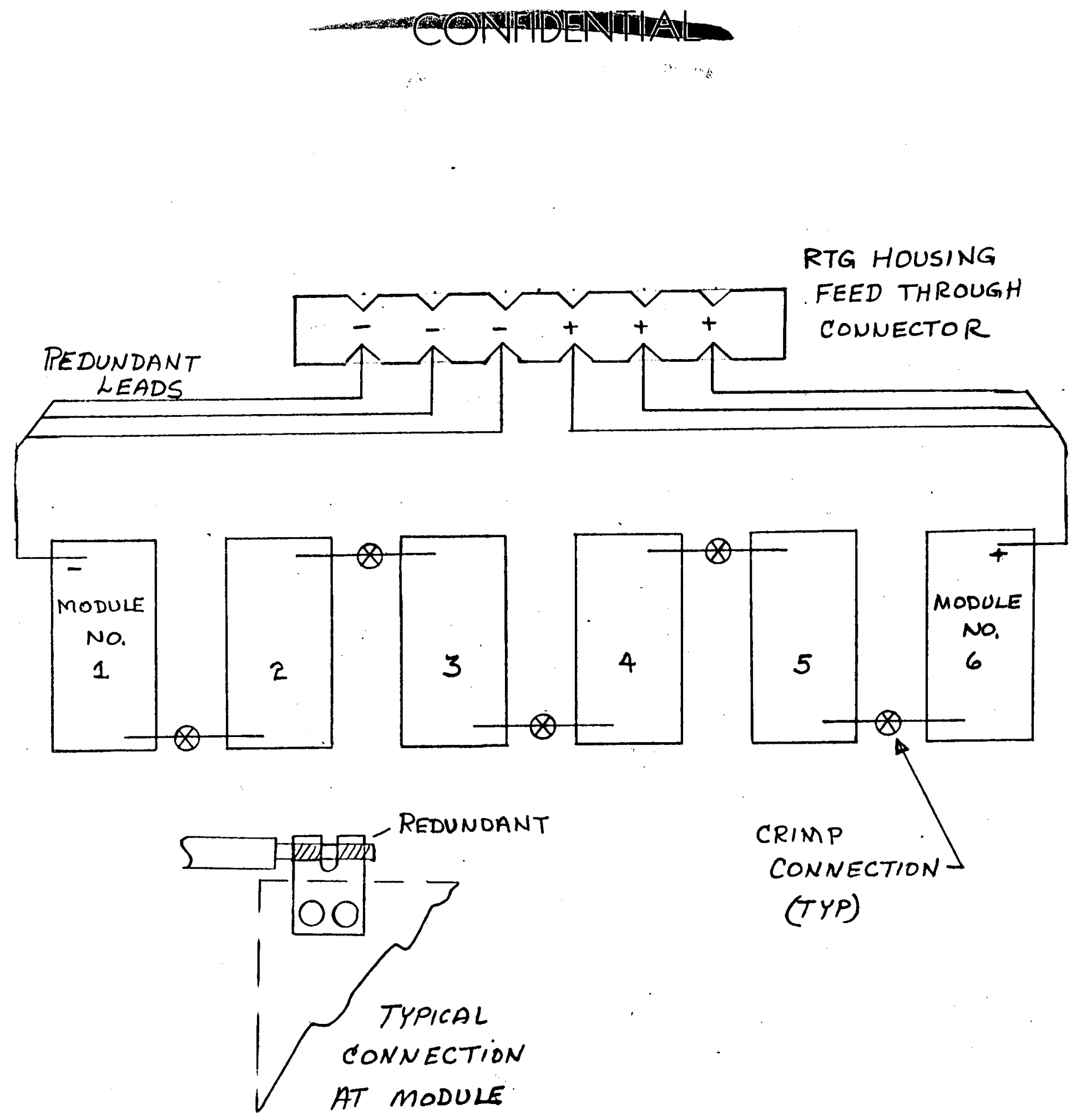

FIG. VI-2. RTG WIRING NETWORK (THREE COUPLES PER PARALLEL BRANCH)

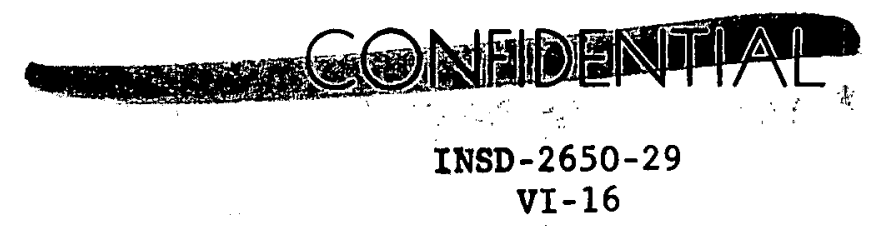




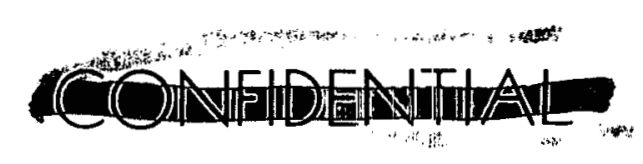

support, (2) electrical insulation characteristics of the wire in relation to temperature and environmental gases and (3) the termination devices and the method by which they are applied. The heavy gage conductors used in the RTG and the methods for supporting and routing these conductors, coupled with design, quality control procedures and screening methods performed during acceptance vibration tests, minimize the existence of the first two classes of failure. The type of wire termination devices and methods used to join them constitute the greatest potential contributor to unreliability. The type and quantity of these devices are therefore used as the basis for the prediction. The electrical design incorporates three redundant circuits through the housing electrical connector for both the positive and negative leads. A single wire interconnects the modules, with each wire being spliced during fabrication using a crimp connector"

The unreliability is determined primarily by these five crimp connectors between modules. Reference VI-5 provides failure rate data for a limited number of types of connections. The average failure rate is 0.016 failures/million hours for crimp type connections. One-half this failure rate has been used since quality control procedures may be expected to result in a joint better than average.

The reliability for the mission time of one year using the exponential failure rate method of predicting is determined by the product rule expression, equation VI-I,

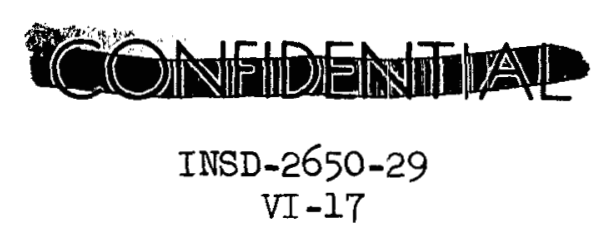


where $R=$ probability of failure during time ( $t$ )

$$
\begin{aligned}
& \mathrm{n}=\text { number of connectors }(5) \\
& \mathrm{t}=\text { time }(8760) \\
& \lambda=\text { failure rate }(0.008 \text { failures/million hours) }
\end{aligned}
$$

Substituting values into the equation yields a failure probability of 350 parts per million or a reliability of 0.99965 for the mission.

The electrical connector, based on the failure rates presented in Ref. VI-5, constitutes a negligible percentage of the total unreliability. This is true since the power circuits are triply redundant through the connector and the mode of failure is primarily a socket/pin interface.

The wiring network contributes to degradation of power with time only to the extent that one of the parallel paths (wires, connector contacts, etc.) should open. No detailed analysis has been included in this study since the probability of such failure is judged sufficiently small that its influence is negligible at the system level.

b. Thermoelectric couple network reliability

Figure II-4 in Section II-A illustrates the circuit configuration associated with the thermoelectric couple network within the module for the three and two series-parallel thermoelectric couple arrangement. The failure probability for the thermoelectric couple network is related primarily to the open circuit mode. Short circuits are extremely improbable as compared to the open mode due to the physical configuration employed in the module.

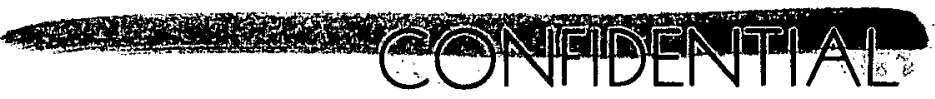


The thermoelectric network desigr incorporates both mechanical and electrical redundancy. Connections between the thermoelectric elements, hot shoes, cold straps, etc., are all bonded to provide circuit continuity which in itself incorporates redundancy by virtue of the ladder network. Each connection, in addition to being bonded, is pressure-loaded through a piston-spring arrangement. The arrangement minimizes the resistance in the thermal path and provides mechanical redundancy to the bonded connections through pressure loading. The ladder design tolerates a number of individual couple failures without resulting in an open circuit. Allowing some couple failures reduces the power output and thus must be compensated for by overdesign (added couples) or deduction from the available power. There is not a direct relationship between the percentage of couple failures and the percentage of power loss since the failure affects the adjacent couple(s) in the parallel branch in which it is a part as well as the remaining couples. The increase in current through the adjacent couples decreases the power due to off-optimum operation. This is cancelled in part by the small increase in delta $T$ across the remaining couples. An exact loss can be calculated for any given case, but experience shows that for couple networks having three couples in parallel, the loss in power is approximately $1-1 / 2$ times the individual couple power output.

For the proposed Viking application, an allowance for the loss of one couple at the system level has been made. This is conservative since the probability of the loss for the time of the mission is less

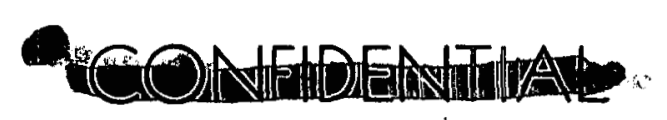


than 5\%. This was computed using a generic catastrophic failure rate for $\mathrm{T} / \mathrm{E}$ couples of $3.96 \times 10^{-8} /$ hours or lower at a confidence level of 50 percent which has been calculated from the over 40 million operating device hours. These hours were accumulated on generators using seriesconnected couples. Generators using series-parallel connected couples were not considered since failures of individual couples are not detectable. The failure rate was calculated using data accumulated on 2P/2N, 3P/2N, TAGS-85/Isotopes $\mathrm{N}$, and TAGS-85/2N type couples.

The failure of one or more thermoelectric couples has been evaluated from the standpoint of its effect on power output and the probability of circuit failure. In the RTG design, redundancy of thermoelectric couples is provided by a series-parallel (ladder) arrangement with three couples in each parallel branch and thirty seriesconnected branches for a total of ninety couples. The use of two couples per parallel branch with forty-five series connected branches increases the voltage by fifty percent. The reduced current results in a saving in wire weight and an increase in voltage converter efficiency.

Figure VI-3 compares the reliability of the triple, and two parallel network arrangements for any period up to six years versus number of allowed failures. These curves were calculated using the binominal expansion expression truncated to allow for a limited number of failures. No significant difference exists between the triple and two parallel branch circuit for less than three allowed failures. It should be noted that additional intermodule wires are required for the two-parallel

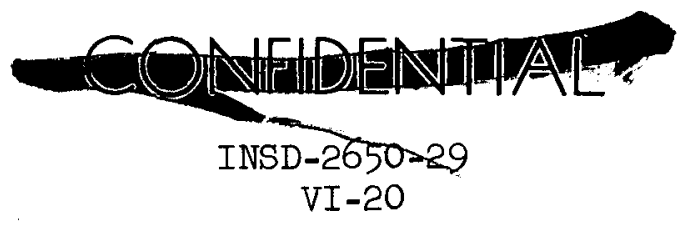



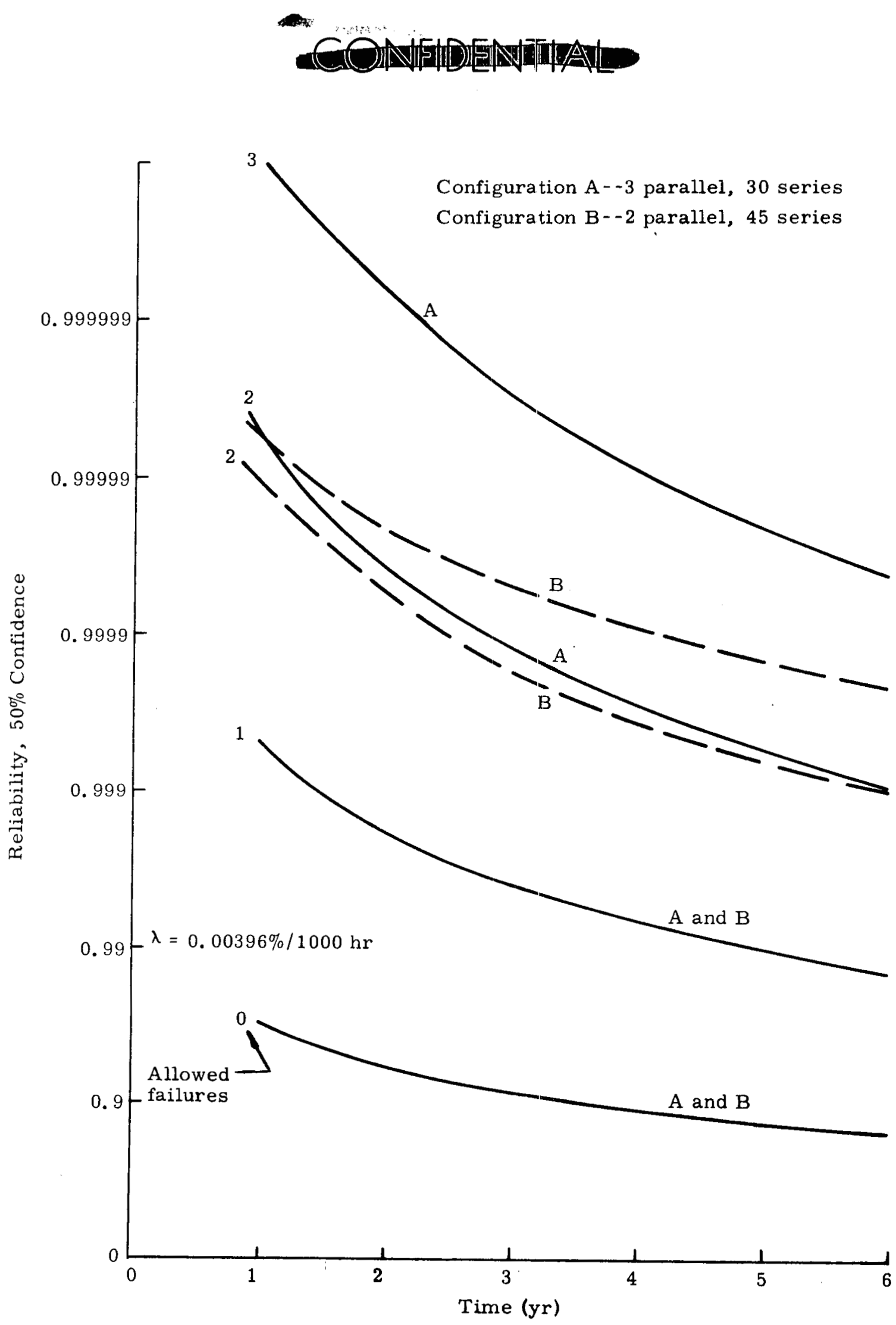

FIG. VI-3. COM PARISON OF CATASTROPHIC RELIABILITY T/E COUPLE NETWORKS FOR 2 AND 3 PARALLEL COUPLE CONFIGURATION

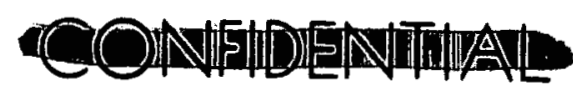

INSD $-2650-29$

VI -21 
branch arrangement. Again in the two parallel circuit configuration the power loss due to a couple failure does not bear a direct relationship to the percentage of couples that fail for the same reasons as stated previously. Here the loss in power is approximately twice that of an individual couple.

c. System reliability

The connection of RTG's in various configurations such as series or parallel necessitates that the binominal expansion mathematical

expression be considered and applied to the entire thermoelectric couple network regardless of the physical packaging into discrete generators. Table VI-2 compares the reliability of the T/E couple arrangements representing the two and triple parallel branches for various quantities of generators connected in series. This case was chosen as most representative of the various system configurations. Note that where either zero or one failure is allowed* the reliability is identical for both the triple and two parallel thermoelectric couple network. Here a loss of a couple affects power only. For higher quantities of failures, even greater than the number in the parallel branch, results in a high reliability since the probability of all failures occurring in the same branch is remote.

* The allowed failure is a matter of definition and is determined by trading off probability of couple(s) failure versus loss in power. The probability of failure of the network becomes significant only when large numbers of failures are predicted.

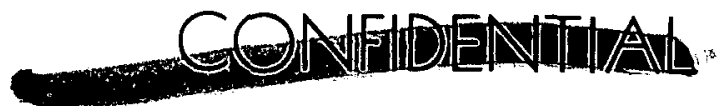


TABLE VI-2

FAILURE PROBABILITY IN PARTS PER MILLION

FOR VARIOUS T/E COUPLE CIRCUIT NETWORKS AT ONE YEAR

Number of $\mathrm{T} / \mathrm{E}$ Couples (Parallel/Series)

(1) Generator

(90 couples)

Allowed

Failures

0

1

2

3
(2) Generator System ( 180 couples)

$3 / 60 * 2 / 90 *$

6053260532

$1860 \quad 1860$

$39 \quad 48$

1
(4) Generator System (360 couples)

$\underline{3 / 120 * 2 / 180 *}$

$117400 \quad 117400$

$7159 \quad 7159$

$294 \quad 312$

$9 \quad 31$

* First number denotes number of parallel paths; second number denotes number of series connected parallel paths.

Thermoelectric couple power output varies with inherent aging characteristics. The effects of time on power are included as part of the generator power output analysis performed in Chapter II.

4. Generator Prediction

Table VI-3 summarizes the failure probability of the generator configured to the Viking application. The data presented has been developed in the preceeding paragraphs. The results show that the most significant contributor to the unreliability of the generator is due to meteoroid penetration of the housing which results in the loss of internal fill.

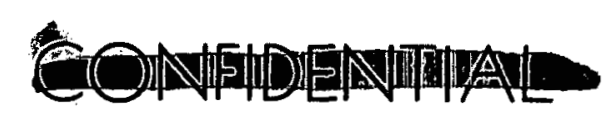

INSD-2650-29

VI -23 


\section{TABLE VI-3}

PREDICTION OF GENERATOR RELIABILITY--CATASTROPHIC TYPE FAILURES

$\underline{\text { Item }}$

Reliability $\quad$ (Parts/10 $)$

Thermal

Heat Source

0.99999

1

Mechanical

Housing

0.99999

1

o-Rings

0.99921

79

Meteoroid Penetration

0.99900

100

Electrical

Wiring Network

Connections

.99965

35

Connectors

.99999

1

Wire

.99999

1

Couple Network

.99953

47

(One allowed failure)

Total

0.99735

265

\section{RELIABILITY--POWER DISTRIBUTION}

Total system reliability-power distribution characteristics have been developed for two RTG configurations at end-of-mission. The configurations are based on (1) a generator having an initial fuel loading of 675 thermal watts and TAGS-85/2N type thermoelectric couples

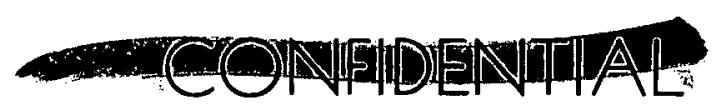

INSD-2650-29

VI -24 


\section{(20)}

and (2) a generator having an initial fuel loading of 625 thermal watts and $3 \mathrm{P} / 2 \mathrm{~N}$ type thermoelectric couples. Within each of these configurations, distributions are presented for a two-and four-parallel generator circuit arrangement. The difference between the parallel arrangement and a series or parallel-series (possible in the four RTG arrangement) is negligible until other system components such as dc-dc converters are defined. 1. Mathematical Model

The mathematical formulation employed to compute the total system reliability-power distributions was developed from the following equation:

$$
R_{(P)}=P_{N} \cdot C_{N}(P)+P_{N-1} \cdot C_{N-1}(P)+P_{N-2} \cdot C_{N-2}+\cdots
$$

where

$$
\begin{aligned}
R_{(P)} & =\text { total reliability at any power }(P) \\
P_{M} & =\text { state probability of exactly } M \text { branches operating } \\
C_{M}(P) & =\text { probability of exceeding } P \text { watts if } M \text { branches are operating } \\
N & =\text { number of parallel branches in the system } \\
M & =\text { number of operating branches, i.e., N, N-l, etc. }
\end{aligned}
$$

2. State Probability

The state probability was computed using the equation:

$$
P_{M}=\left(\begin{array}{l}
N \\
M
\end{array}\right) R^{M}(I-R)^{N-M}
$$

where

$$
\begin{aligned}
\left(\begin{array}{l}
N \\
M
\end{array}\right) & =\text { binominal coefficient } \\
R & =\text { reliability of the individual branch. }
\end{aligned}
$$

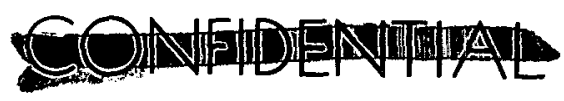

INSD-2650-29

VI -25 
The individual branch reliability is represented by a single RTG. This value was developed in Table VI-3 as 0.997 for the mission time of one year. This value is applicable to both the TAGS-85/2N and $3 P / 2 N$ thermoelectric couple design.

3. Power Distribution

The probability of exceeding $P$ watts, $C_{N}(P)$ was computed using the general equation:

$$
C_{N}(P)=\frac{1}{\sqrt{2 \pi}} \int_{-\infty}^{\frac{P-\bar{p} N}{s \sqrt{\mathrm{NK}}}} \quad \exp -u^{2} / 2 d u
$$

where

$\bar{p}=$ mean or average generator power output

$\mathrm{s}=$ standard deviation of generator power

$\mathrm{K}=$ number of generators per branch (1)

$N=$ number of parallel branches ( 2 or 4 )

The mean power output, $\bar{p}$, was calculated to be 40.7 and 26.6 watts for the TAGS-85/2N and 3P/2N type generators respectively at end-ofmission with a generator housing seal tightness of $3.0 \times 10^{-5} \mathrm{scc} / \mathrm{sec}$ and a fuel capsule helium release rate of 100\%. A conservative standard deviation, $s$, of 1.32 and 0.87 watts for the two type generators (3-1/4\% of $\bar{p})$ was assumed based on the combination of the individual variances related to electrical, thermal and pressure parameters. Variance factors include (1) the thermoelectric conversion unit of approximately $0.8 \%$ at the design hot and cold junction temperatures at beginning-of-life, (2) the capsule loading of approximately $1.6 \%$ at

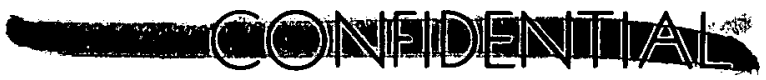




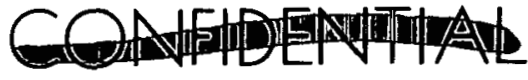

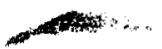

time of loading, (3) the pressure variation due to initial generator fill gas charge and leak rate of the housing seals during one year mission of approximately $0.42 \%$. The variation associated with the thermoelectric conversion unit was computed from test data accumulated from production couples and that for fuel capsules from measurements of initial loadings. The variation due to seal leak rates was computed using the data presented in Fig. II-8 in Section II-A. Here the effects on power for various helium release rates and housing seal tightness are shown. The $100 \%$ helium release rate is considered representative of actual operating conditions, and thus variations due to this parameter have been ignored in determining the $0.42 \%$ variance. These variance factors are supported by data accumulated on ten (10) fueled SNAP 19 generators using $2 \mathrm{P} / 2 \mathrm{~N}$ type thermoelectric couples. For the generators the beginning-of-life variance was $3 \%$. This value has been modified to allow for the elapsed time to completion of the Viking mission and believed to be representative.

\section{Results}

Figures VI-4 and VI-5 present the total reliability-power distribution characteristics of TAGS-85/2N type generators at end-of-mission (one year after launch) for the four-and two-parallel generator arrangements, respectively. The four-generator arrangement has a probability of 0.96 of delivering 157 watts 'or 0.99 of delivering 154 watts. The two generator arrangement has a probability of 0.96 of delivering 77 or 0.99 of delivering 76 watts.

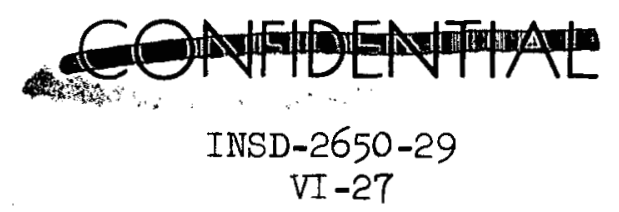




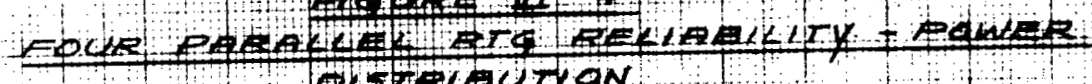

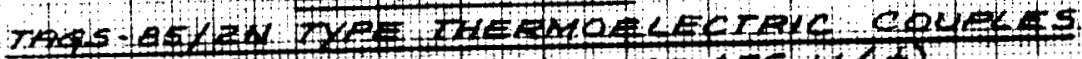

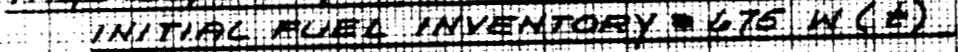

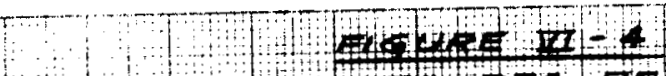
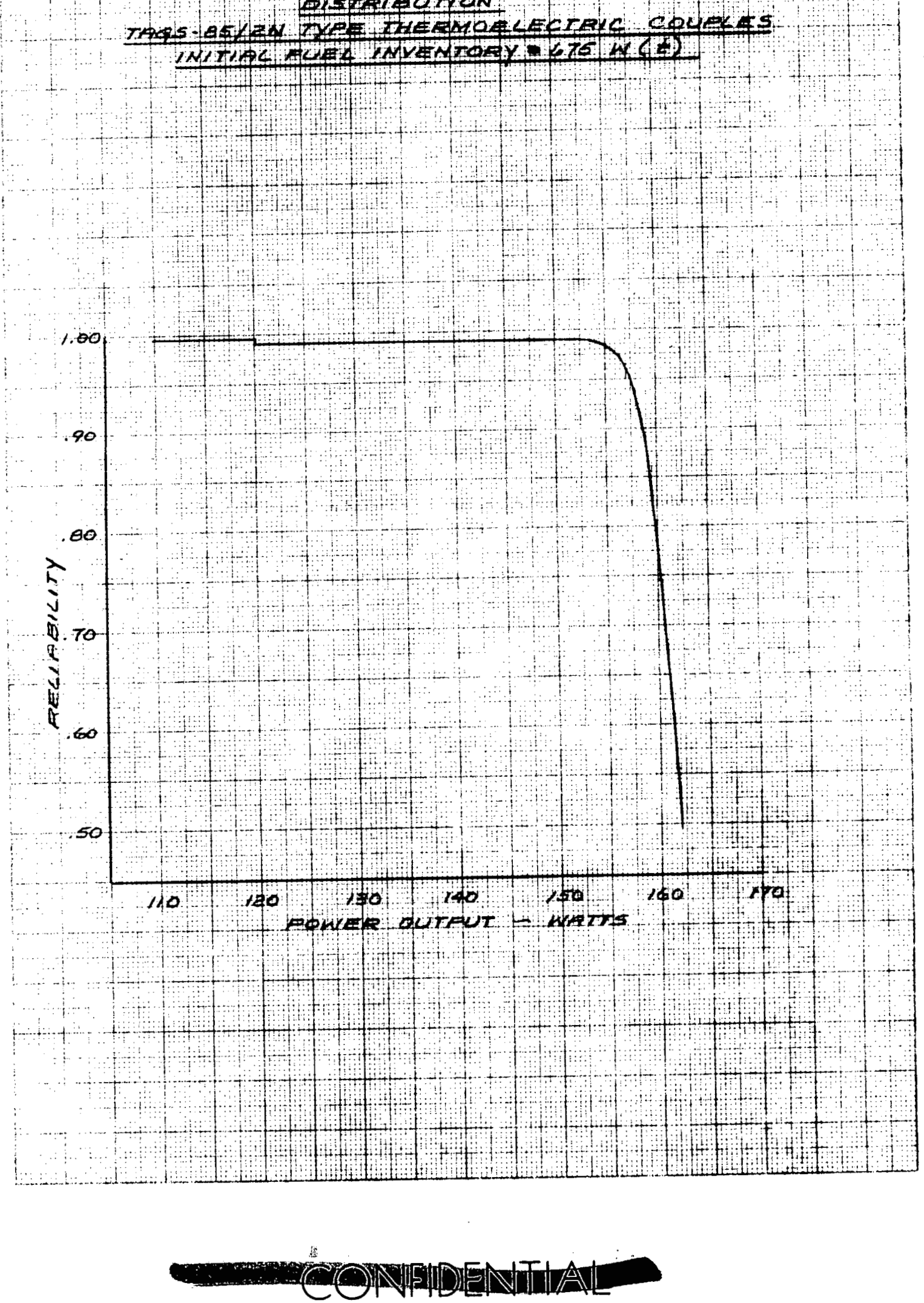

INSD - 2650-29 

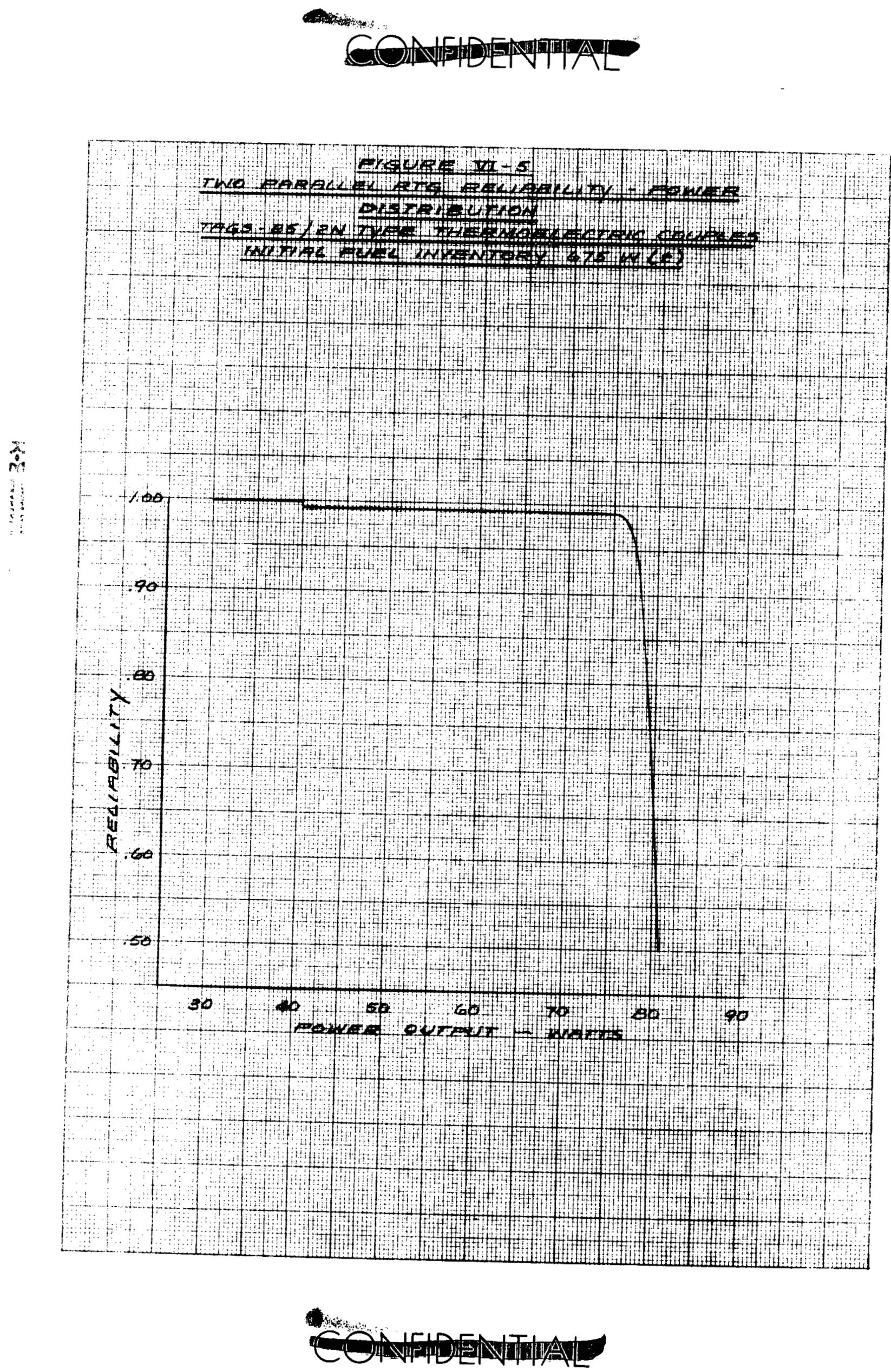

INSD -2650-29

VI -29 
Figure VI-6 presents the total reliability-power distribution characteristics for the $3 \mathrm{P} / 2 \mathrm{~N}$ type generators at end-of-mission and for the four and two-parallel generator arrangements. The four-generator arrangement has a probability of 0.96 of delivering 101.5 watts and the two-generator arrangement has a probability of 0.96 of delivering approximately 50 watts. Thus the 3P/2N RTG may be applicable to the RTG/battery hybrid power system, but is not capable of satisfying the power requirements for the all-RTG system.

When the generators are considered in conjunction with other system components, the intercept at the power axis of the curves will be reduced due to losses in the generator branches. The principal contributors to the power losses are wiring and voltage converter. The total power system reliability will be reduced to account for the failure probability of devices connected to the generator. Plateaus will become more pronounced and the advantages of series, parallelseries and parallel generator connections can then be traded-off against minimum and desired power requirements.

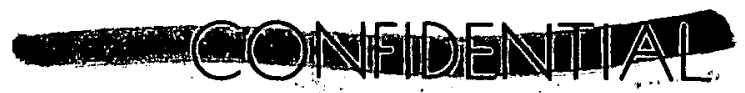

INSD-2650-29

$\mathrm{VI}-30$ 


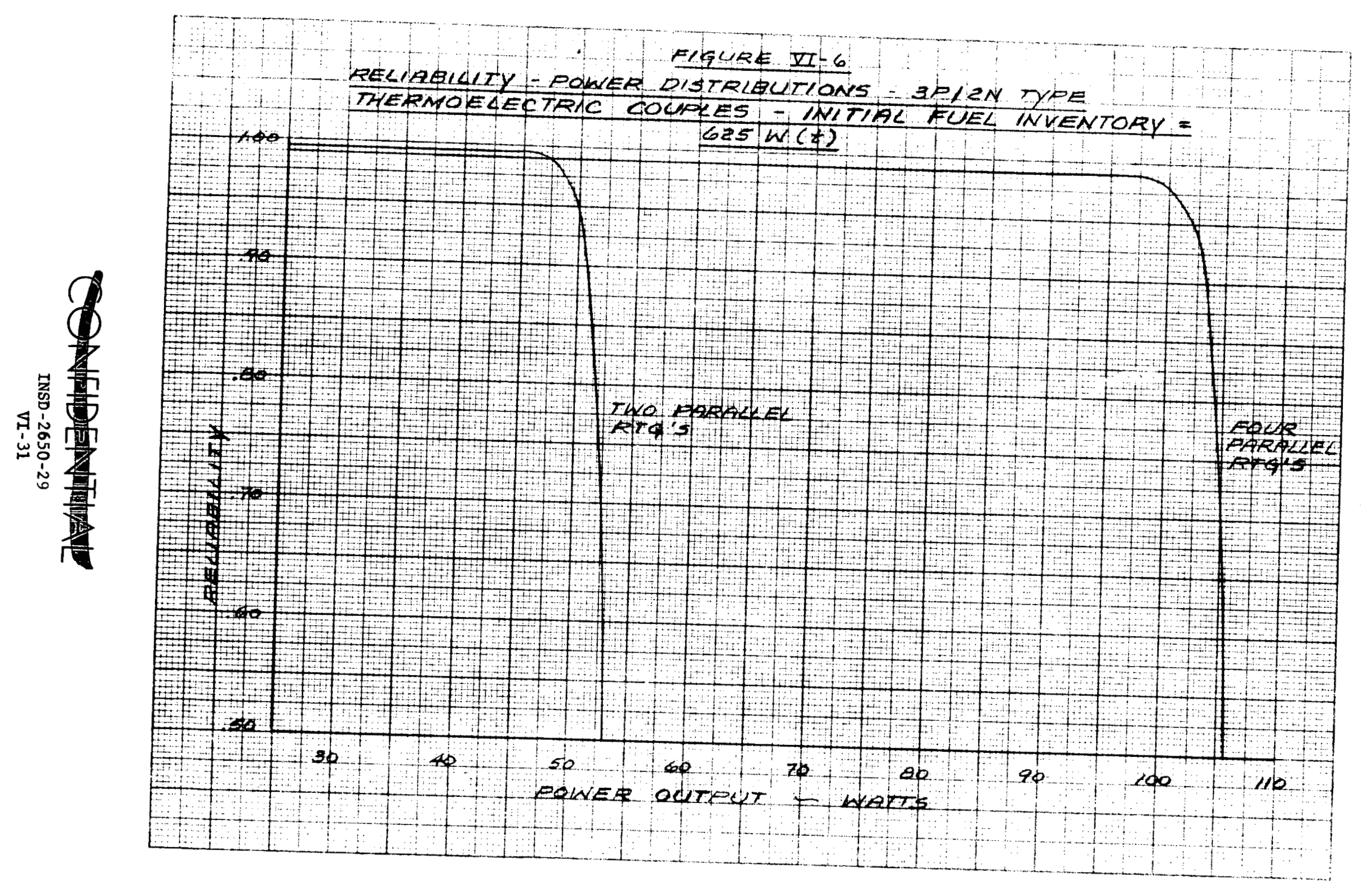




\section{REFERENCES}

III-1. "Multigas Permeability Analysis and Pressure Predictions for SNAP 19 Generators," C. Goebel and P. Brennan, Isotopes Report MND-3607-230, February 1968.

III-2. "The Behavior of Organic Materials under Simulated Space Environmental Conditions," S.E. Podlaseck, Martin Research Memorandum. 130, November 1963.

IV-1. "SNAP 29 Preliminary Safety Analysis Report," Safety Analysis Document (Vol. 3), MND-2062-33I4-3 (CDI), June 1968.

IV-2. Kite, F. D., and Bader, B. E., "Pad Abort Thermal Flux Model for Liquid Rocket Propellants," Sandia Laboratories, Albuquerque, New Mexico, SC-RR-66-577, November 1966.

IV-3. Conway, T.W., "Solid Propellant Contribution to the Titan III Fireball," Isotopes, Nuclear Systems Division, SNAP 29 Memo INSD-3312-22, September 22, 1968.

IV-4. Kornhauser, M., Structural Effects of Impact, Spartan Books, Inc., 1964.

IV-5. Goodier, J.N., "Thermal Stress," Design Data and Methods--Applied Mechanics, ASME, 1953.

IV-6. "SNAP 19 Jupiter Pioneer Application Study," Isotopes Nuclear Systems Division, INSD-2650--20, March 1969.

IV-7. "SNAP 19 Safety Analysis Report IRHS Supplement," Martin Marietta Corporation, MND-3607-133-S, March 1968.

IV-8. "A Probabilistic Treatment of the Aerospace Nuclear Safety of Strontium 90," Martin Marietta Corporation, Nuclear Division, MND-3062-28-2 (Vol. II) (CDI).

IV-9. Edrington, T.S., "Probability of Hazards Associated with Intact Re-entry of Radioisotope Fuel Capsules," SC-RR-64-1799, Sandia Corporation, Albuquerque, New Mexico, November 1964.

V-1. "Radiati on Protection Training Manual for the SNAP 19/Nimbus B at Vandenburg Air Force Base," NASA, Goddard Space Flight Center Document X-450-68-38, January 1968.

V-2. "SNAP 19 Phase III Final Report, Volume I," Martin Marietta Corporation, MDD-3607-239-1, May 1968.

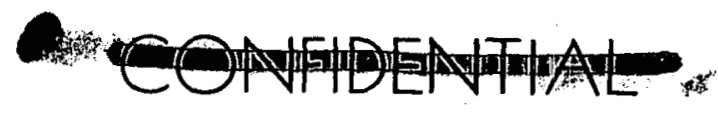

INSD-2650-29

VII- 1 
V-3. "Loading, Transporting, and Unloading Procedure of SNAP 19 RTG Subsystems anä Associated Ground Equipment," Martin Marietta Corporation, 452B1900110, January 1969.

V-4. "Portable Monitor Package Connection and Operation Procedure," Martin Marietta Corporation, 452B190011.1, January 1969.

V-5. "Nimbus B RTG Handling Procedure," General Electric Company, 4723-WTR-B 008, November 1967.

V-6. "Detailed Test Procedure for In-House Handling of the Nimbus B Spacecraft Radioisotopic Thermoelectric Generator," GeneraI Electric Company, DTP-4720-B-05, October 1967.

V-7. "Standards for Protection Against Radiation," USAEC Rules and Regulations, IOCFR20, August 1966.

VI-1. Failure Rate DATA (FARADA) Program FARADA Information Center, Corona, California.

VI-2. "Voyager Environmental Standards," National Aeronautics and Space Administration - OSSA, Voyager Project office, Sept. 1967.

VI-3. Private communication V.C. Frost, Aerospace Corp. to R. Hannah, Isotopes, Nuclear Systems Division.

VI-4. Dixon, W.J., "Major System Design Problems for Deep Space Probes," Journal of Spacecraft and Rockets, Sept. 1967.

VI-5. MII-HDBK-217A, Reliability Stress and Failure Rate Data for Electronic Equipment.

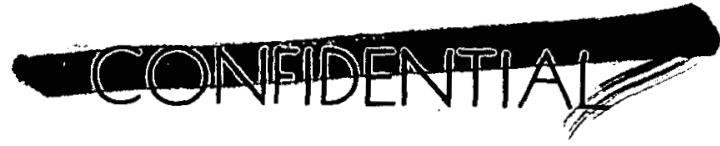

INSD-2650-29

VII-2 


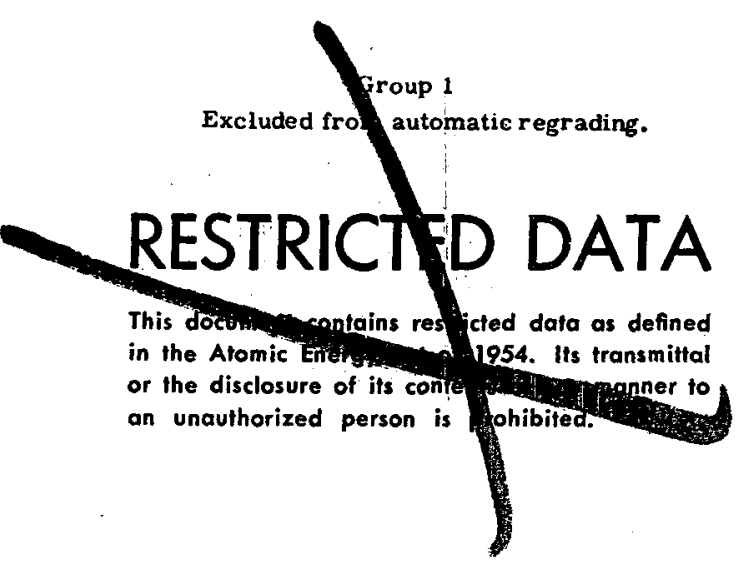


